2

THE PORTAL OF

: EVOLUTION :

DY A FELLOW OR THE GEOLOGICAL " AND ZOOLOGICAL SOCIETUES 


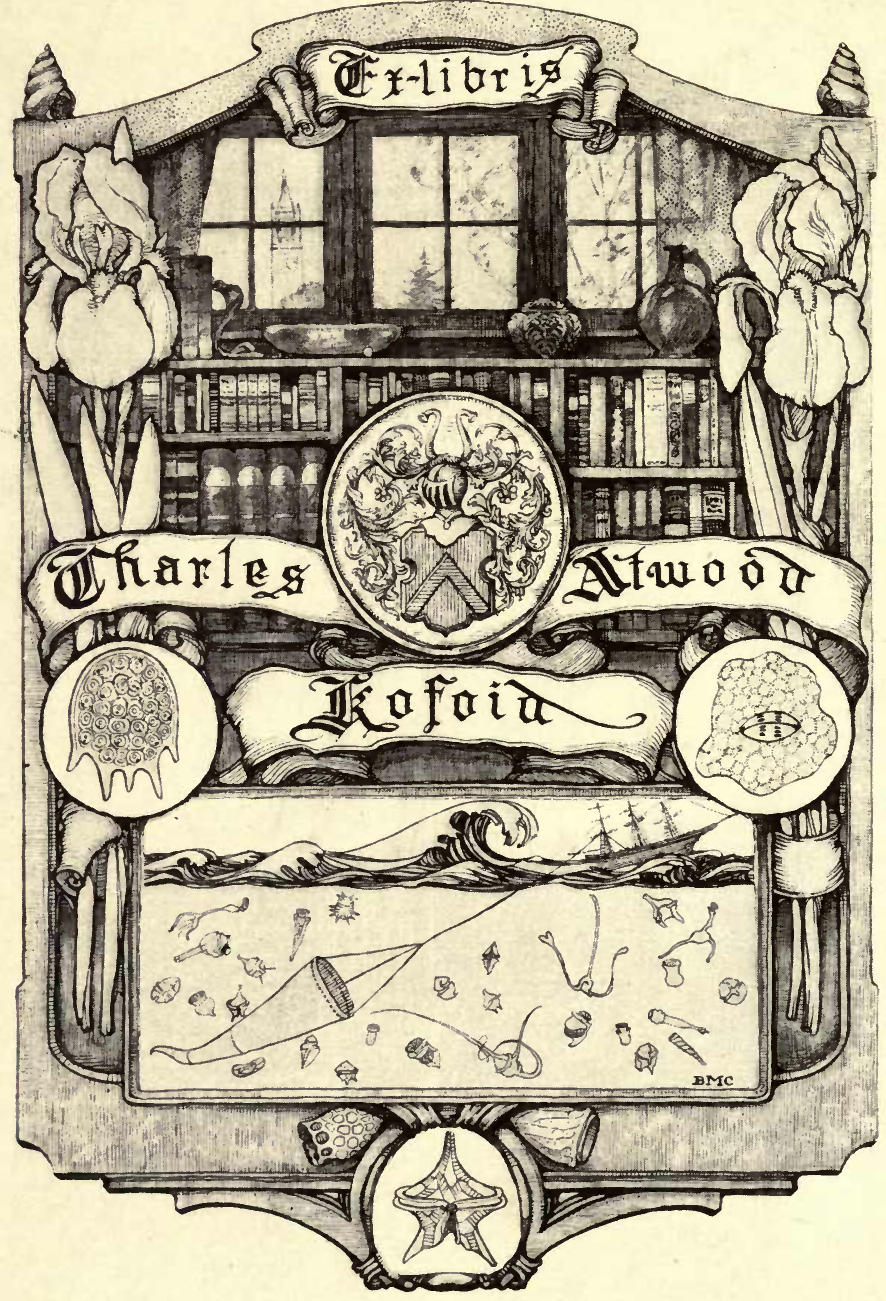





\section{THE PORTAL OF EVOLUTION}





\section{THE}

\section{PORTAL OF EVOLUTION}

BEING A GLANCE THROUGH THE OPEN
PORTAL OF EVOLUTION AT SOME
OF THE MYSTERIES OF NATURE

BY

A FELLOW OF THE GEOLOGICAL AND ZOOLOGICAL SOCIETIES

\section{纱}

HEATH, CRANTON. LTD. FLEET LANE, LONDON, E.C. 
FIRST PUBLISHED IN 1918

(All rights reseried) 


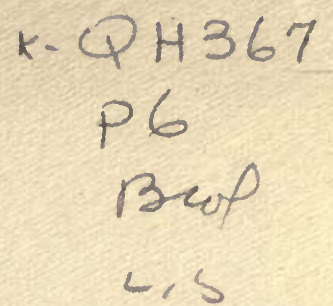

DEDICATED

TO THE

HON. CAPTAIN B. E. CLIFFORD

22nd Royal Fusiliers

The Author respectfully dedicates this treatise, knowing that the Captain's knowledge of History and Science will enable him to appreciate the difficulty of its production even in the present simple form. 
Cahill \& Co., LtD., Printers, London and Dublin. 


\section{ONTENTS}

CHAPTER

PAGE

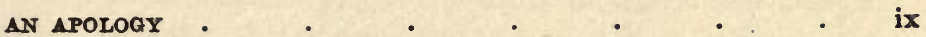

INTRODUCTION . $\quad$ - $\quad$. $\quad$.

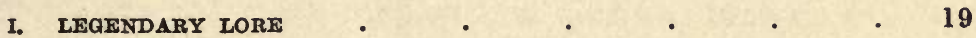

II. HOW THIS TREATISE CAME TO BE WRITTEN • $\quad$ - 24

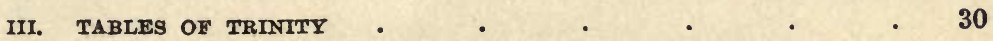

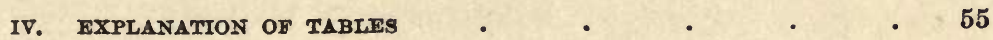

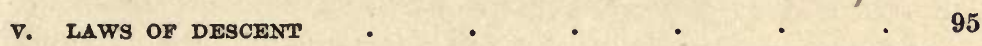

VI. REBIRTH AND HEREDITY $\quad$ - $\quad$ - $\quad$ - $\quad$ - $\quad$ - 115

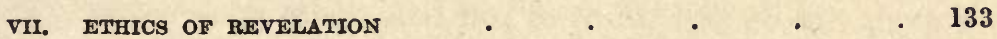

VIII. PURGATORY AND DAMNATION

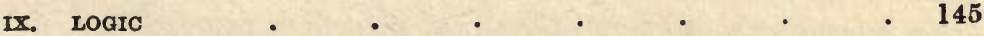

X. VIRTUE AND CRIMK . . . . . . . 149

XI. THREE CLASSES OF MIND $\quad$ - $\quad$ - $\quad$ - $\quad$ - $\quad$ - 179

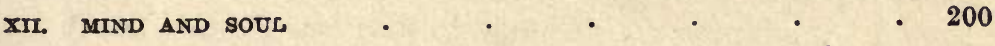





\section{INTRODUCTION : AN APOLOGY.}

I wISH it to be thoroughly understood that the object of this treatise is not to weaken anyone's faith in their own religion, but rather to turn their own and every other religion, to a better use, and gain a more practical understanding of its true significance, and every religion that ever has been or will be, must be and is a ladder that should help us to climb to immortal life up the spiritual path of evolution, thought, love, and wisdom, and to get nearer to God and Heaven.

But unfortunately it is impossible to view the many phases of evolution without treading upon someone's pet corns, or religious beliefs. I must ask the reader, therefore, to remember that it is the duty of each one of us to honour and respect the beliefs of each other, and not to think less of one another because we happen to have different opinions. Personally, I am of the opinion that that religion is the best for each man which enables him to lead a better life and be of the most use and service to his fellowmen; and that even if a man belongs to no accepted religion, and leads a life that is useful and does not injure anyone, he is a better man than he who prays at every street corner, and robs or slanders his neighbour. Hence it is only bigotry to condemn the opinions of others because we hold different ones. All and every religious belief that has not become perverted by superstition or otherwise degenerated must come from God and so be good; therefore, respect it as being the electric wire that carries divine revelation to another; and with this apology I ask the reader to believe as much, or as little of this treatise as he likes. For it is not meant to be a scientific assertion of a scientific problem, it is only a passing glance at scientific subjects from the standpoint of an individual mind. It is only a collection of crude thoughts put into a new light in as logical an order and 
$\mathbf{x}$.

sequence as the writer can manage to work out in the course of the two or three years he has as yet been able to devote to the subject, and in putting them before the public his object is to open up to thought and consideration a new view of evolution that appears to him to be as interesting as it is novel, and to all appearances, logical, hoping that wiser and better informed minds may be capable of doing more justice to the subject than he is himself.

His main study has been to avoid as much as possible all technicalities so as to make it as understandable as possible to the untutored mind. But if the comprehensive mind did not sow the seeds of thought there would be no plants for the constructive minds of science to rear and cultivate, nor for the minds poetic to beautify.

With these words of apology I will now leave the reader to accept or reject as much or as little as he likes, content if I can manage to interest him and cause him to give more thought to a subject, the value of which is but little understood, or if my insignificant efforts may enable him to get a better grasp of the subjects or any of the truths it contains than he could have obtained without my poor help. I may here state that some of the views expressed are even opposed to my own beliefs. But it has been my object to state the case from a purely unbiassed standpoint. To do this it is necessary to smother all your own convictions, lest they warp your judgment. This in many cases I have had to do. 


\section{INTRODUCTION.}

IT is a striking illustration of the way God controls the actions of one and all of us to make them of use to the community as a whole, that at the same time, as at the bottom of the tree of scientific knowledge, my humble self has been elected as the insignificant means to elucidate in the crudest manner possible some of the mighty links that assist us to connect divine and human nature together by the extraordinary revelation my hypothesis contributes to the connection of the Creator and created in the mystery of his trinity. He has also placed at the head of science a man, in Professor Schuster, who has marked his position of President of the Association and Secretary of the Royal Society by the fact that, on taking the Chair, he made a speech which emphasises the principle which is the practical undercurrent of my treatise-namely, a direct attack against the dogmas of materialism, and is the highest championship ever made upon such an occasion of the principles I have endeavoured herein to impress upon my reader, viz., the desirability of unity of action on the part of Science, Government, and social and religious and every-day life. It is my hope (perhaps a vain one) that my weak efforts may be of some use in bringing about this great result that has emboldened me to place this little treatise before the public.

I know I have been rudely offensive in the style I have chosen, but nothing is surer to evoke correction than insult, and I wish my effort to evoke controversy, so that its truths may be proved and its faults corrected with the utmost despatch, and I therefore concluded that the more heinous my crime the sooner its correction would be supplied by wiser minds than mine, and consequently the sooner its virtues would be realised and the less chance there would be of its 
xii.

faults making any permanent impression upon future thought.

In the course of his speech Professor Schuster remarks : "In the common aims of Science and Humanity," I wish to go one step further and say the common aims of Government, social and religious, are all bound up in the Science of Evolution, controlled and governed and proved and directed by the Trinity of the God that has created them.

In his closing paragraphs he remarks : "Do we not find " in the worship of success, the seed of that pernicious ambi"tion which has maddened a nation and plunged Europe into "war? Is this contempt of all idealistic purpose not respon"sible for the mischievous doctrine that the power to possess " confers the right to possess, and that possession is desirable " in itself, without regard to the use which is made of it?"

And I maintain that now, as I try to point out in this treatise, that we have arrived at the stage of evolution, when the Holy Ghost is about to descend upon mankind, not as of old in visible tongues of fire which were not to abide with man, and were only a symbolic illustration of the more practical descent of the Holy Ghost in the twentieth century and subsequent centuries, in the invisible but more lasting form of the real light of wisdom coming out of the brains of man in tongues of speech, a form of divine revelation that now that man is beginning to evolve a mind of understanding will enable him ultimately to know the truths of divine revelation in a manner that will make the whole world kin, and by destroying war and strife to create a future of Unity of Charity and of Use, and another trinity of Knowledge, Love and Wisdom, which two trinities will evolve the final trinity of Peace, Comfort and Content. And these three trinities make a trinity of trinities that is to evolve heaven on earth by creating the trinity of results of Joy, Pleasure and Happiness, when man will at last have a just claim to demand the third and final trinity of God's three miracles that are to mark his prerogative to rule nature, the miracle of Immortality. That the Professor realized that we are nearing the commencement of this third great departure on the road of Evolution, that the birth of the spirit of Understanding, the true deseent of the Holy Ghost which the last century has started by the mind of man having at last become fit, at least amongst its wisest men, to receive 
the spirit of the Soul of Wisdom, and so by the hand of Science instead of, as has been the case in the past, by the hand of ignorance, to lead mankind to the wisdom of God, is illustrated by this quotation from his speech.

"When we glance," he says, " at the various occupations "of the working parts of a nation comprising the student who " communicates or extends knowledge, the geologist or agri"culturist who discloses the stores of wealth hidden in the " soil, the commercial man who distributes that wealth, it " seems as if we ought to be able to name the qualities of " each pursuit which are most needed to carry out the work "successfully."

But I must here state that this can only be attained by the realisation that in the trinity of Science, Religion, and Evolution is the stamp of the likeness of God in His creation, and that the stamp of trinity is the trade mark of divine truth. So that Nature, Science, Religion, Knowledge and Man must all bow their heads at the demand and to the correction of His Trinity, and that it is only by Science expounding Revelation, Religion (teaching by Love not, as in the past, by Ignorance and Superstition), and Governments educating the people in habits of energy, perseverance and economy, which is the soul of wisdom, that we can truly receive the Holy Ghost; but this can only be done in the spirit of Charity, not by ignorant strife, wars and contentions, by selfish love of aggrandisement or wealth, or by religious intolerance or hate, or idle waste of time.

I must conclude this chapter by stating that if in this treatise I have been compelled to offend the dignity of religion, my excuse must be that my deep conviction of the fact that if the doctrines of materialism were not destroyed once and for all time to come, and Science was allowed to advance on materialistic lines, it would not be long before it destroyed all practical possibility of the existence of any form of religious belief as an active force in the evolution of the world, and take mankind back to scientific savagery of a material idolatry. So I conclude that if I could veto for ever hereafter the doctrines of materialism and make my extraordinary revelation the means of proving that all and every part of existence is part and parcel of the Deity, created, impregnated, surrounded and controlled by God and His Trinity, I should make Religion 
xiv.

immortal, and condemn to instant death the demon of Materialism. So great was the good to be achieved thereby that I came to the conclusion I had better risk the giving of insult to past religious beliefs as the lesser evil of the two. For instance, if I saw a comrade about to be shot in the head, and were to knock him down with a blow in the face and so save his life, I should expect, not only his forgiveness, but his gratitude, great as the offence might have been. So, if, as I feel, I have been both rude and clumsy in the methods I have used to impress the truth of God's control of evolution and creation, I must ask you to allow the end to justify the means.

Before closing this Introduction, I may state that the hypothesis put before the reader in this treatise, appears to me to be in accord with the aims and objects of Evolution. Like many other writers, until it was forced upon my mind in the manner hereafter narrated in Chapter II., I should have considered this as being beyond the ken of mortal man. Professor Darwin in "The Origin of Species" (page 429) writes as follows:- "There is a grandeur in this view of life with its " several powers, having been breathed into a few forms, or "into one, and that while this planet has gone cycling on " according to fixed laws from so simple a beginning, endless "forms most beautiful and most wonderful have been and are " being evolved."

Mr. Henry Drummond writing in his work on "The Descent of Man" (page 49) says :-_ "But can an intellectual " answer satisfy us more than the mechanical one which it "replaced? As there was clearly a moral purpose in the end " to be achieved by Evolution, should we not expect to find "some purpose in the meaning? Can we perceive no higher " design, no worthy ethical result which should justify the "conception as well as the execution of Evolution? We go "too far perhaps in expecting answers to questions so tran" scendent. But one at least suggests itself whose practical "value is apology enough for venturing to advance it. When" ever the scheme was planned it must have been that the time "would come when the directing part of the course of Evolu" tion would pass into the hand of man. A spectator of the "drama, for ages too ignorant to see that it was a drama, and " too impotent to do more than play his little part. The dis- 
" covery must sooner or later break upon him that Nature "sent him to become a partner in her task, and share the "responsibilities of the closing acts. It is not given to him " as yet to bind the sweet influence of Pleiades, or to unloose "the bands of Orion. In part only can he make the winds " and waves obey him, or control the falling rain. But in a " larger part he holds the dominion of the world in lower life. "He exterminates what he pleases, he breeds and destroys, " he changes, he evolves, he replenishes the earth with plants " and animals according to his will. But in a far grander "sphere and in an infinitely profounder sense his sovereignty " is passing to him. For by the same decree he finds himself "the guardian and the arbiter of his personal destiny and that " of his fellow-men. The moulding of his life and his chil" dren's children in a measure lie with him through institution " of his Creation, Parliaments, Churches, Societies and "Schools, he shapes the path of progress for his country and " his time."

I am not conceited enough to hope that I can do much myself to further these great aims of Creation, but if the Hypothesis I have endeavoured to expound in this little treatise can act as a finger-post to direct wiser men than myself along the right road of Evolution so as to impress upon futurity the great duty entailed upon mankind by creation of which his individual life is but a drop in the ocean, or a grain of sand upon the shore of humanity. I feel it my duty to place it before the world, no matter how imperfect or erroneous my first conceptions may be, so that time, in the hands of wiser brains, may evolve a handsome man out of the unsightly babe of my imagination. I must ask the reader to take the intention as an excuse for what might otherwise appear an insult to his beliefs, with the hope that my weak efforts may thus, in time to come, do something to produce a useful whole, but it can only be a small seed, nothing more, black and unsightly perhaps, but one nevertheless I feel may some day evolve a beautiful flower.

Before closing this introductory chapter I must ask my readers to be patient and forgiving with me for the way in which on certain points I repeatedly take him over stale ground. To the higher order of mind this is nothing less than an insulting waste of time. But I am ever being made aware in the course of conversation how little capable is the ordinary 
xvi. INTRODUCTION

mind of man, at the present stage of his mental evolution, of combining the two tasks of comprehension of obtuse questions, and at the same time exerting his imperfect faculty of memory. So I have deemed it wisest to be tautological to overbearance in the criticism of the wise student, rather than overtax the strength of the beginner. 
BOOK I 
THE

\section{PORTAL OF EVOLUTION}

\section{CHAPTER I}

\section{A FEW EXAMPLES OF LEGENDARY LORE}

My aim in writing this treatise has been to avoid making it in any way a scientific work, my object being to bring a scientific subject into as simple a form as possible, so as to be easily understood by the casual reader, for had I set myself the task of proving each step and fact as I went along, it would require a large volume, and then I should most likely have failed in the object I had in view, namely, to place the principal facts required to prove the logical sequence that I wish to place before the reader step by step in a manner that could be easily understood, that he who runs may read.

For a work of such magnitude would have left the pathway of logical deduction so intersected by crossroads of scientific technicalities and by-ways of explanation that it would have bewildered the untutored mind, by the mass of scientific matters, ideas, and proofs. The drift of the logical arguments would have been obscured from view by the maze of cross issues, and the shadows thrown upon the pathway by the overhanging boughs of the tree of technicalities, so that the trend of the arguments would have been lost.

My object has therefore been to confine this treatise solely to the facts necessary to demonstrate the logical arguments and needed to prove the concurrent course of Nature, and my hypothesis; and to arrange them in the order of their logical sequence, and by so doing to reconstruct Jacob's ladder that reached from earth to heaven; content for the present to uprear the sides of the ladder and bore the holes for the rungs regardless of the fact that some of the rungs of proof might be wanting, leaving those who have devoted more time to the study of Evolution than I, in the course of a busy life, have had time 
or opportunity for, to supply the rungs of proof ; content to take the reader upon this occasion from creation to the present time and leave the rest of the journey to be undertaken in a more enlarged edition at some future date when I have given the subject more time and study. I just give the reader a passing glance of the road from creation to heaven, on either side of which is posted the sign-posts of Infinity marked NO THOROUGHFARE to the Mind of Man.

Before entering upon the treatise, I would like to give an instance of the manner in which the truths of fable, religion and revelation get obscured by time, superstition and bigotry, and which have to be dug out therefrom by means of inverted logic, that is, by arguing from effect to cause, instead of from cause to effect. In the part of England from which I comeDevonshire-it was, and still is, the custom when I was a boy to go round, I think it was on the sixth day of January in each year, and light bonfires, bang tin cans and such-like performances to drive away the pixies that might otherwise destroy the crop of apples. I cannot say that I ever saw much difference in the yield on this account, but I can enlighten the reader upon the origin of this apparently absurd custom.

Prior to the dawn of English History the population of England was Mongolian, or more correctly of Paleolithic origin, possibly the remnant of the great Mongolian emigration that followed the retreat of the Aryan migration of about two hundred thousand years ago, when driven back by the great Glacial Period from Iceland into Russia, Persia, India, Greece, and Italy; after which it was presumably followed by this great Mongolian wave of emigration which populated all northern Europe and of whom the Esquimaux are still the unadulterated descendants. These formed the prehistoric population of England and were the brownies of our fairy tales. Into the midst of these quiet and unwarlike inhabitants of England, who with their Mongolian development had retained their love of agriculture and horticulture, swept a savage fighting horde of Finns, Picts and Scots, the pixies of our fairy tales, who ruth. lessly robbed our Mongolian ancestors of their vegetables, apples and pears. Hoping to be able to breed up a fighting half-caste race who might be able to oppose these invaders, the Mongolian Englishman of that day stole their male infants and put their own brown ones in their place. Hence, the 
fairy tales of the nasty brownies who ran off with the naughty little white boys and girls if they did not behave themselves.

Whether from this half-caste breeding, or owing to the strain of Phønician blood that had crept into the West of England from Carthaginian and Roman commerce in tin, it happened that upon a certain sixth of January (year unknown) the Mongolian of the West of England fought and defeated the red-haired pixies, i.e., the Picts and Scots, and drove away these awful raiders who destroyed their orchards and apples. Hence ever afterwards this victory marked a day of national rejoicing, bonfires, and feasting, which in time gave place to the absurd superstitions and custom now in vogue. In just such a way has the truth of revelation been buried by religion or superstition. Another instance of the manner in which fables often contain the history of the past, I will take the nursery rhyme of "Ride a Cock-horse." The King of France, knowing King Henry VIII.'s love of pleasure and women, thought it easier to conquer the English king's ire with sweet smiles than his stout men-at-arms with sharp swords, so turned the English invasion of France into a monster pageant known as the Field of the Cloth of Gold.

Amongst those who came forward to save France was a charming French Countess-I regret to say I have forgotten her name-who was a champion hawker and owned a white Arab palfrey, then almost unknown in Europe. This sporting damsel challenged all the gallants of England to fly ler hawk or race her horse. If she won with her hawk they were to give her a bell for her hawk's hood, if she won with her steed the loser was to give her a ring for her finger; if she lost with the hawk, the winner was to receive the white horse as his prize, if he beat her steed he was to gain her hand in marriage. But she scored on all sides with an unbeaten record, with the result that she won more bells than she could put on her hawk's hood, so she hung them on her stirrup shoe, so that, when at the end of the pageant she returned to England with Henry VIII. to adorn for a while the English Court, she had rings on her fingers and bells on her toes. She subsequently declined to become one of his many wives, and upon her return to France, all London who could muster horse, lame, cripple, or cock-horse, turned out and rode down to Banbury Cross to see this fine lady get on a white horse, where 
she was given the biggest send-off ever given to any commoner up to that date.

So in like manner the student of Evolution has to hunt the truths of revelation out of such and more difficult corners and tangled masses of superstition, bigotry and fables. But often fossil remains, drawings, sculptures and antique inscriptions come to his assistance and give him more reliable data than early history or religious fable. As for instance in the case of the Brownies under review just now, although the history of that date is almost a forgotten relic of the past, yet so much more reliable is the pencil than the pen, that our idea of the Brownies or Mongolian inhabitants of England has been kept alive faithfully by the pencil even though the existence of these people in our land of England is all but forgotten, yet we have not forgotten their make or shape. For when we wish to depict our long-forgotten ancestors whom we have relegated to the realms of fairyland we do not forget to adorn them with the Chinese almond-shaped eyes, high cheek bone, squat nose of the prehistoric Englishman of Mongolian descent. So also Nature has in the birth of each one of us retained a drawing of our previous existences, for Embryology has established beyond dispute that in the early stages of our conception within our mother's womb we again assume the types of worms, fishes, animals, and in some cases, of plants that did their part in evolving our present existence. So also in fossil remains and shapes and forms, in rocks and stones God still preserves some links and data that may some day help us to regain the truth, and to recognize them again when we may dig them out and uncover them from the mass of dead leaves of superstition, fable and bigotry, etc., under which religions, governments and man's craving for power, wealth, and pride have so carefully buried the light of God's revelations.

I only hope that this little treatise may, in wiser and better hands than mine, do something to reveal the past, and enable us the better to use such knowledge for our guidance in the future, and may be the means of making many who have hitherto looked upon Evolution as a science meant only for learned scholars, to see that it is a branch of knowledge we can all study with advantage to ourselves and our general welfare. And I hope the useful key that this little treatise contains may help others besides myself to unlock the door of Evolution 
and be able to more clearly understand the truths, both of Nature and Revelation, and to distinguish between what is true and what is false. For do not forget that knowledge and science are both inclined to err, and that it is only by the proof of use and experiment, and by logical deduction and arithmetic that we can prove what is right and what is wrong, and by the assistance of the divine revelations of Nature, as God evolves our mind to a fit state to receive them, and so the better to understand the Universe that surrounds us, that we can arrive at a true estimate of why we exist and for what end we live. 


\section{CHAPTER II}

HOW THIS TREATISE CAME TO BE WRITTEN

Two or three months ago a lady who was staying with me went to a clairvoyant-ladies will do these sort of things-and when she returned while we were having tea, told me, among other things, what he had told her was, that she was staying with a gentleman who was a great thinker; he was not a religious man in the ordinary acceptance of the word, but just an ordinary man of the world. But was a good-natured, honest, straightforward man, kind and considerate for the good of others. He was a man of many moods. He was not rich, but steadily making a success of whatever he undertook, but that he would make a name and become a greater success if he were to write books instead of the work he was engaged in. "Oh," I replied, " that shows he is a fraud, for that is the very last thing I would ever think of doing. I am totally unfit for that sort of work; my spelling is a disgrace to civilisation, and my composition is abominable. I should never be such a fool as to try and do anything I felt myself so unfitted for." Yet here I am doing the self-same thing. I have only mentioned this fact to show how little I contemplated this undertaking only four or five months ago, and that but for the marvellous sequel I am about to relate I should never have entertained the idea of writing it at all.

A week or two later a young man introduced himself to me at a restaurant. He told me he did not know why he had done so, but felt some power compelled him to do it. $\mathrm{He}$ became my shadow for a fortnight or so and I could not shake him off, and in the course of this enforced acquaintanceship, so far as I was concerned, he persuaded me to read a book entitled "The Cosmo Conception of Rosicrucianism." I read it through and put it down with the mental comment that I had not thought it possible for any human mind to so far profane the honoured name of Logic as under its name to 
present to the public such a distorted conception of biblical and astronomical facts conjured up to produce such impossible, improbable and illogical deductions. A week or two later be persuaded me to accompany him to a meeting of the Theosophical Society. The Chairman commenced the proceedings by asking all present to pray for the grace of right thought. I do not know if the others prayed from their lips only, but I, fearing that I was in an atmosphere of very wrong thought, offered up the prayer from the very innermost depths of my heart and soul to be kept out of error.

I then returned home and taking up Drummond's " Ascent of Man," which had been lent me by a friend that afternoon, commenced to read it. While so engaged, and without having any connection with what I had been reading, or any of my thoughts either then or previously throughout the day-it was a Sunday evening - the following, to all appearance absurd and ridiculous idea or thought came into my mind: "God the Father and God the Holy Ghost marry God the Son." I tried to banish this ridiculous collection of words out of my mind so that I might be able to follow the trend of the arguments I was reading, which did not seem to me to be too clearly expressed by the author. But all my efforts were in vain, for no sooner did I banish it and start to read again, than back returned to my thoughts what appeared to be a meaningless affirmation, "God the Father and God the Holy Ghost intermarry with God the Son " ; till in despair I threw down my book and, with little thought of doing more than banish the annoyance, so as to have some chance of getting to sleep, for do what I might I could not get the thing out of my head, I decided to take up a pen and a piece of paper and see what the result would be if I were to work out a series of intermarriages between the different attributes of the Trinity of God, treating all the attributes of God the Father and those of God the Holy Ghost as being males, and the attributes of God the Son as being female.

After about half an hour or so spent in intermarrying these attributes and their concurrent attributes, the result was that the two tables, that will be found at the end of the chapter, lay on the desk before my astonished gaze, on two sheets of writing paper, produced almost without my comprehending what I was doing or what it was going to evolve. I stared with 
amazement as what it contained slowly dawned upon iny astonished mind. "And still I gazed and still the wonder grew " that two small pieces of paper could contain all I saw.

I sat there thunderstruck, and motionless, unable to take my eyes off those two pieces of paper which now lay staring me in the face, slowly but surely forcing upon my mind the enormous magnitude of their weight and importance, as their meaning became apparent to me. For there I beheld, with the exception of the two first stages or days of Creation, Evolution and History, nineteen out of the twenty-one days of existence in the order that they had taken place, if I made allowances for the insertion of the trinity of the soul of man at the place where Evolution showed his mind had been evolved, so by inserting the trinity of his soul as above, and assuming that Heaven and Immortality would be the two last days of Creation, this gave me nineteen out of the twenty-one days of existence as they have, and most probably will transpire in the course of Evolution.

They opened clearly before my mind's eye as I had never been able to comprehend it before, the truth and meaning of the mystery of one Almighty Creator of all things, who was one being possessed of three personalities, each of which contained seven attributes of marks or qualities; the necessity for the creation of the world, of man, or earth, sin, virtue, and heaven in a clear and understandable light which I could never before have thought of or conceived had any connection with Evolution, and which it appears to me unlikely that I or anyone else would have ever conceived; had not this apparently ridiculous collection of words come into my mind, for under no ordinary circumstances should I have turned to the attributes of the Trinity of God for the solution of the problems of Evolution, but I should have endeavoured to reason them out in an ordinary way had not this apparent answer been vouchsafed to my half-expressed prayer in this extraordinary manner.

The intermarrying of the attributes of God's personalities had indeed placed in my hands a key that would, in time, with thought and study enable mankind to unlock the door and enter the portal of Evolution, and ultimately to be able to understand divine revelations, at which through the slightlyajar door I was now gazing, and getting a first and very im- 
perfect glance of a subject the enormity of which, and the wealth of knowledge and understanding that this little key would be able to unlock, when I could hand it over to wiser minds and heads than mine, fairly appalled me.

With its assistance God, Earth and Heaven could be brought within the understanding of man, the same as with a telescope dim and indistinct objects are brought within the range of the eye with increased clearness and distinctness. For, as is explained further on, it is only during the last one hundred years that the property of understanding has dawned upon man, so that up to a few short years ago the mind of man had not sufficiently advanced along the pathway of Evolution for him to be capable of understanding divine revelations; and as God never permits any portion of his wisely organised system of creation to evolve till the world is ready to receive it, he had ordained that his revelations should be made known only in parable and fable, and so has kept this marvellous key a secret until to-day, and I now understand the significance of these words of Christ's when he said to his apostles, "To others it is not given to understand; only in fables and parables. I come not to destroy what your fathers and the prophets taught, but rather to expound and make clear their teachings that seeing you may comprehend, and comprehending you may believe, but when the Holy Ghost shall come upon you $\mathrm{He}$ will teach you all things, even to the consummation of the world."

And as will be shown hereafter this coming of the Holy Ghost is not to be any visible or miraculous apparition as was the apostolic display, for, as will also be shown hereafter, both the Spirit of God the Father in the past, i.e., the Spirit of Divine Revelation, has been and always will be transmitted from father to son, so also with the Spirit of God the Holy Ghost, i.e., the Spirit of Understanding, which is the Spirit of God the Holy Ghost, and which is transmitted from father to son shall in the course of Evolution be granted to mankind when the real descent of the Holy Ghost shall in the ordinary course of Evolution become known to his mind, and so enlighten his understanding that knowing he may understand all things even to the consummation of the world. And so wonderful a light did these two pieces of paper appear to me to offer to man's mind, and in such a marvellous manner did 
they tend to act as a finger-post to point out the way to arrive at the true understanding of all the mysteries of revelation, that even at the risk of being thought profane and conceited, I ultimately decided to try and unwind their mysteries and make them known to others, hoping that some amongst my readers might be able to improve upon the constructions I have put upon them so as to be able to make them useful to mankind in the future.

I am far too humble to imagine that these two tables are the result of any knowledge of my own, but am more inclined to look upon them as some more than usual inspiration than as a creation of my own imagination, for I am not of an imaginative disposition and in a busy, active life have got into looking at facts in a hard, practical manner, and have a very small opinion of any theory that will not stand the test of experiment, use, or mathematical demonstration. Therefore, under these circumstances, knowing that I have a decidedly logical and mathematical mind, I decided to see how far these tables would stand the test of logic and mathematical investigation, and if satisfied with the result that I would risk all criticism and chance its publication in the hope that it might enable others besides myself to get a clearer idea of the truths of the revelation and of the knowledge of the past, which I always consider to be the best way of learning how to make use of the future, also hoping that it might do something to remove bigotry and superstition, two evils which have in the past done so much to retard man's advancement, and hung like a mighty curtain between the visions of the soul and man's understanding of truth.

When the reader turns to the two tables of the Trinity, which I have written down just as they appeared to me that Sunday evening, I think he will, upon further study of their significance, agree with me that for such a result to accrue from so apparently nonsensical a collection of words, and from an assertion that at first sight appeared to be almost blasphemous, is something more than chance, and for the same reason he will understand that for me to have evolved them from any rational line of thought is equally as inconceivable; yet so necessary have they been to the correct elucidation of this treatise that if I tried to work it out without their being before my eyes to check off my work, as also the mathematical 
table that I subsequently evolved from them, my work was sure to become twice as difficult to comprehend. For this reason I have had them printed in duplicate, so that the reader can tear one copy out and paste it on a card so as to refer to it with greater ease if he cares to do so, without injuring the book, for if he keeps them before his mind when reading the rest of the treatise he will find it much easier to understand this little work. 


\section{CHAP'TER III}

\section{TABLES OF TRINITY AND A SHORT EXPLANATION THEREOF}

\section{THE ATTRIBUTES OF GOD'S TRINITY.}

\section{TABLE I.}

7. Attributes of God the Father are as under
7. Attributes of God the Mother are as under
7. Attributes of God the Soul are as under:
1. SPIRIT

2. Power

3. THovght

4. Imagination

5. KNOWLEDGE

6. Peace

7. JoY
1. Existence

2. Love

3. LIFE

4. Comprehension

5. Invention

6. Comfont

7. Pleasure
1. Sour.

2. Wisdom

3. MIND

4. UNDERSTANDING.

5. UsE.

6. Content.

7. HAPPINESS.

NotE.- Line one are the three attributes that go to make up the essential qualities that make up the Trinity of God. Line four are the three attributes that combined in pairs (the three are never combined in mankind) make up the human Soul or Mind.

Note.-Joy, Pleasure and Happiness produce Heaven, thus reading across the last line would give us Pleasure (8), Happiness (9), and Heaven (10), and the figure ten by Table Four would stand for Eternity, so in this table, as in the next two, we find that Heaven appears as a multiple of 10 , and all multiples of 10 , are mathematical values of Infinity, and gives rise to Immortality in the three tables alike. When we have attained these twentyone stages of Evolution and development, whether in this world or in the next (for I maintain we can make this world heaven or hell by the lives we lead), we have reached Heaven, which can contain no greater blessings than perpotual JOY, PLEASURE and HAPPINESS.

\section{TABLE II}

The reason for the divorces of God's Trinity will be explained hereafter. They are obtained thus :-

First, God divorced the second personality of His Trinity, "Existence" (which is the spirit of Love) from ETHER.

- This gives the first line of tables II. and III. 
When Existence is divorced, on the first day, our first line reads the first time, as marked " A," the second as marked "B." Repeat the same process when Soul is divorced on the second day.

"FIRST DAY OF DIVORCE."

Section "A." SPIRIT, AND SOUL, MAKE POWER OF VARIATION AND MOTION.

Section "B." SPIRIT, SOUL, AND POWER, MAKE DISINTEGRATION.

"SECOND DAY OF DIVORCE."

Section "A." SPIRIT, AND EXISTENCE, MAKE LOVE, CHEMICAL ACTION, AND CONTRACTION.

Section "B." SPIRIT, EXISTENCE, AND LOVE, MAKE AFFINITY.

Notw. - The first of these results of ithe divorce of God's Trinity, is that of variation of the smallest ions of the electrons of Ether, which this hypothesis pre-supposes to be 21 invisible electrons-smaller than any yet discovered - the second brings about their reunion in place of their variation by disintegration. The first result produces Gas, the second Fluid.

\section{TABLES OF TRINITY.}

TABLE II. SECTION A.

The next portion of Table II. Illustrates in tabulated form the 14 marriages of the attributes of God's Trinity.

1. SpIRIT

2. Sour

3. Power

4. WISDOM

5. Thought

6. MiND

7. Imagination

8. UNDERSTANDING

9. KNowhedGe

10. USE

11. Prace

12. Content

13. JoY

14. Happiness marries ExISTENCE

ExISTENCE

LOVE

LOVE

LIFE

LIFE

, Comprehension

COMPREHENSION

" INVENTION

, Invention

„ COMfort

" Comrort

, Pleagure

" Pleagure and begets Creation.

\begin{tabular}{|c|c|}
\hline & LrFE \\
\hline & IMAGINATION. \\
\hline , & COMPREHENSION \\
\hline & KNOWLEDGE \\
\hline & HUMAN WILL \\
\hline & UNDERSTANDING. \\
\hline & INVENTION. \\
\hline & UsE. \\
\hline & Peace \\
\hline & CoNTENT. \\
\hline & $\begin{array}{l}\text { CONTEMPT OF } \\
\text { WrONG. } \\
\text { HAPPINESS. }\end{array}$ \\
\hline & Wrsdom. \\
\hline
\end{tabular}


TABLE II.-SECTION B.

Marriage

of the

Trinity

Days or Stages of Evolution
B. SPIRIT
Sour
and Power
$=1$. Disintegration
B. Spirit
EXISTENCE
, LOVE
2. AFFinity.
1. SPIRIT
EXISTENCE
, Constiruction =3. Matter.
2. Sour
EXISTENCE
, LIFE
=4. Creation.
3. Power
Love
, Imagination
=5. Marriage or Eex.
4. WISDOM
Love
, Comprehension $=6$. Mind and Man.
7. Imagination.
8. Comprehension
9. UNDERSTAND- ING.
5. THоб Gнт
LIFE
,, KNOWLEDGE $=10 . \mathrm{STUDY}_{\mathrm{T}}$.
6. MIND
LIFE
, Human Will =11. Government.
7. Imagination
COMPREHEN- , SION
UNDERSTAND-
ING $=12$. SCIENCE.
8. Understanding Comprehen-,, Invention =13. Commerce.
9. KNOWLEDGE SION
INVENTION , UsE
=14. Conquest of Matter.

(NотE.-This is as far as Evolution has yet advanced.)
10. Use
Invention and Peace
$=15$. END OF WARS.
11. Peace
Comfort
=16. AGE OF USE and Charity.
12. Content
CoMfort
, CONTEMPT
of $=17$. Prevention of Crime.
13. JoY
14. HAPpiness
Pleasure
" HAPPINESS
=18. REWARD OF
Pleasurfi
" Conquest of
FOLLY =19. HUMAN WISDOM.
20 and 21. Must be the final results of Evolution $\left\{\begin{array}{l}20 . \text { Heaven. } \\ 21 . \text { ImMortacity. }\end{array}\right.$ 
These results of the two divorces and fourteen marriages of God's Trinity added to the Trinity of the human Soul. No. 4 in Table I.-give the twenty-one days or stages of Creationnamely, No. I, DISINTEGRATION; No. 2, CONSTRUCTION; No. 3, MATTER; No. 4, CREATION, No. 5, MARRIAGE; No. 6, MIND; No. 7, IMAGINATION; No. 8, COMPREHENSION ; No. 9, UNDERSTANDING; No. Io, STUDY; No. II, GOVERNMENT; No. I2, SCIENCE; No. I3, COMMERCE; No. I4, INVENTION; No. I5, PEACE; No. I6, ART OF USE; No. I7, PREVENTION OF CRIME; No. I8, REWARD OF VIRTUE; No. I9, WISDOM; No. 20, HEAVEN ; No. 21, E'TERNITY, as the twenty-one stages of Evolution. Now, as Immortality is No. 2I by our Mathematical table, it must be the commencement of the Fourth Epoch of FINITY, or the complete result of a Trinity of Creations, and the complete result of Creation presumably is Eternity, which is to be everlasting and unalterable, it follows that Evolution must finally stop at No. 2I. So we have travelled through two stages of animal creation, viz., EVOLUTION and INVOLUTION; 2, HUMAN MIND and SOUL, and one of material creation, CONVOLUTION, which I have endeavoured to demonstrate by a two-thirds proof in Logic, namely, by use of Evolution and mathematics. And Immortality commences the never to be completed age of finite Eternity.

If the two first are filled in and the Trinity of Soul is inserted after No. 7, the place assigned to it by. Genesis, as I have inserted them in Table III., both Evolution and this table are found tu correspond. 


\section{TABLE III.}

Being a Table of comparison of the results of the Marriages of God the Mother with God the Father and of God the Soul with the 21 days of Evolution.

Results of the Marriages

Days of Evolution.

\begin{tabular}{|c|c|c|c|}
\hline 1. Divor & & DISINTEGRATION & Age of Destruction Gas. \\
\hline 2. Divor & & AfFinity & Age of Flames or Construction. \\
\hline 3. lst $\mathrm{M}$. & arriage & Matter & Ago of DaRkNESS or MATTER. \\
\hline 4. 2nd & , & Creation & Age of Plants or Creation. \\
\hline 5. 3 rd & , & Marriage & Ago of MAMMOTH ANIMALS or ANGELS \\
\hline 6. $4 \mathrm{~h}$ & " & Mind & Ago of LUCIFER or MIAN. \\
\hline 7. Trinity & of 7 & CIMAGINATION & Age of ADAM or WILL of MAN. \\
\hline 8. Soul o & f Man & COMPREHENSION & Ago of Cain or of Agriculture. \\
\hline 9. SeeTal & ble I. & UNDERSTANDING & Ago of Abel or of Civilisation. \\
\hline 10. 5 th $\mathrm{M}$ & larriage & $\begin{array}{l}\text { STUDY AND } \\
\text { INOWLEDGE. }\end{array}$ & Age of Reliaron. \\
\hline 11. 6 th &, & GovernMENT & Age of Government. \\
\hline 12. 7 th & , & SCIENCE & Age of Discovery. \\
\hline 13. 8 th & , & Commerce & Age of Commerce. \\
\hline 14. 9 th &, & $\begin{array}{l}\text { CoNQUEST OF } \\
\text { MATTER }\end{array}$ & Ago of Invention. \\
\hline 15. 10 th & ", & Peace & $\begin{array}{l}\text { Age of The End or } \\
\text { Wars. }\end{array}$ \\
\hline 16. 11th &, & Use \& Charity & Y Age of CoMront. \\
\hline 17. 12 th & , & $\begin{array}{l}\text { Prevention } \\
\text { of Crime. }\end{array}$ & Age of Pleasure. \\
\hline 18. 13 th &, & $\begin{array}{l}\text { REWARD oF } \\
\text { VIRTUE }\end{array}$ & Ago of Happiness. \\
\hline 19. $14 \mathrm{th}$ & 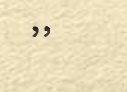 & $\begin{array}{l}\text { PERFECTION } \\
\text { of HumaN } \\
\text { WisDom }\end{array}$ & $\begin{array}{l}\text { Age of Joy by the } \\
\text { CONQUEST OF FoLLY }\end{array}$ \\
\hline 20. & - & Heaven & \\
\hline 21. & - & IMMORTALITY & \\
\hline
\end{tabular}


TABLE IV.

\section{THE MATHEMATICAL TABLE OF THE TRINITY OF GOD WORKS OU'T THUS.}

The Figures Nos. I, 2, 5, and 8.

These denote imperfection, that is to say, results that are incomplete either in the stage or epoch to which they belong; or that will never become perfect in the course of creation. Or they may denote a combination of one or more perfect trinities with part or parts of an imperfect trinity.

The Figures Nos. 3, 6, 9. The Figures of Trinity.

These denote results that are complete or permanent, but not everlasting, although No. 9 may in a few cases be practically eternal.

The Figures No. 4, 7, and to are everlasting.

The Figures Nos. o or ro, or multiples of these, denote Infinity or everlasting existence in Evolution, as they also do in Mathematics.

It is probable (see concluding remarks) that the mathematical grouping of this Table of Trinity may be applicable to other branches of science which I have not sufficiently studied to endeavour to demonstrate their application, although in my concluding remarks I have been bold enough to hazard a suggestion as to how they may be turned to use in atomic chemistry.

\section{ILLUSTRATION.}

Now, subjecting Table I. to these figures, we get the following results. Imperfect Numbers I, 2, 5, and 8 .

Now, No. I line, that is SPIRIT, EXISTENCE, and SOUL. These are perfect and eternal so far as God and Infinity are concerned, but as we are dealing with Creation, they are rightly in their place as imperfect, for they are to be removed to make Infinity finite and Creation visible.

Now taking No. 2 line, POWER, LOVE and WISDOM. These are also imperfect, for the power of human will is never to be able to will and perform. This is forever to be the prerogative of God; man must be content to will and do the best he can. Love, likewise, is never to become perfect, for 
human love is never to be free from distrust or jealousy. Human wisdom is to be forever incomplete, for man is never to be absolutely free of sin or failure, for, as will hereafter be demonstrated, if such a result were to transpire, he must become another Infinite being or for ever remain a mortal animal.

But line No. 5 is our next line of imperfection. These are KNOWLEDGE, INVENTION and USE. These are three qualities that are never to become perfect, for man is never to be entirely free from errors in knowledge; so long as the world goes on there is to be further room for invention, and he will never learn to use his abilities or surroundings with such perfection that he will be entirely free from abusing to some extent, in some way or other, Nature's gifts, or missing her opportunities.

Line No. 3 and No. 6 are the complete trinities. Taking line No. 3 first, we have THOUGH'T, LIFE, and MIND. These are to become complete in the course of evolution, but are not to be everlasting, for Thought is to give place to Reason, Life is to give way to Immortality, Mind is to be replaced by Soul when evolution is complete. Taking line No. 6, we have PEACE, COMFOR'T, and CONTENT. These three are to become complete during evolution, and are to complete the evolution of man, but are not everlasting, as they are to be replaced by line No. 7, which is eternal and is the JOY, PLEASURE, and HAPPINESS that make Heaven. This only leaves line No. 4 unaccounted for, which, like No. 7, is eternal and everlasting, and we find it reads IMAGINATION, COMPREHENSION, and UNDERSTANDING, the three attributes of the Trinity that constitute the Human Soul, just as SPIRIT, EXISTENCE, and SOUL were the divine attributes of the Divine Soul of the Creator.

I think this is enough to illustrate to the reader how this mathematical table acts, and may be used as a check on any table of trinity when we are able to reduce matters in evolution to a tabular form.

My first feeling was that I might be a dupe of some mental hallucination, and that in a day or so I would see the absurdity of the ideas these tables had conjured up in my mind, so I endeavoured to dismiss them from my thoughts, but at the end of two or three days I decided that I would again look at 
them and see if they did in reality contain the importance that appeared to be in them when I first beheld them. For as I found that I went about my business and that my head was as collected as ever, I came to the conclusion it was no temporary derangement of my imagination, but a stern reality, so I decided that I would try and think and work out this wonderful problem that these two slips of paper contained.

Table I. contained nothing new to me. For years it had been taught me from childhood as the Trinity and the Personality of God, and that the twenty-one attributes therein contained constituted the sum of the seven gifts, graces, faculties or qualities, term them what you like, that the three personages of God's Trinity were believed, each respectively, to confer or grant or bestow upon mankind. How old or how long this belief has been held or taught, or whether or not its historic origin is pre-Christian, I cannot say, but if the latter, its tabulation in the exact order $I$ have given it, is certainly post-Christian. But some of the old eastern legends I have read make me inclined to fancy that its earliest conception, in a partially evolved form or in the forms of presentiment, is pre-Christian, although in a less tangible order of thought in a dimly comprehensible manner.

With two exceptions, namely, that the two first stages of evolution were wanting, the results of the marriages of the attributes of the Trinity which I have evolved, contained the whole of the stages of the world's evolution, provided that the trinity of the Human Soul (Line No. 4, Table I.) be inserted at the place which corresponded to the birth of mind in mankind in the course of evolution, and that Heaven and Immortality were added as the final results of creation, not only up to to-day, but even to the end of the world, from Eternity to Eternity. Why was it not complete, and why did not these marriages of God's Trinity account also for the two first days or stages of Creation? Why these two missing links? I strove to think the puzzle out, when it dawned upon my mind that if fourteen out of the nineteen days I had arrived at were marriages of God's Trinity, it would not be illogical to conclude that the missing two stages were divorces instead of marriages. And if this were the case, a still more wonderful solution of the problem of evolution rose before my mind as to the manner in which creation had taken place, as will be shown hereafter. 
But I will now proceed to put into tabulated form my work so far as I have taken my reader.

(See Table III.)

SHOwING the order of creation ORDER of evolution as shown so far as the science of evolu- by the results of the martion has at present been able riages of the attributes of to evolve it up to the present the trinity. time.

I. Destruction or Disinteg- (These two are divorces, not ration

2. Attraction or Crystallisation

3. Construction or Recrea- I. Creation. tion

4. Matter

5. Life

6. Man

7.

8.

9.

HERE IS THE END OF GENESIS.

10. Religion

II. Government

12. Science

I3. Commerce

14. $\left\{\begin{array}{l}\text { Conquest of Matter, the } \\ \text { Age of Invention }\end{array}\right.$
2. Matter.

3. Marriage

4. Mind.

AND THE CORRECT PLACE FOR SOUL TO BE INSERTED.

5. Study.

6. Government.

7. Science.

8. Commerce.

9. Conquest of Matter.

ro. End of Wars.

II. Charity.

I2. Contempt.

13. Reward of Virtue.

I4. Wisdom and Happiness.

If the two first are filled in and the trinity of Soul is inserted, after No. 6, the place assigned to it by Genesis, as I have inserted them in Table III., both evolution and this Table are found to correspond up to to-day. Then in the right-hand column I have continued them on to the end of time, with the following days which seem to correspond: 15th, End of Wars; $16 \mathrm{th}$, Age of Use; 17th, Prevention of 
Crime; 18th, Reward of Virtue; Igth, Conquest of Folly; 2oth, Heaven; 2Ist, Immortality.

I stared at the tables as you see them now. Although I conceived the comparison the moment I first looked at Table II. when I saw it lying in front of me that Sunday evening, yet at first the full significance did not dawn on my mind; in fact, it has only become apparent to me as I have steadily tried to work it out step by step, and I still feel that I am, as the title of this treatise implies, only beginning to comprehend a very little of what it may lead up to in abler hands than mine; in fact, I am still only beginning to take a cursory glance through the portal of evolution and that it will take years of study to get to the doorstep or inside the door.

One of the first things that struck me was, why did it not contain the first two stages of evolution, when it contained all the rest, and more besides, even to the end of time? Why were not the stages No. I, Disintegration, and No. 2, Affinity, also down as marriages of God's Trinity. Then it suddenly flashed into my logical mind that these two might be divorces, not marriages, of the Trinity, and if so, what other interpretation could there be of their significance than that to bring about creation God had divorced or withdrawn twenty of the twenty-one attributes of the Trinity, and had thus divided his infinity into two parts-Infinity and Finity. For, logically, he could not have divided it into two finite parts, for that would have destroyed His Infinity. Then how was $\mathrm{He}$ to produce the Universe and yet be logical? For it stands to reason that being infinitely wise, he must be perfectly logical. (Note: I am endeavouring to take the reader as near as possible, step by step, along the lines of argument I followed when I reasoned this out.)

Now, for argument's sake, what would be the result if we presume that God the Son is the female gender of God? For this reason, and the better to impress this upon the reader, and it is essential or he will not be able to follow some of the arguments adduced, I shall henceforth use the expression, "God the Mother" instead of "God the Son." Please do not think, dear reader, that in doing so I intend to be the least disrespectful; nothing is further from my mind. I may here take the opportunity of stating what will be more fully demonstrated in its place, when we are dealing with the first 
chapter of Genesis, wherein, when stating the creation of the soul of man to God's image and likeness, the wording is so expressed as to imply that the likeness of the male and female gender of man is also a likeness of a like gender in God. This would lead us to conclude that the true interpretation should read "God the Mother of Creation becomes the Son of Man by taking a human male body to cover Her divine soul,", and as we go on we will demonstrate why this became necessary on probably three occasions so as to enable women's love, comprehension and invention to be transmitted from father to son and grandson. It will also be shown that there were probably three such redeemers born during the course of evolution-one in pre-historic times, Buddha, in almost prehistoric times, for we may say that the name only is historical, for the Buddhism of to-day is a corruption of an older cult, Christ making a trinity of such births, if this had not been done, religion would not have lived long enough to last till man gained understanding, but would have been entirely lost and destroyed by the onward march of governments and civilisation, for there have been times when religions have been almost wiped out of existence to permit of the evolution of governments and science. So it appears to me that there were three occasions that called for redemption. With apologies for this digression, I will now return to the place where, for the sake of argument, I was about to see what would result if I made the supposition that to create a finite existence of God would withdraw the second and third personalities of God the Mother and God the Soul and their respective seven attributes (See Table I.) from the personality of God the Father, and leave His first attributes to control creation, and then gradually return the powers of the attributes of God the Mother and of God the Soul to co-operate with the powers of the attributes of God the Father, and so evolve creation.

This appeared to me to be the only logical supposition of the way in which the Almighty could create a finite part of His infinity; and the only way to attain finity without at the same time destroying infinity. For if you take away any portion of infinity it at unce ceases to be infinity, so that there must be a re-arrangement of the portions of Infinity, not by their total disconnection from infinity, but only by a rearrangement of $\mathrm{His}$ attributes can $\mathrm{He}$ create a finite existence 
within the infinite. And it stands to reason that such finite part must be part of infinity, no matter how small a part, distinct but surrounded and impregnated and controlled by His Infinity, for no other supposition can be imagined that would not set a finite limit to infinity, and once you limit infinity it must become finity instead of infinity; therefore there is no other proposition feasible or tenable.

The second unassailable hypothesis that we arrive at is that God being a Trinity, any part of His existence must also be a Trinity or it is incomplete, as it is only then part of a trinity, and if this is not so, Genesis is incorrect in teaching that all creation is in the likeness of God. It therefore follows that all that is complete in Nature must be reducible to a trinity, and therefore to be true or correct must not exceed a numeral value of or over the figure three or it is not a perfect likeness of God; and revelation is most emphatic upon this point that all creation is made in the likeness of God's Trinity, and likewise that if it is less than three it can only be an imperfect part of creation, or in other words a part that has to be further evolved, or it must be a combination of a complete trinity with an incomplete portion or a combination of several complete portions with incomplete trinities. It therefore follows that as God is a perfect trinity, and all creation is after His likeness, all things in Nature, to be perfect, must be in trinity or reducible to trinity.

I must therefore impress upon my reader that nothing in knowledge or science, or even in religion, can be accepted as finally proved, but remains only a probability, that will not stand the test of reduction to trinity, and it is only a probability if its component parts have a numerical value of less than three.

The trinity of logic is Experiment, Use and Arithmetic. Now evolution is the only test of experiment we can obtain of Creation, for the Universe is beyond our control, and it is above our mortal powers to be able to experiment to any large extent with creation. Hence we are in most cases reduced to two of the three parts of logic, viz., Use and Arithmetic, and when by logic we can find the mathematical value, and by evolution the use also of creation, we have two values out of three, so we are now justified in concluding that we have at least a probability of truth. 
I must now apologize for this digression, but it appeared to me that if I made it in this place, it would facilitate the reader's comprehension of some of my subsequent arguments.

Having by this time decided that this was the most logical assumption of the manner in which God has created the Universe out of a finite portion of Himself. The next question I arrived at was: Why and wherefore was the necessity for Creation? Why could not Infinite Perfection be content with Infinite Perfection? And this is the only logical answer logical reasoning could give to my enquiring mind.

Firstly : Infinite power of light and action, the finite qualities of the first personality of the Almighty Creator, rebelled against infinite inactivity.

Secondly : Infinite power of existence and love, the Spirit of God the Son (or Mother), rebelled against having nothing besides itself to love.

Thirdly: Infinite Wisdom, the Spirit of God the Holy Ghost, decided that it was wrong for infinite power to have nothing to do and that if there was anything that would deteriorate infinitely perfect love it must be love of self. For knowledge of how to act for the good of others; love sufficiently strong to labour for the life and existence of others; and wisdom great enough to control our actions so that they injure no one, and to show charity and mercy to others, are the only possible means of advancement. Indolence, Selfishness and Absence of self-control are the three forms of folly that damn and deteriorate and extinguish all advancement, and bring about the extinction of mankind.

This gave the logical necessity for a finite creation and a finite existence as will be further demonstrated in its place. Some obtuse persons have said to me: "Where do you get your Creator from? Who made him?" I will endeavour to point out that eternity is the logical sequence of time, for the well-balanced mind can conceive no idea of an end to time. There is the stamp on all sides of creation of infinity. We have even a difficulty to realise that we are going to die; we are always inclined to think that it is the other fellow who has to die. We can conceive no idea of time except as the minute - dot on the clock of Eternity. We do not neglect to enter into undertakings that cannot possibly be completed during our own lifetime. Although we do not confess it, we realise that we live in the lives of our children. 
We search in vain through the firmament of space for any sign of finity, but it does not exist so far as the eye can see and pierce, and beyond that, so far as the most powerful telescope can penetrate, endless reduplication marks the stamp of infinity, past the limits of our understanding, past our utmost comprehension; even past the furthest boundaries of our wildest imagination, all points to infinity, and convinces us that infinity is not an imaginary idea of a distorted mind, but a stern reality of absolute fact. Time is only the moment of our finite mind, the dot of our individual existence, the starting point on all sides, whether past or future, of the boundless ocean of eternity. The globe on which we live and move and have our being likewise is but a dot in the firmament of the heaven from which we start to measure the magnificent sea of God's Infinity (see concluding remarks) studded with innumerable islands of suns, planets and stars that combine to make up the ocean of an unbounded Universe, surrounded by, impregnated by, and controlled by the infinite power (of the waves of ether that constitute the Infinite, Almighty Power which we call God) that continues to create them.

Infinity is the strongest of all the divine revelations, and was implanted from the first moments of creation in our minds. Hence we cannot conceive the finity of existence of all around us points to continuity. In just the same manner we cannot conceive that an existence can come into being without having been made or created by an Infinite Creator, hence if all that is invisible is infinite and all requires a creator that has a visible existence, it logically follows that its Creator must be invisible and also be infinite and omnipotent or he would not be able to create or control it. It also follows that such a Creator must be possessed of infinite power of existence, and be possessed of infinite wisdom, without which attribute infinite chaos must forever destroy the harmony of existence, and it follows as an incontrovertible axiom that this creation must be of Infinite Existence and that Infinity can have no creator or it would not be infinity if it had a greater power than itself to create it. This now being demonstrated, the question reduces itself to one of : Why should the infinite Almighty desire to create a finite creation? Why not be content with His infinite existence? For infinite perfection should have perfect content. There is only. one answer to this. It is the exception which proves the rule. 


\section{THE NECESSITY FOR CREATION BY}

EVOLUTION.

The beginning of all was an infinite spiritual being, for if it had not been spiritual it would have required to have a creator ; for we cannot conceive an infinity, the bounds of which are not invisible; and being an infinite spirit, it must exist IN ITSELF, OF ITSELF, and FOR ITSELF. Now an infinite spirit possessed of infinite Power, of infinite Love, and of infinite Wisdom realised :

That Infinite Power rebelled against infinite inactivity.

That Infinite Love yearned with an infinite longing for something besides itself to be beloved.

That Infinite Wisdom decided that if it had not been infinitely perfect infinite self-love must have destroyed its perfection.

For the greatest of all perfection is Charity or love of others, and the greatest of all crime is self-love or selfishness.

Hence God could not fail to realise that the only forces that could deteriorate His perfection were the absence of a cause for activity and the want of something to love besides Himself.

The Trinity of the Almighty is SPIRIT : EXISTENCE : SOUL.

The Trinity of Nature is POWER : LOVE : WISDOM.

The Trinity of Man is IMAGINATION : COMPREHENSION : UNDERSTANDING.

The Almighty being a pure and perfect spirit can therefore have neither SIZE, SHAPE, nor DIMENSION, but must be UNIVERSAL, INVISIBLE and IMMEASURABLE, or $\mathrm{He}$ would not be an INFINITE SPIRIT EXISTENCE. Now if the Almighty desires to have some means of activity, and some object on which to lavish His love, only one logical possibility exists by which such an end can be obtained and at the same time comply with the above requirements which we have demonstrated to be necessities. The creation of an object, or finite portion of His Infinity to be of HIMSELF, SURROUNDED BY HIMSELF, and CONTROLLED BY HIMSELF, or it would not be a part of His Infinity. And it must be different from Him or $\mathrm{He}$ would have created two infinities, quod absurdo. Hence as $\mathrm{He}$ is a spirit it must be a material finite portion of the invisible, immaterial whole. INFINITY is Spirit, Existence and Soul; MATERIALISM 
is Power, Love and Wisdom. Up to the present stage of evolution mankind has only evolved power, love and a small moiety of wisdom, so of necessity he must be mortal. When he succeeds in evolving a soul of wisdom, of necessity he must be immortal, because if he is not eternal he is not a true likeness of God. Hence the creation of a material existence; that he may have something to do and to love, God created a material sweetheart in His own likeness to fulfil this end. Logic also demands that it also should be eternal. This neces. sitated His power becoming active. Therefore His infinite wisdom stirs into action His Infinite Power, by withdrawing the attributes of Existence and Soul and those of Spirit, Power excepted, from the rest of His infinity to materialise His Spirit of Power, like the blue sky between the stars or the clouds therein, which constitute Finity and Infinity.

And lo and behold! not in a day but in an instant creation is an accomplished fact because with God to will is to achieve. But had God made the accomplishment of His wish an instantaneous action, it would have been an infinite act of will and love, and would have been instantly satisfied, and in so being would have frustrated the object of its conception, viz., perpetual action. For to fulfil its destiny, being the conception of an infinite being, its material existence must also be infinite, and its development of infinite duration, or it would fail to satisfy the wants of an infinite being. This is another reason why the final perfect evolution of mankind must result in Immortality and Eternity.

So we find that Convolution, Evolution and Involution are not only the natural, but the only possible way of producing a finite, material creation, that will stand the test of logic, out of an infinite spiritual one. But kow is this to be done? Now infinite Wisdom at once realised what a finite mind might fail to perceive, that the only way to materialise spirit was to divide, not separate, a portion of spirit existence from the rest. So God Almighty withdraws all but the first two of the attributes of God the Father, namely, the spirit of invisible activity and the power of light and motion and leaves these two to act in unison with the first attribute of God the Soul, which is the Invisible Spirit of Wisdom. This first conception of evolution, therefore, starts creation by the formation of gas. The age of disintegration, commonly called the Age of Gas, so accom- 
plishes the first divorce of His Trinity. We now come to the second divorce. He now withdraws the attribute of God the Soul, Invisible Wisdom, and substitutes in its place the first attribute of God the Mother which is Existence, leaving this second trinity of creation Invisible Power, Material Power (which is chemical action), by crystallisation and Existence. This trinity created the age of Affinity or Construction of the nebular system, and produces the material universe of visible existence, thus making the second stage of creation, the age of Flames, and the second divorce of God's Trinity, the divorce of the spirit of wisdom; which gives rise to matter devoid of thought or wisdom.

We have now disposed of the two first days of divorce during which on both days only one attribute of two of the Three Persons of God's Trinity has been at work. But the rest of the plan of creation is to be a progressive one ; the future course of creation is to be one of an increase of new and fresh influences or forces, not one of reduction; so the rest of its stages are not divorces, but marriages of the attributes of God's Trinity.

Reading now along line three of Table II. we find that the spirit of Motion and Light now marries, that is to say, is increased by that of Existence. This marriage gives birth to Love in its lowest forms of affinity, viz., reading on to the results we find that the forces of Chemical Action, Existence and Love, make up the Trinity of Matter. This has truly been the case as regards the creation, for we have now arrived at the final completion of the creation of Matter, and the conception that is to give birth to Plant Life is now laid in the formation of the world of Matter. So henceforth Nature is no longer to be a selfish creation, existing for itself. The struggle for the existence of others is now to commence and makes the dawn of Love in evolution, for the plant is to sacrifice the labour of its life, its beauty and flowers, to give birth to its seeds which are to create the lives of other plants which are to follow it. And the whole of future evolution is to be devoted in some shape or other towards living for those who are to come after us. Oh, how much better a world it will be to live in when the further advancement of evolution will make man wise enough to comprehend this fact, and I sincerely hope that this little book will help him to learn the great lesson of the 
love of others. This completes the age of Darkness, during which Evolution has been devoid of life.

We have now got to line four when the fourth attribute of the Trinity, two male attributes of God the Father, viz., Spirit and Power, and two of God the Mother, Existence and Love, which have so far ruled the world's creation, are to be still further assisted by the advent of the third attribute of God the Father, namely, Thought, according to our second marriage in Table II., in which we find that Instinct, the lowest order of mind and soul, marries Existence and begets Life; and although Imagination is not born until the seventh day when it starts the conception of man's soul, nevertheless soul may be said to be conceived in Nature on the fourth day when Life, the dawn of Soul, comes into creation on that day by the existence of plant life, that earliest evolution of thought on the part of Nature for future requirement. Thus Soul is in its embryo state through the fourth, fifth and sixth days, and appears in plant thought on the fourth, in material love on the fifth, by the conception of sex which is the dawn of the perfect material love of connubial affection, and in the embryo stage of wisdom in the evolution of animal instinct which starts on the fifth day, but only establishes the birth of soul on the eighth day by the dawn of man's comprehension. For it is not till then that Nature possesses an infinite soul. Yet you see in this sense it is not out of place that soul should make its first appearance in a visible form as representing its invisible attribute in our Tables upon the fourth day. The result of this is Creation, as plant life becomes more perfect and animal life comes into existence on the fifth day, for "The eve of one day is the dawn of the next," so Genesis tells us, and as in the course of evolution each action of God's attributes takes over three days.

This gives the appearance that the tables of trinity is a day in advance of that of evolution, because the result is not apparent in the course of evolution till the next day. So in line four we get the fifth attribute coming into play to create animal existence, Marriage and Sex, by the evolution of animal sex on the fifth day. This is the result of the earliest dawn of marriage now predicted in our Table II., which then goes on to show us that Wisdom marries Love on the sixth day and so produces the conception of Comprehension and the birth of Thought, as animal mind comes into existence, which 
is to prepare nature for the birth of the human mind three days later on the eighth day, and civilisation on the ninth day of creation. But as mind in animals is the commencement of Soul in mankind, it is all in due order of my Hypothesis, and also of Evolution, that Soul and Wisdom should here combine for the first time in our Table to prepare for the conception of the human soul opposite Religion and Study. But this will be explained hereafter, so I will not go into it here, but simply remark that this period corresponds with the creation of the mammoth race of animals, which is represented by biblical angels; so in this sense both the marriages of Trinity and Evolution correspond, for the result marriage corresponds with the completion of sex in its highest development human marriage. After the fifth day, when the ant-eaters, etc., are evolved, upon this the sixth day sex becomes complete as the creation of human marriage takes the place of indiscriminate selection in the course of evolution, and on the seventh day Mind is conceived and thus marks the creation of the likeness to God in the mind of mankind, so that the first. appearance of Soul in our Table was right in its order because the Human Mind is in one sense the first dawn of soul, although it is not the birth of the human soul. I therefore concluded that I would be justified in here inserting the trinity of the human soul, namely, IMAGINATION as the seventh day, COMPREHENSION as the eighth day, and UNDERSTANDING as the ninth day, as these three qualities represent the human soul in the same manner as SPIRIT, EXISTENCE and SOUL represent Infinity and Deity.

I then found that they corresponded with the seventh and eighth and ninth days of evolution which were devoted to the production of Human Will, by means of the Evolution of Imagination, the production of Skill and Agriculture through the evolution of Comprehension, and on the ninth day of the dawn only of Civilisation by the dawn only of the wisdom of Understanding. I now found that the marriages of God's Trinity again corresponded with the course of evolution. For the fifth marriage of the Trinity reads THOUGHT marries LIFE and begets KNOWLEDGE. Thought, Life and Knowledge make Study, and we find in Evolution that on the tenth day at which we have now arrived, Study commences to create Religion, and Religion is the first great result of Thought in 
the evolution of man's mind. We then come to the sixth marriage of Trinity, which reads MIND marries LIFE and begets the POWER OF HUMAN WILL. At this stage of its history the world is evolving Government which assuredly is the power of human will. The ninth marriage informs us that KNOWLEDGE weds COMPREHENSION and begets UNDERSTANDING; RESULT Science; and again we see that on this, its twelfth day, evolution has arrived at the dawn of the age of Discovery now that Science is beginning to dawn in the mind of man. Our next marriage reads UNDERSTANDING marries COMPREHENSION and begets INVENTION, the result of which is COMMERCE; and again we find on the thirteenth day at which evolution has by now arrived, conditions of barter and commercial intercourse are now extending the limits of evolution's second stage, the struggle for the life of others by the means of commerce.

The ninth marriage of Trinity ushers in the present or fourteenth day of Creation, and reads thus: KNOWLEDGE marries INVENTION and begets USE. Now the result of Knowledge, Invention and Use is that these three forces when combined enable mankind to conquer the forces of Nature, hence we may truly say that the result of this marriage of these forces of God's Trinity is the conquest of Matter, and surely the age in which we are now living is the age of Invention, and may truly be said to have produced the conquest of the material forces of Nature. For with our Telescope, Railways, Telephones and Flying Machines, have we not compassed more in the last thousand years or so, than has been accomplished in millions of years?

The rest of our marriages point, not to the evolution of the past, but to that of the future. So we find that this fourteenth day of creation corresponds with the result of the marriage of God's Trinity which our Table points out to be man's conquest over the elements, the fear of which first taught him to believe in the existence of an Almighty Creator, but which from henceforth he is to harness as prisoner to his triumphal car, and in so doing leave behind the past ages of superstition, bigotry and the darkness of ignorance. When in the coming fifteenth day of Peace amongst Nations and men of goodwill, he shall produce conditions that will make it possible for him, on the sixteenth day of creation, to evolve an age of USE, and 
CHARITY. As I have now arrived at the realms of futurity, I will leave my reader to put his own construction on the rest of these wonderfully significant marriages; but as I have shown that for over fifteen thousand millions of years, or more, certainly not less, they have coincided with the course of creation, it logically follows that they are also likely to do so in the future.

I think I have now demonstrated the manner in which God withdrew the attributes of God the Mother and of God the Soul and most of those of God the Father from the rest of His Infinite Being to bring about Creation, and is slowly returning them to bring about Evolution. So in this manner a finite existence became evolved. And the Infinity of the Almighty is materialised by the substitution of a finite visible part within an infinite invisible whole. But I here ask you if God is infinitely wise and infinitely powerful why did he not create a perfect existence? Why did he produce all this misery and suffering? For many reasons. To begin with, if God had created a perfect creation it would not only have had to be in His Likeness, but to be perfect would have had to be a perfect likeness of Himself. This would and could only have resulted in the existence of two infinite beings, quod absurdo, and we should have obtained the highest of religious evolutions when we arrived at idolatry. Also if there had been no struggle involved, VIRTUE, which is the principle of finite perfection, would never have been reached, and God being wise was sure to aim at adding some more magnificent form of Infinity to that which existed, rather than do anything that could reduce its glory and lustre, and in the creation of a virtuous finite existence wished to add fresh glory to the whole. And I have already shown that in so doing he would have frustrated the object of Creation, so the only way open to Him was to create a finite part differently constituted, but not separate, from Himself, which, through toil and suffering and labour might after millions of years of constant energy by its perseverance in Labour, Skill, Economy and Wisdom, evolve the greatest amount of Virtue possible that he might have a bright and shining diadem with which to crown His majestic head.

My Tables and figures and Nature and Evolution go to demonstrate that at the end of the world when man gains immortality there will be the same distinction, for then this 
world will be ruled by the will of man instead of the power of God, subject to a fee simple of veneration to his Creator, and three of the attributes of God the Father, viz., Invisibility, the Power of God and Memory, will be withdrawn even when man has evolved the soul of wisdom and is able to govern himself as well as the rest of creation, which he will be able to do when all the attributes of God the Father, God the Mother, and God the Soul, which were withdrawn to start Creation, shall have been slowly returned and man shall have evolved wisdom enough to understand divine revelation, which at present he can only comprehend. Religion cannot teach him to understand, for as will hereafter be demonstrated, religion is an attribute of God-the Mother and can only teach him to comprehend and believe because, being one of the properties of God the Mother, it can only descend through the female agency of mankind; so until man has evolved his own soul he will not be able to fully understand revelation, or control his acts with any approach to perfect wisdom.

Hitherto his fight has been to conquer the material forces of Nature, assisted by the possession of comprehension, faith and belief, through the refining influences of woman's love miraculously assisted by the God-born redeemers she has given to the world.

So now God withdraws his second and third persons from His first personality, and so sets free his first attribute of God the Father, the infinite power of activity; and the world's evolution now commences to be governed through the first Epoch of Faith, the age of blind obedience to the power of the Spirit of God; then through the second Epoch of Hope, by its fruitful trust in the undisputed belief in the doctrines of its redeemers through the ages of religion; and lastly through the Epoch of Charity which has in the last hundred years begun to dawn in the mind of mankind.

So now that the Spirit of God the Mother and God the Soul is withdrawn, Creation takes place in the order and sequence shown on the right-hand side of Table III., and a new existence commences by the molecules of ether of God the Almighty flying into space in the form of gaseous ether to be whirled throughout endless space, till Love returning shall slowly draw their particles together again by the action of affinity, 
the child of the divorce of Spirit and Wisdom, and the return of Existence, the first quality of God the Mothcr, commences to be reunited, and as the power of the Spirit of God the Mother slowly increases in activity in conjunction with the Spirit of God the Father, to create Life, Love, Imagination, Comprehension and Religion, the rudiments of which are evolved as the second and third personalities of God's Trinity return to Creation.

The dawn of the world commences with the creation of innumerable molecules of gaseous or loveless ether in its turn to give place to fiery planets, in their turn to become rocks, stones, earth, water and air, and to be subdivided into dead and living matter. And the material world becomes an accomplished fact, for infinity begets existence, existence begets destruction, destruction begets recreation, creation begets life, and Matter, the by-product of reconstruction, comes into existence, for Matter is only the portion of existence not required by recreation for the reconstruction of life which becomes motionless. For in the same way that infinity necessitated existence, so finity necessitated destruction and disintegration, which in turn necessitated reconstruction, again necessitated recreation. Thus a material universe made out of dead and live parts is evolved ont of but contained within an infinite immaterial spiritual existence. But remember, Infinity, being infinite, cannot be increased or reduced, or by all laws of reason and logic it would cease to be infinity. And with reincarnation a limited amount of soul is returned to the world with the creation of the mind of animals and of man, and with the reunion of Existence and Soul to Spirit, and the consequent production of Human Will, Love and Wisdom as the controlling forces of Imagination, Love and Minds are created to supersede the previous developments of the Trinity of Instinct or animal mind, composed of power (the force of action), Thought and Life, and thus the second epoch of Creation dawns upon the world of Evolution, THE EPOCH OF HOPE.

Before bidding adieu to the Epoch of Faith, I must pause to define the distinction between Power and Will. POWER is the Spirit of God that is able to will and perform; WILL is the power of man that is finite by which he performs what he is able, and the Epoch of Hope is to evolve his will. 


\section{THE EPOCH OF HOPE.}

As Evolution proceeds on its slow course through this Epoch of Hope which extends from man's triumph over the animal creation, when learning how to sin by evolving a will of his own which gave him the possibility of ultimately gaining the reward of immortality, down to the year of I800 A.D., we follow the gradual return of the Spirit of God the Mother and her attributes to mankind through the agencies of woman's love and the influences of religion and redemption to the completion of the Epochs of Hope; of Devolution and of Evolution. For Faith and material life were governed by the spirit of divine obedience, till love dawns to cast the light of belief and comprehension after the dark night of Faith when creation was dominated by the uncomprehending obedience of matter and animal existence to the all-powerful control of the Infinite Spirit of God the Father, to be superseded in its turn by the return to creation of the Spirit of God the Holy Ghost in the ages of the yet unborn-in the Epoch of Charity-which has just begun to dawn during the last century, in which man is to learn to understand the truths of divine revelation.

When "knowing, he shall "understand all things even to the consummation of the world," and last but not least be a religion unto himself and learn how to use, not abuse, the knowledge God has granted to him but has denied to the angels or animal kingdom. But bear this in mind, the extent of the spiritual creation cannot vary but may alter, matter may vary but cannot alter in quantity, the Almighty cannot become greater or less, God cannot grow or vary; and continues to surround and govern and control all and every part of the fragment of Himself (for the whole universe of heavens and planets and stars and earths is but a fragment of the immensity of the Infinity of God), whose power is invisible, unaltered and unweakened by its severance, and continues to control and nourish the fragments of Infinity $\mathrm{He}$ has created, while the final objects of His human work and animal life are being evolved. For man is only given a limited amount of freedom of action, and the use of his free will is limited practically to a few choices in his life, as to whether or no he chooses between good and bad, and the rest is practically in the hands of Fate, and he and all else must for ever be subject to the 
unalterable law of descent, or, in other words, the survival of the fittest, so that all of us that have not lost our chance of immortality may say with Christ : "Before Abraham I am." Think, oh you who are tempted to selfishly injure your neighbour by being indolent, wasteful or vicious, before you condemn some, if not all, of your children or their children's children to lose their souls before becoming eternal, for then God will not grant you a new soul, and you will ultimately condemn them by your sins to lose their chance of Immortal happiness, as the earlier creation of plants and animals have already done, and their souls can then only be absorbed by the souls of those who prove themselves better fitted to survive.

A soul that God has, by millions of years of evolution, handed down to you to still further bring to perfection if you have the courage and energy to devote to your duty and the good of the rest of your fellow-men, and which if you fail to do, your children will in the course of evolution become "blocks and stones and senseless things," condemned to eternal damnation or at best to be absorbed by those who are descended from families who have not wasted their opportunities or prostituted their love of God and their fellow-men. Oh, do not destroy that image of Himself in your soul that can alone grant to your children the power of regaining in future ages the possibility of attaining an appreciable likeness to the Soul of God the Holy Ghost which was withdrawn that creation might exist, and the attainment of which is to be the ultimate reward of those who persevere to the end in the fight to be the fittest and most useful and most charitable of mankind; particularly those whose charity takes the form of kind acts, deeds, and the forgiveness of their neighbours' faults, and who assist others in the battle of life, rather than acts of almsgiving, except in such cases as really call for relief. For we must always remember that advice given unasked is impertinence in disguise, and assistance unrequired in the same way destroys the spirit of self-reliance and energy, which are and always will be the highest virtues. So indolence and the reliance on the bounties of others always produce loafers and unemployables, who are the greatest of all criminals. For heaven is, as the Scriptures state, only for those who gain it " by the sweat of their brow," that is to say by mental or physical labour. 
I now intend to call the reader's attention to the interpretation of these Tables. Taking line one we have the first of the two divorces of the Trinity of God, the divorce of Love and Existence, that is of the entire second personage of God from all but the first attribute of the first and third personalities of His Trinity. This removes Love, Life and all the other female attributes of God (see Table I.) and all but the first of the two male personalities. This divorce brings about destruction and disintegration of the electrons of the ether of infinity.

This must be the first stage of creation, for the hypothesis of creation is Disintegration begets Destruction, Destruction begets Reconstruction, Recoustruction begets Affinity, Affinity begets Creation. Now to bring this about (for the reader must bear in mind that it is a necessity of the development of creation by my hypothesis that at no time shall the entire twenty-one attributes of God's Trinity be entirely present, dominant or active, at one and the same time, or you would have two Infinite Creations-a logical impossibility). It is therefore necessary that all but one or two of the attributes must be divorced or withdrawn from the rest to enable the finite portion of creation to exist. So we are now about to follow the gradual withdrawal and return of the diffefent attributes of the Trinity of God as they bring about creation in the course of evolution. This is started by God withdrawing all the attributes of God the Mother and allowing the first attribute of God the Father, the spirit of Motion, Light and the centrifugal repulsion that distributes his influences and graces and activity throughout the INFINITY OF HIS ETERNAL AND OMNIPOTENT EVERLASTING EXISTENCE, to act on their own resources, controlled by his Infinite Wisdom only, but which in the course of evolution dominates and controls creation, result-Disintegration and 
Gas. The withdrawal of Love or Existence from Spirit and Soul now leaves the Finite portion of Infinity to be controlled by infinite power, and to a slight extent by infinite wisdom, which in this case resolves itself into motion, the logical result of which is the activity of infinite invisible power or motion controlled, to a slight extent, by infinite wisdom, but uncontrolled by Love or Affinity.

Now, activity controlled by wisdom and uncontrolled or uninfluenced by affinity or thought must produce and can only produce the wisest form of destruction-namely, ether in the form of gas. The result of this is the first stage of Convolution and No. I, the first day of Genesis, and No. I in Table II., which produces the formation of and existence of gaseous ether in infinite motion, which is the stage when God created light, the stage of destruction and disintegration which is to evolve the firmaments of Heaven. God said "Let there be light."

No. 2, the second day of Genesis: We now come to the second stage, and to No. 2 in Table II., when the second divorce takes place. Now Soul is divorced to be gradually returned to this earth when Man is evolved. But until then the evolution of the world is to be carried on and directed by the First and Second Personages of God's Trinity only, and visible existence is to be produced by the return of the first attribute of God the Mother which was withdrawn at the first divorce, and Existence or Love returns to assist Power or Activity to carry on the evolution of construction by the return of the Spirit of Love producing affinity of the molecules of disintegrated ether which the Spirit of Power has now distributed throughout space, and the world of planets, and stars, and earth are created by the love of affinity drawing the molecules together again, and so forming nebulae, for the affinity of Love of each other has caused the particles of ether to reunite by the forces of chemical action, attraction, and gravity before they were whirled into the endless limits of eternity, that bourne from which there is no return, which would have resulted in total destruction. This is what is termed the Age of FLAMES. The divorces of the Trinity are now complete and the marriages commence.

No. 3, Power, the finite attribute of Spirit marries Existence and begets Love, the result of which is Reconstruction (see line 3, Table III.). This means that the Spirit of God, 
which is invisible, is now to be replaced by the power of God becoming visible. Creation is no longer made up of invisible gases, but assumes form and shape, and is now transmogrified into visible forms and shapes of material stars and planets.

No. 4. We have now arrived at line 4 in our Table, which is the fourth stage of evolution, and the fourth day of Genesis. Turning to our Table we find that it celebrates the marriage of Soul and Existence, the daughter of which marriage is Life, for plant life now comes into existence, and so starts creation. Hitherto we can hardly say there has been any creation. The world has only existed devoid of life or self-control in any of its fundamental acts. It has only been a dead inanimate by-product of the work of the Creator from whom it has been severed, or what in the true sense of my hypothesis I may better term almost dormant influences of the attributes of His divine Trinity now about to slowly awaken from their slumbers. And the creation of plant life is its first act of awakening.

No. 5. On the fifth day or stage of existence, this awakening progresses in the evolution of animal life, the completion of which is to arrive at its maturity with the evolution of sex and mammal animals. Hence Sex or Marriage may be taken as the correct spiritual index figure of this period of evolution.

No. 6. Concurrently, but a stage further along the road, we also find the sixth day of creation commences its course along the track of evolution by the creation of nerves, brain and animal mind on the sixth day of Genesis, which are to culminate in their perfection in the highest evolution of animal existence, the man-apes who are to dominate over all other forms of material existence. Up to this period of creation only the influences of the three first attributes of the two first personalities of God's Trinity can have been said to have taken any active part in creation, viz. :

r. SPIRITUAL INVISIBLE POWER OF MOTION, the first attribute of God the Father (Table I.), becomes active in the formation of the invisible electrons in the invisible gas destined ultimately to become visible dust, out of which nebulous formations are to arise. This constitutes the first day of Disintegration, the first word in the fourth column of Table II.

2. EXISTENCE, the first attribute of the second person of God's Trinity (Table I.), now begins to exert a preponder- 
ating influence, and the second force in our Table II., Affinity, collects together the dust of electrons, and

3. Nebulae and planets fill the firmament with innumerable stars and planets, and so we move on till the invisible power of the first day becomes the visible material power of the chemical action of material construction (see line 3 , Table II.) and the world is ready for the dawn of creation, and we have now two forces of God the Father and one of God the Mother active instead of dormant forces of creation.

No. 4. On the fourth day, the second attribute of God the Mother, Love, becomes active with the creation of plant life. as the love of the mother for the offspring starts with the material creation of love, the creation of seed, and so moves creation on a step further ahead.

No. 5. On the fifth day or stage "Thought," the third attribute of God the Father (Table I.), comes into play as MARRIAGE, and Sex causes the first dawn of matrimonial affection or love of others, and sows the seed that is ultimately to give birth to society and its distinctions.

No. 6. On the sixth day the third attribute of God the Mother, Life, comes into existence, creating the mind, for until the mind was evolved even animal life could not be said to be more than partially evolved.

No. 7. On the seventh day Imagination, the fourth attribute of God the Father, becomes active, and the human mind, supplanting the animal mind, we can now with the activity of four qualities of God the Father and three of God the Mother say that the first foundation of the soul, the first attribute of God the Soul begins to exert its influence in its mildest form, and that with the dawn of the human mind comes the first creation of man and the first true likeness in nature to the Trinity of God in Nature, although it will be two days later with the dawn of Civilisation before we can say that the soul is born and this likeness even approaches any form of reality, when on the ninth day Civilisation ushers in the birth of soul.

But to return to Table II. On the sixth day we find Wisdom marries Love and creates Comprehension to give birth to animal mind. On the Seventh Day Imagination, by urging him to set his will in opposition to Nature, paves the way for Comprehension to be born on the Eighth Day of evolution (see Table III.). 
But to return to the Fifth Day of creation of Sex, this day or stage is now to find its first dawn on this the sixth age, stage or day of creation of the angels or animals, which means the mammoth animal creation, which is to be superior to man, but which he is destined to ultimately supersede and conquer. But this mammoth creation is to be the most perfect age of animal creation, and we have arrived at the first dawn of marriage in the creation of the animal world. This is the eve of the Fifth and the dawn of the Sixth Day of Genesis.

The Seventh Day of creation is the last day of the Epoch of Faith or creation of the world, and marks a new departure in existence, to account for which has puzzled all past students of evolution, but the Tables I. and II. remove these stumbling blocks (see Chapter 4, Book II., on Evolution of Mind). For man is to commence to evolve a soul as well as a mind, as we shall show. This is not to take place yet, but Wisdom and Love having now married, the conception, not birth, of Human Will starts, which resolves itself into Will in mankind, which man has now attained by learning to sin, and by learning to stand upright he has made the evolution of a soul possible. Take note here that this new departure concludes Convolution, and is the first creation of God's likeness in mankind.

So we arrive after the stage that is on and after the Seventh Day at the Epoch of Hope. Now up to this stage of evolution the development of the world has been conducted by the guidance of the personality of God the Father, assisted only by a very partial influence of the attributes of God the Mother, but from this point Creation will be dominated over by the influences of God the Mother, slightly assisted by those of God the Soul as well as by the Spirit of God the Father. But God the Soul will only exert a very limited influence over the development of man's mind until after the year I800 A.D., which marks the manhood of soul in mankind by his evolving the power of Understanding. But we have arrived now at the dawn or conception of Soul, if not at its birth, which commences with civilisation on the gth day; so now the reading of Genesis is altered. It is no longer "God made this" and "God made that," but " let us make man to our own image and likeness," for we have come to the earliest age in the course of evolution when the conjoined influences on the world of the three personalities of God's Trinity unite to further the 
evolution of Creation. For now the mind of man is to be evolved by the process of evolution in the course of time to produce the trinity of the human soul (see line 4, Table I., i.e., the powers of Imagination, Comprehension and Understanding). And with the creation of man's mind and soul, out of the instinctive mind of animal, evolution makes a new departure that is to be the labour of the Epoch of Hope. Coming events cast their shadows before; thus we will find that the latter part of the Epoch of Hope is devoted to the evolution of religions, governments, and science. The time we are now dealing with is the end of the Epoch of Faith, which finishes with the creation of mankind from his animal existence, during which epoch of Faith conformity to the will of God has controlled all creation. The first part of the Epo:h of Hope commences with his civilisation and fight against the savagery he has created in his efforts to become the most perfect human beast imaginable, and so prove his right to be placed at the head of the animal creation. But before entering upon the Epoch of Hope I will review how far we have travelled along our Table II., and we find the seven days we have travelled stand thus : Ist, SPIRIT ; 2nd, EXISTENCE; 3 rd, POWER OF GOD; 4th, LOVE; 5 th, THOUGHT; 6 th, LIFE; 7 th, SOUL on the one side; and on the other: ist, DESTRUC'TION ; 2nd, CONSTRUCTION ; 3rd, MATTER; 4th, CREATION or LIFE; 5 th, MARRIAGE; 6th, MIND; 7 th, SOUL OF MAN.

Now if we submit these figures to our mathematical Tab?e, Table IV., we find that Nos. I, 2, 5, and 8 represent imperfect or transitory stages of creation. Now picking these out, we have DESTRUCTION and CONSTRUCTION, which are imperfect and transitory stages, also MARRIAGE, which will during Evolution fluctuate between polygamy and monogamy. No. 3, MATTER, and No. 6, MIND, are to become perfect by the end of the world and complete in some form or other. And No. 4, LIFE, and No. 7, SOUL OF MAN, which are to last for all eternity but which are not to be perfect till man gains IMMORTALITY.

Before going further I wish to draw attention to what will be demonstrated in our subsequent chapters-that nothing is correct in knowledge, science or religion, so far as it relates to evolution, which will not bear the test of being reduced to 
a perfect trinity. For if it is not a trinity, it is not a true likeness of God, and Genesis is most emphatic in its repeated reiterations of the fact that all nature is in the likeness of God's Trinity. Therefore I wish the reader to note all complete results are the product of three concurrent forces out of which is evolved a new result, that forces not in trinity never become complete in nature. We must therefore seek for a trinity of causes if we desire the truth of any proof of theory. This means that if you reduce a thing to its trinity you have a very sure way of checking its correctness and ascertaining if it is true or false. I may here state that the study of these Tables has enabled me to correct many misconceptions I have hitherto held on the science of evolution and of life by putting them to this test. I therefore think it will be well here to make a review of the trinities which mark each day of the twentyone days of the three weeks of creation:-

First week is the Epoch of Faith, the trinities of which are : Ist. Spirit, Wisdom and Action make Power: Age of Gas. 2nd. Spirit, Love and Action make Chemical Action : Age of Construction.

3rd. Power, Love of Affinity, and Existence make Matter.

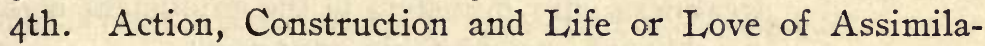
tion form the creation of plant life.

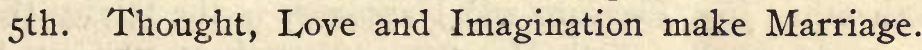

6th. Wisdom, Love and Comprehension make Mind.

7th. Mind, Life and Action make Will : Creation of man and $\sin$.

Second week is the Epoch of Hope, the days and trinities of which are :

8th rst. Mind, Thought and Imagination make Knowledge: Age of Agriculture.

9th 2nd. Comprehension, Energy, and Justice make Civilisation.

Ioth $3 \mathrm{rd}$. Imagination, Love, and Soul make Religion.

IIth 4th. Mind, Life and Power make Government.

I2th 5th. Knowledge, Study and Comprehension make Science.

$3^{\text {th }} 6$ th. Understanding, Comprehension and Invention make Commerce.

I 4 th 7 th. Knowledge, Invention and Use conquer Nature.

(This is as far as the world has now progressed.) 
The future is about to evolve the third week, that of CHARITY, whose trinities will be as under :

I5th Ist. Use, Invention and Peace make end of Wars.

I6th 2nd. Peace, Comfort and Content make brotherly love and Charity possible amongst communities and societies of mankind.

I7th 3rd. Comfort, Content, and Charity destroy Jealousy, Individual Animosity and petty ambitions, thereby creating contempt for crimes of selfishness, hate or revenge, and cruelty and intemperance.

I8th 4th. Comfort, Pleasure and Happiness are the trinity of rewards which the fast approaching culmination of His evolution is now bestowing upon mankind as the reward of his well-fought battles to become the fittest of the fit.

Igth 5th. Happiness, Pleasure and Contempt of Folly are the Trinity of rewards which is to be the recompense he is to receive in return for learning to sin with such perfect self-control that his human weakness only ministers to the enjoyment of his neighbours, not to their annoyance.

2oth 6th. Joy, Pleasure and Happiness is the trinity that makes earth Heaven, so that those who can be wise enough during this life to live up to this perfection of natural wisdom can make this earth Heaven before death.

2Ist 7 th. Life, Soul and Wisdom are the trinity that is to enable the majority of mankind when they have destroyed the devil of human beastliness which placed them above the animal kingdom, to finally triumph over the fallen angels and gain the final reward of Immortality.

Before going further I must make a few remarks on this epoch. One of the characteristics or marks of evolution is that it never advances straight ahead but first moves three steps forward down the column of Spirit. (This has been noted by most students of Evolution, but without any particular theory as to the manner, or reason or way in which its retrograde steps were brought about, for it was difficult to define to what 
extent or in what manner this was influenced. I now wish to illustrate to the reader how these Tables and my Hypothesis explain the method God has adopted.) The Spirit of Power moves three steps and then returning to the column of Existence moves that on another step, now retraces its path to the column of Soul and moves that on a step. In this manner each column is kept two steps ahead of the one on its righthand side, and as will be illustrated later on in this treatise, each evolution in turn is destroyed to make room for the one that is following in its wake. Genesis, it will be shown, is written in the same order. I wish the reader to keep in mind that what is a virtue in one stage of Evolution is a crime in the next. Thus in the Epoch of Faith murder is one of the virtues which enables man to triumph over the animal kingdom, but it becomes the highest crime by the end of the Epoch of Hope. So in the Epoch of Hope war is made the highest of virtues, but in the Epoch of Charity, yet to come as irvolution advances, war is to become as high a crime as murder is today. But were this not so, Commerce would never have been established, or Invention evolved or the world exploited. So also in the latter part of this same Epoch of Hope, Selfishness is to be the virtue that is to spur man on to conquer worlds and create Commerce, when it is in its turn to be conquered by Charity, after which man will be able to wipe out all classes of crime, which will be achieved by Evolution exterminating all who cannot learn to sin without injury to their neighbour, which is ultimately to become the acme of perfection. And this will be the only way that man can gain Heaven and Immortality. For sin will cease to be an evil when man can $\sin$

Firstly : Without marring the pleasure of others.

Secondly: Without injuring others or making them discontented.

Thirdly: When by so doing he adds to the pleasure and happiness only of others, not to their injury.

Hence it follows that when man learns how to sin without causing Discontent, Sorrow or Grief, sin will no longer be a crime. For what wrong can there be in an act which injures no one, and only increases the happiness of others?

The mathematical table which this Hypothesis evolves shows the equation of creation to be 
GOD equals 2 males and I female equals Infinity.

MAN equals I male and 2 females equal Immortality.

ANIMALS or ANGELS equal I male and I female equals Death.

This works out as follows :-

GOD who being INFINITELY PERFECT can neither SIN nor DIE.

MANKIND who being FINITE, when perfect must sin but cannot DIE.

ANGELS or ANIMALS which being for ever IMPERFECT cannot SIN but must forever DIE.

For had man not learned to sin he could never have evolved a Will of his own and thus would never have been able to merit any reward for acts performed and there would be no need of Heaven, for there is no virtue in being good because you do not wish to do wrong (see chapter on Virtue and Crime), for it is only when we overcome wrong that we merit reward. But do not imagine, dear reader, that I wish to advocate sin at the present time, any more than I would have advocated peace in the past, though since I have discovered this table I am convinced that the day will come when wars will be no more and crime will practically be a thing of the past. But it is only a few months back that I held very strongly to the opposite opinion, and would have argued just as firmly that it was absurd to imagine that wars would ever cease. The reader must realise that sin is weakness and folly as apart from vice or crime.

It also follows that if Man should become perfect, and at the same time cease to sin and gain immortality, he would then be God's equal, which would of necessity evolve two Infinite beings, for man is made in the likeness of God, and logic will not admit of two Gods, for if such a thing were possible, there would logically be no sin in idolatry; so you see what a mess you get into if you start to dispute this equation. On the other hand, if he ceased to sin and should not become perfect, he must forever remain no more than a high-class animal and be unworthy of Immortality, for it is only his prerogative to $\sin$ that places him above the animal kingdom; which in many other respects are more perfect than he is. So that when you take all these matters into consideration, I must 
admit so far as I am able to judge, it is wisest not to aim too high, and to accept the only logical solution that remains, which is that the height of perfection of life is temperance in all things, not total abstinence, and that it is better to be an honest sinner than a hypocritical saint.

Now I have already shown that evolution moves three paces forward and then two back. When we review Table II. in this light we notice that God first divorces Existence, secondly divorces Soul. He then advances Power to Thought, which brings us three paces down the column of Spirit and then goes back and brings Existence up to Love. Then moves Spirit up to Existence to create Life, and then goes back to fetch up Existence another step to create Animal Love, and now goes back again three steps to Soul to get the seed for the Mind of Man, and then goes across to the Left to get Love to come to the front to start animal marriage. When the reader comes to the chapter on Genesis, in Book II., he will see that the same method is observed in the description therein given, and that this is what is meant by the use of the words "the eve and the dawn were the third day."

Turning to our Table, and reading horizontally across the page, we get Power, Existence and Love make Matter, but reading diagonally across the page from the column of Existence to the column of Spirit, we get Thought, which is now to come into existence by an increase of the return of the Spirit of Love to creation so as to create Life on the fourth day. In the same way on the Fifth Day we retrace our steps diagonally to the column of Soul and bring up the lowest order of this personality of the trinity to create animal mind and animal life which are to be the development of this age of evolution, although strictly speaking Soul will not dawn till the Seventh Day, when man is to gain Imagination; yet the creation of the animal mind may almost be considered as the earliest dawn of Soul, nor will it be born until the coming of Understanding on the Thirteenth Day. I will in a subsequent chapter show that the dawn of Soul on the Seventh Day, and its birth on the Tenth Day mark two great new departures in the methods or laws of Nature and Evolution, a fact that hitherto no Hypothesis adduced by science or students of evolution has been able to account for, that is, the change and development of the mind of man from the mind of animal. 
Now the eve and the morning of the $5^{\text {th }}$ Day, make up the $5^{\text {th }}$, 6th, and the 7 th Days which are to mark the creation of the body, mind, and of Imagination on the 7 th Day, which is the day that marks the first dawn of Soul proper in the mind of man. Thus, if the reader studies Tables I., II., and III. carefully, he will find that they are correct in order and correspond with the course of evolution. I wish here to point out to the reader that the biblical day of Genesis is not a day of the week, but a day of evolution. The entire course of evolution is made up of three epochs or weeks of seven days or stages. These are-Ist, Faith or Convolution; 2nd, Hope or Evolution; $3 \mathrm{rd}$, Charity or Involution. But as Genesis only deals with the first week-namely, pre-historic creation, its statement is quite correct that the world with which it had to deal was made in six days, and finished on the 7 th, for it took six days to make the world and the Seventh Day was devoted to making man's mind and was to mark his superiority over the world of angels or creation of mammoth animals, as also the evolution of human will, which was to be his first step towards the development of the human mind and soul. So the statements are quite correct.

To return to the Sixth Day, with which we are now dealing, we find it marks the dawn of animal mind and the inception of Imagination, in its humbler form of animal instinct. In the column of soul we find we have arrived at mind. Now the Sixth and Seventh Day mark that at this period the development of God's Trinity is to commence its first stage by the evolution of the animal mind, which, as will hereafter be shown, is evolved from the attributes of the Trinity of God Almighty, and also to impress upon our minds that the Spirit of revelation is now to take an active part instead of being dormant, as it has been heretofore, in the creation of matter during the seven days of Faith. But we must bear in mind that in this the animal stages or ages of evolution there is nc, such thing as virtue, for virtue necessitates knowledge of right and wrong. Hence we can only at present follow the evolution of the lower types of the properties of the development of the Trinity. Hence the germ of a more perfect development of mind is in this period confined to the animals selecting the most perfect of their numbers in physical development to act as leaders to the rest. And man as ape men 
start the germ of veneration by selecting their fittest as leaders in their effort to supplant the kingdom of angels or other animals of mammoth creation more powerful than themselves.

This is the first step of man's upward rise, made probably about the end of the 6th Day, to which our Table has now brought us, and which is ultimately to create that spirit of emulation that is to make him the king of beasts or the Lucifer of this the age of Lucifers or of human beasts or devils. When on this, the 6th Day, he learns to use his dawning self-will to kill for the love of killing, for hate and for amusement, not for food or self-defence, and so murders his fellow-animals, and this evolves to its highest degree the art of sinning by becoming first a murderer and then a cannibal, and so obtains superiority over the rest of creation by excelling in the arts of sin, for it is by learning to sin in temperance, justice and moderation that man is to achieve his redemption at the end of evolution. So perfection in this epoch means perfection in vice and crime, and can there be any greater perfections in the arts of crime and vice than those of murder and cannibalism, the two animal crimes that now make mankind become the most perfect animal in creation by becoming a human " devil " (for mankind, not God, made the only devil that has ever existed); and in this way the mammoth animals (who are the angels of Genesis) fell from the high estate of their early magnificent creation, to be supplanted by the comparatively insignificant creature man, whom, in their strength and might they had cast out of their earthly paradise of plenty and compelled to take refuge in the limbs of the trees above their reach. So mankind, having now taken the advice of the serpent, that is to say, followed its example by becoming carnivorous, and so eating of the fruit of the tree of knowledge of good and evil, that is to say of meat instead of fruit, the natural food of other apes.

It also appears probable that religion is to be ultimately supplanted by man's perfect knowledge of the truths of God's revelations when he shall have so far developed as to be able to walk in the perfect Understanding and Comprehension of the knowledge of the truths of revelation, instead of, as at present, having to be led by the hand of religion in Faith, Fear, Love and Obedience. And at the same time it enables our Table to point out that when he shall in future gain 
immortality a more perfect form of marriage will supplant the more animal one, at present existing on the Fifth Day, by the evolution of a more perfect form of the marriage of kindred soul to soul that shall be eternal and everlasting, and devoid of jealousy, infidelity and other passions. And when the world is fully populated with all wise beings, and woman, having with God's assistance redeemed mankind by her love and suffering in childbirth, becomes barren and earns the reward for all eternity of the true and constant love of a perfect husband, which has for ever been the aim and goal of her human hopes and existence, and free from the burden of family cares, in this manner to reap the just rewards of her well-fought battles, and then birth and death shall be no more except in a minority of cases which will remain to punish those who fail to evolve to perfection, and will be necessary to replace death by accident, which even in heaven will necessitate a few cases of rebirth, for although crime will be practically prevented, it will never be entirely abolished, so punishment by death must still come in a few instances.

Reverting now to the Fifth Day, the creation of animal life as separate from that of birds, fishes and plants, and we find that when we read across the Table we have progressed down the column of Soul to the result of marriage, and have arrived at the conception of comprehension, which is to be born on the Eighth Day when ceremonial marriage is to take the place of animal marriage or indiscriminate selection, under civilisation and religion, as they replace the lower orders of savagery and idolatry. (Note: I may mention that much has been written on this subject, but since I have started to study the course of evolution from the base of these Tables of God's Trinity, I have come to the conclusion that all other ways of satisfactorily accounting for these transitions must fall wide of the mark.)

This again brings us back to the Seventh Day, the age of Cain or animal murder, when man by conceiving the germ of imagination learns to sin, and evolves a will of his own, whereas hitherto the angels or animal kingdom have had no will of their own, so have followed the will of God, but man, by learning to sin and stand upright, has established a new departure in evolution, for by so doing he has developed his will, which is in due course of time to evolve his mind, and a soul that will enable him, by overcoming the crimes his sins 
may lead him to commit, to become worthy to gain the reward of slowly evolving a perfect soul, worthy of an immortal existence.

But in the Epoch of Faith he has only had to develop a perfect body and shape. We now find that by his love of fighting, and by the fact that during his life he has also learnt to stand erect, he is fit to evolve a mind. This has not been the result of a moment, for whereas it has, so far as we can approximately estimate, only taken over half a million of years to evolve his mind up to its present standard, we cannot put the time devoted to the development of this upright position down at less than nine or ten millions of years, so much more rapid is the development of mind than of body. And there is nothing more striking than the second great departure that has taken place during the last one hundred years. I allude to the rapid manner in which we now change our opinions on subjects as compared with the rate of thought before man had come, in the course of evolution, to the age of understanding, which he has only attained during the last century. When we stop to consider that it took the Egyptians over two thousand years to realise the folly of drawing an illustration to explain the meaning of each word they wrote, this seems to me to be as great an advancement as that which he made when he left off barking or chattering like an ape, and started to talk.

He has now learnt to stand upright, and this, as will hereafter be demonstrated, permits of his coming under the influence of the electrical currents and influences that produce mind and soul. Under these influences he will in future be able to develop and acquire the properties and attributes of God the Holy Ghost, to be influenced by which forces to any great extent, it is necessary that the spine should be in an upright position. Thus his animal mind of thought is turned into a human one, endowed with the soul of Imagination, Comprehension and Understanding, so that he is now able to evolve a soul capable of the powers of conception. This marks the first great departure in the course of evolution. The second does not arrive until somewhere about the year I 800 A.D., and we are now discussing a period somewhere about three hundred thousand years before Christ.

Dear reader, please try to keep this constantly in mind, 
that the evolution of the attributes of God the Father are always two days in advance of those of God the Mother and three days in advance of those of God the Soul, although the three evolutions overlap and are so to speak concurrent but more or less antagonistic.

Now, turning to Table III., you will find that the Seventh Day, with which we are now dealing, marks the age of Cain, or the stage of evolution which is devoted to the fight between Savagery and Civilisation, when man, having attained perfection in murder and cannibalism, thereby established his supremacy over the rest of creation, and so fitted himself to receive a soul of wisdom, or at least its first attributes of Imagination and Comprehension on the Seventh, Eighth, and Ninth Days to evolve Agriculture and Civilisation. When the germ of Understanding is now to assist him to develop civilisation and agriculture, and help him to overcome those crimes by leaving his life of nomadic hunting, and taking more to a vegetable diet, for the sin wherewith Eve was tempted was when the serpent or mammoth creation of reptiles tempted her as an ape to leave a fruit diet for one of meat and asked man to kill to appease her hunger, not for self-protection, which constitutes animal murder. Woman is now to be the means of making him relinquish his life of hunting and murder, and as her love of home now begins to exert some influence on her life, of helping him to reform these crimes, and to evolve religion and society and so to merit the reward of forgiveness.

So as he progresses during the Eighth and Ninth Days, the age of Cain or age of agriculture, and the age of $\mathrm{Abel}$ or age of civilisation, to evolve the qualities of soul, viz., Imagination, on the Seventh Day, and Comprehension, on the Eighth Day, and the dawn of Understanding on the Ninth Day, his mind will then have sufficiently developed for woman to be able, by the aid of religion, which is evolved on the Tenth Day, to crush the head of the serpent of man's murderous and cannibalistic propensities.

We have now carried the comparison and explanation of our Tables II. and III. so far as they relate to the Epoch of Faith, and have arrived at the Eighth Day, which is the first day of the Epoch of Hope, during which man is to perfect his human body by the acquirement of habits of work and 
energy, and, having now been turned out of the Garden of Eden, he has to earn his livelihood by the sweat of his brow, through this Epoch of Hope, which is the epoch of strife, wars, cruelty, selfishness and hate, during which he is to evolve a human instead of an animal mind.

This epoch, therefore, commences with the age of Abel and Cain as representing the Aryan and Mongolian forms of civilisation, and its first two days are devoted to the formation of the human mind by the evolution of the powers of Imagination and Comprehension, which produce Civilisation and Agriculture. It will be seen from this why I have inserted in its particular place in Table III. the human soul of Imagination, Comprehension and Understanding, which is the Trinity of the human soul, just in the same way as Spirit, Existence and Soul is the trinity of the Soul of the Invisible God. Please also compare with Tables I. and II. The development of these qualities of soul is next to give rise to the evolution of religion and study and governments, in the order shown in Tables II. and III.

This age marks the evolution of agriculture and the dawn of civilisation, which we may justly consider as also the dawn of the human mind and the first conception of the birth of man's soul, in the form of human wisdom, which, you will notice, marks the Sixth Day, by the dawn of mind, Table III. The reader's attention is here drawn to the fact that the trinity of soul, which forms the first trinity of the result of the trinity of attributes, if read down Table I. to line four, that is to say, Spirit, Power and Thought make Imagination, gives in line four Imagination, Comprehension and Understanding if read across the page, and is also the trinity of the soul of man, and its production in the mind of man is the main object, work and result of the whole labour of evolution from the commencement of creation to the end of the world.

This forms the work of the Epoch of Hope, and is also the end of the seven days of creation in Genesis, described as the Epoch of Faith. Now the finite trinities of mind and soul are-

The first finite trinity of God, POWER, LOVE and WISDOM. 
The trinity of the soul of man, IMAGINATION, COMPREHENSION, and UNDERSTANDING.

The trinity of the mind of animal, ACTION or MOTION, THOUGH'T and MIND.

So the reader will now see that this is the fittest place for the insertion of the trinity of soul, in Table III., and when we have inserted it in this manner, which is done and shown in Table III., after marriage No. 4, Day Six, see Table II. We find that as we have also inserted the two divorces of trinity in their place at the commencement of Table III., this places Religion, which is No. 5 in the Table of marriages as No. ro, so it now corresponds with the result of the fifth marriage which appears as Study in Table II., and as Study evolves Religion it is not out of place in this arrangement, and then all the rest of our marriages of trinity are found to correspond with the days of evolution and creation. I am also of opinion that the Hypothesis I am now expounding is the only one that will account for the involution of man's mind (see Book II., Chapter 6).

We noted that on the Seventh Day we celebrated the triumph of man over the animal kingdom by his learning to sin, and henceforward till we reach the Fourteenth Day of the world about the year I80o A.D., man will be devoting his bodily energies to the evolution of his mind and to the conquest of the world of matter he is to govern when he has learned to conquer the crimes it was necessary he should commit to enable him to conquer the world and the animal kingdom; not to conquer sin, as divines would have us believe; and to learn how to be able to gain the reward of the virtues he is thereby evolving. As he learns habits of temperance and overcomes abuse of God's gifts, he will proceed to evolve his soul.

I think. I have now reached the fit and proper place to illustrate that there is a marked difference in the abstract view we are compelled to take in a subject like this from the manner in which we have to regard the same subjects in ordinary conversation or in our ordinary acceptance of the terms. And although not intending to advocate $\sin$ in its common acceptance of the word, or to detract from the enormity of crime, it is nevertheless necessary to the true understanding of the 
subject that I should here pause to illustrate to the reader that in the abstract Sin, Sickness and Poverty are the three great blessings or weapons that God has given to man to arm him for the fight of evolution and to enable him to ultimately attain virtue. For now man by learning to sin has sown the seed of human will and wisdom-for sin is only a collective name for folly and failure-which will evolve into the existence of the birth of understanding in the nineteenth century on the thirteenth day of evolution, and its conception on the eve of the ninth and morning of the tenth day, which marks the birth of religion, and will be completed on the thirteenth day when Commerce, the child of Religion and Government, is to come into the field of evolution, after which man will by invention of steam and other mechanical contrivances, complete the chain of universal commerce throughout the world.

After which wars, of a hitherto unprecedented magnitude, will start, not as heretofore for the conquest of Empires, but to bring about the prevention of crime, and to destroy those unfit for mental development. For up to the end of the Fourteenth Day of creation body is to control mind, but in time as we reach the end of the Fourteenth Day presumably somewhere about the year 2000 A.D., Wisdom is to achieve the results of its triumph over Government by Ignorance and produce universal peace amongst nations and teach man to use, not abuse Nature's gifts of time and energy and brains, and establish forms of government that shall enable mankind to overcome crime in himself as well as to conquer the material world, so completing the evolution of his mind and soul which started in the mind of animals on the Sixth Day, and in men on the Seventh Day of the Epoch of Faith, runs through the Epoch of Hope, and is to be complete on the Seventeenth Day of creation, thus intermingling the Spirit of God the Father with those of God the Mother and of God the Soul.

I will here digress to remark that the term God the Mother will be used in this treatise solely because it is important that the reader should grasp the existence of a female gender in the Trinity of God so as to realise the force of the arguments adduced in support of the Hypothesis I am endeavouring to place before the reader, that the first and third persons are of male gender, and the second is the female gender of God. 
But we have as yet only arrived at the Seventh, Eighth and Ninth Days of Evolution which mark the inception of Soul and the birth of Mind in mankind, when God said "Let us make man in our own image and likeness." This is the first occasion since the commencement of creation, that the whole of the three persons of the Trinity of God the Father, God the Mother, and God the Soul have all three conjoined to take part in the work of creation. So upon the Seventh Day which completes the creation of the world in the Bible God has carefully used the words: "God created this, or God created that to recreate itself to its own image and likeness." But now the wording is altered to "Let us create man to our own image and likeness," thus strongly marking the new departure that is to be taken in the evolution of man's mind. But up to now the work of creation has not been made in God's image and likeness, for God cannot sin, so sin cannot possibly be made in the likeness of God, and likewise up till now evolution has been confined to the creation of a material universe and the body of man, and as God is a spirit nothing that is not a spirit or spiritual and invisible can be in the true likeness of an invisible spirit. The only possible likeness in matter can be its trinity of force being a likeness of His Trinity.

But now man is to perfect his material evolution by becoming an adept in the arts of sinning, which is one of the three great blessings of creation, and so evolve his material and bodily perfections of courage and energy and become possessed of virtue. I hear you say, dear reader, "but sin is not a blessing." On this point I am afraid we must agree to differ, unless you will agree to alter your opinion, for perfect virtue can only be evolved by overcoming crime; and note sin is not an evil, for in the abstract nothing that produces good can be evil, and it is only by sin and failure that we can learn to attain to perfection and earn the reward of virtue. But intemperance in sin is crime and crime is always an evil. The second great blessing of life is ill-health. This is ordained to be the language used by God to warn man not to abuse the body and bodily capabilities which he has entrusted to the care of each one of us for the short space of our mortal existence in order that we may, by making the best use of it possible, pass on a better and more perfect body and mind to 
our children, but failing to make use of it we are to detract thereby from our children's chance of gaining immortality. Or else God uses ill-health as a means of punishment for past offences, and as a means to caution us to make greater efforts to use, not to abuse these gifts of bodily strength in the future, for the evil of ill-health is not sickness, but death, in the same way that the evil of crime is intemperance or misuse of opportunities to do good or the failure to use them to the best advantage, not total abstinence from sin or defect, for it is better to attain virtue and merit reward, than to become a useless saint devoid of all virtue, for good acts performed simply because we have no inclination to do wrong do not fit us to perform any acts of real virtue requiring selfcontrol above the common. In just the same manner if we never had any sickness there are very few of us who would take sufficient care of our bodies, or use them so that they would ever be fit for any extraordinary acts of endurance.

Sickness also performs a very important function from time to time by acting as a safety valve for the removal of the impurities of past carelessnesses or excesses. And the work and study of future physicians must be rather how to prolong his life by removing causes of sickness around and within him, than how to cure disease-to prevent, rather than to cure. For until man had evolved the power of correct understanding, or how to know the truths of nature and revelation, it was not advisable that the lease of man's life should be a long one, a short life being better suited to hasten his advancement; but after he has acquired the knowledge of understanding, this will not apply to the same extent, for when mankind shall have learned how to use, not abuse the talents God has allotted to his care, the next stage of his advancement will be the third and final advancement from the beaten track of evolution that is to prolong his life into immortality. But so as not to lose the sequence or issue that forms the Hypothesis of this treatise, I must try and avoid as far as possible all side issues, and only glance at those which are necessary to the clear elucidation of my subject, for in this treatise I am endeavouring not to do more than glance through the portal of evolution. I may say I feel like one who has come through a very dark passage and then opened the door into a brilliantly-lighted saloon, and who tries to make a rapid, 
but at the same time very comprehensive view of what is going on inside, but whose vision is dimmed by the glare of sudden light, and I must therefore ask the reader to pardon me if I am tempted to leave many proofs and side-issues barely touched upon in the present work.

The third blessing is that of Poverty, and had not God invented this most perfect whip, man would never have evolved much above a very low order of animal in courage, energy and bodily development, and would never have striven to withstand the pinch of mortification that is necessary to obtain the habits of care and economy which alone can gain him the rewards of wealth and comfort and the other blessings of civilisation which will be amongst his future evolutions.

In the past it has been the duty of religion to teach man to bear poverty in patience and content in the hope of obtaining the reward of an imaginary heaven. Now that we have further evolved, it becomes our duty to learn and to teach our fellowmen that salvation rests, not in blind submission to poverty and suffering, but by learning first to be content with the lot in which our birth has placed us, and secondly to ardently strive to improve that lot by patient industry, untiring labour and habits of thrift, temperance, unselfish generosity, and charity, and by so doing to rise up at least one, if not more of the rungs of the ladder of wealth and social advancement, and that it is the past lives of our forefathers that decide our capabilities, and that it is the use we make of these and of the time and opportunities at our disposal, and to our own efforts and a better understanding of the truths of revelation and nature, not to religions or laws, that we must look for the possibility of future advancement of our children and their children's children, by learning to sin wisely in unselfish unity and charity. And to realise that no matter what may be our nationality, belief or creed, we are all bees in the same hive, and that it is by our united efforts to carry as much honey as possible, not by mean jealousy, or by shifting the burden on to the backs of others, nor by labour squabbles, class laws, fighting and wrangling, or discontent, that we are ultimately to make short the winter of our discontent by a contented summer of co-operative production, learning to use, not abuse the gifts of nature, and by helping our fellow-men a result which will probably be evolved by a more enlightened 
unionism of freedom and co-operation taking the place of the present age of the unionism of slavery and selfish desire to feather one's own nest at the cost of the loss to our neighbour of his equal rights of competition and rights of freedom and just liberty to compete against us, that we are to gain that Peace, Unity and Content, and the age of brotherly love that will cause poverty to lose its sting and liberty its slavery, and thus produce by the unity of co-operative enterprise in a world of study and peace, that millennium of content, joy and charity that is to give birth to Heaven. But we may rest assured that heaven will not remove the distinction of good and bad, rich and poor, weak and strong. For if it did it would deny to mankind for all eternity the very virtues that it has taken the world millions of ages to evolve, and the very rewards which have become the dearest ambitions of his existence, viz., social superiority and the reverence and respect due to success, which would be a very poor return for the mighty fight that he has made to attain superiority over his fellowmen, namely-

Ist. The Respect granted to the deserving by their inferiors.

2nd. The Veneration of good deeds performed.

3rd. The performance of works of Mercy and Charity to the unfortunate.

4th. The just right to glory in an ancestry whose lives have been well spent.

For take note, before a man can gain immortality, all who are possessed of the crimes of Cruelty, Selfishness, Vice of Pride (i.e., the pride that makes a man too proud to do his share of work, too mean to help his neighbour, or too proud to carry out the duties God places upon him in his state of life) will, by the wisdom of future governments and the survival of the fittest only, have practically ceased to exist.

So this making of the mind of man to God's image and likeness is to be the future work of Evolution. Involution commences on this, the Eighth Day of Evolution with which we are now dealing, with the evolution of Agriculture and Civilisation. In the past God has probably taken over fifteen hundred thousand million years to form the creation of life 
and the universe, and the Trinity of God is now about to combine to form man's mind during the short space of less than a million of years that make up the second and third weeks of creation which form the Epochs of Hope and Charity during which the world is not, as in the past, to be governed by God the Father only, but by the united action of the whole of his Trinity. Now on the Eighth Day we are to celebrate the first dawn of Comprehension, which is the soul of Religion, in the mind of mankind, and in so doing start the second week of creation. I have mentioned the above figures to give the reader some idea of the enormity of the time already spent over creation, not as any accurate statement, but the actual periods are more likely to have exceeded this limit than to have been less; and the figures will only give him some idea of the time it has taken to create the heavens, the earth and the body of man, so that he may grasp the necessary conception of the slow progress of the development of the body as compared with that of the mind, and this will most probably be less as regards the soul of man in the years yet to come.

When it has taken God so much time to create the world so as to make it a fit abode for human habitation, I am constrained to pause in my onward march and ask my reader to meditate for a few minutes, and to consider how insignificant is his greedy thirst for wealth, joy and pleasure during life except as a means to perform the duties he owes to God and his neighbour and the community, and to make the best use of his time for the benefit of those amongst whom his life and lot is cast and so to bring within his power the possibility of the rewards of wealth, honour and social esteem and eternal life, confident that if the aim of his life be to make the best use of his labour, energy, time and skill, he can trust God to reward him if he is on the right track, and to send him failure and poverty if he is on the wrong one, so as to put him back on the right path, confident that if he takes the lesson to heart he will some day before he dies be rewarded by success, after which he will be able to bequeath to his children the right to possess and retain such a magnificent legacy as Immortality and through them to participate in its rewards and pleasures.

We have now reached the period of Cain and Abel, which marks the fight for supremacy of the new departure which 
the incoming of soul into the mind of man in the form of mind by the evolution of the qualities or attributes of Imagination and Comprehension, and the dawn of Understanding, bring about as the age of Agriculture is evolved; of which age Cain is the biblical symbol, and which is to produce the dawn of Knowledge and Civilisation on the next, the Ninth Day.

As the fight rages between the savage and more murderous Cain, the civilised man of agriculture, and the herdsman, huntsman and patriarch who are symbolised by Abel, Seth and Enos, which two forms of civilisation I herein term Mongolian and Aryan, in which sense I use these words. This period occupies somewhere between one hundred and two hundred thousand years before Christ. This period is also marked by the dawning influence of women's love which is now to make the seed-bed in which religion is to take root on the Tenth Day of creation. (See Tables II. and III.). But what more than all else marks this period of the Seventh, Eighth and Ninth Days is the birth of the soul of mankind in the more highly-developed races of the world at this time. (See Book II., Chapter VI.) (Note : all through this work I shall use the terms "Mongolian " and "Aryan " in this very wide sense). Now if you refer to Table II. you will find that Soul first appears on it as number four and so marks the dawn of animal creation, and life is the first dawn of soul, so it is not in truth in the wrong place, for animal life is the first creation of electrical force when nerve and brain are first laid down as the electrical wires, so to speak, that are to prepare man for a soul. On the Tenth Day of Religion (opposite to which appears Study), IS the Fifth marriage of God's Trinity we now find this is the place to which in Table II. it corresponds and belongs, and so it appears in its correct position in Table III. But practically all the four days, the Seventh, Eighth, Ninth, and Tenth, are devoted to the dawn of soul, religion and civilisation in the mind of mankind.

As man evolved Imagination and woman Comprehension, which two faculties are to create the birth of man's mind and the inception and conception of his soul, for as I have already pointed out the evolution of the attributes of God the Soul are three days of creation behind those of Spirit or of those of God the Father and two stages behind those of God the Mother, so it is on the Eighth Day of creation 
that we arrive at the age of Agriculture which is the result of the evolution of the faculty of Comprehension, the female faculty of the human soul. And agriculture is to be the means of advancing man's mind sufficiently to start the evolution of Study and Religion on the Tenth Day, for as will hereafter be illustrated the mind of a farmer is one of the combinations of the female or comprehensive classes of mind (see chapter on the Three Classes of Mind), so with the age of agriculture comes the formation of home life and home ties, in place of the nomadic life man has hitherto lived. Man no longer makes his wife and children join in the chase but leaves them at home to cultivate his garden or till his fields. Home ties now start to develop, and society commences to evolve with religion, and from this on he is to be the protector of his wife and children, and their bread-winner by the sweat of his brow.

But he is ever in danger of the attacks of the tribes of robbers or uncivilised men who molest his home during his absence, murder his family, and rob his farms or home, so this age marks also the banishment of his murderous brother law-breakers, who represent the uncivilised savage nations of this age. As the Bible expresses it that Cain went into a "far-off country of wicked men where he takes to himself a wicked wife," that is a savage wife. It is also probable that the primitive mode of punishing crimes of theft and murder and other crimes against early civilisation was by expelling the perpetrators from out the bounds of civilisation, is also here depicted in Genesis, for early legislation and religions must have been of the most primitive description, and any reader who will take the trouble to study the laws of the Medes and Persians (see Volume I. of "The Historians History of the World "), will easily perceive that the first clauses are the early laws (for history tells us the laws of the Medes and Persians could not be altered) which are an eye for an eye, and a tooth for a tooth; but the subsequent clauses become more rational, hence we may fairly conclude that at first death was an almost universal punishment for all and every crime, and that it was well under these circumstances for the criminal to make himself scarce so soon as possible. And if the reader will take the trouble to note the method of the Biblical description of the children of Adam, he will be struck by the fact that it reads: "And Adam knew Eve, his wife, 
who conceived and brought forth Cain, saying I have gotten a man through God. And again she brought forth his brother Abel, and Abel was a shepherd and Cain was a husbandman."

Now it appears to me from this point onward that Cain became a greater murderer than Abel, because husbandry by increasing individual rights of tenure made a new inducement for murder, for the nomadic shepherd shared his flocks in common, whereas the primitive farmer or gardener claimed sole ownership to the product of his spade, and commerce or barter was as yet unknown. This increased raids and wars and so increased murder sevenfold, hence as I have already mentioned, it is ever the case that civilisation and knowledge and town life tend to increase, not to decrease crime. So robbery and murder became at first more common amongst civilised nations, than nomadic ones.

I must here point out that the first description of Adam's sons goes on to describe the children of Cain as holding preference in the sight of God although they were murderers, till the children of Abel supplanted them. When you come to read the chapter in Book II. on Cain and Abel, the reader will notice that this is just what happened at this age of evolution. For it appears that at first Chinese civilisation developed Imagination and Agriculture throughout China and southern Asia, and also the simplest forms of religious worship, which was afterwards supplanted and improved upon by the Aryan races, who when driven back by the glacial period from northern Europe superseded the Mongolian civilisation in religion and government. Now the Mosaic people being an Aryan race, Moses would, after the manner of the historians of prehistoric and early historic times, attribute to his own country of Palestine all previous legendary history his people might have brought from China, India, Egypt or Persia, regardless of what country it had really taken place in, or to which it owed its original fables. Now as all these events happened hundreds and thousands of years before the time of Moses or the Jews, we must not wonder at their inaccuracy in matters of detail or time, and only wonder that still any record should exist that should have any correct agreement in any order and sequence of facts. More than this we have no right to expect; and it is absurd to expect correct details in Biblical teachings. 
Now, as I have mentioned a minute ago, this age also marks the early dawn of religion, and as I shall point out elsewhere it is probable that this early stage of Mongolian civilisation gave to the world its first form of worship, it is also probable that it gave to the world the first of the probably three heavenborn sons of God the Mother that were to create religion and enable man to inherit woman's powers of love and sympathy, comprehension and invention.

So I here take the opportunity to ask my reader to pause and consider the wording of this quotation from Genesis, "And Adam knew Eve his wife, who conceived and brought forth Cain, saying I have gotten a man through God." And I ask you, dear reader, does not this wording imply that at this time of evolution there was such a birth of a God made man?

So we now find that woman has commenced the work of her existence, namely, the redemption of man, for on this the Ninth Day she starts to increase his love for her and her home and her children, and to cure his love of murder and cannibalism and hunting, hatred and revenge, and his insatiable love of meat food, and to turn his attention to the consumption of a greater amount of vegetable food, and, as the cultivation of the soil increases, small settlements arise and tribes and villages grow up and the ground work of civilisation commences.

Now, reading across the line No. 9 in Table II., we find that Comprehension gives us the dawn of Understanding, which marks the age of Civilisation in Table III., and the conception of the science of agriculture.

We now arrive at the Tenth Day. This is marked by the fifth marriage of God's Trinity, Table II., viz., Thought, Life and Knowledge, the result of which is Study, and Study evolves Religion, as shown in Table III. This is the greatest miracle in the Epoch of Hope, namely, the miracle of our redemption, which is to enable woman to redeem and civilise man by the aid of three God-born men and religion, and is second of the miracles made by God to prove his prerogative to rule man and the world he has created. In the Epoch of Faith he reverses the laws of heat and cold and of weight in water to prove that he can rule natural laws when he thinks fit to do so. And in the Epoch of Hope he makes this exception of redemption to prove that he can alter the laws of birth, 
and had he not done so, the qualities of love, sympathy, mercy, invention and belief could never have been possessed by man. But the ardent prayers of woman's love are now to be granted, for God is coming to her assistance so as to enable her to conquer the cruelty of man, and to enable him to comprehend and believe the truths of God's revelation, even though he is not sufficiently advanced to understand them. This is to be brought about by the creation of a Godmade man, so as to emphasise His prerogative, the third of which exceptions is to mark the law of death as this one does the law of birth, when in the final Epoch of Charity man is to gain Immortality and so to stamp upon our minds God's prerogative to rule the world by showing he can rule the laws of Matter, Life and Death. Therefore who can dispute his right to rule the Universe $\mathrm{He}$ has created, and the knowledge, minds and thoughts of man by the wisdom of His Trinity, of which he hereby makes a trinity of manifestations?

In Table III., we find that the birth of Religion is the result of the evolution of the age of Study of the knowledge of the dormant revelations of God, so we find Study rightly corresponds to the evolution of religion, which is to make the great distinction between man and the animal creation by establishing his control of religious laws which are to pave the way for the building up of Governments and the creation of kingdoms and empires and the progress of civilisation as the dawn of understanding in man's mind, which is to arrive at maturity on the thirteenth and fourteenth day of creationsomewhere about the Nineteenth Cenury A.D., starts with the dawn of soul. But during the meantime, a period of approximately eighty to one hundred thousand years, man is to be led blindfold by the hand of religion in faith and belief clothed in the garb of superstition, bigotry, fable and parable till after the complete birth of understanding, when the mind is to become capable of receiving the Holy Ghost, who is, in years now about to come " to make known all things even to the consummation of the world when knowing he may be able to understand " what Christ gave to him to be known only in parables, namely, to know the true meaning of God's Trinity and of divine revelation, and to be able to expound this truth by scientific discovery. In the meantime he is to learn to carry out in dumb faith and in blind obedience the laws he 
is to evolve by the religion and governments he is about to create. After which, when he shall have learned, by commerce and invention, to control and to govern the world of Matter, he shall next learn how to govern himself and to use, not abuse, the world that God has created for his ultimate reward. During the one or two hundred thousand years that mark the growth of civilisation and religion man has been hitherto learning to see, study and to comprehend the works of God which his mind is yet too young to understand, but having risen above the state of animal mind, he is beginning to comprehend with the dawn of soul the meaning of forces that hitherto only filled his mind with fear, grief or pleasure.

This period also marks another point in the development of my hypothesis, namely, that as soul returns to man, so the attributes of the first person of the Trinity, God the Father, are to be withdrawn. For it stands to reason that the whole of the three personalities of God's Trinity cannot be present at one and the same time, or the result would be the existence of two infinitely wise beings, and two infinites could never exist at one time; therefore during this period the power of memory is withdrawn from the mind of man to admit of the evolution of civilisation, and is replaced by the acquirement of the attributes of Imagination and Comprehension to permit him to evolve a mind capable of indistinctly recalling the principal but indistinct results, of past events, the full knowledge of which would cause him to despair of all advancement.

The first result of the dawn of religion in the mind of man is the comprehension of a higher ideal, and for a time this is sufficient to restrain him from any grievous violation of the requirements of primitive laws and order of early civilisation, but as civilisation always has the effect that it offers newer and more attractive allurements to crime than were possible before it came into existence, so even to the minds of its earliest promoters it soon began to offer new inducements to sin; jealousy, covetousness and larceny began to increase, and the leaders and students of religion and its daughters, superstition and necromancy, found that the teaching of a better ideal did not suffice to keep order and prevent crime; so, as fear is still the leading and controlling power of man's mind, the seers and students, who formed the religions teachers of the day, now set to work to elucidate some means of instilling 
some order of fear by means of which they may be able to control their erring flocks; hence they, not God, create a hell of punishments, which now takes the form of the transmigration of soul whereby if you injure your neighbour in this life you are to be condemned to suffer punishment in another life by being interned in the body of his horse, cow or donkey till you have made restitution by work or suffering for the evil you have done him in this life, by the evils inflicted on you by others while you were so transmogrified.

To appeal to the mind of that day nothing that was not supernatural would have been any use. For man was at that age of the world's evolution just recovering from the supernatural fears which the contests against the two hundred thousand years of the glacial period had evolved in his semi-developed mind. But as knowledge and civilisation were gradually enabling him to gain an ascendancy over these fears, and as he now begins to understand their causes, so their effect as a deterrent from crime decreases as fast as the temptations of civilisation tend to add to the attractiveness of crime, and in this way the fear of this form of hell no longer suffices to deter him from doing wrong, and it becomes incumbent upon his religious leaders to evolve a newer means of hell and punishment or a higher ideal of worship, so we find this leads up to the next step in advancement and brings us to the next age, the age of Governments, No. II in Table III., which is the result of the sixth marriage of God's Trinity, for if we turn to line II of Table II. we read Mind marries Life and begets Human Will, and is it not true that Human Will is made up of the two powers or forces of mind and life, and that Government is the outcome of the use of our faculties of Mind, Life and Human Will, just as much as Religion is but the evolution of Thought, Life, Knowledge and Study? So we find that the more we compare the course of the world's evolution the more we find that the hypothesis continues to be systematically carried out, for each stage is but the evolution by nature of some new combination of the attributes of God's Trinity, just as each new form, shape or species is but a new combination of the atoms of Matter that previously existed. And we also find that now we have inserted the trinity of man's soul in its correct place in the Tables, the marriages of God's Trinity again coincide with the progress 
of evolution. I must here again impress upon my reader, who has followed the course of our explanation in Table II., each conception is now three stages behind its equivalent birth in Table III., which he will note likewise shows Government as its resultant. We find that Wisdom was conceived in the Mind on the Eighth Day to give birth by the Sixth marriage of the Trinity to Government on the Eleventh Day; hence the Eleventh Day of evolution and the Age of Government now come under our review, and are also remarkable as the birthday of the lowest order of Wisdom. And it is but a small step from the rule by religious laws to that of government by . civic ones; but small as this step appears, it is to effect the downfall of its parent, for the result of this new evolution is that religion ceases to be henceforth based on an appeal to the latent existence of the spirit of revelation, ever dormant in the soul of all mankind. For man now studies to make revelation and religion subservient to the aims and objects of Government, the child of Human Will, which soon results in their corruption by the creation of fresh superstitions and new forms of bigotry in the teaching of religion so as to enforce the aims of the successive forms of government in their evervarying successions, for the early forms of both religion and government rely on Ignorance as their most powerful tool.

So we find that each style of religion is perverted and adapted to suit the government in power. But at the same time that it is destroying some of the truths of revelation it is also evolving a better knowledge of new ones. Thus the desire for reverence of the early rulers of mankind makes them aspire to the reverence hitherto granted to the sun, moon and stars, images and idols. But just at the same time that this alteration is doomed in one age of religion to be lost and destroyed by bigotry and superstition, it is also making a further development towards religious truth in another form of goverument. So we find the king now coming into competition with the priest, and these powers come into conflict with one another, the outcome of which is that the priest has at last to take the second place; so man learns the great lesson that an earthly kingdom will not admit of two rulers. And so dawns within the infantile mind of man that heaven will not admit of two Gods. Thus out of the downfall of the early Chinese religions springs the first conception of One God and 
his Trinity of Persons. As Brahmism and Buddhism replace the earlier form of Idolatry, and these early fables and parables of primitive religions, so as to assist the rise, formation and rule of Government, are now clothed in robes of superstition, necromancy, fortune telling and sorcery till what little of the truths of revelation these early religions did contain is lost in the idolatrous worship of the Sun, Moon, Stars and human joys, pleasures and griefs, till it is all we can do to trace the faintest outline of the magnitude of the truths they originally contained and taught.

But from this unshapely mass of ruins, born of the hero worship of the Aryan race, who from worshipping and idolizing their warriors, kings and princes, now move one step further and at last conceive the mighty truth, which formed the coping-stone of the teachings of Buddha when he gave to the early Hindoo the belief of one Almighty God born of a virgin and possessed of a triple personality. But these teachings are again to be lost and still more thoroughly obscured by the modern Buddhism in even darker and still more ridiculous idolatry than before, and from out of the decadence of which, with the downfall of the old Indian and Persian Empires, these teachings are to rise again under the star of Bethlehem as a brighter and more glorious religion by far, than any form of worship that had hitherto shed its light into the dim recesses of the dull mind of man. And in years yet to come I am hopeful the hypothesis I am now trying to expound may, with the aid of Science, in time evolve a knowledge of true revelation as much above what is already possessed as the Christian heirloom is majestically above the head and shoulders of Idolatry.

So we now find one religious belief falls into decay to permit of the evolution of another form of government. Likewise each government in turn dies, to be replaced by a more perfect evolution than the one that has preceded it in the course of religious evolution, as each in turn springs, Phœnix-like, out of the ashes of its predecessor. And now science, if not raising up the inanimate idols of antiquity, has, out of Christianity, built up a still more dreadful form of idolatry in its inordinate love of Intemperance, in its bigotry and worship of power and wealth, of selfish ideals, and class hatred than the idolatrous superstitions from which it sprung-a bigotry 
which has doomed more lives to death under the sign of the Cross than Rome massacred to create the first nation of commerce, and build its mighty empire. So religion gives birth to Government which by causing stability, comparative wealth and ease, follows as a natural result. This gives time and opportunity for study and advances science, which on the Twelfth Day begins to influence the existence of the world.

If the reader turns to line 12 in Table II. and reads Imagination marries Comprehension, he will see that it is not incorrect to say that the outcome of this marriage or manhood of the evolutions of Imagination and Comprehension is the birth and childhood of Understanding. Science by our Table, is to give birth on the Thirteenth Day to Commerce. For is not Commerce the complete material product of civilisation which was conceived on the Sixth Day with the creation of animal mind, and born on the Ninth Day, with the result, Study, which is the material evolution of Science.

If my hypothesis is correct, three days or stages of evolution are devoted to its conception, three days to its childhood, and three days to its manhood, after which follows the result of these evolutions, the material and psychical existence having formed two such periods of evolution. Hence, looking back, we find that our Table II. predicts as follows :that Soul starts Existence on the fourth day with the creation of life to give birth to Imagination on the Seventh Day by the birth of a soul in man, and comes to maturity in the germ of religion on the Tenth Day and arrives at manhood on the Thirteenth Day with the creation of Commerce, which History shows us is the child of religion, fostered under her care and protection, and fed with the feeding-bottle of religious wars, greed and bigotry. The result of this is the final gift to man, that of Invention, on the Fourteenth Day, by the birth of Christ, just as the first redemption gave mankind the grace of Love and its concurrent power to imagine and pray to a God whom he could not see or comprehend, which led to Idolatry, the first form of Religion, by making it possible for man as well as woman to possess the female quality of Love, and so laid the foundation-stone of devotion. So in like manner the second redemption by Buddha gave man the power to comprehend Mercy, Honour and Justice as he rose to not only imagine a God, but to comprehend that there existed 
but one God in a Trinity of three persons, and in this way he received the germ of woman's quality of Comprehension and was able at last to strive for Heaven. Then with the birth of Christ, our third redeemer, man received the last gift woman, through God's assistance, is to bestow on man, the precious gift of Invention, which is to enable him to conquer the world, and the duty of the evolution of religion is complete so far as the material results are concerned. Then with the creation of Commerce on the Thirteenth Day its object is attained with the realisation and birth of Invention on the Fourteenth Day, after which its power is to sink beneath the sun of Science as the Holy Ghost's power commences to become dominant over the power of God the Mother as Human Wisdom rises superior to Religion, in just the same manner that the material predominance of the forces of God the Father which ruled material creation up to the creation of man, becomes, in the Epoch of Hope by the birth of Religion, supplanted and subservient to the predominance of the powers of God the Mother.

On the Sixteenth it completes its second evolution, as its psychological evolution is advanced on the Sixteenth Day to Charity, which is the childhood of its second evolution, as the human mind was the childhood of its physical evolution, and now arrives at the end of its manhood on the Nineteenth Day by the completion of its final result, Heaven, on the Twentieth Day, which also brings the second evolution-more correctly styled Involution-of Government to the completion of its manhood; so we arrive at the psychological completion of the evolution of religion with its second result, the final aim and object of all creations of religion, namely, Heaven on Earth, which is its complete evolution in its three forms-physical, mental and psychological. Of the mental evolutions, Religion, Government and Science are the only three that are to be complete; the others will vary throughout eternity.

If we follow out the evolution of Government we find it is conceived on the Fifth Day by the evolution of Marriage or Sex, for marriage laws were evidently the earliest forms of social laws, as the protection of the wife and children is the first law of home government, which forms the nucleus of all governments, for civil law is only an enlargement of home rule. Then three days later we arrive at the birth of Government with the conception of comprehension and the 
evolution of agriculture, which call for the laws and protection of property, as private ownership is evolved by agrarian rights. On the Eleventh Day comes the conception of the childhood of Government, and we commence its manhood with the formation of state government. On the Fourteenth Day we have completed the manhood of Government in its mental and physical evolutions, and on the Fifteenth Day we arrive at its final mental result, when we are able to prevent wars, and buy and sell national property as well as private estates under legal courts. Taking its psychological evolution, the conception of which starts with its physical birth on the Eleventh Day, the day it appears in our Table of Marriages, just as Religion did on the Tenth Day. We find its psychological childhood starts on the Fourteenth Day, when man conquers matter, and will arrive at its manhood on the Seventeenth Day, when he is able to prevent crime. Its manhood becomes complete on the Twentieth Day, after Religion has converted Earth into Heaven, when the bulk of mankind will be too wise to sin without injury to his neighbour, and perfect joy and pleasure and happiness have been attained by man having learned how to govern, not only the world God has created, but also to govern himself, and to relieve his creator of the trouble of managing the estate of this world.

Then he will be possessed of Wisdom, but little short of the infinite wisdom of his creator, subject to a feesimple of veneration and obedience to God, which he is now wise enough to give freely, not given as is that of the animal through inability to obey or from ignorance of right and wrong or how to sin wisely and without offence. So then he will be no longer obliged to pay the wage of death, which is the penalty of his misdirected sin, so at last is not only worthy of Heaven, the final result of religion, but likewise of Immortality, the second and final result of the mental, physical and psychological evolution of government. And the earth, having now also completed the object of its creation, will be absolved from final destruction, the end of all planets which cannot produce a perfect man, and God can forevermore rejoice in the perfect crown of creation, the work of His infinitely perfect Wisdom, and revel in the luxury of a sweetheart who can give him an eternal and perfect love.

But Commerce and Peace, the Reward of Virtue and Human 
Wisdom, are never to become complete evolutions any more than was man to receive the complete graces of the first four attributes of God, or his perfection would become supernatural. And the conquest of Matter by man and the prevention of crime being now complete; but being material evolutions, not mental, are relegated to the oblivion of the past. The other material evolutions can be carried through their three, six, or nine trinities of evolution in the same manner, and through psychical evolution, till in like manner Heaven is arrived at.

Science, being an entirely psychological evolution, becomes complete in one act instead of two. Thus Science is conceived on the Ninth Day with the completion of the mind of man, is born on the Twelfth Day, on which day it appears in our Tables II. and III., and is to reach its manhood on the Fifteenth Day with the evolution of Peace, and complete its manhood by the evolution on the Eighteenth Day, by giving to man the reward of virtue, perfect content. The result of this his last perfect evolution is to be perfect human wisdom, with its concurrent blessing, Infinite Pleasure, Happiness and Contempt of Folly. And surely he who has attained three such infinite blessings as these should be able to sin so wisely and with such moderation and temperance that he never presumes on his neighbour's just liberties; and can this earth hold higher blessings? And the man who cannot evolve content under such possibilities is no more than a human brute or devil, who will be justly condemned to labour, live and die a slave throughout eternity to the passions he has been too weak to conquer, justly condemned by his betters to the eternal disgrace of slavery in a government prison at a state-owned occupation.

We have now arrived at the age of History, so it is scarcely necessary for such a humble pen as mine to do more than just trace the line of sequence further.

But I must remark that from China to India, Persia, Egypt, Greece and Rome, and from Rome to Modern History, as the European empires rise and fall at the bidding of the magic wand of study and science, as following behind the roar of the cannon with sure and steady steps, arises from out the savage civilisation of the past Commerce, the daughter of Religion and Government, which is rapidly transmogrifying earth into heaven, as Religion, Science and Commerce hurry over the 
face of the globe, leading by the hand their granddaughter, the bright-eyed, fair-haired Joy and Comfort making child of Study and Science, Invention, who with tottering steps follows her leader and tries to keep pace with grandmother's footsteps, but who is destined to become the mighty queen of earth; and is to enable the mind and soul of man to convert this world of ours from one of murder, war, cruelty and selfish greed into one of brotherly love, joy, pleasure, content and happiness, and so by conquering the world and destroying war and crime to finally convert it into a perfect and contented heaven and a fitting home for immortal man.

This brings us to the age now dawning, the Fourteenth Day of creation, wherein man, by his inventions, is to conquer the whole world, by bringing it entirely under his control. In so doing he will, by learning how to use not abuse his inventive power, produce on the Fifteenth Day, the Age of Peace.

For this power of invention will make war such an expensive luxury, and the cause of such unprecedented poverty, that it will in the near future teach mankind that war which, in the Epoch of Hope has been one of its three highest virtues, namely, Cruelty, Selfishness and war, is a barbarous device; though without making idols of these three gods it would have been impossible, in early days, to enforce religion and laws on the community, to build up empires, or to establish commerce. These, however, are in reality only wolves in sheep's clothing, and they will, with bigotry, tyranny, inordinate love of wealth and greed, have in the future to give place to a more perfect understanding of revelation and a better knowledge of right and wrong and a more perfect form of tolerance, practical charity and co-operative production, in which the object shall not be to punish crime under the vain hope that the criminal can be converted, but to forgive the sinner and prevent the criminal from breeding, and so prevent the perpetuation of crime. This will ultimately come about as man evolves the legacy of Understanding, into possession of which he is now coming, and which will teach him not to abuse the home, mind and soul God has endowed him with. Then upon the Fifteenth Day he will move one step further than at present, conquer war by creating peace amongst nations, in the same manner as by Science and Invention he has conquered the world and created commerce, and learn how 
to attain comfort on the Sixteenth Day when, by establishing peace amongst nations, he shall use armies only to prevent war in its worst of all forms, civil war, and so having raised it to its highest stage of virtue by using it only for the punishment of crime, after which it will in its turn be recognised as only another form of murder, to be made use of justly, only as hanging is at present, as a means of capital punishment.

By creating universal peace, he shall so far progress along the track of evolution that he will, under conditions of peaceful federation, be able to turn his attention to forming more perfect governments by no longer making idols of religion, selfishness, love of grandeur, wealth, power and influence, and so discover at last that by extermination of crime, by a more perfect realisation that breeding is the means of evolving virtue, he will be able at last to forgive his neighbour's sins, so long as they do not injure him, and by so doing create real virtue by practising greater charity, also by encouraging cooperation in mutual requirements for the production and distribution of wealth and comfort for families and communities, and so dethrone the idols of individual wealth and grandeur and selfish monopoly by learning to convert his superfluous wealth into capital by the creation of mutual companies and co-operative means of livelihood, so as to benefit his less fortunate neighbour, who, in his turn, as he becomes enlightened and more generous, will realise that poverty, like sin, is a blessing, not a curse, and so come to venerate not envy, as he does at present, the wealth of his neighbour, while the wealthy man will in his turn realise that true happiness lies not in the pleasures that wealth and ease can buy, but in the reaction upon us of the happiness we create in those about us by competing with our talents, time and labour to do our utmost to enrich others. This brings the world to the Sixteenth stage or day of existence, the creation of Brotherly Love and the Age of Comfort. This leaves only four stages to be evolved-namely, Joy, Pleasure, Happiness and Heaven.

When man can become perfect enough to-First, sin without offence, he will have perfect joy; secondly, to enjoy pleasure with temperance and without intemperance, he will have attained perfect content and health-for content is impossible for an unhealthy body or mind-and be on the right road to economy and charity; and thirdly, to realise that Joy, Content and Pleasure can only be obtained by working, not for 
pecuniary remuneration, but that he may add to the comfort of others. He will then be able to grasp the great truth that time and money are only two names for the one form of wealth. That it is not money, but a question of how much time and strength our brain and constitution will permit us to devote to helping in the assistance, maintenance and the enjoyment of others that will obtain us the rewards of Joy, Pleasure and Content for and in our physical and mental devotion to strive to labour that others may live, to bear the troubles, cares and reverses of life like men, not selfish animals, and to be careful, wise and temperate and economical, that, by finding the greatest amount of profitable employment for ourselves and our weaker brethren, God may deem us worthy of success by giving us the control of wealth, and last, but not least, the love and respect of those beneath us. For, failing to gain this last, the reward of true charity, kind words, generous deeds and assisting the worthy to advance, and forgiving and helping the frail and weak, is the true Charity that covers a multitude of sins, and for which alone we are to receive the rewards of Joy, Pleasure, Content and Happiness.

True virtue is to let the useless poor starve that we may enable weak but willing workers to live; to help those who help themselves, for it is folly to help the man who will not help himself, no matter what his misery or poverty, for this only encourages pauperism, which, after folly and indolence, is the greatest of all crime and should be punished by slavery for life in a government prison, not by wasteful giving of alms in useless directions so that we may receive the plaudits of fools; to forgive the weak and repentant sinner, whose sins are teaching him the wisdom of amending his failing and erring ways; to be courteous to inferiors and love and take them to our hearts and homes in exact proportion as they show us honour, reverence and respect; to respect and love and obey those above us, so that when we are wise enough to rise they may assist us to enter the everlasting dwellings of our fathers; not to look down on our inferiors or envy our superiors, for these sins are greater offences in the eyes of God than murder in anger, or polygamy in marriage. And last, but most important of all, we must learn that true happiness can only be obtained by catching on its rebound the happiness we give to others by leading useful lives and can only be the reward of a life well spent. 


\section{CHAPTER V}

\section{THE LAWS OF DESCENT}

HAVING now given our reader some idea of the hypothesis of my treatise, we will proceed to devote a few chapters to some of the more important issues of argument, for it is allimportant to a clear understanding of such a subject as the one we are now reviewing that the reader and the writer shall view the same mental edifice from the same standpoint, otherwise an entirely different view is taken by different minds, and to get a proper understanding it is necessary that both reader and writer should meet on a common ground of hypothesis and definition, and when they have so met and can comprehend each other, they can then compare their differences of opinion without causing mutual confusions.

So I intend to devote the rest of Book I. to the elucidation of facts or of arguments, the use in common parlance and concrete acceptance of which are very different from their abstract meaning. For in common parlance they are received as applicable to the age in which we live and exist, and in our case it is necessary to use them in the sense best suited to all times and ages, or to the particular demands of Evolution as the time under discussion. In this way we will now take the Laws of Descent, which govern the law of the survival of the fittest. Now, there is nothing God lays more stress upon in the biblical account of the creation than the law that like begets like, and that what is bred in the bone comes out in the blood. I therefore intend to point out that although in many matters of detail these laws are to every appearance scarcely visible or, rather, unrecognizable, yet when we review them the combined collection of circumstances in the main cases of repetitions are so marked as to leave such a clear and unmistakable course of reproductions as will suffice to form a broad general rule out of what at first glance only appeared to be a diversified conglomeration of distinct and wholly separated occurrences. Just as, for ex- 
ample, in bodily features the members of a family vary so much that they have no resemblance to each other, nevertheless, running through the family is some distinction of feature that marks a decided bond of family union, not apparent in every member of the family, yet so often reproduced that in the majority of its members we are able to detect the family likeness, and in the majority of cases its members changing so little that we are able, if we review the portraits in an old family portrait gallery, to see how the present type is only the growth of the combined types of the past.

I intend to demonstrate that mental reproduction obeys the same laws.

Now, before going further, I wish to point out that some of the most important matters the reader must never for a moment lose sight of, if he wishes to comprehend this treatise, are :-

Ist. That there is a female gender to the Trinity of God, to emphasise which I use the term "God the Mother " in place of "God the Son."

2nd. That the first law produced by our logical review of the cause and probable manner of creation, once we admit that man is created in God's image and likeness, necessitates a likeness in gender as well as in soul; also that at no time can the three persons of God's Trinity be entirely reproduced in man or we would be creating two infinite beings.

3rd. We have, therefore, when the chain of our logic has given the opportunity, endeavoured to point out that all creation was produced by the withdrawal from creation of two of the personages and attributes of God's Trinity, namely, God the Mother and God the Soul, and that the attributes of the different personages are gradually returned. And we find that all the attributes of God will never be wholly present, for a part or at least some of His attributes are withdrawn, namely, first-the Spirit of Invisibility; second-the power of the Will of God is replaced by the will of Man; third-the power of memory is withdrawn as imagination takes the place of thought to permit of civilisation, as reason supplants 
instinct, thus at no time leaving the whole of God's entire personalities present simultaneously in finite creation.

4th. Also that the first Epoch of Creation is at first devoted to the evolution of the first three attributes of God the Father and of God the Mother who have practically the sole charge of creation during the rule of the Epoch of Faith which is devoted to material creation, and concurrent herewith and gradually re-entering into and striving for representation is the force of divine love, the first attribute of God the Mother, in its lowest form of the affinity of Matter. Thus is the material universe created. Then the next three days are devoted to the further increase of the powers of Love and Existence which gradually evolve life, first in the form of plant life, then in the form of animal life and instinct. In the Epoch of Hope Love is to dominate over the power of spirit, as woman, assisted by religion, is to overcome the power of man's will, as woman's love conquers man as completely as he is to conquer the world of animals and Matter and rule the world God has created. This occupies the first fourteen days of creation. Then when the first two epochs have produced these results, the final Epoch of Charity is to be evolved when the power of God the Soul is to appear in the attribute of Wisdom now gradually dawning in the mind of man throughout the latter part of the second Epoch in the same way as the spirit of love dawned in the first epoch; but love is not to complete its work till the middle of the third.

So during the second epoch the third lot of attributes of God the Soul are to dawn, and gradually, not abolish, but gain the ascendancy and control of the power of the other two personages when man, obtaining perfect wisdom, shall no longer be capable of crime and shall thereby become worthy of immortality, when mankind obtaining perfect wisdom shall also be able to gain perfect self-control. I may here remark that the words devil and evil are synonymous, as in Hebrew the word means "the evil one," and our English word is a corruption of the French words diable or demon, hence devil means an evil man. 
I must now place before the reader the unalterable laws of descent which have through all ages been the most important force in deciding the supremacy of evolution and the survival of the fittest, from the time that God first created life by God the Mother bringing Love and Life and Existence into material creation which had up to that time been governed solely by the spirit and power of God the Father, viz., by faith and obedience. Nothing is more impressed upon our minds by Genesis than the fact that like begets like, and the practice of this belief has done much to make the Aryan Races superior to all other races and also to make monogamy possible.

Nothing proves this more clearly than the fact that whereas man when he constructs or reconstructs his work and improves on an original design destroys what he has improved upon, whereas God in His recreations reproduces past productions in His new constructions. For once He had created life he no longer permitted anything endowed with life to lose it until it became fit for reproduction, but decided and decreed that many parts of its previous existence should be reproduced in its recreation even though no longer of use. Previous to the creation of Life, Matter not required for the immediate reconstruction of life is thrown on one side as dead matter, but no sooner does love enter sufficiently into creation in conjunction with spirit than this is no longer permitted, for now the first and second persons of the Trinity are sufficiently reunited, and life in an animate form is created and infinite existence is again to be the reward of the fittest of the animal creation in the immortality of mankind, that is to say, of those families of mankind who persevere to the end and do not condemn their souls to eternal damnation by losing their energy, virtue, charity, and brain power; this latter is ever the outcome of the best utilisation of their energy by preceding generations of our ancestry, or is destroyed by acquiring habits of sloth, selfishness or intemperance. For life is eternal so long as its perfection is not destroyed by one or other of these crimes.

Under other circumstances only the body can die; life does not cease to exist. Animal Life is the next to be evolved on the same lines as Plant Life has been evolved, for if we recognise that this hypothesis is correct, it is only logical to conclude that if the separation or divorce of the Trinity of God and its gradual reunion is once accepted as the cause and 
object of creation, then it follows as a natural sequence that all creation must be carried out on the same lines and in accordance with the same set of laws and regulations, and being the work of infinite Power, Love and Wisdom, it follows that infinite wisdom must conduct the whole of creation on the wisest possible plan; therefore the scheme of creation must be perfect in all its parts, and one and all must dovetail and fit together in perfect order and sequence, or wisdom would have failed in wisdom. So it follows that animal life must be evolved on the same lines as plant life has been evolved, and the mind and soul of mankind on the same lines also. The plant world can evolve fresh and more perfect plants, but only on fixed lines of descent. The oak when once evolved as a separate species of plant can only recreate an oak, not an ash, and the ash cannot recreate as an oak. The same law must apply to futurity and to all classes of evolution. Each line of evolution is to beget itself, evolving in itself only one form of reproduction after the earth had cooled to the temperature that was to make its type a fixture, henceforth to be slowly evolved to perfection in accordance with set laws and principles in set lines and types, or else to stand still and deteriorate until replaced by a more perfect evolution than itself, when it should become obsolete so soon as it was of no further use in the scheme of creation, when it is to lose its power of recreation, and thereafter to be absorbed, not recreated by its more successful competitors in the march of evolution, but in some few cases may be resuscitated by crossing or rebreeding with a more advanced though similar type.

I will now endeavour to show how this is brought about in evolution. The first act of creation before the existence of life was the construction by the organised recreation of Matter becoming divided into segments of itself, like partitioning one room into a number of cells which enlarge and expand as they assimilate surrounding Matter or organisms, or fresh portions of the infinite ether; so vegetable life arises from material existence by the collision of its particles just as the particles were evolved when affinity caused a collision of the particles of gases. In the same way further formation of cells are produced to form further creations. In this manner animal life is evolved from vegetable life. The reader who wishes to go further into these details must read up some of the many works 
on evolution and embryology. It is not my intention to make this treatise a work of proof or science, but merely to draw attention to facts that go to illustrate my hypothesis. So by a further formation of cells which are destined to form the new germ, and out of the seeds of which are to grow the stems and branches of plants and trees of vegetable life, whose seeds are to reproduce in the future the exact reproduction of the original plant, its limbs and boughs. Then follows the creation of similar cells and germs destined to form small jelly fishes, who by springing into life from plant life, severed themselves from plant life and floated about the water to be slowly evolved into fishes. One striking instance of this earliest creation of protozoa or semi-animal existence which was possessed of the lowest forms of animal development yet possessed also of the most extreme vitality, is a small jelly fish made up of a series of segments; this curious little protozoon breaks up into a series of segments, and the divided portions swim about quite contentedly enjoying separate lives, till meeting another like segment they reunite together and form one instead of two or three lives. Another form of protozoon grows in the form of a plant with cup-like flowers which break off and form the female living animal, but before this happens the flower-like cup produces a small pistil which becomes a worm, which is the male. The two float about the waters till meeting they unite and breed a new form of animal life. So was animal life evolved out of plant life.

These and such like early forms or germs of life went on multiplying till they filled the sea with myriads of similar seaweed-born animals destined to form jelly fishes, and subsequently to be transformed into fishes. Their form, shape and future existence were decided by the class of plant they evolved from or the food upon which they might subsist. These protozoa or early forms of animal existence gradually further evolve until they produce the more perfect forms of fishes, reptiles, birds, animals and ultimately Man. Then the Spirit of God the Mother, the Spirit of Love, entering still further into the production of creation, animal mind begins to be developed. After this commences the first dawn of soul when Man evolves the powers of conception and imagination, and receives the first attribute of God the Soul that enters into finite creation. 
Now this is demonstrated by the science of Embryology, which illustrates the laws of descent in the manner we have already hinted at. God does not destroy the plans of the houses he builds because he has produced more perfect designs but starts with the first plan and rebuilds each one as an outer covering till he arrives at the final design. This is done because he wishes these facts to be a lasting memorial of instruction to illustrate to us the infinity of life and existence, and the immortality of creation, and the perfection and indestructibility of the scheme His Almighty Wisdom has propounded, and to impress upon us how insignificant a portion of creation we are.

Now to show how the science of Embryology demonstrates the laws of descent : first the ova are produced in the male and female parent by the partitioning of the original ovum into cells. In this manner one ovum after another is produced behind the other so that the vital chain of life is not a fresh life but only a new link in the old chain, or an extended multiplication, reduplication or extension of continuous existence. So at the back of each ovum another is formed which is the exact duplicate of the ova already formed, so at the back of each, another comes into existence endowed with the same powers and vitality as its predecessors but without in any way impairing the strength, vitality, or life of its predecessors. The first spermatozoon so formed is ejected, then the second, third and fourth and so on, the last germ so formed remaining behind to recreate itself in others, after which it must follow its predecessors. These germs, coming into contact with the female germ, the two unite, the male carrying with it the power to reproduce the germs of mind, spirit and soul, the female granting to the united birth, love, life, body, shape and form. Then in the womb of the mother the embryo in each animal birth goes through in succession the process of reproduction of many, if not all, of the forms of its previous animal existences that it possessed or passed through in its course of evolutions, each of which tended to decide what form of animal life, species, form or shape it was ultimately to attain. These varied changes occupy for a short time during the first days of pregnancy their place and order in the life of each one of us before the ultimate form of man becomes completely evolved in the womb. Thus the body of every man passes through some, if not all of the varied forms of his previous existences, 
some still extant, others extinct or so imperfectly reproduced as to be indistinguishable. The mind of Man is evolved in a like manner, varying in each case as the mental organisation of his mind is a reduplication of some or other of the qualities that predominated in his previous existences, or in the minds of his ancestors, just as his body was a reproduction of its previous animal existences, but with the differences that his soul is a perfect likeness of his Creator, and of the Trinity of God, while his body is only an imperfect one. Thus the particular previous animal existences (and although not indicated in any visible form), the previous plant life may and most likely has had its influences in deciding the species of animals produced. So it is quite reasonable to conclude that in the formation and evolution of the mind of man each recreation is only a reproduction of the human minds that preceded it, just as the human mind is only a reproduction of the animal mind and of the animal emotions that preceded it, out of which (as will be demonstrated in another chapter) are evolved by the action of God's Trinity, the emotions of the human mind and the soul of man as the other personalities of the Trinity re-enter into the creation of man's soul.

Lest I may fatigue the unscientific reader I shall try to confine this treatise, as its title implies, to merely peeping through the partly open door of evolution, for he is the reader for whose benefit I am chiefly catering. So the scientist must forgive me if I am compelled to draw on the imagination at times to fill up the gaps in evolution so as to connect my logical sequence; and the reader who is over-exacting in demanding absolute proof for every statement must remember that I am trying to write this treatise in a simple, unscientific manner solely to demonstrate my hypothesis, not as a scientific work.

Thus showing that man in his turn became jelly fish, worm, lizard, fish and animals of various forms till he arrived at the stage of an ape that was probably somewhere between the Gibbon Ape and the Chimpanzee, which ape outstripped all others by becoming a meat-eating ape, a cannibal and a murderer, until he ultimately arrived at his present perfect shape as man, while other kinds of worms, fishes, animals and reptiles combining in different manners evolved other varieties of animal species. It must not be concluded, therefore, that any other animal except some form of ape could ever evolve 
into the shape of man. The laws of the survival of the fittest and of heredity, and of the whole hypothesis of the Creation by God's Trinity, forbids such a possibility, which would frustrate the laws that God has made binding ever since the completion of form, shape and species became fixed, viz., that like begets like. Hence we may conclude that all apes who by that time evolved to the perfection of the apes who became man, became men. Probably an ape somewhere between the Gibbon and the Anthropoid monkey, or possibly two or three of the Anthropoids, but other varieties for want of courage or energy, or from not seeking a meat diet, combined with their failures to attain a perfect upright posture during the periods when violent changes of shape were admissible, failed to merit the reward due to such perfections in such acts as were the virtues of the age, and failed, therefore, to evolve in like manner or to become men. We may liken them to the horses, which instead of fighting a gallant race, run off the race-course and so get left out of the running. So also the animals that mated with a preponderance of inferior animal species during these periods degenerated into inferior forms of animal existences (this will be further explained in Book II. when we follow the course of evolution). But at present I wish to confine my remarks more to the subject of the present chapter, the Laws of Descent.

Until the time when the final changes of species, shape and form gave way before the birth of mind, in every case as each kind of animal loses its value in the plan of evolution or fails to strive for further perfection of energy and brain, it does and will become extinct to make room for the more perfect animal that has evolved on better and more perfect lines than the one it has chosen and selected to follow. Thus the more energetic apes that studied to swing themselves from bough to bough instead of crawling along them, and subsequently, when they had thereby evolved an upright posture, descended to the ground and were bold enough to strive to hold their own against the more formidable reptiles and the animals which roamed the earth and which consequently took to a meat diet, superseded those of their less courageous colleagues who chose to remain in the security of an arboreal life and luxuriate in fruit diet during the earlier stages of existence. While the other animals, although man's superiors at the start in 
form, shape, size and energy, by falling into habits of indolence, laziness and gluttony and sloth, lost their powers of vitality and fell behind those which sought development heedless of the greater dangers thereby encountered in the strife for existence on the earth, which entailed more toil, danger and exertion to attain and so outstrip their weakerwilled competitors in the race for existence.

Thus the Orang-utan, Gibbon and Chimpanzee are the nearest approach to man, yet the Gorilla nearest resembles man in shape and size, and was even mistaken by Hannibal for a very savage race of men. In spite of this the Gorilla has never attained to man's estate through not learning to attain a permanently upright posture, to evolve a thumb, and so could not evolve a soul. In the same way the Aryan Races are able to evolve higher codes of morality than the Mongolian Races.

I must now return to my demonstration that our past existences form part of our present life, and I may mention that instances have been authentically proved where the caul at birth has so strongly retained the resemblance of our ape life up to the moment of birth that it has been covered with hair and retained the features of the ape; also the hair that grows on our arms has the same perpendicular direction of growth that is the marked characteristic of all the apes who formed the habit of swinging from bough to bough. I have dwelt on these matters to demonstrate to the reader the manner in which previous breeding decides future evolutions and to show how the same law will hereafter be shown to decide in Involution (the first stage of which the world has only just reached), with even greater force in the development of mind and soul in the future than has been displayed in the evolution of the body in the past, for in mental evolution heredity is more predominant over variation than it is in physical development, for all that is divine abhors variation, and God being infinite wisdom cannot err, so has fixed laws which we call natural laws, and which being created by infinite wisdom, are less capable of alteration than those of the Medes and Persians, to whom we are indebted to this day for the basis of our Ten Commandments. One of the natural laws is that. Matter is subject to variation, but not to alteration, but mental development is subject to alteration, not to variation. 
I shall now pass on from the development of the animal body to the relation these same laws bear to the evolution of mind and soul. Now just as in our birth many forms of our past animal existence are again reproduced in our individual life, so in our souls the past experiences of our previous ancestors are reproduced in our minds and thoughts, in proportion as our individual mind or the mind of our particular family, which is reproduced in our individual brain, is a reproduction of theirs and thus produces similar fitness in ourselves for those acts or arts in which they excelled. But we also find that as we cease to use certain qualities, owing to the fact that civilisation removes their necessity, they become less strongly developed, and the races which have least advanced in evolution often retain qualities that their more advanced brothers lose; thus we find that some of the inferior races have retained more of their animal propensities which their more civilised neighbours have lost. For instance, the Aetas or pigmy inhabitants of the Philippine Islands have retained such a high power of smell that they are still able to trace where a man walks by the smell of the ground over which he has walked, and in some cases to recognise a man by the smell left behind although he may have passed out of sight. Whereas the sense of smell amongst more civilised varieties of mankind has ceased to exist to the same degree owing to his higher civilisation doing away with the necessity for its use.

But to return to the point now at issue, the mind of man is, as I said, only a hereditary reproduction of the minds of his ancestors; thus if you are born with a mind that is a throwback to certain ancestors you will be able to recall under like circumstances should they arise in your lifetime, the experiences of such of your ancestors as have had similar experiences, provided that they have had similar minds to your own; that is to say, from the time of your birth back to the life of the earliest ancestor that you throw back to, but not to the experiences of like ancestors previous to that ancestor, nor to any ancestor of whose brain your own is not a reproduction, or of whose soul yours is not a rebirth. I may here state that the class of brain you may possess, or the class of memories that you may recall, is not decided by the number of such ancestors, nor by the minds of your parents, but by the actions that your 
father may be engaged upon at the time of the germination of the embryo that gave you birth, and after your birth by the way you cultivated such hereditary qualities during your life. Whatever the main mental qualities that your father is utilising at the time of your conception, that is the main factor in deciding the class of brain you will be possessed of, and your fitness for any particular state of life, the particular talents you will have; and what memories of his ancestors he is recalling will decide to what ancestors you will throw back and the amount of proficiency you will be capable of attaining, and the further the throw back thus evolved, the more correct the deductions will be on the particular subjects or acts which the brains, talents or experiences of your ancestors or of members of your family may enable you to recall, exert or utilize. While the occupation you are most likely to succeed at will be that which the experiences of such ancestors best fit you for. The reason why certain members of families are failures in work and occupation at which members of such families usually succeed is that they throw back to ancestors whose lives and experiences do not coincide with the particular state or the particular circle of events or environments that are again being re-created or re-enacted in the country or community in which they live at the time of their rebirth. Of course this may and always will be affected by their choice for good or evil. This is why certain families produce big percentages of poets, sculptors, statesmen, doctors, parsons, carpenters, tailors, bootmakers or tinkers.

Now it may appear to the reader that in making the statement that the mental talents of mankind are, from my observation and experience, the result of prenatal actions of the parent during the period previous to conception when the productive system is producing the spermatozoon I am making a new departure, but I would like to point out to my readers that shortly after writing the above statements, which were the outcome of my personal observation extending over many years of experience in stock-breeding and a close observation of humanity, when I chanced to read the following remark of Charles Darwin in "The Origin of Species " when commenting on the variation of physical, not mental faculties, which I think is worthy of insertion, as it goes to prove that the statements I have made are a further illustration of the 
conformity of one general principle in Evolution both mentally and physically, being one and the same adaptation of one uniform and fixed process of the infinitely perfect uniformity and conformity of creation and evolution in all its shapes and phases. Darwin writes as follows. "Origin of Species," page $I 7$, chapter I. :-

"Geoffroy St. Hilaire's experiments show that unnatural treatment of the embryo causes monstrosities; and monstrosities cannot be separated by any clear line of distinction from mere variations. But I am most strongly inclined to suspect that the most frequent cause of variability may be attributed to the male and female reproductive elements having been affected prior to the act of inception. Several reasons make me believe in this ; but the chief one is the remarkable effect which confinement or cultivation has on the functions of the reproductive system."

This is a striking instance of the conformity of mental and physical evolution, and I may as well impress upon the reader that $I$ had not read this quotation at the time $I$ wrote the previous portion of this chapter stating that mental talents were decided prior to conception. But it must be borne in mind that about three hundred years must elapse before the repetition or recurrence of like events in the course of history, so that many men and minds are reproduced that are unsuited to their environments, so that although they have the same talents as made great men in other days, they die unnoticed and unappreciated. Hence it is that just as the bodily survival was decided by the hereditary preponderance of certain animal strains of utility, so the preponderance of mental proficiency will be subject to the same deciding laws of descent, and by the amount of superior energy a family, nation or race may exert, will be decided the survival and fitness of such a family in mind and soul to retain the rights of rebirth and re-creation, and the extinction of the unfittest of others till crime shall be no more.

Do not make the mistake of considering wealth as a class distinction, for it is not; it is only God's reward for efficiency. I use the word class here and elsewhere in this treatise as 
meaning fitness for a certain class of duty in life or work, for the employer and employee belong to the same class, for what benefits the trade of the employer makes the means of employment of the employees so that their interests are one, if they would only realise it, and the employee could only understand that in freedom of contract lies his one means of preventing the combination of the employers to raise the price of commodities, and so reduce the purchasing power of high wages until he is poorer with the high wage than he was with the low one. But this is digressing from my subject.

Now those who succeed and are able to direct, form the highest class of society, and statistics show that the percentage who are able to excel above others is about seven per cent.; and we find that in the succeeding generation this seven per cent. contributes from four and a half to five per cent. to the management and direction of the community, whereas the remaining ninety-three only contribute two per cent. towards the seven per cent. who make up the managing portion of the succeeding generation. This difference is too great to be a mere chance, and can only result from hereditary fitness and unfitness, and the possession of hereditary capabilities for certain occupations for which they are indebted to the experiences of their ancestors, though I do not mean to say that they will succeed if they are placed in some other status of life. Thus the man who can best manage a large undertaking is least likely to make a success of a small one. And the fact that the genius or markedly successful man is often one of the two or three per cent. who rise from the ranks is most probably due to one of the following two factors-either his having had a large number of ancestors whose experiences particularly coincided with the circumstances which are again being re-enacted, for it must be borne in mind that the power of the mind is the outcome of physical superiority in energy, without which mental superiority is not attainable.

It is a throwback to a remote ancestor who was at some past date in evolution vastly superior in mental development, but whose family became degenerate or was deficient in some qualities which required the altered environment of greater poverty to develop them; whose family failed in the past because they could not keep pace with their competitors in a higher class, either from physical defects, the result of the 
abuse of their bodies, and consequent destruction of their physical power to sustain the heavy demands for sustenance made by the mind upon the body to support the extra strain resulting from the mental friction necessary to combat extra difficulties in a higher and consequently more strenuous social condition of life. These faults could most probably only be removed by several generations of intermarriage with those whose lives in a humble social sphere had evolved the physical development required to produce the necessary stamina to bring to full perfection the knowledge and experiences acquired by previous generations of ancestors, whose lives had been spent amidst higher mental environments. Also the higher mental exertions of such ancestors demanded mental rest for three or four generations, which their relapse into a lower order of social environment alone could afford. This is probably one of the reasons why the failures of good society fall to the bottom and produce the height of degradation, and the successes of the poorer classes so often are the geniuses who most adorn its apex.

This is why six generations of laziness bring upon a family the loss of the vital powers of the recreation of their minds, brains and souls in their offspring, hence the reason that in past evolutions the acquirement of too great an amount of ease and luxury has invariably degenerated, and often exterminated whole families and nations. But as woman produces the body, not the mind, in her offspring, the women do not lose their energy, only the men; but should women become immoral they lose their powers of bequeathing to their children healthy bodies as surely as men lose the power of transmitting mental vitality when they become lazy. These are the main causes of the deterioration of all degenerate races, and the superior races have been the outcome of hardier combat and struggle against severity of climate and adverse circumstances of existence whose migration has increased their brain power.

Aryan Races have migrated more and have had to fight harder than any others against the approximately two hundred and fifty thousand years of the Glacial Period, and have made themselves vitally the strongest race in the world. These are the races to which all decayed nations in the majority of cases owe their resurrections, which are brought about by their being conquered by races of superior physical develop- 
ment who have thereby restored the lost vital powers to the degenerate races they conquered, and by so doing have added to the physical powers of the conquering nations the mental advantages of past civilisation, the memories of which the loss of soul had made dormant in the conquered race. For, say what you like to the contrary, energy is the life of the soul, and we cannot too strongly impress on future generations, yet to be born, that work and plenty of it-not the eight-hour day and "government-stroke"-is the only thing that can enable them to gain heaven and prolong their lives, and that all other virtues are of no avail without it.

As the first stage of the evolution of life is a long struggle of physical existence to conquer matter so as to produce energy sufficient to utilize knowledge, so the future stages of involution now about to commence will be a like struggle of the mind and soul to conquer selfishness, war, crime and cruelty by love and charity and thus to acquire a perfect soul, so that man may learn to use in the best manner possible the knowledge evolution has enabled him to acquire; in love, peace and comfort.

Now I will give a further illustration of heredity. The mind of the agriculturist is a mind of comprehension. This makes him more capable of observation than to weigh or reason cause and effect. It also makes him adverse to theory and wedded to practice and experiment. It is also the mind of a soldier and statesman, but it is not the mind of the scientist, business man, lawyer or mechanic, artist or author. Hence as agriculture is a science less of knowledge than of observation, to be a really successful farmer the two following qualifications are the ones most essential-experience in observation, and a past ancestry of men who have devoted their lives to a close observation of nature rather than to a close study of detail and science. This is why the farmer is always reluctant to accept the advanced ideas of science until full experiment and observation have proved them correct. It will therefore be found that if twelve youths are selected from families that are bred from town or professional families and are sent to an agricultural college, the chances are that only two or three will be successes as farmers, and that nine or ten of the children of families that have had an unbroken line of agricultural ancestors will, with less knowledge, outstrip them in practical efficiency. And it is highly probable that if the ancestry of 
the two or three who were descended from professional parents could possibly be investigated, we should find that at some past period their families were descended from an agricultural stock that had drifted into city life. The same will be found to hold good with all trades and professions in the majority of cases; but as demonstrated by the examples given hereafter of milking cattle (see Book II., Chapter V.), the exceptions to the rule are often also the exceptionally efficient, and most proficient cases of capability of genius.

This is why though in the majority of instances the largest number of statesmen, doctors, lawyers, parsons and soldiers, etc., are descended from families who have like ancestry; yet it often happens that the most brilliant success is descended from a family which is the one we would least expect to produce it. This is owing to the fact that it is probably a long throwback on one side which gives a larger fund of memory of past experiences combined with a mind that is also a throwback to a dual ancestry in the same family who have had experiences capable of developing another class of mind. Thus a person whose brain throws back to an ancestry made up of both imaginative and comprehensive minds (see Book I., Chapters XI. and XII.) will give a combined result capable of producing experiences both of observation and imagination, and the possessor thereof will be a superior soldier, parson, inventor or farmer. Whereas a mind that throws back to an ancestry of students, men of business or professionals on the one side, and a highly comprehensive ancestry on the other side, may produce by the dual combination of the two classes of mind a highly efficient statesman, lawyer, solicitor, judge, or business manager or mathematician.

Now God in His wisdom, when he gave mankind the power of imagination to make the civilisation of the world possible, withdrew the power of memory from the minds of men. This is restored in the following manner: whereas animals are allowed to reproduce the memory of their forbears, in the case of mankind it is only returned as occasion arises when he meets with like circumstances, that require certain knowledge of which his ancestors have had experience. He is then able to think with the knowledge of the experiences of his dead ancestors by recalling the memory of their acts, but is only able to recall the experiences and thoughts of those who 
possessed minds and brains similar to his own, and led lives similar in occupation to that which he has now to lead, and for which he has like talents or capabilities. I do not mean that he can recall the entire thoughts or experiences of these ancestors in detail, but that he is able to think as they thought and avoid faults that their experiences could prevent when called upon to perform like acts to theirs under like circumstances and environments. Thus in a family who has given to the world a long line of soldiers or statesmen, their descendants who have military capabilities will be able to recall the experiences of the particular military ancestors who have had like military experiences, but not the experiences of their political ancestors. The family which is descended from an ancestry of carpenters and blacksmiths, the one who has abilities to make a first-class carpenter will be able to recall the past experiences of the dead carpenters to whom he may throw back, but not necessarily the experiences of the blacksmiths in a like degree. This is the reason why some persons with only a slight amount of present knowledge, but more hereditary genius, are often able to produce more correct and perfect results than those with a greater amount of knowledge, because the latter, lacking the experience of similar knowledge in their past ancestry are unable to correct their impressions by past experiences. It is also why people born in different circumstances of life and classes of society are unable to view or interpret the same arguments or facts in the same manner.

Those persons whose ancestors have for generations viewed life from one standpoint are unable to form a correct opinion of it from another. They may be for the moment impressed by the opinions brought forward by those whose ancestors have had experience on matters on which their ancestors have been ignorant, and the force and truth of the arguments brought forward may be undeniable and incontrovertible, and the truth and wisdom expressed may be selfapparent; but so much stronger is the prejudice of past beliefs of past generations, that it at once outweighs the new impressions which are swamped by the preponderating influences of the past experiences of their ancestors, and it will take several generations of life in an altered social position to overcome this tendency. For this reason you will find many great geniuses whose brilliant abilities only accentuate their 
errors, for their abilities becoming employed in directions opposite to the fitness of their breeding and hereditary talents, they cannot think correctly on the particular subjects that their present occupation may demand, yet so great are the gifts of cleverness and knowledge of which they are possessed, that they are able to lead others on in false directions to their own destruction. And wiser heads with less genius are unable to convince them of their folly, till it is too late, because they lack the experiences of hereditary knowledge of departed progenitors, and because their hereditary antipathies prevent them from being able to impress their hearers. But in the future, as mankind evolves the powers that the evolution of his soul of wisdom will bestow, we may hope that it will enable him to understand and direct his actions by the advice of those who have had experience that his ancestors may have been deficient in. And in the future it will be found necessary to cure ignorance and crime, less by teaching than by paying more attention to scientific breeding of the human race, and to turn our attention not to educating the foolish so much as to breeding from the wise, and so prevent rearing a nation of clever fools, but rather to breeding up a race of wise, industrious, sober, economical and useful men, who will give a good result for the time, labour and knowledge expended on their education; and I am convinced it is only by restricting and preventing the breeding of the vicious, extravagant, foolish and intemperate and greedy that we will ever attain the prevention of crime. We must turn our jails into workhouses for the benefit of the weak, poor and unfortunate, and make them houses of detention where the criminals will be prevented from breeding and perpetuating crime and folly, for crime is only another name for folly. We must elaborate some scheme for increasing the breeding of the fittest, that is to say, of the most successful, and of decreasing the breeding of the unfit, that is to say the failures and unemployables.

I must now revert to what appears to me to be the true form of immortality of the soul, for it appears to me that immortality as is generally conceived in the idea of an individual life of an individual soul, is not in accordance with the plan of creation as divulged by the knowledge of evolution, and that the true conception of immortality must be sought by a more perfect knowledge of the evolution of plants, animals, and 
man, when it will be found that the evolution of the mind and soul has, and is to be carried on on exactly the same lines as has been followed in the evolution of the body, and that it is only by the means of more perfect study of evolution, read in conjunction with a more perfect understanding of what constitutes God and His Trinity and its connection with the creation, that we will be able to ascertain how we are in the wisest manner to direct our lives and rule and govern our people so as to produce the maximum amount of peace, comfort, content, mercy, justice and charity. This is why I maintain that the science of evolution is one that is worthy of being made more understandable and more interesting to the mass of the people, even at the cost of not adhering in a hard and fast manner to scientific rules of procedure.

Now, the idea of immortality to which evolution points is that the immortality of the soul is one continuous passage of life in its spirit form from generation to generation, throughout the whole family existence, having a continuous reproduction like the life of animals and plants, an individual life having a continuous existence in different and successive bodies, and I shall therefore devote my next chapter to Life and Death, or Rebirth and Heredity (see also Book I., chapters XI. and XII., "Mind and Soul"). 


\section{CHAPTER VI}

\section{REBIRTH AND HEREDITY}

As will be seen when the reader comes to the chapters on Evolution; Life, Death and Rebirth were necessities to God's scheme. Hence before attempting to read these chapters, we require to ascertain the logical or correct ideas of rebirth. There are many strange opinions on this subject, made beautiful by various poetic and imaginative religions, all of which are prone to take us out of the land of comprehension into the land of imagination, and the object of this work is to prove the course of evolution upon a certain hypothesis, not to enable the reader to understand evolution and creation.

That must be left for wiser minds than mine, and future generations, to perform. For being possessed of a comprehensive mind, not a constructive or mind of understanding, my duty is to place conceptions, no matter how imperfect in scientific detail, before the reader in logical sequence so that the more studious mind may be able to follow the narrow line of road that leads to clear understanding, and to tear off the clothes of misrepresentation where my hypothesis brings them under notice of such minds; and for them to review and criticise and ascertain the correctness of the arguments adduced and to pick out the grain from the chaff. I am therefore endeavouring to place before my readers a certain sequence as a means by which they can weigh as in a set of scales the teachings of evolution, history and religions, and to endeavour to point out the logical demonstrations that follow and a means of checking their correctness or incorrectness by the hypothesis I have introduced. Now, the logical mind being the active mind of mankind, it is ever in a hurry, rushing from fact to fact, modelling and shaping designs and plans, too busy to collect the material of knowledge to fill the cart of study or to find time to stop and build up the edifice of perfect knowledge, leaving to the minds of understanding by the advancement of 
science the hunting up of the proofs of knowledge and experience to be placed before the world for review and judgment, that it may save thought from falling into the maze of intricate pitfalls that knowledge and science are continually presenting to its view by sifting the grains of truth from out the mass of fiction presented for its review. I will demonstrate in Chapter VI. of Book II. on Development of Mind, and in Chapters XI. and XII., Book I., that there are three classes of mind; that mind and soul are the products of the attributes of the three different persons of God's Trinity, and therefore one class of mind cannot perform or control more than the one class of knowledge or work.

I am only submitting a sound hypothesis, at the same time knowing that many of the arguments adduced may be incorrect in detail, trusting to the reader possessed of a mind of understanding and of greater knowledge to find the weak places and strengthen the girders and the frame-work of facts in the bridge of controversy that I am endeavouring to throw across the rivers of Superstitions, Bigotry and Doubt, which intersect the valleys of Evolution. I hope also to pull down the false clothing of vivid imaginations and superstitions which have made truth taste sweet and pleasant in the past at the cost of its transmogrification, so that in its bare nudity a more scientific mind may follow in my footsteps and make clear and understandable what I can only enable others to comprehend, for the comprehensive mind only makes wisdom visible; the mind of understanding must remove the obstructions to a clear and detailed perception of facts, and I must leave to each one of my readers the decision as to how much of the clothing of bigotry and superstition he wishes to leave on or tear off to suit his individual power of understanding, hoping in the meantime that my thoughts may act as a fingerpost pointing out the true and direct road to virtue and wisdom, instead of having to travel along the more circuitous carriagedrives of science and religion. I offer this hypothesis to the public in the hope that it may be used as a primary work to be, as its title implies, a kindergarten to more advanced results of further study, and may act as a short-cut to a better understanding both of science and of religion; but it will in all probability require the labours and thoughts of many men and many years to bring so deep a subject into a concise science 
that may be applicable in a more concrete form to the daily requirement of life.

With this introduction I will now endeavour to explain the laws of re-creation as expounded by my hypothesis. In the primary stages of disintegration the products of motion, light and heat, the result of the combinations of the return of the first attributes of God the Father and of God the Mother (don't leave the power or influence of God's control out of consideration; that is where science is inclined to go astray in atheistical hands), produces chemical action, with the result that rebirth or re-creation follows as a natural result, and Matter, the by-product of reconstruction, is created as the only possible outcome of material not required for present use. A finite portion then becomes dormant, that is to say devoid of the active influences of God's Trinity, a state of inactive existence we call death; but, as Christ expresses it, "he is not dead, but sleepeth," for the science of radio-activity clearly demonstrates that no Matter is possessed of life, which exists either active or dormant, in the spaces that impregnate all material existences by the ions of electricity that creates its motion.

Hence death necessitates rebirth or re-absorption, re-creation or reconstruction, according to the matter that is to be reconstructed, or the manner in which it is to be reconstructed. But as God runs evolution on a fixed line of a complete and comprehensive plan, by the separation and intermingling of the attributes of His Trinity, subject to certain rules of heredity and variation. It follows that life can only be recreated in the same manner and by the same forms by which it has been previously created. That is to say, it must be a re-creation of a variation of the same hereditary evolution from which it springs, or that preceded it. That is to say it must be a reproduction of those portions of existence of which it contains the maximum component parts subject to the laws of the survival of the fittest. This will be decided by its hereditary abilities for reconstruction under specific limitations of reconstruction, influenced, often visibly, sometimes invisibly, but more in appearance than in reality, to a limited degree by its environments, subject to which conditions it re-accumulates and re-absorbs portions of the surrounding matter most suited to its forward advancement or retrogression, as the case may be; in proportion to the energy and motive power of the 
spiritual vitality of its pre-creators both finite and infinite that it may be possessed of or is capable of reproducing.

As the soul is immortal it can never die, hence once a soul is evolved, nothing but the destruction of the higher attributes of God by acts of indolence and wasted opportunities can condemn it to extinction; and once its vitality is lost, all powers of rebirth or re-creation are lost for ever, and the by-product can only be absorbed by other bodies possessed of vitality.

Hence death is the inactive state of Matter which for a time is devoid of life through want of chemical action, heat and motion, the results of the forces of radio-activity which we call soul, but the soul, so long as it has not lost its vitality by crime, is free to seek a new abode as it travels along the road to heaven and immortality. But before proceeding further I must ask the reader to remember that all virtue and vice, fitness and unfitness for use or abuse, are all matters which are subject to the laws of descent, and that man's power for good or evil, like all other qualities, is only to be decided in fitness for survival by the law that like evolves like; and it is only by the fittest mind evolving the fittest souls that the soul of any family will be able to triumph over body as mind has triumphed over the material world and the animal kingdom, and has and is fast subjugating nature. To some extent during the transient periods of individual existence environment and genius may exert a temporary influence, but in the long run the laws of descent prove to us that this retransition of the spirit is the reconstruction of the infinite soul in a fresh finite body which advances only on restricted lines of immortality; hence rebirth can only follow logically by the reincarnation of the souls or soul that preceded it in the souls that are to follow it in the same family, but not in a soul with which it has no relationship. It therefore appears to me that the most logical deduction is that the life of animals, man and plants, is one continuous extension of an undying soul, that is to say, that the individual soul is but a new limb put forth in the family tree of immortality, growing fresh leaves as it passes through the stages from birth to death, shedding its leaves and sowing fresh seed in its offspring and assimilating its nourishment as it grows and evolves. I maintain also that the soul is the spirit of the mind of the family passing from father to son or to grandson, coupled with the existence of the 
qualities of God the Mother, love, life and body, so long as the Spirit of God gives it power to live. For the logical deduction from evolution is that the death of the body of man is not the death of his soul, but is only the transition of his soul to the minds and the souls of his children in the bodies of their mothers.

I may here point out that having got this far, we may well ask "What is this evolution of the soul, and how is it brought about?" Now, we must bear in mind that the male only reproduces Soul, Thought and Mind and the energy of vitality in his future offspring, while the female will produce the body, health and strength of the child. The father, therefore, will be the direct cause of the reproduction in his children of Thought, Mind and Soul, which are to be the means by which mankind is to conquer and govern nature. But woman, to whose charge has been given the building up and formation of the physical frame, and the completion of the material body capable of supporting a human soul, is not to transmit the male qualities of mind and soul, but to lay the wires, as it were, for the spiritual, electrical currents of religion, love, life and sympathy, which were to soften and refine the soul of mankind by the ultimate conquest of his cruelty by the spirit of love. This is shown in some of the Eastern Legends, and beautifully depicted by Moore in his poem, "The Fallen Angels," in which is summarised the belief of the Three Persons in One God. Hence woman's duty is perhaps higher even than man's, for to her has been confided the redemption of mankind, and if it had not been for the influence of her love and early teachings and patient devotion to her young, by which she has prepared the way for religion, it is doubtful if man could have evolved a soul at all, and the evolution of mind would have come to a standstill, as it has in savage races.

For it was the mother's love that gave to mankind the power to rise from earth to heaven, for, as Moore's poem points out, the Spirit of Light could give to man only Thought and Imagination, which could only create a discontent with earth and its trials and troubles, and a desire to abandon the strife and quit it for an imaginary existence in some brighter planet or star where strife and labour would be less arduous. No sooner, however, does the Spirit of Love enter through woman's acts of redemption in the form of 
God-made man than all this is altered, and from that time woman's influence is to elevate man's mind to further efforts of hope and courage to conquer the world of Matter, and, as comprehension still further enlarges his mind, to live for others not himself.

Now, the forces of love travel diagonally, so as to diffuse the influences of all the attributes equally throughout creation; thus the attributes of God the Mother tend to intermingle with those of God the Spirit, whose forces travel horizontally, and with those of God the Soul, whose influences travel perpendicularly. The Spirit of Love, therefore, ascended to Heaven and brought down the Spirit of Soul to create the mind of man in its material form of wisdom, which, combined with the Spirit of God the Father, now evolved to the stage of Thought, which is by this addition advanced to Imagination, marks the creation of man in Genesis; and it is this advance from Thought to Imagination that starts the soul of mankind from the instinct of an animal, and will thus make it possible for man to raise his thoughts to Heaven in the conception of a life hereafter, and so place him above the rest of creation as he evolved the other two qualities of his soul, Comprehension and Understanding. I wish the reader to fully grasp that there is a vast difference between the physical development of soul which we call Life made up of nerves, brains and Matter, which are but the conducting medium of the psychical forces we call electricity and radio-activity, which produce energy, vitality and soul. These electrical forces represent the influences of God the Soul as those of God the Mother have their visible prototype in protoplasm and material creation by chemical action, affinity and combination, and those of God the Father in Light, Heat, Contraction and Expansion.

The energies of God the Father are seen in Light, Motion and Disintegration, the forces of God the Mother, by Chemical Action, Affinity or Love, and the energies of God the Soul in brain, positive and negative electricity. So as each of these trinities of energies and forces becomes the predominant motive powers in Nature, we find some new attributes of God's Trinity evolves some new Evolution of Nature, and each in turn destroys the previous evolution to establish a more progressive one. So on the Eighth Day the Spirit of God the Mother brings to man from 
Heaven the Soul of Love, the spirit of which she could by nature transmit only to her female offspring until God, by the miracle of redemption, enables her to transmit the qualities of Love, Sympathy and Charity and Invention to her grandsons as well as to her sons and grand-daughters, otherwise she could by Nature only transmit these qualities to her sons, daughters and grand-daughters, not to her grandsons, and from that time Love and Religion become hereditary and possible to man as well as to woman; but the characteristics of body are not immortal, so are not affected by the miracle of redemption, which was to give man a soul of mental, not bodily or physical powers. Thus it was woman's love that ascended to Heaven and, by converting Imagination into Comprehension, enabled him to believe in the revelations of God and to attain habits of love of right, virtue and truth, which were in the future to conquer his selfishness, cruelty and deceit, and enable him to become civilised and evolve governments, religions and commerce amongst such nations as are descended from those thrice-redeemed Aryan races. So we find that mankind from this time onward is to be no longer governed by power alone, but is to be subject to the soul of love, which is to raise woman almost above punishment.

This is not a new teaching, but one of the revelations of the past which has caused man to love and respect woman. But I wish you to remember this when I further show that woman's influence on heredity is physical not mental. Hence in the case only of abuse of fidelity and immorality does God inflict the punishment of the Mother's sins on the child, but in the father all want of energy, folly, extravagance or injustice, unless the quality happens to be a virtue of the Epoch, is visited on his children. But although woman's love has raised mankind above the rest of creation by giving birth to his soul by the means of redemption, it does not alter the qualities of the physical development, for although religion had brought about the incarnation of the soul, it is only since the birth of understanding, about one hundred years ago, that the soul of wisdom has begun to influence the mind of man, and, just as the soul of woman has produced love and religion, so the soul of man will, in like manner, have to evolve wisdom and immortality in years to come. But in the future mankind must evolve their own souls of wisdom in the natural course of 
evolution, subject to the laws of nature, not by miracles of redemption, till, by evolving wisdom enough to understand the truths of revelation, they can become a religion unto themselves by learning to use, not abuse God's earth, which they are destined in the future to control when they have evolved a soul to which crime is repulsive, and knowledge of medical science shall be sufficient, not to eradicate disease, but to prevent it and so prolong life into immortality.

When about two hundred thousand years ago, by evolving Comprehension in the mind of mankind, woman made possible the conquest of the savage will of man by creating in his breast a love for her, stronger than a mere animal nature could evolve, the Spirit of God the Mother is brought into the world in order to overcome the energy of the power of God the Father as materialised in the stubborn will of man, and teach him to see the value of a belief in a heaven which he could feel and believe, but which he in his blind faith unenlightened by the Soul of Wisdom was still unable to understand and was still too ignorant to imagine.

By the laws that govern Evolution, the most probable solution is that the soul of man is one continuous rebirth of its unbroken existence in separate physical bodies, which are but as worn-out suits of clothes which the mind and soul discard as they get out of fashion in the forward march of Evolution. I feel certain that in an indistinct manner all the truths of revelation are and have been active forces in the evolution of the mind of man, dim and indistinct like a light shining through a fog, but none the less present. And that as man first evolves imagination, these become the groundwork of the early religions and superstitions of creation, which gave rise to the early ages of superstitions, beliefs in spirits, or Gods fairies and sprites, who held and ruled or controlled the lives of mankind. We see in these early beliefs the infantile mind of the past trying to comprehend the properties of the spirit of Fate, by which God rules Creation, just as a child peoples its world with fanciful imaginations of joys and pleasures and hopes destined never to be realised. Then boyhood, rising above imagination, seeks to emulate the strife of manhood in his ambition to excel in sports and pleasures, and so evolves the interests and ambitions that are to produce the energy and competency of manhood. So in the past the dormant revelation 
of a life to come has created first the idea of the reincarnation of spiritual forms in material bodily forms, because the mind of man was not sufficiently evolved in the childhood of evolution to comprehend the action of spiritual forces (such as the magnetic and electrical influences) that surrounded, permeated and controlled the world of Matter; hence he could not realise nor understand in his primitive and finite existence such a revelation as that the infinity of God's Trinity surrounds, permeates and controls the Universe. Now I am convinced that unknown to us, the actions of sidereal disturbances, comets, etc., are but means used by the all-wise fatality of God to equalise the distribution of the forces that perpetuate the life and existence of the separate planetary systems by equalizing the distribution of the forces of radioactivity, life and energy, of the laws and forces of which we have a very faint conception or knowledge. Hence, it is not to be wondered that our ancestors having less of this knowledge, conjured up all sorts of fantastic religious beliefs and conceptions of the revelations of rebirth and immortality which they yearned to comprehend but could not understand.

I am confident that all such beliefs, religions, and parables contain grains of truth and have all done much to point man's thoughts to the real truths of nature. But we must turn to Evolution for their interpretation. And it is easy to follow the gradual growth of the knowledge of the consciousness of revelation as it dawns in man's mind as his growing soul slowly influences his mind in its yearning for a soul of wisdom that will enable him to comprehend and understand the immortality of the world God has created for him. Thus in the course of the world's evolution we trace the course of religion from fear, surprise and curiosity in the unknown powers of nature up to the present stages of religious beliefs, then from belief and devotion to a yearning to know more than religion can teach of his infinite being. First, man prays to the most prominent visible forces of nature - the sun, moon, stars, air, winds and waters - and begs them not to destroy the imperfect works of his mind and of his hands; then as his fellow-men meet and fight the overwhelming forces of nature through the two hundred and twenty thousand years of the Glacial Period, he begins to acknowledge the fact that superior birth and breeding, even if it may 
not in every case produce superiority in bodily or mental capabilities, at least produces in the main superior pluck, virtue, energy and vitality; so during these ages of prolonged and terrific strife against nature, man slowly realises the importance of honour to the victor, obedience to a ruler, and reverence and devotion to him who succeeds, the three cardinal virtues of creation that are for ever to raise and place the fittest men in the highest positions in the majority of cases. I say majority of cases because it is a law of evolution that out of chaos comes order, out of evil comes good, and out of sin comes virtue, and that the exceptions only prove the rules.

Now many scientists have wondered why there was so long a glacial period, because the ripening influence which it produced on the material universe by pulverizing the soils of the world seems to have been overdone by its prolonged continuance. This was only one of the causes that necessitated its existence, the production in the mind of man of the powers of energy, courage and perseverance to complete his bodily development and so enable him to conquer nature; the production also in his character of habits of honour, obedience and reverence which were to fit his soul to receive the knowledge of God and His Trinity were far more important results than the production of the fertilization of the earth; hence the prolongation of the Glacial Period. Thus the veneration of the victor was to grow out of this strife and to lead man a step further in mental evolution. The rulers and prophets, no longer content with obedience and reverence, demand to be worshipped as gods. Then came a contest as to who should rule the soul of man, the king or the patriarch; and it dawns upon the mind of man that as there could not be two earthly rulers, it followed that there could only be one God.

So is idolatry replaced by belief in one God. Then with higher knowledge of one God and His Trinity comes the birth of advanced religions, caste, feudalism, and aristocracy, and thus was produced the downfall of idolatry. So likewise was the revelation of immortality present, but dormant in the mind of man; he would never have dreamed of an immortal God or of an infinite creation, nor have sought for a logical hypothesis for immortality, the first dawn of which was the conception of reincarnation in the body he then possessed, for his soul was too young to conceive a soul 
that was not subservient to bodily existence; but as it is the law of nature to go from one extreme to another, as opposite forces expend themselves in their fight for supremacy, to evolve a concurrent force out of their joint actions which cease to be a disturbing force as the antagonistic forces become more temperate by intermingling and exhaustion, so in mental evolution we find the same rule applies. In like manner as the superhuman or psychical forces of nature and God's Trinity evolve new impetuses and inspirations in the minds of men, his beliefs start in a variety of confused ideas which gradually mingle together to produce an understandable whole as one imperfect ideal is influenced by other incomplete ideals from the abstract imaginations that combine to produce its creation and existence.

We now find that the ideas of rebirth carried to extremes by the religions of antiquity, particularly in Egypt, where the bodies of the dead are embalmed and sometimes even encased in pyramids to ensure the future return to mortality, which is only an imperfect idea of immortality, when they hoped to outshine in social pre-eminence those who were not so carefully preserved. In the same way every religion has, and will till man has evolved a perfect understanding, capable of knowing what is right from what is wrong, and a more perfect will capable of doing what is right for the good of others, rather than selfishly making charity begin, instead of end, at home, and learns to do the will of God because it is that alone he was created for, and therefore is his duty. He will continually distort all revelations to suit the particular fanaticisms, aims and objects of the age of evolution in which he lives. Without these fanaticisms as a means of organization, it would have been impossible in the past to have organized virtuous minorities in a sufficiently efficient manner for them to have become powerful enough to have overcome the vicious majorities which the degeneration of past ideals of lower orders of virtue gave birth to.

Thus various forms of rebirth and reincarnation have been invented in the past to suit the different phases of evolution. I am not trying to argue for or against any one form of rebirth or religion, nor do I wish the reader to consider that I am laying down the one herein exemplified as proved or demonstrated. I am only placing before him for 
his consideration and review new ideals and thoughts, and must leave him to decide upon their merits. Moreover, because under the light of my hypothesis they appear to me to fit in better with the whole of the scheme of creation from the standpoint of that hypothesis and also from modern scientific investigation. All past theories of rebirth strive to blend together a destructible body with an indestructible soul, and to create an infinite soul within a finite individuality surrounded by a finite body, or an immortal soul within finite limits and with the qualities of infinity. This appears to be somewhat illogical and disregards the fact that the soul, being in the likeness of God, must be a pure and invisible spirit, and being so must logically be beyond the reach of death; while the body, not being in the likeness of God, must become perfectly free from crime before it can be an immortal abode for a perfect and immortal soul, which must be influenced from without as well as from within the body.

Now it appears to me that the only logical deduction must be that the soul cannot die, and therefore that when the body dies the vitality of the soul can only live in the souls it has created just as the vitality of a plant can only live in the seeds it has produced. This is why I have placed before the reader in Chapter XII., entitled "Mind and Soul," what appears to me to be the form of immortality most in accord with this hypothesis and with evolution, and consequently the most reasonable view of the matter, namely, that the soul is the united possession of the family to which it belongs and is being slowly evolved to a perfect comprehension of the limits of good and evil and will after death participate in the further development of the acts, objects, aims and abilities of the family to which it belongs, and which have been the source of joy and pleasure of their life which will be reproduced in the lives of their children, but devoid of the pains and sufferings which they experienced during their own individual lifetime. Such a conception appears to my mind to offer the greatest inducement to virtue, and also to coincide with the whole scheme of evolution, and to be the fittest reward of virtue and the most rational means of attaining immortality and perfection. But all ideas that the souls of the dead should pass into any other existence than that of the family that gave them birth do not appear 
to me to be rational or in accordance with the laws that govern the scheme of creation in the past.

As in the evolution of the world we get the only experimental experience of the truths of revelation, and of the effects of religious teachings in the past, so it appears to me that the more we study this interesting science from the standpoint of the Trinity of God, the more we will find in it the only reliable sources from which we can in the future evolve perfect ideals of a perfect religion and perfect forms of government, and so be able to clear up the errors of superstition and bigotry and gain a true understanding of the truths of revelation. A religion that can perhaps some day become universal and be capable of destroying the embittering enmities of colour, creed and race without which the growth of national and social animosities, strifes and discords would never have existed; but at the same time we must remember that these same animosities have done their share in the production of virtues which otherwise we should never have evolved, nor would we have been able to correct the principles of government, either social or religious. For if there had been' no crime in the world we would not have learned to value virtue, nor would we have been able to learn how to forgive our neighbours' faults, which is to be the great duty of the coming Epoch of Charity and the principal virtue that we shall have to acquire. This will also decide which of us is to become worthy of immortality, for it is by learning how to forgive our neighbours' sins, so long as they do not interfere with our happiness, that we are to acquire that most perfect form of Charity. This is what is to enable us to gain heaven, and this is one of the defects that women have to attain a great advancement in before we will be able to live with the greatest amount of liberty compatible with perfect freedom, for at present they are more cruel in their condemnation of their fallen sisters than men are selfish in their greed of wealth or jealous of the rewards of wealth and position granted to their superiors, which are the two crimes we have most to cure if we are to gain perfection and evolve such principles of state, social and religious government as will enable the whole world some day to live under laws conducive to universal Peace, Comfort and Content.

When the increase of science no longer used for individual 
cruelty, greed and selfishness ends, but devoted to universal prosperity, benevolence and charity shall evolve commerce without deceit and trade without strife, wealth without arrogance, and the receipt of benevolence without its producing indolence, and the habit of dependancy on others and pauperism in place of energy. For it is the loss of energy that destroys all the well-laid schemes of mankind to reduce poverty, and after this man will have evolved and won heaven, whether on this planet or another I will not presume to say; but it is most probable that he will slowly attain to immortality when he will receive the just reward of his well-fought fight to attain perfection.

This will be rewarded by his becoming immortal, but till then Life and Death, birth and rebirth are necessities of evolution. But as it has taken in the past millions of years to evolve his body, so it may take millions of years in the future before the advances of medical science can prolong life forever. I must here point out that until commerce is further developed and we have evolved to a sufficiently high state of perfection to be able to live without doing anything that injures or offends others, and to try to bear each other's burdens, not to throw down the load when it becomes heavy, life and death are necessities of existence. For we do not play because we are young, but we are young that we may the better play, and if one generation did not die out to make place for the other, evolution would not evolve. For the older we get the more we fall into fixed grooves. So age must give place to youth that youth may change its abode and seek pastures new and fresh fields of enterprise.

When the world is perfectly wise and fully populated with wise inhabitants who can live together in perfect charity, this will no longer be necessary as it is to-day, for then the earth will be fully stocked and governed by perfect beings in a perfect manner, and commerce having become universal, no further need for constant change will be necessary. To this revolving state of continual change, life and death are necessities, for if youth had not caused us to shift from place to place to seek fresh occupations, we would never have developed as we have done, nor have been capable of half the advancements that we have already attained, let alone the more complex ones that we shall have to evolve in the future, 
and it would be impossible for us to adapt ourselves to the new requirements that the further advancement of the world will call forth. We would remain only a hereditary reproduction of our ancestors fitted only for the occupations they performed. This is why whenever a species or nation becomes sedentary, and loses the stimulant to competition given by locomotion it stops short in its progression. This is largely emphasised in evolution, so that in plant life we find that the power of hereditary reproduction is much less subject to variation than in animal life so far as future resemblance, form, shape and continuation of the species are concerned, and there being no motion, variation is but slightly needed; but in animals and man, species and families vary so much in form and mental characteristics that the family likeness is but slight. But on the other hand, in animal existence motion makes variation nearly as powerful, and in some cases far more visible and marked a force than hereditary development if less fixed or permanent, and in the evolution of mind this is more marked than in the body.

Thus families may vary at times perceptibly, and may jump from one extreme to another. For it is a fact that both mentally and physically the tendency of heredity under certain circumstances is inclined to produce extremes in breeding, which makes it difficult to distinguish the hereditary result from the variation. This is most noticeable when we have resort to incestuous breeding, the result of which form of breeding is to produce extremes of very marked types and lasting heredity. But this is only obtained at the cost of the maximum amount of variation during the next three or four generations. Thus the perfect type we wish to obtain is arrived at by the first two or three generations producing an extreme of the type we do not require, that is of culls, after which the permanent type is evolved in a most fixed and marked degree, and the percentage of culls drops to a minimum. War has been the greatest means of such culling in the past. In the same way the plant continues hereditary shape much longer than the animal existence. An oak leaf is an oak leaf in all places and under all conditions of soil fit for its growth and cultivation, and shows but little variation in form or shape as compared with the variation of animal shapes under altered conditions. Whereas 
change of place; food and climate alter animals in a great variety of ways; for example, in form, shape, colour and activity and strength. Hence, were there not life and death, age and youth, the world of knowledge and commerce, and the enterprise of the past would never have come about; species would never have been evolved; races would never have intermingled; new nationalities, empires and colonies would never have come into existence. Also age is inclined to get into certain grooves out of which it refuses to travel and becomes inoperative, and if death did not replace one class of heredity by another variety of the same class, one generation of a nation by different reproduction or variation of the same nationality, knowledge and the world's progress would stand still at the inception of its existence and never progress to its birth or conception. For one generation stops when it has advanced matters to a certain point, then the next one takes up the evolution, and advances it a step further for two or three generations then demands rest and retraces its steps. Thus youth causes progress on the one hand and on the other old age makes for stability and productiveness, so in one part of the globe the young transmit civilisation to some other part where it flourishes anew, in many cases to return and re-invigorate its parent stock to produce a better race out of the intermingling of different nations with different experiences. The larva of the snail, which is one of the most sedentary of animals, is one of the most energetic of grubs, and many very active animals pass their youth in a torpid state.

But as man is one in which the age of activity is youth, I will confine myself to this phrase of activity. As already stated, we do not play because we are young; but we are young that we may play; that is, that we may circulate the survival of the fit amongst the unfit, and so tend to produce fresh varieties of existence till we arrive at a perfect production of body and brain. So until we had evolved perfect bodies we were subject to a great variety and a marvellous multiplicity of evolutions of physical shape and variety so as to create new productions of species. But now that we have evolved a perfect body, such variations are but slight by comparison, but the near past and the near future are the ages of mental variation, during which we have been passing from 
instinct to mind and from mind to soul. So at the present there is a more than usual amount of variation in the minds and souls of families and nations; nevertheless, we cannot fail to mark that just as the power of heredity is more fixed in plants than in animals, so also it is more fixed in mind than matter, in character than body, in talents than habits.

That the Aryan is an Aryan in mental qualities is so marked that after two hundred and eighty thousand years we can recognize his characteristics as unaltered, although varied by environments, whether we meet them in the Himalayas under tropical suns or amidst the snows of Iceland, the two extremes where it still remains least intermingled with alien races. And we have no difficulty in picking out or detecting its power of Government, Love of mercy and respect for Justice, whether we find it in the mountains of India, the steppes of Russia, or valleys of England, or faintly illustrating the impetus which a sprinkling of its blood gave to Rome, Greece, Palestine and Persia in the past, where struggling to show, if only for a time, its influence on these races it is finally lost in their decadence by its never having been sufficiently strong in force to permanently supplant the characteristics of an overwhelming majority of Greek, Semitic or Latin blood. So again we easily distinguish them from the Latin or Teutonic races. And has not the present war been a striking instance of the failure of fifteen hundred years of science and civilisation to alter or vary the Vandal temperament to cruelty that stamps the Hun in the German race?

Still more marked is the difference between the Yellow, Black and White races in their mental separation. This is why it appears to my mind that when the Epoch of Hope has attained its perfect conquest of the world by the will of man and power of invention, during the Epoch of Charity that will follow it, it will be incumbent upon future ages to reform governments and religions, not by the punishment of crime, but by turning attention to the abolition of free selection in marriage, and supplanting the propagation of the perfections of mental fitness by fit and proper breeding, and destroy the age of crime and vice by prohibiting the right of marriage to the degenerate members of humanity, although I would not advocate abolishing free selection amongst the fittest of humanity. And it must be borne in mind that heredity of 
mind is such a much stronger factor than that of bodily reproduction, that when all the world is properly brought under civilised rule, and war is abolished, racial differences adjusted by international arbitration, the limits of national rule and control more wisely defined, and commerce made universal so that the greatest number can live and be maintained upon the earth in the manner best suited to the climate and agricultural conditions of the world, the study of governments will no longer be racial distinctions, but natural adaptability, local fitness and utility, and one of the branches of national or scientific duty will be to evolve such local and scientific qualifications as will best produce the most useful population in the climates best suited to their utility.

This will not come about in our lifetime, but I am convinced that in the Hypothesis I am now placing before mankind, lies the fingerpost that points along the road of Evolution as the scientific road that must be clearly studied from the standpoint of this Hypothesis of God's Trinity, if we are to help our children to learn the true and most perfect forms of control and future legislation so as to bring about a perfect state of law, order and government that will thus enable all to live in perfect peace, comfort and content, which is the only means of our obtaining the joy, pleasure and happiness that will convert the earth into heaven, and which must be brought about by means of a better understanding of the influences of hereditary aptitude and a clearer realisation that the distribution of wealth is the reward God bestows, not upon the work of one lifetime, but upon the combined efforts of many generations. 


\section{CHAPTER VII}

\section{THE ETHICS OF REVELATION}

Now that we have learnt to change our opinions rapidly, God is slowly opening to our mind's eye a panorama of revelation undreamt of in the past. At the bottom of all religions and dormant within our souls are a few dogmas of revelation awaiting the evolution of our minds to a sufficiently high standard to be able to receive and understand them. When we can thoroughly understand these in their purity and integrity, religion as we now understand it, or as it now exists, will have performed its duty, and will have to make place for some more enlightened form of selfcontrol, based on sound common-sense, for as mankind acquires the spirit of wisdom his conscience will have so evolved that each man will become a religion unto himself, one more perfect than any present form of religion. All religions are alike inspired by God, though I doubt that they have been inspired in the fabulous way that we have been brought up to believe. This appears to me to be only a relic of the custom in past ages of superstitious government, both civic and religious, of trading upon the credulity of the ignorant; nevertheless, every religion of note has, and does, contain all the essential truths of revelation that are really necessary for the right guidance of every man who is really desirous of the good of others rather than his own advantages.

But as in the past the mind of man has been and is at present insufficiently advanced to understand the truths of revelation (except perhaps in the case of one or two persons in a thousand) who are so far developed that it is almost impossible to tempt them to do or think wrong, and to whom, even at present, no religion that ever has been could be of any help to enable them to lead a better life than they are in the habit of leading with the present limited evolution of their minds and souls, and whose ideals are even now higher 
than any existing form of religion, but the remainder would not be so good as they are had they not religion to help them. Thus in past ages kings, priests, apostles and prophets have with the assistance of God's inspiration invented and created religions to suit the stage of evolution in which they lived, and the characteristic most suited to the manners and customs of the nationalities and communities in which they laboured to establish them and to retain them so far as to control the people without resource to brute force. Further than this God would not permit religion to advance till man's mind was fit to receive it, lest its teaching should interfere with the pre-ordained order and precedence of His scheme of Evolution. So you see, dear reader, what a mighty truth the Buddhist teacher of ten thousand years ago had evolved when he taught the doctrine of Fatality, and that the higher orders of revelation should not be permitted to the knowledge of the masses but only to the most highly-enlightened expounder of divine laws. The careful reader of the New Testament will be struck by the manner in which Christ shelved and gave equivocal answers to all the requests on the part of the apostles when they sought to inquire into future events which the state of the human mind of two thousand years ago was not then sufficiently evolved to receive.

But I am more convinced, and the more I study the further I am convinced, that from the earliest days of creation, long before the dawn of life, all and every revelation, whether yet known or yet to be discovered by mankind, with the assistance of the enlightenment of God and His Trinity, either has been or is yet dormant in every part and particle of creation, even to the smallest grain of sand, and is awaiting patiently the evolution and enlightenment of the soul of man, assisted by scientific elucidation of religious teaching, to be turned to some use and effect in the grand scheme of THE EVOLUTION OF CREATION, MIND AND SOUL. But God has left to mankind the evolution and creation of all and every form of religion, only condescending to enlighten and inspire its teachers to such an extent as under the infantile conditions of their minds He from time to time deemed them capable of comprehending a portion of the mighty problems of His Infinite Wisdom. And when you realise, as you will if you study the hypothesis that the soul of mankind is only 
now beginning to evolve in the course of creation, you will comprehend the wisdom of the course he has pursued. He has surrounded each one of us by pure and perfect revelations, as taught by a true knowledge of the laws of nature, abiding the time when the mind of man shall have evolved sufficiently to be capable of understanding them. These early and present teachers of religion have had, and most probably will still have for many centuries yet to come, to adjust their teachings to the puerile development of man's mind, and to do this had to clothe their dogmas in multitudinous cloaks of variegated colours and textures of superstition and bigotry, to dim the splendour of God's Majesty that it might attract and not frighten man's weak and imperfectly developed mind.

Hence the knowledge of evolution can only serve one purpose; and what is more, evolution is the only means by which true revelation can be obtained, or has been obtained in the past, for it is only by the pressure and influences of the struggles of evolution in past ages that mankind has become aware of the existence of such revelations as he is possessed of (see the chapter on the Evolution of Religion in Book II.), that is by the light of God and His Trinity, by which light we will be able to understand and sift these truths of revelation from the mountains of superstition that have concealed them from our view for millions of ages, and so in the future one religion will replace another as they have done in the past in the onward course of evolution, retaining the truths and discarding the falsehoods and creating new and more beautiful religious ideals in place of those they destroy, brighter and richer by the fresh revelations that they have brought to the light of man's lamp of understanding.

Thus each destruction of an existing form of religion and reconstruction by another form of divine enlightenment is only a fresh step along the onward march of religious evolution to keep pace with the upward evolution of man's mind as the growth of his soul increases his powers of comprehension and understanding in the ethics of religion, theology, and the ever-dawning ethics of revelation; and a more perfect knowledge of the mysterious being he acknowledges as his creator becomes daily more comprehensible to his understanding with every advance of religion and science, as science and evolution remove the curtains of fable, parable, 
superstition and bigotry which in the past have obscured the brilliancy and lustre of their truths, lest their marvel and magnitude should destroy his hitherto weak and imperfectly developed mind which has been incapable of withstanding the mighty glare of the marvels they contained and the premature knowledge of which would have destroyed his reason. I am confident that all and every religion of the past will contribute some quota towards the elucidation of some divine revelation, the true and perfect knowledge of which will ultimately enable mankind to sin without crime or offence to others, and will enable him ultimately to formulate such a perfect state of social laws as will finally grant to humanity perfect freedom when earth will become heaven. But hereditary evolution has and ever will have to do as much as religion towards the advancement of mankind.

It is well here, perhaps, to pause and give the true definition of freedom, government and religion.

FREEDOM is a limited possession of liberty bounded and fenced only by such laws and regulations as are necessary to enable each member of any community to have the utmost amount of liberty possible without outraging or trespassing upon the just rights and liberties of his neighbour. Too great an amount of liberty can only be granted to one class of society at the cost of enslaving another class.

GOVERNMENT is therefore that which protects in the best manner possible the life and property of the community and gives to its people the greatest amount of freedom, and keeps its people in rightful possession of that which is theirs by just acquisition, the result of the use of the energy, brains and thrift of each individual, in just proportion to the use they make of their powers and abilities of work, management, production or thrift for the general, not the individual benefit. All that goes beyond this must be approached with care and caution if we would avoid the evils which most certainly will result if we unnecessarily curtail the freedom of the community, by an over-desire to increase the liberty of any one or individual section thereof.

A perfect Religion is that which so directs the judgment and discretion of the portion of the world, country or community or social subdivision thereof which it controls as to encourage them to venerate their rulers and to keep the state 
laws without compulsion, and to promote the most perfect formation of a virtuous conscience, and moral habits in the way which will most effectually prevent the individuals it controls from acting in a manner detrimental to the good or to the views and beliefs of its co-religionists. Secondly, and this, if not the first is the most important necessity, that it should do the most to impress upon its members the truths of revelation in the manner and forms most calculated to be understood by them, in the lights, and garbed in the parables and dresses of imaginative beauty, that will make the truths it contains appeal in the strongest manner possible to the congregation. Hence it follows that all and every religion that is based upon the truths of revelation can and does enable certain members of the community to lead better lives than they would do without its assistance. That is the best for the community in question which enables it to live in the greatest numbers under conditions of peace, comfort and content.

It is incumbent on us to respect the opinions of others on religious matters, no matter how antagonistic they may be to our own ideas of right or wrong, and to remember that even though they may not coincide with our own beliefs they may teach and contain the same fundamental truths on which we base our beliefs, and that if they fail to appeal to our minds and modes of life, they may appeal more strongly to the minds and lives of others than the views and beliefs that appeal to us. I, therefore, maintain that religion is best for each man to follow which best enables him to do and perform the duties of the state of life of those amongst whom he has to live and associate. It may be that in thousands of years hence mankind may evolve to such a uniform state of perfection that a universal religion may be possible, but even when immortality is gained such a result does not appear likely, because there will be rich and poor in heaven as much as on earth, the only difference will be that when we attain perfect government in state and religious laws, and acquire perfect benevolence, perfect social agreement, and true unselfish charity in words and actions, dire poverty will no longer exist. But it would not be just to damn and exterminate all who could evolve perfect bodies and minds, because they had not evolved perfect virtue, or just because their virtue were in our esteem less important and less magni- 
ficent than other men had attained to, for they might be just as useful in some other way. For this reason I maintain that we must honour and respect all religions alike, and that the days when any one religion could lay claim to superiority or infallibility over another are past never to return. That it is man's duty in future to endeavour to bury all religious, social and racial differences; to aim at teaching that all class and social distinction are but aids to individual freedom, and by co-operative means of production to gradually bring home to the minds of the masses that ownership of wealth is not an individual right or possession, but a mighty trust in the hands of a few for the good of the many, the possession of which is but God's just reward to those whose fitness in the system of evolution has by birth or genius and the hereditary possession of certain qualities, best fitted them to become the good and faithful steward whom the Lord has placed over his household to give them their meat in due season.

That true Peace, Comfort and Content can only be the outcome of the united actions of one and all of the community, using their time, energy, talents and ability to the utmost and trusting its distribution or reward to the all-wise Creator who has in the past controlled its distribution with wisdom and judgment far above the discretion of mankind, the alteration of which human laws and powers are unable and ever will be unable to control and materially alter. That the inspiration of mankind cannot prevent the necessity that all religions must alter and adapt themselves and their teachings to the advancement of evolution, and the outlook of a better power of understanding of the laws of nature combined with the dogmas of revelation which only can be learnt by a more perfect knowledge of the truths of revelation as revealed in the past evolution of Creation, and by a more perfect understanding of nature in the future. That in a more perfect knowledge of evolution and history, not in the mysterious fables and parables of past superstitions and bigotries, prophecies and miraculous teachings of past religions can we look for the true solution of the correct ways to shape our future lives and laws, whether of state, society or religion. It is true, nevertheless, that these truths and revelations are the ground-work and foundation of every and all religious teachings, and it is therefore equally true that if we are to evolve 
a true and correct understanding of the absolute revelations of God to man, both science and religion must join hands, and as Professor Tyndall says, "Sink their differences, priest and philosopher alike," and consent to walk side by side along the road of evolution, agreeing to give and take in the future and to assist each other by science bending its head to religion, and religion altering its long-loved dogmas of the past and endeavouring in the future to bring them into line with the increased knowledge; God must ever be taken into account, so that a further development of soul will enable man in the future to understand what in the past he has had to obtain second-hand through faith and belief. For in the future just as Christ has opened the eyes of man's soul to see and believe, so the wisdom of man's brain assisted by the aid of the Holy Ghost's inspiration in the scientific knowledge he is to acquire in the future, which is to bring down the wisdom of God the Holy Ghost upon this world of ours and enable him to know all things even to the consummation of the world. And if the Hypothesis of this treatise is (as I feel confident it will be) the means of establishing a common meeting ground for consultation and comparison of ideas between science and religion whereby they may settle their disputes, allay their discord, and produce a more reasonable and less mysterious doctrine of the best and most perfect rules by which man can rule, manage and conduct the duties of his state of life in the future, my labour will not be without result and the seed I am now sowing will bloom into a mighty plant watered by the rains of man's soul and manured by the gifts of scientific research, beautified by the flower of the enlightenment of the revelations of past religions, fables, parables and teachings as evolution makes them clear to the wise souls she is evolving.

Now if we review the course of Evolution in the past, the growth in man's mind of the primary conceptions of the truths of religion have been a mental development of the soul out of the animal mind slowly presenting to his soul, as he evolved, the powers of thought, and directing the course of creation in exact accordance with God's scheme of evolution, thus enabling all creation to follow the destiny for which it was created, without any individual imagination, will or selfcontrol, until the end of the Epoch of Faith, when the soul 
of Love and Comprehension (see Book II., Chapter IV., on the Development of Mind), entering into active conjunction with the spirits of God the Father and God the Mother, enables man by a mysterious interposition of God Almighty to first imagine the truths of Faith he cannot understand and then to see and believe them. The imagination of them, produced by an imperfect comprehension of the marvels of nature, leads, as a natural outcome of the evolution of his superstition, to Idolatry as a result of fear of the superhuman in nature.

But the creation of religion and comprehension was a departure beyond the power of human nature to produce, and without which the human mind, civilisation, Commerce, science and invention would have been forever beyond his possibility. But now that religion has evolved these powers and placed the powers of soul, wisdom and understanding within his grasp, he is capable of a further departure as his mind becomes more enlarged. But the evolution of the soul, being a male not a female attribute of God's Trinity, Soul like mind and thought and imagination, is a natural evolution natural to man without further superhuman aid. So if my hypothesis is correct, it is quite in accordance with the natural evolution of man for him to evolve his own soul. Once its divine incarnation is complete and the birth of understanding has been evolved within him, thus it logically follows, if the hypothesis is correct, that as science advances all religions of the past must be absorbed and reformed on scientific as well as on religious lines to adapt them from a spiritual to a practical measure of utility. Such a result will be found to fit in with the order of evolution as set out in the marriages of the Trinity, Tables II. and III.

It would have been as far from the laws of descent and evolution and the whole scheme of evolution, to have expected a mind capable of understanding truth in early man, as to look for a protozoon with the fully developed heart of a bullock, thus necessary as religion has been in the past, its influences in the future must be supplanted or at least adapted to the evolution of thought and wisdom and knowledge, rather than by life, love and comprehension which is the trinity of religion, and to bring this about it will be necessary not to exaggerate, as has been done in the past, but to explain the truths of nature while the physical body and the 
mind of man were in course of evolution and formation, and to explain them in a more enlightened manner when man has completed the evolution of body and mind.

For it is quite apparent in the last hundred years even the masses have learned to think, we must turn to breeding and selection to evolve the powers of soul, which is to enable man to rule and govern himself, as he learns to reason as well as think, in the same way that the mind has enabled him to conquer the world, so reason must enable him to conquer himself. Reason is the outcome of breeding from those whose lives have compelled them to reason rather than to obey, and who will, in the majority of cases, breed those best able to reason. First religion teaches us to obey; but it takes study and science and experience to teach us reason, which is the outcome of wisdom and habits of selfcontrol, not of learning and knowledge. Hence only those can reason who have ancestry who have had to study and think for themselves, and have learnt obedience and selfcontrol. Religion by teaching the thoughtless to obey could thus bring them under the control of the wise, but it is powerless to teach them wisdom or self-control.

Wisdom is the result of generations of self-reasoning and experience. This is why wisdom is not a necessary adjunct of the saint or the enthusiast, but is more often the property of the sober-minded, hence it is only by stopping the breeding of those mentally unfit to control themselves that we can breed up a majority of wise men, which must be the main aim of futurity, for thought in the minds of fools is like a battle-axe in the hands of a madman, for religion can only govern the ignorant; the wise man must be able to govern himself or he is not truly wise. Therefore it appears to me that in future we must make our jails places of work, and confine our criminals for life, giving them the benefit of their labours, but preventing them from breeding fresh criminals; also that those who will not work must be compelled to do so for the benefit of their wives and families, and not allow to breed a future lazy race, which is the great cause of the destruction of the vitality of nations. But this is too exhaustive a subject to go into in a treatise like this, as it would fill a volume and then not be completed. I only mention it here as indicating the direction in which the finger-post of 
evolution points. But it is far more likely to be evolved by a new departure in the course of evolution than by the direct action of the mind of man, or by legal restrictions. Such, for instance, as an increase of barrenness on the part of lazy and pleasure-loving women, and such alteration in our status quo, according to my hypothesis, must be brought about by the release, on the part of nature, and the absorption on the part of mankind of a more than usual amount of radio-activity from material creation, or from the planets and the ether that surrounds them. This, I take it by my hypothesis, has probably accompanied each great change as a fresh attribute of trinity, or a number of such attributes have brought some evolution or collection of evolutions to completion at various stages of evolution. 


\section{CHAPTER VIII}

\section{PURGATORY AND DAMNATION}

HELL, in the usual acceptance of the term, we may dismiss as being only a necessary invention of man for the more perfect government of an imperfectly evolved mind. The necessity of such a doctrine will be shown in its right place, but any such conception necessitates that God should be both cruel and a fool, both of which are incomprehensible to a logical mind, for how could infinite love be cruel, or how could infinite wisdom inflict an everlasting punishment from which no good can be attained? But purgatory and damnation are necessities of evolution. Purgatory is and must be the long and bitter struggle and the necessary suffering that evolution inflicts in the continuous fight for a perfect existence. Damnation can and must be the eternal destruction of any species, race or family who, failing in the struggle for existence, dooms itself to eternal death by extinction, and so loses both life, soul and power of self re-creation.

Now, the whole of Evolution demonstrates this form of purgatory, for God not only inflicts punishment in this life by imposing poverty, sickness, disease and premature death on those who neglect to make the best use of their time, brains, mind, body and soul, but by the laws of descent perpetuate the punishment on their offspring. In many cases this purgatory is the means of rousing many to make a better strife for existence, or by humbling them in their own esteem, prevents excessive conceit, producing over-rashness or excess in other ways calculated to debilitate their physical and mental qualities, or is used by God to show them up so that they may become an example to deter others from like excesses. But all faults against our state of life, all selfish acts, and all sins of indolence and omission other than those sent to us for our good and advancement for a portion of our lives or a fixed period of evolution, will be judged in the balance of fate 
with regard to how far they have injured or retarded the scheme of the Almighty's creation, or injured the good of our fellow-men. And in proportion as the acts we perform excel in good or evil, so many of our children will be condemned to decline or advance in the scale of development, or in other words, will be rewarded by social advancement or punished by social degradation. But as man is to have a free chance in his redemption, we are each given two or three opportunities in life to decide whether we are to be the lucky or the unlucky members of our particular families and, in accordance with the excellence of our virtues or the vileness of our crimes, the question of the future chances granted to us and to our children of the possibilities of rising or falling in the esteem of others will be decided; but should we, during life after life, fail to endeavour to redeem the past, we will drop so far behind in the progressive march of evolution that individual after individual will be condemned to humiliation and the race will become extinct, and the few who do not lag behind will be absorbed in the stronger race. And so the survival of the fittest will be accomplished in the future in mind and soul, as it has in the past governed the survival of body and matter, till all that is useless has been condemned to loss of life, and so become damned for all eternity. For damnation can only mean the loss of the power to re-create oneself and one's soul in the bodies of one's children. 


\section{CHAPTER IX}

\section{LOGIC}

THE trinity of Logic is Thought, Comprehension and Wisdom, and it is one of the three portions of the trinity of Truth, which is the outcome of these three factors of its trinity, Thought, viz., Imagination or Theory, Comprehension, viz., mathematics or logic, and the Wisdom of Use or Experiments. What we cannot submit to the test of these three cannot be said to be undeniably proved. What we can test by two is a probability, and by only one is a possibility. Logic is the arithmetic of the brain, being only a form of mathematics. This is why the mind of comprehension or logical mind is more reliable than the mind of imagination or theory, or the mind of understanding or science, because it is the mind that is most prone to grasp the truths as if by instinct.

Now it therefore follows that if we can only bring one of the attributes of Logic to bear upon any subject, we can only assert that we have obtained a possibility; if we can bring two of these attributes we have reached the boundaries of probability, and if we can bring a subject under the three heads of Theory, Mathematics and Use, we are then able to prove if our theories of Imagination or our knowledge of Understanding are true or false, right or wrong.

Now, we cannot experiment with creation, because the Universe is beyond our control. The only means of testing its use is by our knowledge of its past evolution and by history. Consequently the value of the science of Evolution is but little realised by the mass of mankind, yet it is one of the most important means by which we are able to ascertain the true manner in which we must learn the truths of God's revelations, and by which we are able to sift correct inspirations from the creations of man's over-fertile imagination. Hence it follows that both the theories of religion and the knowledge of science must be put to the test of logic and 
mathematics before we can obtain a probability in place of science and theory, which can only offer us possibilities. The combination then of Knowledge and Imagination, both attributes of God the Father when viewed from the standpoint of Comprehension through the spęctacles of Mathematics and Logic, enables us to raise our imagination of religious inspirations and revelations to the standard of probability which we arrive at when we combine the attributes of God the Mother with those of God the Father, and it is the aim and object of this treatise to illustrate these facts.

We must, therefore, when we have done all we can to check it by Logic and Mathematics, pass each subject on to the minds of understanding and science, which are attributes of God the Soul, to check the probabilities of truth by the wisdom of the science of evolution, history and chemistry, till we are able to prove thereby what nature, in the past, has proved by use to be the undeniable truth of the probable assertions I am submitting to the reader, leaving to them the eradication of any errors in the demonstration, and the proving or disproving of the truth or falsehood of the hypothesis I have herein endeavoured to make a probability by its logical discussion. I can only hope that in time this hypothesis may prove to be more important than the possibilities held up for their guidance in the past, and so possibly induce the public to become more interested in the sciences of evolution, history and revelation than they are at present, and to seek for more knowledge and understanding in the future than they have done in the past.

Now, knowledge and science may both often be found to be subject to error, for in the mind knowledge is the witness who marshals the facts of the case before the judge of understanding where science is the counsellor or advocate, after which the jury, Logic and Comprehension, decide what is the value in the eyes of the laws of wisdom, and their decision is final. As I have demonstrated in other places, Comprehension is the eye of the soul of man. Imagination is man's spirit of Thought producing Knowledge, and Understanding is the soul of man producing human Wisdom. But Imagination, Understanding and Knowledge are all inclined to err more than Comprehension, which, being the science of Experiment, Logic and Mathematics, corrects the errors made by knowledge and science. Therefore by Logic, Experiment and Mathematics 
we are to obtain Truth, as the knowledge and Science of Evolution makes it possible to understand the use of them. Therefore to follow me through Book II., it is necessary for the reader to grasp the mathematical and logical nature of God's Trinity, and reduce it to a mathematical order and sequence, or he cannot calculate truth from falsehood of my Hypothesis. I may here refer to Table IV., which gives to the reader a mathematical formula by which to check off the other Tables involved, and ascertain if the trinities they contain are perfect truths, or will become perfect during evolution, and those which will last into eternity. And it has been my aim in this treatise to subject the Hypothesis it contains to as accurate a logical and mathematical arrangement as possible, so as to enable my reader to review each case as impartially as possible and from a purely abstract point.

This necessarily entails the expression of many an abstract theory and idea that may or may not be correct, but all of which must be viewed purely from their abstract point of view if the reader is to be placed in a position to use the mathematical facts they contain in a purely logical manner; and to enable him to do so it has been necessary to present to him many phases of thought which, though correct in the abstract, must be greatly altered and adjusted before they can be used as the concrete forces to create practical and useful concurrent forces applicable to our lives and existences. But unless we first find the primary forces and causes of events, it is impossible to arrive at a correct and true understanding of the results we wish to attain or desire to produce in the future. The action of Logic in mental work corresponds to the action of the chemist, who must first obtain the elementary chemicals before he can combine them in a variety of proportions to produce different compounds by chemical combination.

In the same way all my mind can do is to bring the different facts down to their elementary forms, place them in logical sequence, and leave them to clever and more enlightened minds of wiser students to evolve from them by study and controversy a more perfect whole. It therefore follows that there must be of necessity many errors, or at least necessity for further proof in a work of this kind that knowledge and study will in the course of time correct, but without the possession of the abstract conception it would not be possible to 
weigh or decide its value of usefulness. I have therefore decided to give it to the world with all its faults and failings, hoping that the controversy and thought of other minds may be able to evolve a useful manhood out of my naked infant. I shall feel content if the reader is willing to admit that I have given him a logical description of an extraordinary and, I hope, interesting and marvellous conception, leaving it to his mind to use all or any part of it as his inclination, knowledge and judgment may determine.

I am devoting this part of my book to defining the abstract review of some of the most salient items that go to make up the whole hypothesis and to the best of my ability to point out their analogous relation to the misconstruction of past ideas of Genesis. I shall then endeavour to compare the Table of marriage of God's Trinity with the course of evolution in Book II., and when this is done, I must leave it to my readers' praise or condemnation to decide if it is worthy of the years of study it would entail upon me to prove and perfect its conception. In the meantime, if I can only succeed in demonstrating that it has as honest or just a claim to possibility (I won't say to probability, I leave that to my reader to decide) as any other hypothesis hitherto adduced to solve some if not all the problems or cases I have brought under review, it may at least do some little good in advancing the onward march of human thought along new roads of conception. 


\section{CHAPTER X}

\section{VIRTUE AND CRIME}

"Not he who says Lord, Lord, but he who doth the will of my Father, shall enter into the Kingdom of Heaven."

Nor those who profess to be good, but who do good to others are truly wise and blessed. I have mentioned elsewhere that the reader must bear in mind that in this work $I$ am writing purely from the abstract standpoint, and in a purely unscientific manner, so he must guard against putting a concrete interpretation upon the views expressed.

Now, when I came to read over this chapter it struck me that as regards its contents, as also the constant statement that sin is a virtue, which is one I have been frequently compelled to make to elucidate to the reader that the virtues of to-day could not have been achieved but for the sins that past evolutions caused us to commit yesterday, any more than could our individual virtues of to-day exist but as a result of the sins and faults and failures of our youth. Now, to make this introduction, which, upon re-consideration, I feel called upon to insert as a prelude to this chapter, I must point out to the reader that virtue consists not in being good, but in doing good. There are many very good persons who do more harm than good. Moderation is the perfection of virtue when coupled with requirement. Many otherwise good acts lose their virtue when not required, yet in a few cases extremes may become virtue as well as crime. Intemperance in the commission of any sin is what alone makes crime, and total abstinence may be either virtue or vice. The aim of evolution is to destroy all crime and vice, but not to destroy sin and virtue. These are to exist in heaven as well as on earth. This is why a religion which taught the truth, the whole truth and nothing but the truth, would not be worth its salt, 
for it would fail in its most important duty, which is to form beautiful ideals of exaggerated perfection, far and away above the realms of stern reality, far beyond the boundaries of the exactness of truth. If it did not do this, man would not, by striving to attain the impossible, attain the possible, but would in consequence fall far short of the possible. In just the same manner if the ambitions of sanguine youth did not build castles in the air, age would never even achieve the building of a hut on the earth.

Thus I might have chosen to demonstrate the degree of right and wrong in a less offensive manner had I selected morality and immorality in place of polygamy and monogamy as my illustrative subjects, but so fine are the lines of distinction between these two, and so varied are, and ever must be, the high and low water marks that different communities and different classes of society will ever have to make the adjustible and ever-varying boundary lines of the more concrete virtues of everyday life, that it would have necessitated a volume, instead of a chapter, to have approached this subject without danger of the reader not personally knowing where to draw the line between the practical limits of concrete action and purely abstract thought. I therefore decided it was wiser to select murder and polygamy as a means of example, because the present magnitude of their concrete criminality would prevent the reader making the mistake of confounding my attempt to point out the abstract position of virtue and crime and sin into the absurd idea that this chapter can condone wrong in the concrete form of his individual liberty of action. This any but an idiot knows must be decided by the laws that make the boundaries of the freedom of the community in which he lives.

My object in going into these various branches of definitions prior to making a short sketch of the most probable manner and course of evolution is, that, to follow it easily, it is in many cases necessary first of all to unburden the mind from the narrow and limited ideas that social customs and fashions of the age in which we live have made the customary and present acceptance of such terms, so that we may look at the matter under discussion from the wider standpoint, namely, the position they hold as a part of the great scheme 
of creation and of evolution, not as they stand to the particular age or epoch in which we live. Hence it must be borne in mind that God, being infinite goodness, can allow nothing to exist except for a good purpose. Therefore, Virtue and Crime can be considered only from this standpoint as comparative terms in relation to our well-being at the particular epoch or age in which we live. For the survival of the fittest is the indomitable law that is to decide what is to exist and what is to be destroyed till all shall be perfect. So it follows that all sin and crime have their duty to perform; that crime is just as necessary to the production of the scheme of creation as are good and virtue; for although intending throughout creation to drive and direct the created being by the reins of Fate, and giving man a small amount of will of his own, God, nevertheless, intends to control to some extent the world he has created and to retain the power to decree what is best and what is the just reward of the acts of those to whom he is giving the reward of an immortal soul, as he returns to finity the portions of His Trinity that have been withdrawn to produce a material existence, but at the same time the power of man's control and will is to be limited despite its being somewhat increased throughout the course of evolution.

On the other hand, the triumphs of folly over wisdom by selfishness, sloth and pride, on the part of man, are to cause decrease of brain and degeneration on the part of the individual, and the crimes of immorality, cruelty and infidelity on the part of woman are the defects that are to destroy the powers of the reproduction in mankind of a sound and perfect body, and the virtues of love, sympathy and charity. Hence there is no act that is not right if performed in the most perfect way to fit and suit the circumstances in which our fate places us, and the age of creation in which we live is evolving. If it is the duty of our state of life, God will reward the act if it be right, and let it go unpunished, provided it is an act required by the age of evolution or the circumstances of our life. Hence, murder in the form of war may even yet go unpunished by God; yes, and even be rewarded, for at different ages of evolution God permits many crimes, either as a means to ensure our attaining and learning to value the virtues necessary to the state of life which we have, by our 
choice for good or evil, selected, or as a means to further and bring about the ultimate destruction of the souls of those whom God in his wisdom sees would fail to accomplish the particular virtues he requires as our particular and individual contributions towards the benefit of the community, were it not for the lessons these defects teach us to overcome.

Men may be permitted to fall into sins of impurity (not immorality, see distinction hereafter placed on the two) to prevent his becoming so proud of his mental or physical achievements that he would by his arrogance turn from him the assistance of his fellow-men, and as we are parts of a component whole, as creation is only a part of the infinity, so our first duty is to help each other to overcome necessary evils of the past as evolution advances. Therefore God decides our lives by their usefulness to others, not by the benefits they confer upon ourselves, and our actions are only part of a series of results destined to fulfil their useful place in a perfect scheme of evolution of which we are but so many pawns or pieces to be moved forward, or along the road of virtue, or backwards along the path of crime, and thus to produce more perfect virtues, or to be moved downwards instead of upwards in the social scale until removed off the chessboard of creation by our final extinction in the onward march of human progression in which for a time we are permitted to remain despite our sins, as a means of punishment for wrong-doing or as a danger signal for others to prevent them doing wrong. In Chapter XI. I will point out the three classes of mind which produce Thought, Wisdom and Love.

This makes the virtues of one class the failures of another class of person. Hence without sin the world would only deteriorate instead of advancing. Please do not confuse sin which is failure or folly with crime which is abuse or misuse of our opportunities for advancement. In the same way if there was no such thing as sickness we would have nothing to stay us from overwork and exhaustion, or from destroying our health by abuse. The punishment God will inflict on our sins, therefore, is not according to their criminality as decided by the laws of religion, state or society, but according to how far they abet or retard the performance of the virtues we are individually capable of, and the exercise 
of which is most important to enable us to make or mar, use or abuse, perfect or destroy the gifts or talents of body and soul which he has committed to our charge for us to use or neglect our opportunities to advance the good of the world's evolution. Thus it often occurs that His rewards and punishments of wealth and pleasure, health and happiness, appear to us to be misplaced, and his inflictions of poverty, grief and debility to be unjust in their imposition. Whereas it is only our ignorance of the temptations, struggles and contests that $\mathrm{He}$ in his wisdom imposes upon each one of us for the ultimate good of the whole that causes us so often to condemn the sins of our neighbours, whereas if we could look upon them from the divine standpoint, instead of from the petty standpoint of our limited power of comprehension and understanding, we would find that many faults that go unpunished by man in our lives are greater than the sins of our neighbours, which are not punished by God, although they would be condemned by man; that the rewards of wealth, comfort and content bestowed upon our neighbour could equally have been ours had our lives been equally well conducted for the good of others or the advancement of evolution.

Remember that when I make excuses for crime, it is only in this sense I do so, because if we are to take an unbiassed view of the evolution of creation, it must be from the standpoint of the period under review, and the virtues which that period is evolving and the crimes it is eradicating. Thus in the early age of the Epoch of Faith, Gluttony, Indolence and Sloth were the first virtues of life. Then these were succeeded by a later age wherein these crimes ceased to be virtues, and became crimes that were to extinguish and exterminate the mammoth or most perfect animal creations ever made. Then cannibalism, savagery and murder next became the highest virtues, the exercise of which was to place man above the angels or animal kingdom. These then are to become the greatest crimes against civilisation, the virtues of which are now to be war, selfishness and cunning, which are in the Epoch of Hope to be the means of evolving Religion, Commerce and Government, which are thereafter to become the worst crimes men can commit, and are to be replaced by the virtues of Peace, Brotherly Love and Charity when man 
shall evolve a perfect soul. And in the same manner the individual sins of each one of us are destined to evolve our virtues, and our crimes in just the same way are destined to benefit the community, either as an example to deter others from the committal of like crimes or to increase our individual disgust of evil and admiration of virtue, or to be a means of punishment for sins and failings that are injurious to our neighbour or highly detrimental to the production of the virtues most suitable to our individual requirements; or the qualities necessary to enable us to perform such acts as will assist us to become of most use in adding to the maintenance, and content of our fellowmen and the evolution of wisdom.

Therefore God in his wisdom permits evils that we may be able to evolve good therefrom, and so the end justifies the means, but we may rest assured that we can perform no act that injures, annoys or destroys the happiness of our neighbours without its being punished by ill-health, poverty or our falling in the social esteem of our neighbours, and even death, and that will not be visited by misery or unhappiness in our own lives and those of our children. All acts that are opposed to or inclined to prevent our perfect fulfilment of the duties of our particular state of life, or detract from the fulfilment of the duties we owe to others, will not escape punishment, neither will the performance of the duties of the individual and particular circumstances, for which our talents and capabilities best fit us, go unnoticed, but will be rewarded in our children. So each of us has not only the salvation of our own individual soul to perform as a sacred duty, but also the salvation of our children's souls. The performance of such duties decides how far we are to gain heaven or hell in this life, and what reward or punishment we bequeath to our children.

But the effect of our acts on the happiness or unhappiness of our neighbours, the good or harm we do to others, the extent to which we assist or fail to assist the maintenance and livelihood of our fellow-men will decide in our offspring their chances of losing or obtaining hereditary virtuous or vicious inclinations, and of their leading a good or bad life. So also the happiness of our own lives is not the outcome of its surroundings, such as wealth, pleasure or health, so much as the absence of extreme poverty, sorrow, ill-health or debility, and it will not be the result of the blessings we strive to attain, 
but in all cases is God's reward for the happiness and pleasure we create, and the kind acts we do to others that will decide the amount of our joy, pleasure and happiness. For it is not the force nor the direction in which we throw the ball of kind acts that creates the enjoyment and happiness of others, but the force of the rebound of the happiness we so create that adds to the comfort and enjoyment of ourselves and our lives and creates our happiness by its rebound; and it is not the good or marvellous deeds we do, but the happiness that others derive from our perfect performance of the small trifles of the everyday acts of an everyday life that induces our neighbours to contribute to our own heaven or hell on earth, for our own happiness or grief in our modern civilised communities is dependent on others. Thus it happens that those who try to be very goody-goody neither attain the greatest happiness nor confer the greatest good on their fellow-men, whereas the kindhearted sinner is often the greatest benefactor and best friend and companion. So it comes about that sins which in some of us would be unpardonable, in others only produce virtues (and good) that far outweigh the evils they do, and so, not only go unpunished by God, but even merit His reward, and remain unpunished by man as well as by God. On the other hand, acts that in the majority of cases are in themselves most virtuous and are allowed to go unnoticed by man, are unpardonable crimes in the eyes of God. In other cases, from the different manner and circumstances of their performance, produce unthought-of evils that more than counterbalance the good those who perform them hope or desire to accomplish.

But the parson who decided his teaching, or the judge who would interpret the laws, not as they are written, but in accordance with their own judgment, would be unfit to hold their positions either as parsons or judges. So the world's punishments are often unjust, and those of God often appear to be unjust in our eyes. Thus it is that in a subject like the one we have now under discussion, it is impossible not to offend the just and correct concrete opinions of others to some extent when viewing the case from an evolutionary standpoint, and if the subjects were not reviewed from every standpoint by a mind unfettered and untrammelled by the present and necessarily limited boundaries of what is expedient in the 
majority of existing cases in the present age, time and moment, it would be impossible to arrive at a true conception of what is the truth that lies at the bottom of the ever-changing phases of evolution in human laws, religious rules and social customs and fashions. This is why I have deemed it necessary to reduce so many subjects to their most abstract interpretation, that the reader may form an unbiassed estimate of the importance of the extraordinary Hypothesis that is the base of this treatise, yet which, nevertheless, I feel convinced when better understood by the aid of future study and research will be the foundation on which will be built an edifice of more perfect understanding of right and wrong, a more perfect form of government, and a wiser system, not for the punishment, but for the prevention of crime and the reward of virtue.

Hence the sins which are conducive to the virtues of our state of life will go unpunished.in our lifetime, but will possibly have to be atoned for by some of our children, and our virtues, in the same manner, will produce greater virtues in our children and raise some if not all of them to a higher standard of virtue and a higher standard in the social scale, either in their lifetime or in the lifetime of their children's children, and vice versá. So the good we perform in God's eyes will either raise us in social advancement, add to our happiness and increase our wealth and comfort, or else confer the like blessings on our children and their children should these blessings not be conducive to our own good. So even though they may be unknown to the world, our virtues and sins, according to how they appear in God's eyes, bring their rewards of wealth and health, joy and happiness, or their punishments of poverty, ill-health, intemperance and insanity, and damnation or extinction of our souls as well as of our bodies if we err, and the reward of immortality if we do what God most requires of us; and also make this life on earth a heaven or a hell according to how we make the best use of our time or how we waste it. This is one of the reasons why we should be far and away more careful and considerate than we are as to how we find fault with our neighbour's sins, for we know not if they are for the public good or ill, or if they are sent to him to make his life more perfect in virtues, the possibility of the attainment of 
which we in our pride and arrogance are unable to realise; for they may be above any act of virtue we have capability to perform, so far superior are his talents to our own, whereas we ought to bless our stars that such high or difficult performances are not required of us, and not begrudge him the higher rewards he obtains at the price of undeserved public condemnation, under whose scorching breath we should writhe in direst agony, where he fights bravely on and wins in the long run. For the same reason we often complain of our lot in life and envy the lot of others, because we are unable to know his fault or virtues, temptations or graces, and complain of the injustice of God, whereas it may be that we do not correctly gauge how we ought to act for the benefit of our neighbour's happiness, and we ought never to forget that our own happiness is the reward, and solely the reward, of the use we make of our time, talents and capability to labour for the good of others and the community, rather than for our own good. Or again, our lot may be the punishment of the sins of our parents or our grand-parents, whose sins we may have to atone for, but the nature of which sins we are completely ignorant; but in this case we may rest assured that we have at some time of our life been given the opportunity to choose for good or evil, and that that choice has decided the course of our future life and happiness, and whether or no we had to atone for the sins of our parents or be rewarded for their virtues.

JUDGE NOT.

Judge not the working of his heart and of his brain; You cannot see, what in your dim sight appears a stain. Maybe, the contest fought and won, whose awful strain Would leave your pride with bended knee, Craving for mercy midst your cries of pain, A sight for pity in your misery. Judge not ! for "Judgment is Mine," saith the Lord. Judge not, the fault and sin by which you think he is undone,

May only be the outward sign of inward grace That would leave you vanquished where he won. In fight so fierce 'gainst some appalling sin Its very breath would scorch your smiling face; 
And where he rises victorious from the fray,

Well tried and strengthened to hereafter win

A fiercer fight some other day,

In dust and dirt and dire disgrace

You'd be left writhing on your face.

Therefore the only correct definition of crime and virtue must be that Crime is sin carried by misjudgment, intemperance or hate to the height of folly, for all crime is folly; and Virtue is sin carried by Charity, Love and Humility to the feet of Wisdom, for wisdom is the height of virtue. It matters not if the crime in itself be a virtuous act or not, God will only judge it by its effect upon or for the good of others, not by the perfection the performer sees in it thus we see many goodygoody persons whose extreme zeal for virtue leads them to perform acts virtuous in themselves that are obnoxious and sometimes injurious to others, and which thereby, despite their zeal for good, instead of being an example to be willingly followed by all good people, they degenerate into bores that are shunned by all, and their highly decorated virtues are only vices in peacock's feathers. Virtue in the abstract is any act or combination of acts (for one wrong act may produce a more valuable result than a combination of three good acts of less value, and may so merit reward, not punishment) which produce more good than harm to our neighbour or our offspring, and so merit reward, not punishment. I have purposely left self out of consideration, because God rewards our actions, not by the good or harm they do to ourselves, but by the good or harm they do to the community or to others, for it is only our conceit that makes us think that we are individually of more value than a snail or a fly.

I do not wish this chapter to be taken in its concrete sense, only in the abstract, as illustrating how Good or Evil has to be viewed from the standpoint of evolution, so that we may get a clearer and better understanding in the manner in which we ought to apply past knowledge, so as to evolve the greatest benefit from it in the future. Now, so long as we remember that veneration to God and Religion are essential factors in the true realisation of the laws of nature, and must overrule all scientific knowledge, it is possible to produce good concrete results from abstract evils. But lose sight of the predominant 
powers of God, fate and hereditary fitness, and we soon arrive at very false concrete maxims. German philosophy of to-day is a striking instance of this, for the maxim that it is a law of nature that God permits all forms of evil that good may come of them, which in the abstract is correct, does not justify the error that this law holds good in the concrete application of it to our individual lives. For moderation, not either form of extremes, constitutes virtue, and although it is well to know the extremes both of vice and virtue, that we may be equally careful to avoid both, for it is possible to have too much of a good thing as well as too much of a bad one, and the height of virtue is to adapt all our acts to the existing circumstances amongst which we have to live, aiming always at the middle course of moderation and avoiding all extreme courses. I will mention some of the striking instances of the evils that arise from putting abstract truths into concrete application, for to apply abstract truths to utility, without evil results, in many cases necessitates divine wisdom, a degree of perfection that God has but man has not, and never will have, so man's fallibility often turns their truth into falsehood. It is this that gives rise to religious bigotry and scientific pride.

It is this which is the cause of German atrocities, Zeppelin raids and submarine warfare, and breaches of treaty obligations, by each nation leaving the path of moderation on the plea that national aggrandizement justifies national arrogance, just as science errs by making the error that special - knowledge in special directions gives the right to be dogmatic in assertion, which is no more the right of science than it is of religion, and scientific intolerance, labour intolerance or intolerance in demands for liberty and democratic principles deserve to be as severely condemned as do religious intolerance, bigotry, scientific arrogance, abuse of power, social contempt of inferiors, or lack of social respect to superiors, monopolies to benefit employees or employers (but in this case do not forget that democratic monopolies, such as trades unions, are worse than autocratic ones, for the former benefit the individual to the detriment of the state and community), or social animosity. So we find that the German philosophers, by ignoring God and subjugating the right to grasp and retain all that is come by in accordance with national laws, either in war or commerce, and by forgetting that state, just as much as 
religious laws are prone to err, and that only the power to use to the best advantage for the benefit of all concerned, either persons or nations, really confers the right to possess. And as power to use to the best advantage varies from generation to generation, with nations as much as it does with individuals, unless all nations, as well as science and religion, adopt a more give-and-take policy, all attempts at permanent peace and national tolerance are out of the question, and both parties must make huge sacrifices to meet each other.

I will now give another instance of how abstract truths may be perverted to concrete evils. The German philosophy that might is right is an example of how far this evil can be carried to excess, and once we forget to remember that God alone can control our acts or the distribution of wealth and power, man can only upset or control the correct balance of distribution on give-and-take lines. So German autocracy errs by assuming that the state has the right to arrogate to itself the power to rule the souls as well as the bodies of its subjects, and that the good of one state or nation confers the right for it to dominate the freedom of all others, and that nothing is evil that you have the might to enforce. English philosophy errs on the other hand by trying to make God subservient to its greed, by claiming that you have the right to keep and hold unjust privileges by law, and to grant individual privileges to minorities irrespective of the claims of the community.

So although God rewards and punishes us in this life and the lives of our children with the utmost detail and justice, he considers us only as a chess player would consider the pawns and pieces on a chess-board. Thus at one time murder was the greatest virtue, but now when done through spite and under wrong conditions, it is the greatest of crimes, but when done in self-defence, or as a means of capital punishment, and even yet in times of war, it ceases to be a crime and becomes a virtue, in the same way that under certain conditions polygamy is more moral than monogamy. But in making these statements I do not mean to champion murder or immorality. They are always crimes in the concrete, just as much, or very nearly as much, as laziness and gluttony, which are the greatest of all crimes, laziness, gluttony and meanness being the three crimes in men, and immorality, jealousy and spite 
the three in women for which God exterminated whole families and nations. But until the laws of caste and heredity became the laws of mankind, polygamy was and still is in nations where equality rules, the order of the day, and must be again if we were to do away with social distinctions, an absolute necessity of advancement and of the survival of the fittest. As it is then the only possible way to attain the progression of the human race through the most successful, men getting the greatest number of wives, so with all nations that have no system of social distinctions, it is still the rule and advisedly so. But it is a common mistake to think that polygamy cannot be as moral as monogamy. History shows that it is six to one and half-a-dozen to the other, provided that polygamy is carried on under wise laws and restrictions.

To view this question impartially we must consider the aims for which God created marriage-that is, to join in unity and harmony husband and wife, to produce the breeding of the fittest, and to create happy homes, and united interests of labour and self-protection in a family, and to increase the population. I am citing this instance for the reason that extreme cases make the best examples. The reader must bear in mind that the object of this chapter is to show that in the pure abstract nothing is wrong and that it is purely a matter of circumstance, surroundings and conditions that make right and wrong, not the act itself, and it is a law of evolution that evil is justified by good results. I will therefore now point out that a polygamous marriage may be just as moral as a monogamous one, if made and conducted in a country where it is legal and under conditions of law and evolution that justify the act, and that so long as the man confines his affections to and devotes his means to making those happy and contented who make his home and rear his offspring, it will be a moral home. But the man who lives in a country where it is only permitted to marry one wife, and who devotes his affections to women who do not assist to add to the happiness of his home, and the unity of his offspring, and whose concubines do not increase the family unity, and whose children he neglects to provide for, does not carry out the duties of the state of marriage, and lives an immoral life, whereas the man who has two or three wives, and is true to them all, is moral and virtuous. The distinction lies in the different conception of 
what constitutes moral obligations on the part of man. There have been and are yet in many countries, times and conditions that make polygamy the best form of marriage, and if we abolish social inequality, or if anything should largely destroy the lives of men on a large scale as compared with the deathrate of women, which has been the case in the savage, murderous and warlike times of the past, polygamy might come into fashion again and polygamy might even rise to a higher state of virtue than monogamy. For instance, the Mormons can truly boast that for the twenty-five years that they had the full control of the making of their marriage laws there was not such a thing as a house of ill-fame and scarcely any drunkenness in Utah, and that happiness and content and prosperity were at their highest. This system of polygamy was abolished to prevent Utah becoming the richest State in America, not for moral reasons.

I think I have now cited enough instances to make it clear that it is circumstances and cases that decide between virtue and vice. It remains therefore only necessary to dwell for one moment longer and to point out that virtue and vice in God's eyes and in those of mankind are not synonymous. Right and Wrong are defined from man's point of view by state, social and religious decrees, and must be governed by them until mankind has progressed further along the road of evolution, and has so far progressed that he is able to control all his actions and to do good for the sake of doing good. For instance, for a bank manager or any person in a position of trust to be dishonest is a serious crime, for it is a sin against his state of life. But for a starving man to steal a loaf of bread to save the life of his wife and family is a virtue in the sight of God, but nevertheless must justly be punished by man's laws, because it is impossible at the present stage of evolution to enforce laws at all if many exceptions are to be made. Again, immorality on the part of a clergyman would be a vile crime, because the duty of his state of life is to uphold morality, but a hot-tempered parson might be a very virtuous man, and his temper might only make him the better able to stir up his congregation to acts of virtue, whereas in the case of a king or a judge in the eyes of God, immorality would be a second-rate sin, as morality would not be one of the requirements of their state of life and would therefore be 
a venial sin compared with temper or hate, as these officials would be in a social position where an outburst of temper could unjustly condemn others to death. God will not punish in accordance with social, state, or religious laws, but in accordance with the manner in which our acts fulfil our destinies, and the duties of our state of life. Hence we must decide for ourselves what is right or wrong if we wish to save our children being punished for our faults. We may evade the laws of the state by escaping detection; we can run the risk of social punishment if we do not conform to the laws of society as required by the portion of society and of the community in which we live, but if we violate the laws of God, and do not make it our bounden duty to make all our acts subservient to the duties of our particular state of life, we may rest assured that nought can save us from punishment in this life and also punishment in the lives of our children. This is a common cause of poverty. Now, the one thing that can alone make or decide the superiority of one religion over another is, and can only be, its power to assist the government of the country to rule without having to inflict imprisonment or capital punishment, and the inducement it sets forth as an ideal of perfection to its adherents to make it sufficiently attractive to deter them from crime. And I know of no greater inducement to lead a good life than to keep the remembrance of the fact that every act of our lives will be rewarded in our own lifetime and that of our children if we are virtuous, and vice-versâ, if we lead bad lives will perpetuate this reward or punishment.

Those who will make it the creed of their lives to try and use each and every hour of their existence to the best advantage and in the best possible manner, and who will consider the good of others before their own, make excuses for forgiving the sins of others, because they hope God may reward them. And we may then rest assured that if we really try to perform our duty to the best of our ability and act up to such a belief God will give to us and our children enough to suffice them for their daily bread and will make both ours and their lives happy in the class of society most suited to our happiness and utility, and keep us and them from harm. And so far as concerns the rewards or punishments of others, that is the concern of the state, not of our individual lives, unless we are in duty bound to make or enforce the laws. And 
as regards the reward or punishments of nations, this is decided not only by the virtues or crimes of the individuals, but more by the ultimate results that will accrue to mankind as a whole and the part it has to play in the scheme of evolution. Thus it often happens that the greatest good of mankind is attained by the increase to a preposterous degree of the crimes perpetrated by the rulers, or the masses, of a particular nation; yet the good that thereby results to the world at large more than counter-balances the crimes that the nation or its rulers commit, as the case may be. Thus the crimes of one nation or people, and the follies of its misgovernment or the private sins and crimes they commit, often do more to advance evolution and to teach and enlarge the minds of mankind as a whole, than all the acts of virtue they could by any possibility perform or accomplish.

So we see that where evolution is concerned the abstract statement that there is no such thing as evil is correct. For God being perfect wisdom and mercy and justice cannot do or permit evil or vice or injustice. Hence it follows that good and evil are only comparative forms of existence as compared with our individual liberty, freedom and happiness, and as weighed and defined by individual communities to which we belong. It consequently follows that the only way to be virtuous is to make the best possible use of our time, abilities and energy for the good of the community, at the same time using all possible care not to injure our neighbour in any way that may. really be harmful to him, and to trust to God to reward us accordingly. For Christ says : "Trust then, oh! ye of little faith, in My Heavenly Father, whose grace is sufficient for thee if the sin be not unnatural."

I will now give a couple of historical instances of the manner in which the highest benefit to other nations and to the world at large is often the outcome of the sins of one nation or its people. For instance, nothing in history could be more vicious than the Huguenot persecution in France, or more criminal than the acts of the statesmen who brought it about, yet it is an undeniable fact that it was one of the most powerful factors towards the general advancement of commerce in the course of history by driving a lot of capital in the hands of a collection of the most enterprising men, possessed of the most advanced business acumen of the day, into the new world. 
Men who would never have left their homes otherwise, and so did much to advance and raise the general integrity of commerce, by improving the breeding and integrity of the commercial men throughout the world. Again, had it not been for the semi-religious animosity against the Puritan lovers and champions of commercial combination and unionism of that time, Penn and others would never have migrated to America, and so set on foot one of the most active ages of colonisation on sound lines; whereas up to that time it had only found favour with the outcasts and robbers and the buccaneers and adventurers, who made up the bulk of the early colonists.

Hence, we see that cannibalism, superstition, murder, robbery, even polygamy and idolatry, have all been the highest virtues at some time or other of evolution, and that as much good has come from these crimes in their day as has or is likely to come out of the virtues we cherish to-day, not least of which are love of wealth, love of power, cruelty, business sharpness, cleverness at making cannons, shells or dreadnoughts, but all of which are some day to be as great crimes as murder is to-day. But all these crimes go unpunished by God because they are virtues at the time of their committal, so they not only go unpunished as far as the nation is concerned, but in most cases bring God's rewards on the nations, for punishment is reserved by God for the individuals who perpetrate these crimes, or it is visited on the heads of their children, not on the nation.

But there are three crimes that are visited not only on the individual but on the whole nation also. These are :-

rst. Gluttony and Intemperance.

2nd. Laziness and Sloth.

3rd. Slander, Hate and Jealousy.

These not only bring their punishment on the individual by the curse of poverty, ill-health, crime and degeneration, for nothing produces crime like jealousy and hate.

The virtues that make a nation prosperous are :-

I. Temperance and Thrift.

2. Energy and Perseverance.

3. Justice and Mercy.

I put these in couplets because they are companion vices in the one group and companion virtues in the other. 
There is one great error that must be cured if we are to make any advancement towards the prevention of crime. That is, the public must be taught that what we generally call education (but erroneously) is only culture, not true education, and that knowledge is a two-edged sword, producing both excess of virtue and of vice. I hear you say "if education is not the possession of knowledge, what then is education?" Education is proficiency in the knowledge most required for the path, work or business of life, combined with habits of rectitude, a love of work and duty, and habits of discipline before all else, and of economy, thrift and moral rectitude. Hence to educate our children is to make them virtuous tinkers, tailors, ploughmen, carpenters, miners, parsons or doctors - not to teach them to read or write, sing or play music; these latter are branches of culture, and will not bake bread for starving children or keep our jails empty. And the one education we want is how to make the best of our energy and time so as to maintain our fellow-beings in joy, peace, happiness and content. For culture is only the manure of the mind, and it can only enrich the growth of educationit cannot create it.

Now, if the seed is good it will produce virtue; if it is the seed of folly, extravagance, and sloth, it will only grow into vice. Hence, if we wish to educate our children, we must inculcate in them habits of charity (i.e., a desire to assist others by the use of our time, strength and energy-for pecuniary aid is the least form of charity, and luckily, except in the form of capital, we are seldom called upon to use it ; real charity is to work for all, speak kindly to all, and act kindly to all, and to assist those who are worthy of help to rise in the social scale). Hence, we must first educate our children by teaching them habits of charity, mercy, and justice, combined with those of perseverance, industry and economy. These are the true seeds of all virtue, and if these seeds are not sown, all literary knowledge and culture is only good manure wasted by spreading it on unsown ground, or, at best, on ground sown with the weedy seeds of folly, extravagance and laziness, weeds which can only produce a fine crop of vice. But if we sow the right seeds on mental soil already prepared to receive it by habits of energy, perseverance, skill and thrift, we only require proficiency in the knowledge we most require 
for our state and occupation in life to be perfectly educated, useful, and, if habits of moral rectitude have been also included, we will not only be useful but also virtuous. But the acquirement of knowledge we cannot utilise except in the few cases of exceptional literary ability when there is sufficient genius for the knowledge so acquired to be above the average and so be exceptionally useful, is only so much time wasted.

As time and money are the same commodity under different names, we must not forget that our time and wealth are the property of the community, to whom we are accountable for their use. We cannot all be parsons, doctors, or statesmen, for these are professions that are unproductive of food, clothes and the necessities of life; and thus culture is not necessary to the majority of us, and although singing, music and dancing may be very useful to those who can afford them, they are not necessities of education, and a dancing master will not add to the profits of a coal-pit. The producer always has to provide for two drones, or two workers, whose rate of remuneration is above the return value in production among the bread-winners of a community; and were it not for the fact that the wage the good or skilled workman earns is more than double and treble the wage he is paid, it would be utterly impossible to pay the indifferent worker anything approaching a living wage. For an average fluctuation of $£$ Io a year will raise or lower the birth-rate, and the bad worker cannot even expect a living wage. It therefore always works out that the industrious, energetic and thrifty man has always to support twice his number in the community who fail to earn, otherwise than nominally, the average value of income or wage they are paid so that they may not starve. This is why we always err, if we err at all, by paying high wages too long, not low ones, and so create poverty. So our aim must be to reduce the non-productive members of the community by teaching them, not knowledge, but to understand that it is habits of perseverance, industry and economy, and the love of duty to God, our superiors, and our neighbours, not wages, that produce the reward of wealth and happiness, and that it is by striving for the good of the whole community, not by private or individual success, that wealth and happiness are attained, for the truth is that we are honoured for the success that brings our wealth. It is not success or wealth that brings honour, or that creates 
true happiness, but the use we make of our time; thus if we have acquired wealth by murder or theft or corrupt practices, the thought that we are criminals in the eyes of God or our neighbours soon destroys our happiness, unless we are so degenerate as to be past redemption. So again, you see, it is circumstances and surroundings that decide right and wrong. Thus it always comes about that too liberal a distribution of literary knowledge will, unless the person receiving it is previously educated as above described, always tend to increase crime, not virtue, by making vice easy and attractive and work disagreeable and distasteful, and so degenerate instead of raising a nation.

But in illustrating virtue and crime I have got into the subject of education, which is much too big for the space I intend to allow to any one subject that does not necessarily belong to the hypothesis of this treatise. But before leaving the subject I must call the reader's attention to the fact that, now that we are relinquishing past control by means of ignorance, the only means left by which we can hope to supplant the use of this force we are endeavouring to destroy, and that can in any way efficaciously replace its actions, must be to substitute more practical principles of education in place of those at present in vogue. As I have already remarked, culture is the manure of the mind, and the tendency of the present day is to put on too much of the manure of culture, and to devote too little attention to the groundwork of education, which is habits of work and utility. We give too much knowledge and too little wisdom or commonsense and technical instruction; too much liberty of action and too little freedom of competition; too much veneration to genius and cant, and too little veneration to hereditary qualifications and individual energy; and too much attention to levelling down society by aiming at equal elective numeral representation, and too little consideration to building up national efficiency by making its social advancement the reward of labour, skill and thrift, and failure in extending a helping hand to industrious and sensible men to rise in the social scale; too much time to converting the sinner, and too little attention to preventing the criminal breeding fresh criminals; too much attention to modest observances and too little condemnation of immoral behaviour.

We send our children to school, where they are taught to 
develop on only uniform lines of social characteristics, which tend to make them automatic machines, but fail to develop their individual talents, particular capabilities, or family characteristics. It is in these matters of personal aptitude in individual qualification that the German system of education excels over ours. They pay attention to first discovering what talents a student has and devoting themselves to evolving as many of these as is compatible with utility in all its branches of any profession, at the same time omitting all culture not essential to that trade or profession, and allocating their payment of wages or remuneration in proportion to efficiency in all branches of each occupation, whereas we have confined ours to special efficiency in one particular detail of production, or construction and efficiency. For it is the Jack of all trades who becomes the master of all trades, although he may be an efficient workman in none, and it is the all-round man who can lend a hand at the greatest number of requirements of his trade at moments of stress and difficulty who steers the business vessel into port, not the sail-maker who makes the sail but is incapable of other work. It is the all-round man who deserves the highest wage, not the trades-unionist who will only work at his own job. Evolution is emphatic in its assertion that this all-round efficiency is the highest means of superiority and advancement in the long run, although for the moment special aptitude may appeal more to our senses.

Thus the mammoth and huge reptiles excelled man in their development of muscle and bone, but failing in the all-round development of their bodies, mind and brain and activity, ceased to advance beyond a certain stage of development, because their hereditary powers, being confined to one speciality, excellence in physical development was purchased at the cost of destroying all their means of progress, and so lead to their ultimate extinction. Now, I have repeatedly stated that energy and heredity are the two great motive powers of evolution, but all work and no play makes Jack a dull boy, so we also must not forget that we cannot ignore altogether the place that genius, variation and adaptability hold in creation. This is markedly visible in the errors of Hindoo Caste which being designed to perpetuate heredity and energy destroyed its ends and aims in its conceptions, by ignoring yariation and genius entirely. So if we wish to evolve a per- 
fect system of education, we must seek to find a system that will combine common-sense or wisdom with utility as well as with skill and culture. We teach our children writing from 9 to 9.30 , arithmetic from 9.30 to 10 , music from ro to 10.30, singing from $\mathrm{ro} .30$ to $\mathrm{II}$, and so on, and it is time to leave school before we have found time to teach them common-sense, or how to work hard; to be contented, or the rudiments of moral rectitude, respect to authority, and to grant social veneration to those above them, and condescension to those beneath them, obedience and humility to those in command, which are the more important qualities which our grandfathers made the basis of their system of education. We bring our children up arrogant and useless, and call it independence; idle, extravagant and insolent, and call it liberty, instead of restricting their independence that we may increase the freedom of the community.

And it is only by teaching them the lessons of evolution and by showing them that God is not a mythical being in the sky, but an absolute essential of their existence, and that society and its distinctions are necessary evolutions to permit of freedom, not arbitrary and unnecessary enactments of selfish oppressors, and that time well used, not wealth, creates comfort, that acts well performed, not worldly assets, create happiness, and that efficiency and success can alone merit wealth and respect, and that idleness, waste and intemperance bring the just punishment of poverty, ill-health and crime in their wake, and that success as a nation must be achieved, not by trying to fix the distribution of wealth by Acts of Parliament, but by educating the people to labour with promptness, skill and co-operation, justice, mercy and obedience, so that they may make of themselves a well-disciplined army of commerce to fight the struggle of love of production as efficiently as in the past our military army has fought the struggle for national existence, by wars that have made empires and cities. That it is not by knowledge but by discipline and selfcontrol, co-operation and efficient management that a nation will in the future have to prove its superiority; not by duties and trade restrictions, or tariff warfare will it be possible to win the battles of commercial enterprise, which in the future are to replace the bloody battles for territorial aggrandisement which in the past have been the means of deciding national 
superiority. If my hypothesis can give a better and more understandable knowledge of how the truths of evolution and nature can be turned to account in practical life, when the days of peace arrive and evolve a common form of belief in the existence of a common unity of aim and objects that will in the future tend to more enlightened ideals of universal brotherhood and mutual co-operation between nations and creeds, so as to act as an incentive to produce better co-operation and less antagonism between individuals and different social classes in the process of production and distribution, and a more practical system of education in morality and utility in our social and religious education as the result of co-united and mutual efforts of both religion and science to combine to produce a higher system of state government, free from all animosity of race, class or creed, my efforts will not go unrewarded. It is with these hopes in view that I wish to impress upon you that knowledge, science and culture are only mental manures that can, and do, cause mighty growths of variation and genius, but do not make up education any more than in manure alone lies the science and arts of agriculture.

As with the land, if we spread the manure, and do not sow and cultivate the soil, we only get a heavier crop of weeds. So in like manner with the mind, if we distribute literary knowledge broadcast on a nation that has not previously been educated to habits of energy, perseverance and economy and moral rectitude, we only produce an increased development of vice, indolence, folly and extravagance. This is why all ages of great literary advancement in the past have only hastened the downfall of a nation, because its rulers have confused culture and literary efficiency with true education, of which it is only the manure that will increase the growth of vice and virtue, but not of necessity the advancement of the nation. For increased culture and knowledge is a double-edged sword which as often brings the downfall of a nation by confining its energies to one development out of all proportion to the development of others of which, although they may be of slower development and therefore not at first as likely to attract our notice as the more brilliant flowers that either science, invention or religion may be fostering at the time, are in reality of far greater importance to our welfare and advancement. Now, it is a law of nature that the weeds always 
start to grow before the crop takes possession of the soil unless by intense cultivation, or all weeds have been caused to grow and been destroyed by weeding or ploughed under the soil before the seed was sown. The same law is strictly adhered to in mental as well as physical developments.

So if we wish to get a crop of virtue from literary knowledge, not a superlative crop of vice, we must not be content to manure the ground with culture and let the weed of war, animosity, strife and might overrun the fields of our minds and souls, or the crop of virtue will be almost exterminated by socialism, anarchy, rebellion, and religious and social fanaticism and hate before the crop of useful virtues, we are striving to attain, bears fruit. The German 'Kultur' that incites its people to war, degraded by the vilest form of savagery, is a striking illustration of the manner in which Science, Religion and Invention may run to weed and increase vice; but out of the growth of such weeds as the war and our trades-unionism, the French Revolution and the Protestant Reformation and Huguenot persecutions, and the crimes of Nero, spring the seeds of virtuous advancement, in the same manner that in our individual life it is the ill-natured slander of narrow-minded persons which stimulates us to our greatest efforts to remedy our individual sins or failings.

So if we would guard against like failures in the future ages of religious and scientific advancement, we must be most careful to see that our state laws curtail individual liberty, to ensure the encouragement of a love of work, ambition for skill in unscientific as well as scientific efficiency, and universal thrift, and to organize a commercial system of a well-disciplined army of mechanics in place of antagonistic trade organizations which tend to make one profession anxious to gain special preferences over another and to set employers and employees at loggerheads, instead of working in unity and dividing losses as well as profits.

It is easy to get the employee to divide the profits but he must also learn to take his share of the loss in other ways besides the one of contribution to taxes, such as working overtime free of charge upon special occasions, putting his heart and soul into the work and its success, as his employer has to. He must also learn to curtail his individual liberty that he may add to the benefits of the business or 
community; and that what is more important than skill, knowledge and culture, if he wishes these three plants that produce the flowers of comfort, content and happiness to grow, is that he must first weed out of the masses of the people all such weeds as indolence, slovenly work or extravagant waste of time (he can leave it to his superiors to attend to such more remunerative duties as management, control, distribution of wealth and accumulation of capital, without which his wage cannot exist), and the government and parsons must turn their attention, not to punishing crime and converting the sinner or saving the poor from starvation by charitable doles, but to preventing crime by confining the criminal and compelling him to work under conditions of slavery (for it is a virtue to make a slave of the criminal, loafer and unemployable) and preventing these men from breeding further forms of degenerate humanity. For if you abolish war, you must either restrict the breeding of the unfit and unhealthy, or encourage starvation, one or other, there is no alternative between these two. You must stop the young and foolish and extreme enthusiast being permitted to preach discontent, disrespect, and disobedience, which are the highroads to poverty and revolution.

It is only by such a system that we can hope to eradicate the growth of weeds that the manure of increased literary knowledge is ordained to produce that man, by eradicating them, may be worthy to reap a crop of advancement. And because they neglect to keep up the energy of the nation by implanting high ideals of the value of work, skill and co-operation, obedience and respect to their superiors, and love of honesty and rectitude, and instil in the minds of the young the use and advantage to all classes alike of social distinctions are the reasons why religion is losing its hold upon the people. It is only because the necessity of placing the above principles as the most necessary qualities to national success has not been fully understood, that all literary ages in the past have only accomplished the downfall of past nations because they have not first educated the masses of the people to receive higher knowledge by first implanting higher principles to create a greater love of work, energy and rectitude. So if we wish to succeed where our ancestors have failed, we must first teach the mass of the people that there is a force that rules 
us all, and which decides the ends for which and by which we live, move and have our being, and that to God, not to man or man's laws, will we have to look for the rewards or wages of our acts, and on our own energy and the efficiency of the work we do will we have to depend if we wish to merit these rewards; or else our knowledge, science and culture will be lost in the future as it has been in the past, and we will find, as other decayed nations have found, that we cannot allow man to think for himself, until after we first teach him to govern himself before he can be fit to be granted increased liberty of thought. And we will find that without that foundation of energy, use and charity, science, like modern artillery, is only a more rapid means of death and destruction that is hurrying us on to an untimely end. It is one of the many strange analogies of history that when the rulers of a nation are the greatest criminals and sinners the mass of the people are the most virtuous, and that when the leaders are the most virtuous, the mass of the people become the most degenerate and steeped in crime. This is only the result of the fact that Evolution is the work of reactions, and it is these reactions that evolve social distinctions.

Now at the present time the German philosophers are making the greatest of all errors in endeavouring to establish a dogma of materialism and militarism which can only take the world back to the early days of Chinese civilisation. But the English philosopher is on the right track, for at the same time as he is increasing his knowledge in all branches of science, he is endeavouring not to lose sight of the mighty influence of God and His Trinity, and of His Revelations as the domineering factors of creation and of evolution. We gaze with admiration at the beautiful development of English ideals of philosophy, and England's advanced ideals of charity, justice and mercy, and her desire to grant liberty and knowledge to her people by her idol of education, but when we look at the face of England's idol and extol its beautiful countenance, with eyes of ruby light and broad expansive forehead, we regret to find that its feet are made of clay. When we turn to the German idol of education we notice with disgust that its head is the materialistic, loathsome image of some antique heathen deity, but as we are turning away with disgust, we observe that it is shod with Wellington boots 
of the best calf. No matter how degenerate, false or unsound the philosophy of its leaders of science may be, its system of education, though not so well adapted to the wholesale distribution of knowledge to the masses as our system, has the advantage that, while it gives equal facility to all who have real genius in the chances of acquiring the acme of knowledge their profession most requires in all its branches, it is very much better calculated to inculcate energy, perseverance and obedience into the masses of the people than ours is, and tends to give more efficiency in all branches of its trades and professions than ours does. This is a matter we will do well to copy from them, because it is in this respect better than ours.

They are making a race of industrious, useful men, capable of heing governed, docile, and respectful to authority, whereas we are rearing up a race of idle loafers, unreasonable, ungovernable and unruly, selfish, greedy and insolent and unemployable. But if we copy them, let us beware of copying their errors and sins, by any loss of godliness, charity, justice and mercy. For even though we have an idol of education that is far more beautiful and of higher ideals of perfection than other nations, its feet are of clay, and it will not profit us anything if it is bought at the high price of the greatest of all mistakes-viz., by granting knowledge and liberty to the masses, heedless whether our system evolves folly, indolence, extravagance and love of pleasure, instead of wisdom, energy, thrift and moral rectitude and the necessary restriction of liberty that freedom demands. For an idiot is only a fool, when all is said and done, but a clever fool can make a waster, a drunkard, a loafer or a blackguard, a rogue or a thief. Knowledge can make a clever fool, but it takes breeding to produce talents and wisdom, and law to produce order. I love England, and I do not love Germany; but we find fault with our wives because we love them, and we only shrug our shoulders when other men's wives and children go wrong, but this does not justify their going wrong or our shrugging our shoulders.

Though I intend to make this treatise as concise and initiative as possible, I could not pass this subject by without commenting upon it, for I realise that so great a factor is knowledge and education going to be in the future as regards the prevention of crime and the encouragement of virtue, and 
so much in the future will science have to do the work that religion has done in the past, that I should leave this chapter incomplete had I not made these remarks. And I must point out that far and away as our ideals of philosophy may be above those of the rest of the world, if we do not reform our system of education, and make it somewhat after the German system, we will find when we have evolved further knowledge in the future, that the masses of the people will not be fit to receive such knowledge, and that in this point Germany will be a century ahead of us, and will then have learnt the folly that her ideas of materialism are sure to teach her. This will place her in the right position to profit by our mistakes, and she will steal our brains as she is now anxious to steal our trade and colonies, because she has given more attention to developing the energy, efficiency and wisdom or sound common sense of her people, which is of greater importance than developing their knowledge.

And it is because I feel that if mankind can be taught the truths of God's Trinity that my hypothesis contains, and so learn to realise the why and the wherefore of creation and the aims and objects of his existence, and the reasons why and wherefore he is permitted to exist, and the duties of life that evolution teaches and imposes upon him, are the passports for such permission, and which give us the right for its renewal and continuance of such permission to continue to live in ourselves and in our children. Such knowledge may do much to impress upon mankind the necessity for him to aim at higher ideals of perfection in perseverance, energy and economy, and to strive to control his actions for the good of others and to realise that he owes his own happiness to the labour and acts and consideration of others more than to his own acts, and may do much to teach future generations to know and think without wanting to become loafers and wasters, which the present trend of trades-unionism and trade strife is fast producing. For under modern conditions of civilisation we cannot even strike a match to light a pipe without being under an obligation to the lives and labours of others. I am of belief that unionism has many advantages, but if it is to do good it must take the form of unity between employer and em. ployee, and must advocate freedom of contract, and aim at increasing the efficacy of work rather than at trying to fix 
wages. I lent the results of a careful analysis of the distribution of wealth in Australia, estimated on twenty years' statistics, extending from 1893 , when the banks all went smash, to I9I3, the height of modern prosperity, to a Judge of one of the Arbitration Courts of Australia, who wrote me as follows commenting on these figures:-

"I have looked over the figures you lent me with much "interest. One of the lessons which they seem to teach "requires enforcing in these times; that is, that the existence " of a rich class is a thing which is of great value to the " community, because the rich class is the saving class. "Without Britain's accumulated wealth, where should we " have been during this war, and who are those who have " accumulated it? I think investigation would show it was "the rich who have accumulated it, not the wage-earners."

These are very potent words when spoken by so high an authority. I must here also cite one of my own experiences. For some years I was directing a building society which erected cottages for poor men so as to enable them to purchase on exceptionally easy terms of weekly rent. One of the most impressive results was that although its operations were confined to one town and its suburbs, and it declined to undertake work outside the suburban area, nine out of every ten clients were men born and reared in the country districts who had acquired habits of thrift through past generations of thrifty agriculturists ; for thrift, like skill in manufacture, is an hereditary quality, not a spontaneous variation like genius. Now, there were ten persons to one in the town engaged in various trades who were town bred and reared. Most of them were in receipt of higher wages than the country reared citizen; yet so much is the extra inclination to extravagance, love of enjoyment and pleasure engendered by town life as compared with country life, that in a few generations these qualities of thrift and extravagance become hereditary in such a marked degree as to reverse these percentages by one hundred per cent., that is to say, entirely reverse them. We should therefore make our principle aim that of securing the best work, and all means of attaining the greatest efficiency of work, and thereby decrease the possibility of unemployment. For all attempts to fix 
wages except by fair and free competition can only increase the cost of production, or lead to the production of commodities of inferior value, and so lower the purchasing power of the worker's time, and it is with our time, not our money, that we have to pay for all we use, eat or drink; and if we wish to improve this we must create associations that will act as registry offices which will guarantee to the employer full value for the wage he is willing to pay, and to the employee the equivalent wage for the skill he is capable of, and first chance of constant employment at high pay to the most skilful man. But the wage must be in proportion to skill, not to occupation or trade-a good mason, ten shillings, a bad one five, and an average workman seven shillings. But the trouble will always be to reduce wages fast enough when depression commences, so as to be able to prevent want of employment. If you leave them alone they will always rise fast enough, so long as profit encourages the circulation of capital, for a small rate of profit is preferable to no profit at all, and the rate of wages should be decided by the number of certificates of efficiency held, and the demand for employment and skill of the employee, not by Acts of Parliament.

Finally, it will be a better educational system of how to make our lives, time, skill and thrift useful to our fellowcountrymen, not by a system of wholesale distribution of knowledge, which only makes wisdom valueless, nor by a universal franchise, which only converts power into vacillation and indecision, that we are to enable self-control to turn folly into wisdom. And do not forget that all folly is some degree of crime, and all wisdom some degree of virtue 


\section{CHAPTER XI}

\section{THE THREE CLASSES OF MIND}

IN its right place we shall have to point out how these three portions of Imagination, Comprehension and Understanding that form the trinity of the human soul have been evolved on the seventh, eighth and ninth days of Creation, which represent the period referred to in Genesis as the creation of human mind as apart from animal instinct. They also mark the early dawn of civilisation, and, what is of most importance to our hypothesis, the return to creation, for the first time in the course of evolution, of the three personalities of God's Trinity, as up to this stage only the attributes of God the Father and God the Mother, or those of two of the personalities that have been withdrawn to admit of creation, have taken part therein. But now the spirit of God the Soul is being returned to creation to permit man to be able to evolve mind, the primitive evolution of the soul, that final perfection of himself that is to make him worthy of immortality.

In this chapter, however, I especially bring these facts under the notice of my reader, not to explain the mind of man in its relation to creation, but to make clear to him, from the abstract point of view, the three different grades of his mind or soul that correspond with the three personalities of God's Trinity, so that he may comprehend that just as mankind is divided into social groups of states, societies and religions, so also his soul is divided into three classes-IMAGINATION, COMPREHENSION and UNDERSTANDING. These three qualities constitute the Human Soul, just as infinite spirit, existence and soul make God, and although conceived in the womb of evolution at the stages or ages of the Epoch of Hope, must not be considered as being then created or born into existence, but each takes time to evolve, just as our body is evolved in nine months, our mind in about twenty-seven months; and nine times as long, or about twenty years is re- 
quired to create the birth of our minds, and fifty to sixty years to create full-grown wisdom in the life of man. So probably in the life of evolution it will take proportionately similar periods working co-jointly throughout thousands of years in nature, as they do in life in the course of a few years, to evolve mind and soul in man, but the absolute birth of soul does not commence till the age of Charity. This chapter is rather being written to prepare the reader for the consideration of these facts and to point out to him that such a hypothesis as the one we are now reviewing is too mighty and important a subject, bearing as it does upon too many various issues to be solved by the brain of any one man, but must be reviewed by many men of many minds before it can be knocked into such shape, size and appearance and expression of opinion as to be of clear understanding to all classes of mind. Past and future evolutions must prove who says what is correct; but I maintain that in the truths of religion, aided by the light of God's Trinity and instructed by the science of evolution as in time we understand these better, are and can alone be the keys by which we will be able to find many of the correct answers; but if the treatise may furnish a new and more correct book of answers in a large number of cases to a larger number of mental sums, difficulties and enigmas of religion and creation, than any previous hypothesis has been able to account for, it will do all and more than the author has a right to expect. I must now return to the subject of our chapter-namely, the three classes of mind which form the three likenesses of God's Trinity in the soul of man.

The first is the group of mankind which possesses a mind in the likeness and image of God the Father, that is to say, a mind of imagination, which, as we elsewhere demonstrate, is the lower or first evolved portion of soul in man. This mind is male (see Table I., line 4) and is the fourth attribute of God the Father.

The second of these groups is the mind of God the Mother, and is the mind of comprehension, which indicates the return into creation of the spirit of both God the Father in combination with that of God the Mother to create the dawn of Love and Sympathy and religion in the mind of mankind. This is the female mind and the second order of mind, and the fourth attribute of God the Mother in Table I. 
The third class of mind is the outcome of the return to creation of the attribute of God the Holy Ghost, and is the mind of Understanding and the soul of Human Wisdom, which, as it becomes evolved, is ultimately to fit man to rule creation. It will take much longer to evolve than the other two classes of mind, and is only yet in its infancy in the march of evolution, for although conceived about eighty thousand years before Christ, its birth is A.D. I800. It holds the same place in the soul of man as scientific knowledge does to unscientific knowledge in his mind. It is, like imagination, a male order of mind. The two male orders of mind are of male descent, whereas the mind of comprehension is of female descent, subject to such alteration in the laws of descent as have been made possible by the mysteries of the redemption of mankind. These are referred to elsewhere. All mankind is made up of a combination of two of these three classes of mind, and they decide our fitness for certain occupations, or the efficiency we are able to attain, our likes, dislikes, talents, genius, social positions, tendencies to do good or evil.

These are all dependent on the combination or proportional influences of these three classes of mind. But, as is hereafter illustrated, the efficiency of our minds in these respects may be subject to variation in individual instances by environments, such as wealth or poverty, health or debility, which may be sent as rewards or punishments for the past use we make of such talents, or as a means to stir us to some more perfect use of our capabilities in any one particular individual lifetime. But such individual instances do not materially affect the question we now have under consideration. The measure of our success or failure in the performance of the duties required of us by our state of life will be decided in the main by the class of mind we are born with, and the value of our talents and capabilities to the communities, not by the trouble or labour they entail upon us, but by the value that the majority of our fellow-men place upon them, and the reward or punishment that God may see fit to grant or deny us and our children in accordance with our acts and those of our parents. I will now review these three classes of mind in the order and separate distinctions of their general characteristics, which form the subject of this chapter. 


\section{THE THREE CLASSES OF HUMAN MIND.}

I. The Imaginative Mind, the trinity of which is To Think, To Conceive, and To Imagine.

This class of mind is the rudimentary mind of man as compared with the instinctive mind of animals. It is the mental bird, the child of thought, action and knowledge, but not the mind of wisdom. The butterfly of Thought, the eagle of Soul, surpassing in its rapid flight the rays of sunlight and leaving them far behind. It soars from earth to heaven regardless of its course, too free of thought to allow itself to be fettered by exactness of detail or accuracy of statement. It is the mind of beauty, art and prayer, passing rapidly from thought to thought, ever bee-like, sipping the sweet of knowledge, building castles in the air, sowing seeds of imagination, for the other two classes of mind, comprehension and understanding to investigate. It is the duty of the mind of comprehension to grow and cultivate the roots of Invention, Consideration and Experiment, and Logic, so that knowledge may be filtered through the stem of experiment, after which it must be tried by the mind of understanding, which puts it to use, and weighed by the mind of comprehension in the scales of logic and truth, and if not then found wanting, knowledge, the result of the mind of imagination, will be passed on to be corrected by the labours of the minds of Comprehension and Understanding, the latter of which must supply the wisdom of scientific knowledge, by which truth is to be tried and proved to the satisfaction of the mind of Comprehension before it will be fit to use to form the branches and leaves of the tree of human wisdom and judgment, subsequently to be converted into the flowers of justice, capital, wealth, and so form the future seeds of advancement and improvement, which are ultimately to evolve human perfection, happiness and immortality.

Thus we find that each class of mind and men have to combine together to work out the perfection of the stages of Use, Peace, Comfort, and Content that are to be the next evolutions of future creation that are to fit mankind for the rewards of the last three days of creation, the days of Joy, Pleasure and Happiness, that are to make this earth a fit abode for im- 
mortal man. Now in this chapter I shall endeavour to point out to the reader the different qualities of these three classes of mind and the fact that they all three have their different duties to perform, and that all other classes of mind are a combination of two, but never of the three primary classes of mind which are represented by the three distinct theological attributes of the human soul. The minor or crossed combinations of one of the two male minds with the female mind of comprehension produces all forms of our ordinary human mind, but the predominance of its most efficient characteristic must decide under which category we class it as either an Imaginative mind, a Comprehensive mind, or a mind of Understanding. And according to the predominance of one or other of these qualities, so will be decided how we are best fitted to perform the individual duties of our states in life, and to perform the objects and ideals for which God has created, and evolution has fitted us, so as to enable us to combine together in the future to work hand in hand regardless of all distinctions of rich or poor, nation, class, colour, race or creed, that we may hasten, so far as possible, to bring about the final completion of the evolution of the world and its transformation into Heaven.

The above is the logical deduction, not only of the strange interpretation contained in this hypothesis of the Trinity of God and its influence in creation, but of nature and science also. And if science and study can do what I feel incompetent to perform, that is, to prove in the future that this hypothesis contains the correct interpretation of creation, it would still be valueless if it failed to create a higher ideal and inducement to urge mankind to strive to unite together to help one another to complete and perfect the creation God is evolving, and to learn from past evolution how to best use our Time, Energy and Brains so as to do our duty as directed by God, Fate and Evolution, and so evolve the future happiness of mankind. I will do my best to point out elsewhere how and when these three classes of mind have been created or evolved in the exact sequence of the hypothesis I am trying to explain, but I think it right, even at the expense of being accused of being tautological, at times to repeat the arguments, as this helps to demonstrate in an impressive manner the salient portions or illustrations of my hypothesis. I have, 
therefore, more than once referred to the order in which the different classes of mind were evolved in evolution so as to prove that their order not only coincides with the order that they hold in the creation of man's soul, but their order of merit, use, and efficiency and of utility and value to mankind also coincides with creation in evolution and the hypothesis.

Now we find that it was by the electrical currents of wireless telegraphy that woman's love, affection and thought sent up to heaven in earnest prayers when ruthlessly ill-treated by her loveless husband that was the cause that first brought down from Heaven Imagination, the gift of the first person of the Trinity of God which was to permit of the evolution of the Trinity of the Human Soul and the lowest order of the human mind, which was evolved on the seventh day of creation, and so began the formation of the soul of mankind, when woman prayed to heaven to soften the hearts of the children she loved, and not to let them grow up in the savage likeness of the cruel monster man, whom she feared, loved and worshipped. She begged of her yet unknown maker to send down the grace of mercy to the human beast and devil that his hard fight for physical supremacy over animal life and the forces of nature had made of man, as it evolved the characteristics of cruelty, combativeness and selfishness that alone would enable him to conquer worlds, make empires and evolve commerce, and that made the cruel domineering brute and beast that by evolving murder and cannibalism had thereby become able to overcome the animal kingdom; and such a brute had this made him, that he hesitated not to cruelly maltreat her and devour her offspring. But if this had not been so he would not have evolved above the rest of the animal world. It was natural reaction against this cruelty that produced the mind of imagination, the lowest order of mind.

It is the Spirit of God the Father in the soul of man, not woman, the spirit of light and inspiration so well and beautifully depicted in the Persian Legend that is the foundation of Thomas Moore's poem, "The Fallen Angels," in which woman's love is brought in contact with the light of God's Grace when her soul takes wings and flies to heaven, leaving him disconsolate on earth. This is but a legendary account of what took place in evolution on the seventh day of creation, the last day of Genesis, when the soul or mind of 
imagination dawned in mankind. The mind of woman is the mind of comprehension, but in practice, most women's minds are a combination of Imagination and Comprehension, and as she added comprehension of God to man's Imagination, her thoughts rose to heaven in prayer.

Although it should belong to Chapter V. of Book II., I have tried herein to portray the probable manner in which woman's prayers and sufferings for the sake of her children made mankind worthy to receive the gifts of a human soul as each of the three qualities of his mind became evolved in the course of three separate evolutions, for I thought by so doing the reader would better grasp the distinctions and separate individuality of the three classes of mind. And what more beautiful and appropriate surroundings could God have devised to herald in the advent of the human soul and mind in place of the animal one, or the first dawn of soul in man, and religion in woman, than the perfection of beastliness that man had evolved opens up to our imagination when we consider all the probable surroundings of this period of evolution? What fitter cradle for the birth of the soul in mankind than the ardent prayer that the devoted mother can well be imagined to have offered up, in spirit if not in words, when her cruel and relentless husband, with his murderous and cannibalistic qualities now fully developed to their highest pitch, enraged by the fact that the Glacial Period, at which we have now arrived, and which is contemporary with the evolutions of Imagination and Comprehension, and which is now driving him back from all his mighty conquests throughout Northern Asia and Europe into the Heart of India, Persia and Southern Siberia, full of bitterness and rage, he, who through millions of years conquered all material obstacles and out-lived and out-fought all the mammoth creation of angels, mighty as was their superiority over him, and brought all the animal kingdom in submission to his feet, finds himself at last defeated by cold, wind, flood, air and water and by the mysterious powers of nature which he is powerless to defeat.

Powers he can feel but not conquer. Hungry, cold and starving, he is driven into his cave, for snow, wet and storm have destroyed his courage, depopulated his hunting grounds, and wiped out of existence his fields and gardens. In his rage and anger, cold and hungry, he returns home and, 
seizing in his hand the child of his own loins, he ruthlessly tears it to pieces and devours it before the weeping eyes of its devoted and long-suffering mother. Is not this, I ask you, or imagine if you can any circumstances that could appeal more strongly at the foot of the throne of God's Mercy than the above, or try and think if you can imagine any more appropriate place for the commencement of man's redemption by God and woman than this one that our Marriages of God's Trinity, in Table III., and evolution in its course and in Genesis, all point out to be the right place for the dawn of man's soul and the evolution of his mind. Is it any wonder that God answered such prayers as I have asked you to imagine, by sending the first redeemer to mankind at this age of creation, "When Adam knew his wife Eve; who conceived and brought forth Cain, saying I have gotten a man through God "? As I will explain elsewhere, Cain is probably typical of the age of evolution, in which Imagination, the first trinity of the soul of man, dawns upon the world.

When we try to read Genesis and Evolution, together with the hypothesis I am endeavouring to explain, evolution points to the probability that both in the age of Cain and Abel, and in the age of Seth and Amos, which biblical names appear to personify the first and second redeemers of mankind, who apparently existed, not as individual men but as personifications of evolutions or changes in the course of mental evolution and civilisation, which evolutions become personified as some greater expounder of the religious evolution that was in course of being evolved, became a more concrete philosophy in place of the abstract realisation of some innate revelation that man in the course of the evolution of his mind was becoming conscious of, as he strove to imagine the possible why and wherefore of the mysteries of transmogrification that he beheld going on round about him in nature. Apparently such truths of divine inspiration were being evolved and slowly making their forces felt as a controlling influence upon his habits, customs and powers of understanding, as the emotions of his human mind and soul were in the course of evolution being slowly evolved out of his animal instinct. The period of these evolutions may be approximately set down, the first as between fifty or one hundred thousand years, which we may call the Age of Cain and Abel; the second, as the last twenty-five or 
fifty thousand years B.C. ; and the Age of Adam as the previous period of somewhere between one or two hundred thousand years that make up the three hundred thousand years which we may roughly assume as an approximate estimate of the period that we commonly describe as the Glacial Period, and includes the three ages which are spoken of in Geology as the Stick Age, represented by Adam; the Stone Age, represented by Cain and Abel; and the Metal Age represented by Christianity.

During the second of these periods, the Age of Cain and Abel, the evolution of Imagination, therein becoming incarnate in the mind of man, must have culminated in some prehistoric redeemer as the visible personification of the in: visible birth of Imagination, and miraculous powers of hereditary transmission of a higher form of love than that of animal affection. In the last of these prehistoric periods, up to the time of Noah, who marks the end of the Glacial Period, the age of Cain and Abel attained a like personification in the Buddha of the Easterns, who appears to be synonymous with the Seth and Enos of our biblical traditions, and whose birth indicated the dawn in the mind of man of the spirit of Comprehension, which enables man to comprehend that the rewards of nature were bestowed upon those who could learn to realise that right was might, not might right, and which takes its concrete form by the children of Abel placing Honour, Justice and Mercy, and the respect to those in power and authority on a higher level in their mental evolution than the greed, cunning and avaricious deceit that the superstitions of Eastern idolatry had made the underlying principles of the Mongolian children of Cain. This marks the miraculous gift of the transmission of Comprehension in part to the mind of man as well as of woman. Lastly, Christ and Christianity mark the third of such miracles, wherein the last of the gifts of God the Mother to the children of God the Father and God the Soul is to be made to the human race, thereby to extend to future generations of men in whom the higher evolutions of soul have been made possible by the intermingling of northern and southern civilisations by granting to them Invention, and so complete the trinity of such redemptions with the completion or manhood of comprehension as a practical evolution of the human soul.

Having now shown how Comprehension has come into 
existence to be both the life and soul of religion, and is the finite representative of the second attribute of the soul of the second person of the Trinity of God in the soul of mankind, and is the soul of belief and of love and of woman, which became complete at the birth of Christ, in the same way that the mind of Imagination was conceived in the age of Cain and Abel and extended to that of Seth and Buddha. Imagination is one of the minds of man, not of mankind, because it appears, if all is to be in order and sequence, that the souls of men are the minds of Imagination and thought, and the minds of Understanding or Wisdom, not the minds of Comprehension, which is, from the standpoint of heredity, fundamentally the mind of woman; and it appears to me that it was to work the miracles of redemption by enabling man, through the birth of three heaven-born men, to be able to assimilate some of the qualities of the mind of woman that is the true reason why God worked these miracles of redemption, so as to bring about the combination of the three classes of mind. Now, Imagination is the soul of Action, Thought and Knowledge, and let me here point out to you that this soul of Imagination is the soul of the lowest quality of the three classes of mind in man, the mind that can think and perform but cannot reason.

The mind of Comprehension is the second class of mind that believes, obeys and perceives, but is averse to very technical knowledge, thought or reason, and the mind of Understanding is the mind that is slow to think or believe and is reluctant to accept knowledge without strong proof and substantiation of the theories and arguments adduced by the two creative minds of Imagination and Comprehension. Hence we find that minds of Imagination are the minds that have the most brilliant power of conception and decoration, and comprise the masses of the workers and geniuses of mankind; but are impractical and incapable of self-control, prone to great flights of Imagination, but lacking the self-control that is necessary for direction though capable of infinite attention to detail, but are impulsive and spasmodic in their energy, and are the minds of the masses of the people and of artists, authors, poets and orators, and the mind of the artisan or mechanical labourer. This is the reason why when the power of government gets into the hands of the people, legislation which is more theoretical than practical is the order of the 
day. The mind of imagination was that which gave birth to the earliest forms of civilisation until the evolution of comprehension developed agriculture and religion, and so prepared the way for civilisation and government (see chapter on Cain and Abel in Book II.).

Now it appears to me that the conditions of evolution about the seventh day point to a time when forces were at work to enable mankind to evolve the soul of Comprehension as an advancement on the lower order of the mind of imagination, so that he might evolve the rudiments of religion by the creation of idolatry, and also as evolution advanced the mind of understanding and government to a knowledge of God and His Trinity under prehistoric Buddhism. Modern Buddhism, dating from I500 B.C., points to some earlier form of creed, prior to that date, whose doctrine of a creator with infinite powers to rule and control, of which power human authority was the symbol, had an existence, but that this creed was abolished some three to four thousand years before Christ, because it created an aristocracy so powerful and arrogant that the people rebelled against its abuse of truth and created modern Buddhism in its stead, somewhere between 1500 and 500 B.C. Yet it is probable that to this religious doctrine, whose dogmas are long ago matters of past evolution, we owe the origin of the qualities of sympathy, honour, mercy and justice, which have since become the birthright of the Aryan races. And it is also probable that the account in Genesis is mainly a record of the historical and astronomical and religious studies of the prehistoric philosophers of India and Persia and Southern Siberia, transmitted through the channels of antique and long-forgotten and contorted fables, legends and parables, descriptive of long lost, past and -confused memories of religious and mental evolutions that may well make us marvel at the exactness of the truths of divine revelation they contain, much as they are jumbled up like dice in a dice-box, and perverted in the course of verbal transmission, yet are in reality mainly records of mankind's indistinct recollections of the manner in which in the course of evolution he slowly evolved in turn the three different classes of mind, which are ultimately to be the foundation upon which is to be reared the edifice of his soul of human wisdom, when in a subsequent stage of creation he is to start to evolve 
religion, government and science. As in answer to woman's prayer God sent the first of the three redeemers, or some such operation of divine grace to evolve Comprehension out of Imagination, the first attribute of the soul of man as a reward for woman's patient sufferings that she had so nobly borne under such circumstances of grief and trial during man's stubborn fight for physical supremacy over the perfect devil his animal existence had created, and out of which was to be evolved his mind and soul, by the blessings of divine enlightenment that was to make the new departure or alteration in his animal mind to that of a human mind, which, as will be shown in Chapter V., Book II., has so puzzled the most enlightened students of evolution to account for, and we will then demonstrate how the hypothesis we are trying to prove supplies the connecting links in the development of mind and soul.

But the subject of this chapter is rather to define the relative position of the three separate classes of mind which has to decide the fitness of each one of us to the particular duties we have to perform to assist each other to bring about the correct course of evolution in the future. Before we enter into the task of showing how, as a whole, these changes came to be evolved, it is impossible for me to conceive that the attributes of God the Father, which carry with them the whole truths of revelation, were ever absent from creation. They lay dormant perhaps awaiting the development of the mind of man, but they were not dead; they are and have been only sleeping till, in the coming Epoch of Charity, the threshold of which we have just reached in the forward march of evolution, should open up the gifts of the wisdom of understanding to our minds. Dormant they may have been through the absence of divine Love and Wisdom, but none the less present, awaiting the evolutions of creation and the passage of time to make them manifest. So on the seventh, eighth, and ninth days of creation, we will in the course of our treatise show that they are evolved in the following order-first Imagination, second Comprehension, and third Understanding, which are the three classes of human minds I am now trying to define. Now I wish you to understand that Comprehension is the result, as it were, of the triple forces of Love, Thought and Imagination, in the same way as Imagination was of Life, Love and Thought, but Imagination is evolved on natural 
lines, while Comprehension is a supernatural evolution; but Understanding, like Imagination, is a natural evolution on the part of man, that will require no act of redemption to bring about its evolution. Its trinity will be Knowledge, Comprehension and Wisdom.

You will then be able to comprehend more clearly how the three classes of mind differ from each other and how they have been separately evolved when you follow the course of evolution in Book II., and how the evolution of the mind of Imagination will be the result of the predominant forces until nearly the middle of the Epoch of Hope.

Subsequently the spirit of Love and Comprehension predominates then as man evolves Understanding, which is the spirit of Wisdom; divine power will be slowly replaced by the control of human will, as implicit obedience is replaced by Religion, Love and Life in the Epoch of Hope, with the result of the evolution of Wisdom. But at first imaginative knowledge is the first that is brought into action, as the gradual growth of the mind of man takes the place of animal thought, until Comprehension shall be sufficiently influenced by the soul of Wisdom, as the latter slowly brings human intelligence to perfection during the age of charity, which is to complete the development of Understanding. But remember that of all the attributes of the mind, knowledge is the most inclined to err, so that the difficulty with the imaginative mind is to keep it in check, which is the duty of those who are possessed of a comprehensive or logical mind and of a mind of understanding, the latter being the mind of science. We are not all possessed of minds of the same qualities, class, calibre, or capability, so that each of us, according to the predominant qualities of the class of mind we are possessed of, have to act as an anti. dote to the minds of others and to check the mistakes which others make and also to increase the usefulness of the knowledge that they each acquire, so that each class of mind may be able to assist the other to do or use what they lack the talent to perform.

Thus the mind of Wisdom or Understanding, influenced by the mind of comprehension, is able to check the faults made by the minds of Imagination by their experience, observation and truth and acquisition of facts, without which check its knowledge is of little value or use. For knowledge does 
not make wisdom, but often only tends to increase the field of action for vice, extravagance and folly.

Now, the place that Imagination has to fill in evolution and practice is, as I have tried to demonstrate, to evolve a mind capable not only of thinking but of conceiving and acquiring knowledge to be used by more highly evolved minds of Comprehension throughout the Epoch of Hope, to create study, religion, government, and to pave the way for Understanding, Science and Use by sowing in man's mind the seed of these qualities which are to grow as evolution advances. Now, this mind of Imagination is the mind that represents the properties of Action, Will and Knowledge, but not judgment or reason, and corresponds to the physical forces of light, and is the mind which enables man to think and conceive, but not to comprehend or understand. Hence it carries us to all sorts of ideas and conceptions, builds up all sorts of theories without regard to right or wrong and without waiting to weigh or consider their logic or reason. It is the mind that beautifies all our thoughts and actions in just the same way that light gives colour to all the surroundings of nature. It is therefore the mind of the poet and artist and of the literary genius, and in conjunction with some of the attributes of the comprehensive mind, lays the foundation-stone of agriculture, manufacture and invention. But just the same as nature in evolution ever tends to combine two of the Epoch of the Trinity with a portion of the third, so in the evolution of our minds God generally combines the attributes of two classes of mind with a seasoning of the third, but very seldom combines any large portion of the attributes of the three.

In deciding to which class of mind a man's brain belongs, we can only define its position according to which class has the preponderating influence over his actions. The trinity of this class of mind is Thought, Knowledge and Conception. Animals are only possessed of two of these attributes, viz., Thought and Knowledge and action, which, with the power of motion, makes the trinity of Instinct as a separate resultant of God's Trinity as compared with the mind of man. So not being possessed of Imagination and Conception, which are the fourth attributes of the Trinity of God the Father and God the Mother (see line No. 4, Table I.), animals can neither imagine, comprehend nor understand, and cannot 
therefore possess a soul of wisdom, so they have thought without imagination, affection without love, knowledge without understanding.

\section{The Comprehensive Mind.}

This is the second order of mind, and is pre-eminently the mind of woman. But there are two combinations of this mind, or what we may more correctly term two forms of marriages of this mind with the two male minds, Imagination and Understanding, which may now both be possessed by men, while the mind of Comprehension can only be possessed in part by him. This mind is the personification of the divine attributes of God the Mother, and bestows on the mind of man all that, like woman, is lovely and beautiful in his soul, namely Existence, Love, Life, Comprehension, Invention, Comfort and Pleasure. It is the mind of Logic, Truth and Belief, and is the spirit of Love, Conception and Observation. Those possessed of it are truthful, honest and extremely affectionate, and are more desirous to obtain proficiency, truth and high ideals than to aim at the attainment of wealth or knowledge or selfish gain. They make the men with the highest ambitions and the greatest integrity; they seek for success rather than for reward, for power rather than for wealth, are ambitious above selfishness, and grieve more over failure than loss.

They are the class of men who most often strive to turn the mistakes of the past to advantage in the future by using past knowledge to perfect future use, although they do less to acquire knowledge than those possessed of a mind of understanding; nevertheless, they are the most progressive of men, for if they are of a less studious nature than those possessed of a mind of Understanding, they are possessed of the mind of the greatest practical observation and of the greatest mental energy, so are able to do more with half the amount of knowledge. They are the most inclined to alter their opinions when reasonable data are advanced for the change, yet are the most tenacious of their principles.

Now, just as the mind of Imagination was the wings of Thought, ever seeking to find fresh realms of knowledge in which to roam in search of new ideas of beauty and thought, to become the seed of knowledge, science and wisdom for the 
minds of Comprehension and Understanding to cultivate, so the mind of Comprehension is ever seeking through the realms of revelation, knowledge, and experience and mathematics for means of invention to lay at the feet of the mind of Understanding to be turned to practical use, comfort or pleasure as scientific proof matures and ripens. Also the mind of Comprehension is the mind that is most inclined to analyse all the gems of knowledge that the mind of imagination and understanding may offer for its consideration, but it is a mind averse to prolonged argument or minute detail, always wanting to rush ahead and arrive at a practical result, leaving to other minds the labours of proof. Being gifted with the soul's eye of comparison, it weighs, observes and considers the right and the wrong of nature and life, and wisdom and understanding. Just as Imagination is the witness, so Comprehension is the Jury, and Science and Understanding is the Advocate in the Court of Wisdom, where Use sits as Judge.

With this mind, if combined in small quantities with the quality of Imagination in preponderance, it produces artisans, artists, poets, authors, etcetera ; but should comprehension predominate in this combination, the mind becomes a mind of observation, as in the case of farmers, agriculturists and soldiers. If combined with Understanding, it produces what we term a logical and mathematical mind. These results vary in exact proportion as to whether the mind is influenced by the attributes of the Imaginative mind of knowledge, or by the attributes of the more precise mind of Understanding or wisdom, for in man it will be a combination of itself and one or other of these two minds of male gender, but not of both, Comprehension being a female mind. In the same way if the imaginative mind be possessed of a portion of the female mind of Comprehension, it is but little influenced by the other male mind of wisdom; for you must keep in your mind's eye that the distinction of gender in God's Trinity passes in likeness and influence throughout all creation and leaves the same dis. tinction of gender on all God's works, so that the mind can be no exception, to this rule.

In the same way, when the mind of Comprehension is combined with the mind of Understanding, it will hold no parley with the other male mind of Imagination and scoffs at its want of exactness in knowledge as out of court, by branding 
it as silly and misinformed and lacking in technicality. Just as the solicitor in a court of justice tries to pull the evidence of the witness to pieces and make him ridiculous, so the mind of wisdom or understanding refuses to play, speaks with the mind of Imagination, and condemns its teachings as uninteresting and lacking sufficient proof. Thus we find imaginative people do not appreciate the learned, but make their friendships amongst those who are less exact, and refuse to accept science unless dressed in the frocks of fiction, fable or miracle, in just the same manner that many people give their business where the get-up of attractive advertisement draws, in preference to seeking the better profits of a less attractively got-up commodity at a lower price.

The Comprehensive Mind is strictly female, and all male forms of its development are brought about when a child's brain through some pregenitive cause, owing to a more than usual mental activity on the part of the mother, gives a more than usual amount of development of the female productive germ, and Comprehension is the result. This often causes those who are possessed of mighty comprehensive minds to be below the average standard of bodily physique; in the same way mental genius in woman is the result of a super-usual development of the male productive germ. It is then possessed to the largest degree of the female qualities of perception and comprehension. Likewise, in the case of men, it over-rules the male qualities of knowledge if combined with a mind of imagination, or judgment or wisdom if married to a mind of understanding. It will in either of these cases, with only a small amount of knowledge, produce marvellous results, but it is seldom inclined to be bothered with details of proof. It grasps at truth and exactness in a greedy and marvellous manner, but when married to Imagination is often oblivious to consideration as to cause or effect; once it fancies it has the true results it disdains the why or the wherefore and loses itself in its enthusiasm. But when married to Understanding it grasps the truth instinctively with a rapidity difficult of comprehension, and is the least inclined of all classes of mind to make mistakes. It is, as I have already said, emphatically the mind of women and also of religious enthusiasm when strongly influenced by Imagination. This is why women appear more religious than men. 
The reader must make allowances that I am here reviewing the male cross only of the mental offspring of the combined minds of the father and the mother. It would take a volume to go into the subject fully. In the female mental reproductions, more preponderance would have to be given to the female qualities of perception, comprehension and invention, and less to those of knowledge and judgment and reason. When combined with the mind of Understanding, its powers of reasoning exceed all other classes of mind. It is the most logical in its deductions, but sometimes inclined to be over dogmatical in its assertions. Nevertheless, it is the mind that in men most willingly admits its faults, but in women will admit its sin but declines to admit its faults, though in both it is ever ready to make amends for its errors. In the minds of women it becomes keener in its perception but more obstinate and less open to reason, and this is the reason why a woman more often than a man grasps the truth, when a man with all his superior powers of will and wisdom is at fault. But in woman Imagination usually predominates over Understanding in the construction of her mind, which makes her hostile to persuasion. If this were not the case woman would lose her love and sympathy.

The Trinity of this mind is to know, to see, and to believe. This is why it is the mind of Religion and Agriculture as well as the mind of Invention, Experiment and Logic. The possessors of this mind are the men of whom we say "They are no one's enemy but their own."

\section{The Mind of Understanding:}

This is the third class of mind, and is always considered the highest standard of mind. It is the mind of soul and wisdom and science, the same as Imagination is the mind of light or creative power, thought and action, and comprehension the mind of truth, love and justice. It is the mind whose duty it is to build up the edifice of use on the foundation of theory and truth, supported by experiment, which the minds of comprehension has laid to be finally beautified by the poetic mind of its architect, Imagination. It is the mind that will have to complete the structure by testing the weakness of all classes of knowledge by scientific experiment, proof, use or 
profit. Its duty is not to judge or decide; that is the duty of the Comprehensive mind; but to test the fabrics of knowledge submitted by Imagination and Comprehension, and see that they will bear the strain in use. For Use is the judge that has to pass sentence on the value of our mental or physical abilities and work. Its duty is therefore to use, systematise and cultivate the seeds that the minds of Comprehension and Imagination have sown. It never investigates, creates or beautifies. It is the conservative mind of man tenacious of past customs and beliefs and principles, opposed to all new advancement or innovations, reluctant to believe till convinced against its will, but untiring in its energy to prove and perfect what it undertakes, obstinate and unreasonable in its very reason. Yet it is the mind that corrects many mistakes and supplies what is wanting in the conceptions of the two previous orders of mind. It is the mind that ultimately, after slow and careful trial of good or evil, truth or error, improves upon the first inventions of comprehension when put by it into experiment to be turned to practical use. It is the mind of deep study and thought, of reason and patient energy, and continually and ultimately perfects all permanent mental creations.

But it is blind to its own shortcomings and loth above all minds to admit its errors or change its opinions; for, remember, with all its proofs, science is more prone to err than logic. It is superabundant above all other minds in pride and conceit, and so acts as a strong antidote to the multitudinous errors that theory, knowledge and Imagination place as evidence before the jury of comprehension, and were it not for the legal advice in the rules of procedure submitted by the mind of Understanding, the jury, that is, the mind of Comprehension, would often be at its wit's end to form a verdict even of probability, let alone of truth, to present to the mental judge, viz., practical utility. But do not forget that small scientific mistakes often make big practical losses, so that if science is not referred back to the minds of logic and comprehension for a verdict, it is nearly as often wrong as is the evidence adduced by the contradictory witnesses of knowledge and imagination. Both the minds of Understanding and of Imagination must always be subject to the minds of logic or comprehension which have to decide between the truths of the knowledge they adduce; yet, nevertheless, the mind of Under- 
standing is truly the highest order of mind, for it is the mind of soul and wisdom, and it alone can raise man to a perfect understanding of how to differentiate between truth and falsehood by the production of proofs necessary to assist comprehension or to show man the truth that, seeing, he may believe; but it requires the mind of God the Holy Ghost (that is the Soul of God, which is complete understanding) to be free of error. The human mind of Understanding will in time teach man all things even unto the consummation of the world, that knowing, so far as possible divine wisdom, he may understand, which is better than seeing and believing.

This is the work Science will have to perform in the future to advance religion. But to know truth from falsehood, right from wrong, what is correct from what is error, requires that both science and religion must act in obedience to the mind of Logic and Comprehension. It therefore appears to me that it is only by a better knowledge of Evolution, read in conjunction with these tables of the Trinity, that we will ever be able to check, weigh and decide with perfect correctness the errors both of science, knowledge and religion, and to come at the true meaning and perfect understanding of, and a clear knowledge of the perfect wisdom of a complete human comprehension of divine revelation which alone can teach us perfect self-control. And that it is only the mind and soul of man that is made in the perfect likeness of God's Trinity, although all creation is to some extent in the likeness of His Trinity in so far as it is always made up of a trinity of forces. Thus motion, heat and chemical action is the trinity of light that tend to form matter; motion, love and thought is the trinity of life which forms divine and human existence and so on through all creation. And that it is only by a correct understanding of these facts and of the Trinity of God and the various manners and forms in which it influences creation that we can truly learn to comprehend nature, and check correctly so far as to clearly understand science, life and duty, and learn how to use, not abuse, nature's gifts.

This is the mind that man is now beginning to evolve during the last one hundred years, and which is to enable him to conquer crime, and learn how to govern himself in the future Epoch of Charity now dawning, in which he is to 
acquire a mind capable of understanding, which mind will enable him to conquer himself in the future, as he has conquered the world of Matter in the past by the minds of Imagination and Comprehension. But Imagination could only give him the barest rudiments of knowledge to make him the poorest of agriculturists. It took Comprehension to enable him to evolve science and religion, and it will take not only a mind but a soul of Understanding to enable him to conquer crime and to become a religion unto himself, which he must do before he will be fit to receive Immortality.

This mind of Understanding is the mind that makes one man superior to another in Wisdom, Power and Wealth. For it is the power to understand when and how to do right by the possession of the qualities of wisdom (i.e., of correct judgment), justice and mercy that makes both wealth and superiority, and it is the possession in a superior degree of some or all of these qualities combined with energy and perseverance and economy that makes wealth, not wealth that makes superiority. Hence we are wealthy because we are superior to our neighbours, and because our ancestors and families have been superior to other families, not their superiors because we are wealthy. And because the mind that our family has developed is superior in the majority of the members of our family to the majority of other families:

This mind of Understanding is the mind of the philosopher, king, ruler, or business manager, and the man who devotes his time and energies to acts of public benefit and who lives not for his stomach, bed and pocket, but for the honour, ambition and glory of the public weal. So we have before us a great struggle to abolish war and strife, either religious, racial, or industrial, to adjust social injustices (but not social inequalities), and to fix the limits of individual claims, and public rights, which may well make modern man tremble at the future in store for him and his children. 


\section{CHAPTER XII}

MIND AND SOUL

"But touching the resurrection of the dead, have ye not read that which was spoken of by God saying unto you: I am the God of Abraham and the God of Isaac and of Jacob. He is not the God of the dead, but of the living." St. Matthew. Chap. XII. Verses $3 I$ and 32.

Now, the beliefs of the mind and soul which we call religion are but so many different views of the truths of revelation and evolution reviewed from different standpoints, in the same manner that four different persons looking at a mountain from different points of view, would all draw or depict the mountain differently, yet each would be right; and it is only when the many-sided views of each and all of those viewing the subject are compared, or someone has travelled all round the mountain that a true idea of its appearance can be obtained.

So it is with our beliefs and opinions, religious or otherwise, for not from the standpoint of religion, nor of science, nor of order, nor of society alone can absolute truth be obtained, unless read and checked by God's Trinity and revelation. Thus we are like four persons viewing the mountain of truth, and we have throughout all past ages fought and contested as to who is right and who is wrong, and our disputes and arguments and our ideas have been expressed, not only in thoughts and words, but in acts and wars, and our disagreements have been written in the blood of men for ages past and most likely will be for ages yet to come, before mankind will consent to walk round the mountain of revelation and evolution and compare it from the sides of Imagination, Comprehension and Understanding as well as from that of belief and custom, from the one common point of view-namely, from above, which we find in the science of evolution when read in the light of the influences of God and His Trinity is 
forever ruling and controlling them throughout creation, which is the one mutual point of advantage from above, like the man in the balloon who sails over the top of the mountain and sees all sides at once.

I do not wish the reader, therefore, to imagine that I am putting these and many of the new hypotheses and new ideas expressed elsewhere as facts that are proved and demonstrated. I only put them in order and sequence in this treatise as they appear to be the best calculated to coincide and to meet the requirements of evolution when viewed from the standpoint of universal adaption to the laws of creation, and as items that my hypothesis of the trinity of creation brings into prominence and they form a part of the picture which the general view of creation from this point of vantage offers to my mind's eye. It will be for other minds viewing the same ideas from different standpoints to decide whether or no, or how far they may be correct. And both the past and future evolution of the world is the judge who will have to collect evidence to prove or disprove my hypothesis; but were I not to place them with the rest I should feel that I had left out half of the picture that has been presented to my mind and that it was blurred and incomplete. They are, therefore, presented to my reader purely as a subject for consideration and controversy.

Now, reviewing all nature in its slow and gradual evolution it appears to my mind that as all else is carried out on fixed lines of a preconceived process of development, apparently conducted and controlled by the influences of the Trinity of God, so also immortality must be evolved in the same manner and on the same lines, and must therefore be also one continuous growth and evolution of life as a product of ether on the same lines and in the same manner as the rest of the infinite plan of creation of the world from out the infinity of ether which surrounds it, until it blooms into the perfect flower of the immortality of men; and that just as health, sickness, disease and death are only the means or force used by the Almighty to further perfect bodily development, so also sin, crime and virtue are only parts destined to produce more perfect mental developments of wisdom in the future; for when all is said and done, all virtue is but so many degrees of wisdom, and all vice but so many degrees of folly. I also take it that the same laws that govern bodily 
development and plant life must also govern mental evolution, for just as animal and vegetable life follow the same laws of evolution and reconstruction by birth, life, death and disease, and of re-creation and reconstruction by birth, death and rebirth, it is only logical to assume that the immortal life of the soul and mind is likewise evolved and governed in a similar manner.

Now, in the life of plants we get a clearer means of illustrating the process of rebirth and re-creation than it is possible to arrive at in a study of the life of animals, just as we are able to see and define with more accuracy the limits of the processes of reconstruction in mineral and material existence in plants and animal life than in mental life, because transformations resulting from chemical action and manual labour can be followed more minutely and with greater accuracy than the results of the re-creation of life and the evolution of mind and soul and psychical changes. For in the reconstruction of matter we can follow each change as it takes place step by step under the process of chemical action or under the hands of the builder, but in the re-creations of animal life, mind or soul there are three or four processes which are concurrent, united, and seldom intermittent in their action and forces, both of heredity, of environment, and of variation, which are all influenced by the invisible electrons and forces of radio-activity which transmit motion to matter, and being both invisible and disconnected from Matter, all tend to make the problem more difficult to follow in detail.

I will therefore endeavour to trace the course of life from seed to plant and back to seed again, and thus show that life is never absent nor separate, but only becomes invisible when dormant, and visible when surrounded by a bodily shape, just in the same way that my hypothesis points out that creation is but the visible portion of the Invisible Infinite Creator; or, taking another form of illustration of the invisible and the visible forces of nature, say Ether and Clouds, Light and Matter, or again as in Electricity. This force is dormant and invisible till its current is broken, but when we break the current by a short distance that is insufficient to destroy the concurrent forces of negative and positive pellation and tractation, it then becomes visible in the luminous form of light, so one can say in the one case it slumbers or is dormant, in the 
other active. So in like manner, I take it, life is dormant or invisible when not clothed in a material or bodily surrounding, awaiting to be recalled to visibility by re-creation or rebirth. Then I will endeavour to show how the hypothesis of immortality that I am about to suggest in this chapter appears to me to be the most rational conception of immortality, because it is based on the same process of evolution as is that of material, plant and animal existence.

Now let us, for example, take a grain of corn; the life of the future seed is the same life that is existent in the parent plant, only that it is reproduced in greater multitudes of the same seed or germ that produced the parent plant, in the head of the new ear of corn, but it is the same life and has never ceased to live. It has only kept up one continuous stream of intermittent activity, of construction and reconstruction, during the whole growth of the seed and plant, so the life of the present seed and of plant is the same life as that of the parent seed and plant; it is only the shapes, the motion of electrical activity, and the chemical action that have stopped or been intermittent, and the stages of inactivity between its different stages of germination, growth, flowering, seeding and its dropping from the parent husk, a perfect seed to grow again reactive in its rebirth in the life of the new seedling that have temporarily ceased. But there is no such thing as death in any of these changes, only activity, rest, chemical action and dormant electrical inactivity, such as when we eat, drink, walk or sleep, talk or keep silent is only a change in our activities.

The real death of the seed only takes place when unsuitable conditions destroy its possibility of re-creation or future activity, such as prolonged periods of fermentation at the time of stooling or malting, which will destroy its power to form roots, or by an excess of moisture under unsuitable conditions of temperature which are adverse to correct fermentation, by creating a false fermentation conducive to rot or decomposition, thus destroying for ever afterwards its power of re-creating a like plant. So the souls of the good are immortal, and the souls of the bad will some day cease to exist, or, if they do not cease to exist, at least remain as a bi-product of life re-absorbable by vital portions of creation, but minus the power of re-creation or rebirth, or as in the Crustacea who discard their shells and grow new ones, the loss of the shell is 
not loss of life, so in such cases these transmogrifications are not absolutely a birth and death but rather a rebirth of fresh visible re-appearance of one continuous recurring life. So our use of the words life and death is erroneous, for the death of our body is only the changing of the dress or habiliment when our soul puts on a new suit of clothes as the last suit becomes worn out.

It is only when the seed germinates under conditions of poor soil or unfit temperature that prevent it from growing and becoming a plant that death really takes place, and once you destroy life or vitality it is impossible to re-create it, either in plant, body or soul. So when we, by neglected opportunities or by repeated crimes, become cursed to the extent that our family or a branch of our family dies out because they have become useless to their fellow-men, it is only then that death really takes place or that it can be said that our soul dies and we are damned for all eternity, so that our life no longer exists. So likewise in the mind and life of animals and men, under adverse circumstances or by neglect of opportunities and abuses of their constitution or mental qualities, they destroy their power of the re-creation of vitality or of breeding mental wisdom, and thereby bring down the extinction and deterioration of the race or species. This alone is death.

It is therefore only logical to conclude that mind and soul are evolved on the same lines as animals and plants and that the loss of the life of the soul does not take place at the death of the individual but only upon the extinction of the family or race represented by any such individual existence or combination of like family existences we call species or races or families, and that such extinction is the damnation of such soul or souls which by abuse or want of energy lose all chance or claim to the powers of re-creation. Now when we find that trees are becoming diseased or deteriorated, we prune the limbs or pull off the faded and dead leaves, or winnow out the weak and under-grown seeds from the strong and healthy ones. So it appears to me that God weeds the bad souls from the good as he finds their crimes are no longer of use to the evolution of the virtues of their fellow-men, and permits their crimes so long as they act as an incentive to the virtues of others. It also appears to my mind that the soul of the father blooms afresh in the souls of the children, weeded and pruned by the 
hand of God, and will ultimately leave only those who lead good and useful lives, and that in proportion to our bad deeds so a proportion of our children and their children are doomed to deterioration and possibly to extinction. For God makes all indolence and vice and waste of opportunities the cause of final extinction of the unfit, and determination in all energy and increase of virtue the road to perfection of fitness in animal and mental powers, and to final immortality in the case of man. Thus it appears to me that our virtues and vices are transmitted from father to son and from generation to generation until a future generation brings them to perfection if the family preponderates in virtuous members or excels in virtue and prunes out by death and extinction of individual families or branches of families those who in the long run fail to progress. Damnation, therefore, can only be the extinction of any branch of any individual family, or the final extinction of any collection of family branches, nation or species, who by abuse of intellect, talent, or want of energy, wisdom or selfcontrol so allow their physical or mental abilities to depreciate that they forfeit thereby their claim to reproduce in their offspring the power of re-creation demanded by the advances in evolution. Nevertheless, when the evils only exist in a lesser degree, future generations may by marriage or intermingling of individuals or races redeem portions of a family, race, nation or species from total damnation, if such minorities produce by their failures and decadence certain virtues in which they preponderate even if the bulk may be condemned to destruction for failure in the majority of cases.

In this way the Almighty prunes out by death and ultimately grubs up by extinction that portion of the family or race that fails to evolve the virtues required by the particular age of evolution or particular circumstances of your life, or are so deteriorated by vice that their further existence is detrimental to the rest of the community, or who have failed to develop up to the required average, and so are left behind in the spiritual fight for the survival of the fittest, just as the animals who failed to evolve brains in physical evolution have been outplaced by those who did.

With apologies for this lengthy but desirable transgression, I will now continue the illustration of the evolution of plant and animal life and of mental life. Now when the seed is sown 
the first operation is that the seed sends out two small watershoots or suckers. These never become roots, but they are all the semblance of roots that grow till after the stooling period is complete, but as soon as there is sufficeint moisture in the soil to cause the seed to malt, this form of growth starts and continues so long as the temperature is between forty-five and eighty degrees Fahrenheit. This stooling process continues, but this cannot produce any roots, only stools, so, after the stool appears above the soil, the sooner an alteration in the temperature, to either side of these degrees, takes place, the sooner the malting stops and the remainder of the flour is turned into starch and the growth of the roots commences; but should the temperature remain between forty-five and eighty degrees, in the case of a grain of wheat, then the whole of the flour is turned to sugar of milk and the plant is unable to form a root. But the earlier a change in temperature takes place to turn the remainder into starch, the stronger will be the growth of the root. But should it be slow in taking place, the roots will be so few and so weak that when the spring warmth comes, the plant will fade and die, but if the change occurs shortly after the appearance of the stool above the ground, there will be a heavy crop of roots. Many men who profess to be scientific agriculturists fail to grasp the importance of this particular stage of plant growth, which, as a practical farmer, I have always found to be one of the most important factors in deciding if it was necessary to re-sow a crop or not, or to prune a tree or not. This change also decided the subsequent growth of roots and the supply of sugar of milk to the stem and leaves that are destined, when summer comes, to supply and form the flowers and seeds.

The same life runs on from seed to stool and shoots, then from the stool to the roots, then to the trunk and stems, then to the flowers; then the sugar of milk fills the husks and forms the fresh crop of seeds, and the whole life of the dying plant passes into the vitality of the newly-formed seeds when summer or autumn heat finally converts the sugar of milk into the starch and flour of the new seeds which is to make the life and vitality of the next generation of plants, and in trees, any surplus goes to create next year's leaf and seedbuds, then the seed drops and lies dormant to live again in a new plant. Each of these stages is not a fresh life, but a re- 
creation of the same life, and the seed only remains dormant awaiting suitable conditions to enable it to live again in another plant or tree.

So in like manner it appears to me that our souls are only dormant at death, and live on in those who come after us. Just as the strength and vigour of the parent plant is that upon which depends the strength and vigour of the succeeding generation of plants, so we find that the cultivated plant, or the well-bred animal is superior to the weeds or mongrels. So I take it, the lives we lead decide the physical and psychical strength and abilities of our children, and that our souls live on, in the minds and bodies of those who come after us. So, "He is not the God of the dead but of the living," as Christ tells us.

It therefore appears to me that it is only in accordance with the rest of the wonderful harmony of creation, that the same course has been adopted in the growth of the mind and soul, as we find to hold good in the uniform plan of the evolution of the rest of creation (see Book II., Chapter IV., which is devoted to the evolution of mind). This must be my excuse for presenting to my reader for his consideration this new idea or conception of the most logical form of immortality which appears to me to coincide more closely than any other that I can conceive with the general plan of evolution.

Now both in animal and plant life we find there is one long creation and re-creation of one and the same life. So also it appears to me that the immortality of the soul must follow the same rules, and is not an individual immortality, but one long continuous chain of ever-existent soul or souls, and that birth and death are but as minutes on the face of the clock of evolution, and our bodies are but as suits of clothes changed with each tick of the pendulum of Eternity as each minute gives place to the one that preceded it, yet one and all contributing to make up the total of the hour of creation, slowly repeating their evolution, tick by tick, till evolution and redemption shall cause government, science, and religion to combine their influences, when we can get these three ruling forces of mankind to unite to bring about perfect wisdom and self-control of man, thereby enabling us to travel gradually along the road to perfection and immortality. But do not expect the journey to be an easy or rapid one. Look, dear 
reader, at the hairs on your forearm. They lie in the opposite direction to those on the rest of your body; that is to say, they point from the wrist to the elbow instead of downwards from the elbow to the wrist. This is a relic of the days of your existence when by hanging by your arms for over ten million years, exposed to the wet and rain, the alternate moistening and drying of the hair caused it to lie in that direction, and half a million years of subsequent development under conditions of comparative civilisation have not reversed their position. This is a characteristic shared by you only with the Gibbon apes, and a few other families of the anthropoid apes.

So do not think that laws or civilisation are going to make any rapid alteration in your state or conditions. It must be the work of time, breeding and evolution. Hence I take it that individual life is but the leaf, as it were, of the family tree of existence. And that just in the same manner as each leaf of the tree performs its service towards the growth of the future season's leaves, seeds, and limbs of the plant, so each individual life performs its sectional duty towards perfecting the growth of the human family tree in the forest of nationality. Now in each tree some leaves bloom, and lasting partly through the season perform their functions, not only of absorbing nitrogen and evaporating surplus moisture, but those that continue to grow throughout the season into the autumn months, as they wither, return the surplus amount of nitrogen that they have absorbed in excess of what the above demands require, back into the sap to form the buds of the leaves, flowers and fruit, so as to produce, during the next season, a more perfect and larger crop of leaf and seed.

But not all the leaves that bloom in spring are destined to live on to the end of the autumn, but some are required only in the spring of the year to create a heavy evaporation so as to prevent an excess of moisture in the sap which would render the seed too pulpy and so be less able to resist the tendency to rot before it could take root (this is one of the most probable causes of black spot and bitter pit in apples and pears) and too prone to acid fermentations which would tend to reduce the strength of its vitality, and make it liable to rot before it found suitable soil for its growth. Other leaves are destined to fall off so soon as the hot weather comes, lest by excessive updrawal of moisture, or too great evaporation of water in the wood and sap owing to the increase of summer warmth, they should 
burst and crack the bark, or should so dry up the sap that the fruit would not be able to properly ripen the seed, and leave it unfit and too much inclined to rot in the ground before sufficient rain fell to ensure its re-growth; so in the summer some of the leaves drop off, while the rest remain on till the end of autumn when winter's winds begin to blow, and frost and snow drive the remaining nitrogen down into the sap and roots to ripen the sugar and glucose, etc., for next year's growth, the better to fit the tree to grow fresh crops of boughs, leaves, fruit and seed the following year. During the winter months this nitrogen turns the saccharine matter in the roots back into starch, to rise again in the spring, when it will cause the buds of leaf and flower to shoot anew, and if there is not enough nitrogen returned in the autumn, the fruit blossom will not set.

So it appears to me that the same lines must be likewise the most logical and reasonable modes of procedure to be adopted by the creator in the evolution of the mind and soul of mankind, and that, therefore, in the individual lives of mankind, their minds and souls are, as it were, the leaves, fruit and seeds of the family trees that grow in the forest of humanity, whose duty it is to perform like functions, and that an individual life and soul are like a flower and seed in the growth and development of human existence, so that each generation of mankind is only, as it were, a season's growth of the family to which it belongs, whose duty it is to bear its crop of useful actions and virtues, and each individual life being the leaf of the tree has to feed and mature the flowers of mind, the fruits of wisdom and the seeds of soul till the family plant shall floom at last in the gardens of immortality when mankind, after continuous seasons of life and death, shall have at last so perfected himself in his family growth in all the virtues that each respective family strives to produce as to be no longer subject to death, the penalty of folly and opportunities wasted and of sin in the sense of failure and neglect, not in our ordinary acceptance of the term, but of such crimes as are foolish enough to injure others or our own health and chances of re-creation; for when all is said and done, all that is wise is good, and all that is foolish must be wrong (subject, nevertheless, as to whether it is a necessity of the particular stage of evolution or not which may turn evil into good, or vice versa). 
Such a conception of Immortality is not only reasonable and understandable, but it is the logical sequel to the evolution of life, body and mind, and is made still more probable when read from the standpoint of my hypothesis, so it should also apply to the evolution of the soul.

It is also feasible to conclude that the life of the soul of man is immortal in the same manner that the life of plants and animals is not a fresh life but only an evolution of life or a reward of the previous lives, of which and from which it has been evolved. That is to say, the life of the soul is also an unbroken reproduction of the same mind and soul of the family that has so far evolved it to its present state of evolution. And that just the same as the leaves drop off the trees when they have performed their duty in each season's work, so our individual bodies drop out of existence when they have performed their respective parts during the short season of our individual existence, and that mankind, like all else, have their seasons as a part of the uniform plan of creation.

This seems to correspond in the life of the soul, just as seasonal life does in the case of the leaves of a plant, and that just as the vital portions of the sap descend to the roots in winter to re-create the strength of the limbs and trunk of the tree during the following season and so produce a fresh growth of flower and seeds, so likewise our souls return to our families at our death to reproduce themselves in the minds and thoughts of our children, thereby increasing their powers and capabilities for good or evil, as we, by living a wise or foolish life, shall thereby decide the proportion of the number of them that shall progress or deteriorate, become immortal or be condemned to the damnation of eternal extinction in the struggle for the survival of the fittest; the good being used as examples to be emulated, and by their useful acts assist to lighten the future struggle of life in the lives of their children as civilisation adds to comfort; the bad being used as an example to deter others from like follies, and as a means of punishing the sins and failures of the unwise, or as a means of convincing others of folly, and so teach them to convert their sins into virtues and their failures into successes. Please realise and remember that this is the crucial test and distinction between good and bad. The good are those, no matter how great their faults may be, who have the courage and perse- 
verance to turn their sins and failures into successes or usefulness, and so become wise and worthy of repetition on to the final days of immortality. The bad are those who, lacking sufficient powers of energy and self-control, allow their sins to become a nuisance to their neighbours and whose loss of opportunities make their lives a wasted failure and so constitute the unfit souls that are to be damned by extinction before the days of immortality arrive.

But the sins of both the good or the wise and the bad or the foolish are wisely permitted to exist because they both equally advance the virtues of the majority who make up the whole, of which both the good and the bad are but small minorities. But in every case true Virtue or Wisdom brings its just and equitable rewards in Success and Social Esteem, and Crime or Folly its condemnation by Failure and Social Degradation both in our lives and the lives of our children. So our souls live on from age to age, reproducing themselves in the growth of succeeding generations, each contributing their quota, after many relapses and failures to the slow but gradual advancement of the community as it gradually moves along the steep high-road of progress towards the city of immortality, destined as time rolls on to slowly become more and more free from vice and crime till "The winter of our discontent is made glorious summer " sunshine by the evolution of eternal life, when the more perfect development of our family tree shall be fit to bloom in Paradise.

And what better inducement can we have to make the best use of our time, body, mind and brains than the belief that every act we perform in this life for the good of our fellowmen (I am of the opinion that acts performed solely for our own good and that do not in any way contribute to the maintenance or enjoyment of others may give us temporary pleasure and so be God's means of rewarding our past virtues or those of our progenitors, but can give no lasting happiness, nor bring any regard upon our children, and if bought at the price of the suffering or annoyance of others, they will bring a greater amount of subsequent suffering and disappointment on ourselves and punishments on our future life in the bodies of our children, unless taking the warning they contain to heart, we make atonement and restitution for them before our death) will meet with its full and complete reward of happi- 
ness and pleasure and increased proficiency in the qualities required by our state of life, but not necessarily of wealth or social advancement, for the whip of poverty or ill-health may be a better stimulant to further energy and enterprise in our particular case than wealth and success would be; but they and all acts performed for the good of others will carry their reward of joy, pleasure and happiness in and throughout our own lives and the future lives we are destined by their value to lead in the bodies of our children throughout all future ages.

So as joy and happiness make heaven, it is in the power of each of us to make a heaven or hell of this life, and to condemn our children to future heavens or hells in which we as well as they will have to for ever participate. The principal difference between our bodily life at present and the future lives we will live in our children's bodies and those of their children who by the possession of like developments of mind will make them fit abodes in the future for our particular variety of soul and its efficiency and virtue, appears to me will probably lie in the fact that whereas in this life we have to bear the physical strain of existence and the mental grief of our failures and shortcomings, should our lives be spent wisely and usefully, such anxiety and remorse will be removed from the future psychical existence of our souls, which I take it will then impregnate and, to some extent, direct the acts of our future offspring in just the same manner as the Spirit of the Creator impregnates and controls the Universe He has created, but relieved from the anxieties and griefs of our children's material existence. Likewise to those who have failed to use their short period of mortal existence to advantage this relief will not be given unless or until their future offspring by repeated mortal lives of suffering and penance remove the purgatory imposed upon such souls for their selfishness, follies and extravagances. For during our mortal life there is no grief heavier to bear than the sorrow that accompanies our knowledge of the shortcomings of those we love.

If we lead useful lives, our souls will be granted true knowledge of good and evil, which will constitute the judgment that Christ predicted is to follow our departure from this mortal globe, for it is possible to realise any state of existence that could intensify satisfaction over good done, or remorse for evil committed, except the knowledge of how to do good to 
those we love, in the one case, and our impossibility to do good no matter how sincere our desire may be in the other case, which it logically follows must be the case if the soul is granted a knowledge of good and evil, subject to the right to use this knowledge in proportion to the preponderance of good or evil in the acts we have performed during our sojourn in our material bodies throughout our family's past existences which will decide our power to assist and direct throughout future ages those for whom we will thenceforth be given a divine in place of a human love. Can you imagine a more perfect heaven or a more infinite hell?

So I take it death will not stop our participating in what transpires in the world. But our future powers of influencing its future evolution will be decided by the lives we lead when on earth, or more correctly while dressed in human attire. But our souls will now be so wise that they will realise that vice has its duty to perform as much as virtue, in producing the evolution of human perfection. This is why man, and man alone of all creation, is allowed to sin, and why learning to sin placed him above and apart from the rest of Creation. Think carefully over this paragraph. It may do much to help you to condone the sins and failings of those who are weaker mentally or physically than yourself, simply because their families are less highly evolved than yours chance to be. It is your duty, except in flagrant cases, to help them to advance. Hence after death our souls, if our lives have been just, will not grieve over the loss of the individual souls who err, realising that even if they are the withered and fallen leaves of the family tree, they have done some good towards producing riper blossoms and fruits. And the bad, also perhaps, though never destined to gain immortal life or leave the realms of poverty, folly and suffering by gaining access to the higher standards of future society when it is able to evolve wisdom and immortality, for it appears just as improbable that the whole of the world will attain heaven and immortality as it is improbable that sin or poverty will cease to exist in heaven.

The most we can hope to attain is to separate the good from the bad so as to enable them to live apart without interfering with each other's happiness; so the bad, who are after all nothing but the fools and failures of life, are but like the fallen leaves of the family tree which drop and rot about the 
roots of the trunk of the tree of existence, yet their rot and decay tend, in some form or other, to produce the good of the rest of the family or nation in much the same manner as the autumn leaves when they fall, fertilize the growth of the forest trees and the seedlings that grow up beneath the shadow of their boughs and limbs. So those who deteriorate by contrast add to the brightness and lustre of those who succeed by giving them the means to practise the virtues of Mercy, Charity and Forgiveness.

What more powerful incentive can there be to prevent waste of time and acts of crime and selfishness than the belief that our sins, faults and failings will be visited, not only in our own lifetime by sickness, poverty and humiliation on ourselves, but will condemn some, if not all of our children to eternal damnation, poverty and loss of immortality.

This is the manner in which evolution points out that mankind has been and is going to be perfected and made more magnificent as he is pruned, by the advance of time, of all the dying, dead and broken limbs of failure, indolence and folly, all of which will, as we evolve, be cut out by the ruthless pruning-knife of the laws of fate and of descent and the survival of the fittest, until our family blooms as a full-grown tree in the eternal forest of heaven.

"And why take ye thought for raiment, consider the lillies of the field how they grow, they toil not neither do they spin, and yet I say unto you that even Solomon in all his glory was not arrayed like one of these. Wherefore if God so clothed the grass of the field which to-day is and to-morrow is cast into the oven, shall he not much more clothe ye, O ye of little faith."

So it appears to me that the life of the mind and soul of mankind are but the leaves of the family tree of the soul, and that each family of souls bears the same relation to the nation or race as each tree does to the forest, so in our bodies and souls our individual lives are but a slightly varied reduplication of the souls and minds of our parents or ancestors, subject to such slight alterations as variation may produce in the ordinary course of evolution. So also our minds and souls are but a gradual development of the minds of the men and animals who have preceded us. Hence, it seems to me that our souls must likewise be evolved in the same manner and upon the same lines and principles, with the one difference that 
being a more perfect likeness of God, when we have perfectly evolved them, our evolution will be complete, and as the likeness would not be complete (as God is immortal) unless we also became immortal, it follows that those who are able to evolve to the highest standard of human perfection, must also become immortal. But as our soul is the final development, it is also illogical to suppose that it has always been and always must be immortal. And it also appears to me that if life and soul are immortal, then what we call death can only be a temporarily dormant stage of evolution, and that as the great distinguishing mark of creation is visibility, and of infinity invisibility, it is only in accordance with the uniform plan of creation that the immortality of the soul should be disguised from our puerile eyes by the cloak of death till we have evolved our souls to a stage of perfection that our physical existence becomes subordinate to our psychological one.

It therefore seems to me that the life of our soul can no more cease with the life of our bodies or be a separate life and existence than ducks can grow from trees, nor can it roam about irrespective of the material creation from which it was evolved, as many of our scientific forefathers considered, but must be one continuous life running through from body to body in one undying, unbroken stream as does the life of the animal and plant from which it has been evolved, and must continue in one unbroken and undying stream divided for an instant only by the rocks of death as the waters of a river are divided by the rocks and stones in its course, so likewise the life of the soul flows along the river bed of existence to remingle together as each rock of death is passed, till the river of our family existence shall flow into the sea of immortality, there to unite in the sea of kindred souls who have evolved above the narrow-minded banks and confines of indolence, greed and waste, and at last have reached the ocean of a perfect existence devoted to Use, Charity and Mercy where they can disport themselves under conditions of Joy, Pleasure and Happiness undisturbed by the noisy clamour of the breakers of jealousy, slander and hate which marred their passage down the river-bed of the struggle for existence, but which struggle has fitted them to struggle for the life of others rather than for their own, which is the aim and object for which they were created to live henceforth in the ocean of a well-regulated 
national community where the wise men, not the fools as is the case to-day, preponderate in the management of the state.

So the life of the body is but an individual leaf of the tree of the family soul, just as the leaf is to the tree or plant, and our lives which are committed to our care to be cultivated and fostered by acts of use and good employment, thus to bring about a more perfect development of more perfect ideals which are to bloom in our children and grandchildren.

Again, our thoughts are not our own, they can only be the re-incarnation of the thoughts and experiences of our ancestors which we are permitted to reproduce. Like the operator of a magic lantern reproduces upon a sheet the pictures on the slide he inserts in his lantern, so we reproduce in our life as like occasions recall them, a few of the varied pictures of the past knowledge and experience of our ancestors; so in the same manner we are able to recall from the granaries of their past memories, or from the knowledge of the memories and experiments of others and of their ancestors by the knowledge we may be able to acquire by the study of the wisdom of past ages. Prior to the printing of books we were entirely dependent upon the memories of our family.

But I also take it that just as in the plant past cultivation decides the vigour of the present growth, so the past good or bad acts of our ancestors decide our capabilities for good or evil, and to some extent what our talents may be; but as I have already stated, the latter largely depends on the acts of our parents at the time of our conception. Also the circumstances of the age of evolution in which we live, and the particular circumstances and surroundings of each particular act, and the effect our acts have in regard to our duties to our neighbour decide in God's eyes the amount of our virtues or the enormity of any offence we may commit, and that the right or wrong of our acts is measured by the duties we owe to the family, race or community to which we belong, and amongst whom we live. I am also of opinion that the power of choice or of self-direction of our acts which God permits us are of very limited extent and are confined to our deciding at a few of the most critical moments of our lives the course we shall pursue, except in the merest insignificant details of our actions, but that in accordance with the decisions we make for right or wrong upon these two or three critical 
occasions, so is decided the rest of the fate of our lives and whether or no we are to be the useful members of the community, to rise or to fall in the social scale, and, last but not least, whether or no we are to be the degenerate members of our family who are to pay the penalty of expiating the past sins and failures of our ancestors.

I also consider that our acts are weighed by the good or evil we do to others, not by our social success or failure, and that if our good deeds exceed our bad ones in proportions of, say, seven to three, and that we have ten children, then three of our children will be doomed to go to the bad and seven to the good, or to advance, or vice versa to failure, and this decides the fates which they have to choose between.

But as the reader will have realised when he read the chapter on Virtue and Crime, both good and bad are equally useful in the production of a more perfect state of evolution in the future, but that the tendency to good or wise acts will increase as evolution advances. Thus if upon these two or three occasions we choose for evil, we are destined to go to the bad thereafter, or our lives are destined to be good and useful if we choose aright, according to the proportion decided by the sins of our parents; all the rest of our lives is controlled by fate for the good of the community as a whole, we being only allowed thereafter to decide how we are able to act in mere details and to a limited extent, and our lot in the social scale, our poverty, wealth, strength, or ill-health is decided by God in accordance with the particular duty $\mathrm{He}$ intends us to perform in His work of evolution, either as a reward or punishment of the efficiency or otherwise with which we perform the acts our fate imposes upon us in proportion as wealth or poverty, strength or debility tend to act as a means of advancement or retrogression of the community in accordance with whatever may be the order of evolution at the particular period in the particular nation, or what will make our lives most conducive to the public good.

But on the other hand so much of the control of our lives is left in our hands as will permit us to decide for good or evil the lives of our children, and whether their lives are to be for good or evil; so, He is the God of the living, not of the dead. But to us is left the decision as to whether or not the future leaves of our family tree are to wither and die, or 
are to produce more perfect buds, flowers and seeds in the future. Think of this before every act you perform if you wish to learn the lessons that evolution teaches, and then tell me if you can find a better master or teacher, or a greater inducement to be virtuous than such a belief. Try to realise how insignificant an aim, object or ideal is the mere struggle of your individual life, or love of wealth or desire for pleasure compared with the all-important fight for the good of others that such a belief inculcates as the object of existence.

For it is the good you do to others that brings happiness and content in its wake. Try and realise how great and eternal is the trust imposed upon you and how short and trivial your material enjoyment of the momentary existence of your individual life is when compared with the psychological eternity of happiness that the unselfish use of the energy, labour, and skill, demanded of you during the moment of the material life that is given to you to enable you to lay the foundation stone of an eternity of enjoyment, of the worthy aims and ambitions you are permitted to set up as your ideals, and which will, most probably, be the ideals of your children for all eternity if you use the short space of your temporary sojourn in your mortal body correctly, and which are to decide whether or no your offspring are to move onwards towards everlasting perfection, or are to be condemned to expiate your neglected opportunities by eternal punishment; to rise in the social scale or decrease or stop breeding and so move onwards towards extermination; or, on the other hand, if you make good use of your time, talents and opportunities for the good of others, to be able to eradicate some unfitness for eternal perfection that your family may have evolved which may have been a virtue in the past, but which has now, with the advance of evolution, become a vice, and to perfect those in which your family has excelled. For those in our family who tend to re. produce such family traits as are no longer required by evolution have to be exterminated to make room for its more advanced members or the children of other families who have evolved to a higher standard of fitness than we can lay claim to.

Nevertheless, the crimes or the failures of your family may have done good, in which case you may be allowed the chance to expiate them and so prolong the existence of your family soul, for their crimes may have produced virtues in others. 
The advance of society is evolved by the alternate reaction brought about by the extremes of society in each succeeding generation practising the opposite crimes and virtues to those practised by the preceding ones. Thus the crimes of the rich produce a feeling of disgust amongst the poor which induces them to practise the opposite virtues in their effort to excel their superiors, but in so doing they get to ignore the virtues of those above them, which virtues are probably of greater value and importance than the crimes that they condemn, but as these are also far beyond their attainment or comprehension, their inferiors fail to appreciate them. Thus the poor excel in the crimes that are the antipathies of the virtues of their superiors and the virtues opposite to their crimes. Then reaction sets in and their superiors become ashamed of their own crimes when they see them side by side with the opposite virtues that their inferiors are now practising, so set to work to correct these faults also in themselves, but in so doing allow some other sin to become a crime. This again sets the mass of the people at work to evolve a new and fresh form of virtue. In this manner the top and bottom of society are the two extremes that are made up of the extreme characters that evolve the extremes of good and evil, saint and devil.

Society is formed on the same principle as water boils but by reversing the process. For the unfit descend and the fit ascend and descend as they advance the average standard of the perfection of the less rapidly effected masses who represent the stability and negative forces of society as the top and bottom represent the motive influences of progression. Thus both ends of society tend to improve the mass, and this is why society is a necessity to enable us to modify stringent punishment, and this is where the abuse often comes in when we forget that the principal use of society is to enable us to condone the sins of our neighbours and so obviate the necessity of enforcing the laws. Thus we often abuse it by turning it into a means of uncharitable condemnation and of injustice and strife, instead of using it to increase the unity, charity and forgiveness of the social failings of our neighbour and of assisting him to become more efficient and to rise in the social scale, and to find out the best way to put up with their shortcomings and so increase the charity, justice and mercy of the masses in the struggle that evolution is now beginning to call upon mankind to undertake. 
But how this can be best attained is too extensive a digression for me to attempt in this treatise. But those who fail and become criminals often tend to evolve greater perfections in the community at large, and by so doing in some cases are allowed to make atonement for their parents' sins, if it so happens that the crimes of the sinner are not so gross as to condemn them to damnation. Thus the fallen may, when they have gone through the purgatory of poverty, again be permitted to be improved by the lessons it teaches, and in this manner their children, and in some cases themselves, are again permitted to rise in the social scale, sometimes even higher than those of their family who have not been doomed to sin, poverty and failure; but in any case their sufferings add to the rewards and lustre of the members of their family who have chosen for good, not evil, and even if they are damned by extinction, their few good acts may add to the ultimate virtue of the souls of their family who have lived their lives aright.

There are few of us who are so bad that we have no good qualities at all. What greater inducement can we have to do good and produce virtue than the beliefs that in exact proportion as our honesty, integrity and charity to others marks our superiority to others, so the future of our lives and the acts of our children's lives, or the lives of their children will become more productive of virtue, and so the prominent virtues of our descendants will raise them in the future just the same as the virtues of our ancestors in the past have made our virtues in the present possible, and also decided our present position in the social scale that we may so restore their chance of immortality; and in the same way the vices of the successful and rich will condemn some of their children to deteriorate in the social scale, and perhaps to ultimate extinction if their vices exceed their virtues.

Now I have pointed out that the leaves of the tree do their respective operations in preparing the way for the next year's growth, so it appears to me that the life of each one of us serves to perform its specific duty in evolving the perfections of humanity in general, and our family in particular. So also the wicked are useful in their way and do nearly as much to serve a part in the production of an ultimate perfection of evolution as the good, so what is in itself often an evil is permitted, yes, even ordained by God that greater good may 
result therefrom. But God alone can judge in a case like this. For I must ask my reader to remember that in our animal and past existences the acts that made the highest perfection and virtue were the very ones we now consider the greatest vices.

Thus animal murder and cannibalism were the virtues that developed the perfection of self-will in man which raised him above the animals and fitted him to evolve a soul by evolving his superior bodily strength, activity and energy without which strength he would have been unable to evolve thought and to support his mind. So also in the last three hundred thousand years selfishness and cruelty have been the highest virtues without which man could not have conquered nations and built up empires. Then had not superstition become the first virtue of its day, man would never have been sufficiently obedient for it to be possible to control, rule and govern him by elementary religions, whose strength lay in their trading on his superstitious credulity, and early forms of government until his mind had evolved a sufficient power of imagination to conceive the existence of God, and the elementary knowledge of the revelations of the truth of nature enabled him to control them by ignorance. This was what enabled mankind to move a step further on the road of evolution to religion and virtue by learning to believe what he could neither see nor understand, after which bigotry became the highest virtue without which it would have been impossible to evolve fanaticism; and it is only through fanaticism that the virtuous minorities throughout the course of history have been able to conquer the degenerate majorities, and this has in the past, and for a short time longer must still be the process by which the survival and triumph of virtue over scientific vice has been made possible. Next selfishness becomes the highest virtue and is the virtue of the present age, the age of the triumph of science and commerce, and its extension throughout the world, for but for the greed of wealth and the love of fame and display, the development of civilisation would have long since been lost in drunken orgies, family hates and feurds, lazy affluence and cruel oppression.

And we find that the day is not yet past when prowess in war, deeds of grasping by the powers of might rather than by the right of justice, the possession of wealth by arts of fraud and cunning rather than by skill and wisdom are considered as 
the highest ambitions of man, but we are gradually nearing the age when the good of humanity will take precedence over the powers of might and the ability to use will alone confer the right to possess, and the power to control will alone confer the right to direct. And peace and mercy, justice and charity will be more honoured than war and rapine, greed and might, for in the future we must learn to triumph over war by peace, abuse by use, ignorance by skill, indolence by industry, selfishness by unity and charity, murder and hate by mercy and justice, poverty and discontent by order and management, and free liberties of just competition is to triumph over the slavery of unjust preference.

So evolution teaches us that those individuals alone attain true virtue who turn sin to a good account by converting failure into success, temptation into self-control, and by avoiding crime. For it is only the punishments that society and religion heap on the head of dishonesty that evolve honesty. It is only the reaction of disgust at the crimes of murder, theft, etc., of the lawless that produces security of property and life. It is only glaring sins of immorality that have evolved humility. It is only poverty that has evolved skill, energy and thrift. And last and most important of all, because it sums up all the others put together, it is only folly that has produced wisdom. And thus it has been and must be till man has evolved a soul sufficiently wise to discern that it is wiser to settle differences between nations by arbitration rather than by war, the aggressive nation having to pay a heavy penalty which will assist the aggrieved nation to increase its productiveness, rather than to impoverish both nations by destruction of property, and still worse, destruction of millions of lives and livelihoods, thereby destroying their wealth and reducing their population; to buy and sell territory in a just and honest manner, rather than to acquire it by war and plunder; to act generously and honestly in business rather than with greed and cunning, realising that what adds to the wealth of one of the community adds to the wealth of all as it circulates throughout the community, and that it is by unity in production and competition in labour and enterprise, not by jealousy and industrial strife, that a nation grows wealthy.

In the past valour and wars have made nations and commerce, 
but now Invention has made war too costly a pastime even for nations to indulge in. Again, in the past social arrogance has, by the aid of ignorance, made a class distinction between rich and poor possible, and so has been able to govern by keeping the masses in ignorance and thus to control crime. But in the future what is erroneously called education, but should be termed culture or instruction, must give place to greater inculcation of energy and increased freedom of thought and action and the destruction of sects and privileges that tend to make crime so powerful and folly so arrogant that it will become impossible to enforce the laws, or curtail the abuse of liberty that makes the individual unruly and so leads up to civil wars of unprecedented magnitude which will necessitate a form of government by military police till the mass of the people learn the value of social distinctions.

They must learn that money is not wealth, but is time well spent; that riches do not make happiness, but that a life spent to add to the comfort of others does; that it is better to do good than to be good; that you must show respect to authority in all its forms, and reverence to those above you if you would have them respect your rights and liberties; that the restriction of liberty alone permits freedom; that we must first consider the freedom and just claims of others if we would have them contribute to our happiness and consider our claims to equal freedom, because we do not and never will extend assistance to others if they do not deserve our gratitude first; that success is the reward of time and skill well used; that wealth is the reward of success, not success the result of wealth ; that success is the outcome of habits of industry, perseverance and economy, and that wisdom is the child of judgment and self-control, not of knowledge or science. The two latter are the parents of invention and skill, their only two children who die in their infancy if not fed on the milk of continuous energy and perseverance. Further, that it is better to be ignorant and useful than clever and useless; that knowledge we cannot utilize only tends to create discontent and increase vice; that riches are the just reward of management and success, and that poverty is the correct cure for indolence, and that humiliation is the best preventative against failure.

For we must eradicate pride and conceit ere we can gain wisdom, and crime will not be removed, only deterred 
by punishment, but must be prevented by stopping the criminal breeding; not by making him confess his sins, but by incarcerating him where he cannot commit them in such a manner as makes them a nuisance to his neighbour; for imperfect repentance only creates incapability to discern between right and wrong, and that loss of constitution is the plant that grows from the seeds of immorality, and that it is wiser to instruct the young in what is crime and teach them how, when and where to avoid it, than to clothe it with mockmodesty.

Now I have transgressed from my subject in this manner because I wished to point out to my reader that it is only logical to assume that just as in the past the body and mind have been evolved by the survival of those who were physically the fittest, and by the extinction of those who were physically unfit, so it is reasonable to conclude that in the future no markedly different mode of procedure will be adopted by God in the psychological development of the soul. Hence in the past, as the sinner has often been the fittest to produce bodily superiority, mental virtue has been at a discount, and it has been a higher virtue to punch another person's head than to talk Latin or Greek.

But we are now nearing the commencement of the Epoch of Charity, which is to evolve our souls. So in the future Wisdom is to be superior to and is to conquer might, by making the social distinctions more marked and giving greater honour and respect to the wise, the successful and wealthy, the just, the honest and the merciful, who are those who are the best and fittest members of the community, and are therefore the ones we should most try to perpetuate, that is to say all those who are useful, careful, industrious and economical, and who try to do all the good and kind acts they can to others. If they have these virtues we must wink at their sins, failures and shortcomings, so long as they are not vulgar, rude, extravagant, mean, dishonest or lazy. These three last are greater crimes than murder, or are to be so in the future. Let women kindly remember that in the future the greatest crimes they can be guilty of are infidelity, jealousy, hate and slander. I may. say these are not crimes, but sins in men. I consider vulgarity and rudeness cover immorality, which is often allowed to go unpunished in man that it may act as an antidote 
to pride and arrogance, but in woman immorality is the greatest crime of all crimes. Women must remember that their fallen sister who lives with a man whom she is unable to marry is less of a sinner, provided she be a loving and devoted helpmate and brings up their children as she should, and will be rewarded by God for the correct performance of the duties of the marriage state; whereas the woman who remains faithful, but who ceases to love her husband or loves another who does not support her, is little better than an adultress or harlot in the eyes of God if she neglects her marriage obligations or leaves his home, and, no matter how chaste she may remain, will incur God's heaviest punishment both on herself and upon her children; whereas the former woman, although the greater sinner, may be punished in this life by poverty, but not with unhappiness nor discontent, and will be rewarded for all eternity in her children, perhaps with higher rewards than are granted to the saint. And remember that infidelity on the part of a woman is a worse form of immorality than polygamy on the part of a man.

So the rules of the survival of the fittest must apply to the soul as well as to the body, and this can only lead us to the conclusion that God will in the future give greater vitality to the souls of those who foster virtue rather than crime, by rewarding the good deeds of men by higher powers of production of body, brain and soul in the same manner that he has in the past rewarded those possessed of physical vitality and bodily energy with higher powers of production and reincarnation than those excelling in mental ability and genius. This brings me to the conclusion that true immortality is not the immortal existence of any individual life and body, but of families and nations. The teaching of bodily immortality is an Egyptian teaching, which went so far as to teach that we should live again with the same bodies, but we have one mummy in the British Museum seven thousand years old, and no soul has come for it yet, nor is the owner likely to.

Hence it is far more probable that immortality lies in the fact that our souls live in our children, and that our souls at death pass into the souls of our children so far as to influence their lives for good or bad, according to the lives we lead. Thus those whose virtues exceed their vices will continue to improve the lives of the good amongst their descendants for all 
eternity, and those whose vices exceed their virtues will continue to live on in the soul of the bad members of their families, so increasing their vices till God destroys their powers of reincarnation, when the wiser and better evolved members of mankind will exterminate those whom God does not previously destroy by bodily degeneration, the outcome of vicious habits carried to the excess of folly. Death is a necessity to remove the bad until the unfit in soul become extinct and the wise only remain, whose wisdom will at last have become so great that they will be able to prolong their lives even into immortality by scientific prevention of disease, when the world being at last fully populated with an all-wise population, able to live in perfect Charity, Peace and Comfort, with perfect moderation and temperance, shall never more abuse their health and strength, and so, attaining perpetual youth, live for all eternity, the immortal successes evolved out of mortal failures, as fit inhabitants for an eternal kingdom.

Before closing this chapter, to confute such ideas as have prevailed in the past, I must say that the whole of evolution is opposed to the supposition that a departed soul can pass into any other habitation than that of the family from which it comes, any more than an oak tree could be clothed with sycamore leaves or an ash or pine tree burst forth for a single season decorated with oak leaves, and then return to pine spurs the following season.

It is probable that in the majority of mankind the soul of wisdom is not yet sufficiently evolved to receive such ethics of religion or revelation as this hypothesis has revealed to me, and it may be centuries yet before they can be transferred from the abstract ideals to the more complex concrete realms of practical utility in daily life. But there may be a few amongst the most highly developed minds of to-day who can turn them to practical use by aiming through their means at higher ideals than they have hitherto been able to grasp, and I feel confident that by the slow-going clock of evolution the time is not far distant when they must become the foundation stones of future religions, society and governments, as the percentage of true wisdom grows in the minds of the people. This must be my excuse for what at first sight may appear a blasphemous insult to past beliefs. At the time of Christ the ethics of Christianity were as much in advance of human de- 
velopment as are the ideals herein expressed, but one thousand years after the mind of man no longer discarded them. Five hundred years hence the same may apply to what I have written in this chapter. For instance, Christ told us that His Heavenly Father was the God of Light. This appears to be the case, as the seven attributes of God the Father appear in a measure to coincide with the spectrum of light. But so little was scientific knowledge advanced two thousand years ago that the people would have laughed if he had stated that God the Holy Ghost was the God of Electricity, which science is now proving to be a correct statement. When I wrote this chapter I had not read a solitary work on radium or radio activity. I knew that radium had been discovered, but I had been taught when a boy to believe that life existed in Matter, not in space and vacuum, so at the time of my writing this theory of immortality it appeared to me that I was expounding views that were unsubstantiated by facts and experience; but, as I have stated elsewhere, if I am to be strictly logical, it is incumbent upon me to write whatever my hypothesis directs, not what appears to me to be correct.

I am not free to put down six because it looks a prettier figure than five, if five is the figure that comes in the sum I am endeavouring to work out. I wrote this chapter in October, I915, and arrived at the conclusion that life must be an unbroken and infinite existence apart from body, yet at the same time impregnating, surrounding and controlling both body and mind. That mind and soul were separate spiritual and external existences as much apart from the material existence of both body and life as space and ether are from the visible material creation which they surround, impregnate and control, just as the invisible infinity of God differs from the finite visible portion of the Universe $\mathrm{He}$ has created, surrounds, impregnates and controls. So it likewise appeared to me that Mind and Soul must be the psychological likeness of God to which mankind was created and which was to raise man above the animal creation by enabling him, as he evolved wisdom, in the same manner, but in a lesser degree, to create, rule and direct the world, just as God created, rules and controls the Universe. Also that God being the infinite form of Invisible Spirit, Existence and Soul, ever existent and immeasurable and eternal, so the human soul must be likewise invisible, eternal but mea- 
surable, that is, limited in extent, or it would not exceed in power two-thirds of control of infinite power, and if it were only one-third of infinite power it would not be above the powers of the animal mind, and therefore could not become eternal. These conclusions were the results of logical deduction, and at the time I wrote the chapter I was still under the impression that life owed its origin to Light and was part of Matter, and that space and vacuum were devoid of life. It was not until January, I916, that I read some works by Professors Soddy and Benjamin Moore, and by Sir Oliver Lodge, which demonstrated that the discovery of radium and investigations of modern science have proved beyond dispute that all the forces that direct and control life, mind and soul and the material universe lie in the spaces and vacuums of ether that surround, impregnate and control creation, and that electrical and radio activity is alterable and unvariable in its effects, and is indestructible. Whereas all Matter is unalterable in its sum total, variable in its construction, yet indestructible in its existence, for if the last were not the case it would cease to be part of infinity, and by so being would destroy the universality of infinity, which all goes to prove that God the Holy Ghost is the God of radio-activity.

This, therefore, is only another argument in support of the correctness of the hypothesis that I am trying to elucidate, as it instances the marvellous manner in which it enables by its sole use, with very little scientific knowledge. to help me, but simply by pure logical or mathematical deduction to arrive at facts by a short-cut in the course of a few months through the Trinity of God, that it has taken the wisest men of science years to prove.

Does not this go to show what I have pointed out from time to time in this treatise, that science must not be too proud to bow its head to the truths of revelation or scoff at the existence of divine inspiration? At the same time religion must not be so haughty and arrogant as to refuse to alter, when made necessary by undeniable proofs, its teachings and to reconstruct them to suit the advancements in the evolution of revelation, just the same as all other forms of evolution must conform to the law of the survival of the fittest and the destruction of the unfit. So religions must alter to suit the times, or the people will cease to respect them, and laws that the people will not 
respect cannot be enforced by the strongest governments, be they social or religious. So religions must be from time to time reconstructed as God permits new and fresh beams of the sunlight of divine inspiration and revelation to penetrate the dense mists of fable and superstition that obscure the hazy atmosphere of the yet but partially developed understanding of man's as yet unevolved soul, but at the same time we must be careful not to destroy any religious belief until it is utterly useless. And it is the duty of science to lift the mists as its forward evolution enables mankind to comprehend and ultimately to understand the fresh streams of divine inspiration that may, at long intervals, flow into the river of human wisdom as it wends its slow and tortuous course along the valleys of time towards the ocean of eternity. For both science and revelation are but so many separate streams of the wisdom of the infinite creator that are to swell and increase the currents of human wisdom, and are the waters that have in the past, and will in the future, do most to fertilize and enrich the growing soul of mankind and ultimately fit it to bloom in Paradise when earth shall become Heaven.

Hence let us endeavour not only to abolish war on earth, but also try to abolish religious animosity, so that we may one and all help to swell this river of divine wisdom, by condemning the criminal to extinction, the lazy to comparative starvation. But, in so doing, let us go carefully and remember that correction, like charity, must begin at home, and that before we can do these things we must first learn to forgive the sinner, assist the unfortunate, say a kind word in excuse of our weaker brothers and sisters, and give a helping hand to the weak, even though it may be doubtful if they deserve it. Anyway, you are on the safe side, if you are careful, to give them the benefit of the doubt, and, above all, wage an incessant war upon superstitious and bigoted intolerance, either of race, caste, or creed, and on selfishness, hate, and greed. We can do this if Religion and Science will drop the hate and bigoted animosity of the past and become friends and co-workers in the future. 
IMMORTALITY.

Out of the spirit Infinite

Life sprang like a fairy sprite

To give to matter spirit free

That man might at last eternal be.

Not to live but one short span

Starting where each life first began,

But to live afresh in many forms

As each new mortal shape adorns

The soul which lives for evermore

To live afresh as it had lived before,

If it should go the way it had to go

And learn its Maker's will to know.

Love then to life and body came

That man for others joys might aim,

Thus making existence upward tend,

Be like unto his Maker in the end.

Love's precious gift that woman in heaven sought,

Which by redemption to earth she brought,

That she might purify man's thought,

As self-sacrifice to him she taught.

Hence if you would forever live,

Ere you receive, first you must give

Devotion and affection to your friend,

Then happiness God to you will send,

To those who make this golden rule

Of every act the perfect tool ;

And cease not in the constant strife

To shape all good deeds of their life,

So that birth and death may ever add

Good deeds abounding over bad,

Of virtue as each life is run

Shall make the total of the sum.

So when at perfection they arrive,

Their souls in heaven will ever thrive,

Lustrous, with all the good acts done

Since their past existence first begun.

Better thus live, and learn to sin,

Each day wisely, and thus to win

Reward, because our race we nobly ran,

Than end a single life where it began. 
For if you do not upward rise

There is no method you can devise,

To stop your virtue's slow decay,

And give your chance of heaven away.

Fiternal life alone to those belongs

Who striving for right, forgive all wrongs ;

For many who do each act aright

Find when they've fought this earthly fight

Their victory won at others grief and pain

In God's eyes far outweighs their paltry gain.

Better, than trying to be too good,

To die, and know to others you've done good.

Remember the words that Christ has said

"I AM GOD OF THE LIVING, NOT THE DEAD." 


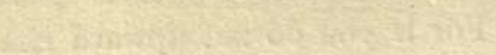

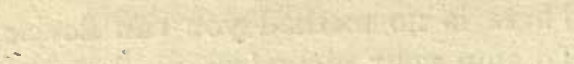

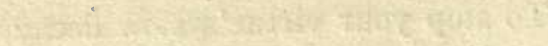

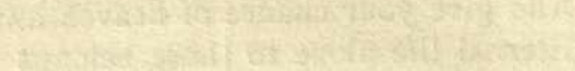

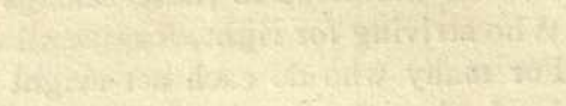

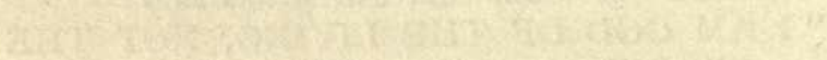




\section{N D E X}

A.

Age of Youth

Attributes of the Trinity of God

A resume of the Hypothesis . Abstract of Right and Wrong

A slight capitulation of the aims of Evolution

Angels (biblical) mean animals Adam and Eve

\section{C.}

Continuity of Design and Nature

the mind of our predecessors in our own mind

Character

Comprehension, the mind of

Crime and Virtue

Crimes that never escape punishment

Cheap production will decide the superiority of a nation

Course of Life

Creation, manner of

- necessity for .

why imperfect .

Cain and Abel

D.

Directivity and Management are hereditary

Danger of perverting Abstract Good into Concrete Evil .

Descent of the Holy Ghost .

Descent, the laws of

Dawn of Imagination

Days of Evolution

Divorce of Trinity $\quad 30,37,39$

Difference between God's and man's estimate of Right and Wrong

Dawn of Mind
PAGE

200

Divorce of Trinity $\quad 30$ to 39

Dawn of Mind and Religion . 85

E.

Embryos recapitulate previous existence ? 101

Education and Culture $\quad 165$

Evolution and Soul . $\quad 83$

Evolution, nine stages of $35,53,60$

Evolution, mathematical table of $\quad \cdot \quad 35,53,60$

Epoch of Hope a 53-60

Error of too hasty a condemnation of sins . $\quad 157$

Explanation of the attributes of the Trinity of God $\quad 38$

Eighth day of Evolution 48, 78, 97

Eleventh day of Evolution 49-104

Equation of Creation .64-77

Ethics of Religion and Revelation

$133-143$

F.

Finite Creation, Necessity for

and manner of :
Finity and Infinity :

First day of Creation $\quad$.45-56

Fourth day of Creation $\quad-46-57$

Fifth day of Creation $47,57,82$

Fourteenth day of Creation . 49-59

Fifteenth day of Creation 49, 55, 59

Family likeness . $\quad$. 96

Freedom, Government, and Religion . . 136

G.

God, Gender in $\quad .39,96$ His likeness in man 59 Origin of belief in one GoD

Government and Religion : 86

Genius, the result of pre-natel environment $\quad 106-110$

General plan of Evolution . 98 
Genesis compared with Evolu-

tion

PAGE $.34,45$

Glacial period, its influence on the mind of man.

H.

Hypothesis, the

Heredity and $R$ 24-34

. 95

Heredity and Rebirth

115
$53-60$

en the epoch of

$\begin{array}{ll}\text { Hell, first conception of } & 85 \\ \text { Holy Ghost, the coming of : } & 26\end{array}$

Heredity, Variation, and

Descent .

- the transmission of

- as a reason for preference

in employment

I.

Imaginative mind picture of the dawn of mind

184

Immortality, of the individual improbable, of the outside of family impossible

Infinite Beings, impossibility of two

105

42

125

50
L.

Legendary lore

Likeness to GoD in Man : 59

Likeness of Trinity in man . $\quad 74$

Laws of descent and heredity 95

Logic. . $\quad 145$

Life, Evolution of : $\quad 98$

M.

Man and monkey

Mathematical table of the Evolution

102

Male and female qualities of GoD

Mind and Soul, Evolution, Constitution, and immortality

Memory, withdrawal of from Creation $84,195,111$

Manner of Creation 40
Origin of this Hypothesis

o.

Necessity for a Finite Creation 42-44

National prosperity in the past, destroyed by literary knowledge

Ninth day of Creation $49,59,78$

Mental efficiency . $\quad 109$

Memory, loss and retention . 111

Male and female transmissions 120

Mind, imaginative ${ }^{\circ} \quad$ ir 182

Manner of Evolution of Society - $\quad 200$

Mather of Creation animal and man . . 50

Merit and reward . $\quad 64$

Order of physical and mental Evolution .

P.

Prehistoric Englishmen $\quad 21$

Progress, future of the world 91

Purgatory and Damnation .84,143

Progress and retrogression, Laws of in Evolution 62, 76

Powers and Process of Memory

\section{R.}

Religious tolerance - ix, $\mathbf{x}$.

Right to use, not to abuse . xii.

Reliability of written rather than traditional evidence, pencil drawings more reliable than fables

$\begin{array}{lr}\text { Rosicrucianism } & 24 \\ \text { Rebirth of heredity } & \quad\end{array}$

35-60 Rebirth of heredity Reproduction of Mind and

Body

RELIGION, Growth of from fear

- must conform to Evolution.

and Government

. 86

Reward and Merit . . 64

Redemption, necessity of . 40 


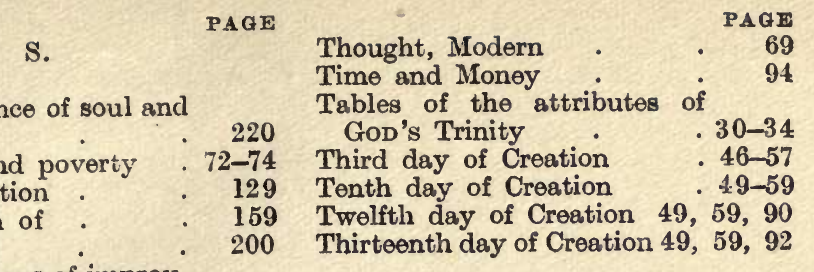

Separate existence of soul and

$$
\text { body }
$$

Sin, sickness and poverty

Sports in variation

Soul, Evolution of

Soul and Mind

Science as a means of improv-

$$
\text { ing racial utility }
$$

Second day of Creation

Sixth day of Creation

Seventh day of Creation

$48,58,69,79,84$

Sixteenth day of Creation 49-59

Stage of Faith, Hope and

Charity - 60

Sin $\quad 63,72,74$

Similarity of physical and psychical Evolution

Sin, poverty, and ill-health as blessings

T.

104 Virtues and Faults, Visitation

74 on our children 121

Various ideas of rebirth $\quad 125$

Variation and Monstrosity . 106

Trinity, Table of Table of and explanation

Divorce of

$39,37,99$

Likeness of in man
- xiii.

Understanding, Mind of

\section{9}

94 
Ravert

$4 x^{2}=2$

the

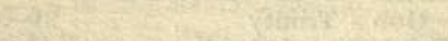

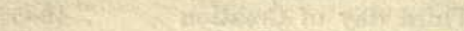

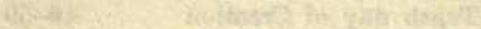

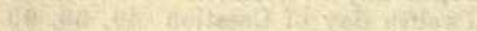

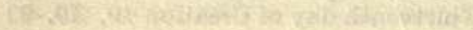

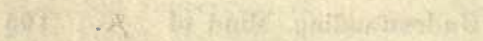

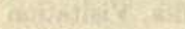

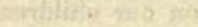

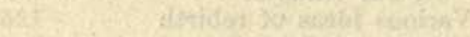

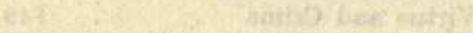

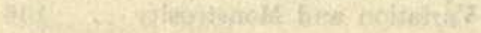

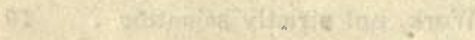

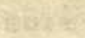

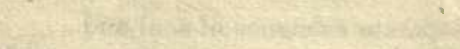
Q4.

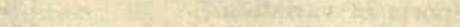
852 (07)

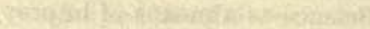

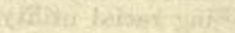

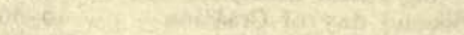

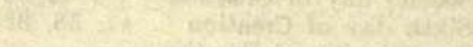

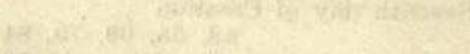

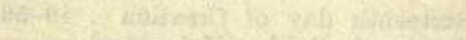
105:

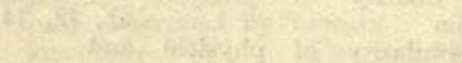

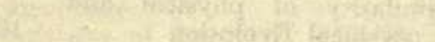

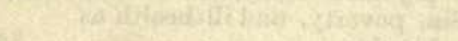

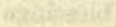




\section{BOOK II}

\section{THE THRESHOLD OF EVOLUTION}




\section{CONTENTS}

CHAPTER
I. COURSE OF EVOLUTION
II. THE EPOCH OF FAITH




\section{CHAPTER I}

\section{COURSE OF EVOLUTION}

IN this book we will endeavour to trace the course of the evolution of Matter and the gradual evolution of creation and compare the same with our hypothesis, taking first, the Creation of Nature, then of Life, of Plants and of Man; his conquest over the animal kingdom; then over the Devil he has himself created; then over the world (at present the evolution of the world has not advanced beyond the second stage of its existence, wherein man is only beginning to understand how to control the universe of Matter), and he will, as the course of evolution advances, learn to govern all nature and ultimately to use all things without abuse; and lastly to conquer himself, and by so doing, to gain the reward of Heaven and Immortality. In this treatise, however, I do not intend to go beyond the present age of evolution.

In order to become the highest evolution of the animal or angelic period, the age of beasts, he had to become the most perfect devil, for can you imagine a bigger devil than a perfect human beast. This brings us to the end of the first Epoch, that of Faith, and we will therein prove that angels are only the subjects of the animal kingdom which could not control their acts, so could not sin, because they had not yet developed perfect wills of their own, but were ruled by the will of God, thus proving the creation of the world of angels and their fall to be the Mammoth Creation, which, despite its magnificent development, by its final extinction was conquered by the mental superiority of Man, who gained this by the creation of the Devil, which he became when he learnt to sin by becoming a murderous cannibal and crafty beast. In the past, as will be clearly demonstrated as we go on, man has had practically no powers of understanding till within the last hundred years, but he has now reached the third and last stage of his development, and will in future be able to understand as well as comprehend the truths of Revelation, and so be able 
to strip off the cloaks of superstition and bigotry which have clothed Revelation in the past. And Faith the first, and Hope the second Epoch of Creation are then complete. In the Epoch of Hope man is no longer to blindly obey what God decides as in the stages of Matter, Plant and Animal Life, which was the order of the day in the Epoch of Faith. He is now fit to receive a mind or partial soul, and he has now to get the seal patent of his Immortality, which is to place him forever above the angels, i.e., the animals, for now, by sin being able to merit reward, he is able to attain to virtue and immortality, which was denied to the animals. For Virtue is sin carried by temptations overcome to the feet of Wisdom, and Vice is sin carried by frailty to the feet of Folly, and man's duty in the future will be to sin wisely, that is without offence to nature or his fellow-men; for man free from all sin, when immortal and perfect, would be God's equal, and the existence of more than one perfect infinite being is a logical absurdity. Hitherto God has devoted fifteen to twenty millions of years to the creation of Man's body, and hundreds of millions to creating the worlds of angels (or animals), for the term angels as used in the Biblical account evidently implies that Mammoth creation which was the animal existence ruled by the instinct of the animal and the power of God's will, and so, being sinless, were man's superiors in good acts, but not in virtue.

We have now arrived at the Epoch of Hope, wherein Love, the second personality of God the Mother, is to conquer the devil, man, who has been evolved out of the fallen angels, who, though at first Man's superiors in size, shape and goodness, stopped short of becoming devils by not learning to sin by the time the earth had cooled below one hundred and forty degrees, after which no further rapid or marked bodily development remained possible, so they were thereby unable to evolve either mind or soul, or acquire virtue, their progress ceasing at instinct and thought. Now, the human mind commenced with Imagination and Conception; Reason commences with Comprehension, and Belief and Wisdom with Understanding. After this the struggle of Evolution is to take the form of a contest between the human devil that mankind has now created, and civilisation, law, order, justice and mercy, in which fight Religion, the product of man's fear and woman's love, is to take up the cudgels through the second seven days of creation that 
make up the Epoch of Hope and thus produce the human mind. In the age of Charity, commencing somewhere about the year I 800 A.D., mankind is to begin to evolve his soul of wisdom, and Science and Invention are to convert the physical fight into a psychological one, in which wisdom is to finally destroy the serpent of murder, cannibalism, robbery, selfishness and greed, which qualities constitute the devil that man has created, the serpent on whose head woman has put her foot, by the evolution of love and religion during the Epoch of Hope. And now the Holy Ghost is to descend, in the Epoch of Charity, which is now just commencing, and take up his abode in the minds of men, thereby increasing their wisdom in science and revelation till he can learn to control his acts and passions, and thus be won back to God and virtue, and so finally destroy the serpent of vice which crawls amongst the filth of the earth.

The creation of the mind of a devil in the brain of mankind completes the first stage of Convolution, and the dawn of evolution and the seven days of Genesis which constitute the Epoch of Faith or first seven days of the evolution of creation which are now complete. The temperature has now fallen below one hundred and forty degrees, and further change in the shape, class and species of men and animals is thereby brought to a close. Henceforth, to all intents and purposes, the physical evolution of the world is complete and will only continue on lines already evolved. Future changes will be mental rather than physical evolutions, but it will take the first half of the Epoch of Hope to perfect the bodily energy of mankind so as to fit him to evolve and utilise a mind which he is at the same time evolving, for the three Epochs overlap each other in the same way as the days do in the course of evolution, wherein three concurrent evolutions are ever progressing each in advance of the other throughout the entire course of creation.

But mankind by evolving sin has now made it possible also to evolve a Mind and Soul, and, most important of all, to evolve Virtues, for without the power to sin he could never have made any conquests of wisdom over folly, or success over failure, so would have been forever devoid of any just claims to have laid at the feet of God's throne of judgment as reasons why he should be granted health as a reward of temperance, riches in return for economy, respect in return for self-control 
and management, love in return for charity, honour as the reward of justice, a soul rich in wisdom and discretion in place of animal instinct, or immortality in place of death, and as has already been demonstrated in Book I., must have remained for ever an animal and content without the means of advancement; for further advancement has been denied to the animals who have failed to evolve the art of sinning by attaining to the powers of self-will, self-control and charity.

The fruits of the earth have become less prolific, and now instead of growing in rank profusion to create rapid development which in its superabundance produced indolence and consequently the extinction of the unfit of the animal creation, to make place for further hardships of cold, starvation, work and war which are required to harden and strengthen man's body so as to render it fit to stand the wear and tear of the mind upon the body and so prepare man for the reception of Religion, Knowledge, Comprehension and Understanding, after which he will receive a soul instead of a mind, which last evolution commenced about I80o A.D. But evolution is a force that does not advance in a direct course, but following the law of the return of the attributes of Trinity to Creation, by which forces God Almighty governs it, it advances each stage first three steps forward and then destroys what it has done, retraces its path two steps backwards and advances the next force of nature or attribute of the personality of God's Trinity a step forward and again destroys what it has evolved, and then advances the other force or attribute of nature forward and then returns to the third column of the soul and completes the third stage. Then again advancing the next power of Spirit further along the course as the separate personalities of God's Trinity in turn participate in creation, so that at every period there are three evolutions moving forward, each contending for supremacy and destroying each other to produce the next evolution in like order. Thus Revelation becomes obscured by superstition to create imagination, until it is practically lost in the maze of witchcraft and necromancy which are to give birth to Governments and Religions, then Divine Inspiration comes to the assistance of Revelation and pulls it out of the mire of sorcery, and it in its turn is again lost in the mists of idolatry. Government then supplants Religion to enable it to create Study and Science. When Government 
and Civilisation have brought crime to its second stage of perfection in the days of the Roman Empire, Religion advances for its third and last flight under the command of Christ, the third and most perfect Son of God the Mother made man.

Science then comes to the aid of Government to create Commerce and lead Conquest along its second step of advancement through the darkest and brightest ages of Religion and so give birth to Feudalism, which will by its laws of heredity advance the laws of descent past their first step of caste until Understanding shall dawn in the sky of evolution to supplant Superstition and Bigotry by a full and perfect understanding of God's Trinity, and so prepare man at last to receive true revelation and the immortal soul that is to grant him an everlasting existence and happiness. Then he shall be king of a self-conquered world, governed by a self-conquered king, ruled over by a self-created religion. For when understanding is complete, man's soul, now fully developed, will have at last become a Religion unto himself, and he will have learned to hold wealth without selfishness or meanness, but with generosity and charity, and to rule in peace with Mercy and Justice; and to love without Jealousy, Hate or Revenge. And so man will have learned to sin without crime and therefore have completed the equation of his existence, when death, the wage of sin, carried by folly and abuse to the extent of crime, shall be no more. 


\section{CHAPTER II}

\section{THE EPOCH OF FAITH : THE COURSE OF EVOLUTION}

BEFORE we follow the course of evolution let us first consider what are the trinities we have to deal with, and how we are to compare our Hypothesis and its tables with the course of evolution. The Trinity of God is :-

First-God the Father the Spirit is male; second-God the Mother is female; third-God the Soul is male, and the whole is an invisible Trinity, the spirit of invisible Power, Existence and Soul. See Table I., line one.

The next consideration is the trinity of creation which is divided as follows. A Trinity of Epochs :-

First-Faith; second-Hope; third-Charity. Each epoch or week is divided again into seven days. Faith is the epoch of belief, and the seven days into which it is divided are :-(I) Gaseous Existence, (2) Fluid Existence, (3) Matter, (4) Plant Life, (5) Animal Existence, (6) Creation of motive life and sex, fishes, etc.; animals and conception of mind, (7) Man, and conception of Love. This is the Trinity of Faith, because during this period creation is governed by the powers of the spirit of God the Father which is the spirit of motion or action, destruction, Reconstruction and Creation, and which rules the world until in the Epoch of Hope, when love starts to rule the world by the Spirit of God the Mother (I think it well to use this term as indicating more the feminine gender of God, rather than the term God the Son). Now it must be remembered that the qualities of God the Father are born, from the earliest creation, to transmit revelation to man, and that all qualities of the male personalities of God being male are transmitted through man, not woman; and God the Mother whose qualities are female are transmitted through woman from mother to daughter, son or grand-daughter, not from Father to son or grandson; and the properties of God the Soul (this word is used in preference to God the Holy Ghost) are also 
male, and like the spirit of power are also transmitted from father to son or daughter, not from father to grand-daughter.

Now the revelations of God must have existed throughout creation for they are present in all creation although dormant till they are developed by evolution, until which time they are little able to influence the acts of man. As the power of the will of God is supplanted by man's will, as he evolves a mind of thought, knowledge and understanding, he begins to realise their truths. Thus when all revelation is understood by man, he will be able to rule the world without abuse and become immortal, and creation will be complete. Although I have known for years what the attributes of God's Trinity were, until God in the way stated at the beginning of this Treatise made manifest to me their connection with creation and evolution by the conception of the female gender of the second person of his Trinity, I could not understand, or logically weigh the true way in which God had brought about Convolution, Evolution and Involution. But since I drew up the Tables it has become mathematically understandable to any mind of strong comprehension or possessed of logical power. Hence in the first Epoch of Faith Creation is dominated by Faith, the trinity of Faith being Force, Action and Obedience, that is, to act, to think and to obey. Hence in the Epoch of Faith Creation feels the force of God, thinks the thought of God, and Obeys the will of God.

Now the Trinity of Existence is made up of the Trinity of God, Man and Animals, or Angels, and as we slowly evolve a mind worthy of receiving the attributes of God's Trinity as they return and take their place in Evolution so our minds and souls become evolved.

Now I do not hope to do more in this Treatise than to prepare the reader for the conception of the Hypothesis it contains. I pointed out earlier in Book I. that one of the first results of my calculations was the hypothesis that the second person of God's Trinity is female, but so strong is the reluctance of the human mind to realise that long-accepted beliefs may be wrong, that it still seems strange and weird to my conception, and I feel I am trying to give the reader more than I possess, but one of the results of my first attempts to utilise the wonderful extended powers of understanding that this conception had given me, was that I was able to grasp with an excessive con. 
viction of its truth that God created the world by withdrawing the powers of God the Mother and God the Holy Ghost frow the portion of His Infinity that were to become finite existence. To keep this clearly before the reader, I will ask him to excuse me if I here repeat the logical arguments I adduced when the conviction first came upon me, if only to refresh his memory and to emphasise their importance.

INFINITY OF SPIRIT EXISTENCE IS GOD, and is contained in the electrical forces of Ether. The whole of Creation, as I pointed out in my previous work, tends to confirm the necessary existence of Infinity, and as I have already pointed out the Almighty must have come to the conclusion that if it were possible for divine perfection to become imperfect, the only forces that could possibly deteriorate its perfection were the want of something to do, and something to love. It therefore required a finite creation to perfect an infinite one, for the following reasons.

His infinite power rebelled against infinite inactivity, and infinite love demanded some object outside itself to be beloved, for self-love is the most degraded of all love, just as love of others is the most perfect of all loves. But how is this to be accomplished? If the Almighty had divided himself into two equal parts there would then have been two infinite beingsa logical absurdity-or if into two unequal parts there would have been two finite creations, and no infinity, which would have meant the destruction of infinity. This would have been equally absurd and ridiculous, for without infinity it would be impossible to control finity, and without control there could be no real wisdom, and divine wisdom could make no greater mistake than to destroy its divinity. And infinite wisdom must be logical, for logic is the science of truth, and divine wisdom cannot err. Therefore, as previously demonstrated, the only way was to create a finite part of himself which must logically be part of Himself, in Himself, and controlled by Himself. It therefore follows that if $\mathrm{He}$ decided to create a finite part of Himself that was not to be an equivalent of Himself it must be an equation of Himself but differently arranged and devoid of some of His attributes, or a part of some of His attributes. Hence it follows that there were only two finite existences possible, because if creation had contained three finite existences there would have been four separate existences, 
and as the numeral figure of the infinity of existence is three, it is not possible to sub-divide three into four parts without creating a fractional part, and it is a logical necessity of existence that it should be an entirety or it could not be existence, and the Bible is emphatic in stating its likeness to God. Thus there were only two existences of finity that could become creations, or by any means become complete and eternal without exceeding trinity, besides His own existence. And God being perfect could create nothing that is not to become perfect, or else for ever remain an attribute or part of creation to be for ever absorbed as required by the created parts endowed with life.

Now as a result of the same logical deduction it follows that whatever is endowed with life must be one of three things, a perfect likeness of God, a partial likeness of God, or an imperfect likeness of God, and we find that Mankind, Animals or Angels and Plants comply with these three conditions. Hence as God is the perfect Trinity of Infinity, all portions of creation must be in some form or other produced by trinity or they could not be a portion of trinity, and so would not comply with what we have shown to be one of the necessities of finity, that is, that it should be part of the trinity of infinity, so we also find that Matter, although it is not an existence of trinity, must be created by the action of a trinity of forces or it would lose all claim to be a portion of a creation of infinity.

We have already demonstrated that creation to be a perfect form of existence must be a perfect form of trinity. This is alone found in mankind where we have all three forms of creation combined, viz., a material body, which is an imperfect likeness of God; a spiritual mind, which is a partial likeness to God; and perfectly evolved man who will have an immortal soul, and so becomes at last a true if an incomplete likeness of God, although, as I have pointed out, it cannot become a perfectly equal likeness or it would become a second form of infinity which is impossible. And animal existence which is a partial likeness of God having a material body and a material mind. Lastly, Plant Existence, which is an imperfect and fractional likeness of God, having only a material life lacking both mind and soul. Then we have Matter which is not an existence, but only a discarded portion of existences, which are created, so to speak, not by God but by the evolution of 
life, for where there is no life there can be no likeness but only a resemblance to the God of Life. This gives us a Trinity of Creations and a Trinity of Existences.

Now I have already demonstrated that God, being a perfect Trinity, all things made by Him must bear the trade mark of Trinity to be perfect, so all facts to be proved or demonstrated as being truths of Creation or Evolution, if not capable of being reduced to a trinity, must be considered as requiring further proof or demonstration. They yet require some addition or they cannot be more than a possibility if they have only one factor of trinity, or a probability if they have only two factors in their favour. Again, if only one force of action is apparent we must seek for the existence of two others before a complete result can be obtained; also no new evolution or distinct force of creation can arise till after a trinity of forces have produced their effect, and it further follows that the result produced from one trinity must form the first step in a new trinity which will have to be completed in its turn three times before any staple result can be obtained, and this is where the mathematical Table IV. will be found useful, not only in evolution but also in other Sciences.

To return to my subject, it is also illogical to suppose that an imperfect sweetheart would satisfy a perfect lover, so the only trinity possible is the one we have just pointed out, the trinity of God, Man and Angels (or Animals).

The question has now resolved itself into the question as to how this is to be brought about. As already shown, the only way this could be accomplished was by God withdrawing twenty of the attributes of His Trinity from the whole twentyone, and gradually returning these withdrawn as evolution progressed and so bring about its advancement to produce a perfect creation at the finish. I have now followed each logical sequence till we arrive far enough to continue the further course of evolution.

God therefore decided to create the Universe wherein each part should, after three stages of progression and retrogression, in turn come to its own perfection. Each in turn to start from a perfect minority which is destined to deteriorate as it increases until its deterioration produces in time a bad majority destined in its turn to give place to a more advanced minority which should be replaced in turn by a deteriorated majority and be 
succeeded by a still more advanced minority, and so on till the perfect majority should at last be formed which would obtain mankind his final reward of Immortality. As in each of the three cases of progression some new form of evolution is produced as some additional attribute gives birth to a new and more advanced evolution, so the world is made up of good and bad, or to be more correct, of perfect and imperfect evolutions.

We must therefore realise that sin is good-vice only is bad, or more accurately, all folly is bad, and wisdom alone is good. The reader must also realise that any force which tends to improvement is good; only that is bad which deteriorates. If he fails to understand this he cannot distinguish between Goodness and Virtue. To be good and only to do no wrong because you do not wish to do wrong is not being truly good : to make the best use of your time for the good of others and overcome evil is what constitutes real virtue. To be virtuous is to overcome vice by transforming sin into virtue, by creating success out of failure, and by controlling our acts so that our sins and defects injure no one. As infants we are all fools and sinners; Virtue and Vice are later acquirements.

Virtue is the result of sin or folly converted into wisdom and use, and sin may therefore in some cases be a good quality, but vice is always a bad one because it results from loss of desire to improve. Not so with sin, because it is often only by falling into sin that we are able to learn our faults, and by correcting them to form virtues. And it is only by, overcoming our sins that we are likely to gain the reward of self-improvement. For he deserves the most reward who brings his faults within the limits of moderation. I would remind the reader here to take this illustration to heart. Temperance is a virtue, but total abstinence may be as great a vice as intemperance, for if we never had ill-health we would never learn to value health and we would never aim at living with care, moderation and abstinence, and by so doing acquiring perfect strength. Also if we never sinned we would be God's equal as soon as we became perfect, and would thus create two Gods and justify idolatry. Therefore sin is a necessity of immortality, but man must learn to sin wisely, and to sin in moderation, hence the object of man's creation is to perfect himself in all ways until he can be a perfect sinner. Animals failed in this respect because they could not be perfect devils 
like men, who by attaining perfection as devils were able to become perfect saints. Hence we have to follow him through the first stages of evolution to see how he becomes first a perfect devil, then in the Epoch of Hope his strife to become a perfect sinner as the world evolves by the creation of the religion that Christ came to teach so that he could put into practice Faith, Hope and Charity. This takes us through to the end of the Epoch of Hope and also takes us up to the present time.

In the ages to come, in the Epoch of Charity, man is to become so wise that he can at last be a perfect saint, when many sins will be forgiven him because he will have learned from the Redeemer and woman how to love much, and then his equation will be two females and one male, and his trinity of creation will be complete and give way to Immortality in the percentage of two women to one man. I would not presume to suggest how this is to come about, I only mention it as a mathematical necessity of the Hypothesis. For at last man will have learned to conquer the Animals, then the world of Matter, and finally Woman, and God will have combined to teach him how to conquer himself. Lastly, the Holy Ghost will descend and so enlighten his mind with divine wisdom and correct understanding of good and evil that he will be too wise to sin foolishly, and if he became too wise to do wrong he would be as powerful as God, and this God never intended he should be.

And this evolution will complete the Trinity of Faith, Hope and Charity, which makes up the three weeks of creation. Thus in following the course of evolution in the subsequent chapters I am endeavouring to help the reader to trace the course of my hypothesis through its various stages of the return of the attributes of God's Trinity to creation; each stage or day of evolution corresponds to the action of the new attribute which is influencing its development, and shows how in the scheme of evolution the three concurrent forces are at work to produce opposite results which we term good and bad; but it must be remembered that these terms are only our way of expressing advancement and retrogression, and that both are equally necessary to the production of a perfect result, and it would be more correctly expressed by the terms destruction, construction and reconstruction, because good gives place to sin, and $\sin$ gives place to vice to secure the creation of virtue, 
until the whole, or at least a large majority, shall become perfect. Do not think I intend to be a champion of crime, I only want my reader to grasp that as both are equal necessities of evolution, while we do our utmost to retard vice, and encourage virtue; we must in future realise that the height of virtue is to be as lenient as possible to the sins of our neighbours, and in place of the bigoted idea that the sinner is to be despised and converted, to substitute the more enlightened one that sin is a necessity, but that we must eradicate crime by stopping the criminals recreating criminals and failures, and punishing them by taking away their freedom and making them work for the good of the weak and unfortunate.

It is a law of Nature that evil must attain to perfection before good can come of it, so that evolution becomes perfect in its own vice before it gives birth to the new virtue of the next evolution in order of sequence which is about to evolve. Each age must aim at a higher ideal than the one that preceded it, and it is only bigotry to demand that what have been the religious or social convictions of the past are to be and must remain the beliefs of the future. Both religion and society must be prepared to advance with evolution as well as science. The aim of creation is to fit mankind to become a perfect likeness of God in his soul, and the way one person can work out his salvation may be the opposite to that which saves his neighbour. The higher the ideals we can evolve, no matter how opposed they may be to our past beliefs, the more rapidly will we hasten the gradual return of the attributes of His Infinity which God has withdrawn to evolve creation.

In the first book of my Treatise I have endeavoured to explain the meaning of the Tables of the Trinity and what they contain, and bring the reader into touch with such abstract ideas as will enable him to divest himself of the meanings that customary uses and narrow-minded restrictions, and the laws, habits and customs of to-day have placed upon their significance. For if he is to comprehend this mighty subject and realise the important facts that this connection of the Trinity of God with the course of evolution displays to us, he must be able to realise that in a more perfect knowledge of evolution and history of the past stands the finger-post that is to direct mankind on his future march along the road to Immortality. 
In the past we have had no better means-and it is probable it may yet take thousands of years before we can evolve a better one than religion for controlling our lives and actions.

Every enlightened mind cannot help realising that well as religion has performed its duty in the past we are nearing the marriage festival of the nuptials of Science and Religion which will in time grant us a means of self-control even more conducive to real virtue than religion. In the past Religion has been the young and beautiful bride of Imagination, the fourth son of God the Father. Remember, Religion is the child of God the Father out of the Mother of God's Trinity and the humanity of woman (I do not mean the Mother of God, the Blessed Virgin, but the female portion of God Almighty the female gender of God's Trinity) which marriage has produced its miracles of the redemption of mankind, and in the same sense that Imagination is the first part of the finite Trinity of the human soul, and is therefore the fourth son of the first person of the Infinite Trinity of God the Father, so is Comprehension (the Mother of religion) the fourth daughter of the second person of the Almighty Trinity, God the Mother. This is what I mean by these marriages of God and Religion. They are the intermingling of the attributes of the Trinity of God-Power (m), Love (f), and Wisdom (m)within the Soul of Man-Imagination (m), Comprehension (f), and Understanding (m) ( $m$. signifies male and $\mathrm{f}$. female).

It is this intermingling during the course of evolution that is to ultimately evolve the Soul of Man in the Epochs of Hope and Charity, as Nature did his animal mind in the Epoch of Faith, and Religion his human mind in the present Epoch of Hope. Now during the Epoch of Faith there was no marriage between all the infinite personalities of God's Trinity, only between two of the infinite personalities of God, viz., God the Father and God the Mother. The forces of Spirit of the invisible power of God the Mother whose attributes Love and Life alone marked creation by the marriage of the finite portion of the powers of Will and the powers of Love. Human Wisdom is the first finite portion of the third personage of God's Trinity, God the Holy Ghost, who had, until the creation of Imagination and Comprehension in the Soul of Man, no existence or influence over creation. The Universe is but a visible portion of Invisible Infinity, or existence without a soul. Now 
the first action of God by the withdrawal of two personalities of His Trinity from the other was the cause that made a portion of His Trinity, viz., the Sun, Moon, Stars and Earth, different from the rest, by making it a visible and material existence out of the invisible portions of the eternal ether from which he had evolved, not separated it when he created gas and the earth, stars and moon. Every part of creation always was and always will be part and parcel of God's Infinity; the only difference is that one part is visible and created existence, and the other part is the invisible infinite ether from which it has been created. Just as human life is but another combination of the gases of the air on which it lives and breathes, and the invisible electrons from which it sprang and to which it owes its motion and existence, in the same manner all creation is but a finite part of infinity which surrounds the created portions of the Universe and impregnates and controls it by the invisible forces of its infinite space of ether out of which it has been reconstructed.

And the ether that fills the void between the planetary system is just as much an invisible living portion of God's Infinity as the visible planets he has created are a part of his finity, all tending to form and constitute a part of the uncreated infinity. So there may exist, and probably do, twenty-one invisible forces, all of which we are not yet able to comprehend, but which go to make up the twenty-one electrons which constitute the twenty-one analogies in Nature to the twenty-one forces of God's Trinity, and which united probably form the infinity of ether by which we live, move and have our being. Those electrical forces of Nature, the invisible actions of which we are to some extent able to realise, if not comprehend, by the discovery of wireless telegraphy and radio-activity, and on which sources of invisible activity science is yearly increasing our limited knowledge and granting us a better and more reliable means of understanding than has been vouchsafed to us by a limited knowledge of the truths of revelation which our ancestors have stored up in the granaries of religion and history.

It is to try and illustrate this invisible unity of infinity and finity that is the main object of my treatise, and it would only be an act of presumption on my part, or on the part of any finite mind to expect to completely understand infinity, 
for you cannot put the ocean into a thimble; and if the Hypothesis I am endeavouring to illustrate can do anything to make the unity of finity and infinity more comprehensible to the finite mind of man, it is impossible to estimate to what extent future knowledge and investigation may not be able, as science advances, to extend the finite limit of man's understanding. But greatly as it may be possible to enlarge the understanding of man, it is inconceivable that it will be able to equalize its comparative minuteness to more than that of a grain of sand as compared with all the sand of knowledge in the world. So great is divine wisdom above human knowledge; and if knowledge is to help man to a more perfect existence, it can only be by increasing his knowledge of his own insignificance and by his learning to realise how small a part his individual existence is when compared with the infinite creation, even though we measure him by his family, not by himself alone.

I must therefore here explain to my reader that in placing this extraordinary Hypothesis, which has been forced under my notice in the remarkable manner narrated, I have only done so under the full conviction that in so doing I am only a weak instrument in the hands of my Creator, which he intends to use in giving to the minds of my fellow-men a new departure in the evolution of thought. No other belief would have given me the 'courage to place before my readers views and ideas so strongly opposed to all past convictions. And I wish him to understand that in so doing I do not wish to argue for or against the views I express. For example, when a man engaged in deep mental study or writing says to his wife, "Please turn the children out of the room, they annoy me," he does not mean thereby to remove his children for ever from his sight, only to remove them for a time that he may the better attend to his occupation.

So in writing this treatise I have sought to banish all my own past, present and future beliefs from my mind so that my writing will be totally unbiased, and have only tried to express such lines of thought as appeared to my mind to be the logical outcome of my hypothesis and which seemed to me most calculated to facilitate the demonstration of this revelation, and the probable sequences of evolution. These matters are put forward rather as subjects for consideration and controversy which may lead to some tangible good in the future, than with the object of convincing my reader on the 
minor views I may express. I have tried to make it as easy as possible for him to use his own mind as the scales in which to weigh the suppositions of my hypothesis, leaving him to study history and evolution as a course of knowledge which, with the guidance of this Hypothesis will, I feel sure, enable those who like to adopt such a course to obtain a clearer and better understanding of the revelations that bind one man's life and interests to those of his fellow-men, that make one and all of us by necessity dependent on the acts of each other, and therefore ought to make each one of us realise that our future advancement and evolution must depend on a better understanding of the manner and objects for which we have been created, and a more perfect realisation that any advantage to the community, state or nation, or world at large, means a like benefit to the individual, and that nothing can be a real advantage to the individual that is detrimental to the community. It is, therefore, only by adding to the public good that we can benefit the conditions of the individual, and this is the reason that all attempts to fix wages or profits by Act of Parliament have been and always will be failures, because they benefit the individual at the cost of the community.

And it appears to me that if I can demonstrate that the hypothesis which these Tables contain follows the same course as that followed by evolution, both in order of sequence and in manner of procedure, and illustrate this connection during the past fifteen thousand million years or so (the above being the nearest estimate that I can arrive at), it is not beyond the bounds of probability, and well within the limits of possibility that the six succeeding days or stages of the world's evolution will also be the same as these Tables mark out.

The reader will now grasp that in this lies the importance of the line of thought I am endeavouring to present to his mind; and if by doing so I can interest the man in the street and get him to realise that in the evolution of the past lies the only true finger-post to direct him along the road to his final immortality, I feel sure it will be a step in the right direction. And if it causes the more imaginative author and the religious thinker to enter into partnership with the man of science, they may be able to evolve a catechism of evolution that will be a practical religious work of universal guidance to mankind. Just as the writer of historical novels makes 
the dull facts of history attractive to ordinary people, in this way it may be possible to establish a common playground on which Science, Governments and Religions may meet in friendly contest to compare their antagonistic views, and fight them out in other ways than as in the past by bigoted strife, steeped in the blood of mankind poured out in unlimited measures round the statues and shrines of fanatical animosity, intolerance and hatred born of the follies and ignorances of the unevolved and unenlightened superstitions that the primitive mind of man has created to beautify his innate aspiration for knowledge of his creator.

I must now turn to my present duty, and point out to the reader in this second book how my hypothesis and evolution will combine in the Epoch of Charity, which is not yet evolved, to celebrate the marriage of Science and Religion, so as to evolve the higher qualities of man's soul in the same manner as the other attributes have intermingled in the past. In the Epoch of Faith there were no such marriages because the influence of God the Mother was nearly, if not totally merged beneath the control of the Spirit of God the Father, and the Spirit of God the Soul had not then begun to influence the course of evolution. But in the Epoch of Hope, viz., that period between the creation of man as described in the last days of Genesis, and the present day, we follow the course of the evolutions of Religion and Civilisation, as by the properties of Imagination and Comprehension man's mind is evolved to a fit state to receive the Soul of Understanding and Wisdom.

Somewhere about the first two hundred thousand years of this Epoch of Hope is devoted to the evolution of the quality of Imagination which is to enable man to acquire Knowledge and Civilisation. The second half, covering between one and two hundred thousand years, is devoted to evolving the quality of Comprehension, which is to develop the arts of Religion, Commerce and Government as the Spirit of God the Mother assumes the control of Evolution. These circumstances make this Epoch one of supreme development and perfection in the qualities of Energy, Selfishness and Murder in its varied phases of robbery, feuds, vendettas, state and religious wars. But as I have stated elsewhere, nearly all virtues are the outcome of sins and crimes, so this cruelty and hate are the failings that are to build up Empires, 
create Commerce, establish Religions, and evolve as the result of their reaction the Virtues of Love, Sympathy, Mercy and Unity, and Justice in the days yet to come. We will notice, therefore, in this Epoch that as the Spirit of God the Mother slowly returns to creation, these virtues gradually become evolved, not at once, but as in the course of this warfare each evolution destroys the other, to be thereafter rebuilt in a more magnificent style as religion teaches us to see and believe what we cannot understand. But in the Epoch of Charity Religion is to be married, not as in the past to Imagination and Comprehension, only, but to Understanding also, the third person of the soul of God in man, as Knowledge and Science add the soul of the Wisdom of Understanding to his past development when he will be able in future to supersede his past beliefs by a clearer comprehension of right and wrong.

It must be clear to enlightened minds that as this evolution takes place past religions must be reformed by the increased knowledge of Science till man will in the future become a religion to himself. Now even in the present enlightened age of creation (for the Sun of Understanding as yet only " stands tip-toe on the misty mountain-top ") there are very few men who have attained the ideal of perfection and who do no wrong -I do not say that they are without sin, for such a state of perfection, as I have tried to point out in this treatise, will not even exist when earth becomes heaven, but whose sins are so safeguarded by wisdom that they injure no one and so do no wrong to others, which is the most we can hope to attain. But as this stage of Evolution extends into the future, it would require the gift of prophecy to discuss it. In the next few chapters I will endeavour to make a comparison of the principal facts of Evolution with Tables II. and III., so that the reader may be in a position to draw his own conclusions and extend the comparison as his knowledge dictates, and will leave him to form his own ideas from such comparisons in the past as to what the probable evolution of the future will be if thought out with the aid of the results of Tables I., II. and III. 


\section{EVOLUTION AND GENESIS}

IN the Epoch of Faith we trace the first seven stages of creation. In these stages all is controlled by the first person of God's Trinity, the first attribute of which is the Spirit of Power or Motion. The first three stages are governed by the forces of the trinity of Matter, viz., Disintegration, Attraction and Consolidation, which, ruled by the forces of Light, Heat and Chemical Action, resulted in the formation of Gas, Earth, and Water which constitute the Material Universe and occupy the first three days of Genesis. The next four are devoted to the following evolutions of Life-Assimilation, Circulation, and Respiration produced by the Second Person of God's Trinity, whom, for reasons given, we call God the Mother, and who now begins to enter into the ruling of creation. Her forces during the first seven days are the trinity of Existence, Love and Life which become more apparent during the last four days of the Epoch of Faith than the forces of God the Father, whose influences of Spirit, Power and Thought controlled material existence. These forces of God the Mother by intermingling with those of God the Father produce the trinity of Life, plant, animal, and mind on the fourth, fifth and sixth days, and on the seventh day Animal Mind is brought to its perfection, and Imagination, the fourth attribute of God the Father, lays the foundation of the Human Soul, and so heralds the entrance of the first influence of God the Holy Ghost into Nature on the seventh day by the creation of the mind of man.

In this chapter it is my intention to place the first chapter of Genesis alongside the treatise on Evolution, interlarding it with notes so that the reader may compare the two.

GENESIS.

First Biblical day is the three first days of Creation and Evolution.
EVOLUTION.

As I have already stated, the Almighty started Creation by withdrawing the Spirit of 
(Ist Day.) In the beginning God created the Heaven and the Earth, and the Earth was without form and void, and darkness was upon the face of the deep.

(2nd Day.) And the Spirit of God moved upon the face of the waters.

(3rd Day.) And God said Let there be Light, and God called the Light Day, and the darkness he called Night.

Note :-As we pointed out in Chapter 5 of Book I., Evolution moves three steps forward, and two steps back, but never straight ahead. Note also that the same course is here pursued in Genesis, for God means to impress this on our minds. For the reader will see that the first day of Genesis travels into the three first days of the epoch of Faith, and the second day as described in Genesis goes back and commences on the second day and travels on to the fourth day of Evolution, and when we come to the description in Genesis of the third day, it commences on the second day of Creation, and travels on to the fifth. This was always a puzzle to me until I obtained my mathematical table of the trinity of creation which I have given in Book I., Chapter 4. But when this mathematical table of trinity
God the Mother and that of God the Soul from the Spirit of God the Father, which left the spirit of Power or Motion in uncontrolled possession of the portions of His Infinity that became finite, uninfluenced by the Spirits of Existence and Soul which had been withdrawn. This, of course, caused disintegration, and under the influence of electrical and other forces luminous gases lighted up the whole of Creation, for the molecules of God's ether are no longer held together by the Spirit of His divine love, therefore they are now whirled through space, as Milton expresses it, "In dire confusion, rout on rout, confusion worse confounded "; and so God created the firmament and the Heavens were lit up by burning gases, devoid of love or affinity to hold them together, which travelled through space with the mighty rapidity of light, illustrating, as Nature does in all things, the infinite power of the Creator. For the trinity of power in Nature is, first, the Power of Action; second, the Power of Heat (for, as Professor Davey conclusively demonstrated, Heat is the result of the rapid motion of the molecules of air and the Matter under combustion) ; third, Chemical Action of recombi- 
is used all this becomes plain to our understanding.

2nd. Second Day of Genesis.

God said Let there be a firmament in the midst of the waters and let it divide the Water from the Waters.

(NoTE:-Probably the Molten Belt originally made a circle round the Equator).

And God made the Firmaments and divided the waters which were under the Firmament from the waters which were above the Firmament.

(The heavy atmosphere of this age, and the rise and submersion of the earth).

And it was so (the first of the Trinity of great deluges). And God called the Firmament Heaven and the evening and the morning were the second day. (Here God still further illustrates this law of Evolution, three steps forward and two steps backwards. Then he now takes us in His Biblical account to the evening or eve of the first and morn of the second day, but throws in the explanation that the first day as described in the Bible extended to the morning of the third day, or in other words that the process of Disintegration was not to be complete till after the dawn of the third day of Creation, and the third, fourth and fif:h days of Evolution.) nation. This makes up the Age of Light and carries us to the end of the first day of Evolution. The second day of Evolution is the age of Fluid and Crystallisation to produce Matter, Earth. and Water, which are to be evolved on the third day. Darkness is over the Earth, for the vapour of steam that surrounded the world hid the sun at this age. Then God created the Earth, the Sun, Moon and Stars. Hence we get the third stage or day of creation narrated on the second day, when Love, the Spirit of God the Mother, begins to return to the finite creation, and produces the Age of Flames or molten planets. The planets are made by the love of attraction and contraction, as the first attribute of God the Mother returns to Power, the attribute of God the Father, which caused the molecules of gas to lose their hatred of each other which had made them expand and so form gases. But now the atoms start coming nearer together as the love of affinity makes one atom adhere to another, and as this increases they form the liquid or molten stage of the Heavens and of the Universe. And the Sun, the Moon and the Stars are now created. This love of the attraction of molecules for each 


\section{EVOLUTION AND GENESIS}

And God said Let the other goes on increasing till all Waters that are under the the Heavens are full of Heavens be gathered together, myriads of planets and worlds and let the dry land appear, and stars in the form of nebuand so it was.

lae in dust. Then the

(NOTE:-This is really the cooling of the earth and the end of the third day. Notice Heavenly bodies produces the it is expressed by "And it further consolidation of the was so.")

And God called the dry land earth; and gathering together the waters he called them seas.

(NOTE:-T $h$ is completes the third day and we now move on to the Fourth Day, then retrace our steps to the Third Day as above, and then go on to the Sixth Day before we conclude the description of the Fourth Day.)

And God said Let the Earth bring forth grasses and herbs yielding seeds, and the fruit tree yielding after its kind. (NoTE :-Here please note how God emphasises the laws of descent and heredity to impress upon our minds how much more important they are than those of variation and environment, which produce species and geniuses, for we must remember that we are now dealing with an age when the changes were of such magnitude that we marvel however they could have taken place at all, yet at this place he chooses to repeatedly state that His subsequent creations are not to change but material creation. This is the age of Flames, which, as the earth continues to cool, produces dense clouds of steam and vapour which surround the earth with a canopy of clouds which obscure the light of heaven, and produce the first stage of darkness mentioned in Genesis. Thus the whole of the molecules of Matter further consolidate with increasing density and the trinity of material forces is complete, viz., Motion, Heat and Chemical Action are now to control the first finite result of Creation, the World of Matter (Figure 3 in the Mathematical Table in Book I, page 35). Please note that the figures of complete evolutions are 3,6 , and 9 . Now, Matter is Figure 3, so by this Table it is the first complete product of Evolution. So this third day completes its consolidation from its previous semi-molten state, in which it has been surrounded by heavy atmospheres of vapour, which now descended in the rains of the first deluge of Evolution or sinking 
to be lasting (See Chapter on Descent, Book I.,, and God would not have continued to perpetuate the likeness of trees, plants and animals in rocks, stones and clay, and even, as Embryology proves, in the wombs of our parents, if he did not mean to teach mankind that the laws of descent are unvariable.)

Whose seed was to multiply in itself upon the earth. And so it was. (End of the Fourth Day.) And the earth brought forth grass and herbs yielding seed after its kind, and the trees yielding fruit, whose seed was in itself (the likeness of man whose seed was to be in himself), and the evening and the morning were the Fourth Day.

(NoTE:-In the above we have again the third, fourth and fifth days of evolution, described as the fourth day of Genesis, because the completion of one evolution overlaps the start of the next two.)

And the Evening and the Morning were the Fourth Day. On the Fifth Day God said Let there be light in the Firmaments of Heaven to divide the day from the night, and let them be for signs and for seasons, and for days and for years, and let them be for light in the firmament of the Heaven to give light upon the of the earth's surface, for it appears to me that the biblical deluge was the third of a trinity of floods or ages of abnormal downpours, two of which occur in this Epoch of Faith, and one in the present Epoch of Hope, the glacial age of Science. In the third day of evolution these rain-clouds of steam condensed and descended in rains, making the first of a trinity of floods, but so intense was the heat of the sun at this period of Evolution that the bulk of these waters returned as vapour in the course of thousands of years ; so that the bulk of these waters are again returned into the heavens in the form of steam, to again descend during the fourth and fifth days so as to form the seas and waters, and the earth as it contracts and expands is alternately submerged and raised above the surface of the sea, to form new continents and seas, varying in their extent and depth, so as to enable the gradual production of new varieties of plant life and animal species, and produce the hot and cold periods of evolution, the glacial ages that tear and rip to pieces its rocks and stones and intermingling them with the debris of past animal existences to make a soil. In this way "God made the waters, 
earth. And it was so. This was the order that the revelation of God was to descend to all living beings, in the form of the light of divine revelation, this day being the dawn of mind in animal, which was not created till the fifth day of Evolution, although it was in existence, but it lay dormant from the first day of Creation. We now come to the light of day, which was created on the Fourth and Fifth Days of Creation.

And God made two great lights, the greater to rule the day, and the lesser light to rule the night.

Here again we retrace our steps to the third day of Evolution, when the moon parted from the earth. So the undercurrent of Genesis throughout, while explaining the course of evolution in its description, follows the modes of Evolution.

He made the stars, also God set them in the Firmament of Heaven to give light unto the earth and to rule over the day and over the night. And God saw it was good.

Note:-As this day does not progress past the Fourth Day of Convolution, the eve and the morning is not inserted after the description of this day in Genesis. We now retrace our steps from the Fifth and Sixth Days of and divided them upon the earth." Any student of Evolution will be able to follow these periods in any work he likes to study, but for the beginner I should strongly recommend "The Story of Evolution," by Joseph McCabe (published by Hutchinson \& Co.). As in these waters a vast amount of seaweed life grew, plant life dawned upon the world in a most superabundant growth of submarine plant existence, which, under the high temperature prevalent at this period of Evolution, produced a growth of plant life, the prolific extent of which is beyond our conception. This is the fourth day, the day or age of plant life. Then later some of these seaweeds became small jelly fish, or protozoa, gifted with the most wonderful powers of vitality and most minute semivegetable and semi-animal productions, half plant and half jelly fish, in such shapes, which increased and multiplied in the heated waters till the oceans were alive with millions of these, the first creations of animal life, as has already been explained in Book I. These formed the germs of animal out of plant existence, and some of them form the vertebrates of animal existences. Thus we come to the 
Evolution, which were de- evolution of animal out of scribed in the third day of plant life, which now evolves Genesis. In the next, the the survival of the fittest, the Fifth Day of Genesis, we commence at the Fourth Day and progress to the Seventh Day of Evolution; therefore this day also finishes with the mention of the eve and dawn.

The Fifth Day of Genesis. And God said: Let the waters bring forth abundantly the moving creatures and fowls that fly above the earth. (NOTE :-The first creation of animal life above water was of course fishes and reptiles, and amphibia, the previous existences to animals, birds and man, but it is probable that those evolved from scaly fishes produced mostly birds. Upon the firmament of earth, and great whales (the kingdom of angels or mammoth animals who were superior to man, but which man was to conquer when he became a devil), and every living creature that moveth which the waters brought forth abundantly. (The whale probably returned from the earth to the sea, so this indicates the fish stage of man and beasts after their kind.) The laws of descent are again marked as the ruling and unvariable laws of creation, and in this case it marks in a special manner their application to man, for God then starts afresh.)

force that is to evolve man and prepare the way for man's supremacy over all other Creations. But you must bear in mind that in the high temperature that then existed, the most marvellous forms of transition were possible according to the various forms of submarine growth to which these little protozoa and varieties of jelly fish imparted animal life and thus formed a variety of animals according to the submarine plant from which it derived its life as sex became a new attribute of existence on the Fifth Day. As the earth further cooled belts of dry land were formed round the globe, and were submerged or raised above the waters as heat and cold produced life, plant or body, as the cooling or expansion of its matter releases the electrons that give life on the globe. At this point it must be taken into consideration that the highest mountain of the world is no more of a protuberance above the earth's surface than a split pea would be if glued on a football. Nevertheless, this extra enlargement or contraction produces cold or heat which was sufficient to cause a preponder- 
And every winged fowl ance of the material evolution after its kind. (NOTE :-This repetition is here made, not before but after God has revealed to us in Genesis the dawn of mind and soul, so as to point out to us that mental as well as bodily perfections will for ever be not a question of advancement in civilisation or surroundings, but one of the results of the survival of the fittest by the hereditary laws, that like begets like, both in mental as well as in physical development, that is to say it will be so in the majority of cases; and here please take note that prior to the Fifth Day of Evolution and Creation this was not the case, for in the Fourth Day, as regards early forms of plant and the primary forms of animal life, and from the first as regards the creation of matter, like did not beget like in all cases, for it is not till the formation of the verteibrate fish that like begets like in animal life, for according to the plant that gave it life, so was fashioned the animal to which it gave existence. But once the bodily form of these animals was complete, God binds them by the laws of descent.)

And God blessed them saying $\mathrm{Be}$ fruitful and multiply and fill the waters in the seas, and let fowls multiply in the and multiplication of living forms as heat increased growth or a greater preponderance of new varieties or species of life in a permanent form, as contractions of its surface liberated new forms of radioactivity to create new forms of energy and life as fresh attributes of God's Trinity were in this manner changed from dormant to active forces in the course of Evolution, before the earth had completely cooled, after which Matter and Species were to be changed, by past, rather than new forces through variation, until each attribute completes its evolution.

Fifth Day of Evolution : At this period the plants grew with terrific fertility, and to enormous sizes, for the whole of the world was of tropical heat; in fact, of a much higher temperature than the tropical heat of to-day, and most of its growth was of the palm variety, which also marks the tropical growth in this age of creation.

And the animals which were the first to leave the waters were the mud-fish, amphibia, and reptiles, which grew to mammoth sizes, as the temperature at this age of Evolution was higher in the temperate zones than it is to-day in the tropics, and the evolution 
Earth. And the evening and the morning were the Fifth Day. (The morning of the Sixth, and the dawn of the Seventh and Eighth Days.) And God said Let us make man (it is not as heretofore "God made man," but "Let us make man." This marks the Sixth and Seventh stages of creation, and is the dawn of Love and Soul in Man, when he learned to sin and gain reward, and for the first time in creation God the Father, God the Mother and God the Soul have all combined to make Man, only the first two persons of the Trinity having had $a$ hand in the creation up to now.)

In our own image and likeness (the apes who became man) and let them have dominion over the fish of the sea, and over the fowls of the air, and over the cattle, and over all the earth and over every creeping thing that creepeth upon the earth. (Note:-Now, is not this reward enough to warn us to curb our senseless thirst for wealth, Power, and the conquest of the countries and goods of our neighbours and other races, and to leave war and strife behind as worn-out tools no longer necessary, now that Understanding has at last in the Nineteenth Century of animals or angels was excessive in shape and size, and their development was much more rapid owing to the abundant growth of this age than is possible at later periods of Evolution, when the earth had further cooled and contracted. But for the same reason they were less able to stand the cold, and consequently they succumbed and became extinct, and animals who developed at a later date, when the temperature had fallen, being of a hardier mettle, though at first vastly their inferiors, ultimately became their superiors, because they surpassed them in energy. Hence the mind of man, when recalling this stage of evolution, has contorted this phase of history into a state of mental superiority, whereas it should only be read as meaning a superior state of physical perfection, and the perfection of body, not mental perfection, was God's order of merit in Evolution at this stage of development. But as time goes on, physical merit, size and shape are to give place to superior powers of suffering and resistance, which are the seeds that in man's future development are to grow to the properties of Will and Determination and which when evolved were to enable him to rise superior to all the rest of 
dawned upon our hitherto un- the animals or angels who had developed minds, and, to- developed before him, and gether with misty Comprehen- which, so far exceeding him sion, will enable us to realise in power and strength, he had that in returning to a greater to make a greater struggle to valuation of birth and heredit- become their master, and so to ary reproduction of like (the obtain his survival at all, he creed of early civilisation) lies had to fight his way in fear the road by which we must and trembling. This developed travel, not by the road of in him the fierce, indomitable ignorance, superstition and himat....

,..., for ', you read carefully you will see that male and female are attributes of God Himself when $\mathrm{He}$ says "In the image of God created He Him (God) male and female. Male and female created he them (man)." Now if you read this with a full stop after the first mention of the word female, you can comprehend that it implies that MAN WAS most virtuous of all animals. For man was evidently a late, if not one of the last of the mammoth period of animal creations, hence he has less chances of self-protection than any other animals that did not discard their reptile existence till after the mammoth age, and it was these qualities that made him ultimately able to overcome the highest develop- 
Earth. And the evening and of animals or angels was exthe morning were the Fifth cessive in shape and size, and Day. (The morning of the their development was much Sixth, and the dawn of the more rapid owing to the abunSeventh and Eighth Days.) dant growth of this age than And God said Let us make is possible at later periods of man (it is not as heretofore Evolution, when the earth had "God made man," but "Let further cooled and contracted. us make man." This marks But for the same reason they the Sixth and Seventh stages were less able to stand the cold, of creation, and is the dawn of and consequently they sucLove and Soul in Man, when cumbed and became extinct

Threshold of Evolution, Book 2, opposite page 29.

\section{ERRATA.}

Verse 27-Genesis Chapter I has been misquoted, it should read:

"So God made man to his own image, in the image of God created he him male and female, created he them male and female."

In other versions of the Bible the reading is sometimes stated thus :

"And God created man in his own image, in the image of God created he him; male and female created he them."

(Author).

(NOTE:-Now, is not this re- velopment. But as time goes ward enough to warn us to on, physical merit, size and curb our senseless thirst for shape are to give place to wealth, Power, and the con- superior powers of suffering quest of the countries and and resistance, which are the goods of our neighbours and seeds that in man's future deother races, and to leave war velopment are to grow to the and strife behind as worn-out properties of Will and Detertools no longer necessary, now mination and which when that Understanding has at last evolved were to enable him to in the Nineteenth Century rise superior to all the rest of 


\section{EVOLUTION AND GENESIS}

dawned upon our hitherto un- the animals or angels who had developed minds, and, to- developed before him, and gether with misty Comprehen- which, so far exceeding him sion, will enable us to realise that in returning to a greater valuation of birth and hereditary reproduction of like (the creed of early civilisation) lies the road by which we must travel, not by the road of ignorance, superstition and bigotry, to that knowledge of God and revelation; that Evolution can alone evolve us sufficiently to be able to live in peace, comfort and content, with charity, mercy and justice to one another.)

Seventh Day of Genesis. So God made man to his own image, in the image of God created $\mathrm{He}$ them male and female. (NoTE :-Even if my poor powers of logic have failed to convince you that the second person of God is female in gender, will not the interlineal reading of this last quotation of Genesis convince you; for if you read carefully you will see that male and female are attributes of God Himself when He says "In the image of God created $\mathrm{He}$ Him (God) male and female. Male and female created he them (man)." Now if you read this with a full stop after the first mention of the word female, you can comprehend that it implies that MAN WAS in power and strength, he had to make a greater struggle to become their master, and so to obtain his survival at all, he had to fight his way in fear and trembling. This developed in him the fierce, indomitable courage that was to ultimately gain him such power of will and energy as would enable him to so develop his body as to make it a fit receptacle for his mind. For the same reasons his female mate was made the most timid of all animals, which necessitated that he should do more than any other animal to protect her. This was ultimately to make him the fiercest animal in creation and the most cruel and brutal of all beasts; but as it is by suffering and energy and perseverance that we are to gain virtue, so these qualities are ultimately to make man the most virtuous of all animals. For man was evidently a late, if not one of the last of the mammoth period of animal creations, hence he has less chances of self-protection than any other animals that did not discard their reptile existence till after the mammoth age, and it was these qualities that made him ultimately able to overcome the highest develop- 
CREATED male and female in ment of animal existence and the likeness of the same gen-become the greatest beast. der being also present in the For, as until to-day, ill-health, personalities of his Creator. sin and poverty are amongst Note also the distinction of our greatest blessings, ever "Him" and "them." It urging mankind to strive with appears to me that this pas- increasing energy to attain sage of Genesis tends to en- health, wealth, virtue and comdorse the correctness of the fort, so sin was the main cause hypothesis I am trying to illustrate to my reader, viz., that in the soul of man is the likeness of the first and third persons of God's Trinity, and in woman is the likeness of the second personality. Of course, these are combined in mankind by marriage to some extent, but their not being entirely combined is but one distinction more between the finite and infinite, but which nevertheless is quite in accordance with the only logical assumption of the creation of finity, within the bounds of infinity. It also shows the why and the wherefore, and the necessity for the miracle of redemption by the Sons of God the Mother, made man in Cain, Seth and Christ. Although I am of opinion that the results of Evolution point to the existence of two prehistoric redeemers, which would make a trinity of redemption, but it is quite in accordance with the rules of the evolution of Religion, that all the historical past traces of their existence should be obliterated, of his being able to excel all other animals. And just as we see to-day, although the average distribution of wealth is settled by the laws of descent, which are the strongest of all laws, still those who obtain the huge fortunes of today are frequently those reared in the greatest poverty and hardship. And in the same way those who are well-bred, if they become failures, sink to the direst poverty. There is never much alteration in the wealth of the masses, who only advance at the same rate as evolution. And you will ever find that God in His exceptions only proves the rules of His revelations, laws and rules and regulations. I will here leave my subject to point out the three exceptions made by God to assert His prerogative to rule over all creation. The first of the three is made in the Epoch of Faith and materialism, and is the one exception to the laws of chemistry and natural philosophy. It is this:-The laws of Nature 
for in the case of all past re- rule that all things grow cords, God has made it His lighter and expand with heat, practice only to leave just enough evidence to establish the connection of the present and the past, but has seldom if ever completed the sequence, so that the influence of the past may not destroy the present, and in the case of religious evolution this is even more marked than in any other case, as, for instance, no sooner had Christ established its final development, than Jerusalem is condemned to destruction and the bulk of the Jews are driven out of Palestine, so that their past beliefs may not prevent the forward march of Christianity; for it is a necessity of the evolution of all religious beliefs that they must advance with, and adjust their teachings to some extent to suit the times, or, like all things in Nature, that do not advance, they cease to be the fittest to suit the stage or age of evolution, when they soon deteriorate in practical utility, and are discarded by the people. But the truths worth retaining become absorbed as the ground work of some better form of religious belief. and grow heavier and contract with cold. But had no exception been made to this, in the Epoch of Faith, the whole of life would have become extinct as the earth cooled; for when ice formed at the poles, it would have sunk to the depths of the sea and so cooled the waters of the ocean that the entire globe would have been covered with ice and the land would never have become fertile. He therefore made the first exception to His laws of Evolution or Nature, and decreed that when the temperature declined to 39 degrees the reverse should take place. Again, in the second Epoch, that of Hope or Religion, in order to stamp His superior power, He performs the second miracle of Nature, the three acts of redemption, and just as by the first miracle $\mathrm{He}$ established His prerogative to rule the Spirit of the Power of God the Father, for the first period of His rule over Creation, so in the second Epoch of Hope (or Love and Religion) $\mathrm{He}$ performs the second miracle of Nature and makes the second person of His Trinity become man without the assistance of man, and so God asserted His prerogative over the laws of 
life and birth, by the birth of God-born men as the means of creating religions, and also to enable woman to transmit some of the qualities of God the Mother to the minds of men when God created men without the instrumentality of man through God the Mother of Creation, giving birth to God the Son of Man. This proves His power to rule Matter, Birth, Religion and Life, and he will finally prove His right to rule Death also when he grants Immortality to mankind. I may here point out that all Nature, Sin and Crime, Matter and Body alone excepted, is in the likeness of the Trinity of God by being made up of a trinity of parts or forces. Sin is the stamp or trade mark of Immortality which distinguishes mankind from God or animals. Hence a male and a female gender in God's Trinity is a logical necessity, or mankind would not be in the likeness of God. When I had thoroughly comprehended the fact of the existence of the female gender of God's Trinity, as demonstrated by its marriages, and the influences of gender affecting the actions of the attributes of each of their personalities, as exerted in the past over the course of Evolution, it at once became the key that would solve many of the problems which obscure the course of the evolution of the soul of mankind, and the logical deductions this knowledge has opened up to my mind went far to embolden me to write this treatise.

And again, in the Epoch of Charity, which is just commencing at the present day, and which is to evolve the mind of man and the soul of wisdom in the mind of man, just as the Epoch of Hope has to develop the soul of love and the mind up to its present standard, which has raised him above the animal creation. So as the final stroke of his masterpiece in the work of creation, God will set His trade mark of Infinity and of Trinity upon it when He completes it by working His third and last miracle and creates Immortality, and so for the third time asserts His prerogative to rule the Universe, Matter, Life and Death.

Now we return to our Epoch of Hope, in which Man has to develop his powers of will, energy and endurance, so as to fit his mind to evolve knowledge and thus gain the first development of the divine soul. The Spirit of God the Father has up to now ruled during the Epoch of Faith. Now, if you turn to Table $\mathrm{I}$. and read down the first line, it gives the following trinity-Spirit, Power and Thought make 
Imagination, which is the first result of the trinity of God the Father. Now, reading across the top line of this Table, we have the trinity of the Invisible Creator, viz., Spirit, Existence and Soul, and on line No. 4 we find Imagination, Comprehension and Understanding, which is the trinity of the human soul by the evolution of Comprehension, the female portion of which woman is to evolve in the second Epoch of Hope by the powers of Love and Redemption. Taking the second column of Table I., it reads down the column thus : Existence, Love and Life make Comprehension, which is the gift the second redemption gives to mankind. Then if we read across line No. 4, we read as follows: Imagination, Comprehension and Understanding, which constitute the Human Soul. This is the first half of the two first columns of the two first persons of God's Trinity in whose guidance rests the first Epoch of Faith. And if we read down the third column of Table I. it reads Soul, Wisdom and Mind makes Understanding. But this last which is the true soul of Mankind we have yet to evolve during the Epoch of Charity, the third and last week of Creation which we are now about to commence in the Nineteenth Century. But in the Epoch of Hope, the second week of Creation, which I am now about to review, only the first three attributes of God the Soul are to be evolved.

This is the reason why in the past mankind has had to be led blindfolded by the hand of Religion, because his mind has not evolved the powers of Understanding sufficiently to do more than see and believe, for it is only during the last hundred years that we are beginning to evolve the Spirit of Understanding, and until this attribute of God the Soul is fully evolved, we must take the truths of Nature and of Revelation on faith and belief. For Nature alone is truth directed and controlled entirely by God, and the finite portion of His Infinite Creation is the only part which the Creator intends to make truly understandable to our finite soul. The invisible we can neither see nor understand, so we must take it on faith and belief until we evolve Understanding, and the most that the faculties of Imagination and Comprehension can bestow on our infantile mind is the power to see and believe what we are not yet sufficiently evolved to understand until God grants us a more perfect soul gifted with the higher wisdom of Understanding, for we have as yet only evolved 
the rudiments of soul, and man must be governed by faith and religion that " seeing he may believe" what he cannot understand or know till the further advance of science discovers the truths of Revelation. Hence through the Epoch of Hope we now follow Evolution as it develops in the mind of man the quality of Imagination, and in woman that of Comprehension, which two make the rudiments of the Human Soul. Thus we find that the Epoch of Hope is devoted to evolving the qualities of God the Mother, Patience, Love and Sympathy, by which qualities she is with the help of Christ and his predecessors to make more plastic the savage, stony hearts and minds of men, until, when he finally evolves a soul, he will be able to repay woman that debt, with interest added, he owes her for the wealth of patience, love and suffering which she has poured out for his redemption; for the female qualities of God can only come to man through woman. This was brought about by their having to work out their existence in fear and trembling, for, being physically less fitted at the start to maintain the fight for existence, and also being a later evolution of the mammal creation, man had to exert higher faculties of mind and courage and cruelty, and woman of love, patience, and sympathy and fear to overcome their competitors in the struggle for existence.

Here, again, as in all Nature, extremes meet; so the courage of man and the fear of woman are to be the principal impetuses and forces that are in the future to create man's superior energy and woman's perfection in love and self-sacrifice, and the timidity of his spouse is to lay the foundation of man's greater constancy and chivalry to his female partner in the struggle for life, she who is with God's assistance to redeem the savage cruelty that has made him a greater brute and beast than any other animal in creation, for, as will be seen when we come to the chapter on the Evolution of Religions, it was the fear of the forces of Nature that gave rise to the superstitious dread that first induced man to pray. This is why Religion is for ever prone to become corrupted by superstition, till in the course of time its truths are obscured or lost in its mists, and will be so lost till in the future Epoch of Charity, which commences about the year I800 A.D., when the Soul of God the Holy Ghost shall descend into the soul of man, and evolve the power of his Understanding, of the truths of divine reve- 
lations, which hitherto he has only been able to believe and comprehend with the help of Faith in Religion; and he will, it is to be hoped, with greater wisdom become a religion unto himself, when, as he acquires the power of understanding how to use, not abuse, the gifts of God, some of the attributes of the power of God which in the past have in part been withdrawn from the future control of Nature will be supplanted by man's increased powers of Will and Knowledge and Wisdom as evolution progresses. But enough will be left or else returned in the future to enable him to rule the world more efficiently than he has been able to do in the past, and so relieve the Almighty from the necessity of exerting the amount of control over Nature which has been necessary in the past, and so maintain and further establish the distinction of the inequality of the finite creation from the infinite Creator.

So God by the withdrawal in due course of some of the attributes of the Spirit of God the Father in proportion as man ultimately acquires the gifts of Imagination, Comprehension and also the Spirit of Wisdom, the Spirit of God the Holy Ghost, shall become complete within him in the same manner as the Spirit of God the Mother became complete when Christ enlightened the eyes of his soul by a perfect belief in his Creator by religion, giving to his soul the powers of Love, Belief and Hope, and so advanced thereby the light of Revelation by means of Religion, by which force woman was to conquer man's cruelty, brutality and selfishness, by implanting in their stead the graces of Love, Fidelity and Sympathy, to fit him to receive the soul of Understanding and Wisdom. This gift will in the future disperse and blow away the mists of bigotry and superstition, and destroy murder, cruelty, greed and avarice and dishonesty, and admit the sunlight of the Understanding of God's revelations to still further brighten the lives of men with peace and content in days yet to come when the Holy Ghost will have descended on him to teach him all things, that, knowing God and himself, he may understand how to use, not to abuse, the blessings of this world, as he is now doing by turning to war, hate and selfish ends the knowledge God intended him to use that he might live in peace, harmony and content by striving for the good of others.

This is only a treatise, or I should have enlarged on the development of plant life and shown how the laws of soul and 
life are subject to the same laws of evolution as plants and animals, but I have left that for a future revised and enlarged edition, wishing to take the reader rapidly through the course of Evolution, in order that he may not lose the logical sequence of my hypothesis and of Evolution; therefore, suffice it to say that it was man's fierce struggle with the beasts of this period that made him ultimately become their superior, just in the same way as sickness (not disease) makes a delicate child the strongest of men, and sin (not vice) is the one thing that makes the most perfect virtue attainable, by bringing out man's good qualities, which he would never learn to use if it were not for his realising the faults and failures of his youth, and so learning to perfect the wisdom of his old age with experience, judgment and confidence.

Thus the animals of the mammoth creation, whom God created on the most magnificent lines, the biblical angels, who were vastly man's superiors in size, speed of motion, etc., as for instance, the winged reptiles, which surpassed all subsequent creations for speed, symmetry, etc., and many of them appeared to be built on such perfect lines of strength and durability that it appeared most wonderful that they did not last for ever, so far superior were they to subsequent creations of smaller mammals such as opossums and lemurs that developed mankind. Now we find that in the biblical account of this creation subsequent generations have misconstrued this physical superiority into a mental one and have turned this, the Age of Angels, into a creation of beings who were man's mental superiors, whereas in reality they were only their physical superiors. This is not an unnatural error for them to have committed when we remember that most of our religious beliefs are based upon superstitious fear and dread, purposely exaggerated, which are only written accounts of previous legendary traditions dear to the mass of mankind, and which formed, as it were, foundation stones for early forms of religious government by converting his fear of the supernatural into edifices of more advanced construction that would facilitate and enable them the better to control and advance the government of the masses of the day if clothed in the attractive garb of religion, of fairy tales and fables, sweetened with the sugar of superstitious beliefs.

Yet this seemingly eternal creation of animal life was 
destined to succumb to later, weaker, but in reality more perfect evolutions. For so great was the prolific growth of this age of early plaut life, as well as of early animal creation, that marks this age of luxury in the garden of the world's Eden, that they lived only to eat, sleep and die, and became so idle that they died out from lack of energy; but by so doing made themselves an eternal lesson to teach mankind how great and unpardonable a crime laziness is, and ever will be, in the sight of God. In this way, because they generated no powers of energy or resistance (for resistance is the heart and brain of all virtue, and virtue is but the resistance of opportunities to do wrong; that is why good performed without effort produces no real or permanent virtue, and therefore brings no reward).

These animals, not having risen in the scale of merit by increased energy and perseverance, were not likely to be able to fight on to the days of Immortality or Eternity, so they lived and died and became extinct, because they could not sin. They had no temptation to do aught but feed, sleep and die; but man was to be of sterner mettle, and was to be produced thus:-Being too small to gather the fruits of the earth in competition with such monsters, he lived in fear and trem. bling of the mighty quadrupeds who walked and crawled upon the earth. He therefore strove to climb the trees for safety, and sought his food amongst the berries and fruits, afraid to walk the earth. He was probably a large variety of the Gibbon apes, but the Gorillas and several other apes may have surpassed him both in size and strength and ferocity. To escape these, he started to fling himself from bough to bough and to evolve new virtues of energy and activity, and in this way made his first stride towards immortality. He probably comes between the Gibbon and the Anthropoid apes, and was an earlier evolution than the subsequent development of vegetable-eating animals, who arrived after the mammoth age, when the earth had further advanced, and when the growth of the smaller vegetation had become more prolific.

They were not compelled to make the stringent efforts for self-preservation man had to for existence, and therefore never became the fierce, cannibalistic animal that man did. Then by becoming carnivorous he still further developed his fierceness and energy and his tendency to sin, and so excelled all other apes-although the dog ran him a very close second in 
learning to sin, by likewise becoming a murderer; so has ever since been his boon companion. These are the factors that made the ape men fight harder for mastery than any other animal, and that enabled them to surpass them all. And as to attain virtue each species must first evolve the extremes of vice, and then learn to control these vices, it takes a saint to make a perfect devil, and a devil to make a perfect saint.

Thus man, from having become the most perfect animal (that is the most perfect angel), in the biblical description, that is, Lucifer, the highest angel, becomes the biggest devil. For in this instance the word angel must be read as the animals who were superior in development to man. So Lucifer, in the Bible, is meant to be significant of the races of apes who became men by surpassing all the rest of creation, and becoming the most cruel, brutal and cannibalistic and savage fighters of all animals, and, like dogs and wolves (who evidently in this respect attain the greatest equality to man), he became a sinner by killing for the love of killing.

This is still a mark of his past nature, for his greatest pleasure to-day is to kill for sport, the remnant of his love of animal murder. Yet this love of sport has produced all his highest qualities of honour, justice, mercy, and has perfected his energies and will, besides having made him the most perfect beast or devil. Thus having learnt to sin (which the animals who were his superiors in development failed to do) he became capable of developing his human will (for Power in God is will in man, and infinite power is to will, to act, and to perform; but even a perfect finite will can only will to act and do the best it can to perform). Man's will made him the most perfect beast or devil, and his ferocity, as already shown, made him persevere till he was able permanently to stand upright; and so come into contact with the electrical currents that travel from earth to heaven; which are the currents of Soul, whereas the currents of Power and Will travel horizontally round the earth, like wind and storm.

As it is for fighting that most animals keep on their hind legs, so it was man's indomitable love of fighting, and his swing from bough to bough which combined to perfect his bodily shape, and this, with his love of murder (for to kill for revenge is murder amongst animals, who, with the exception of man and the dog tribe, do not kill 
except for self-protection or subsistence), so perfected his determination that it made him able to permanently keep on his hind legs; and had he not achieved this feat, he would never have become capable of developing his mind or soul.

We have now arrived at the fall of the Angels-the creation of sin by Lucifers (cannibal human apes). All apes did not become meat-eaters, or murderers, and did not learn to permanently stand upright, and therefore were unfit to become men or to receive the spirit of Imagination, which is to develop the mind and make it more than instinct, which is only life, action and thought (the mind of an animal). Man, by gaining Imagination, starts the power of conception in his mind in the following Epoch of Hope. Now Convolution is complete and we leave the Epoch of Faith for that of Hope, and thus complete two trinities of Creation-First, SPIRIT, EXISTENCE and POWER, which make our first complete Existence Matter; No. 3 in Table III. and its resultant or first eternal creation Life; No. 4 in Table II.; second-ACTION, LOVE and MARRIAGE, complete the second half of the Epoch of Faith, and occupy the first six days of creation, on making the second result, the creation of the mind of man in place of animal instinct on the seventh day; when God rests from work, in the sense that from this time onwards part of his labours are to be delegated to man whose mind and soul are henceforth to take some of the burden of the control of creation off His shoulders. This I take to be the interpretation of the words "then God rested on the seventh day," and in which sense the account in Genesis is correct.

This shows what knowledge its compilers possessed of many divine revelations, the details of which we have long lost in the rubbish heaps of departed principalities, empires and governments, for it is only in the last century that we have acquired sufficient knowledge to again interpret these ancient legends, and ascribe to them the true meanings that were impressed upon the minds of our ancestors through their experiences in matters so far above the comprehension of ordinary men of those days, as to almost appear supernatural and miraculous inspirations.

Thus the first Trinity of God the Father, SPIRIT. POWER and THOUGHT, which gives Imagination as the result (see Table I.) is now combined with the first Trinity 
of God the Mother (see second column of Table I.) Existence, Love and Life, which will produce its result Comprehension, on the first day of the Epoch of Hope, and so give rise to the dawn of Soul, the first attribute of the third person of God the Holy Ghost, as Imagination starts the mind of man; which is the first dawn of his soul in creation. Reading horizontally the first line that gives the first three results of the first three trinities of God's attributes, Imagination, Comprehension and Understanding which are to form the future soul of man. Man has now progressed sufficiently to evolve a mind and will of his own, by means of Religion, Civilisation, Government and Science, and thus prepare himself to receive the dawn of the soul which he is to finally obtain in the third Epoch of Evolution, that of Charity. Of course Soul is dawning through the latter part of the Epoch of Hope, just in the same way as mind and love in an animal form dawned in the Epoch of Faith.

The seven stages through which we have now gone are:First, Disintegration; second, Attraction; third, Creation of Earth and Planets, Water and Air; fourth, Creation of Plant Life; fifth, Creation of Fishes, Mammoths and Reptiles, and creation of sex marriage: sixth, the creation of Animal Life and of Man; seventh, Creation of Lucifers or Human Beasts, and dawn of the human mind. This takes us up to the end of the Garden of Paradise, the age when earth, being at a high temperature with a moist climate grew fruits and vegetables in such profusion that the life of each species grew from plants to animals. Existence then rushed ahead to its destruction and its extermination, which was brought about by its being able to live without the effort of hunting for food, and it was only those animals that were compelled to hunt for food that kept their energy. For the one thing more than anything else that makes any existence continuous is hard work and energy, and the one thing that exterminates life is laziness. It is almost the only crime for which God punishes man with loss of the power to reproduce brain.

Angels of the mammoth creation in the Garden of Eden, being too lazy to hunt for their food became extinct and gave place to the smaller and later evolutions of life which çame into existence when the profuse growth of this age of luxury of the Garden of Eden was on the decline, through the cooling 
of the earth, when man becoming a devil, and the earth cooling below I 40 degrees, this age of luxury is stopped for ever, and species became fixed. And thus he was driven out from Paradise to earn his bread by the sweat of his brow, and to be driven on for ever by the whip of poverty and starvation; until he learned to love work, and work for duty's sake and the public good, not for his own selfish ends, pleasures, satisfaction and gratification. When his ideals have evolved to this extent of perfect charity, perfect love of duty, and of work and energy, Science will commence to prolong the term of his life into immortality by the prevention of wasting diseases. 


\section{CHAP'TER IV}

\section{THE EVOLUTION OF MIND IN MAN}

I WILL now devote a chapter to the evolution of mind, before following on the course of Evolution, which is now about to evolve the mind of mankind as apart from the animal mind of instinct, by evolving the first attribute of his soul, the faculty of Imagination which is now about to make the second great departure in the course of Evolution and is to separate the Epoch of Hope from that of Faith and we have just brought to a conclusion, having followed it up to the seventh day of Genesis when God created man in his own likeness by granting him a mind and the dawn or incarnation of a soul. I say dawn or incarnation of a soul, for although during this Epoch of Hope, which commences now that man has evolved a perfect shape, and is to end about the year A.D. I 900 or 2000 , and occupies about three to five hundred thousand years, after which he will evolve a soul. We cannot, therefore, consider his soul as born till A.D. I900, when we commence the third great departure with the Epoch of Charity, during which man will evolve in ages yet unborn the third and last attribute of the human soul, by gaining the power of Understanding, and becoming the possessor of the soul of Wisdom.

For as I have to some extent explained elsewhere, all evolutions have three or four stages of development, which I term Conception, Youth, Manhood, and Old Age, the better to explain the manner of their development. Hence when we review an Evolution which is, so far as I can judge by my Hypothesis, the result of at least the concurrent and intermingled action of the forces produced by the return of three attributes of God's Trinity to active, instead of dormant existence, it appears that each force creates a new phase of this Evolution; as each fresh attribute intermingles its influence, and moves the course of each concurrent influence, three steps forward, then two back, and the next three forward until a 
fourth stage is evolved, as a result which is destined to be the first step in a new order of evolution. Thus, Spirit, Existence and Power of motion, produce the conception of creation, the day of gas, on the first day; then on the second day, Existence, by affinity the lowest order of love produces the second day the first stage of construction by the creation of fluids on to its birth by the creation of visibility out of invisibility. We then retrace our steps from the column of Existence to that of Spirit, and pick up its second attribute, Power of Construction or Motion, on the one hand, to intermingle it with the destructive influence of the Spirit of God the Father, and the constructive one of the affinity of God the Mother of Existence, for fluid is the first unstable product of existence which becomes the conception or incarnation of life, which will be born on the fourth day by the creation of plant life, the result of the activity of Spirit, Existence, and Power.

We term this the first result of a Trinity of God's attributes, and the birth of life with the manhood of Spirit, the Youth of Affinity or Construction, and the Conception or incarnation of power of action in the completion of material construction. This first result, Life, is now to be the incarnation of animal existence, in the same way that gas was to be the invisible incarnation of visible Matter, and so now Life is the incarnation of circulation, which is to be born on the sixth day when mammal creation is to transmogrify circulation into respiration, whose second result is to be the creation of man (but these are subjects I must leave an ampler explanation of to an enlarged edition of this work).

I mention it here to show what I mean when I say Soul was incarnate on the eighth day, but we cannot truly say it has come into existence till the fifteenth day, the day of universal peace which has not yet arrived, although it was born on the eleventh day; when religion made the dawn of Understanding by becoming conceived in Idolatry which was the pregnancy of religion, the birth of which was not to take place till the arrival of its third and last redeemer, Christ, and whose manhood will not be attained till man can avoid crime because it is foolish, and for which he suffers; not because the parson forbids it and society and the law punish it. But this Utopia is not to come till we arrive at the Nine- 
teenth Day of Creation, which will probably be about a hundred thousand years hence.

The Epoch with which we are about to deal, that of Hope, is to be devoted to the development of the human mind, by the evolution of the two first attributes of his soul, the faculties of Imagination and Comprehension; for I take it that these two of the three faculties of the soul, only make the human mind, and this is all that will be completely evolved during the Epoch of Hope-for with the exception of a very few instances amongst the wisest men, the gift of wisdom is not yet evolved-yet the conception of wisdom began some thousand years ago with the evolution of the first attribute of his soul, Imagination. For the Epoch of Faith ended on the Seventh Day with the creation of the power of Will in man, which is the finite creation of the Spirit of the First Person of God the Father in mankind. So we find that the first half of the Epoch of Hope is devoted to the development of the Spirit of God the Father, viz., Imagination, and the second half to the evolution of the Spirit of God the Mother, Comprehension. It therefore appears to me, that as the Epoch of Hope is to commence with the evolution of the mind of man, this is the fittest place for me to pause and show how my hypothesis accounts for the evolution of the mind of mankind.

I have pointed out how the evolution of mind is influenced by the upward and downward currents of the electrical forces of soul. These now begin to effect Man's development, for he has acquired the power to stand upright, which brings the length of his brain and spine into the right position to be influenced by these currents, so he is now no longer to be controlled by the attributes of God the Father, those of blind obedience, but by those of God the Mother, Comprehension, and slightly by those of God the Soul. By the incarnation or dawn of Wisdom, these evolutions are now to advance Thought to Imagination, and Imagination to Comprehension, and so evolve his mind. His soul will not be evolved till after the birth of Understanding after A.D. I80o.

I will therefore in this chapter illustrate to my reader, how, as shown in my Hypothesis, the withdrawal of the second and third persons of God's Trinity and their gradual return to creation, in the form of their attributes has affected, and must continue to affect the evolution of the mind of animals 
and mankind, and so we find these emotions of both mind and soul are likewise evolved from the twenty-one attributes of God's Trinity. It is my intention to illustrate the manner in which the light thrown upon Evolution by the fact of recognising that in the mystery of the Trinity of God lie the motive forces of Evolution, is the real key or standard of gauging the truths of Creation, and how it will aid us to account for many if not all the difficulties which have been a stumbling block to the students of Evolution in the past; in that they have been unable to account for the wonderful difference between the mind of an animal and that of a man. I will also show how all the emotions of an animal mind are only the lowest order of the development of the attributes of God's Trinity; then how the same attributes of God's Trinity as in the course of Evolution man evolved these attributes, as they return to Creation, acting on the lower order of emotions, they have already developed, produce in the same manner the higher evolution of the human emotions that are to evolve the mind and soul of man. This has been a stumbling block in the past to students of Evolution, and I am hopeful that the Hypothesis I am now demonstrating may offer a satisfactory way of accounting for them.

"I know nothing," says Professor Huxley in the Contemporary Review, I87I, "and never hope to, of the steps by which the passage from molecular movement to the state of consciousness is effected." Professor Clifford writes: "The two things are on two utterly different platforms, the physical facts go along by themselves." I hope to show that when read by the light of the Tables of Trinity this is not the case.

"It is all and for ever inconceivable," says du Bois Reymond, "that a number of atoms of carbon, hydrogen, nitrogen, oxygen and so on, shall be other than indifferent as to how they are disposed or were disposed; and how they move or how they were moved; how they will be disposed, or how they will be moved. It is utterly inconceivable how consciousness has arisen from their joint action." But when you can realise the action of God's Trinity in the withdrawal of the influence of the Spirit of Existence or Love, and of Soul or Wisdom from the finite parts of His Creation, and then their gradual return as Evolution advances to be slowly intermingled and so assist the development of Creation, 
all these difficulties vanish, after which the Spirit of Power is to be in part withdrawn; so that at no one period of creation shall the full measure of more than two of the Persons of God's Trinity be existent in the world at the same time.

As we have demonstrated, the complete existence of the three at the same time would be tantamount to the existence of two infinite creations, which is a logical absurdity. But with the use of the Tables and the Hypothesis which they establish, it is possible to adjust and dispel the doubts and difficulties that have hitherto faced the philosopher and student of Evolution in the development of the human mind or soul. Mr. C. Lloyd Morgan, writing in Nature, September Ist, 1892, says: "I for one do not for a moment question that the mental process of animal's and man's mind are like products of Evolution. But the power of Cognizance, Relation and Introspection appears to mark a new departure in Evolution." I hope in this treatise to be able to show that this new departure is the return of the Spirit of God the Mother in the Epoch of Hope, together with the dawning of the Spirit of God the Soul. The same writer continues as follows : "I am not prepared to say that there is a difference in kind between the mind of man and the mind of a dog." I have already pointed out that after the apes which became men the dog, through becoming an expert murderer and cannibal, and by so becoming a sinner, attained nearer towards the evolution of mind than any other animals, except perhaps some of the monkeys. It is only that the dog failed to learn to stand upright, whereas man's life as an ape enabled him to attain this position, which posture has enabled him to evolve still further, and so to become the superior of every other animal; for in manner of hunting and love of killing for pleasure, which constitutes animal murder, the dog as well as man became a lucifer and devil.

" This would imply," continues Mr. Morgan, " a difference in the origin or a difference in the essential nature of its being. There is a great and marked difference in kind between the material process which we call physiological and the mental process we call psychical. They belong to wholly different orders of being. I see no reason for believing that the mental process in man differs thus in kind from the mental process in animals, but I do think we have in the introduction 
of the analytic faculty so definite and marked a new departure that we should emphasise it by saying that the faculty of conception in its various specific grades differs generally from the faculty of perception, and believing as I do that conception is beyond the powers of my favourite and clever dog, I am forced to believe that his mind differs generically from my own."

But when you view the subject from the standpoint of creation as demonstrated in this treatise, all these difficulties vanish, and it becomes plain that what Mr. Morgan calls the new departure, is easily and fully accounted for by the return of the properties or attributes of God the Mother and God the Soul, to do their respective parts towards the evolution of the mind of man. Just as in the same way in the dawn of creation, the return of the Spirit of God the Mother in the form of Affinity, the lowest form of Love, caused the molecules of gaseous ether to draw together and thereby create the forces of construction; which had been dormant during the earliest stages of disintegration; thus causing rest and conglomeration to supplant the powers of action and motion which would otherwise have destroyed the whole of the newly-created firmaments and precipitated them to their own destruction had they not been stayed by concussion and tractation, and precipitated by love and affinity into rest and thus have been enabled to form Matter. So now the same forces are to enable man to form a soul and mind, by forming Thought into Imagination, Life into Comprehension, and Belief, and Mind into the Wisdom of the Soul of Understanding, and to change the invisible power of the existence of God and the soul of God into the visible Will, Love and Wisdom of Man.

Having progressed thus far, we may now endeavour to compare the foundation and development of the mind of an animal with that of the mind and soul of man, and then the mind of an animal with that of a child. "Why not admit our ignorance, priest and philosopher alike?" exclaimed Professor Tyndall. And so for ever both priest and philosopher, I now maintain, must bow their heads and acknowledge that in the mystery of a better understanding of the Trinity of God and its three personalities in one Infinite Creator, and the likeness of the same in the soul of man, and in the evolution of these same attributes and faculties, lies the only means of our ever 
being able to form any true or understandable knowledge of God, Creation, Ourselves, or our Destinies, or of the obligations and duties we owe both to God and to our fellow-men; or to learn how to correct the faults and errors of science, religion and governments. For the knowledge of God's Trinity is the key, by which we are to understand and ascertain the truth or falsehood of science and knowledge, and to strip the cloak of superstition and bigotry from religion, and learn in their stead true charity to our fellow-men.

Mr. Romanes, in his work entitled "The Mental Evolution of Men and Animals," considers that the distinction consists in the placing of one state of mind before another and comparing the relations between them. What else is this, I ask you, but the soul of Wisdom entering into the animal mind of Thought? Please remember that Thought is the third attribute of God the Father, Wisdom is the second of the attributes of God the Soul, and that Imagination, Comprehension and Understanding are the three attributes of God's Trinity that make and complete the Trinity of the Soul of Man (see Attributes of God, line 4, in Table I.). Mr. Romanes continues : "We have no evidence to show that any animal is capable of objectifying its own ideas, and therefore we have no evidence to show that any animal is capable of judgment. Indeed, I will go further and affirm we have the best evidence which is derivable from what are necessarily objective sources to prove that no animal can possibly attain to these excellences of objective life."

Of course not, for as I am endeavouring to demonstrate, the properties of God the Holy Ghost did not descend to any of the apes or animals who did not learn to stand erect and to sin, but only on the apes which became men and which have made up the various races of mankind according to the different species of their life as apes; and then most probably involution, or the dawn of Soul did not take place till long after the earth had cooled to such an extent that all bodily development had stopped; for it was that cooling process that ruled all further development and made subsequent radically physical alteration beyond attainment to any marked degree, and so diverted the course of evolution from a physical to a psychical development. And thus man alone is susceptible to the action of those currents whose influence is necessary to evolve a soul, 
namely, the electrical radio-active currents of ether which pass upwards and downwards through space, while animals are only susceptible to the currents of God the Father which pass horizontally round the earth, and to a slight degree to those of God the Mother which travel diagonally, because the currents of Soul travel at right angles to their spines and brains. I will, therefore, by the following set of Tables, endeavour to illustrate to the reader, how the various emotions of the animal mind have been evolved out of the attributes of God the Father during the Epoch of Faith, how they are to be further developed during the Epoch of Hope with which we are now dealing, and further how in the Epoch of Hope they are to be mainly affected by the influence of the attributes of God the Mother, those of God the Holy Ghost being only slightly apparent in their influence during the Epoch of Hope, but becoming most visible in their effects during the Epoch of Charity which is to be evolved in future ages.

Now we have already stated that the science of Embryology is one that is most useful, if not the most reliable means we have of ascertaining the manner of the development of our bodies. So also we can do much with the aid of our Hypothesis to follow the development of the mind by comparing animal emotions with the development of the human emotions in their humbler form, in the mind of a child, and in this manner realise the close similarity between the animal emotions and the first characteristics of our mental developments in childhood. So in offering these Tables for your study, I have endeavoured to show how the animal and human mind are developed from the same attributes of God's Trinity, then to compare them with the development of the mind, first of an animal and then of a child, pointing out the similarity of development in both cases; and also the fact that the past development of life is but a likeness, of the manner in which man's mind and soul are to be developed in the course of Evolution by the same laws which have been followed during the development of the minds of both animals and mankind.

In Table V. I illustrate to the reader how my Hypothesis when demonstrated with the use of the Tables of Trinity, accounts in a most extraordinary way for the " new departure" in the progress of Evolution, which comes into existence as man develops a human mind in place of an animal one. 
To illustrate this I propose to show in Table V. how the emotions of the animal mind are evolved from the twentyone attributes of God's Trinity, in their baser or animal forms during the first Epoch of convolution or Faith, when influenced only by the predominating qualities of God the Father; that is to say, by the attributes of Power or Motion and of Thought unassisted by the refining influences of God the Mother, or the attributes of Love, Sympathy and Religion, and unimproved by Wisdom, the second attribute of God the Soul.

In Table VI. I shall show how the evolution of the influences of the attributes of God the Mother, which take the command of the Epoch of Hope, acting upon these primitive emotions, still further develops them and brings about this new departure, by further evolving these emotions. Subsequently in Table VII., I will show how the influence of God the Soul, by its influences in the future Epoch of Charity, converts the base animal emotions and sympathies into the more perfect emotions and sympathies of man's soul; in their highest and most virtuous forms, the possession of which higher sentiments will in time fit mankind for immortality. Hence in the Epoch of Faith, which is that of animal development, the attributes of the Trinity develop the emotions of animals. Now Mr. Romanes, who is perhaps our best authority on this subject, makes twenty-four animal emotions. According to my Hypothesis I can only account for twentyone, and I have, therefore, come to the conclusion that possibly Mr. Romanes has duplicated three of the twenty-one emotions, and that Rage is a further degree of Anger, and that Hatred and Revenge may be extensions of Jealousy and Resentment. I therefore include the twenty-one that my Hypothesis will account for in the following list :-

r. Fear.

2. Surprise.

3. Curiosity.

4. Affection.

5. Jealousy.

6. Anger.

7. Pugnacity.
8. Play.

9. Sympathy.

ro. Emulation.

II. Pride.

I2. Resentment.

I3. Love of Beauty. 20. Cruelty

I4. Joy and Grief. 2I. Sense of the
15. Benevolence.

I6. Pity.

I7. Shame.

I8. Regret.

I9. Deception.

Ridiculous. 
TABLE V.

The attributes of God the Father.
Their Development in the Animal Mind.
1. SPIRIT
develops
1. Fear.
2. Power of Action.
2. SURPRISE.
3. Tнобант
3. CuRIosity.
4. Imagination
- 4. Affection
5. KNOWLEDGE
6. Peace .
5. Jealousy (also Hate and Rage)
7. JoY • • • ,
6. Rest or ANGer (Anger being the result of Rest disturbed).
7. Pugnacity (for dogs delight to bark and fight).

The attributes of God the Mother produce in the animal mind-
8. Existence
develops
8. Play.
9. Love
-9. Sympathy.
10. LIFE
- 10. Emulation.
11. Comprehension
- 11. Pride.
12. INVENTION
- 12. Resentment and Revenge.
13. CoMfort
- 13. Love of Beauty.
14. Pleasure
,
- 14. JoY AND GRIEF.

The attributes of God the Soul produce in the Animal Mind-

15. Soul • . . develops . 15. Benevolence.

16. WISDOM • . ",

- 16. Piту.

17. MIND • • • ,

- 17. Shame (In animal the perfection of Thought is Shame of wrong done).

18. UNDERSTANDING - ",

19. UsE

20. ConTent

21. Happiness
- 18. Regret.

- 19. Deceit. (The perfection of animal use of wisdom is to deceive and capture its prey).

- 20. Sense of the Ridiculous (Nothing creates discontent like ridicule).

- 21. Cruelty (An animal is happiest when taking a cruel revenge). 
I must draw the attention of my reader to the fact that all the higher qualities of God's Trinity are developed in the animal mind in the form of the vice opposite to the virtue they represent (see $5,6,7,17,19,20,21$ on the left-hand side of Table V.).

We now move on to Table VI., and in this Table I wish to point out to my reader, that during the first seven days of Creation the power of God the Father ruled all Evolution by the forces of Action, Power and Motion, uncontrolled by the Soul of Wisdom, and very slightly influenced by the Spirit of Love. For as has been demonstrated, the spirit of God the Father ruled the Epoch of Faith, only influenced to a slight extent by the Spirit of God the Mother, and it is not till man was sufficiently evolved to have a will of his own that he was created as man, not as animal, in the likeness of God. Hence it is not till then that the second new departure takes place, for I maintain that the dawn of mind in animals on the Fourth and Fifth Days of Creation marks as distinct a departure in Evolution over the material and vegetable kingdoms, as the dawn of the birth of Mind on the Seventh, Eighth, and Ninth days of Creation which marks the second departure by the creation of the mind of man as compared with that of the animal, and that the completion of Mind and Incarnation of Soul on the Fifteenth Day, the present stage of Evolution, by the birth of Understanding, marks the third and final and most important of this trinity of departures in the Evolution of Mind.

I will therefore now proceed to continue our comparison by the aid of Table VI., in which I desire to illustrate how the return of the four or five first attributes of God the Mother, who is, throughout the Epoch of Hope, to rule creation, and the first three attributes of God the Soul, combined with the attributes of God the Father, and then with the united influence of the entire Trinity as the power of God the Soul reenters into creation. These influences are to be the means of creating these three departures for which the laws of nature are insufficient evidence, and in Tables VI. and VII. it is my object to point out how the hypothesis of this treatise is the only one that can satisfactorily explain these hitherto unaccountable departures, by demonstrating that they are only a turther extension of the action of God's Trinity upon the emotions first evolved. 


\section{EVOLUTION OF MIND IN MAN}

TABLE VI.

The Anims! Emotions

are
Attributes of God the

Father and of God the Mother are
The Emotions these attributes produce are

1. Fear influenced by. Spirit evolves 1. Timidity. Fear

2. SURPRISE SURPRISE

3. Curtosity Curiosity

4. Affection AfFection

5. Jifalougy JEALOUSY

6. ANGer Anger

7. Pugnacity

Pugnacity ,

\section{- Existence ",}

- A. Reverence.

gives cause for
rejoicing).

In the third column of this Table the figures refer to the results of the influence exerted by the attributes of God the Father, and the letters to those of God the Mother.

The Animal Emotions are
Attributes of God the Father and of God the Mother are
The Emotions these attributes produce - $\operatorname{ar} \theta$
8. Plax influenced by Soul

15. PITY

9. SYMPATHY

16. Benevolence

10. Emulation

17. REMORSE

11. PRIDE

18. SHAME

12. Resentment

19. Deceit

13. Love of Beauty " . Content

20. Cruelty

14. JoY OR GRIEF

21. Sense of the LUDICROUS.

,. Mind

". UsE evolves . 8. (1) Music.

". 15. (2) Generosity.

"9. (3) UNITY OIR FRIENDSHIP.

, 16. (4) Charit'y.

". 10. (5) Love of SUPERIORITY.

". 17. (6) Repentance.

". Understanding „, . 11. (7) Ambition.

". UNDERSTANDING ". 18. (1) HumiLITY.

". 12. (2) Contempt (prevention of Crime).

". 19. (3) Caution.

". 13. (4) Admiration.

". 20. (5) Mercy.

". 14. (6) Forgiveness.

". 21. (7) ENJOYMENT OF WrT. 
When influenced by the higher attributes of God the Soul during the Epochs of Hope and Charity the results are as shown in the latter part of the preceding Table. In this case the different arrangement of numbers signifies that in the first column the animal emotions are taken in alternate order in groups of seven-from eight to fifteen and from fifteen to twenty-one, as each of these groups of seven are influenced by the predominance in the Epoch of Hope of the united action of God the Mother in conjunction with God the Soul, and by the influence, in the Epoch of Charity, of the predominance of God the Soul over the influences of both God the Father and God the Mother. In the third column the order is again repeated with the figures $I$ to 7 put opposite so as to divide them into the two epochs with which they are concerned. The first seven, or the animal emotions, occupy the whole of the first two epochs of Evolution, during which they are evolved as material in the first epoch, and mental and physical evolutions in the second epoch, while the other fourteen human emotions are produced in like manner by the mental and psychical evolutions of man's higher qualities, and commencing in the Epoch of Hope and being continued into the Epoch of Charity, in just the same way that the physical evolutions commenced in their animal form in the first epoch, and grew into mental human evolutions by the end of the second.

You will notice also that in the first two epochs, each animal emotion is affected by two attributes and produces fourteen human emotions, whereas in the Epochs of Hope and Charity the psychological development leaves fourteen animal influences affected by the seven influences of God the Soul only to produce fourteen higher orders of emotion in addition to the fourteen lower orders of human emotion, that have been produced in the first half of Evolution. 


\section{TABLE VII.}

The following table shows how these emotions are evolved in their respective order during the Epochs of Faith, Hope and Charity.

By the influence of By the influence of By the influence of God God the Father in the God the Mother in the the Soul in the Epoch

Epoch of Frith.

Epoch of Hope. of Hope.

\begin{tabular}{|c|c|c|}
\hline 1. Fear & . 1. Trmiditx & - 1. ReVERENCE. \\
\hline 2. SURPRISE & 2. AUdACITY & 2. SHYNESS. \\
\hline 3. Curiosity & 3. MEDdLESOMENES & 3. INQUISITIVENESS. \\
\hline 4. AFFECTION & 4. Love & 4. Devotion. \\
\hline 5. Jealousy & 5. SLANDER & 5. Bigotry. \\
\hline 6. ANGer & 6. InDIGNATION & 6. ENERGY. \\
\hline 7. Pugnacity & 7. WAR & 7. Chivalry. \\
\hline
\end{tabular}

By the combined influence of God the Futher and God the Mother in the Epoch of Hope.

In the Epoch of Charity. By the influence of the whole Trinity.
8. Play

10. Emulation

11. Pride

12. ResentMent

13. Love of Beauty .

14. JoY AND GRIEF .

15. Pity

16. Benevolence

17. SHAME

18. REMORSE

19. Deceit

20. SENSE OF THE

21. CRUelty
9. SYMPathy

8.

Note.-The emotions mentioned in the first column are imperfect, and will either cease to exist before the end of evolution or be imperfect to all eternity or are subject to spasmodic influence only on the action of mankind.

In the third column as far as No. 7 includes such emotions as will be completely evolved by the end of the present day of invention which ends the Epoch of Hope. From No. 7 to 21 in the Epoch of Charity are those that will be still further evolved in the future, before man gains perfection therein, and will be perfect ever after. 
The reader will please bear in mind that the dawn of all the attributes of the Epoch of Charity takes place in an imperfect form during the Epoch of Hope, and in a material form during the Epoch of Faith, for Mind is only the childhood of Soul. Hence all through the Epoch of Hope the lower forms of virtue are being evolved, but men will not become truly virtuous till after the birth of Understanding in the Mind of Man, which birth is now commencing. Imperfect Understanding, however, has been dawning in the soul of man through the second epoch of the world, just in the same way as the human mind has dawned in the animal mind in the Epoch of Faith, although it was not to rise above instinct till the dawn of Imagination in the mind of man, which raised mind above the animal mind in the Epoch of Hope.

It will be further evolved when Comprehension gives place to Religion, although it is not destined to become fully evolved till the birth of the Soul, when virtue will triumph over vice, as man's soul becomes sufficiently advanced in the Epoch of Charity to know and understand the truths of revelation, and so becomes a religion unto himself, knowing and doing right for right's sake. Whereas in the age of Religion his mind is only sufficiently evolved to comprehend that such virtues exist, and in the majority of cases according to and by the aid and direction of Religion, to believe and act up to the beliefs and teachings of Religion, not to know and understand how to do right of his own free will, and his will (except in a few individuals who are above the average standard of soul or mind as compared with the average man of the age) is not sufficiently developed to be able to resist the temptation to do wrong when the inducement is fascinating and alluring, and the gratification easy of satisfaction.

If the reader carefully notes Table VII. he will see that the first seven emotions evolve by the return of soul to creation, viz., Reverence, Shyness, Inquisitiveness, Devotion, Bigotry and Chivalry are the seven qualities that have already attained complete development in the mind of man, and which are now on the decline, whereas Music, Friendship, Love of perfection or superiority, Ambition, Humility, Prevention of Crime, Caution, Admiration, Mercy, Forgiveness, and Enjoyment are all emotions that must be still further evolved before man can overrome. Indolence, Self-love, and Meanness to such an 
extent as to be able to labour for the sake of duty and to live for the good of the community rather than for his own pleasure or advantage, and to seek his happiness in the enjoyment and good he can confer upon others rather than the enjoyment his personal actions may produce, confident such a course of action will be rewarded by God with perfect joy, happiness, and content. This is the perfection that all mankind must attain before immortal existence will be his reward. I would here draw the reader's attention to this fact, even though I may have mentioned it elsewhere, the Epoch of Faith is devoted to physical evolutions, and the conquest of one species or genus over another, and the evolution of animal mind. In the Epoch of Hope the main fight of evolution is moved one of its three most important stages forward, and the human mind as it evolves enables man not only to overcome mightier physical creations but use and take advantage of material creations and existences. But its last day of invention is to enable him to overcome and control the very forces of nature.

The third week of creation is to witness a still greater victory. His soul of wisdom which has been evolving since the dawn of religion and government is to bring, as it is strengthened by the evolution of science, a state of mental perfection, that will enable him in years yet to come, not only to conquer the forces of nature; but even to control, govern, and direct the animal and human emotions we are now showing in the manner and order of evolution. By so doing he is to destroy his animal passions, and thereby evolve in the last week of evolution, the seven days that are to mark the manhood as the second week marks the birth of all virtue; and what higher aim can be the end and object of all creation and evolution, than perfection of human virtue?

It seems to me that before we can make any great move in this direction, commerce must become universal so that the necessity for constant change and redevelopment of natural resources will be less marked requirements of the course of the evolution in the future, than they have been in the past. For this reason at present both youth and age are necessities for the advancement of commerce and invention, etc.; but this will not be so necessary when commerce is universal, and the world is fully populated, and when an increase in length of life will no longer retard evolution. But that immortality will 
be obtained by all nations or people at the same time or period of involution, I do not think at all probable. Such nations or persons who first attain to perfection will probably outlive those who do not; and as Science teaches us how to live with greater health and less abuse of our systems, our lives will be prolonged, and those who fail to benefit by the lessons Science teaches, will gradually die out and be replaced by those who are better fitted for immortality; but as God permits nothing to happen in the course of Evolution until the world is fit for it, this will not take place till after we become wise enough to prevent crime being committed in any way offensive to others, as man evolves a perfect system of government by his increased wisdom, and accumulated experience, and extended knowledge, from the experiences of Evolution. This appears to me the final aim and goal to which the course of Evolution and its laws are pointing; but this is too vast a subject for me to discuss in a treatise like this, the object of which is only to point out the most direct and general course of Evolution in the past, present, and future, and its connection and coincidence with, and its relation to, the influences of God and His Trinity on the production of creation.

I will now endeavour to compare these emotions with Table IV. in Book I. in order to show what are imperfect, and what will be perfect in the course of Evolution, and what will last for eternity. The mathematical list of Table IV., Book I., gives $I, 2,5$, and 8 as numbers of imperfection; 3,6 , and 9 as representing perfection; and 4,7 , and Io as representing eternity. Now reviewing these emotions by the test of Table IV. we find the following results in the Epochs to be :- 


\section{"IN THE EPOCH OF HOPE."}

Imperfect.

Perfect.

Lasting.

\begin{tabular}{|c|c|c|c|}
\hline Fear & - Curiosity & - & AFFECTION. \\
\hline SURPRISE & - MeddLesomeness & . & Love. \\
\hline JEALOUSY & - INQUISITIVENESS & • & DevotToN. \\
\hline Timidity & - Deceit & - & Chivaliry. \\
\hline AUdACITY & - EnERGy & - & CONTENT. \\
\hline REVERENCE & - ANGer & • & JOY AND GRIEF. \\
\hline SHYNESS & - & & \\
\hline SLANDER & . & & \\
\hline
\end{tabular}

NoTE.-Justifiable anger will never cease to exist. Man will evolve the power to control his temper, not to alter his temperament, and so convert anger into peace and rest.

In the Epoch of Charity there are :-

Imperfect.

Perfect.

Lasting.

\begin{tabular}{|c|c|c|c|c|}
\hline Pray & • & SYMPathy & . & Emulation. \\
\hline Music & $\cdot$ & FRIENDSHIP & • & LOVE OF SUPERIORITY \\
\hline PrIDE & - & Admiration & & Forgiveness. \\
\hline REMORSE & $\theta$ & LOVE OF BEAUTY & • & SHame \\
\hline REsEnTMENT & & BENEVOLENCE & . & HUMULTт. \\
\hline Ambition & & $\begin{array}{l}\text { CaUtion (evolved } \\
\text { Deceit) }\end{array}$ & of & Charity. \\
\hline
\end{tabular}

Prty

(These will never be perfect; some will cease to exist or nearly so. Others will continue to improve in Heaven.)
(These will continue into the age of Charity before they are perfect, and become perfect when we attain Heaven.)


I forgot to mention that the order. of Table V. is not only a statement of the emotions of animals, but is in the same order as that of their evolution in the animal mind and in the mind of a child; (vide Professor Romanes' "Mental Evolution in the Animal Mind.") It is interesting to notice that the order in which Professor Romanes gives these evolutions, with the three exceptions I have pointed out, coincides with the order of their evolution in nature, and also with the order in which I evolve them in Table V. from the attributes of God's Trinity. Such a coincidence from two persons, working from such different points of observation as Professor Romanes, who is working from the material standpoint, and myself who am endeavouring to regard this subject from a psychological point of view, is astonishing. Mr. Drummond, in his work The Ascent of Man, draws attention to the fact that the same order is maintained in the development of the minds of children, but he points out that this is not all, but that the emotions, as already hinted, appear in children in the same order as they appear in the minds of animals.

Mr. Drummond continues : "At three weeks fear is perceptibly manifest in a little child. When it is seven weeks old the social affection is shown. At twelve weeks emerges jealousy with its companion anger. Sympathy appears after five months. Pride, Resentment, and Love of Ornament after eight months. Shame, Remorse, and Sense of the Ridiculous after fifteen months. These states, of course, do not indicate in any mechanical way the birth of the emotions; they represent rather stages in an infinitely gentle, mental ascent, stages nevertheless so marked that we are able to give them names, and use them as landmarks physiologically to show that the tree of mind as we know it in lower nature, and the tree of mind as we know it in a little child, should be the same tree, starting at the same place, and though by no means ending its branches at the same level, at least grows so far in a paralleled direction."

Having now shown that the same course of Evolution, if viewed from the standpoint of the hypothesis of this treatise, namely, that all these evolutions of sentiment and emotion are in reality only the development of the attributes of the respective personalities of the Trinity of God, evolved both in the order of His Trinity, of my hypothesis, and also of 
nature, Evolution and creation both in animals and in mankind; and are brought about in the exact order and manner that one would expect them to be evolved, presuming that the hypothesis that creation is the result of the withdrawal by God Almighty of the attributes of God the Mother and of God the Holy Ghost and some of those of God the Father from the whole of those of ether, and the gradual return during the course of evolution of the forces so withdrawn; that only the attributes of God the Father, and to a slight extent those of God the Mother, are allowed to control or to develop the animal kingdom, although in their inferior forms these attributes are all called into action; it is not till man has evolved the final shape of his body that those of God the Soul commence to exert some influence on the evolution of the mind of man, so making man, and man only, a true likeness of God.

We find, therefore, that from this hypothesis and standpoint only of God and His Trinity, it is possible to overcome the difficulties of previous students of evolution, and to account for the hitherto " unaccountable departure" which is in reality only a further extension of the same laws that previously ruled evolution of mind, as I have just illustrated.

I have already stated that it appears to me that our individual minds are only a recapitulation of the minds of our ancestors. Now at the commencement of the Epoch of Hope, we find that God withdraws the faculty of memory to permit of the evolution of civilisation, for had he not done so, we would not have had sufficient influence over the actions of our children to have been able to teach and educate them; for if, like animals, man had been allowed to retain the memories of actions which were performed previous to his birth, his authority would have been lessened. Hence it appears to me that if we do not realise the manner in which we are able to recall the knowledge of our past ancestors in an imperfect manner, we cannot conceive how truly insignificant the possession of our individuality of mind really is, and we are in consequence inclined to over-estimate our ability which is the cause of most of our errors. Our natural pride and conceit cause us to make the great mistake of imagining that our thoughts and ideas are our own. We are entirely governed by the laws of descent and the variation of evolution; if we only realised it (see Genesis), like is doomed to beget like-like father like 
son, like mother like daughter. Fate rules all our actions. These thoughts and ideas we hold to-day are not, as we like to think them, the creations of our own individuality. No, dear reader, the exalted order of thought and imagination of to-day has not, and cannot be evolved in a second of time. It is not the work of an instant, nor of an hour, day nor year. The momentous thoughts which emerge instantaneously on the mirror of the modern mind are the result, not of the few hours that the modern inventor devotes to his rapidly-produced designs, nor of the time employed by the philosopher of today in working out the arguments of his scientific investigation, but the outcome of the past experience of his ancestors.

This result is no more possible as an instant creation of his own mind than it was possible for Archimedes of old, because he had discovered the principles of the lever, to lift the world. For granted he could have found a fulcrum, when he exclaimed in his enthusiasm, "Give me a fulcrum, and with this lever of which I have now learnt the principle I can lift the Earth," (for it might have been possible to achieve such an act with the sun as a fulcrum,) but to evolve a lever of sufficient strength and length, or to communicate sufficient power to humanity to permit of the possibility of driving such a lever, if obtained, through the vast millions of miles of space that the motive power would have to travel, was far and away beyond the bounds of human capacity. So with the human mind, the action of our mental productions of to-day is not the result of our individual efforts, but far and away beyond our individual capability. These ideas we proudly call our own are the product of the study, thought and experience, throughout the hundreds of thousands of years of evolution, which it has taken to produce them in the brains of our ancestors.

The evolution of these ideas has been brought about in the following manner. At the beginning of the Epoch of Hope, God took away our power of memory, in order to advance civilisation and to make us more observant, and so assist us to evolve the faculties of Imagination and Comprehension. As early as fifteen years of age our powers of observation are strongly and fully developed, but in exact proportion, as education and practice evolve the use of our memories and reminiscences, this faculty is reinstated in our individual 
minds, so in like proportion our powers of observation decrease. This is why farming, which is a science of observation, not of study, necessitates that those who succeed well as farmers, must be brought up in close touch with nature before they are fifteen years of age, or they will not acquire the habit of noticing the small details which make big practical differences in this profession in life, more than in any other profession; failing which advantage, no matter how they may excel in theoretical knowledge, they are very seldom able to compete practically, with those who have from childhood been in touch with nature, and have kept alive their powers of observation.

I have instanced this here so that the reader may the better grasp that the same laws hold good with the recalling of memories of the past, and the recollections of the minds of our ancestors. In this manner, when God took away our power of memory, for the reasons stated above, he gave us in place thereof, a limited power to recall in an indistinct manner under like conditions and like circumstances the observations and experiences of those of our past ancestors possessed of similarly constructed brains to our own, not those of any of our ancestors. Hence these thoughts and ideas we fondly lay claim to belong, not to our own life, but to the past generations upon generations, who are now granting us a temporary lease of them. And we recall them as we require them, not as we will to call them, for they come not at our call but at the call of like circumstances and requirements, of like scenes and conditions to those that gave them birth in the lives of our ancestors. When we think aright, and succeed at work at which others think wrongly and fail, it is because we have ancestors who lived to see a like occurrence of the same circumstances under which we now live, whereas those who failed have lacked ancestors whose experience could teach them.

Had memory not been withdrawn, fear would have daunted and destroyed our courage. In this manner we are now permitted to recall to our minds the knowledge of our past ancestors, when we require it; for their souls, though their bodies are dead, are part and parcel of the souls within us, and their life and brains still live on in the immortality of their souls, hidden invisibly in the misty caverns and cavities of our brains, and they are permitted to emerge in our thoughts, to aid with the hidden souls of defunct bodies reincarnated in 
us to perfect by their energy, efforts and experiences, our present acts. And thus their souls are the mystic guardian angels of the knowledge it cost them in the past so much thought, trouble, and privation to acquire; but the reward of which it is permitted to them to share by their spirits aiding and directing our minds and thoughts, and so to live in the loves and lives of our children and our children's children, in directing whom, they receive the rewards of success of acts which their valiant struggle may have merited, and made possible in the course of time, but which their lives were too short to complete, and the enjoyment of which they were not permitted to receive, until further virtue on the part of their children should create a perfect soul worthy of the reward.

Hence I am of the opinion that our thoughts are the reflection of the lives and minds and souls of our ancestors as a like re-occurrence of events to those under which they lived arises. In this manner we have the power of recalling their past experiences under like circumstances, provided that we are likewise possessed of a brain similar to theirs, but not those of our ancestors whose brain is of a different type from our own. For instance, take a family whose ancestors had a long line of military predecessors and a long line of political ones. A member of the family who had a military brain could recall the experiences in the lives of military ancestors, or think their same line of thoughts corrected by their experiences in military matters, and on such subjects as they had experiences would most likely think correctly, but would be a failure in political work. In the same way those who were born with political talents would fail and blunder as soldiers and would succeed as statesmen. Again, if another family had a long line of maternal ancestors, gifted with creative or inventive genius, a member of that family, if he had a comprehensive mind, would be likely to attain success as an inventor, but would fail as a soldier or politician. Notice, I say in this case, who have a long maternal ancestry, because invention is an attribute of the female mind of God and consequently hereditary on the female side. Some people have put the question to me : In the case of a family of musicians, how do you account for the fact that an early member of the family is a musical genius, and that other members of later birth are less brilliant? This is easily accounted for, because the 
genius is the exception and is the result of a throw back to a large number of musical maternal, not male, ancestors, probably brought about by both parents being musical and engaging in a musical occupation of more than every-day interest at the time of conception, or by a throw back to some musical ancestors of great antiquity, whose brains are now reproduced.

In another chapter I have given an illustration from the breeding of cattle, showing that these exceptions of phenomenal cases are not according to rule, but may be evolved when least expected. This is the reason why we find that men who are born of town-reared parents, even with the best agricultural training, so seldom succeed as farmers. It is also one of the reasons that makes such a wide gap between the rich and poor, for this difference is a social not a class distinction. There are rich and poor just the same as good and bad in all classes. Wealth is only the result of success, and success is the result of fitness to certain occupations, and the possession of certain hereditary qualifications. Many extremes of poverty or wealth which appear to us at first sight as unjust, are in the order of evolution allowed to exist, or are inflicted upon man as a caution to instruct us that we are not using our energies and talents to the best possible advantage, or to utilise it as a means of bringing out certain qualifications, improvements, and virtues, which past acts of our ancestors have sown the seed of or raised the foundations-perhaps in better circumstances, but which still require some generations to further physically strengthen them by means of physical hardships, before it will be possible to evolve higher mental capabilities in the same direction. The same reason also accounts for the fact that many of our ablest and greatest geniuses rise from families who for many generations have been submerged in poverty, and also for the fact that many of those are blessed with a superabundance of wealth, although we are unable to see the immediate qualities which merit such rewards, but which may be only the just reward of several generations who have borne their poverty and still kept the high mental ability employed in the right directions, and preserved under the most trying circumstances. In reality the possession of large sums of wealth only amounts to a trust ownership exerted by one individual, over what is the united property of the community, and divine wisdom in so doing 
is only managing these details in the best interests of the community at large. But those in the poorer classes look at all these subjects from the standpoint that poverty entails upon them, because the possession of a long line of ancestors who have been reared in poverty, and whose minds have been directed along the narrow road of mental poverty, because their poverty has precluded leisure for mental occupation.

Neither they nor their ancestors have been able to afford the heavy cost entailed by the purchase of books; every moment of their lives having been spent in care and want, which were to teach them economy and evolve their energy; and they have therefore had no time for study nor the means of acquiring the characteristics of judgment or thrift or selfcontrol. Hence they have no past memories of ancestors who have not experienced the difficulties of poverty, nor lacked the mental energy required, let alone the time to think or study. Hence they cannot conceive that it is a duty to devote time and wealth to the public good, and to be charitable in the donation of time, nor that time should receive the payment of honour and esteem instead of cash. But it is the duty of the wealthy to contribute large amounts of labour free of charge, a duty which the poor are unable to perform through the circumstances of their poverty. All their ancestors have had the experience that the main object of life is to sell their time for the highest possible value that labour can obtain, so they do not realize that time and money are the same. How are persons so bred, to realise, that it is the duty of some to devote their time to the benefit of others, with no other reward than honour and respect, just as it is their duty to give fair value in time and work for the pay they receive.

Such people have been reared, under hard physical exertion, so cannot conceive that work is the solace of existence, and that it is the love of occupation that produces happiness, and that it is as much a duty for them to devote their labour for the good of others, as it is the duty of their superiors to devote their time to the same object. They cannot, therefore, conceive that work is a necessity of existence. They yearn for physical rest, so cannot realize the fact that mental work is less conducive to rest and happiness than bodily work, nor that mental energy can be the harder strain of the two. They never look beyond the day's work, so how can they 
recall the past memory of happiness derived from mental intercourse, or realize that the exchange of thoughts can do more to enlarge the happiness of others than physical labours who for centuries have never had to use their reason?

Their mental past has been narrow, so how can they recall the past advantage of broad-minded ideas, when exchange of thought has but little fitted their ancestors, who have never learnt the wisdom of giving up erroneous opinions to accept more correct ideas in place of narrow-minded views, so they are unable to alter their opinions with rapidity or decide between false and true statements, except in such cases where their ancestors have had experience? They have always been led blindfold in the past, so how are they to be their own leaders in thought? You can produce reasons in support of your argument without avail, but those who have led them in the past have done the thinking, and prohibited their right of reason or control, then how are they to have past experience in the art of deciding for themselves, who have never been permitted to be their own masters. But instead of this we are doing just the reverse, for we are increasing their liberties and allowing them to decrease the freedom of the community, by removing the reins of ignorance with which we have driven them, before we have taught them the necessary lessons in selfcontrol; the duties of life that higher social positions entail upon them; or the necessary distinctions that society makes between rich and poor, to equalize the unevenness of the labours and burdens that class distinctions, in occupation, entail upon the variety of labours that are necessary to produce the many requirements of the community, the means of satisfying which are contained in the vested capital of the whole.

We must be more liberal in acts of social assistance. Liberal in pecuniary charity we perhaps may be, but we are and have been in the past too mean in love, social amiability, and sympathy and assistance to the weak and unfortunate. It is the fact that we are now making advances in this direction that has enabled us to lift the clouds upon the horizon of understanding, and caused the light of the soul to dawn in the human mind; but we must make instruction in the different social distinctions, part of the curriculum of education, if we would relieve these evils. This, I maintain, is the greatest step civilisation has made since man left off jabbering and 
commenced to talk. Had I published such a treatise as this two hundred years ago, the powers that were, would have put me in an asylum. I dare say some of my readers may hold the opinion that this would be a wise course and consider it a pity I am not there, instead of being permitted to destroy the dearest beliefs of their childhood. But is it well to be a child, because childhood is more innocent than manhood, and is it not nobler to learn what sin is, and how to decide for ourselves between right and wrong, so that we may be able to fight and conquer wrong? In the past it was man's duty to conquer the world of Matter, no matter by what means.

Whether right or wrong mattered not, for had he not conquered Matter, Matter would have conquered him; therefore, as self-preservation is the first law of Nature, in the earlier stages of evolution, the end justified the means till man became wiser. We have made the highest of all virtue the virtue of murder, for what else is war, and what virtue has received higher merit in the past than the virtue of being able to destroy one's fellow-men and the works of civilised art? I remember Sir Gerald Strickland, who was one of my intimate friends, lent me a book entitled, so far as I can remember, Chronicles of the Northern Countries, which gave the past history of my own and his family, both families being Wardens of the Scottish Border. When I read this book I could not refrain from exclaiming, "What a race of robbers and murderers I am descended from !' But the age now dawning is the age of peace, as the age now expiring has been the age of selfishness and war, and the evolution of energy. So in the future we have to relegate war to a back seat to make place for peace, which will come about by modern warfare becoming too costly a luxury for mankind to be able to indulge therein, so he will have to find a less expensive amusement. Then murder will cease to be a virtue any longer.

In the future the aim of man must be to assist Nature to evolve, by extending the hand of freedom and peace to all men and to all nations. Had this been done in the past, it would have frustrated the evolution of Government, Commerce and Religion; but in the future man will have to devote his mind, not to the building up of empires and the creating of internal commerce, but to conducting the chariot of free trade over the boundaries of all nations and destroying empires, out of the 
ruins of which he is to create universal external commerce. The wars of the future are not to be between nation and nation, but between free trade and protection, and between freedom and liberty. Protection and Liberty are the mother and wet-nurse of socialism and trade unionism. I think we may safely predict that these wars will be the most bloody that the world will ever see, for they will be the death struggle of warfare and democracy, and there is no struggle in life equal to the struggle of despair in death. I have mentioned this briefly here, because I must leave all questions of the future out of this treatise. I can only take the reader up to to-day, for to go into the future as it is opened up to my vision by the Tables of Trinity, is too heavy a task to be undertaken hurriedly. It is one thing to review the past, but one of quite a different horse to predict the future.

I do not consider this treatise the work of my own brain; it is probably the past memories of and experiences and thoughts of a long line of bishops, archbishops, premiers and statesmen, from whom I have the good luck to be descended. I feel certain, my own humble brain could never have conceived it. Six months ago the bulk of the opinions herein expressed had no place in my mind, but they have just trickled in as one logical evolution followed upon another. I have devoted my life to logical deductions, and it is only my confidence in my abilities therein, that gave me courage to undertake this task, and I am sure that none of my readers will be more astonished than I am at the way the hypothesis has developed as the logical sequence grew, and yet I feel the growth has only started, and is yet incomplete in my mind; and on one or two occasions, so great and varied have the developments been, that I have felt inclined to throw up the sponge in despair at my inability to do justice to my subject. 


\section{CHAP'TER V}

\section{THE EPOCH OF HOPE}

THIs period illustrates the intermingling, so to speak, of the Epochs of Faith, Hope and Charity, and is the epoch of the creation of the mind of man by the evolution of the attributes and qualities of God the Mother, and the dawn of those of God the Soul in an imperfect degree, which I have expressed as the incarnation, not the birth of man's soul. This is brought about by the gradual return to the mind of man of the attributes of God the Mother and, to a slight extent, those of God the Soul, in the same way as some of those of God the Father and God the Mother returned in the Epoch of Faith to produce Existence and Life, thus preparing the way for love to be born in the soul of mankind in this Epoch of Hope, in which epoch the dawning soul intermingles with the spirit of God the Mother, the spirit of Love, till love conquers man's cruelty, enmity and savagery, and so prepares the way for mankind to receive a soul in the coming Epoch of Charity, which will start about A.D. I80o.

In this Epoch of Hope the following seven days are evolved : -First, Comprehension on the Eighth day of Evolution, that of Agriculture; second, Understanding on the Ninth day, that of Civilisation; third, Study on the Tenth day, that of Religion; fourth, Government on the Eleventh day; Fifth, the dawn of Understanding with the incarnation of Science on the Twelfth day; sixth, the childhood of Knowledge with the birth of Commerce on the Thirteenth day, that of Discovery; seventh, Invention on the Fourteenth day of evolution, in which we are now living, the day of the conquest of nature by man. This completes the second week of creation, which started with the ages of Cain and Abel, and we may consider these seven days as devoted to the evolution of the mind of mankind, while the last seven days of evolution, which are yet to come, are to be devoted to the involution of his soul. But these I do not intend to discuss here. 
Before leaving the Epoch of Faith I must pause for a few moments, if it is only for the sake of satisfying my reader and helping him to follow the evolution of the mind and soul of mankind on the Seventh, Eighth and Ninth Days of Evolution, by asking him to bear in mind the fact that although I speak of man's soul as existing in this epoch of the seven days now under discussion, it is only present as a very infantile soul, the perfection of which he is not to receive till after the year A.D. 1800 , when the evolution of human wisdom really begins to develop. So in reality it would be far more correct for me to say the evolution of the human mind out of the animal mind, for it is only the dawn or conception of his soul that is now taking place. Nevertheless, it appears to me that this is quite the correct place to assign to the development of his soul in evolution, as it is also the place assigned to it in Genesis; and also the place for me to insert it in my Tables of the marriages of God's Trinity, as I have done in Table III., and as its evolution has here taken place in the course of creation, evolution, we find, coincides with Table III., and the rest of the marriages then again coincide with the days of Evolution.

We now come to the evolution of man's mind, and find that man, through having become the fiercest of all the apes, and the best fighter and hunter, and through perfecting his energy by swinging from bough to bough by his arms, instead of crawling on his hands and feet, has now acquired the possession of a body capable of maintaining a mind through the acquisition of an upright posture, and so has brought himself under the influences of the upward and downward currents of electricity, which are to develop the powers of mind and soul; so he is now fit to receive the infant soul we call mind. This has not been the work of a day, for to acquire this upright position and to develop habits of perseverance has been a long fight, extending over a period exceeding more than ten million years, yet so slow is the development of the body as compared with that of the mind, that in less than half a million years he has developed his mind up to its present standard. Nevertheless, nothing does more to show us how insignificant is our individual life than its comparison with the slow development of evolution. For the hairs of our forearms from the wrist to the elbow still retain the ape direction, and lie from the 
wrist to the elbow, instead of from the elbow to the wrist, or upside down as compared with all the rest of our body, for they cannot forget in half a million years the rains which washed them into that position for twenty millions of years. Yet nowadays we are arrogant enough to think that we can despise the teachings of millions of years, and by Acts of Parliament alter human nature, communities and societies in a day. Yet it takes over one thousand years to make any marked alteration in the mind of man. Thus it took the Egyptians two thousand years after they had invented an alphabet to realise that there was no necessity to draw an illustration of an eye when they wrote the word eye, nor of a monkey when they wrote the word monkey; and it was not till the Greeks pointed out the fact that this was a useless waste of time that the folly of it dawned upon their infantile minds. Yet their civilisation was little short of our own to-day in many forms of advancement. In this respect we have made during the last one hundred years the greatest advancement ever made in the march of evolution by the fact that we have acquired a rapidity of change of thought and a tolerance of opinion never dreamed of in the past, and which will hasten the results and possibilities of future development to an extent that is beyond our conception to realize. For the freedom with which opinions are now permitted to be expressed, and are readily adopted, will do more in the course of a thousand years to advance civilisation than all the armies and religions of the past have done in ten thousand years by their wars to establish governments, empires and commerce.

The first influence which acted in this direction was the evolution of Imagination, the first faculty of the human mind which, by some chance action, taught mankind during his ape existence the advantage of sticks and clubs as implements of defence. This materially acted in, the direction of the development of his mind. The second was probably that he desired when it rained to sit under cover, and, as his powers of imagination increased, he conceived the idea that he could best attain this end by interweaving the boughs of the trees above his head. The Orang-utan has progressed thus far, but not having developed sufficiently to continually stand upright, has not been able to develop further; but the apes, which managed to become men before the earth cooled below $x_{40}$ 
degrees, which stopped all further rapid development or marked alterations in shape, had attained an upright posture and were therefore able to continue their development and evolve a mind and soul. Hence from this onward mankind is now to be permitted, as was explained in the chapter on descent, to transmit his mind to his offspring. But man is only to transmit those qualities which are the products of the attributes of God the Father and of God the Soul; it is woman's province to transmit those of God the Mother. The attributes of God the Father are : first, SPIRIT, that of motion in Man; second, POWER, that of will in Man; third, THOUGHT; fourth, IMAGINATION ; fifth, KNOWLEDGE; sixth, PEACE; seventh, JOY. He will also, when he develops still further be able to transmit those of God the Holy Ghost, which are : first, SOUL; second, WISDOM; third, MIND; fourth, UNDERSTANDING; fifth, USE; sixth, CONTENT; and seventh, HAPPINESS. He has already developed the first five qualities of God the Father, and the first four of God the Soul, which leave the last two qualities of God the Father and Mother and the last three of God the Soul to be evolved in the future. In the past he has learnt to conquer the world of Matter; in the future he will have to evolve a soul capable of enabling him to conquer himself as well as the world of the material universe.

$\mathrm{He}$ is only able to transmit his qualities from father to son, daughter and grandson, not to his grand-daughter. So, in like manner, the qualities of the mother descend in the female line from mother to the sons and daughters, but not to the grandsons. But one of the results of the Epoch of Hope, in fact the most important result, is to be produced by the Mother of Creation giving birth to sons without the assistance of man by the miracle of Incarnation, as in the case of Christ the Son of God the Mother of Creation and woman, which acts of redemption result in woman receiving the power of transmitting the qualities of Love, Sympathy and Charity, and the attributes of Love, Comprehension and Invention to her grandsons as well as to her grand-daughters, which would not otherwise have been possible. But this is not to apply to the rest of the seven qualities of God the Mother, viz., Existence, Bodily life and shape, Comfort and Pleasure. For man is only to have the hereditary powers of transmitting and 
evolving Love, Comprehension and Invention, and then only in the Aryan or redeemed races; by breeding in and crossing with the Yellow races may give them these qualities; which are the rewards of their more strenuous fight against the hardships of evolution. This is why you must breed from the fit, and encourage their predominance, and prevent the criminal breeding, if you would stop crime; not waste your time in trying to convert the sinner. This is why we find that when a race becomes degenerate through the male vices of laziness, gluttony and extravagance, and the women do not lose their powers of vitality, the nation loses the power to create brain, energy, mind and soul, but not necessarily bodily strength, health or life. Should, however, woman fail in Love, Fidelity or Morality (note, the curse does not fall on the cruelty, selfishness or infidelity of men, nor does it fall on the laziness, gluttony or extravagance of women), then the race is doomed to physical, not mental, degeneration, and probably to extinction.

The seven qualities which woman transmits are those of God the Mother, and are: first, EXISTENCE; second, LOVE; third, LIFE; fourth, COMPREHENSION ; fifth, INVENTION ; sixth, COMFORT ; seventh, PLEASURE. And it is because Comprehension is one of these attributes of God the Mother, and therefore, like body, is one of woman's gifts of transmission, that woman is more rapid of perception than man, although she is slower to control her actions by reason. But her comprehension and most of her qualities could not descend to her grandsons, for it is Comprehension, Love and Invention that redemption is to extend as hereditary qualities to man as well as to woman, after which her experiences are to influence the future minds of her male offspring, which is the reason which makes redemption a necessity. For had not God caused God-men to be born, man would not have evolved any virtues of Love, Sympathy or Mercy. Woman, on the other hand, cannot transmit the qualities of Imagination, Thought, Mind, Brain or Soul, which are the attributes of the male personalities of God, so these can only be hereditary on the male side. Up to the present time we have evolved five of these seven qualities of woman; we have yet to evolve Comfort and Pleasure. The seven attributes of 
the Trinity that have yet to be evolved are as follows: Peace, Use, Comfort, Content, Joy, Pleasure, and Happiness.

Now, as stated above, owing to her higher qualities of Comprehension, woman is able to grasp the truth and detect it from falsehood, though she cannot explain how she does so, whereas man, with all his knowledge, is lost, because he is unable to comprehend the right from the wrong in the maze of contradictions that knowledge, religion, and science place before his bewildered mind, except in a few cases of men who have the good fortune to be endowed to a more than ordinary extent with their mothers' powers of comprehension, and in this way have developed a strong logical mind which makes these men able to place truth before wisdom. But you must not forget that man has only a very limited power of transmitting the qualities of the attributes of God the Mother.

As an illustration of this, having been a farmer for many years of my life, I will give an instance in the breeding of stock to explain the case in point. In milking cattle, the quality of the milk is a female attribute of body and is transmitted by the cow, not by the bull; the quantity is a male attribute, representing power and strength, and is therefore transmitted by the bull. It must be borne in mind that, as explained in the chapter on descent or survival of the fittest, there are exceptions in the cases of long throw-backs, but these are phenomena of nature and only prove the rule. Thus you can get a mongrel-bred cow which when put to a well-bred bull will throw an abnormal result either way; that is, it will excel all average results for either good or bad. So in exactly the same way your extraordinary genius or extreme criminal may be bred from a family from which you would least expect to produce him. Now, as I have stated, in the well-bred herd of cattle the bull which has a large percentage of dams which have been heavy milkers will produce heavy milking stock but not of necessity heavy butter cows. But if he is put to a cow that is a very light milker, but whose milk is of good quality, he will bring her stock up to the standard of a good average butter cow.

In reading works on evolution and anthropology on this subject, I have often noticed that the authors are at a loss to account for the limited powers of invention possessed by many races of mankind. Until I had obtained this hypothesis I 
was hopelessly in the dark also, but, with the help of my past experiences in stock-breeding, it is now clear to my mind that the reason for this is that the miracle of redemption enables the races that have been redeemed to excel all other races in the acts that are the result of man acquiring the power to transmit a portion of the attributes of God the Mother over those races whose ancestors have not been so redeemed, and have not been fitted to evolve higher psychical development by contest with greater climatic hardships. It is in this manner that $I$ can best account for the fact that the Aryan or Alpine races and those who have Aryan blood are able to excel all other nations and races in Honour, Justice, Mercy, Sympathy, Comprehension and Invention, but not in Skill and Manufacture. Again it is only the races that have had the hardships of the glacial period to contend with which are able to evolve those higher mental capabilities which I express by the word Aryan, or northern, and which are not to be found in the - southern or Mongolian races. Thus it is only in the northern races of Europe and Japan, which have also had a glacial period to fight against, that we find the higher ideals of Integrity, Control and Management present to any marked degree to-day.

So in the Epoch of Hope we find that woman advances the course of man's evolution, and can help, by her untiring and devoted exertion of Love, Sympathy and Self-sacrifice, to promote the welfare of man and turn him from the paths of delinquency and degeneracy into which his own sins and brutality would most likely have led him, had not God come to woman's aid and by the mystery of incarnation granted her the power to reproduce in her grandsons as well as in her grand-daughters the belief in God and Religion and the virtues of Love and Sympathy, although this does not apply to her other qualities of body, shape and life.

We may as well here take note of the reason why it became necessary for God to perform the one miraculous act in the Epoch of Hope which I have previously called attention tothat is the act of Redemption. You will now perceive that the qualities of Belief, Love and Sympathy, which are the qualities of woman, not of man, could not be transmitted from Mother to Crandson except by a miracle of God, and to bring this about it was necessary that woman should conceive a son 
without the assistance of man. So God decided that God the Mother should conceive three men the sons of God and thus enable woman to transmit the powers of Love and Belief in religion to her grandsons as well as to her granddaughters; for it was necessary he should be able to receive religion thousands of years before he was sufficiently advanced to receive a soul capable of fully understanding the truths of divine revelation, an act that otherwise only woman would have been capable of, and under such circumstances man would not have brought any refining influence into the evolutions of civilisation and government, nor have allowed religion to direct the powers of Study, Science and Understanding which he is now just beginning to develop, and all the salutary effects that religion has produced would have been omitted out of our civilisation, government and commerce; wars would have been carried to the verge of extinction; cruelty and hate would have made man wage vendetta upon vendetta through all time to come; governments would have been nothing but huge combines of the mighty to rob, murder and oppress the weak, and commerce would have justified all deceptions, no matter how base, so long as profit had resulted.

I will now endeavour to depict the most probable course of the development of Imagination in the animal mind of man, which is to make the first step towards the acquirement of a soul, which will be the subject of our next chapter. But it is just as well here to consider how the change was most probably brought about. As God withdrew His Soul and Love from creation to create the universe, so now when he is going to grant man a mind he withu'raws memory from him so as to permit of civilisation, and to allow the development of the powers of conception as man evolves this first attribute of the Trinity of the Human Soul, the spirit of Imagination. Now, animals retain their power of memory and of thought. For instance, they require no teaching in the required acts of their lives, but on the other hand their powers do not extend to study, conception or invention. The bird requires no architect to show it how to build its wonderful and intricate nest; the well-bred sheepdog requires no instruction how to work sheep, but will round up a mob of ducks or geese when only two or three weeks old as skilfully as an old dog works sheep. Man may teach the dog to work to suit man's requirements, 
but for style or manner of working, to fit it for its natural work of hunting and killing sheep or other animals, the dog is the equal of man by the mere exertion of its memory.

God makes no errors. Had memory been left intact in the mind of man, he would never have developed civilisation, religion, government, science, for he would have had no inducement to study, and fear would have prevented all progress. Also had his offspring been able from birth upwards to recall in detail the acts of their parents, all powers of authority and control that the parents are now able to exert over the minds of their children would never have existed. It would have been impossible to have educated the young idea how to shoot. Each one of us would have acted on his own knowledge and memory, and would have discarded the knowledge others might have acquired and been willing to impart. How completely our memory has been withdrawn, except for the right, indistinctly to recall past actions I will ask the reader to judge, by casting his thoughts back twenty years and see if he cannot recall many circumstances in public affairs that should have taught mankind a lesson; yet in less than ten short years the bulk of those, whose ancestors have never had to weigh or consider like events and their consequences, have forgotten they ever happened, although they may have been the worst sufferers, or if they have not forgotten them, they have at least attributed the effects to the wrong causes.

Had memory remained perfect, the past failures would have been so deeply rooted in the minds of mankind that some of us would never have had the courage to face onethousandth part of the difficulties mankind has overcome. And as I will demonstrate hereafter, had we never evolved superstition, we could never have developed any form of religion, for, as in all other animals, memory would have only retained the impression of fear, and man would never have had the necessary courage to succeed. When memory is withdrawn, fear is changed first into superstition and then into reverence, and in this way has evolved religion and civilisation to its present standard, which would have been impossible, and man would have been still no more than a savage animal had not memory been withdrawn, for if fear is aroused, or circumstances arise which have caused fear in the past, so great is the force of past recollection in the animal mind that the 
animal stops not to think or find out what is the cause, or if it is the same sound or cause that frightened it before, but it cocks up its tail and puts down its head and flies for its very existence.

But to avoid this, God at this stage of evolution withdrew memory from the mind of man, and in its place gave to thought the impetus of Imagination, which was the first dawn of the Trinity of the Human Soul, so as to evolve civilisation to its present standard, which would have otherwise been impossible and man would still have been in an uncivilised animal state. But to avoid this, he withdrew memory to prevent past fears and past experiences destroying his courage through the memories of past fears and failures discouraging his new-born ambitions, and to fit him for the fresh demands on his energy which higher civilisation would now entail. This would enable mankind to recall in an indistinct manner only the knowledge and experience of his previous ancestors possessed of the same minds and brains which are reborn in himself; and instead of recalling the exact detail of past events, man is now able only to recall the image of the past. In this manner he is able to embellish them by the additions of his now vivid imagination, a process which places his power of thought on the upward road towards reason. For the human mind has in the past been evolved on just the same principles as that of a child, or savage, or of animals up to a certain point of thought. In childhood Imagination and Observation are much more active than in after life, and in the savage this is more marked than in the civilised man. But the power of observation decreases as he regains memory and knowledge as the individual advances in life. So in early man when Imagination first dawned on the world it was far more vivid than it is now, also his quickness of observation and many other qualities he has now lost, such as smell and touch, which are less strongly developed in the civilised man than in the savage.

For now both men and animals had increased and multiplied and, the earth having grown cooler, there was not the prodigious vegetation of the earlier stages of its most tropical existence during the carboniferous ages. The struggle for life therefore becomes more bitter from day to day, and will continue to do so from day to day till man has learnt to use 
the gifts of knowledge, science, religion, government and invention without abuse. But during this second week, the Epoch of Hope, we are to review how the powers of God the Mother, Love, Comprehension and Invention, as they create their results of Honour, Justice and Mercy, which are during this Epoch to soften, mollify and polish down the hard and cruel struggle for life which the powers of God the Father, SPIRIT (which creates fear), POWER (which is predominance of will, which creates war, strife and cruelty), and THOUGHT (which produces knowledge). These were the powers or forces which predominated during the Epoch of Faith so as to evolve physical perfection, and which make up what Professor Darwin aptly named the " Struggle for Life," so in like manner we may call this second week of creation the " struggle for Love," and the future Epoch which the world is about to enter upon the "struggle for Wisdom," during which the powers of God the Holy Ghost are to be predominant, namely, Mind, Wisdom and Understanding, which are to make up the Epoch of Charity or age of Use without Abuse.

The object of this " struggle for Love" is to evolve an age of ideals and ambitions which are contained in the following Trinity-Religion, Government and Science. That is why this Epoch of Hope is doomed to be the age of robbery, murder and war, in just the same way as the Epoch of Faith was the age of creation, life, starvation and extermination.

But I will here interpose to remark that the reader ought to realise what place the great evolution of this epoch, that of Religion, holds in relation to the other evolutions that go to make up the creation of mind which is the work of this Epoch of Hope, in the same manner as the creation of body was the work of the Epoch of Faith, and the creation of the Soul of Wisdom will be the work of the third week or Epoch of Charity. Now, Religion holds the same place in the course of nature as our schoolboy days represent as compared with the development of our individual lives, for just as our schoolboy period lays the foundation for our more advanced wisdom of manhood which we are to evolve by contact with the world, so in like manner the object of all religions is to inculcate the principle of virtuous ambitions, not to create the virtues. This latter must be done in later life by worldly knowledge and ex. 
perience. So in the same manner were we to place our children with unformed principles to compete against formed ones, we would be condemned as fools for not fitting them with power to resist temptation before we launched them on the sea of vices that go to make up the unruly turmoil of business strife. So when at school we wisely keep from them the more perfect knowledge of the crimes of manhood which correspond to the knowledge of science, so in like manner religion has hidden its teachings in mysteries and symbols. But to maintain that the teachings of religion are to forever outweigh those of science is as great a fallacy as it would be to expect a youth to face the world and succeed, subjected to the cramped regime of school restrictions. So in like manner it is a grievous fault on the part of a parent to send a boy or girl into the world ignorant of its crimes and vices, and it is the parent who is to blame for the child's lapse into vice.

And in the same way it is a grievous evil when religion shuts its eyes with bigoted animosity to the wisdom which the advancing growth of science is about to unfold to it, instead of seeking to enhance its ideals, and reform its teachings by adjusting them to the increased store of knowledge by which science is daily enlarging our means of a truer and a more enlightened comprehension of the hidden mysteries contained in divine revelations. I have inserted these remarks here because I wish them to prepare my reader for the unfortunate necessity of my abstract review of the next three or four days of evolution necessitating that I shall be compelled, if I am to make an unbiassed and possible sequence of the most logical and probable course of events that gave rise to the evolution of Civilisation, Religions and Governments, to uproot many of his dearest beliefs and superstitions of past religion and society, so that I may endeavour to rebuild them upon a new foundation hewn out of the rocks of reason and practical common-sense in place of the sandy foundation of imaginative beauty, of parable, legend, fable, and fairy story. I know he will anathematize me and exclaim with Pericles, Prince of Tyre, "Beloved Truth, how long have I sought thee, and now I have found thee I do not like thee." But if less pleasant I hope they may add to his means of forming a higher ideal more calculated to enhance the practical adaptation of the truths contained in divine revelation to the acts of his every- 
day life, and teaching him that God is not a mystic ideal, but the soul of nature.

Now the stage of evolution at which we have now arrived, about two or three hundred thousand years ago, the Age of Adam, man in his half-ape, half-human development is just entering upon the Glacial period of geology, whose cold by liberating from out the material world some of its latent stores of electrical forces and radio activity tends to produce higher physical and psychical developments. The liberation of these hitherto latent forces is the manner in which God is now about to return as active instead of passive or dormant factors the three attributes of His Trinity, Imagination, Comprehension, and Understanding, the return of which to Nature during the Stick Age is to transform the animal mind of the ape into the human mind of man as described in our last chapter, and so make the power of Human Will, Agriculture and Civilisation possible evolutions, which have hitherto been impossible.

As a result these ages of cold so reduce and make scarce the food supply and warmth and comfort of all kinds and descriptions of life that only those animals whose brain power has evolved to the higher degree of development are able to live through these ages of cold which now destroy all the mammoth mammals, in just the same manner as the cold of the beginning of the Triassic and Permian ages destroyed its mammoth brain. It is quite in accord with my hypothesis that mammal reptiles and so gave rise to the higher order of the motive force which gave rise to life, brain and psychological development of all forms of evolution are due to the alternate expansion and contraction of the earth's surface during the intermittent stages of heat and cold, which are the physical active forces which liberated the imprisoned latent radio activity that has produced the mind or brain muscle and nerve developments of men and animals, destroyed past species and made permanent the most energetic varieties of all animal and living species. But my hypothesis would also lead to the assumption that all genius and excessive bodily and physical development are due to slow but prolonged ages of contraction that liberated the latent heat of the globe and so produced mighty and varied forms of material and physical developments by making active the properties of God the Mother, Love or Affinity, warmth, contraction to produce construction 
as opposed to those of God the Father, motion, expansion, and disintegration to produce strength, vitality and hereditary of energy, and strength and determination, skill, daring and courage, by which qualities man has in the past defeated races of angels who have been his superiors throughout millions of years, and from whom he has fled in fear and trembling to the mountain tops, caves, trees, where his indomitable perseverance and energy and its consequent increase of brain power had enabled him to successfully battle against all previous troubles of existence and now finds he is being steadily defeated by cold, ice, wind, rain and snow. So there grew within him a wondrous superstitious dread of these mysterious powers which his mind was yet too weak to know or understand, but whose dread influences he too keenly felt were conquering the kingdoms he had so slowly won during the ten or twenty million years of his previous existences, and his spirit rebelled against this unequal fight and he started to call upon the heavens, sun, stars, and moon to afflict him no more.

Thus grew the first seeds of religion out of man's fears, superstition and reverence; thus born, is it any wonder that these have been the three tools used by the wise to hew out the mystic rites of religious beliefs, erect its temples and idols, and formulate its teachings and fables in which the wise and strong have for the last three hundred thousand years clothed the truths of nature, in order that they might be better able to govern the follies and rebellions of the weak? Why should we wonder, therefore, that the greatest work of Science to-day must certainly be to dig out from the hot-bed of this religious rubbish-heap of superstition, bigoted doctrine and intolerant claims to infallibility, some semblance to the truth of the divine revelations of God and Nature, for God and Nature are alone infallible? Live to love and trust God; be natural in all you do; honest and kind in word and actions ; energetic, temperate, careful and useful to others, using your capability, skill and wisdom to the best of your ability and strength; fear neither church, man nor danger; learn from the past to remodel your future; remember sorrow and trouble and difficulty are the best masters to teach you success; be gentle with the weak, firm with those you have to direct ; always endeavour to be a man as well as a gentleman. Make this the code of your life, and remember virtue is the 
reward of suffering and sacrifice, success of perseverance and energy, wealth of economy and thrift, respect of honour and justice, happiness of the good deeds and kind words and the consideration we show to others. Content is the greatest reward of all, because it is given only to those who never waste their time, talents, or opportunities, and who ungrudgingly and willingly perform each duty of each moment of their lives, regardless of their own inclinations, ever striving to make every act of their lives as useful as possible to those amongst whom fate and circumstance throw their lot.

Make these, I say, the rules of your life and you will be as perfect as God deems it best for you to enable you to best perform the ends for which he has placed you in this world. You can then trust to him to reward you both in this life and in the lives of your children with a full and overflowing measure of joy, pleasure and happiness. Make this the religion of your life and you will be a religion unto yourself; but to be perfect on these lines requires more wisdom than the world has yet evolved, and vastly more than man had two hundred thousand years ago, so we must not wonder that his first acts of reverence and devotion were to worship the sun, moon and stars; for at this remote period his mind was very material and little above the mind of an animal, and he could not even imagine the existence of God. Low down in the scale of religion as idolatry was, it was a mighty advance over the previous animal conception of virtue, which was to live, eat and sleep, for it taught him to worship nature as he was too young to know his God. Out of this first dawn of imagination grew religion, the child of fear and its concurrent evolution veneration, as fear made man superstitious, so he appeals to the seer and magician, whom his superstitions have developed, and who are now to become his rulers and directors as they were the men whose acute observation of nature had made them better judges of the changes of the weather and better able to forecast its dangers. Thus superstition, the mother of religion, is brought into existence in the mind of man.

These seers then realise that in superstition lies a force more powerful than human strength, and which will enable them to govern the wills of their strongest fellow-men. So we now find from this onward the power of God the Mother begins to rise through woman's love and fear to conquer man's will, 
the possession in a limited degree of which attribute of God the Father had till now made her the slave of her relentless spouse, man, the hitherto undisputed master of animal creation whom she is henceforth to subjugate.

Now I may mention here that this being the stick age nearly all indication of the formation and development of man's mind is obliterated by the course of time and therefore we are entirely dependent on logical deductions and conjectures to supply its evolution. Subsequently the creation of rough and smooth stone weapons and tools marks the gradual growth of man's imagination and conception, but during this period we must rely entirely on conjecture and conception, so I have had to fall back on my imagination to fill in these gaps of the probable manner in which he advanced. It is probable that in the age of his ape development, man when climbing or swinging from bough to bough, fell to the ground, where writhing with pain he became a source of ridicule to his more fortunate companions, who with a monkey's strong sense of the ridiculous jabbered at him.

The next step is natural and requires no great effort of thought to follow it. From being the cause of ridicule comes the emotion of injured pride, from injured pride comes the impulse of anger. He rises instinctively without leaving hold of the stick, and attacking the scoffers, discovers what an advantage he has unexpectedly obtained over his adversary by having a pointed weapon. He then starts to break off boughs to fight with, and a sharp-pointed one which chance puts in his way, by its breaking off in a slant, and a thrust given instead of a blow, led from the use of a club to a spear, and this soon evolved the desire in the future to sharpen every stick; and the germ of incentive thus given to improve upon nature is sufficient, when assisted by the fact that man has attained, with his upright posture, the possibility of evolving the first germs of Imagination; and it is this incentive to improve on nature that now inspires him with the ambition to attain a perpendicular and bipedal locomotion, which was the final physical development which was to permit whichever animal had first acquired sufficient brains and perseverance to evolve these conditions to assume the supremacy of all other creations of nature by being granted a mind as the Olympic Crown of physical superiority. For the creation of man is not, 
as some religious teachers would have us believe, a departure from the laws of nature or a special miracle of God as is the alteration of the laws of heat and cold in the Epoch of Faith, or the alteration of the law of birth by the miracles of redemption in the Epoch of Hope, or as will be the alteration of the laws of death when we become sufficiently masters of our own wills and sufficiently wise to sin without injury and offence to others, which is to be the final perfection of psychological evolution when we have learnt to use, not abuse, the gifts of God and nature, and by so doing produce the maximum population of the earth compatible with the greatest amount of peace, comfort and content, when we will receive the final rewards of joy, pleasure and happiness which will convert this earth into heaven.

So it is probable that man's desire to be possessed of a long weapon of defence, and the discovery that he could use it best in an upright position, were the incentives that urged him on to the attainment of the principle of physical development. Now throughout the whole course of evolution, the species which have triumphed and continued to exist are those which, by evolving excellences of brain power, energy and perseverance, succeeded in triumphing over the presumably greater magnificence of the bodily development of colossal species. So in this last fight for physical superiority we find that the same laws hold good amongst apes. The horse and the dog may have beaten the ape in energy, but not in development of brain or initiative or prolonged perseverance under greater difficulties in the procuration of food; while the reptiles and mammoths increased in body, but not in brain, and had in this manner lost their right to further progress along the road to knowledge because they did not succeed in all the directions required. The Gibbon had by the prolonged length of his reach of arm made himself the most formidable ape when defending himself with a short stick, and supporting himself on three legs became content to remain so far the King of Monkeys. And the Orang-utan or Gorilla evolving the maximum of ape strength was content with a short stick so that by only raising himself upon his hind legs to fight for a moment or two, or by supporting himself by an overhanging bough, he could defeat all his foes with powerful blows and so excel in defensive strategy. But neither of these 
developments was calculated to greatly advance their brain, ingenuity, perseverance, or energy, so did nothing to justify their becoming men. But the apes which became men, having found the advantage of a long pointed stick as a weapon of defence, soon began to realise that to use it to the greatest advantage they must cultivate a permanent upright posture which was undoubtedly the acme of physical development.

To do this they probably selected a long stick, and holding it higher from day to day managed at last to maintain an upright posture, whereas the Gorilla and Gibbon, although they had very nearly equalled man in the struggle for life, like the horse that has speed but lacks staying power, they were not able to reach the winning post first, and as is ever the case in nature, once the aim of evolution in any direction has attained its final completion, all previous evolutions which have led up as secondary causes to this effect, become stable and permanent in a marked degree. So now that the final result of physical perfection of body is attained, all species of animals become more permanently stable, and the struggle of the Epoch of Hope commences between races of mankind instead of between the species of animals, as the conception of soul and the birth of the human mind convert the " struggle for existence" into the struggle for love, by the dawn of Imagination, and turn the physical contests of the Epoch of Faith into the mental struggle of the Epoch of Hope and a psychical one in the Epoch of Charity yet to come.

Thus the first germ of improvement is evolved and man commences his first start on the road to conquer the world of Matter. From this we advance to the stone age where man first found the advantage of fastening a stone on his stick. Then he advanced to the idea of hurling his stick, then later the sling is evolved, and then he progresses to a bow and arrow. As the first stages of his mental superiority open up hidden thoughts to his mind in this age of Imagination, thus sowing the germ of invention, he gradually progresses to the state which led him to the idea of house building, and at the same time evolving the rudiments of agriculture and civilisation in a hut fenced in from danger. The power of imagination is the first germ of his Soul; so you see how correct both my Table III. of Trinity and Genesis are in fixing this period, the seventh day of evolution, as the day of 
the creation of the mind of man. So also the eighth day, which will by my Table of Trinity give to man Comprehension as well as Imagination, or two-thirds of the faculties of the soul of wisdom, is the right day to mark the commencement of agriculture which was the first development of the comprehension of how to use nature's gifts, just as the following, the ninth day, is the correct place for the start of human will and civilisation; and human will is the dawn of Understanding in the mind of man. So with the eighth day, the Age of Agriculture and the Age of Cain, we start the stone age of geology; and as agriculture gave rise to possession of property, which is in its turn, for the first time in the course of nature, to create a vicious inducement for robbery and murder, so is not this stone age correctly depicted in the Bible as the age of murder? For this Epoch of Hope, which starts with the Age of Cain, the Stone Age, is to be the epoch of energy, robbery, wars and murder and ingenuity, till in the next one hundred years or so we are to abolish international wars and so complete this epoch of wars and murder, which will bring to a close the second seven days of creation that make up the Epoch of Hope in which man is to see and believe, with the help of woman and Christ, in a future soul he has yet to win in the seven days to come which will make up the Epoch of Charity when he is to learn by science to know and understand the truths religion is to teach him to see and believe.

But God withdraws the faculty of memory and replaces it by an indistinct power of recalling the knowledge and experience of our previous ancestors who were possessed of the same class of mind as is reborn in ourselves so as to permit of the evolution of civilisation, whereby, instead of recalling the exact memories and experiences of past events, man is now only able to recall such images of the past as a recurrence of events reduplicates in his present life, and to embellish them by the additions of his vivid imagination as described in the chapters on Laws of Descent, and Mind and Soul, a process which enables him to improve upon the knowledge of the past, and which places his powers of thought on the upward road towards reason, and makes him from this time far superior to any other animal in creation. But this power to recall is, I am inclined to think, confined to the experiences of such ancestors as have possessed minds of like qualities as those which we 
possess. I have in the last chapter illustrated how the Human Mind has been evolved on the same principles as that of an animal, child or savage up to a certain point in its development of thought and imagination. I have shown that in childhood observation and imagination are much more active than in after life; so also in the savage we find the same qualities are more marked than in more civilised communities, and in some ways his memory is more retentive of observation but is less active as regards thought, imagination and comprehension. But in the same way his physical qualities are often more pronounced, such as touch, smell, etc., and these again are more strongly developed in animals than in men.

But in after life man's powers of observation and imagination decrease as he acquires knowledge and regains the powers of memory. As in the earlier ages of the evolution of his mind, we find these qualities exert a greater influence on his actions than they do in his subsequent development, so we find his imagination is stronger at this period of evolution than at any other stage of creation, which is one of the reasons why superstitions and magic are the groundwork of all early forms of religious beliefs, and why, as the mind and soul of mankind is further evolved by knowledge and science, man's soul clamours for a more reasonable elucidation of his beliefs.

But to return to the age we are now reviewing in the course of evolution with our Tables of Trinity, we find that this age of civilisation and the dawn in mankind of the faculty of Imagination coincide. Man is just beginning to imagine (he could never have done this had he not learnt to stand upright) that it would be an improvement if he had a cover for his head, so he decided to interweave the branches of the trees above him, and as he was naturally of a cruel disposition it is easy to imagine that the young olive branches of his family are made to assist him in his new labours with ruthless severity, and these get more cuffs and blows than government protection to spare them from the wrath of their early school-master of two or three hundred thousand years ago. But as he sat down and watched the young idea learn to shoot-that young idea in its turn being more desirous to achieve than to work when there were birds, mice and rabbits to be caught-and having keener Imagination than their parents it led to their getting a stage further than their parents and not only entwin- 
ing boughs above their heads and a platform under their feet as their fathers had done. They remember that last wet night when their father had been restless and had kicked about till Bill and Tom had been kicked off the stage and were now hobbling about with lame legs or sore heads as a result, and which had made Bill start thinking and trying to imagine how they could prevent the next kick out. Thus it dawned on their imagination that if they made a network of boughs round the stage they would wake before they were kicked out.

When dad saw this new invention, for he who looks on sees most, he set to thinking also, and ultimately realised that if he barricaded round his trees Jones or Smith would make a noise climbing over the fence when they came to steal that leg of mutton that was hanging to one limb of the tree, or the cabbages he had so carefully grown at the foot of his arboreal residence. For now both man and animals had increased and multiplied, and the earth having become cooler there was not the prodigious vegetation of the earlier stages of its tropical existence. Food was therefore becoming scarce, and as civilisation advanced and the age of Abel the huntsman and shepherd gave place to the age of Cain the husbandman, the latter invented stone implements and other civilised methods of warfare and so became a greater murderer than man has ever been before; besides now that the husbandman has started civilisation towns grew up and with them private ownership of property, and the temptation to murder and rob, which had not existed before, became a new departure in the evolution of man's progression towards perfection as a sinner. So this age of Cain marks the progress from the age of Abel, or the age of pastoral life, to the age of Cain or the age of Stone implements; so the Bible in describing this age of Evolution tells us that Abel was a shepherd and Cain a husbandman.

So man passes from agriculture to civilisation, from the club to the stone age, from a nomadic race of shepherds and huntsmen to a race of gardeners and farmers and villagers, and so at the same time as the southern races, the children of Cain are evolving the rudiments of idolatry and civilisation, of skill, manufacture, art and architecture, which are to transform the camps of the huntsman into the villages of the clan, the nomadic races who are the children of Abel are evolving higher forms of moral rectitude, obedience, discipline and 
order, social charity and autocratic power of control which are to lay the foundation stones of governments and religious philosophy. This evolution, though much older, is so slow of progress that it is easily outstripped at first in the race for the laurels of civilisation by the lower types of progress that have for their aims the acquirement of wealth rather than efficiency, to which the greater comforts of art and of ease have enslaved the children of Cain and whose more material form of religion requires less time to evolve. This gave rise to a state of murder and robbery and war which had not existed before. It in its turn evolves stone implements in place of the bow and arrow which satisfied the wants of Adam, who represents the stick age and age of ape-men, and so creates a more perfect development of man's evolution in the art of sinning by his becoming a robber and a murderer. So man passes from civilisation to agriculture, from the stick age to the stone age, from a nomadic age of shepherds and "such as live in tents" to one of husbandry, a race of gardeners, farmers and villagers, and so at the same time he evolves the faculty of Imagination, the first quality of his soul.

This brings us to the great Glacial Period of Geology, and it is this period of rains, storms and floods which is to fertilise the globe, and lastly, but not least, to so evolve the energy, courage and higher qualities of Unity, Justice and Perseverance in the northern races, particularly the Aryan Race, to such an extent as will fit them above all others to receive the second attribute of the Trinity of the Human Soul, Comprehension, after the birth of which faculty man will be able to advance beyond civilisation and agriculture to the higher evolutions of Religion, Government, Science, Invention, Commerce, and ultimately conquer the Universe of Matter. This period is roughly estimated at somewhere about three hundred thousand years which makes up the Epoch of Hope.

As already described, this period of cold drove the Aryan Race back to the warmer portions of the Globe, bringing with it the higher forms of religious belief, the outcome (as all religious beliefs are of an intimate knowledge of the laws of nature) of a more severe fight against climatic adversity and the increased wisdom, energy and experience that these struggles gave to man, and caused him to evolve higher codes of honour, which if they did not increase the evolution of the 
knowledge and ingenuity of civilisation, did a lot to raise its honour, chivalry, and justice, and to foster and preserve its arts from destruction, if not to create others. So from this onward, to the end of the Epoch of Hope, which is to end somewhere between 2000 A.D. to 3000 A.D., Woman, with the aid of Love, Sympathy and Religion is to conquer her relentless spouse man, so we may consider this as the special Epoch of God the Mother and the Epoch of Faith as the Epoch of God the Father.

Now I may as well mention that the Age of Adam and the Age of Abel, which correspond to the end of the Epoch of Faith and the commencement of the Epoch of Hope, and represents the Stick Age of Evolution, consequently all indications of the formation and evolution of the mind of man at this period can only be arrived at by inverse logical deduction, that is, arguing from effect back to cause.

Subsequently the creation of rough and smooth stone weapons, the invention of which during this Eighth Day, the Age of Cain, made him a murderer for the first one to two hundred thousand years of the Epoch of Hope till Lamech and Tubal Cain, who are the Biblical personifications of the Bronze age, mark the next stage of evolution. So the Bible informs us that "Lamech said to his wives Ada and Sella: - Hear my voice ye wives of Lamech, harken to my speech : for I have slain a man to the wounding of myself. Sevenfold vengeance shall be taken on Cain, but for Lamech seven times sevenfold." This has been truly carried out, for religious wars and iron tools have intensified murder seven times sevenfold, and the curse is not yet complete and will not be over till we abolish international warfare. But as already pointed out, during the early periods of this epoch we have to rely entirely upon conception and conjecture to connect the course of evolution so as to compare it with my hypothesis, which must be one of my excuses to my scientific readers for disregarding all the rules of court. For I am here compelled to draw largely on inverse deduction to fill in the gaps in evolution. I have already demonstrated how the breaking of a stick probably led to mankind's first advancement in developing the powers of imagination, but it may be wise to point out the meaning of the statement of the Bible as regards Eve and the apple. I take this to be a mythical account that 
at this period mankind followed the example of the serpent and mammoth reptiles by eating meat, which, as apes were vegetarians, was to them forbidden fruit to which accomplishment he next added the higher proficiency of killing for the love of sport and did not stop till he had acquired proficiency in cannibalism which placed him almost at the top of the tree as a murderer. But we see even that was not reached till he has in the year of Grace, 1916, used submarines, Zeppelins to destroy unoffending women and children for no adequate military advantage, added to which there is no excuse for such acts of vandalism as there was for cannibalism in ages when man's mind was less evolved, and cold, famine and want of knowledge of how to contend reasonably with such evils were the surrounding circumstances which tended to condone the offence; so that the military murderer of to-day is sevenfold a greater murderer than was the cannibal of three hundred thousand years ago.

But do not forget, dear reader, that evolution permits nothing to transpire that is not justified by the circumstances, and one of the greatest requirements of to-day is that mankind shall realise how necessary the prevention of wars, strikes and social animosities is to the future advancement of evolution. So it is quite in the correct order of the day that both as regards war, trades unionism and business cupidity and scientific jealousy, they should all attain their perfection of abuse at somewhere about the end of the second week of evolution, so that they may create a lasting impression on the minds of mankind and make him realise that he will have to take stringent measures for their repression, as well as to make their re-occurrence an impossibility. But this even will be of no avail if he does not realise that the cure must lie, not in the removal of the evil, perhaps to substitute it by another form of itself, or a still worse evil, but he must go further and study up evolution and history till he can find the causes which create its existence a temporary necessity, and he must set to work to remove these causes. This is the lesson which I am hopeful this treatise and its hypothesis will teach, and if it will only be the means of making the man in the street take a greater interest in the science of evolution, which is the only unerring source of true religious information, albeit that we are only just commencing to realise the lessons it contains 
and are as yet only able to interpret them in a very imperfect manner; but imperfect as this may be, it is already becoming the highest objective of enlightened theological thought that the world has yet attained to.

It is in this sense that to make my remarks more impressive I am constrained occasionally to express sin, murder and cannibalism as virtues, because if the reader is to grasp the true influences of the great lesson, that evolution is a pastmaster of the ethics of revelation, he must realise that in evolution, as in individual life, it is the sins of youth that make the virtues of old age. Now to return to the age we are reviewing, the age of Adam and Eve, which presumably covers thousands of years, man's next great advancement was when Eve listened to the voice of the tempter, the interpretation of which I take to mean when mankind learned from the mammoth reptiles that there was superior nutriment in meat food, and so became a carnivorous instead of a vegetarian ape, and so unlike the rest of the ape family " ate of the forbidden fruit " and became a cannibal and a murderer to which great advancement in the art of sinning, which was to for ever raise him above the rest of the animal kingdom, he soon added the higher accomplishment of animal murder; that is to say, the love of killing for excitement instead of necessity.

Now the Almighty, being the Creator, can justify any act that he considers necessary to carry out his scheme of evolution, and it is only pride on our part to criticise the laws he lays down, one of which is that each evolution must attain perfection in its particular line of advancement before it will be permitted to evolve a more perfect evolution. So we find that the vice of yesterday must be perfected before it can become the virtue of to-morrow. That is why at the age of evolution we are now considering I talk of murder and cannibalism as virtues, because they were the virtues of the age, in just the same way as War, cunning and selfishness and avaricious greed are the great virtues of the last four days of the Epoch of Hope and have made it possible to evolve Religions, Empires, and Commerce. But these virtues of the past are to be the crimes of to-morrow just as much as murder, robbery and cannibalism are accounted crimes to-day, for when tomorrow comes and we start to evolve a soul we must, as St. Paul says, " discard the old nature, and put on the new man," 
so we will have to renounce war, cunning and greed and practice PEACE, UTILITY, and universal CHARITY in the week of creation yet to come. Another law, for all evolution is a trinity of progress, is that every evolution passes through three courses or stages of individual evolution, each inferior to the succeeding one, before it produces a virtuous result in the advancing minority. Thus in the Epoch of Hope, being the age of murder, three forms of murder are produced. First, the murder of Adam and Eve or animal murder; the murder of Cain, or that of anger, when the stone weapons gave a new impetus to warfare; thirdly, the murder of Lamech, murder for the sake of robbery, when the metal age brought war to such a state of advancement that it was henceforth to become an efficient method of forcing opinions, whether right or wrong, upon other people, the murder of national hate and bigotry, and this at last made the evolution of religions and governments a possibility.

I have now given my reader a glance at the most important evolutions that are to make up this Epoch of Hope, and I have advanced mankind to the stone age, or Age of Cain and Abel, which I make the heading of my next chapter. We now advance to the stone age where man gradually found the advantages of fastening a stone to a stick, then of throwing it from a sling, then to hurling his stick, and then a bow and arrow is evolved, and so on till we have swords, battle-axes, Dreadnoughts, submarines, Zeppelins, cannons, and asphyxiating gases, as the final end of this epoch which in the next hundred years or so will bring the art of murder to perfection, after which we will arrive at the age of Peace. So the first stages of his superiority over the animal kingdom open up hitherto hidden thoughts to the mind of man as he evolves this new faculty of imagination which is from now to gradually grow and enlarge until it attains to the present stage, age, or day of Invention. So man gradually arrives at the stage mentioned in the beginning of this chapter where we find him starting to build some sort of a house, which marks the dawn of civilisation and agriculture; then as his imagination becomes more developed he gets a step further by becoming a gardener, thereby becoming an individual property-holder, stores his wealth and so becomes an object of envy to his less thrifty and less energetic neighbour, who is now tempted to rob and 
murder him. This is why Cain the husbandman became the murderer, and Abel the huntsman and shepherd did not.

This is how Abel offered a more pleasing offering than Cain, for he offered a heart possessed of honour, mercy and justice, and so found mercy in the sight of God; whereas the heart of Cain was smeared with the blood of war and robbery, the outcome of commerce, barter, selfish greed, envy and hate that city life had engendered, and this constituted him a murderer in God's sight. This brings me to the next day after the age of Imagination, which is personified by the Biblical description of Adam and Eve, which personifies the stage in evolution when Imagination dawns in the soul of mankind during the Stick Age, an age which is devoted to the first development of his mind and is marked by his becoming carnivorous and so eating of the forbidden fruit. This brings me to the Eighth Day, the Age of Agriculture, the day that is to be devoted to the dawn of Comprehension in the mind of mankind which is personified in the Bible as the Age of Cain and Abel. So as it is by studying the past evils of history that we can alone learn how to prevent the same evils recurring in the future, and that the surest way to learn to lead a useful life is by gaining a true idea of the aims and objects for which we were created, and the manner in which we can breed up or evolve the fittest classes of mankind in the generations yet to come which can only be achieved by a more perfect knowledge of how our present state of existence has been attained.

Another lesson of evolution is the law of heredity. This I cannot too strongly impress on the reader, for we must in the future seek to prevent the breeding of criminals, not endeavour to convert the sinner, but condone his follies so far as possible, at the same time taking stringent measure to insure that the criminal classes are not allowed to impose or trespass on the liberties of the more just and peaceful members of the community. In this respect we will have to impose heavy penalties, for the cure must come by increased freedom to those who succeed or are anxious to work or make the best use of their time and skill, and protecting those from molestation, or from their freedom of action being fettered or obstructed by any excessive use or abuse by their neighbour of unwise liberties permitted to him by the creation of legalised state or industrial privileges. So progress the stages of man's 
superiority over the animal kingdom. As I have pointed out in the course of my work, religion is the one exception to the laws of creation that marks God's prerogative to rule evolution during the seven days that make up the Epoch of Hope, for the three stages of its conception, birth, and manhood are ushered in, blessed and sealed by the hand of God with the miracles of redemption in a manner in which nothing else has been during these seven days. For its redeemers are the one and only instances of the creation of life and birth without the assistance of man whereby the majesty and love of God becomes superhumanly visible to the eyes and mind of mankind. But neither man nor nature can create revelation which has lain dormant in nature throughout all ages awaiting the arrival of the fittest moment for its being made clear to the understanding of the mind of man, as its further development may permit of his being able to comprehend or understand a larger amount of divine wisdom. Revelation is the soul of religion; so my Table II. is right in this sense in placing Soul in the place assigned to it therein at the time that the evolution of nerves and brain laid the electrical wires and foundation of man's soul. In this sense when God first created mind and brain, he sowed the first seed of soul although the evolution of the mind and soul was to belong to the Epochs of Hope and Charity, not to the physical one of Faith. But Mind, Nerves and Brain are the electrical wires, so to speak, of Thought, Life and Soul.

But although revelation, which is the seed of religion, is divine and eternal, so that the ethics of religion are indisputable, it is not so with its teachings which are of human evolution, and therefore like all that is human, doomed to err. For this reason all religions, although they demand our highest veneration and reverence and are the last forms of teaching we should dare to reform or dispute, must nevertheless be remodelled by science and evolution, unless they wish to stand still and become obsolete so far as their teachings, not their revelations, are concerned. For religion cannot create a revelation any more than, without the divine intervention of redemption, man could have become possessed of the mind of woman or any quality thereof, or given birth to a child without the assistance of woman. And but for redemption, the blessings of revelation and religion would have been as tightly closed 
a book and as fast bolted and locked a door to the mind of man as is and ever will be the character, mind and soul of woman to the mind of man, or the wisdom, mind and character of man to woman. Hence it is that when we study religion closely we find all its teachings are the creations of the mind of man to suit the requirements of the particular nation, class or society that has given it birth, or that it is best calculated to govern and control. But all revelation is eternal and divine, and is made up of unalterable truths clothed, hidden and disguised in pretty dresses of legends, fables and parables to suit each religious teaching, and we must hunt for the truths not in any one form of religion in particular, but throughout all and every religion of the past, Christian and Heathen, checking them, but with the greatest care and caution lest we destroy more than we can rebuild, as the advance of science and knowledge opens up new realms and visions of revelation to our view.

All revelation being divine, it is above the control or power of man, nature, or evolution; hence the priest or parson should be dominant as regards revelation, but he is no less likely than science to err in his beliefs and the explanation of their truths until God sees fit by the further evolution of man's mind and soul to grant him the wisdom to understand the true interpretation of the mysteries of creation, which $\mathrm{He}$ has hitherto deemed it wisest to clothe in the teachings of parable and fable lest their brilliancy and lustre might dazzle the eyes of our but partially developed minds. For mankind will not be perfectly evolved psychologically until he evolves such perfect human wisdom and self-control that he will be able to $\sin$ without offence or crime and live in peace, charity, and content. Hence until he has evolved to this extent we must not be surprised if his religions and laws err at times as religions, governments and societies alternately fight for the power to rule mankind; and in its desire to be paramount in the direction of the mind and soul of mankind towards the truths of revelation, it should occasionally, in its ardent fight for superiority, distort its teachings through excessive emulations to achieve laudable ends, and so pervert its good intents to unwise subjugation of free right of individual thought, and so in the past has created more evil than good. But this evil will be reduced as wisdom and knowledge will during the coming epoch of the evolution of the soul enable Right to 
become paramount over Might, but the reader must not forget that this is not, by the clock of evolution, to take place till we reach the Epoch of Charity. The Epoch of Hope, whose seven days we are now discussing, is devoted to the supremacy of Might over Right to make possible the evolutions of Religion, Government, Discovery, Conquest and Commerce by means of War, Greed and Robbery, whereas in the future we are to evolve Joy, Pleasure and Happiness by the means of Knowledge, Invention and Use.

So we find the first half of the Epoch of Hope is devoted to the evolution of Imagination, which evolved in mankind the highest forms of Love, Hate, Jealousy, Anger and Pugnacity, and so built up cities and evolved agriculture and skill of manufacture amongst the Mongolian Races. Then Comprehension, which was to enable him to evolve Play, Sympathy, Emulation, Pride, Resentment and a love of beauty and art amongst the Aryan or northern races, and so make the inter-marriage or intermingling of these great divisions of mankind worthy at least of being redeemed, as he thereby receives the germs or seeds of Honour, Justice and Mercy, which qualities are to enable him during the second half of the Epoch of Hope to evolve Religion, Government, Science, Commerce and Invention. God and Nature have now sown these seeds during the Epoch of Hope which the last century has just brought to a close, seeds which are fast becoming the plants of knowledge, judgment, and wisdom, and which are now enabling him to conquer his worst enemies of the past-fire, air and water; plants which in the Epoch of Charity yet to come, when fertilised by the rains of the Spirit of God the Soul, of Wisdom and Understanding, of a perfect interpretation of Truth, Science and Revelation, and ripened under the sunshine of religious direction (there is a vast difference between direction and subjection), bloom into flowers of Immortality, which are to grow in the garden of heaven on earth.

Hence the Mongolian civilisation could only produce agriculture, skill, manufacture, with its concurrent results of competition, strife and greed, as also a material belief which rose out of a study of meteorological indications resulting in superstition and necromancy which gave birth to idolatry. The northern or Aryan races, on the other hand, leading a pastoral and huntsman's life, evolve a concurrent evolution of civilisa- 
tion of a higher and more generous type which tends to create a greater amount of emulation, unity, and self-reliance. This resulted in a form of hero worship which led to a greater esteem for individual superiority and tribal unity and sacrifice for the public good, and, as their occupation as flock-owners taught them the value of heredity, they came to evolve a belief in Caste, social superiority, hero worship, and honour to the victor, obedience to a chief or leader, little regard for wealth in the form of personal belongings that were not of a portable nature; so that their nomadic life evolved higher principles of honour, justice and mercy than were evolved by their more southern brethren, the Mongolian races. So throughout this Epoch of Hope I will endeavour to take my reader in the next chapter through the course of these two systems of evolution which have laid the foundation-stone of our present civilisation, the details of which are outlined in the biblical account of the children of Adam to the time of Noah, which marks or corresponds to the end of the Glacial Period of Geology. 


\section{CHAPTER VI}

\section{CAIN AND ABEL}

BEFORE tracing the course of Evolution further, I will point out how its course here coincides with the biblical account of Cain and Abel, after which I will proceed to show how the course of this age demonstrates the dawn of Comprehension and the conception of Religion in the mind of man.

Now, the best interpretation I can put on the biblical account of Cain and Abel is that they personify the two great divisions of mankind during the Stone Age-the Aryan and Mongolian Races. Abel apparently represents the great Alpine and Aryan Migration, which, preferring a nomadic life, pushed forward north as far as Iceland. As they were huntsmen and shepherds, they shared the proceeds of the chase in common, combining together to be able the better to hunt and to protect their flocks, which they also shared in common. This, added to the fact that they led a life more closely in touch with nature, made them less selfish, more energetic and inclined to kill only in self-defence or under provocation; so they evolved higher ideals of justice, co-operation, unity and mercy, and were not inspired to destroy towns, arts and civilised customs as were their Mongolian competitors. The Mongolian Races personified by Cain cultivated habits of horticulture and agriculture, and the result of this distinction was that the Mongolian developed more largely the power of skill and manufacture and so evolved greater powers of Imagination and construction at an earlier age than the Aryan Races.

This led to their being the first to evolve a primitive form both of civilisation and of religion. But both these were of the most material description. As hinted in the last chapter, one of the results was that of the private ownership of property, which gave rise to more selfish ideals and to the crimes of robbery and murder, for civilisation is conducive to crime in its early stages of evolution. But in the space I intend to devote to side issues in this treatise I rannot go fully into 
these details, but the reader will gather, when he reads the next chapter on the Evolution of Religion, that the custom of offering sacrifices to a deity was most probably a subsequent development of the latter part of the age now under discussion, so it is presumable that when we read that God accepted the offering of Abel and rejected that of Cain, we are meant to understand that although God permitted the Mongolian Race to outstrip for a time the Aryan Race, the heart of Cain was more selfish, his love of wealth was greater, his habits of moral rectitude less exact, and his ideals were of a lower order of virtue than those of his Aryan brother, Abel, who, although he took longer to evolve habits of law, order and religion, by his life of greater excitement, higher energy and stronger habits of self-denial, evolved a higher order both of body and mind, and so found favour in the sight of God, and was therefore able to outstrip and conquer his more advanced brother.

When some two hundred thousand years later driven back by the Glacial Period, he had evolved higher forms of virtue, of thought, of religion and of government, so was destined to supersede his brother Cain, who was still buried in Chinese materialism and idolatry, and had not yet conceived a belief in a life to come or an immortal existence, when the Aryan Races had evolved a belief in one God, the Supreme Ruler, if not yet in His Trinity. All these facts made the Aryan Races the fittest of mankind and destined to become for ever afterwards the leading races of creation as the northern children of Abel swept down on their more civilized brethren. Now it appears to me that somewhere in this Stone Age comes the first dawn of religion, and if my hypothesis and the deductions taken from what experience has shown me to be the rules of stud-breeding are correct, it then follows that every one of the attributes of God the Mother to be transmissible by mankind from one generation to another on the male side, it was necessary that there should be a redeemer or Godmade man for each of the three attributes of God the Mothernamely, Love, Comprehension and Invention, to produce Civilisation, and so enable man to outstrip the animal kingdom, would henceforth require to be transmissible from the male as well as from the female side, and, had this not taken place, woman alone could not have evolved family unity, love, sympathy, comprehension, justice, and invention. It appears 
to me also that some such action must have taken place over a hundred thousand years ago to have evolved the increased family love, unity and affection and the dependence of the young upon the parents to make such a marked distinction between man and the animals, and to give rise to the power of worship which created the first dawn of religion in the form of idolatry and the dawn of civilisation in agriculture.

I could then comprehend the hidden meaning of these words- "Adam" (who represents the Stick Age prior to the dawn of religion and civilisation) " knew his wife Eve, who said I have gotten thee a Son of God." For this would corroborate the creation at this period of the first of the three God-made men to establish Love, the first of the three transmissible attributes of God the Mother, and would correspond to the dawn of Chinese religion in idolatry some eighty to one hundred thousand years ago. But it is most improbable that God will allow mankind to evolve any form of religion in advance of the evolution of his mind at the age in which he lived, for such an act would be inclined to frustrate the laws that presumably govern his plan of creation. The careful reader of the Bible will not fail to notice that whenever Christ was asked any question relating to procedure and regulation of our acts in the future that were likely to be materially altered as man's mind became further evolved and better acquainted with the ethics of revelation that underlie the truths of nature, he is careful to give his questioners equivocal answers that contain truth, but does not clearly express it, for the true extent of these mysteries is not to be made known till the evolution of science and invention is sufficiently advanced to make known to him what is true and what is false in nature, or until he has further evolved his soul by receiving the attributes of God the Holy Ghost when he shall arrive at the Age of Charity, which is to commence about A.D. I80o, but is really not to take place in any marked degree till after the Fifteenth Day of peace amongst the Nations of good-will; and we are only arrived at the Fourteenth Day of Evolution, the Age of Invention, after which man is to become possessed of a soul capable of understanding true wisdom and correctly distinguishing between right and wrong. Yet it seems to me that man could not have evolved any of the simple idolatrous forms of religion and worship in sufficient force to give rise to Love or Sympathy, 
let alone Charity, of which he has only a limited amount at present in this twentieth century without the supernatural assistance of God.

Then after the days of Enos, which do not commence till after the Metal Age or the end of the Stone Age, according to the account given in Genesis, a second redeemer is born, but this time amongst the Aryan Races, not the Mongolian Race, and again we find the same words, thus :" Adam knew Eve, who said I have gotten thee a son Seth in place of Abel whom Cain slew; and he had a son Enos who walked in the light of God." This would correspond with the existence of Buddha about twenty thousand years before Christ. Continuing this course of inverse logic, which is the only method open to me to follow out in elucidating prehistoric facts, and becomes the only practical one I can adopt to fill in the missing spaces or the missing links of evolution by arguing from effects back to cause, instead of from cause to effect; for please remember, dear reader, I do not put myself up for a really scientifically informed man, I only lay claim to a mind capable of more than ordinary logical deduction and extensive comprehension, and if my ideas on the power of recalling past memories is correct, the good luck to be descended from a long line of statesmen and clergymen, whose past recollections may assist me to arrive at correct conclusions and think with rapidity.

I shall therefore in this way endeavour to take my reader back in thought to the first day of the Epoch of Hope, the Eighth Day, the Age of Comprehension, or the Stone Age, and the Ninth Day, or the Metal Age, in which commences the dawn or rather incarnation of Wisdom and Understanding. In a very limited degree in the mind of man, when he, in the days of ancient India, say, twenty to fifty thousand years B.c. began to evolve his first idea of one God (for what I term ancient Buddhism must have commenced in India at least three to fifteen thousand years B.C.), and subsequently was continued in Babylon, Assyria, and Egypt, when mankind had already obtained a highly developed form of civilisation, Religion and Government (for this stage of evolution is contemporary with Government), which was, I take it, the first dawn of human wisdom, for the power to rule is the dawn of wisdom, just as with religion commenced the first dawn of comprehension or belief, which are twin developments of his mind. In 
my last chapter I showed how Imagination was most probably the earliest development of mind, after which soul began to dawn in the mind of mankind, with the result that he started to improve his surroundings and so started on the road of civilisation and then began gardening and agriculture.

This evolved the necessity for studying how to best cultivate the soil, so the reader will notice how the Age of Cain led up to Study, which will subsequently, on the Tenth Day of Evolution, form the corresponding marriage to Religion in Table III., as Adam does to that of Civilisation in the Stick Age, and Cain and Abel do to the dawn of Understanding and Government on the Eleventh Day. Thus at this stage of Evolution we find the Mongolian Race evolving civilisation and agriculture and a very primitive form of religion and the seeds of science out of superstition and necromancy in the more tropical climates of the world, while at the same time the Aryan and Northern Races, by their hard fight against the Glacial Period are directing superstition along a harder and slower road that is to evolve a more perfect form of religious ideal and a more energetic form of Government and the germs of commerce that are to subsequently replace the more materialistic one of the East and South. In just the same way to-day we have the materialistic "Kultur" of Germany waging war for the establishment of a military form of Government capable of keeping in check the more human but impractical unionism and democracy and folly of party government which will be ultimately supplanted by the higher ideals of the Allies when war has performed its duty in evolution and given birth to a lasting peace.

Each must do its duty as time and competition produce advancement, and the intermingling of the two Races produce co-operation in the future. It is more than probable that the materialistic doctrines of Germany are bound to gain a short ascendancy before the higher ideals of the Aryan Race, which are being upheld by the Allied Armies of to-day, have sufficiently evolved their higher ideals of philosophy to a sufficiently high degree for them to be practicable, or the masses have sufficiently evolved the qualities of energy and unselfishness to be able to receive the higher ideals of perseverance, mercy and justice which the Allied Armies are trying to enforce. Nevertheless, this war will do much to teach man- 
kind these lessons and fit him for the next day in Evolution, the day of "Peace to all men of good-will," when a federation of nations will make use not abuse possible.

In like manner in this Age of Cain we witnessed some two hundred thousand years ago between the Northern and Southern Races of mankind the commencement of the same strife for the same principles that is being fought out at the present time, and which is at the age we are now reviewing to be fought out in Persia, India and China to establish civilisation and early religions and governments at the commencement of this Epoch of Hope as Europe has now got to face them during the next one thousand years. Thus the next five hundred to one thousand years will complete the last of the seven days of this Epoch of Hope, after which man is at last to receive the promise of Christ which $\mathrm{He}$ came to establish at the end of the first three days of the Epoch of Hope by sowing the seed of the coming age of Peace, and so to prepare the way for the dawn of commerce by the completion of Religion which Cain, Seth and Enos were to start.

In like manner in the preceding Epoch of Faith the first three days were devoted to the creation of the world; the fourth day was to usher in Plant Life; the fifth Animal Life; the sixth day was to evolve mankind; and the seventh was to mark the dawn of his mind. So we now find the first three days (which we may estimate at about three hundred thousand years or so) of the Epoch of Hope are devoted to the evolution of mind and of religion in Asia, to give a complete result when on the fourth day of the Epoch of Hope, the day of religious evolution, Christ, at the end of the third day, shall give the final completing touch to its ideals and foretell the day of peace that is to loom in the horizon on the first day of the Epoch of Charity, about A.D. 2000, when man, having learnt by study, science and wisdom, the seeds of which Christ came to plant in the mind of man, and which was to be the seed of the complete likeness of the Image of God in mankind, and which man is to possess in the future Age of Charity, which I presume will commence during the coming one thousand years, when man will have grown the precious seeds of the plant of the Soul of Wisdom. The seeds evolution was sowing during the Eighth and Ninth Days of Cain and Abel were the seeds of Energy, Courage, and Mind which were destined to grow 
into the plant of religion as it was watered by the floods and snows of the Glacial Period, in order that it might teach mankind the mystery of only one God and of His Trinity, and so evolve his powers of Comprehension that, becoming religious, he might see and believe in a God he was not old enough to understand. How much more important must be the precious seed of the soul of Human Wisdom and scientific Knowledge which Christ came to plant that it might shoot in the future Age of Charity after we have established "Peace to all Nations of Good-will," when, and not till then, the Holy Ghost will at last descend into the mind of man and teach him true Wisdom, Mercy and Justice, out of which seed is to grow the plant of his Soul. How perfect this plant of the Human Soul is to be may be gathered by the fact that it has not been only watered, as was the birth of religion, by two hundred thousand years of Idolatry, Murder, Snow, Ice and Cold, and the Rain from Heaven, but ever since Christ sowed it, it has been manured by human blood in fierce wars and commercial greed, fanatical hate and bigoted animosity that have poured out blood like water over the plains of Europe and South America to ensure the growth of the seeds of Invention, Wisdom and Understanding that Christ planted in the mind of mankind when God has deemed it worthy of such rich manuring, how beautiful in its growth should be the plant of Wisdom when grown. And I am sure the world will join with me in a hearty prayer that these rains and floods of human blood may no longer be poured out before the idols of Ignorance, Superstition and bigoted Intolerance, but that the day may soon come when man will receive his soul of Wisdom, and, overcoming War, Slander and Greed, learn to live with Tolerance, Peace and Unity in Comfort, Charity and Content.

The period of Cain and Abel marks the acquisition, as I have pointed out, of the powers of Imagination and Comprehension, or the growth of the fourth attributes of God the Father and God the Mother, in the mind of mankind as he acquires the first and second qualities of the trinities of his soul, after the intermingling of the Aryan with the Mongolian Race during the latter portion of the Glacial Period, which extended over somewhere between two and three hundred thousand years. This brings us to the Age of Noah, the age of floods or heavy rains and glaciers, which made the earth 
fertile and evolved the highest qualities of Energy, Perseverance, and Courage in man, and the knowledge of God and His Trinity in his mind and so produced the dawn of civilisation and of the attribute of Understanding. In this age commences the dawn of Agriculture and Knowledge, and in the Age of Cain the first dawn of Religion, in the form of Idolatry amongst the Chinese and mankind in general.

But as Man's mind is but very imperfectly evolved at this period of Evolution, it would be absurd to expect him to evolve any but a very imperfect and materialistic form of religion, such as Idolatry. All this will be more fully explained when we come to the Tenth Day of Religion, which forms our next chapter. But what we are most concerned with at this age is the fight between savagery and civilisation. It is probable that agriculture and civilisation had their first dawn amongst the Mongolian Races in the form of gardening in the warmer climates, which lent themselves more readily to permanent settlement. The agricultural or civilised portion is represented by Cain, the husbandman, and the less civilised portion by Abel, the huntsman or shepherd, who preferred to lead a nomadic life. During this period the civilised portion live in constant dread of the inroads of the more savage tribes of the north around them, who are continually making hostile incursions into their cultivated districts. Prior to this the children of Abel had departed to the north and populated the whole of northern Europe.

It is probable that during two hundred thousand years Man was practically uncivilised, and that there was very little agriculture till after the Glacial Period. But through all this period of cold and rain it was only the tropical climates that offered any inducement to agriculture. When warmth returned to the North the more civilised Mongolian embarked, in search of new fields of agriculture, on the great Mongolian emigration, which extended even to Lapland, and it is noticeable that the districts through which this great migration swept, namely, China, Siberia, Northern Persia, the richer portions of Russia, Germany, Austria, Belgium, Holland and England, are still the agricultural communities of the worid. Egypt, Persia, and India appear to have had different and later civilisations though also of Mongolian origin, but the extreme suitability of these countries for agriculture is sufficient to 
account for a separate and later origin to their civilisation. Hence it is probable that to China we owe the dawn of agriculture and the early forms of civilisation, and the great Chinese wall shows how much the advance of early civilisation had progressed and how it tried to fence out savagery.

Contemporaneously with this the Aryan Races were evolving higher codes of morality. Now, the result of civilisation is always to produce a love of ease and a distaste for work, to a very great extent because town and agricultural civilisation necessitate not so much extreme exertion as very continuous and methodical efforts, which are more tiring and exhausting and distasteful than more violent exertion with intermittent rest. Then, when rest and ease are at length attained, the possessors become idle and indolent and are disinclined to any excessive exhibitions of spasmodic or superlative energy as the reactionary demand for rest from their labours sets in.

On the one hand the Mongolian civilisation, which gave rise to agriculture, cities, arts and manufacture, greed, dishonesty, business cunning and acumen, is morally a lower order of civilisation and an inferior course of education in fitness and energy, vitality and brain power. Nevertheless, it produces a much higher development of culture, art and skill than a pastoral and nomadic existence; but this is purchased at the heavy price of a false moral standard and a selfish form of democratic government, ever inclined to sacrifice the public good on the altar of selfish love of power and the Almighty Dollar. So in reality the huntsman and shepherd, who are represented by the less cultured and less enlightened but higher principled Aryan Races, whose life and closer intercourse with nature put them more in touch with the truths of revelation; and, when all is said and done, as my hypothesis points out, there is only a distinction not a difference between God and Nature. So it is not to be wondered at that to the ruder civilisation of the huntsman and shepherd we owe the ethics of morality and education and principles of just and honourable government, and the hereditary principles which go to make up the vital strength of a nation.

Art, science, and ingenuity only tend to feed the fires of luxury, indolence, folly, extravagance, waste, at the same time as they evolve genius and artistic variation and improve our environments and surroundings. So we find through the 
whole course of civilisation the Mongolian Races are constantly degenerating in true wisdom, honour, justice, mercy and morality at the same time as by their arts of knowledge and civilisation they are advancing the culture of the world as they evolve the female qualities of Art, Comfort and Pleasure, cruelty, greed and avarice, on the one hand, and the northern races are evolving the male qualities of Knowledge, Peace, Joy, Sport and moral rectitude.

But it is well to remember that these separate evolutions of civilisation have been progressing on their separate roads for eighty to one hundred thousand years prior to about ten thousand years B.C., when they commence to come into violent collision and alternately conquer and reconquer each other, so that we must not expect the permanent advancement in either direction to be greatly marked or wisdom to be largely disseminated to such a degree as to make men reasonable beings in less than twenty or thirty thousand years hence, except in a few instances; but we may be justified in hoping that in time to come this continuous intermingling of these two forms of civilisation may produce some higher form of civilisation in which wisdom may abound over folly. When both the Mongolian form of Government, "Democracy," and the Aryan form of Autocracy will be finally replaced by government by mental Aristocracy in place of physical Autocracy.

But one of the most striking characteristics of these evolutions of civilisation is that where the Mongolian Race push their victorious march, they destroy all previous art before them and leave desolation and waste in their wake. That this is still one of the distinguishing marks of the race, as it was in the days of Ancient Egypt, is seen by the destructive tendency of our enemies to-day, but we must not jump to the conclusion that there is no destructive tendency in the Aryan Races; only that the tendency is very much less strongly developed. So we find that although it is not till the last two thousand years that the Aryan Races have been able to add, to any noticeable extent, to the enrichments of art and manufacture, except by their tendency to preserve it from destruction, and then it has been mainly due to their superior power of control, management and invention, rather than to their skill and genius, for skill and genius are amongst Mongolian rather than Aryan evolutions. I remember reading the account 
of the Vandal Conquest of Germany in The "Times " History of the World, in which the Editor, commenting on the atrocities of the Vandal conquerors, says he cannot conceive that these atrocities could have really taken place, but considers they must have been magnified by the hatred of the vanquished races of Germany for their new rulers. But when in this war Germany has all the world against her, and little to fear from the restraining influence of the fear that her plans may be frustrated by the addition to the number of her foes, which would otherwise act a deterrent to her cruelty, we find that the hereditary tendencies of her Mongolian ancestry outweigh the sedative action of her Aryan rulers, so much stronger are the forces of heredity than those of variation or environment.

So we find that in a thousand years the influence of custom over national character is so slight as to be scarcely visible. Thus in the same way the following characteristics of the English race-viz., their being able to adapt themselves to greater variation of climate than any other race of men, a tendency to meet danger with a smiling face, and the characteristic that he never knows when he is beaten, either physically or in argument, are three that date back to the Glacial Period, when, the British Isles having become separated from the rest of Europe, and as navigation was not invented then, he was unable, like other northern races, to flee from the snow and cold and seek refuge in a milder climate. So we find to-day that despite the passage of over one hundred thousand years, they still remain his predominant characteristics, and this only is another proof of the importance of hereditary fitness, for certain duties and occupations outweigh in all but exceptional cases the influences of environment.

But at the same time we must not forget that although in a large majority of cases heredity decided fitness and adaptability for certain work or production of like results under like circumstances; on the other hand, so great is the strength, in the case of the individual, of the form of variation we call habit that in cases of more than the usual adaptability to variation and contact with powerful and exceptional environment either pre- or post-natal, that are conducive to extreme forms of genius or variation or eccentricity, when these habits may become so marked during an individual lifetime as to entirely obscure and obliterate the underlying 
hereditary tendencies of a family or race for the period of the said lifetime. It is these causes that give rise to phenomenal contortions of physical shape, such as deformities; and of mental developments such as lunatics and geniuses. So we find that extremes of good and evil, such as genius and madness, like a Cæsar or a Nero, a Napoleon or a Kaiser, may arise in any family, totally independent of its hereditary qualifications, and are just as likely to occur amongst one species as another, or amongst one class as another, so should not be used as an argument of condemnation or fitness for reward as regards a family or class, only in the case of the individual.

I have mentioned these facts in this chapter because in all the important characteristics of a Nation it is necessary to go back to prehistoric ages for its birth and origin; and we must not forget that history is, and is likely to be, of little use for the next twenty or thirty thousand years as a means of directing its lessons to a practical use, or to do more than mould local habits and customs so as to prevent present evils and modify customs, but will not help us to remove permanent evils or produce lasting good till we have a more enlarged record of the past. To do this we will have to turn more attention in the future than we have done in the past to promoting the breeding of the fittest by ensuring the highest rewards to success on the one hand and by condemning the unfit or mental monstrosities we call criminals to enforced slavery in state-owned factories at derogatory work and occupations, and prohibiting them the right to breed future criminal classes. This will also ultimately remove the clamour for state ownership, which in the majority of cases does not encourage superlative enterprise and energy.

These, if conducted as criminal or pauper institutions, will prevent state control being carried to an extreme, which abuse was the undercurrent which destroyed even that most perfect conception of human government ever yet achieved, the Roman Empire, by creating an aristocracy of goverument officials, who sucked the blood of the nation by ever-increasing to an abnormal degree the investment of its time, labour and energy in unproductive enterprise, and so creating a demand for ease and luxury far in excess of the possibilities of supply. For it is possible to have too many 
markets and no supply, just as well as too large a supply for existing markets, and it is the want of comprehension of this fact that gives rise to the talk of one community dumping its commodities on another, which is fallacious, for in the whole course of evolution races and species may become extinct because they get too lazy to hunt or work for food; but I cannot find a single instance where they died of starvation through having too much to eat. Yet I do not wish the reader to draw the conclusion that though I place the conversion of the sinner, failure and waster as waste of time, I would not advocate that he should entirely abandon his humane efforts in the very few cases in which it is advisable to perform such works of mercy. I simply contend that we should do more to prevent than cure, whereas in the past we have devoted too much attention to curing and too little to prevention. So in the same way I do not wish the reader to think that when I advocate restriction on criminal breeding, I would advocate universal matrimonial restriction that would extend to noncriminal classes. For evolution shows clearly that all attempts to interfere with the laws of natural selection, which places the choice of her mate in the hands of the female, are prejudicial except under very exceptional cases.

I have mentioned these facts in this chapter because the Glacial Period, which is the age we now have under consideration, is the age of evolution that did most to evolve the conditions that evolved the seeds which produced the roots of these problems of mental evolution, which are vexing the minds of man to-day, and really laid the fundamental casus belli for the physical, commercial and racial conflicts that call imperatively for the highest efficiency in cruelty, barbarity, cunning and invention which we see are now attaining their highest magnitude of possible evolution in the Great War to-day.

To return to the probable evolutions that presumably were being enacted at the time of the Glacial Period upon the world's stage, we find that as this struggle engenders higher competition amongst man and animals to retain possession of the Globe's surface, man having evolved a standing posture relies less on his fingers and more on his thumbs for his selfpreservation. Hitherto he has only required to put a large strain upon his fingers to suspend himself from overhanging 
boughs. So the thumb of the ape is of little use, and is therefore comparatively little developed as compared with that of man. He now provides himself with a long stick, or more probably two long walking sticks, and starts to support his weight on them in a perpendicular position. This he would do when using them as walking sticks instead of holding on to a horizontal bough of a tree. Thus the thumb becomes more necessary. It was centuries of progression in this manner that evolved the muscular power that made the human thumb what it is to-day. It was to this physical development more than all else that man owes his mind. We may correctly say that the evolution of his thumb was his first entrance upon the road to civilisation, so small are the causes that grow into great events, for once the thumb and an upright position are evolved he is master with his spear of the fiercest beast in the forest.

But as the greatest superiority amongst animals is measured by their activity, not only physically (as when we find the quick boxer or swordsman defeats the heavy-weight), but also mentally as in the case of the man whose judgment is rapid and decision of action thereon is prompt who is ever more able to become successful in business and to rise in society than the slow man no matter how great may be the latter's brain capacity or genius. So we find that a thumb, and a thumb only, could have enabled man to evolve a mind superior to that of a dog or a horse and thus defeat these powerful competitors for animal superiority. The evolution of a thumb enabled him to lambaste the dog with a stick, and to fix a bit in the mouth of a horse and so compel these two most powerful of all the animal kingdom (who had even beaten him in the most important of all evolutions, that of rapid motion and energy), to become his slaves and vassals, and so make secure once and for all, his supremacy over the animal kingdom which but for the horse and dog turning traitors would have enabled the animal kingdom to remain man's master for thousands of years longer ere his brains would have outwitted them. Without the assistance of these traitors the animal's physical superiority would have won the battle.

But so great an advantage was the evolution of the thumb that it soon started a hitherto unfelt impetus on the part of 
man to evolve the quality of Imagination which were to start the birth in his brain of both mind and soul.

I have now taken my reader in conception along the road of evolution, I admit, in a very elementary fashion, but I am trying to make this a short story rather than a scientific treatise, a sort of evolutionary novel, so to speak, that may interest the unscientific man, and so cause him to realise that practical rules of life may be adduced from the study of evolution. For many enquirers constantly ask me what is the practical use of evolution, any more than the discovery of the North Pole? I reply that if properly studied and understood, it is the shortest and safest way to arrive at the goal of a useful and unselfish mode of life, and the only way you can arrive at a knowledge of how to convert this world into heaven.

I can only be the coxswain or steersman to direct the course of such evolutions as Religion, Science and Government towards the one common goal of heaven and immortality. It must be the work of the combined efforts of future theologians, scientists and statesmen, who are the oarsmen in the boat of creation, by all endeavouring to pull together in one and the same boat, to propel the craft into the harbour of heaven. So we now find that the environments of evolution are busy at work some one or two hundred thousand years ago to engender more active forms of Imagination that man may the better employ the brain which the upright position permits him evolving, and, by inventing new directions of skill, for the thumb he has evolved in his fight to stand upright. So we now find that his nomadic life as a huntsman and a pastoralist evolves his Imagination. He therefore commences to make tools and weapons of stone to replace those of wood, and this enables him to pursue and slay the beasts which, owing to the increase of population in the southern and warmer climates of the globe, are fleeing north to escape this small member of their family, man, who has made himself their conqueror and is fast hoisting his victorious flag over the more prolific tropical regions where only the most powerful of his antagonists dare remain and dispute his supremacy.

These northern huntsmen and pastoralists, whom the Bible described as the children of Abel and Seth, who were such as loved a free and easy life, in close touch with nature, and who were described as "such as dwell in tents," are to form the base of the 
Aryan Races, who, by the higher comprehension of the truths of divine revelation which are contained in and revealed only by a careful study of God as he exists in Nature, are now to evolve the highest moral codes of Justice, Honour and Mercy, of one God and His Trinity and its twenty-one attributes.

While watching their herds and flocks in the moonlight, they let their imaginations wander among the stars that studded the heavens and dreamed of the Mighty King of the Universe who rules the forces of wind, rain and cold, to prevent the ravages of which is the one thought and care of the patriarchal King of the family or clan whose experience, honesty and wisdom of control they not only worship but obey; whose flocks and herds being held in common bind them together, and whose hereditary powers of judgment, wisdom and mercy, the daughters of superabundant wealth, make him ever thoughtful of their wants and cares. They realise that his wealth and comfort are the outcome of their united cooperation to protect their flocks and herds, just as they realise that it is his wise and thoughtful direction of their united efforts that enables them to combine to protect their herds or hunt their now scarce and wily game, for management, unity and co-operation are Aryan evolutions. Thus he evolves from his Imagination in such environments a higher order of abstract astronomy, comprehension and philosophy, moral rectitude and religious belief in one God instead of in Idolatry.

But the Mongolian or Southern Races, who remained in warmer climates, turn these new acquisitions of Imagination to account in a different manner from that of their northern brethren, whose nomadic life is opposed to loading themselves up with unportable necessities that are cumbersome to transport, so are content with a rug, a billy and a tent for accommodation. Not so the children of Cain, who, the Bible tells us, were husbandmen. These, finding the climate and soil more amenable to improvement so as to fit it to supply their wants without appeal to extreme energy, or the inconvenience of a wandering existence, they prefer to direct their progress along lines of more continuous, although less strenuous, courses of existence, which are not calculated to increase the particular duty of this age, viz., the perfection of Human Energy and rapid mental comprehension. They prefer to follow the shorter line to wealth and comfort along the road of least 
resistance, so evolve Imagination rather than his Comprehension (the latter, mark you, is the higher evolution of the two). He devotes his thumbs and brains to the construction of spades and ploughs of wood rather than to weapons of stone, and delegates to asses and cattle, or beasts of burden, the bulk of his labours; utilising his Imagination rather than his Comprehension, and becoming a husbandman rather than a shepherd. He now commences the rudimentary form of civilisation by permanently pitching his camp in some fertile valley by some murmuring brook, and thus arise the primitive villages, cities and states that are to make the early civilisations of the Stone Age. Growing in wealth thereby, the mighty colonisation of the East extends even to the fertile shores of the Mediterranean. But the Mongolian is less inclined to develop habits of energy and perfection of constitution, physique, order, government and family unity than the more warlike followers of the chase. Like all races who lose their energy by luxury, they become cursed by "Heaven's decree," and so lose their powers of further advancement; so we find that, somewhere about twenty thousand years B.c.. The northern races start to descend upon their southern brethren, whose wealth and luxury have destroyed their energy, and, although they do not advance its arts; they add to it higher forms of government, moral rectitude and greater security in the tenure of property and in commercial enterprise.

Although we have no definite historical account of these inroads, they are corroborated by the steps in the stairway of evolution, and the following verse of Genesis, which would chronologically fit in with the Aryan advent into India and the foundation of the earliest forms of Buddhist and Brahmin theology, which gave rise to the belief in God and His Trinity: "Lemech took to himself two wives"' (see Genesis, verse 19, chapter iv.), that is two races of mankind, "Ada and Sella, and Ada begat Jabel and such as live in tents and are herdsmen." This I take to mean that metal weapons were the result of the nomadic races who now intermingle with (or marry) the civilised Mongolian Race. The hunter and the shepherd were not of the civilised children of Cain, but the children of Abel, who now intermingle with or marry the children of Lemech and Tubal Cain, who are the personification 
of the Metal Age, and who produce weapons far more murderous than those of Cain, and now sweep down on the civilised races in a phalanx of battle and of robbery and of murder far more detrimental to the progress of this age of civilisation than the internal robbery and murder of the covetous children of Cain, who represent southern civilisation. And as it was most probable that the murderous Cain also represents the less evolved minds who rebelled against the social laws of early civilisation, and so were expelled from out the bounds of civilisation, which is described in the Bible as fleeing into a far country (i.e., " uncivilised" country) where they took to them wicked (i.e., "savage") wives. But this marriage of the children of Seth with those of Lemech portrays the return of the Northern and Aryan Races, who intensify the form of murder we call war to a seven-fold more serious crime or detriment to civilisation than were the avaricious murders of Cain; also by their raids tend to evolve commerce.

For as mind can only be evolved to any high standard of body by being trained in physical work, exercise and energy to stand severe fatigue, or to withstand mental labour, for there is no energy so exhaustive as prolonged and difficult mental work, which is far more fatiguing than bodily work, and there is no physical training more effective than that of war and sport. The consequence of this was that the Mongolian Races, owing to their earlier comparative luxury, had not evolved the powers of sustaining endurance and perseverance of their Aryan competitors, so were unable to evolve higher mental evolution until crossed by Aryan competitors.

These now descended upon them, bringing not the harmless murder of petty hostile bands of robbers, but the more dreadful and seven times more criminal form of murder, that of a trained army of greedy conquerors who came to rob and steal, but, unlike the Mongolian Race, were not inclined to burn and destroy not only the wealth but the knowledge, religion and civilisations that it has taken Man and God thousands of years to evolve, and yet after all these years we are still mad enough to honour and respect the warrior, and to devote millions of money to perpetuating war.

True religion has been inspired by God adding divine revelation to man's powers in a superhuman, yes, even as in the case of our redemptions occasionally in a supernatural manner. 
Nevertheless, we are not justified in assuming that as an entire product it is to any large extent free from conformity to the natural laws, which are as much laws of God in reality as those of divine inspiration; the difference alone lies in the manner of their transmittance. It is therefore nothing short of bigoted intolerance for religion to claim infallibility in its detailed teaching; its dogmas of revelation alone are infallible, as are the laws of God and Nature. But its teachings are but the growth of the enlargement of man's mind during the process of his evolution, and must therefore conform with the laws of God and Nature and be as much subject to error, and consequently to correction, as any other development of evolution as are the teachings of science or state or social laws.

For are not they the product of Nature and Man, and equally conform to Nature's laws of variation, as must all other forms of evolution. So the Mongolian Races, not having evolved a sufficient amount of energy and stamina to evolve religion to a belief in God or to evolve any of the earliest forms of law and civilisation, are now condemned by the unalterable law of the survival of the fittest through loss of energy to stop short on the road of evolution and make room for the more energetic Aryan Race, and are therefore doomed to advance no further, as are all those who, by loss of energy (the greatest of all virtues except the Trinity of Mercy, Justice and Charity, which are to be the conditions of Immortality, but which are the last of all evolutions to become complete), so fall short in the scheme of God's plan of evolution and lose their right to advance as have the animals before them.

I must leave such detail as this, or the reader will lose sight of the sequence of my Hypothesis before he is able to realise its importance. As I have already stated, the Age of Agriculture of necessity gives rise to a desire for the study of how to produce better forms of agriculture and a knowledge of how to forecast weather changes. This leads to superstitious worship and religion rather than to laws and order, and evolved more cunning in arts of clever deceit than truth or honour. Hence when the Northern or Aryan Races were driven by the cold and descended upon the Southern, and civilisation of Asia, some twenty or thirty thousand years B.C., as did the Huns and Goths later on upon the civilisation of Europe, Greece and Rome one thousand years A.D. These 
were physically and mentally much more highly evolved, inasmuch as they had evolved higher standards of Mercy, Charity, Honour, and Justice, although they were less highly developed as far as skill, deceit and cunning were concerned, when they descended upon the Persian and Indian Races, so are quick to realise the value of agriculture and civilisation. Having developed through a life in closer touch with Nature have higher powers of comprehension to add to Mongolian Imagination are now, by intermingling, to evolve also the germs of Wisdom as well as of Religion by Government, and so bring us to the day of the dawn of Understanding, on the Ninth Day of Creation, and to complete the incarnation of Soul in the mind of mankind on the Tenth, Eleventh and Twelfth Day, and thus fit him to evolve Commerce and Invention on the Thirteenth and Fourteenth Day. So when they conquer and acquire the northern portions of India and Persia, some twenty to twenty-five thousand years before the birth of Christ, they start a more advanced system of civilisation in place of the Mongolian one.

This, falling into fitter hands, produces the civilisations of India, Persia, Egypt, Greece and Rome, interlarded with the higher ethics of Buddhist and Brahmin beliefs. For with their higher conception of honour to the victor, which gave rise to the customs of Caste and Heredity, they have evolved a belief in one God, and one God only, and in the mystery of His Trinity, as well as a higher code of justice, mercy and unity, as a result of their fights against the cold and snow of the Glacial Period. This enables them to lay the foundation-stone of Religions, Governments, Empires, Commerce and Science, and so to move Evolution on to its next three stages of development. Concurrent with this advancement is steadily growing the germs and seed of religion to which I will devote my next chapter, for now that I have taken my reader to the end of the Ninth Day, which corresponds with the end of the Glacial Period, personified in the account in Genesis by Noah and the Floods, which latter fitted man's body to receive the seed of the third faculty of his Soul, that of the Understanding of Wisdom in its most primitive form of elementary government. But it is only the barest rudimentary knowledge of Wisdom he is yet to receive before the Nineteenth Century, yet as the Ninth Day, the day of 
Seth and Enos, started the belief in one God the Creator of Heaven and Earth, and His Trinity, that belief which Christ came to evolve into the perfect flower of seeing and believing in one God and His Trinity, so that all the future descendants of the Aryan Race seeing might believe. This has brought us along our Table of Marriages to the Tenth and Eleventh Days in Table III. or the Days of Religion and of Government, and in our Table of Marriages this corresponds in Evolution to the dawn of Study and Knowledge to evolve Religion and the birth of Human Will or Mind to evolve Governments. So we find our Tables are correct in their prognostications. These are the forces that in days of Cain and Abel or creation of Agriculture and Civilisation have made a second departure in creation by giving to mankind a mind which is the seed of the soul of Human Wisdom, for now on the Ninth Day, with the commencement of civilisation, he begins to evolve a knowledge of God.

The Tenth Day, which will be the subject of my next chapter, will follow the evolution of Religion from its birth in idolatry till its manhood in the birth of Christ, after which follow the three days that are to complete the Epoch of Hope; on the Eleventh Day, Government; on the Twelfth, the Age of Knowledge, which grows into Science; the Thirteenth, the Age of Commerce; the Fourteenth, of Invention. During the last three days of the Epoch of Hope we are to evolve Commerce and make it universal between B.C. 500 and A.D. 2500. To-day, somewhere about the Nineteenth Century, we complete the Fourteenth Day of Creation, the Day of Invention, and start to evolve the Soul of Wisdom on the Fifteenth Day. During the course of the coming three days of Evolution, which I estimate will extend to four or five thousand years after Christ (as near as I can estimate from the past three thousand years of Evolution), and so allowing about the same time for the evolution of the next three days as has been devoted to the past at about the same rate of decrease in length, for, as Christ tells us, "If these days had not been shortened, no man would have been saved." So this Fourteenth Day, the day in which we live, will continue to grow up to the Seven. teenth Day, and it is to be marked by mankind's final conquest over the forces of Nature; and during this Epoch the result of the three first supernatural attributes of God the Soul, 
the Grace of Understanding, is evolved to teach mankind to use, not abuse, this gift of Nature, as God the Mother of Creation combines with God the Holy Ghost, or the God of Love and the God of Soul combine to control the power of Man's will, which is to replace the power of God the Father, the God of Power, Might and Majesty, which have ruled the world up to the Fourteenth Day of Creation, after which Man's conquest over Nature and thereafter to conquer himself, by the prevention of Crime. This is to be the final result of the Seventeenth Day, after which he will evolve the possession of a perfectly wise soul capable of true Charity, which will be sure to bring about the Ages I have put against the marriages of God's Trinity that mark the Eighteenth and Nineteenth Days that follow after the end of Crime, with some slight exceptions, namely, the Ages of Comfort and Pleasure.

The final gifts of the Mother of God and of Creation to the children she loves, and what better gifts could she give than perfect Comfort and Pleasure? So on this, the Fourteenth Day, the last day of the Epoch of Hope, God the Father completes his reunion with God the Mother, by Invention. He will after this Fourteenth Day, the last of the Epoch of Hope, give to mankind the final blessing of God the Father in a Trinity of Power, Power to will, Power to act subject to the fee-simple of humble reverence and obedience to his creator; and, secondly, the blessing of God the Mother, the gift of "Peace on Earth to all Nations of Good Will," which her divine son, Christ, came to foretell. Ponder and think, oh, ye rulers of Nations, over this the final terminus of the second Epoch of Evolution, the Epoch of Hope and the Epoch of War, and do all in your power to perfect its fitness in the course of Creation by the formation, during the next century, of a Federation of Nations, to be controlled and governed by an international or cosmopolitan army of military police on land and sea, and the abolition of the right of any nation to hold, control or maintain a national or individual army, or to acquire territory except by purchase and sale.

This is now your duty, when the right time comes, in the course of the next few centuries of evolution, as it was the duty of Christ to complete the Age of the Trinity of Redemption by dying on the Cross so as to overcome Idolatry, Cruelty and Savagery in the heart of man by woman's love, 
and so to teach mankind the virtues of Devotion, Love and Unity. Cannot ye, oh ye rulers of Nations, arise above your petty pride, ambitions, and party politics and commercial greed and nail them on the Cross of, firstly, Universal Freedom to all Nations, regardless of colour, faith or creed; secondly, universal justice to all Nations of Freedom in Commerce, Government and Religion; thirdly, united legislation to prevent and punish crime, whether against individual, community or nation? This is the Trinity of Action God now calls on you to perform in the coming epoch, which is to complete the Epoch of Hope which commenced with Cain and Abel.

Can you rise to the occasion as Christ rose on the Cross? For as when Adam and Eve learnt to sin, God gave them a mind so that they might learn virtue; so now to such nations as will take this lesson to heart, and realise that the time has now come, with the end of this Epoch of Hope, when murder and Crime, by God's decree, are to become obsolete virtues of evolution, it becomes your duty to destroy the last remnant of murder, the remnant we call war. For just as murder was the virtue that gave man a mind, destroyed the angels and created the devils five hundred thousand years ago, so peace is the virtue, oh ye rulers of Nations, that ye are called upon by evolution to produce as the crowning evolution of the Epoch of Hope if you wish to gain a soul in the Epoch of Charity.

Can you rise to do your duty as Christ rose to His on the Cross? If not, your Nation must cease to advance, as China and other savage nations have already done. Ponder, oh ye students of Science, over the other lessons Evolution now points out to you, for the success of the coming of the Spirit of God, the Soul of Wisdom, during the Epoch of Charity, which is to start with the day of "Peace amongst nations of good-will," which is to fit mankind for immortality, depends on you. This is the duty which lies at your door. To you it gives a demand in the future that was withheld by God from the Churchmen in the past, and that even they were not permitted to use lest they might abuse it, until the mind of man had arrived at a higher standard of development. It is your duty to interpret to mankind in an understandable manner the revelations of God as evolution unwinds them. Surely, but very slowly to your very, very, very slowly evolving minds, as the gifts of wisdom will be very, very slowly given to man, 
in the coming days of the Epoch of Charity, which are to evolve the third faculty of man's soul, the faculty of Understanding. Think and remember that your right and title to interpret the truths of revelation are as mich bound and restricted by the order of reverence and obedience to your maker and the truths of God's Trinity as man's right to conquer and control the Universe by Invention is bounded by the fates of Evolution. Do not forget you can use and misuse the powers you are about to be given as you evolve the mind of Wisdom. They will be as high and important as the responsibilities laid on Christ when He came to grant the attributes of God the Mother to Woman to enable her to give to man her powers of Love, Sympathy, and Invention, without which he would never have been able to conquer the world. Now that your turn has come, and the duty of Evolution has placed upon your shoulders the duty to take up the work of redemption where Christ dropped it, in just the same manner as Evolution placed the duty on the shoulders of Cain, Abel, Enos and Christ, to take it up where God the Father dropped it when He created Adam and Eve in the image of God's Trinity, it is now man's duty to take up by Science the work of Christ and move it a stage further. Remember it is the image of God's Trinity in Nature that must prove or disprove the truth or falsehood of your theories, the check to the correctness of which is the only reliable keystone that will make a lasting bond in the bridge from God to Man, and the evolution of it by the Aryan Races is the one act of Evolution that places the Aryan-crossed races above the Chinaman, Turk, Hun, South Sea Islander, or Hottentot.

The Epoch of Faith, as we have seen, was devoted to the evolution of Matter and Body; the Epoch of Hope is to perfect Man's energy, courage and mind; the Epoch of Charity is to create his soul by the aid of Science, granting to him a fuller understanding of the object for which he was created. As near as I can calculate it by progressive ratios of logarithms, it has taken from three hundred thousand to five hundred thousand years to evolve his mind; about one hundred and fifty-six million years to evolve his body; about two hundred and fifty million years to evolve Animal from Plant Life; five to seven hundred thousand million years to evolve Matter, Earth and Planets, and anywhere from fifteen to twenty 
thousand million years to evolve Matter from Gas. I only put these as approximate calculations. I mention them here for the sake of illustrating to some slight extent how rapid has been the evolution of the mind of mankind as compared with that of the Universe and that of his body, that it may encourage us to combine together to evolve our souls of happiness.

We find that approximately it has only taken three to five hundred thousand years to evolve man's mind by incessant fighting, yet it took between seven and twelve million years of swinging from bough to bough, instead of crawling along the boughs, as other apes did, before they were able to alter the muscles of the body by transforming the tail into other muscles to suit the upright posture and keep the stomach, bowels and lungs in their new positions, and over twenty million years to evolve an upright posture. I cannot go into details here, for this transformation stage would fill a volume in itself. Yet I take it that all apes who evolved perfection in this upright position, and perfection in murder and cannibalism, had attained the trinity of perfection that was to raise them to the standard of man, and so became men. This marked their perfection in the Epoch of Faith, and so they became Lucifers, or perfect devils of beastliness, and so were fit to receive a mind that in this Epoch of Hope was to evolve perfection in courage, cruelty and selfishness, the three qualities that were to make the greatest virtues of the past three hundred thousand years, which were to be marked as being the ages in which mankind was to evolve Religion, Government and Commerce, for the evolution of which these qualities would be required; to do which he must first attain perfection in these arts, and those of war, energy and perseverance, in just the same manner as it was necessary for him to excel in murder and brutality in the Epoch of Faith.

So we find the pendulum of power is constantly swinging from selfishness, cruelty and war on the one side to love, order and charity on the other, as the fight for supremacy lies between religions, law and order on the one side and might versus right, commercial greed and individual ambition on the other. So the Epoch of Hope is to be the arena in which we are to watch the alternate rise and fall of religion after religion, Government after Government, Empire after Empire, till Religion attains its full growth and perfect de- 
velopment, when the star of Bethlehem rises in the Heavens to shed its light over all the nations of Aryan birth and bring them all together under the flag of Christianity, which is to sow the seed of Justice, Mercy and Charity amongst all Aryan or half-breed Aryan nations by gradually developing the qualities of God the Mother, Comprehension, Belief, Love and Invention in the minds of mankind, and so to prepare them to realise and believe in the divine revelations his mind is yet too young to understand. Till a brighter star-the star of God the Soul-shall rise anew in Science just as the light of God the Mother did in Religion. So, in the future, Science will rise as a bright light in the minds of men, and by clearly and reasonably proving and demonstrating the revelations of God to all such as by Wisdom become fit to receive the Holy Ghost, when it shall at last shine through the mist of idolatry, superstition and bigotry, and make clear the wisdom of God the Soul to all mankind, so that the promised Paraclete may at last descend upon this world in the Epoch of Charity and abide, as Christ promises, with mankind for ever, that he may learn to know all things, even to the consummation of the world, and so banish the cruelty, war and selfish greed that Religion could teach him to see and dread, but could not make him wise or powerful enough to conquer till after the coming of the Holy Ghost, by the creation of the wisdom of a clearer understanding of divine revelation than his previously undeveloped mind could stand the light of. 


\section{CHAPTER VII}

\section{THE EVOLUTION OF RELIGION}

As man developed in his earlier stages he was, as we have seen, the most savage animal in creation, ferocious and hunting for the love of killing and fighting (which is animal murder), and, being a cannibal, devoured even his own offspring. Do not call me a brute for making such a beast of man; please remember that I have to review facts from the stern standpoint of probability, and logic commands that I should have neither beliefs nor sense of feeling, or that, if I have any such paltry sentiments, I should at once dismiss them. And logic commands me to remember that if man is to end by being the most perfect being in creation, he must, to excel in virtue, first excel in all the opposite vices, or else Evolution would be contradictory; and I have already pointed out that but for the three exceptions, one in each epoch, which God has ordained to prove his prerogative to rule all his creations, it never has been contradictory.

One of its fundamental laws is that true wisdom is the result of experience overcoming folly; that all virtues are so many forms and degrees of wisdom, and all evils are but so many forms and varieties of folly. Hence it follows that mankind's excellence in future virtue can only be attained by his first excelling in its opposite vice, and so gain wisdom as the reward of the conquest of folly. Heaven and Immortality are not to be considered as man's rights, but only as the reward of those, who through the whole course of evolution have the energy, perseverance and courage, to fight on to the end, and so gain perfection. And as I have previously stated, it is only by overcoming the inclinations to do wrong, that it is possible to merit reward. It therefore follows that whatever acts the plan of creation is at any age devoted to evolving excellence in, that act must be the highest virtue of the age. Hence before man could rise above the beast creation, he had to become the most perfect beast imaginable. 
This he did by becoming a murderer and a cannibal. Then the next perfection demanded of him, was to evolve the most perfect shape. This he did by learning to stand upright, which made it possible for him to evolve a soul. Thirdly, he had to acquire the greatest possible strength of will that he might become the image of his all-powerful Creator. This he did by becoming the most determined, pugnacious and ferocious of all animals, and the most determined and persevering amongst the races of mankind. In this manner he has during the Epoch of Faith, perfected his likeness to the primary attributes of God the Father and of God the Mother, and it is now his duty to evolve the higher attributes of God the Mother, and the lower ones of God the Soul.

The currents of power have now developed his power of will in the Epoch of Faith, and during the first two hundred thousand years of this Epoch of Hope he is to develop those of Love, which travel diagonally, the reason being that Love is to intermingle the influences of spirit, body and soul. For the intermingling of the female forces of Existence, Love, etc., with the male forces of Spirit and Soul is what constitutes the marriages of God's Trinity in the mind and soul of mankind, which are to make him like unto God's Image. For, as demonstrated elsewhere, this diagonal intermingling of the female attributes of God in the mind and soul of mankind is a marriage of affinity rather than of descent. Therefore to bring this about, the intermingling of female attributes with male ones, the miracle of redemption becomes a necessity of religious evolution, so as to make some of these female qualities hereditary forms of variation. Thus we find that the Glacial Period, by increasing man's fear, which is a female attribute, creates both religion and a greater love and desire for the sympathy, and for the company of his spouse within man's dawning mind than he had ever felt before, and this makes him protect his spouse, and tends to soften his cruel nature in a degree not aimed at by any other animal.

Fear being a virtue in woman and a vice in man, woman has now to prove her superiority in fear and love, and henceforth on man falls the necessity of devoting himself to her protection more than on any other animal. This produces more love for his conjugal surroundings as time goes on and civilisation advances, but until this stage of evolution had 
arrived, it was impossible for woman to exert very much influence over the hard, cruel and stern will of her savage spouse. But now under the diagonal influences of love, which begin to influence him as he acquires more mind, and as increased cold and hunger make their value more felt, religion and redemption begin to sow the seeds of soul in his heart and he begins to be influenced to a small degree by the attributes of God the Soul. These influences of fear and religion begin to develop greater constancy in marriage instead of indiscriminate animal selection, particularly amongst the northern and Aryan races, whose laws of Caste and social superiority make monogamy possible. Woman is from henceforth to advance him along the course of civilisation and evolution by combining with his animal courage the influences of Thought, Imagination and Comprehension, that go to make up the human mind (it will require the further development of understanding to evolve his true soul in future ages yet to come); yet with the aid of her redeemers she will now be able to grant him Love, Sympathy and Mercy and Invention.

This is to come about as woman's love, takes thought to heaven and diagonally ascends to Soul, then diagonally descends back through Imagination and Comprehension (see Tables I., II., III.), to the knowledge of God and the conception of the truths of revelation. Thus she has now attained the results of the development of man's life, will, love and thought to a higher evolution of the human mind, and thus man acquires the germ of soul in the seeds of religion. For the perpendicular posture, which causes the electrical current to descend lengthways instead of at right angles to his spine, is now slowly evolving his powers of Imagination to those of Comprehension, whilst the other animals, owing to their horizontal posture, cannot evolve beyond the attribute of Thought or instinct, sexual marriage and life. This has placed man at the head of Creation for all time to come, but he is now about to embark on a more extensive voyage, that of acquiring the control of the Universe.

The earth having now cooled below I4o degrees, all marked changes of body and shape are complete, and man alone has been able to perfect his bodily powers of endurance sufficiently to evolve a mind or soul capable of evolving religious thought, or of comprehending the truths of divine revelation; but this 
only in a limited degree by the southern races, who did not come in contact with the cold of the glacial periods, and who only received one redeemer in place of three. This development, which we are about to follow in this chapter, will show us how the fifth marriage of God's Trinity, that of Soul, Life and Knowledge, will produce Study and Religion.

The powers of God's Trinity and its marriages, and the test of the likeness to God in Nature by its trinity of forces, must ever make Science subservient to revelation and religion, but at the same time I will equally demonstrate the necessity that Religion must not be too proud to be instructed and reformed by science and evolution. I have already pointed out that the truths of revelation have never been one moment absent from creation. They have been, and many still are, dormant, waiting till man's further development, through stage after stage of evolution, gradually ripens them one by one as his mind and soul become fit soil for their growth, when the flowers of religious belief will ripen into the exquisite fruits of a clear and unmystified revelation, and dropping off the tree of God's Trinity will at last fall on the cultivated soil of man's more perfect understanding, when he shall have cleared it of the weeds of crime, superstition and bigotry, and made it fit to nourish so choice and delicate a seed as true wisdom, like unto the champac flower which the Brahmins say can bloom alone in Paradise. And this is why, not only to nations but to religions also, evolution is now, on the fifteenth day of Creation, upon which the world is just about to enter, sending its angels through the skies to sound the judgment call of "Peace to all men of good will," so that man may learn to use without abuse, and so at last evolve his soul in the seven days of Creation yet unborn.

But the day we are now starting to review, the tenth day of Creation, will usher into the world the birth of this mighty revolution of mind, we call religion, in its first ugly infancy, that of Idolatry, which will bloom into Christianity with the birth of Christ, the world's third and last redeemer, in turn to attain its perfect manhood of wisdom by the power of the Holy Ghost taking birth in scientific expoundation of revelation. Man, if not perfect in this direction, has already, by this tenth day, grown to boyhood in the arts of sin, and so has evolved his powers of perception between right and wrong 
sufficiently to make it possible for him to aim at higher ideals and endeavour to formulate virtue by starting to control such of his sins as evolution no longer requires, so the master of ceremonies now introduces religion upon the world's stage.

But do not forget that of himself man could do nothing to evolve honour, love, sympathy, mercy or justice, for these are female attributes of God, any more than he could have a child without the assistance of woman. In the same way woman is to come to his aid with her redeemers and open his eyes to see, if not to understand, revelation, by her special realm, "the world of religion." Thought and Knowledge, Mind and Soul are male, so he can evolve the Spirit of the Holy Ghost, when God the Holy Ghost will, in the ages of science we have since A.D. I80o begun to evolve, descend into his mind and create in him the soul of wisdom and understanding, in just the same manner as we have watched him develop the Spirit of God the Father in the evolution of Mind and Knowledge by Imagination without any special miracle or intervention on the part of God. This is not the case as regards the female attributes, which were only cases of variation, not of heredity, on the part of man; but during the eighth, ninth and tenth days evolution will enable some of her qualities to become hereditary in her male offspring after the birth of three redeemers, who, during these three days, will be born without the assistance of man; so we find God now performs this miracle to permit of religious perfection and enable mankind to become possessed of honour, love, mercy and justice as qualities of heredity, whereas previously they were only forms of variation; so we are from now onward to follow man's evolution of virtue.

Up to this point evolution has been devoted to the development of Matter, Shape and Energy. My reader will complain that I am taking him over stale ground; but so great is the tendency of the present age to place wealth and pleasure before enterprise and skill, and to confound freedom with a license to avoid the calls for duty and efficiency, that I cannot help again bringing before his notice the fact that laziness is far and away the greatest of all crimes in the eyes of God and Evolution. Let man become lazy, and in exact proportion as he does, will he lose the power of advancing himself or his children in the social scale, and in mental advancement. 
Yet in the midst of war and misery men are refusing to work more than forty-four hours a week. What is the race dwindling down to but a race of wasters, not fit to continue on the face of the earth. Laziness is the one crime for which, more than all others, God, from the days of the mammoth creation till now, has exterminated whole species and races and nations.

What is the use of knowledge or virtue if by loss of energy we bring upon our heads the curse of extinction which Almighty God for ever inflicts as the punishment of indolence? He often condones murder and immorality, but laziness is for ever punished by the loss to a nation of the powers to breed mind or soul, and finally by the loss of the right to some day become immortal. Let six generations of any family become lazy and too fond of idle pleasure, and no matter how brilliant its past career may have been, either physically or mentally, it is condemned to extinction, or at least the branch of it that fails in energy. So also if the bulk of the people of any nation become indolent and lazy for six generations, the nation degenerates, loses all powers of mental advancement, and does not rise again and is unable to progress in the course of advancement in civilisation or brain power until conquered or inter-bred with some other nation whose surroundings of greater poverty and hardship have kept up their energy to the standard evolution requires. No extinct race of animals has died out except when its food has become so plentiful that it has not had to seek for it, or when it has been compelled to succumb to some variety that has evolved superior energy under conditions of greater privation, and so has become more developed either mentally or physically.

So now that mankind has developed the souls of Imagination and Comprehension, and is about to develop the soul of Understanding, it becomes the duty of man as he develops the spirit of wisdom and takes up the work at the point where Christ dropped it; and acquires sufficient mind to understand the truths of revelation, and learns better how to use not abuse the universe God has created, and for him to combat this, his greatest difficulty, and to provide against the growth of indolent habits. This will be a far greater difficulty than the adjustment of the distribution of wealth, or the prevention of crime, and can only be brought about by Religions, Governments and Science combining to impress upon the masses the 
aims of creation and the necessity of social distinctions and by the destruction of class jealousies and racial animosities, and by teaching the mass of the people that success must lie in the united efforts of employer and employee, rich and poor, labour and capital, combining to combat and destroy indolence, failure and want of skill, and stopping the breeding of the criminals and unemployables, and confining unions to the limits of assisting their members in obtaining employment, increasing the skill of the workers, and increasing facilities for the ease and rapidity of work by efficiency in machinery, skill and management; but prohibiting their having any political status or interfering with free and unfettered competition in an open labour market; so as to produce the greatest possible incentive to energy under free conditions of trade and contract, trusting to God to reward him with prosperity in proportion to his utility, skill and usefulness to others, rather than to himself, and aiming at selfish individual acquisition of wealth and power. The right to possess must be the capability to use, manage or control with wisdom, not the might to hold or retain. Might has been the sole standard of possession, and rightly so in the past, for man's one prominent duty in the Epoch of Hope has been to reward physical superiority, and, but for the virtues of cruelty, selfishness and greed, he would have lacked the powers or inducements necessary to have overcome the pain and suffering required to fit his body to receive a soul, or to evolve religions, empires, or commerce, and to exploit the world. But these qualities which circumstances have in the past made into virtues are now to become crimes, and in future he will to a much larger extent have to become his own expounder of revelation and have to decide for himself what is right or wrong, or, failing to do so, to be made a government slave and incarcerated, and should, if necessary, be punished by castration; or else, when war is abolished, we must resort to starvation to rid us of the unfit.

Hitherto man's soul has only partially developed, and God did not intend him to be his own expounder of revelation. In the future it will become his first duty to tear down the veils of superstition and bigotry, and on their ashes to build a clearer and more perfect understanding of the past fables of revelation that were necessary to enable him to see and believe and be interested in the parables and fables and fairy tales 
necessary to beautify and make interesting the truths of revelation, which his want of understanding prevented him from being able to fully comprehend. It was, therefore, necessary to appeal to the only power he had evolved up to that time, namely, the power of superstition, which the male properties of Imagination and Thought, and the female properties of Fear and Love created, and which were to produce his reverence of religion by appealing to the supernatural creations of his brain that fear had evolved. Hence in all past religions these factors were the sole and only foundation on which religion could be based, as the impartial development of man's mind necessitated that its teachings were made interesting by parables and fables which would pander to his superstitions.

With this introduction I have led the reader up to the point where it is possible to trace the course of religion through its evolution from Imagination to Fear, from Fear to Love, from Love to Thought, from Thought to Reverence, and from Reverence to Belief; and in the Epoch of Charity, just beginning to dawn, from Belief to Understanding, from Understanding to Right Thought, and from Abuse to Use, from War to Peace, from Peace to Comfort and the destruction of Crime, from Comfort to Content and Charity, from Charity to the Joy, Pleasure and the Happiness of Heaven on Earth.

It is not my intention in this treatise to follow any but the most concise course of evolution and logic, and to avoid details as far as possible, to pass from stage to stage, picking up only those side issues that tend to demonstrate the main issue, the feminine gender of God's Trinity and the theory shown herein of the withdrawal and the return of the personalities of God's Trinity in the course of evolution and the connection between the two. So I have shown the manner in which man has most probably evolved Imagination, Comprehension and the dawn of Understanding, and is now fit to evolve Religion and Study. We now find the increased difficulties of his severe combat with nature have evolved fears and superstition which make him susceptible to religious influences. As mentioned in the last chapter, man is now driven to believe in a superior power possessed by the elements about him, and therefore he attributes to the sun, moon, stars, wind and water the divine attributes that belong to God. The Spirit of Knowledge of 
Revelation is not yet possessed by him, but has been dormant from the commencement of time in his sleeping soul and the sleeping soul of all creation before him. This becoming active, he now begins to endow the forms and shapes about him with the divinity that his slumbering knowledge of revelation, now trying to awaken and form some tangible existence, has conjured up by the aid of his newly-acquired faculty of Imagination. For the gift of Comprehension has not yet been completely vouchsafed to him, so the existence of one God and his Trinity is still unknown to him. Hence, in his enforced ignorance, he makes gods of all around him and superstitiously worships them. Yet the knowledge that there is a superior power to which he must submit is now becoming apparent to his dawning soul. Hence the mother, by using the superstitious dread she can now implant in her children, finds she can gain more influence over them to bring them into subjection and by so doing she is able to exert some influence to soften their savage instincts and evolve some feeling of love and sympathy within their hearts, and so overcome the cruelty of their natures. For the reader must realise that it was the virtue of cruelty.

THE VIRTUE OF CRUELTY : I use the word virtue here, not Crime, advisedly-see the explanation of Virtue and Crime in Book I., viz., that circumstances decide between right and wrong. So at this stage of man's creation it is cruelty that did most (under the everlasting laws that govern the survival of the fittest) to enable the superior races to triumph over the inferior ones, and by slavery to produce the necessary evolution of persistent labour. Thus her offspring becomes less cruel and more affectionate to her than man had been to woman in the past. Do not forget that all the attributes of God the Mother are transmitted only through woman to the souls or minds of future women, and could not be transmitted from father to grandson, only from mother to grand-daughter, until after the redemption of mankind. But the properties of will and mind, which are attributes of God the Father and of God the Soul, man was able to evolve without supernatural assistance. In the same way the two attributes of the two male personages of God's Trinity are only transmitted from father to daughter, not to grand-daughter, so cannot be transmitted to her female offspring. 
So it was only by the growing fear and superstition of this age that the fond and loving mother could influence her male offspring and so pave the way for his acquirement of Love, Sympathy and Charity from which his cruel, unsympathetic and hard nature revolted. Hence this progress was necessarily very slow, and woman wept many tears when she saw the boys she had by her fond influence toned down to some sort of gentle feeling, when they became men, throw all her lessons to the wind as they neared maturity, and to revert to the vile devils of cruelty their grandfathers had been, for prior to redemption her daughters alone were amenable to the softer qualities.

Hence when man was out fishing and hunting and revelling in blood and destruction, many and many were the tears of love that the mother sent up to heaven, and how much more worthy they were, and perhaps far more virtuous and sincere than those subsequently offered in latter days even though they were clothed in superstition and offered to some dull and senseless idol. No worlder that their constant knocking at the door that we are assured will never for long remain shut to those who earnestly and truly seek the truth in humility, meekness and suffering, was at last opened and produced the greatest of the only three miracles God intended to perform in the whole course of creation to mark his prerogative to govern mankind, should now be performed in this Epoch of Religion, Love and War. For now the daughter of man is by the grace of God the Mother of Creation to become incarnate without the aid of man and so permit him to receive the power to transmit her love of God and her neighbour to the hearts of his male as well as female offspring. Yet owing to the retrograde steps of evolution, after the birth of the first redeemer, twenty or forty thousand years have scarcely passed away, than all woman's work, even with the help of a God-made man to assist her to redeem mankind, is again lost in the dense mists of idolatry and superstition, and God the Mother has again to come to her assistance in the form of Buddha, whose name only is historical, for the Buddha, who was the founder of the earliest forms of Buddhism, most probably lived twenty or thirty thousand years before Christ. The Buddha of modern Buddhism, Gautama, was in all probability, it appears to me, only a later-date reformer who lived after the people rebelled against the corruption of early Buddhism and 
who remodelled the Buddhist religion after a schism which, it appears to me, must have been the outcome of what undoubtedly was the result of the Aryan belief of honour to the victor, conqueror or ruler, and which belief gave rise to the earliest form of reverence to hereditary superiority, which undoubtedly was the basis of the formation of caste. The logical deduction (by inverse logic) is that this belief in caste and heredity created an early form of aristocracy, as the outcome of such a form of belief which is only the logical result that one would expect to be produced out of the trials of the Glacial Period acting upon a patriarchal community whose mind was but dawning, and which in time degenerating into autocracy produced revolution both social and religious. This or some such revolution of prehistoric society is the only possible way to account for the outcome of the subsequent Buddhist religious teachings which indicate (to the mind that is capable of reading between the lines) what must have been at work from twenty to three thousand years before the time of Christ.

It would take twenty-five thousand years to bring about such a revolution in human beliefs. Some such collection of events was probably the cause of the Darian, Hyksos, Mosaic and Aryan emigrations. For it appears to me that the teachings of Buddhism after the date of one thousand years before Christ all point to the fact that some such form of aristocratic belief and government existed 'amongst the early Aryan races, and was carried to such extremes of patrician haughtiness and arrogance that about 2000 or 3000 B.C. it grew to stink in the nostrils of the Buddhists and Brahmins amongst the masses of the people and so gave rise to a series of rebellions and revolutions in prehistoric times, and that these religious feuds were the means of spreading the Aryan belief in one God and His Trinity throughout ancient civilisation. It is probable that this early Buddha was synonymous with Seth or his son Enos, who, Genesis states, "called on the name of the Lord."

It appears most probable that the Mosaic people were an Aryan emigration who migrated from India into Babylon and Assyria and Persia until, their religious beliefs becoming unpopular, they were expelled from Persia into Palestine, as their Hyksos kinsmen were previously driven from Egypt into Jerusalem some thousand years earlier. It is curious fact that the belief in one God and His Trinity did not become a 
universal belief amongst the Jewish people till after their captivity in Babylon, and this makes me inclined to draw the conclusion that, although not a matter of history, it is probable that during their captivity in Babylon they came in contact with some enlightened descendants of the former Mosaic emigrants who stirred into action the more enthusiastic amongst the half-hearted believers. These very likely were men of a higher class whose superior abilities had placed them in such a strong social position amongst the Assyrians and Babylonians that they had not been compelled to flee from the country when the rest of their clan were expelled into Palestine.

But as this is only a short treatise to establish the connection between the marriages of God's Trinity and Evolution it is not practical for me to go further into this subject. I will therefore pass rapidly on to the third God-made man, Jesus Christ, who was to complete the trinity of such redeemers and to perfect religion so as to enable woman to complete her conquest over man, the beast, and also finally to make it possible for man to transmit some of her female qualities-viz., Love, Comprehension and Invention-as well as his own attributes of trinity. Man, whose very beastliness had enabled him to conquer all his former superiors in creation, even to the angels or mammoth creation, and so to become the only devil that ever has, or ever will exist on this globe, is now to be overcome and reduced to submission by the combined-powers of God and the tender love of woman, till some day in the distant future he will be destined to become a redeemed and docile animal now that woman has got such powerful allies on her side as God and Religion.

I have now brought my reader to the final climax of the evolution of Religion and to the ages of history, but before dropping the subject it will be well to point out a few of the factors that have played an important part in religious evolution, and that may be of use in further connecting it with the place assigned to it by my hypothesis and its Tables of Trinity, namely, the tenth day of Creation. One of these factors is the creation of Governments, which are to be evolved on the eleventh day, and are therefore concurrent evolutions. Now it will be found that these governments, as they rise in the wake of religion, are to be alternately its dearest friends and 
its bitterest enemies; its protector to-day, and its slayer and destroyer to-morrow. So we find that evolution is devoted at this time to constant contests for supremacy between Religions and Governments for the right to rule mankind. But the reader must not forget that behind the throne there is a higher power, Fate, the instrument of God's prerogative to rule mankind and all His creations, which is above the greatest powers of man, religions or governments. For man has only a limited power of control over his actions. God alone has power to will and to perform; Man can only will and do the best he is able to perform, the result of which is that God for ever intends to retain absolute control of Creation that $\mathrm{He}$ may be able to reward man's control of his actions by the hand of Fate.

At this period of evolution Fate decrees that to evolve Religions and Governments to their perfection, each shall in its turn become corrupt and degenerate and practically die, to be reborn and rejuvenated in accordance with the laws he has laid down for the rest of evolution, so that each life of religion or government may be an improvement on the one that has preceded it, just as in life, youth is followed by old age, so that out of the decay of one religion shall rise a more perfect form of Government and that the growth and decay of Governments shall evolve more perfect forms of religion moulded on the skeletons of their defunct corpses, and so adapt themselves to the progressive growth of man's mind. And out of these struggles for their existence and supremacy are to arise Knowledge, Experience and Commerce, and subsequently Science and Invention. So now we find that fate decrees that each and every form of religion is in turn doomed to be lost in the mists of Idolatry and superstition till it shall be beyond all recognition and shall be so perverted by man's desire to make it the tool of rebellions and reformations of government as to become degenerate, after which it will again be replaced by a more advanced form of religious reformation. For these reasons God continually wipes out nearly all the details of past religious beliefs and only leaves just enough of their teachings to be sufficient to evolve the next form that evolution requires, which $\mathrm{He}$ has also done with all forms of past evolution, leaving us only a broken chain. Nevertheless, he leaves sufficient links for us to see that it is the same chain, the reason of which is that $\mathrm{He}$ does not intend past convictions to override 
new ideas and lessons, and so to destroy the new principles that $\mathrm{He}$ wishes to establish in their place, so He only leaves the most important links in sufficient number to connect the whole.

We find that in religion, past revelations are only left in sufficient number to connect them with the new ones of His reformations. But $\mathrm{He}$ leaves all the really important truths bright enough to dimly shine through the dense mists of superstition, bigotry and idolatry that gave them birth or produced their death. And in just the same way that religions in the past have had to give place and make room for new forms of government, new forms of government are built upon or out of new religious beliefs and thoughts, and each in their turn is supplanted by a newer and better form, more suited to the form of rule, or more adapted to the requirements of the coming age or time, if not always of a higher moral, social, scientific or virtuous development. Fate has, therefore, in all past ages of evolution contorted and disfigured all teachings, both of religion and knowledge and revelation, so that it would puzzle their founders, Mahomet excepted, were they to return to life, to know to what religion they belonged.

One reason is that only those religions that lend themselves and their teachings to alteration and tend to advance mankind along the road of evolution, become permanent for any length of time, whereas those that do not alter in moral development, as the times alter, do not keep pace with the advancement of man's mind and become obsolete, but even these, like all wornout evolutions, nevertheless perform their respective duties by offering a means of government and control that is not too high an ideal for the less enlightened mind to grasp, and so act as links to bind together the past, present and the future traditions and teachings of revelation. For Confucius would not recognise the modern forms of the Chinese religion, nor would Buddha recognise modern Buddhism in the teachings of Moses, any more than Abraham would recognise the Islamism of Mahomet; and if Saint Peter could return to earth it would puzzle him to know to which of the forms of modern Christianity he belonged. A striking instance of this is that in India, Persia and Palestine, the three countries that have done most to build up religion, all monumental or historical records that could enlighten mankind have been utterly destroyed by the ruthless hand of Fate, until the last century, and it is to the 
pagan lands of the world that the student of evolution has so often to turn for collateral evidence of the truths of revelation. Persia furnishes some of the most beautiful and touching legends of revelation, and the unearthed libraries of Assyria have thrown more light on past records of history and revelation than all else in science and discovery, or all the religious teachings of centuries. But if religion had not altered to suit the age, Civilisation would have never advanced, but have stopped short in the future as it did in the past in the case of China and Turkey. For it is most probable, though being prehistoric, we can only in this instance make a guess that the first God-made man was a Chinawoman's son. For the earliest Chinese religious teachings give the most chronologically correct, if not the most accurate so far as detail is concerned, account of the creation of the world. And it appears to me that the first dawn of religious belief had its origin in China somewhere about one hundred thousand years ago, in the materialistic idolatry of that age, which accounts for the proficiency of the Chinese and Eastern nations in all arts of necromancy.

But the religions of this age of evolution were, of necessity, the most elementary forms of superstitious worship of the earth and planets, so they did not rise to the heights of Heaven, or of a heavenly deity or of a life hereafter. A result it would be foolish to expect, for at this period everything was of the earth, earthy, and mankind was but little above the standard of an animal, and the requirements of the age asked only for the rudest and simplest forms of government, and religion is but a form of government. At the time of the dawn of agriculture, knowledge was little advanced above the rudest forms of gardening, so required that man should devote his time and energies to the cultivation of the soil, rather than to study or science or religious knowledge.

Too great a love of knowledge would have given him a distaste for digging, which when you allow for the poor quality of his farming implements in both these ages, viz., that of the stick and stone ages, farming must have been an arduous and fatiguing task; so it would be hard to imagine a greater crime at this age of evolution than a distaste for hard bodily work, and the student must have been looked upon with suspicion and distrust as a lazy loafer, and the seer and prophet had to be an accurate weather prognosticator before any reliance would have been placed on his magic. 
Contemporary with this development of agriculture, but probably a little in advance of it, was another evolution both of civilisation, government and religion, taking place throughout the more northern and western portions of the globe that was destined ultimately to supersede it, but was slower in its growth, and which for the want of a better comprehensive term I decided to call "Aryan," for, being prehistoric, it would confuse my reader too much to follow the course of my comparisons of evolution with that of my hypothesis if I were to use such terms as Palæolithic and Neolithic and other sub. sequent racial distinctions; so I have decided to take the terms "Cain and Abel," and "Aryan," "Chinese," and "Mongolian" instead. So, contemporaneously herewith, this Aryan civilisation was steadily advancing amongst the nomadic races of huntsmen and shepherds, who, as the Bible tells us, were "Dwellers in tents and caves" (see Genesis, iv., 22).

If my reader will compare Genesis chapter iv., verses I9 to 23 , with what follows in Chapter v., verses 3 to $3 I$, he will be struck by the extraordinary manner in which if he reads between the lines, making allowances for the fact that the children of Adam are only personifications of long periods of time, or stages of evolution extending over somewhere between two and three hundred thousand years; just as in the early history of Egypt we might talk of Memphis as a man who lived from four to three thousand years before Christ, and "Theban" as a man who lived from two thousand seven hundred to two thousand two hundred before Christ, and "Hyksos" as a man who lived from two thousand to one thousand six hundred and thirty-five years before Christ.

Now, reading Genesis in the same way, he will be struck by the similarity of the accounts with what has taken place in the course of evolution as described in the last chapter. Now in Genesis, chapter iv., it gives us, in the children of Cain, the account of the evolution of China and early Chinese civilisation and religion from the Stone Age of Cain to the Metal Age of Lamech. Then in chapter v. it takes up the children of Adam and Abel, about one hundred thousand years; then about another hundred thousand years brings him to Seth, and another twenty thousand years takes him on to Mahalaleel, who intermarried with the children of Lamech. He is then taken back to Henoch and carried on to Noah, who personifies 
the end of the Glacial Period and the first descent of the Aryan races on India and the Persian valley. He will then be struck by the similitude of this description with what really took place during these periods of evolution, namely, that the children of Cain, or the Mongolian races, produced the earliest age of civilisation and first form of religious belief.

The Aryan races, personified by the children of Abel and Seth, represent the first great northern population of the west during the Stone Age; then about the time of the Metal Age they are driven to the warmer climates as the world nears end of the Glacial Days of Noah, and, conquering and intermingling with the Mongolian races, they learn their arts of agriculture and manufacture in metal implements, bringing with them a higher and more enlightened form of religion in the teachings of Enos or Buddha, and so raising the tone of Mongolian religion and civilisation in the days of Noah; then after the trials of the Glacial period the Mongolian races spread through the centre of Siberia and Russia to the Irish Sea. So the Aryan races now retrace their steps and reconquer them and lay the foundation-stones of the civilisations of India, Persia, Egypt, Greece and Rome. Of course, as all this took place before the days of history, the data available to substantiate it is too incomplete for me to make any absolute statements, and I can only do my best to try and piece the fragments of fact together by means of arguing what the most logical and probable course of events would have been, so far as it is possible to draw conclusions from the most likely causes that would produce the results of which we have, alas! only a smattering of knowledge on which to base our assumptions. Even to do this in a satisfactory manner would require a great deal more time and space to be devoted to the subject than I can now spare to it, but I think I have said enough to show that both evolution and Genesis herein coincide, which will be made even clearer to the reader as I progress along the road of the evolution of religion.

As I have already hinted, the next stage we have to follow is the progress of the Aryan races of mankind as they populated the western portions of the globe. As I have already remarked, it is probable that China most likely evolved the earliest form of civilisation and religion. It is often surmised that the probable cause why she has not advanced and 
has been left behind by civilisation of later growth may be accounted for by the legislation of Confucius, but I am of opinion that a far more powerful reason why she has not further advanced was that not having had to face the struggles of the Glacial period, she did not evolve the high ideals of God and His Trinity which had and ever will have more to do with producing the highest order of mental ability, and thus fitting the nations who have so evolved, or unfitting every nation that has not evolved these truths or that have not been redeemed to compete with those so blessed.

It is probable that both these causes have had some effect in this direction, for we find that from the time that Mahomet legislated to prevent any alteration in the teachings of the Koran, the Mahometan is less progressive than the believers in religions which permit of progressive alteration in their tenets to allow of their being adjusted to suit the onward march of civilisation. Thus although Mahomet extended the belief in one God and one God only at the time we find that Christianity was fast plunging the Eastern nations who had not been redeemed back into idolatry, owing to the fact that the lack of Aryan blood in their veins made them incapable of evolving a mind of sufficiently high calibre to comprehend, or believe, much less to be able to understand the mystery of God and His Trinity, and so were unable to rise to the height of practising and realising the high ideals of Christianity. Nevertheless, we must give Mahomet credit for drawing out of the mud of idolatry ten souls for every one that Christ has redeemed even if this was attained at the cost of retarding their mental development, but it is hard to estimate how far their breeding and the influence of their past struggles, failures and successes to combat against lesser or greater odds of resistance in the course of evolution may not have also effected these results. It is well to bear in mind that the beliefs which we may hold and which may be the best suited to advance and fit us for our own particular state of life, or the calls our social state or racial difference may most call for; may be unsuited to the breeding and surroundings of others, so that the different races and nations require different forms of belief and government to evolve the characteristics that their past evolution makes the necessary outcome of their progression under the 
circumstances which go to make up the conditions of their surroundings. Yet an inferior ideal of perfection or belief is far better than no belief at all. This is why it always has been and always will be necessary to exaggerate religious beliefs to a higher ideal than it is possible to perform, or we would not strive to attain the possible.

But it is certain that no other force than that of religion could have kept alive or have preserved to the present day the slightest remnants of these divine revelations, which it has taken all the trials of the Glacial Period and early civilisation to produce and evolve in the mind of mankind; and without which man's mind could never have attained its present standard, that amongst the higher orders of the human brain have now fitted us to receive a soul of wisdom, to evolve which will be the duty of the coming Epoch of Charity. But to evolve and develop religions, governments and Commerce, it was necessary that the Epoch of Hope should be materially one of wars, strife, and greed, against which necessary but imperfect evolutions, God is by the means of religions, ever waging a still more important contest for the supremacy of Love, Mercy and Justice, Honour and Charity.

So we may truly call these seven days the epoch of wars and the struggle for love, just as the first week or epoch of creation and Genesis was the struggle for existence, and the coming seven days are to be the struggle for the soul of wisdom, the possession of which is to fit us for immortality. So we find that in this manner by the nineteenth century mankind is sufficiently advanced for religion, with the help of science, to remodel her teachings and so fit mankind to evolve a more perfect soul in the future just the same as he has evolved a mind in the past seven days whilst he was awaiting the evolution of science, the daughter of religions and governments, to help him to evolve true wisdom during the next seven days of creation, which are to be devoted to the development of Peace, Use, the prevention of crime, Charity, Content, Heaven and Immortality. For in just the same manner that in the days of the Epoch of Hope, woman, with the help of religion and Christ, has been able since the days of Adam to teach mankind to see and to believe the truths of revelation, and so to evolve his mind, and plant the seeds of his soul, so also in the future man, with the help of science and the inspirations 
of God the Holy Ghost is from this onward to start to so evolve his Soul so that he will in time be able not only to see and to believe, but even to "know and understand all things even to the consummation of the world," including the truths of revelation which his mind has hitherto been insufficiently developed to be able to do more than see and believe, and which have not yet been opened to the understanding of man until the last one hundred years except in fables, myths and parables. Now the scales of bigotry are starting to fall from the eyes of man all this is to be changed. If you refer to Table I. and Table III. of the attributes of God's Trinity, you will see that Knowledge and Invention were very slightly understood by man till the last two hundred years, and that we are only at the dawn of Involution, and we can say that it is only during the last hundred years we have learnt to understand or to know anything about science and invention, or the electrical currents and radio-activity that control the soul.

And the aim of my treatise is to point out that the better understanding of the mystery of God's Trinity, from a scientific standpoint, is the only means by which we can prevent the tendency of modern science and government degenerating into the false channels of materialism which is ever threatening to submerge beneath its doctrines all and every vestige of divine revelation, an evil so great that it must be checked at all cost. The present war and the civil wars that are to follow it will all play their part to solve this most important problem of mental evolution, and so do their part to remove the social unrest and the national dangers that increased liberty and the supplanting of the ignorance, superstition and bigotry of the past by a greater amount of freedom of opinion and knowledge which the present age is now producing amongst the large masses of mankind whose minds are not yet sufficiently developed to be able to reason as well as think, and whose wills are yet too weak to be able to direct their footsteps along a pathway through which they have been led in the past by the helping hand of religion, the power of which hand lay mainly, if not solely in the propagation of ignorance and superstition. In the past this has been the guiding hand by which the little cliild of man's undeveloped mind and will has been led. In the last century by the loss of the controlling hand we have thrown away the 
reins of ignorance without at the same time replacing them by some stronger form of control; this threatens to destroy the past evolutions of Love, Unity, and Charity that religion has been endeavouring to teach, in a whirlpool of socialism, materialism and atheism far more dreadful than the superstition, idolatry and heathen materialism that gave birth to the earliest forms of religious beliefs. It is this conviction that appeals so strongly to my mind, and the hope that this treatise by illustrating that it is impossible to separate God and His Trinity from His Creation, man included, that has emboldened me to publish the extraordinary revelation I have received.

And I cannot pass on without stating that, in my opinion, it is to this tendency to materialistic doctrine that we owe much of the social, commercial and industrial unrest, for the existence of which unrestrained liberty, ignorance and lack of wisdom can alone account. For the age of wisdom is not as yet evolved, and there are very few in whose minds the possibility to reason correctly and to act with decision has even dawned, let alone been evolved. It is only our inordinate pride, that makes us blind to our follies, which leads us to presume that we have yet arrived at the manhood of wisdom. But just as in life when we are nearing manhood and are only hobbledehoys, is the time when we are most prone to go to the bad, because our individual wills are now coming to maturity and resent the controlling hand of our parents, and have not yet been taught by the world the folly of our childish love of having our own way, whereas contact with the world of men will teach each individual to find his own level and his right place of utility in the world. So now that nations and religions have released their past hand-grasp on the mass of their subjects, hitherto held by the grip of ignorance which has been the mainstay of both government and religion in the past, we find the world is inclined to run amuck.

But the time has arrived in the course of evolution when science must open up to the knowledge of governments and religion the fact that they must work together by striving to produce a more perfect development of self-control and brotherly love and unity in the division of work and of the means of the production of livelihoods, now that man is evolving Understanding which will assist him to make a better use of the world that he is fast learning to conquer. The 
nineteenth century will produce the third and last important departure in the course of the evolution of his soul, during the third Epoch of Charity, the commencement of which marks the birth of the soul of mankind, and which is to form a new evolution and create a revolution in the mind of man, as great in its results as the change from an animal to a human mind.

And it is now the duty of science and religion to sink their differences, and instead of being the fickle friends they have been in the past, for their friendship has hitherto been like the friendships of children, warm to-day, and to-morrow turned into hate, to be reunited in friendship the day after. But that they must now at the call of so dreadful a common foe as materialism unite in a more lasting friendship of mutual interest which I hope my Hypothesis may help to bring about.

This is the reason why in this treatise I try to offer to Science, Religion and Government and public opinion a common business interest in their lives and redemption. For I feel convinced that in a better understanding of the science of evolution, when read from the standpoint of the Trinity of God, lies the road to a better and more logical understanding of the mystery of God's revelation, and also the true solution of the problems of science and religion, and state and social government, and this should make it possible for them to combine together so as to work with greater effect, by means of their unity, to forward the final evolution of the world, the means to do which they can only attain by endeavouring to destroy past superstition, and bigotry, and elevate man's mind to a higher level that will enable the masses to realise that the wealth and success of one man is but a grain of salt to keep up the flavour of the wealth of the whole, and that what is good for the whole must also add to the good of each and every one of its individual members, and vice versâ.

Truths that the world must learn before society, state, religions or governments can regain in the future powers equal to those of the Ignorance they have had in the past, and it must be remembered that the loss of such powers can only produce one effect, the loss of freedom by granting, in advance of the evolution of their minds, unwise and injudicious liberty to the people we desire to govern, which would be wise enough liberties if they had but evolved more self-control, and it is to follies of this class to which we must attribute all the social 
and industrial unrest of to-day. This can only be avoided by science and all forms of religions and governments finding a common meeting ground that shall combine the most essential truths of revelation with those of knowledge; and by banishing Ignorance and past prejudices of race, social distinctions, national animosity and religious hate, and so become one happy family of united humanity; content to buy and sell national property as they would individual assets, and realising that it is better to pay millions to acquire possession of new territory by purchase and to settle international disputes by arbitration rather than to waste millions of lives and millions of capital (which is only another word for millions of livelihoods) in perpetuating national vendettas by going to war. The age of family vendettas is now relegated to the ages of past evolution, and it is high time that the more dreadful vendettas of religions, nations, governments, races and classes and mercantile strifes were hurried into the realms of like oblivion. This digression should, by rights, form a part of the final chapter, but I have inserted it here thinking the points under review may be of service when reading the next few chapters.

The second force that has decided the trend of Religion, we must remember, is, that all and every Religion that has ever been invented by man and enlightened by God has always been used as a means of government and as a tool of revolution. Therefore, any religion that is to be able to hold sway in a country has always had to mould its existence, not by the correctness of its teachings of the truths of revelation, but by the suitability of its teachings to the government of the country and the manners of the people it has to direct. For God takes care that the absolute truths of revelation are part of every religion in exact proportion to the individual people's powers of comprehension. And many of the most beautiful revelations are to be found in the religions of the East in Buddhism and Mahometanism, also the mythology of Rome and Greece, India, Persia, and other Eastern countries furnish us with some of the sweetest and most magnificent illustrations of the revelations of the past, hidden and obscured though they may be by the cloaks of superstition and idolatry. Thus we find that Josephus, the great historian of the days of Christ, and when the governor of Jerusalem was Pontius 
Pilate. Writes from Jerusalem to Rome forty years after the birth of Christ that he has exterminated all revolutionary sects and creeds except a small and insignificant band of heretics called Christians. But as they are very few in number and mostly poor and without influence, and he does not think it worth while for Rome to belittle her legions by destroying so paltry and insignificant a lot of rebels.

Yet this insignificant body of men were destined to build upon the grand foundation of the government of Rome a religion so perfect that it will last till man has in the course of thousands of years worked out his own salvation and destroyed wars, selfishness and crime, and woman has conquered her love of dress, jealousy and petty animosity. This was the religion that brought about in the course of less than one thousand years the entire revolution of the Roman Empire, and so made the longest step yet made towards Immortality. Till that is achieved Christianity will be the world's religion in some form or another. It will only die when man at last discovers and believes true revelation by tearing off the cloak of the remnants of superstition and bigotry, upsets the idols of religion and society which stand between him and the truths of revelation, and so obscures his knowledge of right and wrong, then at last he will obtain perfect wisdom, yet which said superstitions, parables and fables taught him, the existence of his maker even though they may have retarded his being introduced into His presence; yet without which he would never have been able to see or believe the small amount of the truths of revelation and evolution that religion has so far been able to teach him, or that he has been wise enough to understand. Hence it is well to be very careful to reverence all God's forms of religions even if we cannot believe all that they teach. Remember that they each and every one contain some, if not all, the truths of God's revelation, and most probably all that hitherto God has deemed it wise that we should know. But the duties of the future will be to sort and combine the truths of all religions. Remember they are the battleships in which mankind has hitherto won his greatest victories, and even when any form of religion shall at last become obsolete or out of date, or unseaworthy, we must still give it the honour due to a departed hero and cover it with the flags of honour, veneration and respect. So even if 
you cannot believe all your religion teaches, try and believe all you can, and do and act up to what you believe, for it is the fond reminder of the instruction of your mother, and of the virtues she taught you, and it is the inheritance her mother's mother, and her mother before her have bequeathed to you, and no other power on earth will do as much to help you to love your neighbour as the thought of the mother who loved you in your youth and weakness, and so religion will help you to think kindly of your neighbour's weaknesses and enable you to forgive them their faults, for religion is the weakness and strength combined of the mothers who brought God's forgiveness on your father's sins and made you what you are.

Religion must ever advance and adapt itself, not to science, for science must ever be ruled by evolution, but to Evolution, Knowledge, Truth, and the comprehension of revelation, as the world is advanced by the all-ruling power of God's Trinity as it works out the evolution of creation. The Trinity that gives birth to the Universe, Truth and Man, and by logic teaches all mankind to aim at the trinity of all Virtues, Peace, Wisdom and Charity, which is hereafter to produce the trinity of Use, Comfort and Content, the result of which is to be the trinity that makes Heaven out of this earth, Joy, Pleasure and Happiness, and which is ultimately to gain for mankind the blessing of eternal immortality. It is to assist mankind to do this that God hid away in the wilds of Arabia, Persia, Greece, Palestine, India and Rome, and amidst the fables of all nations and the mysteries of evolution, the truths of revelation which are to help man to know, believe and obey the God who has created and blessed him. The truths that are (when he gains the soul of the understanding of True Wisdom), through a better knowledge of God's Trinity and the evolution and creation as they are unrolled from the past by science and religion, and so made manifest to the soul of man, as they pass through the cinematograph of evolution, to be depicted in the minds of future generations, in such a manner as will enable mankind some day to reduce crime to such a minimum it will be a thing of the past.

But this will not happen till further attributes of God the Holy Ghost are returned to creation during the Epoch of Charity. It is with the greatest feelings of the utter hopelessness of the task before me, that I shall now endeavour to 
join together a series of the most disconnected facts, and so try to convey to my reader the manner in which all religions have presumably become evolved, and I wish my reader to realise how visionary any such attempt must necessarily be, for with the full knowledge of his infinite wisdom, the world's creator has evidently realised that the growth and evolution of the truths of revelation, must be of a kaleidoscopic order, made up of the same bits of coloured glass of revelations.

It is continually seeking a rearrangement so as to strike on the eye of our mental vision in a new and attractive form of beauty ever regaining fresh powers of attraction, yet altered, beautified, multiplied and intensified in increased variety, by being reflected and re-reflected by the mirrors that form the sides of the kaleidoscopes of different religious beliefs, so that they may again and again appeal to our mental sight with revived wonder and attraction, and yet at the same time remain the same half dozen truths of revelation which are only old friends with new faces brightened and beautified by some new form of religion. In like manner we find the fundamental truths of revelation are placed by numerous religious beliefs, in new and varied forms to suit the different evolutions of man's mind at different times of evolution. For when we remember that in every country that has contributed largely to the growth of religions or governments, God has wiped out of existence all records of the past, so that there is little or no connection whatever to fasten the links together, it is easy to realise how they have been contorted.

Thus in China, the first birthplace of Religion, all advancement stopped short eight thousand years ago, so that not only does China add nothing to our records by monuments or temples, but she has never produced any edifice of grandeur, monument or inscription to act as a guide to religious advancement, and its architecture is to-day of primitive savagery. On the other hand Assyria, Babylon, Egypt, India, Greece and Rome have added proof after proof in the records of paganism extending back seven thousand years before Christ; but detailed revelation cannot be traced by history more than five hundred years before Christ in any of these countries, least of all in India, Persia and Palestine, the lands of its birth. I may as well mention here that the manner in which one teaching of religion or sect becomes 
permanent is not a matter, so much of its creed or belief as of the manner in which it can adapt its teachings to the requirements of the people, and its suitability to the creation of the forms of state government in vogue, or rather in course of evolution at the period in question amongst the people under discussion.

For instance, taking more recent developments of modern history, because they are the best known, had not Christianity been the most suited to the revolution and reconstitution of the Roman Empire, it would not have been the main religious belief of to-day amongst the western nations, on the one hand; and had it not contained the belief of one God and His Trinity it would have failed, on the other hand, to fulfil its duty in the evolution of soul, and so would soon have succumbed to a more suitable religious belief. But Rome, by her mighty power of Government and by the enormous wealth she had acquired came to attain to an enormous amount of indolence and luxury, which brought crime and vice to a state of artistic perfection that was fast carrying her people into the worst forms of materialism and corruption. This made her people yearn for a new form of state government, otherwise they would have adhered to the old paganism that had made the tiny Rome of Romulus and Remus the mighty mistress of the world. Its people being rebellious against the vice and corruption of its patrician element, which up to that time they had adored, caused the masses of the freemen who having become so waited upon by Rome's millions of slaves that the people had lost their ancient energy and their respect for their leaders, were therefore ripe for rebellion. Hence the fact that its revolutionary spirits, for the spirit of revolution nearly always rises amongst the fools and discontents and wasters of a community, finding scattered amongst them a small body of higher class men who had been expelled from their kingdom of Jerusalem, owing to their rebellious desire to have freedom of self-government in religion, found in the Jewish emigrants a clever lot of men with like interests, of a better quality of intellect, who could act as leaders in their rebellions, and whose religious meetings gave a safe excuse for their revolutionary organisation. So grew Christianity.

But this is only one of the forces that decide the evolution of religion, the natural or material one. On the other hand 
is the force of the divine side of evolution, and you may rest assured, that had not Christianity contained the revelation of God's Trinity, it would never have been able to maintain its own against the more favoured religions of Rome, which were more suited to the, as yet, undeveloped soul of man at that time, and the more material spirit of the Roman age of physical power and voluptuous pleasures. I wish my reader to keep this comment in his mind while he is reading the rest of these chapters, as also that the trinity of wars is the most important trinity of this, the Epoch of Hope, throughout which we follow the course of the three great contests for supremacy and rule, between religions, governments and commerce, for this is the epoch of wars as well as of Hope :-

Ist. Between savagery and civilisation, or disorder at war with petty states to form empires.

2nd. Religions at war with governments, for the right to rule mankind.

3rd. The wars between science and superstition, bigotry, folly and selfishness to evolve commerce, conquer matter and to build up empires for the use of commerce.

And as each of these contestants in turn strive for supremacy, we find that the birth of revelation is one of trial and labour, and that as each stage of divine enlightenment becomes evolved within the mind of man, so, in turn, it is crushed to death to give birth to a new requirement that is to evolve a new portion of his mind, or to perfect some new energy of his mind, or some new evolution on the development of government, science and commerce.

Now, as I have already mentioned, the first factor that gave rise to the birth of religion in the mind of man was the fear that the glacial period had produced in his dawning mind of the elements that surrounded him. He thus grew to fear the rain, snow and winds that overcame and destroyed him and the works of his hands, and he started to pray to the sun, moon and stars, to the winds, hail and snow, to afflict him no more. Hence he places them above himself, confers upon them spiritual existences, and peoples them with almighty 
individualities and made of them gods to be worshipped. Now one can realise that at this stage of his development what conveys to his mind the highest source of Joy, Pleasure and Happiness is a good feed, so it was only the natural outcome of this stage of his mental development to advance a step further and to offer sacrifice when prayers failed. For our spiritual beliefs are but an imaginative extension of the ideals of our present knowledge of existence and wants, and at this stage his human experience was that when supplication to an earthly prince failed, a gift of value or of food often gained the heart of a prince where all other appeals failed.

Hence he naturally came to the conclusion that the best way to appease the gods of his creation was to offer a sacrifice of a portion of his wealth and property. Thus those who had keener powers of imagination and observation began to realise that herein lay a means of acquiring not only influence, but wealth, ease and comfort. These men therefore devoted more care than ever to the study of indications of atmospheric influences as a means to meteorological forecast, the better to evolve agricultural advancement. And as man attributed to the sun, moon and stars a supernatural power they did not possess, the prophets and seers saw that by pandering to his belief they could, if they increased their knowledge of astronomy, gain an influence over their fellowmen greater than all powers of arms. Thus grew up ideas of a God-peopled heaven in the skies, which led to idolatry.

But at first this led no further, and all the earliest religions seem to have no more ideas of a reincarnation or of future life than they had of God or Immortality. But as I faintly illustrate in the birth of Christianity, there always have been the two causes at work. The desire to govern by religion on one hand, and by government on the other, concurrent with which is a gradual dawning of revelation of divine truth as God's Trinity, is striving to shine through the mists that surround man's yet unborn soul. So we now find the two revelations, or the first two pieces of glass, in our divine kaleidoscope begin to move, and form the two first reflections of God in the soul of man as a belief in invisible controllers (mind I say controllers, because as creator man's mind had not yet evolved enough to imagine, let alone conceive a creator) of the world and a future life. Thus they 
proceed to people the heavenly bodies with spiritual qualities and inhabitants. So comes the belief also in a live spirit world, which is in its next evolution to produce a belief in the three first revelations of divine spirit rule, spirit life, and immortality. This presumably takes the first two hundred thousand years of evolution of mind and soul.

We find that in early religions, the likeness to God in man has not evolved sufficiently, for him to either comprehend the revelation of spiritual life or immortality, nor for him to realise the value of heredity or caste. Their religions teach them none of these truths of revelation. Of the Chinese it is said that their non-advancement is due to the legislation of Confucius, who certainly is not the first redeemer or Godmade man, but might be the first historical mention of a religious reformer of the Chinese redemption portrayed in the Bible by Cain. But on this point it is impossible to do more than conjecture, as there is no evidence to support any conjectures much less proof. Human legislation, though it might be sufficient to stop bodily development and prevent the loss of physical vitality, would not be enough to account for the loss of spiritual powers of evolution, or the evolution of virtue out of sin, nor for the loss of power to evolve mind.

This can only be accounted for by their not having passed through the trials of the glacial periods, thereby losing the good results of such evolutions. Their minds were not sufficiently developed to be able to be worthy of the influence of subsequent acts of redemption, by more than one out of the three redeemers, Buddha being the second (probably the Enos of the Bible), who belonged to the Aryan race, and so their spiritual evolution was not influenced, in such a manner as would make it possible for their men to transmit the female attribute of God, Comprehension, as well as the male one of Imagination. Therefore they stopped short in the evolution of the second portion of their souls, the power of Comprehension, and so lost the power to conceive the belief in one God and His Trinity. This is the most probable solution of the difficulty and would correspond to what stock-breeders term " a want of cross-breeding" in soul, which might be just as necessary for the development of soul, as it is necessary at times to produce perfect variation in bodily breeding. This, it seems to my mind, is the most probable way of accounting 
in a satisfactory manner for their marked non-advancement when compared with other nations who started at a much later date in the race for civilisation. But I must here ask the reader to remember that in evolution good is generally evolved out of evil, for our virtues are the outcome of the conquest of our sins and failures. This is why the greatest saints are often in life the greatest sinners, or at least have the greatest attraction for, or desire to sin, and when they fail to make saints become the greatest blackguards. As I have pointed out elsewhere, evolution is an alternate transition from a good minority to a bad majority, and then back to a good minority again, and will become perfect when nature can evolve a good majority. And the same holds good in the evolution of our minds and souls as in our bodily development, so every evolution must perfect both its extremes.

Is it not better to be an Englishman, Turk, Prussian, or perhaps Italian, and to have lived through ages of sin or scientific crime, and to be able to look back on a past grandeur of civilisation, such as that of India, Babylon, Egypt, Rome, or Modern Europe, and to be able to say "That is what my fathers have done. It is possible for me to do better,' than, like a Chinaman, Negro, or South Sea Islander, to look back only to realise that your nation has stood still on the road of evolution, and lost its way, never to advance, because your ancestors knew not how to conquer sin, and could not therefore evolve to the comprehension or the virtues of ambition, love, judgment, and so had no desire to be superior to their predecessors, charitable to their neighbours' crimes, or wiser than their fellow-men.

So the stagnation of the Chinese and savage nations is not entirely a matter of legislation, but is largely due to the fact that they have never been interbred with races to whom have been vouchsafed the blessings, resulting from ages of contest with, or influenced by, the difficulties resulting from contact with cold and privations, necessary to produce a mind capable of receiving the inspirations of the God-made men, and more particularly of the last and most perfect of these God-made men, Christ, the world's most perfect redeemer.

Now, what astonishes me most is, not that every religion becomes degenerate and corrupt, and so its truths become buried under such a mass of superstitious rubbish and rotten 
leaves of bigotry, but that the truth was there at all, to remain hidden like the libraries of Babylon and Assyria for thousands of years, without being lost or destroyed, until man has advanced and evolved sufficiently for him to receive and understand the revelations which will be slowly but clearly made known to him through the advance of science, as he evolves the powers of reason and perfect understanding, and so gains a soul fit to receive them. The wonder is that they should have been preserved in marvellous and miraculous manner in the Bible and legends and fables of the past.

Thus we find when we read Genesis from the Hypothesis of God's Trinity, as also in other parts of the Bible, that it is absolutely correct so far as the facts go; the interpretation alone is incorrect; and that when this key of the hypothesis is used to unlock the doors of human understanding, we find that science and evolution only tend to substantiate these truths; and make their meanings more clear and that even the order and sequence of the writing of Genesis corresponds with the order of evolution and the hypothesis of this treatise, and that the mysteries of God's Trinity in nature, of descent, and of the survival of the fittest, become clear and make possible a logical, reasonable and understandable interpretation of the revelation contained in the parables, legends and fables that lie therein, hidden, it is true, by piles of superstition, which have in the past been just as necessary a cloak to teachings of religion to make them palatable and presentable to man's hitherto undeveloped mind, as our clothes are a necessity to our being admitted into polite society, although they may hide the true shape of our bodies; but it cannot be denied that they add to our comfort and charm, so that the past teachings of religion added to its charms and made it attractive to the infantile mind of man.

If the truths of revelation had not been clothed in pretty garb of parables, fables, and legends, and so made sweet and mythical fairy tales of religious beliefs so as to make them attractive, they would not have appealed to the undeveloped mind of man in the past, throughout the childhood of his soul, and he would have turned from them with disgust and with scorn and disbelief.

Proceeding along the course of the Bible, we find that the creation of the world, the creation of angels, their fall and the 
rise of Lucifers, the Garden of Eden and the Ages of Adam and Eve, Cain and Abel, of Noah and of the Flood, and the creation of the soul of man, are all so many of the truths of evolution buried in the rubbish heaps of superstition invented by the mind of man to dim the overwhelming lustre of the light of God's revelations, and to make religion useful as a tool of government and of revolutions, and so assist man's upward advance. I have now tried to illustrate how this cloak of superstition was necessary in the past, and, so far as I am able, wish to show how man must now endeavour to make it the duty of science and evolution, so far as possible, to remove the garb of superstition and bigotry so as to help him to evolve his soul of Understanding and to be able to read aright the ethics of the past. To do this I feel sure we must read evolution in conjunction and by the light shed upon it by the hypothesis of the Trinity of God, or else' it will only have the retrograde effect of reducing every particle of knowledge back to the materialism of the past, which has been the main cause of the non-advancement of the Chinese and other uncivilised nations by stopping further advancement in the knowledge of divine revelations, and be as big a clog to the wheels of progress as the material religions of China and other eastern and uncivilised nations have been to their advancement.

Thus Noah marks the stage of evolution we have now arrived at in our discussion, for we have now come to the end of the Glacial Period, or age of deluges and floods, when man has to build rafts to rescue his family and stock, as these periods of rain, cold and snow drove him back into warmer climates. This same cold and frost made him invent alcoholic drinks and stimulants, illustrated by the drunkenness of Noah, so that we see that in our biblical rubbish heap is buried the proof of the order and sequence of these stages of evolution which are a proof that the marriages of God's Trinity are the key to the understanding of evolution and of religion also.

Here we have the three greatest events of this age, the Deluge, the invention of rafts, that was afterwards to evolve shipping, and the discovery of the value of liquor as a powerful preventive of death from cold, which are made the typical acts of the mythical personifications of this age which are represented in the Bible by the account of the life of Noah. 
Now, to resume by comparison, and also to prove that the marriages of the table of Trinity places religion in Table III. in its right place and order and sequence, let us further analyse the developments of the age. It is this age that by its cold and privation is to develop man's hardihood and to produce a body capable and powerful enough to sustain his mind, and so fit him to realise the truths of revelation, by evolving in his brain greater powers of Imagination, Comprehension and Invention, and so fit him to obtain a more enlightened soul. It is also destined by wars and strife to enable him to attain a power of will by which he can master himself. Hence we find that he is now driven back to Northern India and Persia. Here he now evolves the first conceptions of Immortality, the belief in One God, and One God only, and the triple personality of God's Trinity, the possession of which is to stamp the Aryan Races for ever as the highest evolution of soul in the future. Also the truth that like begets like, or the evolution of the fittest by the establishment of caste and other hereditary customs amongst all branches of the Aryan Races.

It often appears to our minds that the Almighty is at fault in the manner he selects to bring about the course of evolution, because being unable to comprehend all the rules of the game, we found our reasoning upon individual failures, and do not realise that they are necessary moves in the game; like a person who does not know the respective value of the chessmen would commit the error of counting the loss of a pawn as the same value as the loss of a queen or castle. These individual failures make the universal successes, just as in chess the judicious loss of a pawn often saves the game. In the course of the evolution of religion at this particular stage of creation, this is most apparent, for it so often produces so many crimes and false teachings that we feel inclined to doubt the truth of its dogmas and condemn it for the crimes it produces, because we cannot comprehend that these very errors will ultimately produce its highest virtues. As we now follow the course of evolution in its ups and downs of progress and retrogression, we find that the strife commences between prophets and patriarchs and the kings and rulers. Both these potentates are now candidates for supreme rule, and so it dawns on the 
mind of man that nature will not admit the possibility of two supreme human rulers. Thus grows the belief in One God. Once this step is taken, the powers of light, heat and motion that ruled the Epoch of Faith give birth to the truths of God's Trinity, which in reality is the revelation that is from this time to be the belief that will henceforth rule creation which like all seed, once the germination commences, must burst its way through the soil, no matter how hard it may be; and revelation is but the seed God has planted in the mind of man awaiting the time when the evolution of the world shall produce the right season, watered by the rains of divine inspiration to start its growth. Then comes its realisation as civilisation advances; and as man learns to create and invent religious beliefs, he realises that $\mathrm{He}$ who has an unlimited power to control nature, must also have an unlimited power to create. So the mystery of God, the Creator, is also evolved, as well as that of God the Supreme Ruler.

Thus become active the two greatest of all the lights of revelation. Such revelations have lain buried like a seed planted too deep in the soil, or sheltered by an excess of overhanging boughs, which lies dormant for ten or a hundred years, but which, nevertheless, when turned up by the plough or when the mighty forest that obscures the sun is burnt down, springs into life from amongst the ashes. So with the revelations out of which are to grow the firm belief in fatality and subservience of man to the will of God, seeds which were sown in the Glacial Period, to be thereafter obscured by the religious teaching of idolatry, but to burst again into life in the teachings of Buddha, to be buried again by the civilisations of India, Persia and Rome, whose love of vice and luxury in time destroyed the original purity of revelations which God through nature, made known to mankind. These again become lost in the mist of superstition and bigotry of these forms of civilisation as their governments are evolved out of the decay of their religions. Because man's frailty and inability to evolve two virtues at once causes him to allow his religious ideals to fade and die for want of being cultivated, manured and watered by intense sympathy and devotion and concentration of national enthusiasm, which qualities it has transferred from the evolution of religion which it has advanced a step up the 
ladder of progress, that it may in like manner raise the next evolution, that of government, to a high ideal of efficiency. After this it will in the same manner withdraw its attention again from government and devote them to the further advancing of religion, as Christ, its last redeemer, will again throw renewed light of divine revelation through the overhanging boughs of political love of wealth and power, which will in turn make religion more influential in human ambitions.

This incentive to religious advancement will in turn be again sacrificed on the altar of the shrine of government as feudalism and Christian forms of government are evolved out of the debris of defunct forms of heathen order and control that grew in the rank soil of idolatrous worship. So again we find the Protestant Reformation supplants Catholicism to permit of modern forms of democratic government. These two veteran heroes, Religion and Government, are henceforth to meet a new and powerful adversary in Science, which has been dawning on the horizon of evolution during these contests and which is now to take birth as an active force in the direction of law and order, and an important exponent of the revelation of God as made visible by the hand of Fate through the evolutions of nature. Hence at the time now under discussion we find Buddhism has a tendency to make God and Fate the same personality and to make divinity subservient to humanity, a teaching which, under the influence of Persian astronomy, is to evolve religion a step further by creating the belief in God as the inspirer, as well as the ruler of mankind. In this manner is evolved and grows the conviction of duty to God and one's neighbour; and out of the hero-worship of the valiant men who led the fights against hail, snow and rain, evolved the worship of heredity, custom and caste, out of which grew the more powerful of all the laws of evolution, that of the survival of the fittest and the conviction that like begets like.

Thus the Aryans surpass other races in giving honour where honour is due, and at the same time make the law of hereditary superiority one of the principal rules of their life in a more marked degree than any other race. Through the spread of the ancient beliefs of India and Persia, which evolved six truths of divine revelation, viz., the revelation of One God, One Ruler 
and One Creator, and the Trinity of God, which makes three of the seven most important revelations of God. These are :First-In a spiritual creator of all things.

Second-That there is one God and only one God who rules all things and our fates.

Third-In the existence of the Trinity of God.

Fourth-In everlasting life and immortality of our existence and souls.

Fifth-In the laws of descent, the survival of the fittest, and that success in this world is the reward of virtues performed, not a right to which we have any claim, so that our aim must be to merit such rewards and to pass such merit on to our children.

Sixth-Is the necessary outcome of the preceding one, namely, that we owe all to the God who has created us, and that our recompense will be measured by the utility we are to the community, and that our lives are entirely in the hands of fate, so we must accept with resignation our lot in life, at the same time doing all we can to improve it by fair and honest means.

Seventh-To place our duty to God and our neighbour before temporary and personal advantages, confident that any good we do to others will in time revert to us and to our children. Remembering that God has given us the power to perpetuate our souls, so we must be careful lest we condemn our children to lose this power.

The seventh we have yet to evolve in the future Epoch of Charity. It is the consideration of the good of others before our own, and is the mainspring that drives the clock of evolution. It is the greatest revelation, the teaching of which to mankind is the principal object of nature, and the knowledge of which is the last piece of wisdom that is to complete the creation of a soul in mankind. These seven truths are the seven most important foundation stones of all religions, and we have now traced the course of the evolution of the first six, so far as by the process of inverse logic it is possible to conjecture the probable course of their early evolution.

The belief in them is now to be taken by the Mosaic people. 
I use the word Mosaic here in its wider sense, for it is now accepted by most students of the earlier history of the East that there was no such man as Moses, but that he personified the remnant of an emigration that travelled from India to Persia and from Persia to Palestine. This emigration, which presumably left India some two to three thousand years before Christ, travelled into Persia, Egypt, Italy and Greece, and about five hundred to one thousand years later back from Egypt to Palestine; then the last remnant formed the Mosaic migration from Assyria into Palestine somewhere about nine hundred years before Christ.

This emigration presumably consisted of the ancient aristocracy of early India, which was made up of its rulers and early religious teachers, who by their arrogance had evoked a revolutionary and fanatic rising which gave birth to modern Buddhism, somewhere between 2500 and 500 B.c., out of which series of revolutions and fanatic disturbances, it appears to me, must have sprung modern Buddhism. For the tenets of modern Buddhism give one the impression that, previous to the historical date of this cult-about 500 B.C.- the religious belief from which it must have sprung was a much higher description of dogma, and of very much older date. Its teachings lead one to believe that its prehistoric parent, judging the previous by the later teachings, taught some form of belief in a God of spiritual quality, of highly superhuman capabilities, and omnipotent power, who ruled mankind by the decrees of an all-controlling fate, and who placed over mankind hereditary kings and princes who grew to claim rights to obedience and veneration, which were little short of divine worship.

For it would, require some such cult as this to be in operation for many thousands of years to account for the evolution of the Hindoo belief in caste, or the Egyptian respect for hereditary representation which is apparent after their conquest by the Hyksos Pharaohs, who, it appears to me, were an offshoot of an earlier prehistoric migration that apparently passed northward into Greece and Italy at a much earlier date, of which the Mycenaean and Dorian migration of ancient Greece and Italy is a prehistoric remnant. It is presumable, therefore, that somewhere about three thousand years before Christ discontent gave rise to some series of migrations from northern India and southern Siberia, probably brought about 
by the custom of caste leading to such an extreme of arrogant autocracy on the part of the princes and patriarchs that the masses of the people rose in rebellion and expelled them. For the student of evolution who realises how slow is the evolution of any such custom before it can leave any lasting mark on the habits or manners of a nation, knows at a glance that any custom that could leave so marked an effect as that of Hindoo caste behind it, and that could last for two or three thousand years, must have taken anywhere from twenty to fifty thousand years to evolve, so would run back a long way into prehistoric ages. Such an Hypothesis alone would account for the extraordinary attempt made by later Buddhist teachers attempting to place an omnipotent and infinite God in a finite body. These tenets as taught about five hundred to one thousand years B.c. are but the natural outcome of an attempt to deprive an omnipotent being of his superhuman attributes. Although evolution is often prone to degenerate, if an effect points to a higher development as its cause, you are generally not far wrong in assuming that at some prior date such a belief has existed, for it is contrary to evolution to proceed for any length of time in a retrograde march. It only retraces its steps to advance in another direction.

These migrations not only transformed the national character of peoples by the intermingling of blood relationships, but by interchange of ideas, and religious beliefs in like manner produced marked advancement in religious belief and more advanced conceptions in man's mind of the truths of the divine revelation; truths it is only possible to understand as humanity increases its knowledge of the truths Nature is ever slowly revealing to mankind. Thus the Persians, being the most advanced students of their day in the science of Astronomy, gave a more concrete interpretation to the Buddhist abstract conception of One God in a trinity of persons, and out of the Buddhist belief in the transmigration of souls grew a belief in a supernatural heaven and a life to come. While there the Mosaic people picked up many of the legends of Assyrian history, notably the giving of the Ten Commandments, and the finding of Moses (undoubtedly Sargon I. of Assyria) in the bulrushes, etcetera. Two of these branches of this emigration finally drifted into Palestine; the first became the founder of Jerusalem when expelled from the throne 
of Egypt about eighteen hundred years before Christ, to be followed by the Mosaic tribe who had remained in Assyria and who subsequently, about one thousand years later, conquered the Hebrews. It is probable that the Dorian emigration which spread to Greece, and a prehistoric settlement in Italy were other branches of this same emigration that travelled further to the north, via the Caucasian mountains through the South of Russia to Greece and Rome, and so left their stamp on the development of Grecian and Roman knowledge and character, yet were not sufficiently numerous to enforce their religious beliefs and national characteristics on these countries, but left the mark of their superior energy, brains and intellect, to further the civilisation of southern Europe prior to Grecian and Roman historic times.

It is most probable that these missionaries of Hindoo cult were supplanted in India by some religious reformation, the outcome of some prehistoric struggle between government and religion which led to the creation in a more degenerate form of the Veda of modern Buddhism which culminated in the teachings of Prince Gautama, when the burning question presumably was that of the immortality of the soul and the eternal existence of soul in man versus no soul, and a separate creation of man and animal life, and a series of rebirths of the human life as a bodily existence. It marks the religious contest that underlies all the historical evidences of that period, and which most probably began to so stink in the nostrils of all India till public opinion revolted and formed a materialistic new religion in modern Buddhism, and so stopped the further advancement of religion in India because it lost the teaching of God's Trinity. This is the evil that modern savants, particularly German, are in danger of again repeating, and it is the current that underlies the present European War, where we see ranged on one side the halfAryan Races, who are represented by the Allied Forces, fighting for Chivalry, Justice and Religion, and on the other side the materialistic doctrine of the non-existence of soul, the power of might over right, and the materialistic doctrine that scientific knowledge is superior to divine revelation, which German philosophy has been forcing on the world. It must be admitted that it is the duty of future science to ruthlessly tear down all the curtains of superstition and 
bigotry that obscure our knowledge of the fundamental truths of revelation, but in so doing not one hair of the head of this venerable patriarchal teaching of God's Trinity, or the spirit of divine inspiration must ever be destroyed, and it is only by science and religion meeting and joining hands on the one common ground of God's Trinity as the basis of all creation, and recognising this as the motive force which directs all creation that we can-evolve progression and not lapse into retrogression of religious and social evolutions.

Now it is interesting here to note that so as to make sure of the development of a new and perfect evolution of the revelation of God's Trinity, it became necessary to transplant it to new soils whereon it might produce new varieties of the same plant. Hence in Egypt the doctrine of transmigration of souls under the influences of Egyptian culture blooms into the belief of an everlasting body. The seed that falls on Greece's sunny isles blossoms into elevated ideals of a heaven peopled with the angelic souls of past saints and heroes, which produces higher ideals of virtue and a higher ideal of philosophy. Again the doctrine of an omnipotent Ruler, the God of order and of fate, and the doctrine of caste acting on the more practical minds of the Roman people is cultivated till it blooms into the mighty sunflower of the government of the country by its patrician aristocracy, elected by its people; that great principle that has done so much to advance civilisation and the formation of Empires and to make Commerce a success.

We must go back three to twenty thousand years or more along the tide of prehistoric fables and myths if we wish to get the grip of the hereditary factors that form the basis of these evolutions; and are drifting back to a still older stage of retrogression in evolution when we aim at the government of the people by the people, for it is the worst possible form of government belonging to ages of savagery, for this reason. The Government of a country can only be the reflection of its electoral basis, and three-quarters of the members of any community constitute its failures, and will continue to do so till we succeed in stopping the fools and the criminals from breeding, for the wise consider before they marry, the fool does not. In the meantime any government will fail to advance the prosperity of its people which fails to keep the control of the franchise amongst the most successful one-third 
of its population. I cannot devote space to discuss this matter here, so must confine myself to the bare assertion of an undeniable fact, that is if history and evolution go to prove facts. But it was the realisation of the true value of rule by its aristocracy that placed India, Egypt, Babylon and Rome at the head of civilisation in the past, and the old German Empire, Holland, France and England at the head of modern civilisation, and last, but not least, gave to the world the belief in God and His Trinity. But wealth and luxury in Rome, arrogance and jealousy in Germany, and the greed of Commerce in Holland, each in turn destroyed the representation of the control of the people by their aristocracy.

The degeneracy of their aristocracy, and the increase of indolence and love of pleasure amongst the people had much to do with producing a result that caused them to drop from their high estate and crumble to pieces. Take this lesson to heart, you of the British Empire, before it is too late, and renew your veneration for the aristocracy that has made England mistress of the British Empire; and take it to heart, you British aristocracy, and remember if you lose your ideals of energy and management, and lead a life of ease and delegate to others the control that your brains, ability and hereditary qualifications fit you for; the masses will not be long before they also become indolent and cease to respect you.

I do not say that people should go so far as the modern German has gone and kneel down and adore the crimes of their rulers. It is possible to carry all extremes too far, but remember that virtues are but the outcome of sins; so one must be lenient to the sins of others while one condemns their crimes; and bear in mind that it is a coincidence that the virtues of a nation grow out of the vice of the rulers; and the vice of the masses are the seeds from which grow the future virtues of their rulers. God does not require the same virtues from all of us, neither does he punish our sins alike. We gaze with horror at the crimes of the modern rulers of Germany, but at the same time we should honour the obedience and trust that its misdirected and misguided people have placed in their advisers. Mark my words, the rulers will suffer for their crimes, but the country will flourish in generations to come for the loyalty of its people.

So grew the laws of Caste, which laws are to be still further 
evolved in the hereditary customs of feudalism and be made clearer of understanding to the world by Professor Darwin's inculcation of the laws of the survival of the fittest, laws which God has asserted and reassured throughout the whole of Genesis and the whole course of evolution.

Now I must return to the parent and strongest seed, that of One God and His Trinity. To still further evolve it and to prevent its becoming destroyed as the other revelations had been when planted in the fertile lands of advanced civilisation, God, after giving it a temporary cultivation in the highest civilisation of the day, the rich mental soils of Persia and Assyria, where it probably picked up the Ten Commandments, and possibly the teachings of trinity, or it was further enlarged upon, just as in Egypt it most probably evolved the dogma of the immortality of the body, and in Greece that of the existence of a heaven in the skies, and in Persia the immortality of the soul was further enlarged upon. These are items in support of which I might fill a volume, but which in the present case I can only pause to allude to, and will content myself with remarking that all these teachings are destined subsequently, after the birth of Christianity, to be picked up and incorporated into the later forms of religious beliefs during the days of the Roman Empire. We now find that to preserve the precious doctrines of God and His Trinity, the early pilgrims fled from India some two to three thousand years before Christ, and having picked up the Ten Commandments from the Medes and Persians, who were at this time advanced to the highest pinnacle of civilisation reached at this stage of creation, carried these teachings into Palestine, for the Ten Commandments appear to be a summary of Assyrian laws.

Many of these ancient doctrines are now transplanted to the poorest possible soil, that of Palestine, which we read was the dumping ground of the outcasts of Egypt, and Persia and the Hittite kingdoms. No possible surroundings could appear less suitable in the judgment of man, for the cultivation and growth of so choice a dogma, but the ideas of God and mankind often differ. For when we consider that the religion of the Hebrews and the Canaanites who peopled Palestine was the worship of Baal and Astarté before the coming of the Jews from Egypt about I800 B.c., and the influx of the Mosaic people about 900 B.C., not as is 
usually believed from Egypt, but in all probability by a roundabout route from Assyria, who first conquered the Hebrews and Canaanites and subsequently the Jews, and who taught them the belief in One God and One God only possessed of a triple personality which was the doctrine of Brahmin cults.

It is not possible to put any great reliance in Jewish history prior to the time of David and Saul, and most probably the early-Books of the Bible up to the end of the Book of Joshua form but a record of all the prehistoric legends of India, Assyrial and the Eastern world of the day mixed up indiscriminately with those of Palestine, as the cosmopolitan mixture of races, that had taken refuge in its mountain strongholds, vied with each other for the retention of the legends and fables dearest to each one of them. So we find that the teaching of One God and His Trinity was not universally accepted by the Jews themselves, but only by the followers of Moses till after their captivity in Babylon, which leads me to conclude that upon this occasion the captive Jews came into contact with some of the most enlightened men of their own race who had taken refuge in Babylon when the rest of the Mosaic people were expelled out of Assyria, who reconverted them to the ancient beliefs that they had originally held in India two thousand years earlier; for remember, dear reader, that the evolution of such deep and lasting forms of divine revelation are the productions of the evolution of the mind and soul of mankind extending over thousands upon thousands of years, and influenced by life under varied environments of evolution, soil and climate. So most probably in some such manner was this doctrine, together with the accounts of the early creation of the world as given in Genesis (which is clearly a record of the religious beliefs of India and Persia in the magnificent days of their prehistoric empires), some even of Chinese origin, and were in some way carried to a nation who were worshippers of Baal, by means of oral and verbal traditions, to form our present beliefs.

I do not condemn polygamy just because it is polygamy, for looking at it from a broad-minded standpoint I can see that in its day it was one of the greatest virtues, and did more than anything else, perhaps, to advance civilisation and enable it to combat savagery. But its day is past, now that the laws of caste and heredity have taken its 
place, and so not only produced monogamy, but enabled it to exist. For monogamy, like autocracy, can only thrive in a country having a privileged aristocracy that strongly enforces the laws of descent and honour to success. Until the laws of descent made laws of monogamy the laws of the land, polygamy was and is the only other means of advancement by which the law of the survival of the fittest could be maintained or made possible, for the fittest man gets the largest number of wives under polygamy, and increases the proportion of the fit over the unfit. As I have pointed out elsewhere in this treatise, the virtue of one age of evolution becomes the crime of another, and vice versa.

So polygamy was a virtue in its day. I will even go so far as to say that if in the future we break away from the laws of descent and customs of veneration to superiority and honour to success, and try to equalize or abolish social distinctions and sacrifice freedom by granting unrestricted liberty in place of freedom, evolution must either degenerate or you must return to polygamy, one or the other, or the nation must cease to advance. Now at the present day the ordinary man will disagree with me on both these scores, but that will not alter the truth of the statements in the least. Now I have mentioned this question, I must point out to the reader that even Christ was most careful not to in any way condemn polygamy, but even goes a long way to support it. Yet that does not, and cannot justify the degenerate and degraded state to which the Hebrews, Canaanites and Israelites had reduced polygamy, for even granting that under wise restrictions polygamy might not be a sin, nothing in the world can justify the degraded state to which the Hebrew and Canaanite religions had descended when they tried to justify the utmost uncontrolled and unbounded forms of polygamy, and even made the sacrifice of newly-born babes an act of virtue and religion in their worship of Baal and Astarte.

To such soil as this God now transplants the choicest of all his revelations. At first sight such an act makes us almost inclined to doubt divine wisdom, but when we stop to consider why he did so, we no longer doubt. In Assyria, Egypt, Greece and Rome this, the choicest dogma of God and His Trinity, was sacrificed in all these more civilised countries 
to the lust for pleasure, and love of wealth, power and display. But in Palestine, which history shows us was the dumpingground of the civilisation of Western Asia, there is comparatively no mighty wealth of a mighty empire at whose shrine this doctrine would be immolated. So this is the safest port for it, in such a storm. To Palestine the revelations of ancient India and China are transplanted, till such time as the last Godmade man, Jesus Christ, shall come upon this earth to perfect all religion by the establishment of Christianity, which is to be the most perfect religion until after God the Holy Ghost shall descend into the souls of mankind, and give them sufficient wisdom to clearly understand all things even to the consummation of the world, when mankind shall at last be old enough to walk unaided by the guiding hand of religion; able at last to know, love and obey his creator for duty's sake alone.

No sooner has Christ come and redeemed mankind than God destroys Jerusalem, and by so doing ensures the reconstruction of the dogma of His Trinity in the varied forms of Christianity so as to be adapted and suited to all the nations blessed with Aryan blood, where it may again incorporate the doctrines of immortal life, a heavenly existence, and the wisdom of Government that the previous Aryan emigrations had given birth to in Persia, Egypt, Rome and Greece, out of which reunion of the Aryan family is to be born into existence modern Christianity. I could if space were available enlarge on this subject till I filled volumes, but as my object is to merely touch upon the most important points, so as to show that the same chain of evolution that is wound round the windlass of creation is continuous, and that it is the same chain that is worked by the hand, arms and axle of God's Trinity which as it turns winds up the rope of evolution. Hence I can only draw attention to those links which, being on the upward side of the axle, are most prominently exposed, so to speak, to view as being the most visible connections in the demonstration of my hypothesis.

We now come to the age when Christianity is beginning to become the revolutionary force that is to supplant the Roman Empire, the downfall of which is to carry these reformations into the other parts of the globe, shortly to be populated by the third great Aryan migration, that of the Norman branch of the Aryan Race destined some thousand years later to spread 
through Europe. These Aryans have lost all and every relic of the past beliefs that once belonged to their ancient race, but wherever their blood flows, there also flows Christianity, for their ancestors have shared the same fights throughout the Glacial Period, and are therefore physically fit to comprehend Christianity. But not so the Turk, Seminoles, Chinese or African races. No law of caste, no law of hereditary descent, no bodily strain in fighting snow, cold and rain have ever fitted them to receive Christianity. No breeding with wives blessed with powers of transmitting female qualities of God has ever softened their native cruelty, or helped to turn their sins into virtues. In many ways they may be better and freer from crimes of drunkenness, etc., than the Northern races, but they are not so advanced in the higher arts of civilisation, such as honour, justice and mercy and invention, though their proficiency in arts of skill, in business acumen, manufacture and production, which are lower forms of evolution than honour, justice and mercy, may be greater.

Crime must be overcome before we can evolve virtue, but the abolition of sin is not necessary for the perfection of virtue. It is the preponderance of good over evil in the acts of the community, not the absence of evil that creates true virtue and advances humanity. For from the abstract point of view which evolution requires us to take up, it is necessary that a certain amount of evil should take place to enable us to comprehend the full value of wisdom. So we find the Southern Races cannot advance so far along the road of virtue and mental evolution as the Northern and Aryan Races. Half-bred Aryan Races are capable of being evolved to a higher degree of mental evolution, so do stop at a fixed point in such a manner; so certain species have retained certain degrees of physical advancement at certain ages of creation, and thereafter can only evolve in like directions.

The Eastern child advances along the road of culture and knowledge at a much earlier period of life than the Northern or Western, but his advancement stops at the early age of twelve or fourteen, whereas the child of the more northern races continues to evolve his mental qualities for twenty or twenty-five years. So at the period of evolution, at which we have now arrived, Christianity does but hurl the nonAryan races into a deeper idolatry and more foolish forms of 
superstition than existed in previous ages before the birth of Christianity. Their mind is not sufficiently evolved to grasp its higher ideals (so to save them from the final loss of the belief in One God, and to grant them a further chance of progression in the course of the future), until they may some day have a chance of intermingling with the Aryan races in times yet to come, when some at least of them whose acts may make them worthy of such a reward, may be ultimately enabled to progress and so gain immortality, even if they may never be permitted to attain to the highest stages of wisdom and so merit the highest eternal reward. So we now find Mahomet rising like a star in the East to assist their salvation by offering them a lower order of religion than Christianity, more suited to their lower mental development, and for reasons previously stated, polygamy is for them still the most perfect order of marriage. In the same manner their lower order of mental development prevents them from being able to comprehend the heaven and ideals that Christianity has tried to place before them. So Mahomet is destined to fill a void otherwise existing in the world's mental evolution by creating a religion suitable to their understanding.

Thus the Mahometan religion between 500 A.D. and to-day spreads and embraces a large number of the non-Aryan races that have risen above savagery, if not as high as the Aryan races have in mental development. So do not condemn the Turk or Asiatic because he is a Mahometan or a polygamist. He may be just as moral and virtuous as you yourself, only in a different manner; but as he has been subject to a different series of evolutionary events your religious food would be his poison, and his would disagree with you.

You cannot undo the past; you can only make the future better. His past has made him and will decide his future. Thank your stars that your past has been made under more propitious circumstances, which have made it possible for you to evolve a better future. We cannot help at the present condemning the faults of cruelty shown in the present war by the non-Aryan races. The Vandal blood will show up in the German and in the Turk, who are nearly devoid of all Aryan blood, so cannot feel the same sense of honour and justice that appeals to us. I say, therefore, let these facts make you realise the high obligations you are under to cherish 
the inheritance your fathers and mothers have bequeathed you, by trying to inculcate in your children a veneration for God and His Trinity, for those whose acts he rewards (you may not be able to understand why) by placing them above you in social power or superiority in wealth; nevertheless he has given you and your children the powers to aim at winning these advantages as also an immortal existence and teach them to direct their lives aright. Try and be wise rather than rich if you wish to succeed, and if you are not vicious or selfish the riches will follow provided they are advantageous to your increase of virtue, but remember mankind is a long way off being wise yet, so you must not look upon it as an easy contract, or wonder if you fail to merit riches as well as success. Fight bravely on so that your children may win them even though they may be denied to you.

Having now shown the most probable manner in which religion has been evolved, and how the place due to it is correctly the Tenth Day of Evolution, I have done all that is required for this treatise. But I may here remark that the Thirteenth Day should, by the numeral rules of evolution which allot three days for the conception of any evolution of soul, be the day of the next birth of a further evolution of like order. That would make the Thirteenth Day, the day of the birth of Human Understanding, and if we turn to our tables, we find commerce marks the first age of Understanding.

Perfect Understanding of right is not to be vouchsafed to man until evolution is complete, when man is to start to become a religion unto himself, which is the epoch we are about to commence to-day. Then taking another period of three days, we arrive at the age of pleasure which is to be marked by man having learnt to prevent crime. And so we complete mathematically two epochs of evolution of the trinity of Religion and the trinities of Soul. Taking another period of three days brings us up to another stage of religion and to number Nineteen, which marks the age of perfect religious Wisdom, and is the final trinity or trinity of trinities of Religion, and the final aim of all religion, for when perfect wisdom rules mankind this earth becomes Heaven, and can religion do more than gain mankind possession of Heaven? I shall, therefore, show but one more illustration of the manner in which religious evolutions are influenced by state governments in the course 
of modern history. Taking England, we see the Christian religion come to the help of government till the reign of Henry VI. when the religious leaders had become the rulers of so much wealth and power that they became corrupt, and so great was this evil amongst the trade institutes of those daysthe monasteries-that the Wars of the Roses are instituted to establish a new departure in the rule of Commerce, for up till now Commerce has been under the rule of religion. This develops Protestantism out of Catholicism, which in its turn degenerates until the reign of Charles I., when Protestantism has become as corrupt as Catholicism was, and it is in its turn replaced by Puritanism, so as to abolish the tradesunionism of aldermanic guilds. But as this does not suit the religious views of the community Puritanism returns to a reformed order of Protestantism after the wars of Cromwell. So all through the history of religion, new religions crop up or new branches of old ones which from time to time become embroiled in state issues and thus bring about their downfall and a new form of religion is started, better suited to the demands of the time and age; or a corrupt government is through religious contest replaced by an improved one.

But as the reader will perhaps now comprehend, our knowledge does not all get destroyed as it did in the past. Wholesale destruction of science is not likely to happen to the same extent as has been the case. But in the present war we have seen enough of German vandalism to realise that until after the future evolution of national peace, this is not altogether-a thing of the past. Some such religious and state contest must have banished the Mosaic emigration from India and so it lost all records of its early religious history, to abolish which presumably the subsequent governments of India destroyed all records of her past magnificent religious developments, and we have to go and hunt for them in the rubbish heaps of the newer religions of Persia, Egypt, Greece, Rome and Palestine. Then thereafter Christianity in its bigotry destroyed the writings of the Pagan authors of Rome, Greece and Egypt, as Rome destroyed the records of Jerusalem, and Mahomet those of early Christianity when he conquered Constantinople. So we must turn out and ransack the homes of Pagan religion, and all religions in our efforts to arrive at the truth, finding, if we look in the right spirit, fresh lights 
in one and all of the teachings of revelation obscured by massive curtains in many colours and patterns of Fable and Superstition. Now and again as with the libraries of Assyria or monuments of Egypt some long-forgotten light of illustration is thrown in our way by science, but as already stated, these strong chance rays of light come not from the homes of religion, but are, as it were, trunks or packages it forgot to take with it, and so left behind on its journey when visiting a friend. But the wisdom of all this is the more astounding, and one of the most undeniable proofs of God's unerring hand through the creation of revelations and religions.

I dare not try to be very explicit because the subject is too vast for this treatise, but I think I have said enough for the reader to trace his way along the road of religious evolution, although my finger-posts are placed very far apart.

This now brings us to the Eleventh Day of Creation, the age of Government, and in the next chapter I will endeavour to take the reader along the three next days of creation through the ages of Knowledge and Science to the ages of Understanding and Commerce till we arrive at the present time, the Fourteenth Day, which is the Age of Invention and mighty wars, in which man is by invention and wars to complete the conquest of the world, and to spread Commerce throughout it by the extinction of international wars. Then the future is to commence on the Fifteenth Day by universal peace. This will practically end my treatise, but if I have shown that these fourteen days coincide with the past days of evolution, it is not unreasonable to suppose that the other seven days, the Fifteenth Day, Peace and the end of wars; Sixteenth, Age of Comfort, Use and Charity; Seventeenth, Age of Contempt for and prevention of crime; Eighteenth, Age of Content; Nineteenth, Age of Wisdom; Twentieth, Heaven; and Twentyfirst, Immortality. This is a faint outline of futurity.

I had intended to close this chapter here, but it subsequently occurred to me that it would be incomplete if I did not write a few words to caution my reader not to let what I have been compelled to show was the probable manner in which religion has been evolved, weaken his beliefs and practice of any form of religion that has or can aid him in the performance of his duties to God and man. Oh! my dear reader, it is my desire to open up to your mind a higher ideal of your 
responsibility to God and to your neighbour, not to destroy your existing beliefs before evolution has sufficiently evolved your soul of Understanding to receive more perfect conceptions of divine revelations. For nothing is more marked in the teaching of Christ than his effort, both by parable and evasive replies to questions from his apostles as regards the future course of evolution, than his care to hide the wisdom that he possessed yet was far too wise to display as he realised that their minds were not then sufficiently developed to be able to understand, or even comprehend the mysteries of the future.

Remember, when we are about to renovate our house or home we do not decide to pull it down until we have consulted an architect as to whether or not it is necessary to do so, and as to whether or not a fresh coat of paint, modern windows, a verandah, etc., will not suffice to modernize it before we destroy the massive masonry that has braved a hundred years or more. So I advise you to leave to the enlightened minds of the day to decide the rights and wrongs of what I have written and of the revelations science is unfolding. Utilise if you like as much of what you have read as will or can assist you to build up purer and more perfect ideals of the aims and objects of life, or will help you to obtain a more perfect idea of your own insignificant position in the magnificent and mighty scheme of evolution of which you form but a part, or that can assist you to make your life more perfect or of greater use to the community amongst whom you live. Try and let the views I have expressed and the teachings of evolution enable you to turn the great lessons it contains to some practical account, and remember that the whole of evolution shows that we do not live for ourselves or for this life, and while we are in our bodies we must "give unto Cæsar the things that are Cæsar's, and unto God the things that are God's."

To Cæsar, that is, to our neighbour, we owe love and consideration, the forgiveness of his sins, that is, his faults and failings, so long as they do not endanger our safety, or freedom, for the faults and failings of one man make the virtues and successes of his neighbour. Venerate all just and honest success. It is the stamp of God in man. Respect and copy those who possess it. Take lessons from the failures of others, not so that you may benefit by them, but that you may avoid them; try and prevent folly of any sort, for nothing is 
wrong that is not foolish, and all that is mean and unjust must be foolish, for sooner or later it will bring its own punishment. To God who ruies the fatality of your existence you owe the best use of your time, energy, brains and talents, and the use you make of them for the good, not of yourself, but of your neighbour, and for the community which will decide, not your wealth-that will be decided by whether or no wealth will make you more or less useful to the community-but your happiness in this life and the chances your children and you yourself will have throughout the years of eternity of being possessed of the Kingdom of Heaven, that is to say, the ability to participate in the enjoyment of those who live after you. These are the great lessons evolution teaches, and if I have written anything that will impress these lessons more strongly on your mind than if you had not read this little work, or that offers a greater inducement to you to aim at higher ideals than you otherwise would have tried to attain, or than your present religious beliefs inculcate, I recommend you to add such to your existing beliefs, and let any such benefits make some atonement for such parts of my work as you do not approve of or which may appear offensive to your individual mind or beliefs. But because in this chapter it has been necessary to show the probable material forces that have had to do their share in evolving those beliefs and have created in you a mind capable of receiving them, please remember, that this does not lessen the fact that the forces of divine inspiration are most probably just as great factors in your becoming possessed of them as ever you have considered it, in the past, under other modes of interpretation.

To me it implies that evolution only proves how utterly we are dependant on the will of our creator and his decision as to whether we have merited the gift of right thought and right understanding to be able to profit by the graces of divine inspiration that from time to time he may vouchsafe to mankind. So do not draw the conclusion that I wish to lower religion or your beliefs in your esteem. Nothing would give me greater pain. Try and realise, as I do, that all the religions of the past are but a portion of the divine light of revelation struggling to shine through the mist of past superstitions till it can reach your soul, so soon as evolution evolves that soul sufficiently to receive their full light. Just as the light 
of the sun had to struggle through the dense clouds of mist and steam, that during the second day of creation made up the atmosphere of carbolic-charged vapour that was destined to descend upon the third day of Creation in rains, and form the waters which were to make the globe fit to support plant and animal life, but under which conditions life as at present was impossible, but without which conditions the disintegration of the rocks and clays that were to form the soils of the earth that were subsequently to be enriched by millions of defunct plant and animal existences would never have come about. In the same way, had not the past misinterpretations, superstitions, and bigoted and fanatical influences impressed our past forms of religious beliefs upon our minds, we should never have evolved souls capable of receiving the more advanced ideals science is now disseminating and placing at the feet of religious belief. Our advanced power of understanding the truths of God and Nature may enable future religious opinions to wreathe a still brighter garland of a perfect knowledge of divine revelations, with which to crown and make more useful and practical the future religious direction of our lives. To raise the organisation of future social manners and customs to a plane of more practical utility as a means of greater unity, and real charity in the forgiveness of the failings of the weak, and assistance to those who are trying to develop their talents and so become worthy of being admitted "into the joy of their Lord" by rising socially.

The first and foremost duty both of science and religion is to fit mankind for a higher mental and physical and social efficiency than he has at present. Any religion that fails to achieve this object is no longer worthy of human respect. Hence, be tolerant of the weaknesses and failures and lower ideals of the religions of others. Make your aim to shape your lives in such a manner that they will add to the pleasure, happiness and content of those amongst whom your lot is cast, and ever aim at attaining and copying the lives of those who have higher ideals of utility than your own, but do not forget that if in some ways your own pet virtues may appear to excel theirs, a careful review of your own pet vices may end in your finding that the utility of their particular virtues may exceed the utility of yours, and that hideous as their vices may appear at first sight to the mode of life in 
which you have been reared, and are accustomed to, yet when taken in conjunction with their surroundings, duties and obligations, their crimes are less conflicting and less likely to destroy the virtues that their social environments demand than your own faults would be. And that the very virtues you glory so much in would be of very much less value if you were to rise or fall from your present social position to either a higher or a lower one. Perfection lies in having the wisdom and self-control to adapt your actions to the circumstances, and company in which time and situation may place you.

If you have not this perfection you cannot rise without offence or fall without disgrace. To sum up, this sermon, mind your own business in the best manner and least offensive manner you can, so that you do not injure or offend others, or act unjustly towards them. Leave others to mind theirs, provided they do not offend, injure or intentionally affront you. And then you will realise that God is only carrying out exactly the same plan in the development of your soul as $\mathrm{He}$ has carried out throughout the whole course of creation. So also in the evolution of religion he has only again foilowed out the same course of evolution when $\mathrm{He}$ makes different religions the various machines of a like order, that are to fertilize the various forms and classes of the various kinds of human minds, which are as numerous as the various races and the different surroundings that gave them birth.

Thus $\mathrm{He}$ is in the same way preparing the mind of mankind for the evolution of his soul, in precisely the same manner as in the past, when $\mathrm{He}$ enriched the world with the past products of plant and animal life. He has enriched your soul with the past lives of your departed ancestors and will permit your acts to enrich the souls and minds of your children. He will in future, as $\mathrm{He}$ evolves your soul, water it with even more copious rain of divine inspiration as $\mathrm{He}$ permits further lights of revelation to shine through the clouds of superstition, fanaticism and bigotry, as He disperses these clouds by the increased light of science and knowledge, safeguarded by a better knowledge and understanding of God and His Trinity, and its influence and connection with evolution and creation. That this treatise may do something to disperse these clouds of superstition and bigotry, and stimulate mankind to make greater efforts to 
acquire habits of more perfect Charity, Justice and Mercy, must be the excuse for the offence I may unintentionally have given. This may be the work of thousands or hundreds of years, during which time your existing religions must be your rock of ages, round which as they crumble away, as did the rocks of the earth, are to be found the fertile valleys of divine wisdom, in just the same manner as the fertile valleys of the earth have been formed by the crumbling away of the primeval rocks of creation. So, in like manner, your souls will be fertilized by the waters of fresh revelations and enriched by the decay of past religious beliefs as they march on in the future; just as Christianity has grown out of Idolatry, so will higher and more enlightened religious forms of evolution replace the beliefs of to-day.

As our souls increase in wisdom, more enlightened forms of religion will be evolved by the crumbling away of past parables, fables, legends and superstitions as the mountain of truth subsides to form fresh soils for the growth of more enlightened revelations, watered by the streams of future divine inspirations as they flow through the growing souls and minds of mankind; and as his powers of Imagination, Comprehension and Understanding are further evolved to be able to realise their full significance as the mind of mankind becomes enriched by the past dead and defunct brains, study and knowledge of previous generations as each age of human existence replaces another, until the whole of mankind is free of crime, till a wise and perfect form of religion is evolved, free from all clouds of superstition, bigotry and fanatical hate, when man can bask in the sunshine of a supernatural understanding of peace, content and charity.

Therefore, even if you, like myself, cannot see eye to eye with what your religion teaches, but feel that you can form a higher ideal of life by adding to what it teaches, do so. For if you try to act up to the highest ideal that you can possibly form, no matter what your religious beliefs and convictions may be, it cannot teach you to do more than that. Believe and comply with as many of its religious teachings as you can. It is the most precious legacy your mother, and her mother before her, has bequeathed to you, so do not discard any of it that you can continue to believe or practice. Religion, like all else in evolution, must advance with the 
progress of man's mind, and scientific investigation, and a better knowledge of past evolutions will in time decide right from wrong; but in the meantime study these matters as much as you like, but do not grasp at every new idea, or you will be like the man who tries to please everybody and ends by pleasing nobody. This is why I have stated elsewhere that if in writing this treatise I have had to tread as heavily or more heavily on my own beliefs. than I have trodden on yours, no matter how carelessly I may have appeared to step.

I could not have written this treatise in a purely abstract and strictly logical manner if I had not first disabused my mind of all and every opinion and belief, except those that the subject demanded me to take under consideration, and holding as I do from my own religious education such diametrically opposite ideas to some of those I have been in this manner called upon to express, I can assure you it has not been an easy task to perform. So ruthless has been the manner in which I have had to stamp on my own beliefs, and I am afraid on yours also, that I tremble lest my efforts to offer you a truer and higher ideal may not have destroyed more than I can rebuild.

I do not place these assertions before you as proved facts, only as views that may be worthy of further consideration and investigation. And as what appears to my individual mind as the most probable solution of a complex and difficult problem. I advise you to do as I intend to do, retain all your old beliefs wherever you can, and put them into practice whenever you can, and trust to God by the inspiration $\mathrm{He}$ will in the future; as $\mathrm{He}$ has in the past bestowed upon the minds of those who strive to turn the advancements of science and knowledge to good account; so elucidate and clear up the hidden meanings and mysteries of revelation, thereby to advance the future evolutions of all forms of religious belief. For religion can no more escape from the laws of evolution than can any other branch of science or knowledge. And remember that when you knelt down in your nightdress to breathe your first infantile prayer at your mother's knee, and lisped "God make me a good boy" (or girl as the case may be), she taught you more in that simple prayer than all science and knowledge can teach you. For she taught you that the great 
aim and rule of your life, that alone can make you perfect, namely, to place your entire trust in God, leaving Him to direct and reward your actions, and by leaving your life in His hands to direct you on your way and reward your acts as He thinks fit, so long as you make the best use of your time, opportunities and talents, for the good of others.

And this you will find $\mathrm{He}$ will always do, not in the way you desire, but in the way that will make your.life the most useful to the community if you will only preface all acts of the day by an ardent desire to perform in the most perfect manner you can your daily duties, leaving their reward entirely in His hands. I say desire, because a prayer not born of an ardent desire is no prayer at all. And with the love she (if she was a good and devout woman, which I take it for granted she was) also taught you the rudimental principles of the religion her mother and her mother's mother had bequeathed to her as their most cherished birthright, remember that she also bequeaths to you their past religious knowledge and experience, and if the religion they held was the most suited to assist the style of life that their talents and social requirements most needed. In ninety-nine cases out of one hundred you will inherit capabilities that probably fit you for a like social position and occupation, so it follows that their beliefs are most probably those most suited to your requirements. Therefore, again I say put the highest value on the religion she taught you, which, you may rest assured, was the best she knew; add to its beauties whenever you can, but be loth to destroy any of its flowers until it is no longer possible to prevent their fading.

Do not lose any chance of adding to its lustre by picking any flowers of further enlightenment that may bloom alongside the roadway of life and add them to your bouquet of high ideals, as your after knowledge and experience may enable you to add to their utility, and so enlarge the religion of your individual soul. But be careful not to discard the stilts of religion until you are sure you are on sound ground. Christ tells us that $\mathrm{He}$ came not to destroy the teachings of the past, but to enable us to see and believe them. But, as I have already pointed out, God grants us enlightenment as regards His revelations in exact proportion as the evolution of our minds fit us to receive them. Not by the miracles of 
dead men's bones, as was believed in the past, but by the united actions of live men's heads and dead men's brains, thoughts, knowledge and experience are we to further evolve virtue. For as I have already pointed out, $\mathrm{He}$ apparently intends only to work three miracles in the course of evolution, in the same way as $\mathrm{He}$ apparently only gives each one of us three chances in life to decide our fate for good or evil, after which fate rules all the rest of our lives.

These three miracles are:-

First: When He reversed the action of heat and cold and that of contraction and expansion and weight and density, which are amongst the most fundamental laws of nature. These He reverses when the temperature gets below thirtynine degrees, but had not this law been entirely reversed, the whole of nature would have stood still, for it is only the expansion of cold that has prevented the entire seas becoming frozen, and has crumbled the rocks to pieces and so produced the soils and made the globe habitable.

The second miracle is-the work of our redemption by men born of women without the co-operation of man, and unless $\mathrm{He}$ had worked this miracle it would have been impossible for man to have received the attributes of God the Mother, or to have evolved a mind fit to receive Love, Comprehension or Invention, which alone could prepare the road to the wisdom of understanding. In this way $\mathrm{He}$ has demonstrated His power to rule first, all creation, and secondly to rule life and birth.

The third miracle will be when after mankind has evolved a perfectly wise soul He will prolong life into Immortality at the end of the coming Epoch of Charity, and so will assert His prerogative to rule Creation, Life and Death. For if my Hypothesis is correct, the aim of creation must be when mankind attains to perfect wisdom and perfect self-control over his actions, and so destroys folly and becomes able to offer a perfectly finite eternal sweetheart to a perfectly eternal and infinite lover. But apart from these three miracles to mark His prerogative to rule nature, all the rest of creation and evolution is conducted on one set plan and principle, and we cannot expect religion to be any exception, any more than any other form of evolution. Thus as years roll on the increase of worldly wisdom may destroy some, and science may 
destroy others of our most cherished beliefs, but increased wisdom is more likely in the long run to add to the strength of religion than to destroy it, for it is, as I have shown in this chapter, nothing else but the best assortment of the accumulated collection of man's wisest comprehensions of the knowledge and revelations of the past, which hitherto he has had to accept on Faith, seeing and believing as best he could.

But a brighter day dawns with the coming Epoch of Charity which is to evolve a higher order of wisdom in his soul, for this is the Epoch that is to be marked by the descent into the mind of man of the Spirit of God the Holy Ghost as foretold by Christ in just the same way as the Epoch of Hope marked the descent of God the Mother in the evolution of religion, and which is to enable his mind not only to see and believe, but ultimately to understand and put into practice the revelations of God. But do not forget it has taken two thousand years to evolve the present form of Christianity. It took about another three thousand years to make the Jews accept the belief in God and His Trinity, and probably anything between twenty-five and fifty thousand years to evolve this belief in the mind of mankind in prehistoric ages amongst the fables of the East, and to convert these fables into any shape or form that was of concrete thought or practical utility as a fixed and recognizable teaching, distinct and unassociated with older forms of idolatry. Nevertheless the Persian philosophy and astronomy had advanced nearly, if not quite as far as we have to-day or it would never have arrived at the knowledge of the revelations displayed in Genesis, till owing to the march of civilisation destroying the energy of the East, this knowledge is again lost in Idolatry.

We have yet to raise the minds of mankind to see that labour and energy are greater means of virtue and happiness than wealth or knowledge; for any nation that loses its energy loses its brains and vitality as its punishment. Add to the beauty and magnificence and truths of religion as much as you can by cultivating higher ideals whenever science and evolution permit of fresh additions to this storehouse of revelation, but remember that God never destroys past evolutions. He only builds more perfect evolutions on and around the past, and you cannot go wrong if like Christ you follow. His example, by aiming at retaining the old as well as the new 
knowledge of revelation until there is no longer any use for the old. As I have shown elsewhere, my Hypothesis and evolution both point out the necessity of the mystery of redemption to enable man to transmit some of the attributes of God the Mother and some of the qualities of woman. These qualities are the foundation stones of all that is refined and beautiful in civilisation and which alone make practicable the Christianity which Christ came from Heaven to improve by His religious teachings, and without which all the most refined characteristics of our souls would otherwise have been as tightly closed a book to the minds of man as the characteristics of woman are, and always will be, and as the higher faculties of man's wisdom are to the minds of woman.

Now it seems to me to be improbable that future revelations, the gifts of God the Soul, whose three final attributes are to complete man's powers of understanding divine revelation will be ushered into the world by any miracle, as were the attributes of God the Mother by the work of redemption. Most probably they are to come about in the ordinary course of the evolution of the brain of man as he evolves a mind of more perfect understanding of right and wrong, as came the early dawn of religion through the evolution of Imagination, and that the promised descent of the Holy Ghost will arise in the form of more enlightened ideas in the brain of man, somewhat as this Hypothesis has become known to me. Soul being a male personality of God, no revolutionary action of the laws of evolution are necessary to bring about the acquirement of such alterations in the soul of man, only in the souls of women; and it is highly doubtful if the acquirement by women of too high a standard of wisdom would be conducive to an increase of human happiness or of feminine loveliness; but I am rather inclined to think that it would decrease the perfection of the qualities of love and sympathy which are the most beautiful stars in her diadem. Under these circumstances there is no call for the redemption of woman. Even immortality cannot make her a more perfect angel than she is. I know I ought to be able to quote a chapter and verse in the Bible for the substantiation of the following belief, but I do not remember where exactly to put my finger on the particular verse, but the following quotation 
seems also to corroborate this supposition of the descent of the Holy Ghost, so I will insert it instead :

"If ye love me keep my commandments. And I will ask my Father and $\mathrm{He}$ will give you another Paraclete that $\mathrm{He}$ may abide with you; the Spirit of Truth whom the world cannot receive because it seeth him not." (I take this to mean, because at the time of Christ the human mind was not sufficiently advanced to believe in forces and powers that were invisible, such as electricity and radio-activity and so was unfit to receive the Holy Ghost) "nor knoweth him, but ye shall know him because he shall abide with you, and (I take this to mean that when the mind of mankind is sufficiently evolved to receive the spirit of true wisdom and so will be able to understand the mysteries of God and His Trinity and to begin to desire to do right for right's sake, then the Holy Ghost shall descend into the minds of men and abide therein. Then mankind will be able to understand the revelations of God the Father, and God the Mother and God the Soul, and of God's Trinity and its relation to nature, instead of as hitherto being able only to see and believe these truths in parables and fables, and through superstition, necromancy and clairvoyancy which is all he had been enlightened enough to do in the past) And in that day you shall know that I am in the Father and you in Me and I in you."

My Hypothesis illustrates this by showing it is impossible to separate any part of creation from God, which will be doubly clear to more enlightened minds when God the Soul of Wisdom enters into man's mind. Surely this points to the truths of the Hypothesis which I have endeavoured to explain, namely, that all creation is a part of the Trinity of God, and that when man can understand the mystery of the Trinity of God, he will be able to begin to realise that creation is the finite part of the invisible infinity of God Almighty, from which a part of the divine attributes have been withdrawn. There is no such thing as two separate creations, but that finity is only the evolution of the material parts of infinity; different, not entirely separate from Infinity; impregnated, surrounded and controlled by the infinity of the life, existence, action and soul of their invisible creator as we find Him present in the infinity of ether, the mysteries of which we are now just starting to realise. This is the 
Hypothesis I am endeavouring to explain, which has been the extraordinary outcome of the marriages of the attributes of God's Trinity as demonstrated in Tables I., II. and III., and which the modern comprehension of radio-activity substantiates.

Hence cherish your past beliefs, if you want my advice, but do not be too narrow-minded to improve upon them by scientific discovery. Evolution brings the Spirit of God the Holy Ghost within the comprehension of your soul, and into the reach of your mind and of your understanding, but be careful not to destroy the house already built in which the wisdom of God is now commencing to abide. Build a more majestic outer wall and modernize the windows so as to admit a greater amount of the sunshine of the light of divine revelation into your soul. We cannot all own houses of the same size or exactly alike, for we have not, and never will have souls that will admit of the same containing capacity of the light of divine revelation or wisdom, or be able to conduct our individual lives on exactly the same lines of virtue, but must always suit them to our brain power and consequent social position so as to adjust them to the varied occupations of mankind.

As I pointed out elsewhere, when God builds our bodies He does not destroy their previous plans, so let us please try to copy Him. You cannot get a better model-and do not let new beliefs destroy more of the past ones than you can help, and realise that religion is the soul of virtue and must ever do more than knowledge to make us virtuous, because it is part of education ; but knowledge and science are the manures that are to perfect its growth, so do not stint it. Religion is a crop that will stand a lot of the manure of further enlightenment before it can be understood by the finite mind of man, for its boundaries are those of infinity, and man's mind is finite. 


\section{CHAPTER VIII}

\section{GOVERNMENT AND SCIENCE}

HAVING now carried my reader along the course of evolution to the Tenth Day of Creation, and endeavoured to point out the manner in which, as the Spirit of God the Soul entered into the mind of mankind and so evolved a human as well as an animal mind, I have taken him to the second great departure from the natural laws that govern evolution, and advanced him to the second half of Table I. marked Involution, which is the third stage of creation, the Dawn of Soul.

In just the same manner that the first two or three years of childhood are devoted to the animal development of our minds, and the next twelve or thirteen years see the production of our character till we near the dawn of manhood, although the emotions of character are being evolved throughout these twelve or thirteen years, they are not complete till we have attained our twenty-fifth year; and although all our animal qualities were evolved during the first two years of our lives, they but slightly affected our actions, which were dominated over by the will of our parents and superiors, until we had evolved a will of our own. This does not take place till after we are fifteen years of age, when the individual Soul of Wisdom begins to dawn in our minds, to grow until after thirty when we attain manhood, and become the masters of our actions. So in evolution, although the dawn of soul commences on the Eighth Day of creation when both Imagination and Comprehension, two out of the three attributes of man's soul have now commenced to be evolved, we may say as he is now getting more than half the attributes of his soul, that he is beginning to evolve wisdom as a force in the world by the evolution of human government, in place of divine control which has alone hitherto had to dominate over creation.

It is now my duty to show, as far as possible, that it is most probable that Government, Science, Commerce and Invention have followed on in the sequence of creation to 
complete the second of the seven days of creation, in just the same manner as I have endeavoured to show that during the first three days of the Epoch of Hope; Agriculture, Civilisation, and Religion, have been evolved in an exact sequence with my Hypothesis, as were the seven days narrated in Genesis, and then the principal duty of my task will have been performed, as I will have taken the reader up to the age in which we live.

But we cannot say that the birth of Wisdom started in the world's history prior to the Eleventh Day of Creation, when the influences of superstition and fear that gave birth to religion and fanatical rule, and the foolish systems of control born and nurtured by trading on the ignorance and credulity of mankind, become supplanted as state government gives rise to the first absolute form of management that directly aims at placing the will of man in opposition to the will of God. This lays the foundation-stone of man's triumph over the laws of nature; and am I not justified in saying that this is a higher evolution of human wisdom than dependence on the ignorance, miraculous apparitions, bigoted beliefs in the infallibility of necromancy, fortune-telling and clairvoyancy; which were the fundamental principles on which all religions have asserted their claims to rule mankind.

That these factors gave rise to man's belief in, and feeling of dependence on his infinite creator, no one will deny, and that in doing so it evolved his first belief in the existence of only one God and His Trinity, which acquirement of a knowledge of divine truth no sane person will dispute, is and always will be the highest pinnacle of wisdom. and the source and rise of all the tributaries of the river of divine enlightenment that flows through and enriches the valleys of human knowledge. Upon investigation we must also admit that the ancient forms of appeal to prophets and idols, were but an early realisation; of the more perfect forms of appeal by direct prayer, since offered direct to our creator. In like manner religion has been the most powerful form of human rule, if often more abused than the more advanced and useful one of scientific government. It only shows the wisdom of the divine plan of creation and its universal system of gradual advancement, that God should first create hopes and ambitions by religious teaching, before He punished our faults 
by the erring condemnation of mortal wisdom. It is only perfectly in accord with His unerring plan, that as mankind evolves higher orders of wisdom and governments, he should do more and more by human intelligence to adjust and control human action, and in so doing progress nearer and nearer to the ultimate object of His creation-viz., to act as the good and faithful steward of his Divine Master, and so become a self-constituted ruler of a self-conquered kingdom, subject to a fee-simple of veneration to his creator.

We now enter upon the second great departure of creation during the Epoch of Hope, when man begins to comprehend and put into practice divine revelation, the abstract teachings religion has evolved, out of which is now slowly being made visible to the imagination of mankind as fear makes him more observant of the lessons of nature, he begins in a humble way to realise that there is more to live for than his personal wants of hunger, thirst and sleep. So from this onward he starts to evolve a more practical order of control than religious government, as out of it he develops state governments, science, commerce and invention, which if less beautiful are nevertheless more useful as modes to enforce, in time, higher principles of wisdom. But even in this year of grace I9I7 ignorance still predominates over scientific wisdom, so that we must not be surprised that for the last twenty-five thousand years religion, which plays on man's ignorance and credulity, has been and still is, so far as the mass of humanity is concerned, a more fitting and proper means of advancing his mind, which even yet is not sufficiently highly evolved to receive the soul of divine wisdom. There are other forces of nature which are helping to develop the evolution of state government, and to teach man self-control of his actions.

So on this, the Eleventh Day of Government, which is to be the first of the four last days of the Epoch of Hope, to the elucidation of which I intend to devote this chapter, we find human will arrives during these four days at its manhood, and exerts palpable influence upon the course of evolution. We also find that it commences to lay the foundation-stone of our souls; by evolving law and order out of religious beliefs and bigoted superstitions, the distorted realisation of divine revelation by our imperfect minds during the previous ages, through which fear and ignorance have led man blindly by the 
hand of religion, through the intricate maze of imperfect knowledge, his illiterate conception of which is now evolving the birth and childhood of human will, by advancing his capabilties of comprehension, which on the Eighth Day gave birth to agriculture. This was the first great step man made to conquer and subjugate the universe, and bring nature under his power instead of living in blind obedience to the will of God, as he did during his animal evolution throughout the Epoch of Faith.

The Tables point out that Government is now to make one of the important forces of creation as evolution develops Human Will by the marriage of mind, the third attribute of God the Soul to Life, the third attribute of God the Mother (see line II, Table II., the sixth marriage of God's Trinity and Eleventh Day of Creation). I have now taken my reader along both evolution and the hypothesis, to the age when eleven graces or influences of its infinite creator are to unite and become active forces, to exert their rule over the further development of creation. In evolution " coming events cast their shadows before them," so we find power or Human Will, the second attribute of God the Father, first makes its appearance in our Table II., on the Fifth Day of Creation, when it combines with Love and Imagination to conceive the germ of human authority by creating marriage, the most perfect act of human will; for if there is one power in life that does more to perpetuate the brain of man, and stimulate his energy to unselfish ambitions, perfect his energy and self-control, and increase his love and charity, it is his love for a good and pure-souled woman, and to the priceless devotion, love and obedience of a true and faithful wife mankind owes all his loftiest ideals of good government, the trinity of which is Power, Love and Wisdom. So we find the order of our marriage of God's Trinity is correct in its position and sequence, in placing the conception of human wisdom on the Fifth Day as the highest order of sex in mammal life, and, by restriction of sexual marriage to state ones, sex is to be raised from a physical to a psychical evolution. This appears to have been the first class of state legislation. It next appears as a predominant factor on the Eighth Day, to evolve agricultural laws as the second act of human legislative wisdom, and three davs later it will attain its manhood by the evolution of Inven- 
tion, which is to enable mankind to complete his conquest of nature. After another three days it will reach its prime when he succeeds upon the Seventeenth Day, by means of a scientific government to control and to conquer himself by preventing crime, and lastly after another lapse of three days evolution is doomed to die with the completion of human wisdom, the last effort of evolution, when, on the Twentieth Day, the earth is changed into heaven. But up to the Eleventh Day the forces that human will has been evolving, are not of sufficient magnitude to materially alter the natural evolution of man's mind, which has, up to the Eleventh Day, been governed by the hand of fate, not by any marked influence of his mind over creation. Hence it has been comparatively easy to connect the sequence of the two courses of the evolution of the world, and of the Trinity of God in Nature, but from this onward it is more difficult to connect the two together, except by merely pointing out, as Table III. does, that the order of their development corresponds in the order of its sequence with their respective development, both in the Tables of Trinity and in the course of evolution and history, a more detailed record of the events of which the concurrent evolution of language will shortly produce. But there are important links between Geology and History difficult to connect.

From this point the influence of natural laws is slowly to be brought into subjection by the power of the will of man, now nearing perfection, by supplanting and ruling the powers of the Spirit of God the Father, which have up to this age of evolution governed and controlled not only the Universe $\mathrm{He}$ has created, but have also held the will of man in a bondage of fear and trembling, at the forces of nature he feared and worshipped because he could not comprehend them.

Between the Seventh and Eleventh Day (the reader will remember that I have tried to impress upon his mind that it takes three days from the conception to the birth of any attribute of God's Trinity in the ages or days of creation) the realisation of the Word of God in Genesis, "Let us create man to our own image and likeness," has come about and produced changes too rapidly for evolution to be able to retain their records. As I have elsewhere pointed out, this coming of the three forces of the three persons of God's Trinity into nature, constituted the likeness of God in man's soul. Previ- 
ously there had only been the influence of God the Father and God the Mother at work in the production of the Universe, and man's body up to the Seventh Day kept its records.

This alters when Spirit comes into creation, for God being a spirit could have no body, and material and animal existence having no soul, they could not be a perfect likeness of God and could have no Spirit existence. Hence it was impossible that there could be any true likeness to the psychical forces of God in man's body or in the universe, except the one likeness pointed out in Genesis, the likeness of the male and female sexes of God's Trinity to the male and female creations of body, and such dim semblances as electricity depicts. But the Seventh Day marked the first great psychical departure of evolution, when God the Holy Ghost gave to the dawning mind of man its first ray of the light of wisdom, as a glimmer of Understanding, the fourth attribute of the trinity of soul, is now conceived in the mind of man, so granting to him a will that could act in opposition to the laws of nature, and could conceive in some slight way the difference between right and wrong, and so make sin possible. Sin, the greatest of all blessings conferred by God, for without sin it would have been impossible to merit heaven or evolve virtue; and as it also created crime it now calls for government to control that inborn tendency to err on the part of mankind, which was to give him the capabilities to do wrong, that he might evolve virtue by doing right, and so ultimately merit the reward of immortality. This is the quality which has placed him above all else in creation.

So long as his body was evolving, there was no image of God in its material development, only the reflection of the dormant and invisible influences of the Omnipotent and Invisible power of the Almighty, by such evolutions as nerves, brain and electrical phenomena in creation and a reflection of the guiding love of the Almighty Mother of the Universe. From this onwards man is to test and destroy the weakness of his physique by the means of $\sin$, so as to make it strong enough to support a mind. Thus up to the Eleventh Day of Creation, fear of the Invisible power of God clothed in superstitious dread of the awakening presentiment, that the revelations of Nature inspired, the knowledge of which could be attained only by faith and obedience to religious teachings 
he could not understand, but must accept on faith and belief in the Spirit of God the Father and of God the Mother which were to rule him till the spirit of God the Soul should awaken in future scientific ages the yet imperfect wisdom of his understanding, which was not to become an active or visible force that could influence his will and raise it from an animal to a semi-divine will by the gift, not of divine but a perfect human wisdom of understanding, a result that was not to take place till his mind was capable of doing more than accept on faith and belief, without doubting the mystery of the greatest revelations that have ever, or ever will be given by divine inspiration to the mind of man-the conception and understanding of the divine Trinity of God, Its Personalities and Attributes.

Until man's mind is sufficiently evolved by the Spirit of the Holy Ghost, granting him sufficient wisdom to enable him not only to conceive and believe in the great mystery of God and His Trinity, will he be able to know, comprehend and understand the full importance of its influences, meaning and actions upon creation. But when God grants him perfect human wisdom, the semblance of which he has up till now alone been able to gain, by seeing its reflection in the silvery lakes of religious inspiration, shining through the eventide mists of superstition and bigotry, yet throwing out the brightest light he has hitherto obtained of virtue and truth, amongst which it has shone as the brightest star reflected upon the crystal surface of the lakes of past religions. Again, I say, until man could not only see and believe in this reflection, not till his mind could go one better, and comprehend and understand the true and full meaning and importance of this great dogma, and fully understand the mystery of the Trinity of God Almighty and its influence upon creation, then, and not till then, will mankind be able to make his longest step forward, towards the final end of his creation by overcoming the crimes of cruelty, selfishness and injustice, and so learn to live in brotherly Love, Justice and Charity. This is what he has to learn in the coming Epoch of Charity now beginning to dawn on humanity.

If the Hypothesis that has grown out of my ardent prayer for the gift of "right thought" which gave birth to this imperfect treatise, can help mankind one inch nearer 
towards a true understanding of God's Trinity, and by so doing hasten the evolution of his soul of wisdom, so that he may learn how to govern himself, I shall not feel that my life has been a wasted failure.

I have inserted the foregoing remarks in this place because having now travelled along the road of evolution, till we have reached the point where we have demonstrated the connection between the Hypothesis and the dawn on man's mind of the Trinity of Soul, by his evolving Imagination on the Seventh Day of Evolution, Comprehension on the Eighth Day, Under. standing on the Ninth, Religion on the Tenth Day.

We have now completed the likeness of God's image in the mind of man, and from this the evolution of the world begins to be conquered and controlled by the mind of man, as well as by the hand of God, as he evolves forms of government. So far we have traced man's fight for supremacy over the fallen angels; or, in other words, over the animal creation, which takes us up to the Seventh Day, and in the first three days of the Epoch of Hope the dawn of his mind, and during the next four days of evolution we are to trace his fight to overcome the world God has created by the united forces of Study, Government and Science, which occupy the Tenth, Eleventh and Twelfth days, till acquiring the knowledge to govern cities, he advances to the formation of kingdoms, and with the help of religions as they are established, learns to govern them. Then calling to his aid the gifts of Science and Invention, which have been presented to his dawning soul by his redeemers, to enable him to create Empires and establish state governments and commerce throughout the world, thus conquering and bringing under his sway the world God has created for him to rule. This takes us up to the present age of existence, the Fourteenth Day of Invention.

It would be presumption to try to go further in a treatise like this. The most I can undertake is to present to the reader the rest of the Tables II. and III. and allow him to form his own opinions thereon, simply remarking that the next day of evolution following upon the present, the Fourteenth Day of Evolution, is to be the day of Peace, the Fifteenth Day that is to herald into the world the Age of Universal Peace amongst all nations, a result which was not to take place till Commerce extends to all parts of the world. Then mankind 
will, under conditions of Peace, be able to evolve the power to truly understand the mystery of God's Trinity, and so devote the last six days of creation to the greater fight of conquering himself and his vices till he shall, by learning to use, not abuse nature, make this earth of ours a true heaven.

On the Twenty-first Day he will become fit to receive his heritage of Immortality, an immortal child of an immortal parent when he shall have completed the likeness in his soul of the God who created him. Some of the concurrent evolutions of this day of government are those of language and writing and history. There was no call for these evolutions during all the previous course of creation. For the origin of our characteristics must be sought for, not in the environs of the different races of to-day, but much further back in the environs of tens of thousands of years ago when his mind was in its infancy. God never permits a new evolution to commence till he has prepared the ground to receive the seed, we find $\mathrm{He}$ has not allowed history to be evolved until eleven out of the twenty-one graces or attributes are evolved. Until more than half of the forces have become motive agencies in nature, so slight will be their influence on the evolution of man's soul that there is no need to preserve a record of their details, order or sequence, as too great knowledge of them would have prevented the evolution of the evils, that were necessary to produce the lower orders of $\sin$, out of which the lower orders of virtue were to be evolved, if the course of creation was to be continued on the same plan its builder had first designed.

I now turn to my work with a greater feeling of incompetency, for having come to the place in evolution where man's power commences to assert its right to govern in conjunction, and to a small extent, in opposition, to the power of God, the difficulty of defining the evolution of the concurrent forces at work and comparing them to the laws of evolution is less clear, for hitherto I have only had to follow these forces travelling in parallel lines. Now I have to follow two or three antagonistic forces, now at war, now working hand in hand, to bring about an intermediate course acceptable to both combatants. I must therefore ask the reader to grant me greater mercy in his criticisms, and not be too hard in his judgments if, for want of time and opportunity to 
devote to study and the acquirement of knowledge during a busy life, my attempt is but a weak one. I will only try and make the best attempt I can. We can none of us do more than our best, and live in hope that God will grant me life, strength and brains, to do better at some future date; and that wiser minds may complete what I can only commence.

Through the course of its revolutions and history, every form of religion in its turn has been doomed by Almighty God to fade and die, for religions, governments or empires are no exception to the laws of life, death, rebirth and rejuvenescence, than are any other evolutions of creation, such as knowledge, science or animal existence. So in the past religion after religion has been doomed to death and destruction to evolve better systems of state government, and governments in the same way have died to give birth to higher forms of religious beliefs, not always more correct in their teachings, but as a rule clearer and more explicit as regards some important dogma of revelation that is, at that particular age, the most necessary religious evolution of the day, and always and in every case better adapted to the requirements and advancements of the particular community in question, as one form of government gives place to another, or one kingdom overcomes another. This has given rise in the past to religious persecutions, and it will be one of our duties in the future to abolish state wars, as we have already abolished to a large extent the religious persecutions of the past.

All these persecutions were seldom in reality waged against religious convictions, but were far more often in reality due to the fact that religious communities had neglected to enforce some necessary principle of state government, or to enforce some necessary form of self-restraint, or else some new form of legal government, or were destroying some necessary form of legal government or new form of virtue that a fresh stage of evolution required, or in its efforts to evolve some new, real or apparent but impractical social reform much needed, but little understood, or that appeared to be much needed by the mass of the people to correct some evil on the part of its rulers, or some crime of the masses that the rulers sought to remove and thus got embroiled in the political contests of the day. For religion is in reality only the voice of the penple clamouring for or against the 
correctness or incorrectness of, the use or abuse, of the divine enlightenment of the wisdom of the few really wise men who rule and control them to whom the Almighty has made known or partially known the mysteries of revelation, and to whom he has confided their interpretation, and who are at the time either correctly or incorrectly expounding them. Thus it often appears to the superficial observer or student of history, whose mind is only capable of seeing one side of the question, and whose less inquisitive nature fails to read between the lines of past events owing to the lack of sufficient practical knowledge of nature and humanity (for the student of science leads a life that often little fits him to be an exact or observant student of human nature, and is inclined to get into one fixed groove of thought or experiment, both of which are inclined to destroy his quickness of comprehension, judgment and decision that are necessary to produce a mind of logic and truth, or that quality of altering and adapting one's opinions to altered circumstances that is only acquired by varied experience and close observation of the minute details that can be learnt only by living in close contact with the laws of nature not only in life but also in youth) or which the personal bias of the author hides from his view. Hence religions are in reality, like all other forms of mental and human evolution, prone to err in detail if not in principle.

In all historical accounts there is written between the lines, so that he who has sufficient power of interpretation may be able to read the hidden meaning they contain, provided he has an impartial and unbiassed mind. So between the life and death of religions and governments lies a bitter struggle and strife between religions, science and governments for the powers of wealth, influence and social aggrandisement, at which shrine wisdom and truth are offered as sacrifices, and this is the warfare that has caused most of the persecutions, both of and by religion in the past, for religion has been throughout all ages not only the most bitterly persecuted but also the most bitter persecutor of the lot. And such so-called religious persecutions are only sign-posts along the roadway of history, pointing out that at that particular date priest and king were waging a bitter war for the possession of power, might and wealth, and as to which of the two should have the right to rule mankind. 
This should now act as a caution to us to endeavour to stop the recurrence of such unseemly strifes in the future, when the same strife will be carried on, not as in the past, between priest and king, but between priest and professor; not between kingdoms and empires but between king and commoner, freedom and liberty, the right to work (which is only another mode of expressing the right to live) against prohibition of each man's free right to work how and as he wishes (which is only another way of expressing or conferring upon one man the right to enslave or starve his fellow-men by prohibiting to his opponent the right of making a fair and unfettered fight for his existence) subject only to such restrictions as are necessary for the restriction of liberty so as to permit of freedom, which, of course, includes the prevention, and when necessary, the punishment of crime.

So in the coming Epoch of Charity we are to drop the wars of empire with empire, and religions with governments, and wage a still fiercer war, if less destructive of life, than the wars of the past, against indolence, selfishness, and love of wealth and pleasure; for the wars of the future are not to be wars of wealth, aggrandisement and glory, but for wisdom, truth, charity, mercy, honour and justice against strife, avarice, greed, crime, dishonesty and folly. Thus we must study evolution with greater care and endeavour to make our lives conform to the laws of God in nature, if we would make mankind perfect, and it is a law of nature that the more valuable the prize the more violent will be the struggle, which is why God has postponed the struggle for truth and wisdom to the last; so that mankind might first be able to evolve a physique and mind powerful enough to be able to endure the long and bitter struggle necessary to evolve a soul of wisdom which is likely to be even more intense than the present war as compared with past wars, viz., a war where the combatants will be so equally matched that until the last moment it will be impossible to decide on which side the victory will be, and crime will at the same time rise to a height of scientific excellence never before dreamed of, just as war and murder have done in the past and present. So we will have, each one of us, to do our little mite to help to shape and guide the progress of future evolution. The conviction of the important part that a combination of action between religion and science will 
have to play in future evolution has done much to make it seem to me to be worth the time, trouble and courage that it has entailed upon me to write this treatise, and to offer a valid reason for my leaving the beaten track of past convictions and to face the disapproval that my doing so will, I feel sure, bring upon me in my attempt to offer a common meeting ground to religion, science and governments; by showing how science and evolution when read and checked by the light thrown upon them by a clearer and more reasonable understanding of the mystery of God and His Trinity and its connection and corporation with and influences over both creation and religion and evolution, by the general if not particular coincidence of facts that result when both science and religious teachings are checked by the attributes of God's Trinity and the mysteries of revelation are correctly interpreted.

This I hope may induce these two mistresses of knowledge join hands in the future and unite their efforts on the principle of give and take basis, and so help each other to make the mysteries of the revelation, which it is their joint duty to expound, clear and understandable to the dim minds of ordinary mortals, and by practising greater tolerance and sinking each their proud and arrogant claim to an infallible knowledge of wisdom that God has not yet vouchsafed to the mind of mankind, to agree to drop their foolish and bigoted antagonism and tear off the clothes of past superstition from their respective idols of belief and knowledge, and by meeting in friendly contest on the common playground of evolution and history, and God's Trinity, combine together to unearth the truths of revelation. The careful student of evolution and history cannot fail to notice that each and every form of religious teaching, no matter how perfect its original dogmas may have been, becomes out of date as the attributes of God's Trinity return to creation to advance the world of knowledge and the minds and souls of mankind, as they all slowly proceed along the road of evolution that directs the course of creation, all point in the same direction as time and the influence of man's will, now nearing its full development, begin to make themselves felt as concurrent controlling influences in the conduct of nature.

So now we find that on the Tenth Day fate begins to control man's action by the hand of religion as his mind com- 
mences to study nature, and this has now so far advanced the evolution of man's mind and will that he has progressed to such a state of fitness as to be capable of receiving the first germ of his human soul of wisdom, which. enables him, at this period, to evolve a mind. If the reader will turn to Table II. he will find that line 6 reads MIND marries LIFE and begets HUMAN WILL, and that MIND, LIFE and WILL are the Trinity of forces that produce all forms of government, MIND, LOVE and POWER being the trinity of good government, and MIND, SELFISH HATE and POWER the three forces that make abuse of government.

Allowing for the two days of divorce, and three of soul, we get 2 plus 3 plus 6 equals II, so two divorces, the three attributes of soul and six marriages, bring us to the Eleventh Day of Government, and we find in evolution Government comes into existence on the Eleventh Day of Creation, so our Table II. of the marriages of God's Trinity is once more correct in its prognostications. From this onwards the struggle for supremacy to rule mankind between religions and governments is to flood the world with murders, wars, and rebellions, by which means are to be evolved in their infantile forms the virtues of honour, justice and mercy and chivalry. I say infantile because it will not be till during the coming Epoch of Charity that mankind is really to evolve these virtues and that of charity, when after the coming day of " universal peace amongst nations," he is under conditions of peace on the Fifteenth Day to learn how to use, not abuse, the means of production and so be in a position to evolve principles of use, justice and charity on the Sixteenth Day. Nevertheless these qualities are being slowly evolved during the whole of these four or five days we are about to review, and the three subsequent days are to be devoted to perfecting these virtues, so that the powers of his soul of wisdom may become stronger than those of his will and mind, when he will, having by this time acquired perfect human wisdom, be able to devote the last two days of creation to evolving Heaven on Earth and Immortality.

The growth of religion in its early form of superstition and fortune-telling, naturally necessitated that the religious fanatic not only sought out the voice of the imaginary divinity or idol of some shrine, that he imagined could assist him, 
but he also expected his priests to have supernatural gifts and endowments, for at this age he was inclined to endow all nature with supernatural attributes, so it became necessary that the priest should be a weather prophet also. This induced the priests and prophets to become students of necromancy and of the law as well as of religion. In the preceding ages, the ages of civilisation and of agriculture, a knowledge of astronomy and meteorological science began to hold as high a place in the requirements of the people as that of religion, so we now find that study is the correct counterpart of religion in Table III., for it was astronomical study that evolved religions, and our Table III. is therefore correct in placing it opposite religion.

This is why the Chinese religion and certain forms of Buddhism contain so many false ideas and teachings which the well-balanced, wise and well-informed mind clearly sees are only the confusions of an imperfect knowledge of revelation, science and astronomy, and why fortune-telling, clairvoyance, necromancy and astronomical facts have in the past been welded together in all manner and forms of superstitious beliefs, such as that astronomical influences can decide and rule the fates of mankind, which in reality can only be influenced by the power of God's Trinity, the effect of what we call fate. But as God is the infinity of ether, there is some small ground-work for such BELIEFS; for God uses astronomical influences to enforce the decrees of Fate in exactly the same manner that He used the concurrent forces of heat and cold, heredity and variation, as collateral influences to produce new metamorphosis in reconstruction (of creation He now uses mental ones to create new) forms of Government or religion, or underlying influences that produce war, or a new revelation of religious ideals and scientific discoveries.

The religious teacher was consulted not only on all matters of superstitious belief, but also on all matter pertaining to war, agriculture, health, and the weather. It therefore became necessary for him to study the laws of nature and the influences of the heavenly bodies. He became a weather prophet and an astronomical student as well as a law giver. His superior knowledge thus gained soon won him the respect of fear and reverence, ever given by one man to the man he feels to be his intellectual superior. Thus study became the 
signal mark of the next stage of evolution after the develop. ment of religion. In a very short time these fortunetellers or seers became the most feared and respected men of the community. Princes and kings bent their knees before the prophets and patriarchs. Thus it came about that when one small city or district took up arms against another appeal was made to the seer or idols to foretell which would be the victorious army, in just the same manner as we appeal to prayer when knowledge fails.

As Study takes up time (and time and money are one and the same article under different names-it is a pity our labour agitators cannot realise more than one side of this truth), the fortune-teller found he could not grow fat on study and fern roots, he therefore turned his knowledge into a means of livelihood by granting it only when accompanied by offerings of fowls, sheep, goats and cattle to his divinity. These were offered as sacrifices, because this made a good excuse for avaricious demands, but you may be sure the priests of old took care that the daintiest morsels of the sacrificed animals found their way to his table, and the highest bribes found most favour with the deity.

Now, fanaticism has ever been more powerful than arms and it urges men to feats of valour and extremes of suffering which even wealth and money have been powerless to conquer. Hence it generally followed that the combatants who were best able to bribe or buy the voice of the oracle became the victors in the majority of cases because of the confidence inspired by the prophecy. But knowledge, as it always does, made crime easy; hence the priest was able to inflict punishment and chastisement on the unbelieving heretic, for his superiority in knowledge enabled him to reek vengeance and vent his spite on those who were more ignorant than himself without danger or fear of detection. This soon made him more powerful than the ruler or king of a city or tribe; hence he conceived the idea of governing, not only his native city or tribe, but the kings or leaders of each tribe or city that came to him for counsel or advice. So grew government out of religion, and from the order so raised grew estates and kingdoms out of the villages and cities. Then a ruler becoming more powerful than the priest or prophet dethroned him of his power. But the wiser man, always being the most ready to 
accept the inevitable (for it is only the fool who knocks his head against a stone wall), soon saw on which side his bread was buttered and that it was a far better billet to be the adviser of a powerful king than to be a weak prophet or religious ruler. So he preferred to become the chosen minister and adviser of the most powerful king or general. This made him a student of law as well as of necromancy. This in its turn gave birth to state laws out of religious ones, and so government became evolved and the student became protected and honoured by the wealthy and powerful, provided he taught what the king desired. This gave him the time and leisure to turn his attention to other branches of knowledge, which brought him a still greater increase of both power and wealth. In this way he became the instructor in agriculture, the law maker and, consequently, the protector and instigator of Commerce, and for centuries the monopolist of the Commerce also.

I think I have now shown the reader the manner in which these three days of Study, Government and Science were evolved in exactly the same order as they appear in Table II. of the marriages, and the companion Table III. of comparison, which is all that is incumbent on me to do in support of the Hypothesis, that in God's Trinity lies the key to Evolution. And as we have now reached the stages of History, the further elucidation of the subject can be obtained by any of my readers who wish to trace the subject further. I need only state that as Governments became more secure, and the possibilities of acquiring wealth more within the reach of every man, more thought and time were devoted to study instead of to war, agriculture and trade. Thus Science was evolved in the wake of government, fostered and cherished by its mother, Religion. Hence arose a new and bitter strife for power, sometimes antagonistic, sometimes intermingled with periods of truce between the alternate competitors for the rule of mankind-Government, Religion and Science, which make up the Trinity of Forces that rule mankind's mind and soul and evolve society. This is the real cause of all so-called Religious persecutions, and these, as I have already explained. only arise when religions are used as a cloak for political organisation so as to enable conspirators to meet together and use fanatical influences that religious organisations plot as a 
means of promoting party and social strifes by using religious meetings to disguise political intrigue, and so urge upon the religious fanatics the opinions of the political wirepullers, who, under the cloak of religion, create rebellion. And thus the state and religious bodies became antagonistic, whereas the principle duty of religion is to prevent unnecessary political strife by the institution of sentimental influences working for honesty and justice, and by the encouragement of the performance, by each one of us, of our obligations and duties to God, the state and society. I cannot impress too strongly upon my readers that the primary duty of religion is not to enforce its dogmas and teachings, but to uphold the social customs of the community in which and of which it forms an integral part as one of the propounders of law and order.

Its principal duty is to promote obedience to the state administration, and so remove the necessity for calling into effect the more cumbersome, expensive and unwieldy action of state legislation. State laws are only applicable when they uphold the will and inclination of the majority of those whom they seek to govern. Religious laws can only increase virtue, obedience and humility when they work in unison with state laws. The state must prevent crime; religion cannot. The jail will ever cure more crime than the parson, but the parson, with the assistance of scientific discovery, can raise the upper classes of a nation to high ideals that the jail is powerless to enforce amongst the lower classes.

Try and realise that state government is a far higher development of practical law and order than religious control Religious government is the remnant of control by superstitious ignorance, which is fast becoming a decrepit old man; for scientific advancement is daily making it more impossible to rule the masses of the people by superstition and fear. It would be ridiculous to say we were to ignore the wisdom and experience of the father because the son promised to be a better man than his father. For centuries yet to come religion will still have to be the most important factor in human progress, while its promising but headstrong sons, Government and Science, are growing into manhood. Religion must be prepared to conform its teachings to the growth of its children, Government and Science, and not to always rule by the rod of intolerant infallibility. Would we 
not condemn the father who prevented his children becoming men by always keeping them in the nursery and administering the cane when they had past thirty years of age, as destroying the highest of their qualities, self-control. So we are now nearing the manhood of Government and Science, and it becomes a duty of the teachers of religion to make their teaching up-to-date, or their flocks will cease to obey them, just as much as the child will revolt from the father who does not recognize that he is becoming a man, or the nation will refuse to obey the laws that custom and society condemn as being obsolete. Hence, if we would stop religions losing their beneficial influence, we must see that they do not neglect to adjust their teaching to modern requirements, at the same time as they uphold social customs, and, above all, that they urge respect and obedience to state authority, and inculcate habits of energy and justice and rectitude, rather than superstitious rites, bigoted animosities and intolerant hatred.

The duty of religion is to act as a brake on the errors that greed, love of power, and discontent with our lot in life are constantly causing to arise, in the evolution and execution of State Government, and so act as the mouthpiece of the people to offer passive remonstrance to the misjudgment of State Government. We must not forget that the clergyman is human as well as the statesman and professor, and that being equally human is equally liable to err. The cure of the evils that have often set priests, statesmen and professors at war in the past, so causing wars and revolutions, must lie in these three masters of social regulation realising that the time has come when their united action must be combined to work out the salvation of humanity, in conformity with the laws of nature and evolution; by assisting the survival of the fit, not the preservation of the unfit. Thus only can they reduce the inmates of our jails and stop the necessity for state punishment. Religion must raise the best of mankind by devoting its energy to producing higher ideals, and in this way urge men to higher virtue and help the willing worker to rise in the social scale, but to be this it must uphold the laws of state and society and inculcate veneration, obedience and respect to authority, not inculcate equality, for there will be no more equality in heaven than there is on earth. Man must raise himself by nobly fighting the battle of life, or God will 
not reward him with an increase of wisdom any more than he did the mammoth creation that preceded him. You can prevent crime, waste and folly, but you cannot convert the sinner, make the extravagant careful and temperate, or give wisdom to the foolish except by preventing the criminal from breeding, compelling the lazy to work, and teaching the foolish that poverty and want are the results of loss and failure, to teach us that our opportunities must be turned to wisdom and virtue. By religion we can save, calling into effect the more cumbersome action of state legislation.

For state government is a higher form of development than religious control, but religion is the brake or check of misgovernment; so religion can only, so long as it is possible, rule the masses of the people by superstition and supernatural fear, and do away with the necessity for imprisonment, which deprives the community of the temporary use of the labour of the criminal, or of capital punishment, which deprives the state of his existence and labour. Thus we find religions are made the cloaks to cover crime, mutiny and revolution. But with increased knowledge and loss of ignorance on the part of the masses of mankind, religions and governments will lose their powers of control, which at first mainly lie in the ignorance of those controlled. Hence, as time advanced and governments became more powerful than religions, revelation was sold to buy kings the power to govern unruly nations, and the truths they taught were bartered in exchange for the wealth laid by kings and princes at the feet of divines, until religion after religion has got lost in fables and parables which now conceal the ghosts of longforgotten or disused truths. It is the work of Science to sift out the truth from the false teachings of religious beliefs and of misgovernment, as man's mind slowly acquires the soul of wisdom in the future and becomes able to form a clearer and more enlightened view of good and evil, right and wrong.

This is the duty of science, aided by further research of history and evolution, as we become better able to understand the true cause of our past creation and the correct course along which we will have to proceed so as to do our little mite to help to shape and guide the progress of future evolution; and if my treatise will help in this work, it will be worth all the trouble, time and courage to face the disapproval 
that its new departure from the beaten tracks of past convictions will, I feel sure, bring upon my head. For each religion in turn degenerated to be in its turn supplanted by a better, as one kingdom triumphed over another, and one empire gave place to a greater one. This has given rise to the mistaken ideas of the causes of religious persecutions and so caused bitter hatred and bigotry. All such persecutions seldom had their origin in religious convictions, although they were often raised against them, though it often appears so to the superficial student of history, who reads one side of the question, and whose less inquisitive mind fails to read between the lines of the historian; whose want of practical knowledge, or the personal bias of the author hides from his view the real cause of the events. Behind all historical accounts lies a bitter strife for power and wealth, and such so-called religious persecutions are only sign-posts pointing to him who reads between the lines, that at that stage of history king and priest were waging war for the possession of power, wealth and might.

Studying these tables of Trinity, as I have been doing lately, they indicate to my mind that in the future such strifes are to end, now that the golden-haired little fairy of Invention is growing into womanhood, and is to be crowned as queen of all the world and even now is raising man one step further and higher in the scale of evolution, by teaching him that modern warfare is too expensive a luxury to be used in future as a means for acquisition of territory, as the loss of the belligerent's capital will out-balance the territorial gain, national aggrandizement, and extension of commerce, which have been the only justifiable excuse in the past for this brutal relic of man's cannibalism and love of murder. When all is said and done, it is only a legal license to rob and murder; and the sooner it is dethroned from its high pedestal of honour, and we learn to grant but little more respect to the soldier than we do to the policeman, or perhaps even to the hangman, the better for the good of humanity.

In the future we must learn that valour has to give place to wisdom and science, and that the only cause that will justify war will be the necessity of punishing international crime, and that the armies of the future must only be high-class police forces. It will be more beneficial for nations to buy and sell or to exchange territory, or such por- 
tions of it as are of more advantage to one nation than to another, and it is better to receive a few millions of pounds from an offending nation, and put our national pride in our pockets, so far as to see that it is wiser to receive the apology of the insulting nation in the form of a pecuniary indemnity as a means of increasing our happiness, industry, wealth land population. The offending nation will realise that it is better to pay the indemnity, than to mortgage its future capital and prosperity by a debt of poverty so enormous as modern and future warfare will entail upon its people, by condemning to death the bodies, and, in some cases, the souls also, when all the members of a family are destroyed, of some of the best classes of our citizens, and by depriving both nations of millions of pounds of capital and millions of livelihoods that vanish and are destroyed in the noisy thunder of war and disappear in the murderous clouds of smoke. Every million means the ruthless destruction of the means of employment of the labour of from four to five hundred breadwinners for a lifetime, at an income of one hundred pounds per annum, and reduces the population to the same extent, to say nothing of the loss of life also entailed; and I feel sure, since I became possessed of these Tables of Trinity, that the end of war, or at least of international war, is now at hand; as also that in future nations will combine to reduce armaments and to enforce national justice by some form of national federation, supported by a cosmopolitan army of international police.

I expect the reader to take these prophetic statements with a small pinch of salt, that is to say, as the merest outline of what will transpire in the future. Nevertheless, I am convinced that they are the shadows which coming events cast before them. It seems to me that the tendency of both science and modern warfare point to the fact that neither prowess, valour, nor religious fanaticism, which have been the dominating factors of the last hundred thousand years, will be of any avail against the mighty costliness that invention has added to modern warfare, and that science, wealth, and capital can only be victorious in future contests. Again, viewing the social discords, so apparently on the increase between man and man, it also appears to my mind that these new combatants will, before this new casus belli is finally settled, bathe the 
world in further civil strife mightier than all civil warfare of the past, and

"Cry "Havock!" and let slip the dogs of war; That this foul deed shall smell above the earth With carrion men, groaning for burial.'

This it appears to me must be the end of the final day of this week of the Epoch of Hope, and war now drawing to a close with its last day of Invention. This Epoch, which has made up the week of the evolution devoted to ages of cruelty, selfishness and war fighting for supremacy with those of benevolence, charity and justice, which are to be evolved out of their expiring ashes during the coming week of the Epoch of Charity, by higher ideals of religion, government and commerce.

I will now run through a few of the facts that go towards distinguishing these three or four days of Government, Science, Commerce and Invention, so as to point out to my reader that they were evolved in the above order as stated (on the Eleventh, Twelfth, Thirteenth and Fourteenth Days respectively in the course of creation) by my Tables.

There is little doubt that the early Chinese civilisation dates back in prehistoric times-say, to anywhere between twenty to eighty thousand years B.C., and we can also reckon it as highly advanced as compared with savagery at so remote a date as twenty thousand years B.c. Its fables and legends are of too mythical a description to be looked upon as history in its more restricted sense, and so uncertain are its narratives that we are scarcely within the strictly historic times until we arrive at five hundred B.C. Yet there is little doubt that ten to twenty thousand years B.C., or possibly fifty thousand B.C., its rich and fertile valleys and territories were decked with fields of rye, and that these southern landscapes were decked with magnificent gardens wherein the palm and other ornamental trees-the fig, chestnut, and pomegranate-ministered to the wants of mankind. Although it can boast of some form of civilisation thousands of tens of thousands of years before any other nation dreamed of even tickling the ground with a wooden spade; and the Mongolian, through being the first of all races to drop its nomadic habits, was the first to evolve some form of agriculture and civilisation, skill, manu- 
facture, cunning, robbery and intrigue. But China is a world of its own, and has never given much to the rest of civilisation, nor received much from it, nor tried to keep pace with its advances. "In this land," says Ritter, " a people isolated from the rest of the world like islanders, and egotistically lost in wonderment at itself, developed in singular manner a strong and sharply outlined national type. Within this type the individuality of the personal unit was to an extraordinary degree repressed."

Its isolated position may have had something to do with this uniform type, but it will not account for all the marked differences and lack of power of progression between the Mongolian and the Caucasian or Aryan races. The former neither alters in manners, form or shape, body or mind. Nevertheless, the Chinese mark the boundary line in civilisation beyond which the Mongolian race in its development has not progressed. (See Historians' History of the World, Vol. XXIV.).

It appears to me that, as I have already pointed out, one of the most important, if not the most important reasons for this inability to advance lies in the fact that China and the Mongolian races have only contributed one redeemer to humanity, so have only a third-rate chance of development, and have not, therefore, become capable of progressing more than a third of the way along the road of civilisation, nor of receiving more of the qualities or attributes of God the Mother than the one attribute of love. It is a curious fact that the earliest branches of the Aryan race who settled in Greece during the Mycenæan age were long afterwards spoken of by the nonAryan population of Greece as the children of the Great Mother, and truly they were so, for it was their possession of three qualities of God the Mother that made them superior to their Mongolian or Semitic neighbours. It is a striking instance of the fact that four or five thousand years before Christ the world must have had some idea of the dual gender of the personality of God's Trinity, although we have long since lost its significance. We find that these Mongolians were unable to receive more than the three first qualities of God the Mother, or her attributes of Existence, Love and Life, and it was not till after the coming of Buddha and Christ that those of Comprehension and Invention were granted to man, and his further power of advancement became assured. 
So we find that neither Comprehension nor Invention are cap. able of being evolved by the Mongolian races, except in a very limited degree, hence they have not advanced beyond the state of civilisation that was developed somewhere between ten to twenty thousand years B.c. in Comprehension, Belief, Invention or Knowledge of the truths of revelation, so remain for ever after at a state of semi-civilisation, until they become crossed with the Aryan or Indo-Caucasian races, albeit they had ten or twenty thousand years' start of the latter in civilisation. "But," continues The Historians' History, " the early ancient history of China, which can be drawn only from native sources, is obscure, untrustworthy, and imperfect. The Chinese lack all sense of historical values."

If the reader will throw his memory back to what I have already illustrated when I showed that fear of what man could not understand or realise in nature created the early forms of religion, study and governments, he will find it easy to realise that the tendency towards superstition and necromancy was the force that gave birth to all these three results, and that it is impossible that born and reared in such an atmosphere, knowledge, science, religion and early history should have any more perfect childhood than superstitious fables, parables and bigotry. Nevertheless, it is probable that the knowledge and study of this age, somewhere between twenty and forty thousand years B.c., caused China to give birth to the earliest forms of agriculture, religion and manufacture, and such early forms of civilisation or control (for " Civilisation" is but a word we use to express life conducted under conditions of self-control, self-sacrifice and order, so as to reduce the liberty of the individual, and permit of the freedom of the community).

It is probable that between twenty and ten thousand B.C., civilisation called for the creation and evolution of Government to restrain the unrestricted liberty of savagery, that the earliest forms of religion were unable to restrain, so the reader will now see that my Tables of Trinity are quite. right in placing Government as the next subsequent evolution to that of Study and Religion, after which we find that the control and order so evolved by these early forms of government permit of the creation, in their elementary forms of towns, trade and manufacture. This, in its turn, sends up 
a petition signed by the united and unanimous clamour of the voices of all semi-civilised nations for murderous armies to protect the products of their labour from still more murderous armies of savage robbers, a duty the mighty Chinese Wall attempted to do, but failed to perform. At the same time superstition and bigotry united to create religious forms of society powerful enough and clever enough to put the "fear of God or idol " into the heart of these rogues and thieves, to do which the religious teachers of early civilisation started to create a hell of dreadful imaginations (for do not forget, that at this age of creation Imagination is the only faculty of his soul that man has yet evolved. He is only starting to conceive Comprehension which will not be born till after the coming of Christ or conceived till the birth of the original Buddha, probably between ten and twenty thousand years B.c.), frightful enough, no matter how imaginary, to deter theft and petty larceny and the abuse of liberty by those who are yet too uncivilised to control their acts sufficiently to comply with the demands of primitive society. Hence from this point until the Fifteenth Day of Peace and the Sixteenth Day of Use and the Seventeenth Day of the Prevention of Crime have been accomplished, we find that war, bigotry and strife are the triumphal music to the rhythm of which the world will have to march and dance.

I now pass on to the latter prehistoric days of early India, Tibet, Southern Siberia, Persia and Egypt in which this contest is now to be carried on on a grander scale, as the Aryan races contend with their more civilised neighbours of Mongolian origin as to which of the two has the higher ideal of civilisation, and so combine their higher ideals of Control, Justice, Truth and Honour, which represent the Aryan or better half of social evolution with the properties of Skill, Perseverance, Cunning and Greed, which the more advanced, but less moral Mongolian civilisation has evolved. The records of these times are but little better known to us than those of early Mongolian history, for God in His wisdom saw that until mankind became possessed of a two-thirds portion of the trinity of the human soul, which is the faculty of Comprehension, too much knowledge of the past could teach mankind nothing of value, and would retard new and fresh, but at the same time contradictory, evolutions of half-realised forms 
of the revelations of nature; so it was not till after Government, War and Order had enabled civilisation to evolve with the aid of infantile science, which is now coming into existence on the Twelfth Day of Creation, the day after that of Government, that the science of writing becomes an art. If my reader will turn to Table II. he will see that the Seventh marriage of the attribute of Imagination and Comprehension conceives Understanding, which gives birth to Science on the Twelfth Day; and if he will read along line nine in Table II. he will find it reads Imagination, Comprehension and Understanding, which are the trinity of qualities that constitute the soul of mankind; and are we not right in looking upon the birth of science as marking the real birth of wisdom, which is to come into the life of creation or evolution and be conceived in the soul of man as a result of this marriage? Although the likeness of God in his mind was created on the Seventh Day, his soul was not born until Science began on the Twelfth.

Nature, like the Chinese, counts life from the day of conception, not of birth. Truly the father of Science is Imagination and its Mother is Comprehension; and if the reader will proceed in the same manner with the next line, or for that matter with every or any line of these tables, he will find that they correspond with what has taken place in the course of creation and evolution. So if he follows out the same line of procedure, he will find that Understanding is the father and that Comprehension is the mother of Invention, the result of which marriage is Commerce, and that Understanding, Comprehension and Invention are the three forces that go to make up the creation and existence of Commerce, which is to come into existence on the Thirteenth Day of Creation, as our Tables predict.

I will now briefly point out to my reader how the intermingling of the two most important branches of the human race (the third or black races I shall not trouble my reader with the consideration of at all as they have had no redeemers, and are therefore incapable of scarcely any advancement, nor have they ever done anything to advance mankind above the level of animals) the white and yellow races are destined to bring about the evolution of Science, Commerce and Invention, which will take us up to the present day of Existence. But before doing so I wish to draw attention to the fact that these two 
days with which I am now dealing - the days of Science and Commerce-represent the first practical evolution of Knowledge and Wisdom, in the course of the evolution of the mind and soul of mankind. And what, I ask you, would have been the good of perpetuating the histories of the follies of mankind if they did not point and could not lead him to the performance of greater virtue? So we find that God did not create writing or history till about five thousand years before Christ because it was not till then man began to succeed in turning sin into virtue by placing practical utility before abuse, so that anything but the barest sprinkling of the knowledge of creation previous to that would have done more to retard than to advance evolution as the superior volume of past errors would have submerged the infancy of wisdom.

All we can do with regard to history previous to rooo B.c. is to glean what probably were the causes of the result that history makes known to us, and so arrive at the most probable course of events. It is possible to realise what a few of these causes may have been and to comprehend what they may have produced, although we cannot absolutely prove that somewhere about twenty to ten thousand years before Christ, some previous evolution of the early forms of religions and governments must have formulated certain forms of belief and control, otherwise the early forms of the governments of nations could not have developed to the stage in their existence in the first days of history; nor could they ever have sprung into existence in so advanced a form of civilisation as they had attained previous to the dawn of history. Hence we can readily comprehend that somewhere about this time, as a result of the intermingling of the two races, there came into the Mongolian races, with their higher standard of skilful civilisation, some of the Aryan races with an evolution of a higher form, of moral civilisation, the result of patriarchal life. These men Herodotus describes as the men "who ride and shoot and speak the truth." This latter quality is highly expressive of their higher moral integrity, and that to those races, so intermingling, was granted a second redeemer, which redemption permitted of the evolution by mankind of the attribute of his soul of Comprehension and so advanced these crossed races to a higher standard of civilisation, and of Honour, Justice and Mercy, just as Imagination had produced Agriculture and 
Religion. So Comprehension now produced Government in place of Religion, which had preceded it as a more elementary and less perfect form of self-control, requiring less knowledge to permit of its utility, and Government now calls for more wisdom to make its execution effective by increasing mercy and restraining destruction.

About 3000 B.C. Commerce celebrates its conception and the Thirteenth Day of Creation begins to dawn on the world's history. We now find that Science and Commerce begin to aspire for the rule of the world, as well as the veteran heroes, Religions and Governments. About the years 3000 to 5000 B.c. these new combatants create the earliest forms of trade and barter, and so by the greater temptations they offer tu the god of avarice, intensify war and strife as the second Aryan migration by the intermingling of the Alpine races with the Seminole branches of the Mongolian race; and Religion, Government, Science and War combine to launch the ship of Commerce upon the waters of the Black Sea and the Mediterranean, where Commerce begins to thrive and flourish in exact proportion as the Aryan blood increases amongst the southern races of mankind. Thus the influences of their dual redemption become an active force in creating the results that the attributes of God the Mother have given birth to.

Even to-day we find the difference that exists where the conquering power of God's Trinity is carried by the Aryan races with this marked difference, that it is the most progressive and that it does not destroy past civilisation as it advances; but where the conquering forces are of Mongolian predominance they cannot advance without leaving devastation and destruction in their wake, and showing cruelty and want of mercy in their acts. As witness of this, we may take the present war where the ranks of the Allied forces all represent the intermingled races, and their opponents, the Mongolian races, are represented by their enemies; another example is the upheaval in India somewhere between 3000 and roooo B.c. that destroyed early Buddhism; and the Mahometan, and Hun and Vandal conquests of Europe, all of which are so many contests for their respective forms of civilisation. We find that as these Aryan migrations take place, they increase, by their intermingling, the powers of control and government and honesty, both in laws and order, and add Science and Invention to the 
superior skill of Mongolian knowledge of agriculture and manufacture. The reader must remember that the Mongolian races have eighty thousand years ancestral superiority over our three thousand years of knowledge of moral codes, so they can surpass us in arts of labour and skill and manufacture, but we cannot compete with them in respect of knowledge, or capability in skill or cunning. On the other hand, we can boast of one hundred thousand years more ancestral superiority over them in qualities of organization, mercy, justice, control and management, the benefit of which they have only participated in during the last three thousand years or so, so they cannot compete with us for the more important and reliable forces that tend towards moral advancement. And it therefore appears to me that the most perfect races of the future must and will probably be evolved by the intermingling of the English, German, French and Russian races throughout the colonies, America and Siberia, and so combine the qualities of skill, ingenuity, and ability of the Mongolian race with the energy, inventive genius and ability to control and manage, and the honour and integrity of the Aryan races.

Under the influence of this influx of Aryan blood between the years 3000 B.C. and 1000 A.D., the advance of the evolution of Government takes place under the Roman Empire, as Rome brings Government to its manhood, and as the world nears the end of the Tenth Day of Religion, which reaches its completion between 10,000 and 20,000 after the birth of Christ, and concurrently herewith is the youth of Science, the birth of Commerce, and the completion of the Day of Invention; the present day in which we live, the Fourteenth Day of Creation, the day that is to enable mankind, so our Tables predict, to bring about the conquest of material nature, which day starts somewhere about the time of the birth of Christ, and will extend to somewhere about the time 3000 to 4000 A.D. So the first thousand years A.D. celebrate the babyhood of Invention on the Fourteenth Day, the boyhood of Commerce on the Thirteenth Day, the youth of Science, the manhood of Government, on the Eleventh Day, and the old age of Religion on the Sixteenth Day, both in the order of the Tables of Trinity and in the order also of the world's creation.

After this all through the last two thousand years we follow the concurrent course of these four evolutions as they strive 
for life, death or supremacy, midst bloody wars born out of their spite and jealousies, as the two new aspirants, Commerce and Invention, endeavour to outshine the veteran heroes, Religion and Government. For during the four thousand years ending 1000 A.D., the Governments of the East and the Roman Empire control the powers of Commerce and Invention directed by the guiding hand of youthful Science. Then about Iooo A.D. Commerce revolts from the rule of Government, and siding with Religion wag'es bloody wars on all sides to establish church rule by Christianising and conquering the known world, and ruling it by the feudal vassals.

I maintain that vassalage was in reality as much a religious as a state development, and was instituted under religious instigation to place the Church of Rome at the head of the world. I read a work forty years ago which minutely described this matter, but the author's name has escaped my memory as I was only a boy at the time. Thus Commerce was handed over to the care of Religion till about the period which occupies the two hundred years between I250 and I450 A.D. when the people finally released it from the control of both church and state, and moved evolution a step further ahead by permitting individual enterprise to introduce that pretty maiden, the charming young damsel, Commerce, to all parts and nations of the globe. So the curse of Cain and Lamech, the curse of murderous warfare, is multiplied by seven times seven and carried to the utmost bounds of the world to crown with laurels the heads of Religions, Governments and Commerce, until after to-day when Science and Invention will join their youthful hands in a war, not of blood, but of wisdom, and demand the surrender of the besieged city of the world of Wealth, which by their combined influences, through the agency of the present war, they are fast bringing to the verge of starvation; and sternly demand the truce of an eternal peace, and the doing away with of this long-abused fallacy of all religions and past forms of government, namely, control by means of ignorance, might and strife, instead of by wisdom, law and co-operation. Although the heading of this chapter in. cludes only two out of the last five stages of the Epoch of Hope I have included Commerce and Invention in it also.

In this manner were involved the earliest forms of government which grew out of the early religions of idolatry as agri- 
cultural knowledge and study and the growth of villages, towns and cities slowly came out of the civilisation of the South of Asia, and the Mediterranean basin, as the Mongolian children of Cain grew and multiplied; while through the more northern portions of the prehistoric world, the Aryan or Alpine races were at the same time evolving, slightly at a slower rate, another form of civilisation in the patriarchal form of hordes and clans of nomadic shepherds, who were to evolve a higher order of psychical civilisation, by their pastoral life which kept them in closer touch with nature, which is destined as the world progresses to evolve the higher mysteries of religious belief and thereafter, the more advanced forms of governments, amongst the children of Abel who were shepherds and such as dwelt in tents, so the Bible informs us.

This occupied anywhere between one thousand and one hundred thousand years B.c., which is the day of Religion, or the Tenth Day of Evolution. During the latter part of this hundred thousand years the early conception and birth of Government is slowly coming into existence, and we will not be far out in our estimate if we allot the period of the Eleventh Day of Government a position in chronology somewhere between twenty thousand and twenty-five thousand years B.C., to seventeen thousand years A.D. So far have these early forms of Government advanced that we find that somewhere between five and ten thousand years before Christ, the kings and rulers begin to call in Science to their aid; and I do not think we will be far wrong if we allot from the year 5000 B.C. to 4000 A.D. as the commencement of the day of Science, for the reader must remember that throughout all creation there are after the third day always three stages or days of creation being evolved concurrently, each one step in advance of the other. Then about the period of between 2000 and 4000 years B.C. the infant science has started to evolve the day of Commerce which is now fast approaching in its full strength and manhood. Subsequently about the year I500 B.C. the intermingling of the Aryan and Mongolian races as the former descend from the north and conquer their more advanced brethren, the children of Cain, they give birth by this marriage of races to the golden-haired child of Invention, and together these three children of Religion and Government set to work to conquer the world of matter throughout this, the Fourteenth Day of Creation, in which we 
are now living, and we may approximately set down the day of Invention as starting about I500 B.C. So much are these matters common knowledge now that $I$ have brought the reader to the realms of history, that I do not feel called upon to devote much further space to the manner in which they have been evolved, but will leave such matters to a more enlarged edition which I hope to be able to offer to him when I have more time at my disposal to devote to further study of the subject, and I feel that I have now said enough for him to be able to follow that the Fourteen Days of Creation that have already transpired have all been evolved in exact accordance with the Table III. of my marriages of God's Trinity, and that such beiry the case it is only logical to conclude that the next seven will also likewise follow in accordance with these Tables of God's Trinity, namely, the Fifteenth Day of Peace, the Sixteenth Day of Use, the Seventeenth Day of the Prevention of Crime, the Eighteenth Day of Charity, the Nineteenth Day of Wisdom, the Twentieth Heaven, and the Twenty-first Immortality. 


\section{FINAL CHAPTER.}

My first duty in this chapter must be to point out to the reader the lessons I have learnt while writing this book.

Sir Oliver Lodge, in his work, "The War and After," writes as follows :- ". . . . the Nation must raise the standard of the greatest Revelation in human history. While as to the Christian Churches-they must admit their essential unity, they must try to regard their differences as they would be regarded from a higher standpoint; religious denominations must cease from squabbling, on pain of losing their hold on the Community. The cry of the religious teacher, in essence, if not in words, must be 'Back to Christ.' "'

This is right enough so far as it goes. But it does not go far enough. "Back to Christ" - yes, by all means, but do not stop at that. God requires more of each one of us. Hitherto Science has been content to take man's mind back to the Creation, but this revelation I have been trying to explain has taken me back, not only to Creation, but to the reason for and the object of Creation, the manner in which it has been performed, and the essential qualities and attributes of its Infinite Originator. It has not only made clear the object of Creation and of man's existence, but it has made plain to my mind's eye the Personification of the Creator in the Infinity of Ether, the Existence of the Creator, and the Infinite and Eternal Unity of the Creator and the created. Pause, think and consider the magnitude of this Trinity of Creation. If Christ was present in your midst to-day, I feel sure he would tell you some such words as these : I came amongst you, I lived amongst you, I died upon the cross for you that I might bring you back, when you were going astray, to the God who made you. I leave you for a little while, but in yet a little while (and two thousand years is but a very, very little while on the clock of Evolution or in the minutes of eternity) I will send the Paracleta who shall 
abide with you (I take this to mean by the divine inspirations that Science will give birth to in the minds of mankind as God the Holy Ghost returns to the Creation, from which his attributes have been, and the majority of which are still withdrawn) and then $\mathrm{He}$ will teach you what I (Christ) would have taught you had your minds been sufficiently evolved to receive the knowledge of " all things even to the consummation of the world," that you may not only, as at present (in the time of Christ) see and believe in the God you would have forgotten and lost for ever, had I not died on the cross to redeem you and by so doing granted you the attributes of God the Mother of Creation, Invention, Justice, Mercy and Charity, that but for my lif ? and death upon the cross you could never have received. And $\mathrm{He}$, the Paraclete, will through the instrumentality of the Soul of Wisdom (as in the onward course of Evolution of Science $\mathrm{He}$ grants it to you), enable you not only to see and believe in the God who made you, but also to know and understand Him and His Trinity, and the Trinity of His Infinite Power, Infinite Love and Infinite Wisdom. As also the Trinity of your Infinite Insignificance and your dependence on Him and infinite obligation to obey His laws, the laws of nature.

Your sole chance of regaining the eternal immortality of Life lies in your eternal struggle for the final aim and object of your existence by the performance of works of Mercy, Justice and Charity, which is the final trinity of your Evolution and Redemption.

Such are the words I assume Christ would have used had the human mind at the time of His life on earth been sufficiently advanced in scientific knowledge to have comprehended sucin a lesson. These are the lessons Evolution teaches me. These are the lessons I wish to pass on to you if you think them worth learning. It is not enough to go " Back to Christ" ; it is not enough to stop where Christ stopped. You must go back beyond Christ. You must go back to the Infinite Being from whom you are created, and of whom you are a finite Insignificant atom, infinitely smaller than the smallest grain of sand is, as compared with all the sand in the world. You must also realise that you have only one duty to perform, if you wish to remain a living particle of the Infinity that created you. You must devote the whole of the infinitely short period of your infinitely short life, to the practice of continuous energy 
and perpetual love of God and your neighbour, and the most perfect wisdom of which you are capable (I say of which you are capable, for absolutely perfect wisdom I take to be a prerogative of God that man is only to receive in a partial degree just as his invisibility, which is only partial as his mind and soul only, not his body, are invisible) if you would hope in some form or another, either in your own life or in the immortal life of those who come after you, to increase for ever the infinitely eternally increasing measure of Joy, Pleasure and Happiness of those souls that fight bravely on to gain utility, love and wisdom and energy.

All three are necessary, for extinct species had utility but nevertheless are extinct because they lacked love and wisdom. And in this way you must not stop where Christ stopped, you must ever strive to go on into the future, helping to evolve the futurity of Evolution, to contribute your mite to the perfection of Evolution as you learn day by day to sin without violence to God or nature and your fellow-men, and to excel in Use, Love and Wisdom. Thus you will finally learn during the existence of your soul in the future lives of your children, the supreme enjoyment of eternal Joy, Pleasure and Happiness in the infinite creation from which you sprang, of which you are a part no matter how finite or in. significant, and of which you will eternally remain, as you eternally have been, a real living particle, unless by repeated failures you lose your right to existence in creation.

Your right of existence, by being condemned to eternal degradation and so lose your life and soul for eternity, and receive the final damnation of all unfit particles of creation that become useless; lose Love, Utility, or Wisdom, which alone are virtue, by being condemned thereafter to be a drop of blood in some animal or bird or insect, an atom of plant, rock, stone or sand, or still less finite particle of gas, or mote in some passing ray of sunshine or putrefying vegetable parasite, and so return for all eternity to the infinity of dust from which you sprang. But, ah! how infinitely more despicable, for from henceforth you will be doomed for an infinity of time to have lost all chance of semblance to your God, now you have lost it for ever-but with what an awful difference! Then for a time only you were without the know- 
ledge of your God, or of what you had lost by division (not separation) from his infinity. Now you are condemned by the final evolution of your soul when God grants immortality to those who have proved themselves fit, to an eternal knowledge of what you might have been; and yet you are condemned to be a grain of sand, stick or stone, doomed thenceforth never to again have the power to live. After Soul has been returned to mankind and has granted him his Immortality, it will be returned to you to grant you last of all an eternal knowledge of what you might have been had the atoms you are now reduced to striven for a better association of co-mingling. And, I ask you, is there in actual life anything more litter than the knowledge that one has been, and but for one's own fault, could yet be better off than he is, yet never again will be. Poverty, trouble, misery, pain and suffering are all easy to bear when there is hope of improvement or of recovery.

Therefore, I say again, we must go back beyond Christ and also advance ahead of his teachings in future by making it the creed of our existence to do our share to perfect ourselves so that we may fit the hole in which evolution may place us by our abilities to work out our share in the general advancement of mankind, confident that if we use our lives and talents to their best advantage for the good of the whole, that whether fate places us in poverty or wealth, health or strength, so long as we do our best with our talents, great or small, in the circumstances, easy or difficult, in which we find ourselves placed, God will reward us with so much of this world's blessings as are the most beneficial to our being able to live in a manner most conducive to our individual happiness. Greater wealth might add to our comfort in some few respects, but it is beyond our knowledge to decide if it might or might not in the whole course of our lives add to our happiness and the advancement of our children, for none of us can say what the future holds in store, and what appears to us as a bright and silvery cloud today may, when it reaches us; be a biting storm of hail and snow that would freeze the marrow of our bones. So we are none of us able to tell the manner in which God intends to reward or punish our acts, and what appears to our dim sight to be a bed of roses to-day may only be a thorn-bush to-morrow, for it generally happens in life that the actions we look forward to as likely to create our greatest enjoyments result in dis. 
appointment instead, and that the actions that lead to our success and happiness are the result of causes we never dreamed of, and could not have foretold or pre-arranged had it not been for the pricks and scratches of past failures. But if we make the best use of our time and capabilities, we generally find that in the long run we gain pleasure and happiness and success sooner or later, and if we are doomed to troubles at first, these very troubles and losses are the instruments of our ultimate happiness, whereas those who shirk their share of trouble and try to evade their duties in youth generally bring misery and misfortune upon the latter part of their lives.

So go "Back to Christ" by all means, for the flower of religion is the most magnificent of the trinity of flowers on the plant of evolution of soul, the grandest tree in the forest of God's Creation. But like the shamrock it has a triplet of roots, leaves, flowers and an immortal seed. Its roots are-God the Father of Creation, God the Mother of Creation, and God the Soul of Creation. Its triplet of leaves that has to feed and nourish its flowers and seed is-the energy of civilisation, courage, and perseverance in enterprise and commerce. Also, the evolution of Invention, Science and Wisdom. Please note how these leaves are a likeness of the progress of evolution and illustrate in their growth the gradual return of God's attributes in the Epochs of Faith, Hope and Charity. For in the Age of Faith the seventh or last day of which marks the Creation first, of Adam and Eve; second, of the Power of Will in man; third, of the dawn of civilisation in the world. This epoch of Faith is governed solely by the Spirit of God the Father, so it only produces one leaflet-that of civilisation. Now in the Age of Hope, the plant of Creation is advanced not only by power of God the Father, but by the united powers of God the Father and God the Mother. So we find that the leaf that is to be completed in this Epoch of Seven Days, which takes us on to the Fourteenth Day, the age of Invention and the thirteenth day of Commerce, is marked, not by the dawn of the unity of the first product of mind and soul-Civilisation-as was the Epoch of Faith, which was the epoch of unity, but that the Epoch of Hope is the duality. The Epoch of Faith is the epoch of the struggle for existence, and the Epoch of Hope the struggle not of life only, but has advanced to a dual contest, 
the struggle for Life and the struggle for Love, so its leafle: is a dual leaflet, that of Enterprise and Commerce.

This takes us along the road of evolution to the toll-gate of its final epoch, the Epoch of Charity, which is also the last epoch of evolution, for it is to be ruled and marked by the united control of all the attributes of God's Trinity, and the whole power of the Almighty is to handle the mighty sledgehammer that is to drive the wedge of wisdom into the dull brain of mankind, so it is the triple leaflet of Honour, Justice and Mercy.

Forgive my triviality, dear reader, but all work and no play is bad for the best of us. I cannot write the above sentence without recalling to my mind an after-dinner reminiscence of my youth. We were sitting round the table sipping wine when my father remarked-apropos of what, I quite forget"It takes a sledge-hammer to drive a joke into a Scotchman's head," to prove the truth of which remark the Scotch lawyer who had provoked it, replied, "I dinna see how that could do it." I am afraid, like the Scotch lawyer, I must plead guilty, for when I look around me and view on all sides as this war goes on, how slow is advancement and how little is the grain of the seed of wisdom as it, at present, is vainly trying to take root and cause a slight germination of the soul of wisdom in the hard, stony, barren soil of the senseless brain of mankind, and then turn to my Table III. of God's Trinity and read therein that the next three days of Evolution are to be-

First-The Age of Peace and the end of wars, on the Fifteenth Day.

Second-The Age of Use and Comfort on the Sixteenth Day.

Third-The end of Crime on the Seventeenth Day.

Were the sledge-hammer that is to drive the wedges of wisdom necessary to produce these three results in the hands of any other workman than God Almighty; with the Scotch lawyer I should exclaim, "I dinna see how it is to be done."

Yet, so great is my confidence in my Creator, and the mighty sledge-hammer of Fate, that I am confident, since I became possessed of these Tables of Trinity and have traced out the marvellous exactness with which they coincide with the 
evolution of the past, that the future evolutions will follow in the same order and sequence as those of the past, now that the time is drawing near on the clock of evolution for the completion of these three mighty contracts on the part of evolution. It will, therefore, be the duty of all those interested in the making of peace at the end of this war to leave no stones unturned to sow the seeds of national federation, whose duty it will be to protect the rights of all signatory nations and to police the world's commerce by means of a cosmopolitan army and navy and to abolish once and for all the right of any nation to have the single right to hold or control any national army or navy. In future there must be only one army and one navy subject to an international supreme court of arbitration, whose duty it will be to settle the boundaries of nations by purchase and sale, not by war, and disputes by fines and arbitration, keeping armies and navies to enforce such decisions only.

With apologies for this digression I will now point out that the two first epochs make up between them a trinity of struggles for existence, viz. :-

rst.-The Struggle for Existence. The World of Matter. "Wealth."

2nd.-The Struggle for Life. Human Mind. "Civilisation." 3rd.-The Struggle for the Life of others. Love. "Religion and Government."

The coming epoch-the week of seven days that are yet to come-is to perfect the result of this trinity of the evolution of Creation.

4th.-The Struggle for Wisdom. Unselfish Use. "Universal Charity, and Perfect Control, and Co-operation."

Comparing this with our mathematical Table IV., we find that the Trinities Nos. I and 2 are either not destined to last, or are to remain throughout all time, capable of further alteration or improvement. These are: Existence, Matter, Wealth, Life, Mind and Civilisation. Those that are to become perfect before we gain Immortality are Use, and Charity and Government. Those that are to last for all eternity are Wisdom, Commerce and Soul. The trinity of Existence, Creation and Wealth (it is well to here point out as an explanation that wealth must always mean the results, product and possession of the quali- 
ties of energy, perseverance and thrift). Don't ever forget this truth, for the want of knowledge or the want of understanding of this truth is the root of all our industrial disturbances and strifes; the corollary of it is that none have any right or title to wealth except in proportion to their possession of energy, perseverance and thrift, or any right to capital except in proportion to their ability to use or invest it wisely. For the power to use gives the right to hold, and the power to hold only lies in the power to manage and control. I may here say that Existence, Material Creation and Wealth make life possible of being maintained. The Trinity of Wealth, Life and Mind makes Civilisation; the Trinity of Charity, Civilisation and Love makes up Religion; the Trinity of Wealth, Civilisation and Religion makes Commerce; and lastly, perfectly honest Commerce, Perfect Human Wisdom and Perfect Charity will turn this earth into Heaven.

I am afraid these many side issues will make it hard for the reader to follow the growth of the tree of trinity I was endeavouring to describe to him. I have now illustrated what the roots and leaves of this tree are; the stem and trunk of this tree are God's prerogative to rule Creation by the power of fate, the mighty engine that draws the train of creation along the lines of evolution, and the carriage of religion can be no exception to any of the other carriages. All forms of religion must conform their teachings to the advancements of science, knowledge and man's power of understanding, or they will run off the lines and be dashed to pieces; so also will knowledge and science or any other carriage that will not keep on the lines of evolution along the railroad of God's Trinity.

It is not enough to go back to Christ; we must do more. We must by the advance of Science keep Christ as our Guard and Brakesman, and by his teaching put a brake on our vices of Selfishness, Injustice and Human Folly. But we must also engage the services of God the Holy Ghost as engine driver, which we are to receive in the future as man evolves a soul capable of differentiating between Wisdom and Folly. This can only be done by Religion and Science joining hands and by so doing helping each other to keep on the lines of evolution by the aid of the mysteries of God's Trinities which will : till further evolve and make plain to all mankind the wonders of revelation, in a more understandable form than has been the case 
under mystic ritual. Our spine, so evolution teaches, is an external growth that has incorporated our spinal cord, not a creation of a new form of our spinal cord. It is the same, in the way we will have to evolve future religions. We must not destroy the past, we must incorporate it in a fresh evolution, not destroy it to create a new one in its place. For even if in distant ages yet to come the religions of the future, like our spine, entirely hide the religions of the past, so far as rites and ceremonies are concerned, provided it also contains the principal teachings and most important revelations of the past, no great harm will be done, they will only become more practical. We must take Christ with us, not go back to him. We must strengthen religion by Science, not pull it to pieces to build up science, or we shall be like the man who destroys the foundations of his house because he wishes to build a second storey on top of the existing ground floor.

But we cannot cultivate the flower and neglect the roots and stem, or the flower will die. I have shown that the leaves of the tree of trinity are energy of civilisation, courage of enterprise in Commerce, and Invention, Science and Wisdom. The flowers are Love, Religion and Charity wlich are ultimately to produce the seeds of Joy, Pleasure and Happiness, which seeds when sown in the soil of Heaven will bloom again throughout eternity as immortal souls. This is to be man's last evolution, after which he will be able to live for all eternity in Peace, Comfort and Content, having become wise enough to control all abuse. The one object of his existence for which he was created is that he may assist in bringing about this evolution of wisdom; therefore, let him study past evolution that he may the better be able to bring this about. If read by the interpretation of God's Trinity it will teach him to form higher ideals of Peace, Mercy and Justice, and this will give him a better harvest of happiness than he has in the past reaped from the seeds he has sown, viz., Might, Greed and Selfishness, War, Bigotry and Hate, and will enable him to live in Joy, Comfort and Content, which is a better form of existence than that of Wealth, Pride and Arrogance bought at the price of War, Strife and Misery and held in the grip of Crime, Intemperance, Dishonesty and Discontent, under the curses of Fear, and Remorse for pleasures bought at the price of meanness, dishonesty and intrigue. 
Oh! senseless man! how long will it take you to learn these lessons that teach you that all folly, selfishness and hate are vice, and all virtue but degrees of wisdom, usefulness and charity? Evolution, above everything else, shows you how to be wise. Study it and become so. Success shows you how to be useful. If you cannot afford time to study, we can all be useful. Copy the lives and acts of those who succeed a little better than you do; do not sit down and curse the man who beats you. Do not try to run before you can walk, or you will fall and break your neck and be unable to walk, let alone run. But when you have learned to walk, learn to copy those who are able to run, by being even more useful; so try and be as useful as you can. Riches are the reward not of labour but of success. Wealth is the power to create; the more you create the greater your chance of wealth. A bare sufficiency for existence is and ever will be the maximum possibility that the majority of mankind can attain. You must work harder and more skilfully than the ordinary man if you would have more than a bare sufficiency for existence.

Wealth is the reward of energy and skill. Learn to work well if you wish to attain wealth. Capital is the reward of wisdom and thrift. You must first become thrifty and skilful, wise and economical, before you can gain riches. Poverty is but another way of spelling failure. If you do not want to be a poverty-stricken failure, do not sit down and cry over spilt milk, by lamenting that if you had only had Jack's show you would have done better. You can bet your life that if you had the talents Jack had you would have had as good a show. But have you the energy, perseverance and wisdom of judgment that Jack has? Stop lamenting, and rather say, if I had only made as good use of my opportunities, if I had only learnt my trade as well as Jack did, and been as careful to study my employer's interests before my own as Jack did. Perhaps I can hear you remonstrate, "But Jack had a good master, mine was a perfect beast." Quite so, but Jack was a willing worker, a hard master would have spoilt him and made him a less eager workman. You were born tired; an easy master would have ruined you, and made a discontented loafer of you. The only chance at the start of your becoming a really useful member of the community was an apprenticeship under a hard, mean master. Remember it 
is as easy for you to sack your master as it is for him to sack you. You reply, "But I cannot afford to lose my billet." He will not sack you even if you are not the best of workers. He will put up with you in the hopes that you may improve; a good master would sack you sooner than take the trouble to teach you. Your master has proved himself a success or he would not be a master. If you wish to be a success, copy his good points, not his mean ones. It is good experience to learn the latter, it will keep you from falling into them yourself, and when you do succeed, may make you a good master instead of a bad one. So learn this lesson to put up with the inconvenience of the situation till you can get a better one, then give your employer the sack; he might give you the sack if he got a better workman at the same wage.

Do not sack him till you get a better place, and remember that a recommendation from a hard master is the best of references, and more likely to get you promotion than a dozen references from easy employers; so it cuts both. ways. Do not turn up your nose at the low wages you receive at the start. Jack did not. He was not such a fool, but he worked all the harder to get a rise in wages, and soon got it. Do not start by grumbling at the faults found with you. It will do you good when you are young, and help to make you contented when you grow old. But do not leave a good master if you have the luck to have one; this is the greatest of all blessings. For two out of three of us make a success of our lives till we are forty-five and lose all we make after that age by trying to make a new start in life when we are too old and too out of date to compete with younger and more up-to-date men, instead of keeping what we have got.

$\mathrm{Be}$ a good father to your children, and teach them, above all things else, that their first duty is to sacrifice for the good of others, not in money, but in kind words, kind acts and forgiveness, combined with energy and usefulness; and if you have done this they will become successes, and if there is any good in them at all, they will not leave you in want in your old age. Content, not wealth, makes happiness. No insult from those you are in duty bound to respect is too high a price to pay for the attainment of the virtue of content, for without it you never will be happy. 
Say to yourself, "If I had taken this advice I might have had a harder life at the start (so had Jack) than I have had, but then I might have been a greater success." Take an old crow's advice; I am sure you would have been, for there is no more certain road to wisdom than troubles faced and conquered, and no royal road to attain the courage necessary for success, but adversity bravely met and overcome. So, if you had put your pride in your pocket, as Jack did, you might have been a greater success than he has been. It is never too late to mend; try and see if it is not worth the trouble.

An ancestor of mine, who was considered one of the wise men of his day in the reign of Henry VII., used a saying that became a proverb: "We are all too proud, from the King to the beggar, particularly the beggar." I think it is as true to-day as it was six hundred years ago, and if the beggar would only acknowledge that he is the failure, it would be easier to govern the world, yet I suppose you might as well try and find a boy of nineteen who did not consider he knew more than his father.

One of the thoughts that has most troubled me in writing this treatise is the fact that it entails such a complete revolution of previous ideas, ideals and beliefs that I have hardly known how to approach the subject without depriving the reader of too many past beliefs and opinions that have been the anchors of past ages, and which must be the principal masts to which he must pin his colours for generations yet to come. I now feel that, much as I have tried to avoid doing this, I have failed on this score, and will certainly be worthy of the reader's condemnation. On this point I have known all through that I was not a fit person for the work I have undertaken, and must therefore ask the reader to be considerate when passing sentence upon me, and to remember that we are none of us perfect in all respects, or at all classes of work, and that a humble confession should be a just claim for ample forgiveness. It is only the logical part of the work that comes in my profession, details I must leave to the scientific student. I may here state that if I have trodden ruthlessly upon the pet corns of his cherished beliefs, I am sure, be he who he may, I have not written what I have without treading still more heavily on my own pet beliefs and opinions. But I would have been unfit to place the subject in a logical form or 
sequence had I not first dethroned all my past beliefs and opinions at least while writing this work. I am convinced that in the Hypothesis I am placing before him, lies a means that in abler hands than mine, will evolve a solution of many past difficulties, and a means of conducing to future good that is beyond the power of my poor brains to accomplish, yes, even to comprehend. If I have placed the statements herein before the reader in a very elementary, unproved and imperfectly illustrated fashion, I have done so for this reason, that I have felt that it will take years of thought and study to enlarge sufficiently on the subject that this Hypothesis contains, or to be able to approach many of the issues herein raised in anything like a detailed manner, without weakening present ideals and beliefs to an extent that would not only be unwise but might even be harmful.

The least said, soonest mended, and I have therefore decided to make this publication merely a short and very imperfect work, content if it is sufficient for my reader to form some conception of the vast realms of thought in a new, and, I feel confident, useful and ultimately beneficial direction, which I trust will in abler hands, helped by wiser brains and minds than mine at a future date, do so much to ultimately produce a wiser and truer conception of what at present are nothing more or less than hidden mysteries waiting to be unearthed by the wisdom of man's mind now that he is gaining the faculty of Understanding some of the truths of divine wisdom, but the threshold of which we are yet only able to approach, not enter. I therefore do not wish the reader to consider I am anxious to argue for or against the views I have expressed. My sole object has been to place as many new views of thought before the reader's mind in a new light as this extraordinary hypothesis has created in my own brain, leaving him to accept what he fancies, and to reject what he dislikes, and add such additions as his mind may suggest.

For the same reason I have not attempted to glance into the future, as this would entail even more risk than I have already taken of offending present opinions; and prophecy is a task I do not yet intend to risk my hand at. But before putting down my pen, I must ask my reader to remember it is not eighteen months since this extraordinary hypothesis became known to me, and even to form the barest con- 
ception of it, and place it in a logical order has been no easy task. But I have felt that if I did not get my first impressions in the infantile nudity of their early birth or conception written down and printed, I should be tempted to write and re-write them, and in my efforts to prove and demonstrate them, would lose the most salient parts of the logical sequence before I could get it into shape. I have, therefore, decided to let it go to press in its present unfinished state, and so give the public every chance of passing the worst possible verdict upon my efforts, feeling sure that my reader's comments and opinions will do much to indicate the errors I shall have to correct, or the portions on which I shall have to enlarge, and the manner in which my Hypothesis requires to be further illustrated and demonstrated. I, therefore, offer the reader these, and any more apologies he may demand for any offence I may have given, for it was not my intention to offend.

There is a great deal I feel I shall have to devote more study and thought to before I would dare to form any absolute opinions on the subject myself. All I have been able to do in the short space of eighteen months or less is to try and evolve ideas and take glances, as it were, at the subject from different points of view as my Hypothesis caused them to rise like the imperfect pictures of a mirage before my astonished mental vision. I just took my pen up and scribbled the impressions they created as each mystic view arose and dissolved itself one after the other before my mind's eye. Some, I admit, have created black and horrible visions that deeper thought may dispel by wiser views, and beautify with scfter lights when handled by wiser and more artistic minds and pens. But believing as I do that there is in the abstract no such thing as evil in creation, and that good and evil are but comparisons we measure and adjust so as to compare the relative opposing forces of evolution one with another at the particular stages, days or ages of evolution; I have tried to get my reader to forget past beliefs and past ideas of good and evil for a few moments, that he may be the better able to weigh and to comprehend the logical deductions and demonstrations I have placed before him. But personally I do not intend to alter many of my past beliefs, except in such cases as the full force of logic and proof and experience may warrant, and I strongly desire him not to leave the 
vessel that he has voyaged safely in up to now, or burn his ship and bridges, just because a more magnificent barque hoves in sight. But should he feel that past and present advancements in knowledge tend to prove that his particular ship is becoming unseaworthy, it is always wise to steer the same course as a new vessel, so that we may have a chance of rescue if our own ship founders.

This is why I have put down, side by side, views that I should not care to hold or use without more proof, with those I absolutely hold, if they appear to me to have sufficient guarantee to be worthy of consideration, or the arguments of my hypothesis warrant my bringing them under the notice of my reader so that he may form a clearer and better idea of its abstract value. Nevertheless, it is an hypothesis out of which, I feel certain, not evil but good will ultimately arise, and that in years to come when it is better understood, and further research enables its suggestions to be more carefully investigated, it will some day create a lasting bond of friendship between Religion and Science as these two great antagonists of the past realise that in it they have one common bond of unity in the Trinity of God and the personality of the Creator, His Spiritual influence and existence as demonstrated by this Hypothesis, which, as it becomes known, and further investigations in the science of chemistry, evolution, astronomy and geology are brought to bear upon it, we will obtain a more perfect knowledge of our creation and past existence. If in this treatise I have sown the seed of future friendship between Science and Religion, I am certain it can only be good seed sown in good soil. Likewise, if it causes the man in the street to study evolution as a means of obtaining a better idea of the aims of his life and creation and so stimulate him to aim at higher ideals of perfection, it will not have been written in vain.

I am aware that this treatise from the manner in which I decided it would be best to write it, not only demands that I should place it before the reader in a form that both strict science and religion would condemn as out of court, but even in a manner that might at times appear to be disrespectful and insulting to past beliefs, but it was not my intention to be in any way offensive to either. I have felt that so various and abstract, and at times opposed and disjointed were the 
numerous half-formed conceptions that it gave rise to and compelled me to touch upon that it was utterly outside the capabilities of a person like myself who has led an active, out-of-door life to undertake, at a moment's notice, so arduous a task, and hope to perform it in a complete, competent, or artistic manner, my excuse must be, therefore, that my father taught me to work, not to write. Yet feeling that the task had been thrust upon me in a semi-miraculous manner, and feeling that I had some little spirit of logical argument and mathematical ability, I decided to do what little I have been able to do and ask others to do the rest, or at least help me to do it, and to forgive my want of literary ability.

So I decided to give the reader my first conceptions, leaving him to form his own conclusions of my early impressions and check them by his better knowledge. I know I have only made a very meagre and brief case for my client, but I felt it was too early in its evolution to attempt to do much. But there is one fact I feel I cannot too strongly point out, that is, that if in the case of the fourteen days of creation which are already past I have shown beyond dispute the connections I have endeavoured to demonstrate, it logically and mathematically follows that the forecast of Peace, Use, Comfort, Content, Joy, Wisdom and Happiness as the succeeding days of Creation are likewise a certain forecast of the future course of Evolution, and that as we study past evolution with more attention, we will with its aid now be better able to mould and develop the course of events in the future to fit in with stages yet to come.

In the past courage, energy and might have been the ruling powers that have governed the world; wisdom and brains and right have been at a discount, but in the future Wisdom is to take precedence of might. Thus in the past all attempts to control the world by wise government have failed, not so much because the wisdom has not been evolved by a few wise brains who have conformed and moulded governments, but because the power to understand wisdom is not yet evolved, and consequently no matter how perfect the schemes, they could not last because the duty of evolution was still confined to the physical evolution of human energy rather than to the evolution of mind and soul and wisdom, so physical force triumphed over psychical influence. Hence the laws of fatigue and rest 
have exerted the predominant power in their influence on the development of governments, and the success of governments has been controlled, not by the wisdom of their laws but by the energy of their law-makers, as each class of the community takes part in the formation and then takes a rest. These seven more days of evolution that are yet to come must be evolved in the same manner as in the past, but with this difference, that the mind will triumph over physical forces.

Now all study of Evolution and Religion has often failed to work in harmony together for very long, because man has not evolved his soul sufficiently to understand Religion, Science or Wisdom. But now we are at last beginning to have a living, not an unborn soul by the birth of understanding, and the possibility of the third great departure in the course of Evolution, the conquest of right over might is now within the realms of probability. This will open up the possibility, as our knowledge increases, of remodelling both Science and Religion as the next ages of Evolution, those of Use and Peace are evolved. In these ages we are to evolve, the powers of reason which are to become active not as a property of an aristocracy only, but as the characteristic of the majority of mankind. But this will mean an entire revolution in the course of evolution as regards our customs and practices in every-day life. Thus we see that the advancement of a nation is a constant struggle by the three great divisions of mankind to obtain the reins of Government, viz. : the agricultural class which represents the three highest virtues in the greatest degree, that is to say, Energy, Thrift and Charity.

These are characteristics not from choice, but from necessity to fight the adversities caused by climate and nature. The agriculturist, therefore, has to evolve the highest superiority in physical energy and the greatest amount of thrift :o prevent going to the wall. Their occupation also necessitates waiting, not for three, six or nine months to turn over their capital, but for a period of one, two or five, or even, in the case of the cultivation of trees, ten, twenty or fifty years for a return on the capital they invest. This makes thrift a necessity of husbandry, hence we use the word in its secondary meaning to denote thrift and speak of a man as husbanding his resources. There is no other occupation so dependant on the assistance of one's neighbour as agriculture, both to protect 
the results and harvest its products. It also necessitates thought for the welfare of animals, and this causes a like thought for the welfare of others. Hence although the town community may have greater means of combination and co-partnership, which tend to evolve arts, science and invention, its interests are more selfish, so the country element is the truest representative of the thrift, honour, and religious sentiments of the people owing to its closer contact with nature, which tends to evolve these qualities, but also makes its devotees less able to combine to produce the advancement of art, literature and commerce. For this reason country co-operation must be more local and confined to a few individuals, whereas in the town it is more universal and more general and uniform and leads in the towns to a more pecuniary form af Charity.

The highest perfection of charity is developed more in the country than in the town - that charity which is the charity that Christ taught, and that gains God's rewards, that which shows mercy in action, magnanimity to friend and foe alike, and produces the highest principles of honour. Whereas the Charity developed in town life is charity to friend, not to foe, and partakes more of pleasure and pecuniary rather than personal sacrifice. Hence Energy, Thrift and Charity are the characteristics of the agricultural community. The town or distributing classes-the commercial and manufacturing classes-stand for enterprise, invention and progress. But as all these commercial ventures give a much more immediate return and result, and are more the result of individual efforts than those of agriculture, they produce greater powers of mental development, more self-reliance, and hence more selfishness than when men have to combine to fight the elements.

Nothing produces our respect for God and the revelations of nature more than close contact with nature itself and its laws. The townsman is mainly dependant on his own exertion, and receives immediate remuneration for his outlay without being dependant on climatic agencies, and mutual services, which causes increase his love of pleasure, selfish greed, and so make him less inclined to be charitable in act if not in cash. So the laws of a country under the predominance of town management tend to diminish national patriotism, because town life narrows men's views in their mental scope and makes for personal and class cliques and petty aims rather 
than for the good of the community as a whole. We must also remember that in the past, had not both classes worked out their existence on opposite lines, we would not have been able to evolve Civilisation, empires, or commerce, for Commerce has grown out of Love of Power, Love of wealth, and Emulation, and created wars and strife from selfish love of wealth, without which Commerce would never have been more than peddling. There would not have been sufficient inducement to create great cities, nor the required emulation necessary for the evolution of empires, and Science and Invention would have stopped short. Hence the characteristic of the commercial class is Enterprise, Invention and Progress.

Next we come to the class that, as civilisation increases, must ever be the most numerous - the Artisan or Manufacturing Class. Their characteristics are essentially want of mental powers of judgment, for their occupation entails no self-reliance; they will ever be ruled and directed by a guiding hand. The result is that their predominating characteristics are extreme selfishness, want of judgment, and love of pleasure, from their wealth being entirely the result of their individual energy, and extreme resentment to submission, because their lives permit of little self-decision and call for little self-control.

They suffer from want of mental range, because their occupations are devoid of the necessity for reasoning out the detailed work of life; because for centuries all reasoning, in all the more complicated undertakings of life, has been done for them, they have only been required to think of the details of work. This makes them narrow-minded, obstinate and unreasonable, and it is a question if, as a class, they will ever be wise enough to govern themselves unselfishly, or free from looking at facts through narrow-minded spectacles. But in the past, and for ages yet to come, it has only been those who have exerted the most superior energy, self-reliance and judgment who have become fit to rule. But it is impossible to work at the maximum amount of energy for more than three generations without a reaction setting in and rest becoming a necessity. Hence as the Epoch of Hope marks the period of evolution devoted to the production of energy, it is one long bitter warfare between all these classes, for superiority in physical existence against non-existence, according to their perfection in energy. Therefore, throughout the Epoch of 
Hope Wisdom is sacrificed to energy. Hence we find that it is one continuous strife between these three classes for the control of Government, and as each in its turn gains the supremacy and holds it for three generations, during which it evolves the legislation most fit for its requirements. The class that chanced to be in power has exerted the maximum energy of its leaders, so is compelled to rest. The next class then gains ascendancy and pulls down what its predecessors built and so destroys any stability of government, until Commerce and Science, Knowledge and Invention come to its aid that they may exert the wisdom of their rule by the forces of thrift, organization and co-operation, which latter in the past coincides with religious advancement and must continue to do so. Then another three generations later the mass of the people gain the reins of government, but lacking the powers of energy and judgment, their rule is necessarily of short duration. Thus the wisdom of the past has ever been doomed to die before class struggle for physical supremacy.

In the present age I take it from my tables, the age of Invention, which is to mark the rise on the horizon of the sky of evolution of the sun of the powers of the soul over those of body will in the future enable the light of wisdom to so brighten the darkness of physical development, that the dawn of the day of rule of Mind over Matter is now to commence, and in the future right is to overcome might. Hitherto might has ruled over right, for the reasons given above. I do not intend to carry out my Tables to the extent of making any particular forecast of the future, but it may be as well just to point out here how coming events cast their shadows before them by making a slight note of what the main features of the forecast of the next two stages of Evolution are most likely inclined to evolve, just to show how my Hypothesis may in wiser hands become useful in the future, and be a means of helping a better knowledge of past evolution to cast its shadow over the evolution of future Governments and Religions, Industries and Manufactures, Order and Society.

The present Age of Invention clearly portrays the triumph of Science and Invention over Materialism and materialistic forces, or in other words the control of courage, wealth and energy by Wisdom, not by Conquest. Wisdom of Use over greed, Capital or Thrift over Courage, and the Energy of 
Charitable co-operation over the energy of Selfishness, Cruelty, Avarice and Greed, and united and organized industry over individual enterprise. It therefore appears to me that we are to make a new departure. The Science of Invention is fast completing man's conquest over the material world.

As I have pointed out, the elements becoming his masters first conquered him and created his appeal to heaven for help. Now that he has received an answer to that prayer, which gave him religion, Evolution has brought science to his aid. He is first learning to conquer the elements he feared, and instead of fleeing from them in dread, he has now made fire, water and air his servants, and, harnessing them to his chariot, drives over land by fire, and sails over water and air with his ships. Now so far he has only made the forces of nature his servants, he has yet to learn how to rule and use them to the best advantage.

$\mathrm{He}$ is now abusing them by making them a means of war and hate and selfish greed of wealth, as he has misused all things in the past, not excepting even Religions. In the case of trade, production and social co-operation he is not using science and knowledge in the best manner, to create charity, energy, and the utility of literary knowledge, but is using them to increase party and class hate, and to destroy the sacred qualities of work and energy, which it has taken man millions of years to evolve so as to know how to work efficiently. Men are doing their best to condemn their children to extinction and damnation by raising up an army of loafers and unemployables, more dreadful than the devils of murder and cannibalism that mark man's triumph in the Epoch of Faith. So the world of loafers, wasters, shirkers, paupers and unemployables that modern civilisation is evolving will have to be made slaves of the state and condemned to work in state-owned factories which will have to replace the jails and confessionals of the past. In the future we must strive to exterminate the criminals, not convert them.

The rulers of nations are little more advanced, for they are using the increase of knowledge of science to destroy life, instead of creating it or, adding to its comforts by increased production, just as their inferiors are using their knowledge to destroy wealth and wasting lives in war, as much as their inferiors are wasting their time instead of making 
the best possible use of it. So the devils of to-day are but little advanced, except in knowledge, over the Lucifers of three hundred thousand years ago.

The first step towards correcting these evils must come about by science and religion joining hands, not as in the past to redeem the sinners or bring them to repentance, but by teaching them that their lives are ruled by the fatality of evolution, and that their first duty in life is to value and know how to make the best use of their time and energy. To learn not to waste or abuse these qualities that it has taken mankind so many thousands of years to evolve, and to recognize that their place in creation is decided by their inborn fitness to fill the notches for which they are best suited. That it is only by making the best use of their time, to increase the comforts and content of their fellow-men and to utilise their energies in the best manner and under the most favourable conditions, so as to make the best use of their time and abilities in the way most suitable to different climates and circumstances, and so produce the greatest power of sustaining life that will make it possible to achieve advancement. There is work for every one of us regardless of religion, creed, race or colour, if we work together in harmony. But I think that the curse of Ham is eternal, for the descendants of some of us must for ever live as the servants of others, not only as regards the black races, but also as regards the failures of mankind. But the residents of tropical climes will most probably contribute the bulk of the unfit, from the mere fact that the greater ease of maintaining life in a warm climate is detrimental to the continuity of their energy, ability and general vitality, so they are ultimately to be replaced by the descendants of those who are evolved under sterner conditions of life and climate.

The future duties of Religion will be to try to make manfirst, charitable towards the sins of his fellow-men, condemning his unfitness, but forgiving his sin when not unduly injurious to his neighbour; second, to teach him his first duty is to obey his fellow-men who are his superiors, and to cultivate the ambitions that made them his superiors; third, to make him realise that by the utmost use of his body and mind and soul alone can he gain Heaven and Immortality, which are to be the rewards of superioritv. Finr, just as want of 
brains and laziness have in the past been the chief means of extinction, so, in the future, laziness and stupidity on the part of mankind will be the sins that will damn man by his total extinction, as they have done all species in the past. So now the age of Invention is to enable man to finally conquer superstition, Cruelty and Selfishness, which are to attain "their maximum of evolution in the next century or so, and we are to see the mightiest wars of the world, first, between nations, till the world is brought under the rule of civilisation and commerce; then will follow civil wars on the largest scale, till anarchy, socialism and democracy are destroyed and peace is to reign supreme, and man, having learnt to use the powers Invention has placed in his hands, will at last do good for good's sake, not for selfish ends.

We are misusing these powers for want of a better understanding of the aims and objects of our own life and creation. How much longer we are doomed to live on before we learn wisdom it is hard to say. The acme of knowledge we are daily nearing, but we have not yet attained true wisdom, which, we may say, is all summed up in the causes of our existence. Why are we created? To learn to overcome folly. How have we been created? Evolution can alone teach us this. How are we to attain to the objects for which we were created? The realisation of the laws that control past evolution are the only true guide. How little we know on these subjects. If this little treatise can only contribute some little help towards the answer to these all-important questions, the paper on which it is written will not be wasted. Here at the present moment, after nearly one quarter of a million years devoted to study and evolving civilisation, how many of us have learnt the great lessons that evolution teaches, that self-protection is not only the perfection of the art of defending our individual life, likes and interests, but of defending the community of which we form a small part. Not in Comfort, wealth and pleasure of the individual, but in perfect endurance of the discomforts of life; by energy in work, skill in action, and co-operation to increase the capital, and so produce the content of the whole; be it home, hamlet, city, community, country or continent, lies the power to produce wisdom and virtue, the seeds of power and success. It is want not plenty, that makes us strive for sufficiency. Efficiency at work, not play, that 
produces comfort. Rest not excitement, that produces happiness; Temperance, not abstinence, that produces virtue. Strive to succeed; nothing venture nothing win. It is by learning to $\sin$ with wisdom and moderation, not by abstaining from sin or failure, that we are to gain virtue and heaven. It is not by our pleasing ourselves but by not displeasing our neighbour that we are to gain Joy, Pleasure and Happiness, not by play nor indolence. And it is not by our efforts for our own aims, but by doing our duty to our masters, magistrates and God our Creator that we are to produce wealth, not by selfishly trying to grasp all we can, but by doing our quota to help those amongst whom we live, move and have our being, that we may achieve advancement. Content with the lot that falls to our share, provided the burden is such as we can carry, grateful that the strong, the rich and the mighty, lift the heaviest weights off our shoulders, confident that if we do our quota we shall receive our deserts.

I must now point out that before we can use our knowledge to advantage, religion and education must take these maxims to heart. In the last paragraph I have purposely put obedience to our masters before our obedience to God. The duty of the individual commences with our duty to our master and ends with our duty to our neighbour, for if we are dutiful to these two we will also be dutiful to God. The duty of the master is to the law and the nation, the duty of the law is to the state, and the duty of the state is to the laws of God. Hence the individual must first endeavour to please the master whose business supports him, and the wife to obey the husband who supports her, then the household to the community, the community to the township or magistrate, the township to the country or nation, and last but not least, the national government to the laws of nature, for nature and God are identical, and these are the only laws whose punishments we cannot escape.

Hence, the Nation, if it is to advance in the future, must study to adapt its course on the lines of past evolution, in such a manner as will be most calculated to produce the most desirable forms of the evolution of its social organisation in the future. Thus I maintain that if we are to educate our 
children to the best advantage, it will be necessary for the leaders of educational and religious reforms to give more consideration to the sciences of history and evolution, and to obtain a more logical grip of the main truths of revelation so as to be better able to educate our children not in knowledge and culture, but in higher ideas of what are our duties to others, not ourselves, and the better to develop production in the highest manner possible, and so to formulate such national advancement as will make each one of us the most useful units in production regardless of colour, race or creed, leaving the laws of the survival of the fittest to decide the points of individual success or failure. One of these measures must be to nationalise the science of medicine, so that the state will supply free medical aid, which will greatly assist in converting medical science into one of prevention rather than cure.

Now with the light that my Table III. throws upon the course of evolution, it appears to me that the first duty of Religion is to destroy the past bigotry and superstition that set one class of the community against the other, by no longer condemning unheard all those whose teachings or beliefs do not agree with their own particular teaching-thus setting one creed against another, but must try to conform to the laws of nature, which are the laws of God. Nations must learn to join hands in spreading commerce throughout the world instead of disputing with each other over boundaries, and by war prolonging national hate and animosity, just because being a different 'race they hold different ideas as to what constitutes rights of ownership; trade or commerce, and different ideals of life and existence. Religion and Science must endeavour to form a common ground on which they can all agree to meet on the main points of revelation and mutual interests, and realise that their duty is to assist each other to enable the different races and social classes of mankind to live together under the greatest possible tolerance, admitting that any religion that will enable a man to live in peace with his fellow-men, and act justly to his neighbour, and acknowledge his dependance on God, and the social rulers who administer the laws of the land in which he chances to live, must of necessity be the best form of religion for that particular individual, but need not of necessity be the best suited to his 
neighbour. Each sect or individual must be tolerant to the other and make allowances for differences in nationality, in social scale, in the occupation of life, wealth or poverty, as all more or less influencing the religious ideals that most tend to produce the least amount of irritation to one's neighbour, and give at the same time the greatest satisfaction to ourselves without injury to others, as the form of belief most suited to our advancement. We must not deny equal liberty to our neighbour to that which we claim for ourselves. Hence as the world advances, religions and governments will be compelled by Science to modify their teachings and alter their laws to suit the customs of the country or class of society for which they cater. Hence all must try and work and interweave into their creeds and dogmas such improvements as science proves to be true revelations and also the best way to worship the Almighty Creator of the world, by making tolerance their first dogma and the seven revelations their first teachings, thus they will learn the true way to worship God is to perform every act of life so as to make the best use of every moment of it for the public good, and, after this, the next most important thing is to avoid injuring the good name of others. The next virtue is to obey the rulers of the state and community to which you belong, and your masters and superiors, and to strive to work out your duty in the evolution of the world by performing the duties of your state of life in the best manner possible.

The only way the preacher can in future keep the pews of his church full will be by becoming more practical in his teachings, and basing his sermons, not on some old, musty text of long-forgotten superstition, but rather on some new discovery of science, some practical demonstration of the duties of honour and respect due by the lower classes of society to their superiors, and the duties of the superiors to study the welfare of their dependants. The evils of greed of wealth, profiteering, either by wages or prices the necessity for the creation and veneration of high principles rather than according honour to wealth, and condoning the amassment of wealth by unjust or dishonourable means, be it in the form either of capital or wages. The future preacher must be pratical rather than eloquent.

It is by such reforms in religion, and a system of 
education that will evolve these virtues that we may become perfect enough in time to forgive our neighbour's sins so long as they do not injure others. This is the highest form of true virtue and charity, and is what Christ means to point out when $\mathrm{He}$ tells us to leave our offering at the foot of the altar and seek the forgiveness of our neighbour before we make sacrifice to God. It is no use giving alms to the poor with one hand, and, by extortionate profits, unjust actions and preferences, to take double the alms away with the other.

Nor, on the other hand, is it less unjust or less evil to make laws that, by fixing wages in an arbitrary manner, may lead to still greater avarice on the part of the poor by inducing the servant to have no qualms of conscience should he give a poor day's work for a good day's wage. We must aim at co-operation between science and religion, master and servant, capital and wealth or wages; unions for distribution of employment; and it is by Charity such as this we can alone hope to dethrone the golden calf of mercantile Greed, which is the same calf that was worshipped by the Hebrew and the Jew, which the Mosaic people destroyed when they brought the commandments of the Persian into Palestine, together with their belief in one God and his Trinity. If we would advance during this coming Epoch of Charity we must learn to promote greater co-operation between the different classes of society, and the formation on a much more general scale of co-operative means of livelihood, so as to benefit our less fortunate neighbour. He in his turn, as he becomes enlightened and more generous, will realise that poverty, like sin, is a blessing not a curse, and so come to venerate not envy (as at present) the superior wealth of his more energetic neighbour. He in his turn is now beginning to realise that true happiness lies not in the pleasure that wealth and ease can buy, but in the reaction upon us of the happiness we confer on others. In this manner we may bring the world to the Sixteenth stage or day of use in place of abuse of Nature, or creation of brotherly love on the seventeenth day by the prevention of crime so producing the age of comfort. This leaves only four stages or days to be evolved, namely:- Joy, Pleasure, Happiness and Heaven.

For when man can become perfect enough to :- 
r. To sin without offence he will have perfect joy and contentment.

2. To enjoy pleasure with temperance and without intemperance, he will have attained perfect contentment and be capable of Charity.

3. To realise that joy, contentment and pleasure can only be obtained by working not for pecuniary remuneration, but that he may add to the comfort of others, and so permit of the world keeping a larger population in greater ease and comfort, peace and contentment, and will endeavour so far as possible to let one and all live. in the way most conducive to each one's joy, plezsure, and happiness, provided one man does not interfere with his neighbour's right to live in a like manner; for this and this alone will convert earth into Heaven. Tu do this he must be able to grasp the great truth that time and money are only two names for the one form of wealth. That it is not money but a question of how much time and strength our brain and constitution will permit us to devote to help in the assistance and maintenance and the enjoyment of others, that is to decide the happiness that will be our reward for the virtue of our labour. This is the only way we can obtain Joy, Pleasure and Contentment and can alone ensure us the true happiness of Heaven, so that by becoming perfectly unselfish and useful we shall at last gain Immortality.

We must learn to live for the good of the community, and so aim at gaining heaven in this Epoch of Charity now commencing. Not by trying, as we have done in the past, to force our belief down another man's throat, but by trying how you can best modify your own beliefs so as to make them less repugnant to your neighbour, and by forgiving your neighbour's sins, because you do not know how far they may be beneficial to the good of the community. There are quite enough crimes without making unnecessary ones. We must prevent crime by stopping criminals from breeding and confining them and making them work for the good of the community.

It is only by the knowledge of past history and evolution we can best learn how to achieve these ends; but universal peace must be attained first. Now we must endeavour to stop 
and to prevent all crime at all costs, but sin we can never entirely eradicate, and we can only aim at an increase of charity by assisting the deserving to rise in the social scale and at aiming to avoid all sins that may offend others, and realise that the enormity of our sin is measured by the offence we give or the injury we do to others, not by your own ideas of its criminality, and this will be decided by the offence you give to your own social set, not by the enormity of its offence to other social sets with whom you do not come into contact but have to live amongst.

Therefore the sins that can be forgiven in one class of the community are the very sins that cannot go unpunished in another; that the sins permissible in one country may be the crimes that would ruin another nation. And as regards nations, that, just as the laws of Evolution are the only true laws of God, so also are the laws of nature the only true laws of Government. As nature is free subject to restriction of geography and climate, every nation has an equal right to live in any part of the globe under conditions of freedom best suited to its existence. Race and social and religious distinctions are three meanings to one word, and that one word is degree of fitness for certain duties necessary to maintain life. Our colour, speech, social superiority or inferiority, wisdom or folly, virtue or crime, health or debility, wealth or poverty, vitality of life in animal or man, bird or fish, are only results of breeding and the survival of the fittest. Hence, in a better comprehension of how to breed, inbreed, or outbreed or cross the different races of mankind, irrespective of colours or class, wise or foolish, quick or slow, stupid or clever, agricultural, commercial or industrial, lies the means of higher perfection of the human species. That just as it has taken hundreds of thousands of years to evolve a gentleman from a cad, a wise man from a fool, a civilised being from a savage, and a Christian from a Buddhist, or Mahomedan from a Pagan lies our right to perpetuate our existence, all of these distinctions may be compatible with one another. You have only to turn to India to realise that these can all be intermingled. In India, in a comparatively limited area, with the greatest possible varieties of climate and soil, we also find there is the greatest possible variety of national intermingling of races and of crosses in breeding that the 
world has ever produced. We find these factors have played a very large part in making the greatest varieties of manners, customs, habits, and class to be found in any one nation. India is a nation numbering its people by hundreds of millions, and in a variety of races by dozens, and its nationalities are more numerous than any other country on the face of the earth. So are its creed and customs; yet they have dwelt together for centuries. Hence we find Christian, Turk, Persian, Mahomedan, Buddhist, Pagan, White, Black or Yellow, all living together in harmony. Because the attractiveness of its climates, richness of the soil, have made it suitable as a means of support and possible for a variety of races to exist under varied conditions of production and subsistence.

Again, in America we find the same thing for the same reasons. Hence nations must take this lesson to heart and realise that Governments, like Religions, must learn to give and take in the future, and remember the stupid days of hard and fast dogmas are days of the past, as also are racial distinctions, for civilisation is fast destroying the distinction of colour. Evolution teaches us above all other facts that life, and life only, is lasting-all else is one continual change of destruction on to construction and reconstruction. The life of God and his Trinity and its image in mankind is the one thing that never alters. The power of energy of the ancients is but the immortal energy of to-day.

Governments, like Religion, must turn over a new leaf in the book of evolution, and realise that the making of the future must be remodelled from the making of the past by adjusting the past to up-to-date advancements; and, instead of one nation warring with another for larger realms in which to carry on commerce on the restricted lines of each nation, creed or as has been the usage in the past. Each nation must make its laws to suit its particular race, creed or clan, and hedging these countries and confines round with barbed wire entanglements of protective duties and religious dogmas, enforced by huge armies and navies, is a thing of the past. We must in future buy and sell or exchange territories as we do the lands within them. Commerce has grown too big a girl to be kept in the schoolroom of ignorance or national restrictions, the outcome of still greater ignorance.

Now, as man gains more perfect mind, such absurd and out- 
of-date customs must be welded into hard and fast chains of co-operation, unity and charity. We must increase our freedom of commerce if we would aim at increasing the possibility of keeping the largest possible population under conditions of the greatest possible average comfort. This can only be done by still further restricting personal liberty and by ensuring by means of a wisely restricted franchise that the foolish are controlled by the wise. For during the last century commerce has come of age and must learn to make her bow, and is the debutante at the dance of free trade, viz., Freedom of commercial exchange and freedom of contract and freedom of religion. The most important Trinity of freedom that can grant true freedom of thought and action is the right of each and every one of us to live how we like, when and where we like, fenced, bounded and restricted only by such laws and regulations as are necessary to maintain inviolable the just liberties of others. For the only freedom nine out of ten of us have is the right to decide whom we shall work for, and what we shall work at, and when and how we shall work. Fredom is the creation of such boundaries and limitations by restricting laws to such only as are absolutely necessary to prevent the liberty of one person or class of the community interfering with the freedom of any other person or class.

It does not extend so far as to allow us to interfere or deny to others the full measure of freedom of action or the full rights of honest competition, provided they do not infringe upon our just rights and privileges. We must not forget that nothing succeeds like success, and that he who by success proves his superiority is entitled to all the privileges that honest competition may confer upon him. It therefore appears to me that one of the first aims of future evolution must be to get a federation of nations to join together to settle international disputes by arbitration, and that the next must be to try and populate the different countries with the people most suited to develop them to the greatest advantage, and that this can only be brought about by evolving a commercial system of international barter of territory by purchase and sale instead of by War; thirdly, that the main means of the development of evolution in the future must be to encourage the breeding under the most suitable conditions of those best suited to create the highest possible qualities calculated to 
produce habits of utility, self-control and economy, individuality, self-reliance and integrity. This can only be achieved by protecting equally the right of all nations, and the rich as well as the poor of all classes of a community alike, regardless of class or nationality. We must not lose sight of the fact that rich and poor is only a social distinction, not a class difference, just as are good and bad, weak and strong, sane and insane. Poverty is one of the greatest blessings and must continue to be a blessing.

Statistics show that we can set down between froo and $f_{200}$ a year as the average limits of variation in the distribution of wealth and must dismiss all above and below these limits as exceptions. But within these limits we must as far as possible enable one and all to bear and share an equal burden of labour, either mental or physical, according to their ability and capability. It must not be forgotten that large incomes and fortunes are not the possession of those who hold them, but of the community, and that all that is not spent on the actual maintenance of the holder and his family is passed on to the wages account of the community by the process of circulation. The holder is only the manager for the community. It is one of the evolutions of modern civilisation that we cannot move, live, or act without being dependant to some extent on our fellow-men. Even if we strike a match, we are dependant on the labour of two or three other professions for the production of the match.

Every advance of evolution is pointing towards the necessity for more local regulation of industrial interests and local Governments of trade regulations, and the fallacy of the aim of unionism in trying to fix a universal standard for commercial interests, rights of distribution, and conditions of employment, etc. But at present the Government of every nation is torn to pieces by its inability to decide the boundaries of local and general industry and where the limits of commerce, public and private rights of ownership and general or individual competition and co-operation and liberties begin and end. As we decide these limits, we will gradually learn how to use not abuse our newly-acquired powers of mechanical invention. This must be a work started at both ends of society and finished in the middle. For it must and can only be evolved by a better knowledge of the value of unity of 
thought and mutual conditions of work and co-operation under peaceable conditions of government. In the past it has been local evolution that has led the world forward. We have now progressed one step better. Steam, Telegraphy, universal postal and news agencies, universal commerce, etc., have in the words of Shakespeare, "put a girdle around the world in forty minutes," and made united action on the part of man not only a possibility but a necessity. It is one of the curiosities of human nature that when there is only a right and wrong way of doing things we always choose the wrong first, because it is only by doing wrong that we learn to do right.

In the last hundred years of peace among nations our individual governments have been doing all they can to destroy peace amongst men, by means of trade unions and selfish combines. The outcome of this has been a general European War, that is to place the control of Government in the hands of those best calculated to protect universal interests (mind, I use the word control), those who control wealth, for under modern customs the possession of wealth is daily becoming not the result of might but of right, and every day's advance in this direction is making the possession of wealth nothing more than the right to control it for the good of others; when this war has decided what nations or federation of nations are best able to protect the rights of freedom and capital against the infringements by one nation on the rights of another in territory and commerce. We will have next to turn our attention to deciding how far one individual may infringe upon one or other of the liberties of another individual. This will produce a period of civil war, then the unprecedented poverty of these wars will cripple business and destroy the luxury that the last century has produced. It will bring mankind to the realisation that with the end of the Epoch of Hope, the Age of Wars, we should arrive at the Age of Peace, after which the struggle will be to establish a local form of democratic municipal government on an open franchise to control industrial legislation and an aristocratic form of central or federated Government elected by a highly restricted franchise or, better still, elected by and from the local governing bodies, supplemented by the highest hereditary ability and genius. Powers of central federated Governments must be of the most limited nature com- 
patible with efficient power of direction and compulsion, and whose administration must extend only to universal, not local, matters and interest. The tendency of to-day is wrong, as it tends to place the control of nearly all forms of legislation and direction in the hands of a central governing body instead of separating matter of local interest from central control.

The centralisation of population in large towns and cities and the congested population in civilised communities make the burden of administration too huge and cumbersome to be managed and directed upon one system or from one central base except in matters of absolutely universal interest. Australia has established a form of Federal Government, but, being a young colony, she has all the faults of youth. Its organisers were blessed with large conceptions, the natural product of a life of fierce contest and close intercourse with nature, but they lacked the maturer wisdom which is the outcome of past experience, of older customs.

So their conceptions, though grand and well meant, lack the more conservative tendency of restriction. Nevertheless it will do much to illustrate to the world the faults and shortcomings of its imperfect conceptions. This may in course of time serve a useful purpose by elucidating to the world in general the false steps made, particularly for the want of due regard being paid in its definitions of the limits and boundaries placed upon its powers of action, which are far too sweeping, for time will show that the powers of administration of the States will have to be greatly extended, and those of the Federal Government greatly restricted, and probably the states will have to be cut up into provinces. Now, it is quite correct to have Military, Postal, Custom, Tariffs and Police, and, I should also say Medical duties, Railway and other general occupations of delivery undertaken by the general administration; but all matters relating to trade and commerce, Trade disputes, Municipal taxation, Charities and local interests, should be strictly matters of municipal State legislation, and must be most carefully safeguarded from any possible present or future infringement or encroachment upon the rights and liberties of the States by the Federal Governments. Such encroachments are its greatest weakness and will be the cause of the faults and failures of its youth until a few centuries of existence have given it age and 
maturity to ripen its wisdom. The great fight of the next century will be to evolve such restrictions and limits to the extra liberties that modern legislation is granting to the masses of its people, who have not yet evolved the power to reason, and who consequently are in danger of using their increased liberties of action and thought. to jeopardise the freedom of their neighbour by arbitration courts and preference to union combines. Hence all trade and labour disputes should be earmarked as strictly state or local matters of legislation, and one of the duties of, and also one of the most important ones in the future of the Council of Federated nations, will be the limitations of these rights of central governments. The power of the Popes of old to decide international disputes is gone, never to return. But we must evolve some federated international council to settle international disputes in its place. The difference will have to be; the Papal power was based on superstition and fanaticism; the new power must be based on the world's united and most tried wisdom, judgment and political experience.

These errors will not have been made in vain, for, as I have already mentioned, it is only by going wrong at the start we can learn the wisdom to go right at the finish, and these errors if committed in a small and poorly populated country will not produce the evils they would in a larger and more densely populated community. Being a young nation, Australia will be better able to remove the effect of the errors she makes and her follies will be an object lesson to older and wiser nations to help them in evolving a more perfect federation of nations in the future, to which the possession of too extensive powers would spell ruin, and Australia's faults will be fresh in the memory of mankind, which has a great aversion to be taught by the experience of past history. So they will help in this manner to show future statesmen during the coming century where these limitations require to be made, so as to restrict the extra liberty given to the community by their increased freedom of thought and literary knowledge. They even help older nations to see how they will have to restrict their limitations, so as to prevent overlapping and interference with the individual liberty of each nation in forming a federation of nations. The American federation is also likely to help in this direction, 
but, being older, will not be taken so much notice of ; so if the nations are to federate, they must study these propositions of the federations of Government in the past when creating a federation in the present. They would do well not to lose sight of Switzerland and Japan; the former because isolated nations avoid rashness, and the latter because eastern and southern nations have greater wisdom and genius than the northern and western nations, although they lack the energy and determination of the latter, which is the mainspring that drives the clock of progression. It is because wisdom and energy are the product of travel and a variety of experiences that has caused migratory nations ever to progress more than sedentary ones. If any federation of nations is to succeed, its success must depend not only on the nations but on granting security to and severe restrictions against the insertion of any clause calculated to restrict the liberties of each nation; and fixing these and setting the narrow limits that will allow the federal community to deal with what little is necessary to the central control, and so confine its actions to that of a privy council, as to make them so limited in their actions that they shall not tread on the corns of the individual liberty of other nations, for any power misapplied, like the policy of a "White Australia," "Preference to Unionists," etc., would only intensify wars, or slow progress.

I may here point out that the great secret of the success of the Government of the Roman Empire lay in the fact that as it conquered other nations it was careful to transplant to some other portion of its mighty empire the military force conquered, leaving the conquering troops to govern the conquered country that there should be no ties of clan or race to destroy future authority. In a like manner must this police army of the Federated Nations be cosmopolitan. It was in this way Rome did most to advance evolution by making for universal empire, against clans and principalities, and so was able to promote commerce on a larger scale than hitherto, and so evolved the most perfect Government of ancient nations.

National federation must make the world one international empire. Now that commerce and invention make a further demand that the boundaries of race and creed shall be still extended or annulled, we will have to resort to similar means of Militarv Government or it will be impossible to pre- 
vent exorbitant and unmitigated sacrifice of human lives and livelihoods in the future. Modern wisdom clamours on all sides that the racial and religious hatred of the past should be replaced by brotherly love and tolerance, and that we cannot, and must not, try to abolish the distinctions of good and bad, rich and poor, high and low, which are measured by the energy, ability, judgment, thrift and perseverance of a nation. As long as there is crime and folly of any sort, and even through all eternity there must be rich and poor and good and bad, just so long will there be weak and strong, wise and foolish, sickness and folly before we can abolish poverty or crime. The most we can do is to relieve poverty, and as we grant extra freedom of thought and of tolerance and of knowledge to the masses, we must in the same proportion reduce the liberties of the idle.

This is the great task that the coming century has to face. It will also have to destroy the internal commercial disturbances that are destroying the heart, lungs and bowels of the energy of modern nations. This present war is but the surface simmer of the terrific boil of civil wars that are to tear and rupture modern civilisation to atoms ere it can embark on its next strife, viz. : replace religious slavery by state restrictions of individual actions opposed to freedom, to evolve peace and usefulness and prevention of crime. This war will produce poverty as a result of the foolish excess of uncontrolled liberty and loss of freedom that has arose through nations giving away the levers of ignorance and superstitions fostered by our religious beliefs, by which they have governed in the past and will necessitate the building up of a new industrial military system of government capable of converting commerce into a disciplined army of productive regiments and battalions to fight the commercial battle of the future. Although it is desirable to abolish international warfare, this can only be done by creating a stronger form of industrial discipline, goverened by a cosmopolitan army, under the most perfect military organisation, to enforce greater reductions of liberty. I have already stated that in this treatise it is my aim and object to only touch upon the subjects under discussion lest they should outweigh the importance of my hypothesis. So I must leave these subjects to other tractates; also at the pre- 
sent moment of war it is not diplomatic to enter into many developments and forecasts till we have more certain data, which this war will provide us with, on which to base our deductions. Nevertheless I must also point out that in the Roman Catholic Church is preserved the most perfect forms of Roman Government. This will ever make this the religion of highest ideals, despite its superstition and bigotry.

State governments will do well to copy the virtues of its organisation, and leave out its superstition and bigotry. At its head stands the Pope, elected by the Bishops of all nations. Ruling its teaching stands the College of One Hundred Cardinals, appointed from all nations according to their excellence of knowledge; these are divided into ten sections of ten, to each of whom is allotted the study of a branch of its Theology. Some such court of nations must be evolved in the future to control the welfare of all nations made up of the most competent men of all countries. But in order to enforce the decrees it will be necessary to aim at the Roman system of control and create a cosmopolitan army to be transferred, so that each nation shall in turn be policed by a military force free from local or political sentiments. Some such court of international control must be evolved in the future to perform the duty carried out by the Popes as arbitrators in the feudal ages and early Christian era.

We call ourselves Christians; but not he who says Lord, Lord! shall enter into the kingdom of Heaven, but he who knoweth my Father's will and doeth it. Now, what is the Will of God? Is it the teaching of any particular religion or sect, Kaiser, King, or nation, popular leader, violent agitátor, either religious or political or mad-brained enthusiast? Surely this is too narrow-minded a conception of the Will of God. I am more inclined to look upon the Will of God as the truths of nature as taught by evolution in the relics of rocks and stone, animal and vegetable existence, and the records of the failure of past animals and men, species and races to perform their allotted duties in the course of existence. Hence, if we would be Christian in deed as well as word, we must aim at higher ideals than those taught by priest or prophet. We must aim to live in peace, love of justice and unity in accordance with the laws, not of man but of God, as taught by the wisdom of nature. But nature 
ever demonstrates that peace only exists in nature, when controlled by infinite wisdom, which mankind will never possess, or when the tumultuous forces of destruction are kept in check and controlled by forces of natural in place of supernatural, or human in place of superhuman forces greater than themselves. Hence if we would be Christian in deed not words, we must aim at first wisely controlling the foolish, justly dominating over the unjust with care and providence if it is our duty to rule others, and we must make it the rule of our lives to obey readily and labour willingly, if it is our duty to labour for the support and maintenance of each other, whether we be the parent supporting the child, the thrifty capitalist maintaining, feeding and supporting the masses of the people who make up the working bees of the human hive and do the less skilled and less important work of collecting by production the human honey. But if there were no drones there would be no comb or wax in the bee-hive in which to store the honey, and a single season could see the hive extinct and the lava unhatched. So in a like manner in the human hive we must have drones, who can save the honey of capital, instead of consuming it on the spot or at the flower where it is gathered by the labourer; and we must have an organised system as perfect as that of the bee if we would enjoy the sweets of life in peace and harmony.

You must have power to control folly and its snarling children, Anarchy, Socialism and Syndicalism, the three bastard offspring of folly, waste and indolence, for it is the poor, not the rich, who are most inclined to shirk the duties of their state of life, for the wisdom of man, like the wisdom of God, ever demands and proclaims that love and action are the two causes that demanded and made creation possible. Hence, if we are to live in love, peace and wisdom, we must have a military power sufficient to maintain the decrees of the few men whom success proves to be wise and God or nature permits to be rich as a reward for wisdom learnt and weakness overcome, which constitutes virtue, just as folly and failure and want of energy are the three qualities that produce all forms of vice. Therefore if we are to be able to maintain or enforce the decrees of a council of nations, it will be necessary to copy the Roman system of a cosmopolitan army, to be organised by transferring the armies of one nation amongst other nations, 
so that there may be combined military forces without local, national or community sentiments. If it is to be fit to control the civil strifes that are to mark the coming century, or to be powerful enough to exert a controlling influence over the destinies of other nations in times of civil strife, it must be built after the organisations and upon similar design as that of the Roman army and the Roman Catholic Church, so as to be truly representative of all nations and able to resist the destroying influence of national greed. For now that the Epoch of wisdom and of Charity is at hand, we must realise that we are to make a new departure and to aim, not at power and might, but at unity and right.

To do this it will be necessary that nations cease to war, and to make a national federation to protect the universal commerce of the world. For the maximum productions of a community no longer demand or are to be decided by its power of conquest, but its energy in mental competition to excel in commercial competition with other nations. Its principal markets are no longer its own people but the buyers of foreign countries and states. It is no longer necessary to foster the energies of one nation more than another, but it becomes the aim and object of all nations to unite together for the sake of the commercial interests of the whole world.

In the past the aim of Government was to make the poor dependant on the rich and to make the rich a fighting class that they might be able to protect the poor. Now that is no longer necessary, and the poor jump at the conclusion that the rich no longer deserve or merit superiority, because individual energy, getting a large scope of utility, imagines it can achieve unprecedented success without the assistance of its betters, just the same as youth thinks itself wiser than old age and scorns the advice of its elders. But evolution does not advance by leaps and bounds, so we must learn to go slowly again and to crawl before we walk, and again realise now that mankind has attained greater liberty of thought and action that we have only changed our coat, not our masters. That unity is still more necessary than ever to our existence. And undisputed obedience must become even less open to dispute, if it is to be, as it always must be, the mainspring of success. We must also be careful that the desire for co-operation does not destroy competition, and the poor will have to learn that the wealthy 
are still, and ever must be, their best friends as well as their superiors. The only difference is, that the rich have now to help the poor by the loan of capital in place of gifts of alms.

'This can only be gained by the poor trying to give the best possible day's work for a fair day's pay, freely and honestly, and to take a pride in the prosperity of their superiors instead of striving to get the highest pay for the lowest possible amount of work. The latter aim can only tend to perpetuate civil wars and class enmities and increase poverty, which is even worse than national war, and the rich man must realise his duties will be increased and he will have to exert more rigid power to enforce control than hitherto. We have abolished the right of robbery under arms, family feuds and vendettas. We must abolish war between the different classes of society, nations, races, and creeds. And after that the feuds between master and man, town and country, capital and labour, and all that interferes with the liberty of each one's useful rights of competition. Now, no one objects to preference to birth in giving employment to youthful labour, for we all admit like father like son, but no one approves of preference to birth over ability in cases of promotion. Hence it is a wise and universal custom to consider the parentage of a youthful candidate, and every reasonable person would do so, but it would only be an act of folly if promotion were given on the basis of heredity or if incompetency was not condemned irrespective of birth, unionism or any other combination.

Hence we must in the future strive to breed out, not fight out, crime. To prevent crime and death, not reform crime or cure disease. To sin in moderation, not to be good to excess. To attain these aims we must organise some means of using our criminal as a means of producing state funds for charitable purposes. State control of manufactures must be confined if possible to criminals and irredeemable failures. When we have in the next two hundred to five hundred years learnt these lessons we will be able to live in peace with one another, in joy and comfort individually as well as nationally. Therefore concurrent with these advancements in knowledge as the science evolution teaches mankind to correct these errors of states, religions and social governments, nations will realise the folly of war and " peace will be granted to men of good will." It should here be remembered that if my 
hypothesis is correct, Christ came not to bring but to introduce "peace to all men of good will." But the making of men of good will was not the duty or work of Christ but of mankind themselves; but now God the Holy Ghost is about to grant wisdom to and disperse it through the minds of mankind, which is to come about by the Holy Ghost descending, not in tongues of fire, as he is reputed to have done in the case of the Apostles, but by the light of science, and to enter the souls of men, to enable him not only to see as in the past, but to understand and know and evolve out of his own brain and experiences better habits of self-control, wisdom and eloquence than even those Christ taught. Higher principle and maxim for his direction and guidance are to be added to those taught by Buddha, not to destroy them, for true revelation, like the laws of Medes and Persians, cannot be altered, but only added to by more serviceable ones.

With the march of science, mankind is to learn that such things as national armies are not to be dreamt of in the sense of the past as a means of evolving nations, and of acquiring territory, and increasing commerce, but that the march of commerce will be belter accelerated by the barter and sale of territory. But as crime only is to cease to exist, and sin is to be everlasting, and the "best plans of mice and men gang agley," it is improbable that we will ever be entirely able to do without civil war, or war as a means of punishment for riot or crime, or as God's scourge for national folly and abuse. The most probable result of the present European War will be some compromise that will in the future lead to some such treaty as this : that first, declaration of war by any one of the nations signing the compact of peace shall be considered as a declaration against all the other nations signing, should any start war without first submitting the causes to arbitration. I feel sure this will do much to stop war in the future. Secondly, I feel sure that the poverty of this war will produce in the coming century; as it becomes felt and understood; will do much to make all nations prefer arbitration to war. So that some form of sale and barter of territory will be arranged thereafter. But the main safeguard of peace must be the purchase and sale of territory. 3rd. That any nation having what has hitherto been considered a "Causa Belli" 
shall submit the same to the arbitration of all the signatory nations, and that they shall all pledge themselves to enforce the decisions of such a federal council of state. Out of this would come a possibility of reduced armaments as other nations joined the federation. Now, the most important wars of the coming century will be the civil wars, and the difficulty of civil war is to get an army to fight its own countrymen. But this will be remedied by all the signing Governments undertaking to transfer or exchange troops with one another. Thereby in the future we will evolve a still more perfect system of enforcing law and order, and assisting liberty.

When the national war ceases the only need of an army will be as a superior police force.

Thus the council of nations will become the central government of the world. Evolution points to centralisation to create co-operation, and local government to preserve competition, so that we must evolve a national council of all nations to act as a privy council in all inter-state matters, so any civil war arising out of riot will in future be under the control of the central council, to whom the nations will look for protection. Thus as time passes, and nation after nation will join this national federation of the future, it will grow to form an unbiassed court, made up of the wisest heads of all nations, who will have to decide the merits of the case, and it will become the controller of all the armies of civilisation, and will be able to enforce their decrees. Of course this will require from 500 to $I, 000$ years. I think I have now done all I can to outline the most probable manner of evolution that my Table III. may point out as the probable lines of the most prominent features of the next five hundred or one thousand years of evolution.

Without entering into detail, which it is not my intention to do, I will therefore point out only one more fact before putting down my pen for the present. That is, that when we realise that it takes forty-five years to amass from $£ 2,000$ to $£ 2,500$ of capital, so as to enable a nation to support one breadwinner at a wage of 40 s. per week, as this is the capital value that has to be reserved every forty-five years to keep up or renew an income of $£$ roo per annum, we see how modern warfare is nothing but an unpardonable and unwarranted form of murder, by the destruction of future livelihoods; and if it is 
possible to do away with capital punishment, it should be possible to abolish the still far more dreadful capital punishment of international war. Now that invention has made war so costly, it is too expensive a luxury for communities to indulge in. We must trust to the survival of the fittest, by the predominance of power and of wisdom over folly, to decide the questions in the future. In the past the necessity for the evolution of energy may possibly have justified the loss of life in days gone by, but the heavy cost of modern warfare makes it such a costly pleasure that no blessings will be sufficient to justify the enormous loss of livelihoods, to say nothing of lives. In the future war will be such a calamity that any sensible nation will appeal in wrath and agony to the central council of nations to prevent and stay such awful sufferings and loss of the past labours of our fathers and our grandfathers as modern warfare is likely to produce if allowed to continue in the future, and we will prefer starvation to war as a means of reducing our population.

I have now said enough to point out that this Hypothesis of God's Trinity, as a key or check to explain or unlock the hidden meaning of religion and evolutions, is worthy of more and deeper consideration than this little treatise will permit me to provide. Yet it may do much to make mankind the better publicly, if not in private life, to shape the future of good Government, and scientific enlightenment, and individual self-control. I also hope it will benefit science, religion and mankind, and so improve each as they become better acquainted with the problems it brings into notice. 


\section{CONCLUDING REMARKS}

As many of our conceptions arise from want of definition, it may be as well for me to here define Infinity and Finity. If asked, we would at once say, "Oh yes, I know the difference between Finity and Infinity" ; yet many of us when asked to define the two would hesitate and stammer, not because in an indistinct way we did not know what the relation was of one to the other, but because we are at a loss to know where Finity commences or Infinity ends. It is this want of the powers of limitation that makes all human folly and weakness and creates all errors. It is not so much that we do not know or feel the distinctions of objects, but that our comprehension and understanding is weak when we have to deal with ideas. This is why in the past we have known and felt there is a God, but we have been incapable of comprehension or understanding the distinction or dividing line between Finity and Infinity, so we are often at a loss to place in their respective relationship the positions of the Creator and the Created. Religion may help us to comprehend and believe in God, but we can only hope to understand God better from day to day as evolution increases the development of our minds and souls, and science yearly adds fresh data to our store of knowledge and experiences of nature and its laws, and past actions will be able to increase our knowledge of God. For as God is Infinity and man the highest order of Finity, it is only by a better realisation of the relative functions and positions of Finity and Infinity we can form a correct opinion of what God is. I think it therefore incumbent on me to define Infinity and Finity.

The stamp of INFINITY is that it is

\section{INVISIBLE, IMMEASURABLE and UNLIMITED.}

Consequently it is as impossible to put a limit to the divisibility and the diminutiveness of the electrons of ether as it is 
impossible to put a limit of measurement to the power of its omnipotence.

FINITY, on the other hand, must of necessity be

\section{VISIBLE, MEASURABLE and LIMITED,}

otherwise it would cease to be FINITE and become infinite. Man, being Finite, may become eternal, but cannot become infinite, otherwise he would become a spirit and cease to be a visible or measurable creation. Neither can he understand Infinity, although he may imagine its existence and comprehend its qualities sufficiently to believe in what he cannot understand. His mind is invisible, but both measurable and limited, and his mind limits his understanding. But his soul is both invisible, unlimited but measurable, so he can exert a measurable degree of belief and comprehension and an unlimited power of imagination of that which he can neither see nor measure. The third wave of energy is the creative electron of Infinity, so I doubt if we will ever find out what the third wave of energy consists of. At present we have positive and negative electrons or ions of electricity; both of which are invisible and unlimited, but measurable in their actions and effects. But we are never to have divine wisdom, only human, and ultimately complete natural wisdom, but never to attain what is supernatural; so I doubt if we will ever learn the third force of electricity. Having defined Infinity, I now hear my reader exclaim, "Then what constitutes the limitations between what is natural, superhuman, and supernatural ?" All is natural that is visible to the eye, measurable by the touch, and can be limited by the understanding of the human mind. But man can only measure the universe from the standard of his understanding of his own environments. He can only comprehend eternity from the unit of his individual life, and can only imagine infinity from the starting point of his own Finity. So only what he can understand is natural. That is super-human which is invisible to his eye, that he can feel, is unable to control, and can only partially understand. That is super-natural that defies his understanding, puzzles his comprehension, and appeals only to his imagination, but which his impartial understanding compels him to admit the existence of but cannot accept without doubting; because the laws of nature, as he understands them, contradict 
or fail to account for a certain phenomena which his soul cannot mount high enough to realise more than the existence of. But man, being finite, it stands to reason that there must ever be some portion of divine knowledge and wisdom withheld from his human ken or it would become supernatural wisdom. If man became possessed of all the attributes of power and wisdom, as well as all the attributes of love and life, he would be equal to his infinite Creator, and you would have two infinitiesQUOD-ABSURDO. Now, as the object of creation is mainly to grant to God a perfect sweetheart, we find that all combinations of the male and the female attributes of God the Father and God the Mother produce the first eleven out of the twentyone evolutions which become complete, and that it is the combination or marriage of these attributes that produce all the tangible factors of existence. These are-

I. The spirit of destruction.

2. The power of construction.

3. The material creation.

4. The vegetable kingdom.

5. The animal kingdom.

6. The human kingdom.

7. The mental kingdom.

8. Agriculture.

9. Civilisation.

ı. Religion.

II. Government.

These eleven Lower Orders of evolution are destined to become complete by the end of the world and cease to exist as motive forces when man's psychological activities commence to predominate over the material forces of his evolution as he becomes wise enough to govern himself and control the world. This just gives material creation the full development of eleven out of the twenty-one attributes of God, because the three first and the seven last attributes appear to be only partially returned to creation. The other ten evolutions, being psychological, are never to be complete, for the soul of man, like the soul of God, is to be eternal, but God is ever to be twice as powerful as man. But as man is to be finite, not infinite, we find the three first and ten last evolutions are never to become complete or become obsolete. For man's soul is to be limited, as is his 
power of will; love alone is to become complete, so that creation may give an eternal sweeheart to an infinite spouse. This may be the meaning of the equation-

Man-2 females to one male.

God-2 males to one female.

So then in man the seven female qualities of God will, when he attains perfect wisdom, be entirely developed, so will equal the sum of the halves of the fourteen male qualities, and in this manner the balance of power may be restored and nature made capable of reverting to a finite state of rest and content, and of permanency equal to the original state of rest that marks the state of stability in its condition of ether as opposed to the everlasting discord of construction and reconstruction that defines existence of finity. The ten incomplete evolutions are to be-
I. Science.
2. Commerce.
3. Invention.
4. Peace.
5. Charity and Use.
6. Contempt.
7. Content.
8. Joy.
9. Pleasure.
Io. Happiness.

These are for ever to be variable, unalterable and intermittent, which are the three qualities that characterise material and finite creation, just in the same manner as stability, Alterability and Continuity are the characteristics of infinity and the electrical forces that control psychological development. This leads me to conclude that we will never become cognisant of the third electrical energy. Positive and negative electrical energy we may ultimately understand the measure and limits of, but not the sub-division of, for their minuteness is to make them invisible. By my hypothesis it appears to me that each of these three ions of electricity should be further divisible into seven more minute varieties of electrical energy, far more minute than the electrons or ions of negative or positive electricity; that these my hypothesis would lead me to conclude that one out of the three ions of electrical power or energy must be not only invisible but likewise immeasurable and unlimited in their forces of construction, I fail to see how a finite mind can comprehend or understand what it cannot measure or cannot see but can only imagine. Being logical, my mind 
rebels against what you can only imagine, and demands that at least you shall be able to comprehend as well as imagine before it accepts or believes what it cannot see or understand. I can both comprehend and imagine that such electrical forces of energy may exist, but they are beyond the extreme limits of my understanding, the limit of which is reached when I can neither see, measure, limit nor control the actions of forces, even though their result may be visible. In these concluding remarks, which have arisen from ideas that come into my mind when discussing the subject matter already written, I have endeavoured to throw out a few suggestions relative to what appears to be some possible solutions of Infinite life and energy, viz., that it must be the higher forces or more minute ions of electricity at work under similar rules whose details we have yet to conceive. For it appears to be a rule of nature that the more we reduce matter to its primary elements the nearer we get to the infinity and omnipotence of invisible power, the immeasurability of vital power, and the unlimited velocity of motion. These invisible atoms of electrical energy seem to be the electrical symbols of infinity that control, surround and permeate matter, and give it life and propel its motion and progress.

Professor B. Moore, in "The Origin of Life and Nature," page $15^{8}$, writes as follows :-

"The origin of life is one of those primeval questions that have agitated the human mind throughout the ages. Some system of creation has formed a basic part of every religious creed in all lands, and the progress and advancement of a people at any given period are reflected in their beliefs on this subject. The general state of scientific thought and knowledge at different times is also indicated by the writings of the contemporary philosophers upon this theme, and the growth of enlightenment from age to age can be traced in the changing beliefs upon the subject."

The reader will notice that the hypothesis of my treatise absolutely connects these two as simply the force of two evolutions, one of physical and the other of mental or psychical energy, running in concurrent lines, like the two lines of a railroad, but both starting at the one point, the creation of the Universe out of the Trinity of God, and that both Science 
and Religion, when truly and correctly read, are only two lines of the same roadway of evolution. Both Science and Religion in the future must not run, as they have done in the past, as if they were fighting for precedence over each other, but must lay down the right-hand line of Science and the lefthand line of Religion at the same rate of advancement as each other by comparing notes in all friendship and respect Endeavouring to help each other to evolve with equal rapidity along the newly explored country of evolution of which they form the principal lines of communication on the same level and grades and as straight as possible; for every curve will increase the danger of a capsize, and if one rail gets much higher or lower than the other, then the carriages will capsize, and if the curve is too acute the motive power of their central cable, divine revelation, will clog.

The hypothesis I am now establishing is the only one that is common to all forms of evolution and the only one that can be in harmony. Once let any forces lose or forget their God, which they do when they cease to be in the likeness of His Trinity, and they can no longer advance in the same manner.

As I have stated elsewhere, according to my hypothesis, all Nature must conform to the laws of God's Trinity, and therefore the laws of chemistry should be no exception. Hence, referring my reader to Table IV., he will see that in that Table may be the data on which atomic Chemistry must be checked. I may know a little about history and evolution, but I am no chemist, so this branch of the work must be taken in hand by those versed in chemical evolution. The question then arises as to how this Table affects atomic chemistry. Does No. I stand for Disintegration, No. 2 for Gaseous Combination, No. 3 for Fluids, No. 5 for Crystallisation, or do Nos. I and 2 , or 2 and 5 represent Chemical Action, Nos. 6, 3 and 9 Stability, Nos. 4 or 7 Vital Energy, Nos. o or ro represent final combination, Rebirth or Reconstruction? Does No. Io represent Eternal Existence, or how far may multiples of ro be extended before we reach a break-down of the Atomic System? These are the questions that the writers I have read on this subject are at a loss to find an answer for. Thus it seems possible that my Table IV., the mathematical table of Trinity, will, in the hands of the high-class professor or student of chemistry, solve some of these questions by evolving a new 
system for a more reliable tabulation of elementary atoms. I have given this Table IV. in just the same way that I have given the other tables of Trinity and the Hypothesis of Creation. But it would be ridiculous to expect me to illustrate all the branches and ramifications of such a subject as this one, which embraces every Science, Trade and Profession in the Universe. Astronomy, Chemistry, Scientific Mechanism are all branches I would not do more than suggest a means of its application to, any more than we would expect that the manager of a large undertaking could be an expert in every detail of his business. But the following quotation from the same work of Professor Moore, page r05, does tend to give the answer to one of these questions, that is, that just as No. 6 marks an age of stability in Animal Evolution, so it also appears to mark stability in Chemistry. Professor Moore writes :-

"It is a curious fact in Nature that there seems to be a position of greater stability when groups of six carbon atoms unite in little galaxies or concatenations. Other groups than those of six do exist, but they are not so stable nor so easily formed under natural conditions such as obtain in living organisms. Although such groups of less, or occasionally more, than six carbon atoms are formed naturally by life processes, by far the greater portion of the substance of living organisms is built up of six carbon groups and multiples of these."

I am now convinced that the answers to these questions will do much to teach us how to prolong our lives into immortality. For instance when such a system of numeral chemistry is evolved in accordance with this table, say a man's blood gives No. 16 as atomic value, and No. I5 as the value of another person's blood, the foods of No. I man might have to be confined to foods of a numeral value of 16 atoms, and the food of No. 2 man to the value of $\mathrm{I}_{5}$ atoms in his food if they wish to keep their health and to prolong their lives. Of course I only hazard these suggestions as items for those who are competent to express an opinion on such subjects. I would not be bold enough to do so myself.

Now it appears to me when viewed both from the standpoint of my hypothesis and when substantiated by the revelations of 
modern science, as we now understand more fully that life lies not in matter as previously conceived, but rather in the invisible electrical forces of space and ether. That the Trinity of God is represented by three ions or electrons, one of which is unattainable, as it should by my hypothesis be invisible, immeasurable and unlimited, and that these electrons are each sub-divisible into seven ethereal forms of energy also invisible, immeasurable and unlimited.

I heard Professor Soddy remark words to the effect that it is probable that an atom of matter can be divided into positive electricity plus X electricity, but that, so far, science had not been able to ascertain if any third ion existed or what its qualities were; therefore until this discovery is made he would continue to express existence in terms of positive or negative electricity and matter; although matter is probably only a combination of some unknown quantity and quality of electricity plus positive electricity, we may never be able to separately distinguish. I take it therefore that God is most probably the twenty-one waves that make up ether, just as the seven colour waves make light. That is to say, God is the whole twenty-one waves of ether, equal in quantity, power and action. Therefore God is ether at rest. Finite creation is a disarrangement of the proportional combination of one or some number of these waves, under some new combinations of waves of electricity in a state of motion as opposed to a state of equality and rest. God alone can be equal, perfectly contented and at perfect rest. Hence God alone can be perfectly happy. For happiness is not a positive possession; it is simply the total absence of any destructive force or influence.

Therefore perfect and unbroken Joy, Content and Happiness must belong to Infinity alone if my hypothesis is correct, viz., that all finite creation is some form of the twentyone attributes of infinity, whose peace, rest and stability have in some manner become disturbed. I can only find one age of equality in Nature, the first stage of gas previous to the removal or disturbance of the invisible soul of divine and perfect wisdom, and it therefore follows that to create finite equality would demand the existence of two in the place of one infinite being, an infinite humanity and an infinite deity, which is unreasonable This may be the reason why those who clamour for equality are deficient in reason, logic or wisdom, 
and are like the age of gas, the highest form of disintegration, destruction and agitation, and the gas bags of humanity.

To return to the statement that God is the twenty-one waves of ether in perfect rest, my hypothesis further demonstrated that-(a) The first personality of God's Trinity is the seven potential waves of motive forces we call Light, because their three primary products are Light, Heat and Combination of Motion under conditions of alternately temporary rest and activity, which we call force or energy. Without the intermingling of some of the waves of God the Mother and God the Soul, the forces of God the Father are devoid of rest, life, self-control, shape or visibility, and are the forces of variation and disintegration in nature. (b) That the second person of God's Trinity, which I term God the Mother of Creation, are the forces of inertia which tend to form Combination, Crystallisation and the Affinity necessary for reconstruction of Matter by gravitation, which tended to create rest, inertia or force. (c) That the third personality of God summarises all the kinetic energies of nature that we call electtricity and radio-activity, and which create rebirth in some new, visible form of invisible activity which produces the higher forms of motion or existence we call Life, Mind and Soul, by means of such physical " outward signs of inward grace" (for all superhuman forces are divine graces). Nerves, Brain and Muscle, which make visible to us the invisible actions of the psychical forces of electrical energy which rule our minds, lives and souls, and which communicate the mystical motive power of the God of the invisible power of.Action, Love and Motion contained by ether. These permeate the visible atoms of created matter which constitute the Universe as it exists, surrounded, impregnated and controlled by the infinity of ether from which it has sprung and out of which it has been created.

You will remember that I laid down as one of the incontestable axioms of Creation that the only possible logical method of Creation was that the world of finite existence should be divided from but not separated from the Infinity of God, and must therefore be impregnated, controlled and surrounded by the infinite ether that constitutes the deity of God's combined Trinity. Now, modern science has during the last ten years begun to realise that this ether is the motive medium of all existence, not only the motive media, I maintain, but it con- 
tains all the motive forces of creation, life and existence. All energy is but the transition or oscillation of the forces of God the Mother between the two poles of her affection, the two male personages of God the Father and God the Soul. Figuratively speaking, to enable my reader to comprehend the finity of infinity, I may class the two males as potential and kinetic energy, and the female attributes of God as the forces of negative electricity combination one of the female and the first male attributes of God the Father as passive energy, with those of God the Soul as kinetic or active energy. It appears to me, as I have already stated, that the ion of force or inertia is invisible.

TABLE VIII.

Qualities of the First Personality.

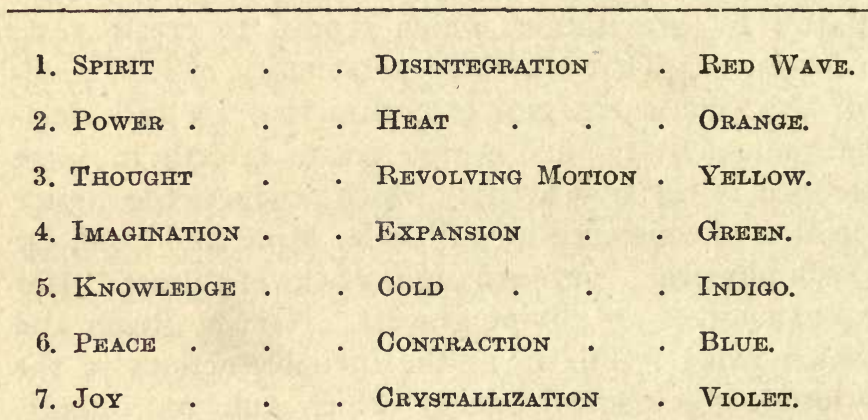

These are the seven pawers or energies of Rotrogression, Disintegration and Destruction.

Qualities of The Second Pergonality.

1. Existence . - Grapitation . •

2. LOVE • . AfFinity

3. Life . . . Protoplasm : . The Wever of these are

4. Comprehension - Chemical Action a as yet imperfectly

5. Invention • - Growth and Sex . ascertained.

6. Use . . Circulation • •

7. Pleasure • . Locomotion

These are the seven powers or forces of construction of inorganic matter, and the combination of these seven with the 
first seven should, I presume, make up forty-ninẹ material elements of nature, which I may call staple bodies of material or physical existence, such as lead, gold, platinum.

Psychological Eneraieg or Forces of God the Soul.

1. Soul . . - Ether . . . or Eleotrical Rest or electrical motive current undisturbed by circulation.

2. Wisdom • . Pellation . . Kinetic Energy.

3. Mind . - . Tractation . . Potential Energy.

4. Understanding - Reason • . . Elemctrical Currentr in Motion.

Psychological Energies or Forces of God the Soul.

5. Use. • • Brain • • . Motion of Thought.

6. Content . $\quad$ Nerves . . . Power of Control of BoDy.

7. Happiness - Radio-ACtivity - Invisible ACTion, i.e, Clairvoyance and Telepathy.

I give preference to the arrangement of the above table as appearing to me to be the nearest analogy between the words that express the seven attributes of God the Soul and the philosophical terms to which they may correspond. But it may be as well for me to present to the reader the following tabulation, as I feel that I am at a loss to satisfactorily decide which arrangement best corresponds or best expresses the forces at work; and different people put somewhat different interpretations on the particular ideas that the particular words we may use as means of conveying and expressing our ideas. For when all is said and done, words are only the instruments of language by which we express the thoughts, sentiments and experiences that constitute the ideas we wish made known to others. 
Psychological Energies or Forces of God the Soul.

1. Soul • . Radio-Activity - Invisible Action, i.e., Glairvoyance and Telepathy.

2. Wisdum . • . Nerves . . . Power of Control of BODY.

3. Mind • . - Brain . . . Motion of Thodght.

4. Understanding - Reason • . . Electrical Current in Motion.

5. Use - • • Pellation . . or Kinetic Energy.

6. Content - . Tractation . . or Potential Einergy.

7. Happiness . . Ether . . . or Electricai Rest, or electrical motive current undisturbed by circulation. Happiness being Content, Joy and Pleasure undisturbed by agitating influences.

The combination of these seven forces with each of the preceding forces of God the Mother should, I surmise, produce forty-nine variable elements of nature, such as Hydrogen, Oxygen, Nitrogen, Carbon, Sodium, etc., making a total, when we have found the complement, of ninety-eight elements. I am not sufficiently versed in the sciences of chemistry and Atomic Values to do more than suggest that some such tabulation may in course of time be proved to be correct, and that we may find it possible to divide metals into fourteen groups of seven, each group of fourteen having seven separate waves; just as the seven primary colours have seven separate waves in the spectrum of light. I only mention these ideas as throwing open to scientific research a system of mathematical grouping that may be worthy of consideration and investigation.

Ancient Buddhist Theologians had some such ideas imperfectly realised, which made them select three and seven as the mystic numbers, and nine and ten as the final numbers of completion; but for want of modern knowledge of scientific facts they tried to explain material existences by emotional analogies. This gave rise to ideas of miraculous activities and superhuman beings to symbolize natural laws and forces of nature. In the same way clairvoyancy is resorted to to 
account for results which we would easily understand if we had sufficient knowledge to be able to define the limits that distinguish between the spiritual and physical forces by which the Infinite Creator governs the finite creation. But as we begin to realise that ethereal waves are the forces that control physical action, we will get a more enlightened idea of cause and effect. Hence when a marriage or intermingling, so to speak, is effected between the waves of the attributes of ether with one of the male personalities of God the Father or God the Soul with the waves of the attributes of God the Mother, different forms of existence become active instead of passive forces in nature. This is the explanation my hypothesis would advance as the solution of the laws that govern the ethereal forces that agitate the activity of electric energies which create physical and material activities and chemical constructions, when the ethereal waves of God the Father and God the Mother combine to produce new substances. In like manner when the waves of the seven attributes of God the Mother combine their forces with those of the Soul, mental or psychological evolutions are produced by such marriages or intermingling of ethereal waves or forces in place of physical evolutions. Thus sound, nerve and electrical vibrations would be waves produced in this manner, just as light would come under the results of the waves of God the Father and chemistry those of God the Mother. Christ tried to give us a hint of this when he said My Father is the God of Life. He would have been put down as a fool two thousand years ago if he had said It is needful that I leave you or the God of Electricity, the Paraclete will not come to you; for in those days people understood no more about electricity than they did about the Paraclete, steam engines, railways, flying machines, submarines or any of our modern inventions, any of which would, two thousand years ago, have been flouted as the conceptions of a disordered mind. This is one of the reasons why we will have to reconstruct our religious views if we wish to make religion a practical force in the control of our daily lives. For it is just as foolish to maintain that the teachings of past religions must not be altered, as it would be to try to win the present war by storming the German trenches, equipped with modern artillery, with the battering-rams of Julius Cæsar. 
These are scientific subjects I have not studied sufficiently to be able to express an opinion upon, but must leave to those who have devoted their time to the study of such questions, such as Sir Oliver Lodge, Professors Moore, Soddy and others to decide. I think it well, however, before letting the work go to print to add these few lines pointing out how it will be posssible to utilise the hypothesis in future, as further knowledge of its great capabilities, as developed by science, government and religion, will be opened up to men's minds as it becomes understood. But as too sudden and too brilliant a light will blind even the strongest eyesight, I do not think it wise to take the subject any further at present, and consider it best to introduce the hypothesis, the faults of which may be condemned and pardoned on account of its novelty and infancy, rather than to attempt to prove or demonstrate matters so deep until after the world has grasped this undeveloped infant of my brain, when the varied lights by which it appeals to different minds may assist me with the help of such scientists as it appeals to, to evolve for it a more perfect childhood and manhood.

But I must draw attention to another point that it is likely to open up to investigation in Chemistry and in natural philosophy, and which the advance of science during the last ten to twenty years appears to substantiate in accord with my hypothesis. Until quite lately it was supposed that Ether which impregnated space was a vacuum without motive powers or any form of force, but modern research has conclusively proved that Ether is not inanimate space but a veritable centre of electro and radial activity, ever living and ever moving and ever renewing vital existence by new and fresh forms of activity. If my hypothesis is correct, this coincides with what it illustrates, viz., that this ether is the infinite existence of God, the invisible spirit of existence of the infinite universe from which portions impregnated, surrounded and controlled by ether have been divided, but not separated, into a variety of multitudinous visible creations out of invisible forces of activity. The details of this view of creation I must leave to be treated in a future sequel to this book.

I may here point out that it is to a large extent to light that we owe the visible activity of all material forms of potential energy, and as I have already pointed out even the ancient Persian legend attributed the three great divisions of God's 
power of direction of this world to the administration of the Angels of Light, the Angels of Love and the Angels of Knowledge. This division is not altogether fanciful, but is only another illustration of how much further Persian astronomy and knowledge were advanced than is usually comprehended.

Now I have illustrated that the first seven days of creation contain the combination of the three first attributes of God the Father and God the Mother, and that so soon as the first attribute of God the Soul enters into Creation the first evolution of the world is psychical rather than physical and is invisible instead of being visible, which completes the likeness to God. It therefore appears to follow that the mass we call Ether is infinite, for it has neither size, bounds nor shape, and nothing is impervious to its entry, influence or control, and from it must emanate all else : (a) Light and power of Creation of distribution; (b) Heat and Power of Affinity, Love or Chemical Action; (c) All electrical or radial energy of motion, mind or thought, or the organisation we call the forces of order, construction or control which make up the psychical influence we call Wisdom, or Science of Understanding, or Mind and Soul. My Hypothesis opens up to the scientific student of Chemistry, Natural Philosophy and Evolution a logical basis of arrangement of Knowledge, Comprehension and Understanding utterly unattainable without its aid. The logical deduction is that the substitution of the word Ether in the place of the Spirit of God in no way lessens the deity of the Spirit, or His right to call for the veneration given to God in the past, because His attributes were beyond our understanding. For God will be no less God because we understand His power the better. This my hypothesis brings within the limits of human comprehension, and it appears to me that a better knowledge of God and a clearer understanding of our relation to Him, connection with $\mathrm{Him}$ and dependence on $\mathrm{Him}$, would tend to increase our ambitions to be worthy of the trust $\mathrm{He}$ imposes upon us by allowing us to exist, rather than weaken our veneration of Him.

It therefore appears a logical outcome of this channel of thought, first, that Light is the material fluid that is the current of the Potential Energy of God the Father as it flows along the river-bed of infinite ether. Second, that Heat is the material demonstration of the potential energy of God the 
Mother that pellates with that of the two male personages of God the Father and God the Soul to create-(a) Material Ex. istence by the combination of its lower order of action that constitutes Heat, Affinity and Chemical Action, and brings about the formation of atoms and molecules which produce matter by the love of adhesion and affinity as these forces of creation intermingle and intermarry; $(b)$ by the higher sexual affinity which produces life, marriage, or animal love.

The greater warmth or combination of the attributes of God and Nature which produces love of others and creates the higher psychical influences of Religion, Study and Government in Mind, and the order and arrangement in the greater stability of construction, destruction and reconstruction which we call life as demonstrated in evolution and the further extension of its invisible forces in the minds and souls of men. Third, that radial and electrical forces are the fluid media of the invisible agencies of the tractation of God the Soul by which the higher kinetic energies of psychical and invisible forces are transmitted through and from the infinity of divine ether to the finity of visible created existence, by what we call the Grace of God. I consider these are contained in the kinetic energies of the fluid motive forces of electricity which constitute what we may aptly term the male personality of God the Soul of Nature. I consider life to be the result of the oscillation of the female force of God the Mother between the two male forces of Potential and Kinetic Energy of God the Father and God the Holy Ghost, each force being represented by seven minor subdivisions of invisible force conveyed by means of waves, like the waves of light.

The nearer the equilibrium of the twenty-one forces is attained, the nearer we approach to that perfect harmony and rest that can alone be found in infinite ether. I take it that the spectrum of ether is one of the twenty-one waves of electrons of infinitely minute waves of infinite energy made up of the personages of God the Father (which may, like the spectrum of Light, be Visible Motion, Distribution and Variation); that of God the Mother (which may be Heat, Chemical Action and the intermingling of Life, Existence and Love or Affinity, by the influences of pellation and tractation with the male indications or God's Personalities, Light and Radio Energy, or Matter and Mind, and so created visible existence 
out of invisible motion. The electron of God the Soul may be a spectrum of electrical and radio activity we have yet to discover in the realms of the infinity of space). I use the words " may be" because the reader must bear in mind that in this treatise I am only placing before him for his consideration a collection of hypotheses which I am trying to explain and elucidate, and which it would be arrogance and vanity on my part to hope to prove in a year, for it is more likely to occupy the labour of twelve centuries than of twelve months to accumulate all the proofs necessary to fully establish solutions to some of the problems raised by my hypothesis.

We have discovered the spectrum of Light, but we must remember that visibility is the particular attribute of the first Personage of God's Trinity when disconnected from the second or female personality of God. Although we have discovered the Spectrum of Light, it is developed by the invisible ion of electricity, or wave of God the Father, but we cannot definitely prove a similar spectrum to positive and negative electrons, although we can measure some of their waves. The complete Spectrum may be so far beyond the finite mind as to be for ever unknown in the visible manner that light is. So we can only hope that as we evolve the brain of wisdom, which, according to my hypothesis we have yet to do, we may better comprehend the Second and Third Personalities. We can, therefore, only live and study on in the hope that as we evolve this wisdom we may be able to discover sufficient of these spectrums of invisibility to obtain a better grasp of the meaning of God and His Trinity, of Infinity and Finity, of Life and Creation, and how to utilise such knowledge and apply theology to chemistry.

My tables do not help me to any great extent in this direction. They predict Peace, Use, Prevention of Crime, the Ages of Charity, Comfort, Content, Heaven and Immortality as the coming ages of evolution, but the student of natural philosophy and of chemistry will have to solve the problems that my hypothesis opens up unaided by any prophetic assistance. Yet all students of atomic chemistry will realise that the last ten years' progress in the science of radio-activity all points towards some such hypothesis as the one that I have endeavoured to elucidate, and will at once realise how modern science is pointing every day as it advances to some such 
manner of creation as the one which $I$ have herein made a first, if weak, attempt to place in a logical order and sequence, and will realise, as I do, that the hypothesis it contains offers the most probable solution as yet conceived to account for the creation of the world, and paves the way for the final discovery of the understanding and conservation of the latent energies that must open up our future means of existence, when, as is at present apparent to all deep thinkers, we shall have exhausted our capital supplies of the stored energy of the light of past ages, such as coal, gold and other mineral supplies upon which modern civilisation is at present dependant.

But this is going into what I have defined in this treatise as the limbs and branches of the tree of evolution, and $i$ must confine this work to the main trunk line only. Nevertheless, I think it well to call attention to a few of these issues which further development and application of my hypothesis along higher roads of science must ultimately lead to before I put down my pen.

The Mathematical Table IV., in the Tables of Trinity, also opens up a very large field of thought and investigation in realms of atomic chemistry which will necessitate years of careful experiment and study before it will be possible to do more than conjecture what it may or may not do to fix some form of mathematical arrangement of the value, nature and further elucidation of the chemical values of atoms, etc., all of which it would be premature to form an opinion upon, but even already Science, as it advances year by year, points to their dependant arrangement upon and government by some such hypothesis as the one I have herein placed before my readers.

Thus I take it that these attributes of God's Trinity are all materially conveyed to the finite world from the infinite one by electrical waves similar to the seven waves of colour and light. We may not be able to realise or analyse these electrons, yet it strikes me that there are also seven waves of force and also of kinetic energy, in Ether, besides the seven of light, which create ninety-eight elements, a few of which we have yet to discover or comprehend in our struggle for the conquest of nature, nevertheless as we evolve our souls of wisdom, in the future, we may be able to discover new waves, such as 
those of radimum, helium, which will enable us to master even greater difficulties in the conquest of nature, and to comprehend psychological forces till some day we may, not only prolong the life of our individual bodies and rule Matter, sea and air, but also creaté a vast amount of the food and raiment for the possession of which we are at present dependant upon the sunlight of past ages, as Science and a better understanding of the wonderful mystery of God and His Trinity will enable us to understand how to make the best use of, and not abuse, our bodies and their surroundings. We may find that each of the Persons of God's Trinity will have its attributes represented by a spectrum of seven waves in the same manner as the seven attributes of God the Father, the Spirit of Light, are represented by the waves of colour which clothe the lilies of the field in their glory and splendour. So we have yet to find similar spectrums of the less material personalities of God the Mother and of God the Soul, who, I take it, are represented in material existence by the remaining fourteen waves that make up the less material and more psychical and ethereal forces than that of Light, out of the twenty-one waves of ether which constitute the attributes of God in space.

Now, if the reader will refer to Table IV., the Mathematical Table of Trinity, he will see that by it figures I, 2, 5, and 8 are the figures of incompleteness, and in atomic chemistry should therefore stand for instability; that the figures 3,6 , and 9 are those of completeness, so should most probably in chemistry be connected with stability, life and permanency; and that figures 4,7 , and ro are the figures of Immortality, so should in chemistry represent the final, unalterable or uncombinable results. This is one of the problems that my hypothesis gives rise to, but which I must leave to the scientific student of atomic chemistry to decide how far these conjectures of mine are correct. Nevertheless, it may not be presumption on my part to endeavour to illustrate how it appears to my lay-mind that there is a substantial ground for the supposition that I have put forward that some such application of this Table may become practicable in atomic chemistry. As an illustration, and in support of this I will give an example of the manner in which it appears to me their discovery will be useful as an index in the classification 
and arrangement of atomic values in chemistry, and by means of which, in the hands of competent scientists, a key may be evolved as their application to the problems of atomic chemistry is better understood.

Turning to page 229 of Professor Soddy's work, " Matter and Energy," we read: "It is known that three $a$-particles, or helium atoms, are expelled in the change of a uranium atom into radium, and that in all, including the subsequent numerous changes suffered by radium, eight $\alpha$-particles are expelled. The atomic weight of uranium is 238.5 . . ." This number is exactly divisible by 9 , so it appears to me that if some such utilisation of my Table IV. of Trinity is employed, it should place it as a final elementary product or as an element incapable of further alloy as it is a multiple of 9. Then, as the atomic value of helium is 4 , it should probably, by the rules of my Table, be a complete primary result. Mr. Soddy continues: "And if we subtract the weight of the three $a$-particles or helium atoms, which is 12 (I2.I), we get the figure 226.5 (9 226.4), which is almost exactly the value Mme. Curie found by experiment." If 226.4 is correct, this again is exactly divisible by 8 , so should, by my Table, be an evervarying final state of radio-activity and one probably either of constant alterability or unlimited in its powers of combining to produce radio energy and heat, but it would be presumption for a lay mind like mine to try to answer these problems.

The utmost I dare do is to suggest their possibility to the student of atomic chemistry for his investigation and experiment. Mr. Soddy proceeds in the following manner: "If we subtract the weight of eight helium atoms, or 32 , from 238.5 , we get the figure 206.5 . If, then, in the changes of the uranium atom nothing else except eight helium atoms are expelled (the mass of the $\beta$-particles expelled is too small to be of importance), the final product should be an atom of weight 206.5. The nearest element to this is lead; the atomic weight of this is 207."

Now, it is asserted by other scientific authorities that the atomic weight of lead is 205.35 ; but if the figure 206.5 is the correct one, then, according to my idea, it would be exactly divisible by seven. This, I presume, would probably indicate that lead is a final result of uranium that could be mixed of 
alloyed but not combined, could adhere but not be assimilated, and would be the least destructible form of uranium.

The student of atomic chemistry will be able from this example to detect the manner and direction in which it appears probable to my mind that Table IV. of The Trinity opens up a wide and unexplored field of future study, and that if it is possible to ascertain its exact relation to chemical science, what an important check or key to calculation it may become to classify atomic values if it were possible to discover in what way it would be useful in deciding chemical properties in relation to their numerical values. In much the same manner as I have in this treatise demonstrated, it tends to point out the incompleteness, completeness or the durability of the component parts of evolution when any of the tables of trinity or trinities that may be produced are submitted to the analysis of Table IV.

These are some of the directions in which the utility of my hypothesis may be extended, the magnitude of which is far too great for me to endeavour to solve. Yet I think that these concluding remarks, although too deep for the unscientific reader, will be sufficient to interest the scientific reader and to illustrate to him how my hypothesis may tend to advance science a few steps along the mental road of evolution. But so mighty is the magnitude of the hypothesis I have herein opened up to controversy, that I feel certain that many of its developments will take centuries to solve. 


\section{APPENDIX}

To absolutely fix a time or date for any of these days or age I have herein reviewed would be an impracticable undertaking. For they each appear to go through nine stages subdivided into sections of three periods, during which three distinct results are produced by each of these twenty-one major divisions of evolution past or to come. The number of evolutions at work appears to vary from I to Io, and the most that can be said at any time is, that one evolution has a more marked preponderance of influence over the united action of whatever number may be at work than is exerted by the other forces or energies that combine to produce the united results. Hence it follows that any attempt to give them anything like a chronological position must be of a very approximate nature.

Besides, the herditary forces that tend to make reproductive activities systematic, are frequently upset by the variation in the lengths and rapidity of their evolution; by effects produced by climate, environment, and migratory influences, which greatly vary in different parts of the globe both the commencement and final completion of any evolution in any one particular locality. Hence we find that the chronological periods of evolution vary in like manner, so in estimating time we can only make a guess at the period from an average start to an average finish. For example, the evolution of man is conducted on the same lines and subject to the same laws as other species, yet the results so far as time and extreme variation are concerned are greatly varied as to their relative start and conclusion in various parts of the world.

The evolution of the human race has progressed at a vast variation both in time, quality and rapidity, when you compare its progress in China with different parts of Europe and Australia. Again, the revolution of Cromwell coincides, so far as political results are concerned, with the French revolution of Robespierre. The foundation of the Prussian Empire coincides with the Norman Conquest in the evolutions 
of government in England. But when you make allowance for the slowness of progress of the second hand on the clock of evolution and remember that 1,000 years is but a day, 360 years but an hour, I20 years but a minute, and 40 years but a second, these are but trivial differences in the march of time along the road of Eternity. So in endeavouring to formulate some sort of chronological estimate or probable periods of the days of creation, if I have estimated the lifetime of the evolution of Government at 27,000 years in one place, it may commence from 10,000 B.C. to I7,000 A.D., this might be its shortest life under favourable environment or auspicious condition; yet, under adverse circumstances, to produce the same effect in some other part of the globe, the same evolution might extend from I5,000 B.C. to I5,000 A.D., with equal probability in some other portion of the world, and still not be mis-stated, at 27,000 years. Hence in appending the accompanying approximate calculation (for it is only a calculation-nothing more) of the probable duration of the subdivisions, my hypothesis makes of creation, I must ask my reader to keep these considerations in view.

It would be absurd to suggest that these periods are anything more than the approximate estimate. It struck me in reading history that as near as I could arrive at a solution of the question it appeared probable that invention has been an active force for from 900 to $I, I 00$ years in the advancement of the world, and that also if I took a mean of that figure $I, 000$, it would be an approximate estimate on which I could base my calculations, for it also appeared to me that each of the corresponding periods, subject to such conditions as I have already expressed, correspond on a progressive ratio of three times the length of time in the evolution that preceded.

Taking the four last days of creation, numbered respectively $\mathrm{I} 4, \mathrm{I} 3, \mathrm{I} 2$, and IIth days, it appeared to me that the estimation of that duration took me back to the earliest possible conception bf historic times, but it would be utterly ridiculous to try to fix definitely their periods, even if my starting figure of 1,000 should be reckoned as a reliable data of calculation. The age of Government is as impossible to fix at between 25,000 to 29,000 years as it would have been to fix the age of invention between 900 and I, roo. Notwithstanding, continuing the same method down to creation of plant life, 
I did not find any vast discrepancies in my figures with geological estimates, so I have decided to let this estimate go. I would simply remark that if the reader likes to start with the final $1,500,000,000$, he may get a more accurate statement by reversing the calculation.

Chronological Estmate of the 14 days already passed.

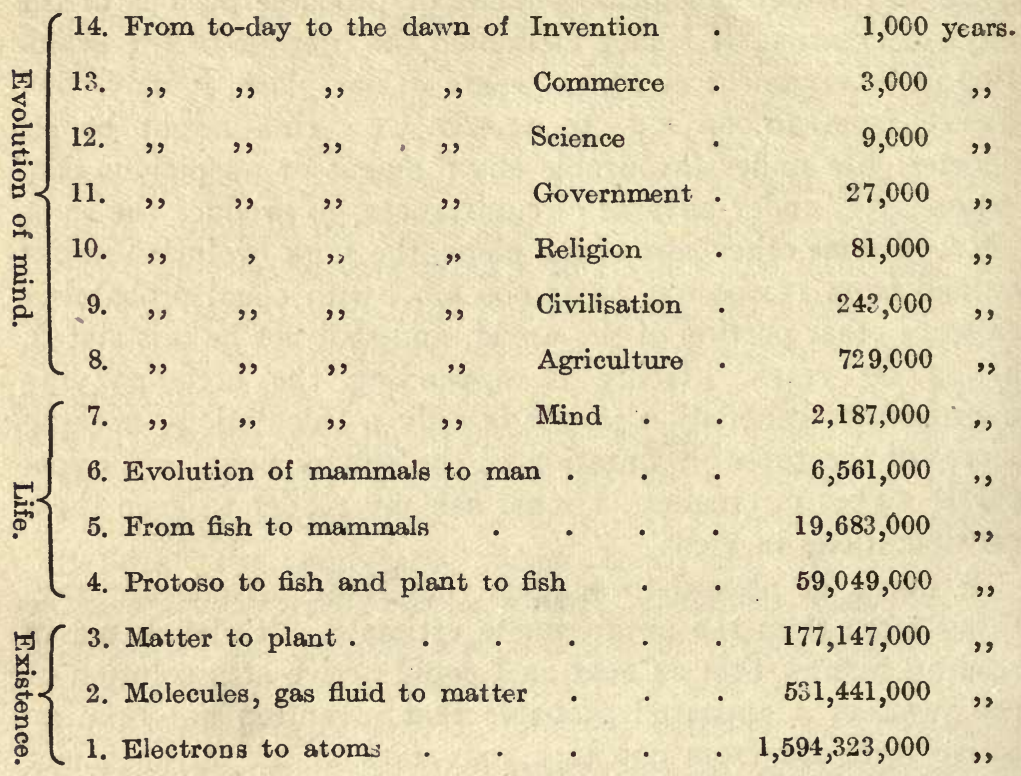


THE SEVEN STAGES OF PROGRESS.

lst $\left\{\begin{array}{l}\text { Gas } \\ \text { Grystallisation } \\ \text { Gravitation }\end{array}\right.$

2nd $\left\{\begin{array}{l}\text { LIFE and Motion } \\ \text { Marriage } \\ \text { Man }\end{array}\right.$
3rd $\left\{\begin{array}{l}\text { Imagination } \\ \text { CoMpremengion } \\ \text { Understanding }\end{array}\right.$

4th $\left\{\begin{array}{l}\text { Reliaion AND Stu } \\ \text { Government } \\ \text { Scrence }\end{array}\right.$

5th $\left\{\begin{array}{l}\text { Commerce } \\ \text { InVention } \\ \text { Peace }\end{array}\right.$

6 th $\left\{\begin{array}{l}\text { Age of Pleasure } \\ \text { Abuge. } \\ \text { AGe of Content } \\ \text { Age of Comport }\end{array}\right.$

7th $\left\{\begin{array}{l}\text { AGE OF WISDOM. } \\ \text { AGE OF HAPPINESS } \\ \text { FinaIJTY OF EVOLUTION }\end{array}\right.$
- Destructive By Disintegration ol ETHER.

- Constructive By the Aftinity or MOLECUIJES.

- Progressive By the Creation of MatTer.

- Destructive By the Re-arrangement OF MATTER.

- Constructive By the Recreation of BODY.

- Progressive By Creation of Mind.

- Deftructive By Creation of human WILL.

- Constructive By Creation of AgriCULTURE.

- Progressive By Creation of CivilISATION.

- Destructive By Creation of War and Bigotry and Creating EXCUSES FOR CRIME BY Misinterpretation of True Revelation.

- Constructive By Re-Establishing ORDER.

- Progressiye By Correcting the ERRORS OF STUDY AND Religion.

- Dhistructive By Creation of Avarich AND THE DESTRUCTION of Honesty, Gratitude and Charity.

- Constructive by the Conquest of MATTER.

- Progressive by Creation of Cooperation AND CharitABLE USE.

By Wear aNd Tear of What Man has Created WITHOUT IN ANY WAY Maintaining Life.

- Constructive By the Prevention of Crime.

- Progregsive By the Just Reward of SUCCESS.

Destructive By Conquest of Folly as Man Attarns Self Control.

- Constructive Attainment of Heaven ON EARTH.

DAWN OF IMMORTALTTY. 
The seven stages of retrogression and destruction are :-

I. The Age of GAS. 2. Creation of Life and motion. 3. Creation of Human Will. 4. The Age of Religion, War and Bigatry. 5. Commerce and Competition, Discovery. 6. Age of Use and final destruction of the Unfit members of mankind. 7. The final destruction of Human folly.

The seven stages of Construction are:-

I. Crystallisation and chemical action. 2. Sex and Marriage. 3. The Age of Agriculture. 4. Age of Government. 5. The Age of Invention. 6. Prevention of Crime. 7. Heaven.

The seven ages of Progress are :-

I. Creation of the world. 2. The Creation of Man. 3. The Creation of Mind with civilisation. 4. The Creation of Soul by Science. 5. The Creation of Peace by the stoppage of War. 6. The Age of Comfort, when we learn to use prison labour as a means to reduce poverty and to give full recompense to success. 7. The Arrival of Immortality.

I know many of my readers will condemn me for classing these first seven forces as destructive. All I can say is that evolution in one sense is never destructive but always constructive. For all nature is a part of the infinite universe, and, as God is infinity, hence, logically, as God is indestructible, all nature must likewise be indestructible is a logical sequence. So perhaps the word reconstruction in many cases better conveys what I mean to express. But the reconstruction of any substance or reorganisation of any condition of circumstances necessitates the destruction to some extent of the form, or shape, or condition of the previous state of existence. If we cut a tree into planks we disintegrate the tree, so that we may be able to build our house. When my hypothesis gave me the word "Disintegration" as the first age of creation and first result of the marriages of God's Trinity, it also gave me the right word for the retrogressive stages of evolution. I know you will say, But, surely, religion is not a destructive force but a progressive one. I am afraid, subject to the explanation and qualifications just stated, I shall be compelled to disagree with you. You may just as well argue that revolution is not a retrogressive form of evolution when compared with law and order; and I have previously pointed 
out that good and evil, so far as the abstract idea, from an evolutionary standpoint, is concerned, is only a matter of comparison of temporary efficiency; just because in a few cases revolution may produce a higher form of government than the one that preceded it. Whether revolution produces a better or a worse form of government is entirely dependant upon the fact of whether those who promote it are actuated by a love of order or aim at injustice or riot; not by any actual property or abstract quality of revolution as a motive force. So likewise with religion, the result attained, so far as evolutionary progress is concerned, is in no way concerned with the truth or fallacy of its teaching, which fact depends mainly upon the amount of divine knowledge of revelation and inspiration which the philosophy of the age may have imparted to its teachers, whereas the amount of good or evil it produces will depend wholly upon the suitability of its teaching to the requirements necessary for the next evolution of government, which is the concurrent constructive force of evolution, so long as it is a strong enough government to enforce its people to work hard, in love and unity, under conditions of order and wisdom.

On the other hand, should the teaching of religion be in arrears instead of in advance of the science and philosophy of the age or community, then instead of being a constructive force it becomes a destructive one; more inclined to create disobedience, discontent, disorder and rebellion with the conditions and duties and obligations of society than to forward the advance of society, utility, content that make up the advancement of civilisation and scientific philosophy. For Civilisation and Science constitute the third and fourth progressive evolutions on either side of the reconstructive force of religion.

The duty of religion in evolution is to destroy the beliefs suited to past forms of social government so as to produce a more advanced form of state government. You will now perhaps be able to comprehend why I am correct in classing religion not as a force of construction or progress, but as one of disintegration and reconstruction. We have only to closely follow the course of history to realise that religion is a science of error and reformation, not one of stability and certainty, as are mathematics and philosophy. And we have only to look at the last 2,000 years of religious evolution to realise that its progress in morality and knowledge has been pur- 
chased at the cost of a heavy fee in the form of scientific retrogression.

But it must not be lost sight of that Thought is the motive force of Revolution; Imagination the motive force of Religion; Knowledge the motive force of Human Will. These are the three forces of Nature most prone to err, whereas Comprehension is the motive force of Agriculture; Logic and Mathematics, Truth. Understanding is the motive force of Science and Invention, and Wisdom the motive force of Civilisation, Charity, Justice and Mercy, and that Comprehension, Science and Wisdom are the three progressive forces of Nature on which reliance alone can be placed.

And, surely, the work of Religion is less to teach the Truths of Revelation, which man only acquired as a result of Philosophy and Inspiration, than it is to adjust the laws of State and Social Government and to bring the results of Philosophy and Inspiration down from the Realms of Imagination, Fairy Tale and Fable to some form of practical Utility compatible with the comprehension of man's mind at the age of Civilisation and existence at any stage of Evolution, by ruthlessly destroying past beliefs to make practical and possible new forms of State and Social Government. I will now recall attention to what I have elsewhere pointed out, that Religion is not to be an eternal force but ceases to exist when we attain true human wisdom. For then man will arrive at a perfect knowledge of right and wrong, and though he will ever be liable to err, because he will ever lack divine knowledge, he will have attained sufficient reason and judgment to commit no crime, because he will realise that all crime is foolish and destroys the happiness of he who commits it. He will then have arrived at perfect manhood and will no more require the assistance of the guiding hand of Religion than the ordinary man of to-day requires to be led by a nurse about the streets.

Before concluding my remarks on the seven stages of Progress, just tabulated, I will call the reader's attention to a significant point. In this table each of the seven progressive stages corresponds to the seven highest virtues that are to remain as the constant progressive forces that are to make this earth Heaven when man at last attains the perfection of Human Wisdom :- 
I. Material Creation is the base of Usefulness.

2. Man's highest quality is to live at Peace.

3. Civilisation is the base of Comfort.

4. Scientific knowledge is the base of Content.

5. Peace is the base of Joy.

6. Comfort is the base of Pleasure.

7. Wisdom creates Happiness and completes the Evolution of Life, Mind and Soul.

We now find that the seven words on the right-hand side of this category make the seven virtues of Heaven, namely :I. Use. 2. Peace. 3. Comfort. 4. Content. 5. Joy. 6. Pleasure. 7. Happiness-as well as the last seven incomplete Evolutions of Creation. There are three other Evolutions that are eternal and lasting, namely:-Science, Commerce and Invention. The previous eleven Evolutions to these ten all become complete before man arrives at Immortality, when, with the completion of the Evolution of Government, by man becoming a Government unto himself, they have ceased to admit of any further room for progress and have lost their capability of exerting any large amount of influence on his future powers of Existence, and will practically thereafter be no longer subject to any amount of variation. 



\section{N D E X}

A.

Abel, Symbolical of Northern civilisation

Adam, Symbolical of the Stick Age

Animal and humen emotions

Ancestors, their minds are reproduced in our minds.

Aims of Christianity

Armies, Cosmopolitan, necessity for.

Atomic values

B.

Brain power destroyed by laziness $\quad . \quad 131,164$

Buddhism . $\quad$. $\quad 136$

C.

Cain, Symbolical of Stone Age and Southern civilisation, 90, 101

Charity, Epoch of . . 223

Causes that corrupt religion . 175

Civilisation, Evolution of - 121

Character, Evolution of . 121

Childhood, Evolution of emotions in

Christ, What He might have predicted had our mind's been sufficiently advanced

Christianity, The aims of .

Concluding remarks.

Comprehension, Evolution of

Course of evolution

Cosmopolitan armies, necessity for

Commerce, Evolution of

$215,242,248$

Creation, Objectives of 223

Crime, Prevention of 112, 263

D.

Dawn of religion . 154

Descent of the Holy Ghost 186, 264
PAGE

123,148

Duties of the future rulers of

Nations $\quad . \quad 122,242$

E.

Emotions, Animal and human 49

Electricity - . 267, 275

Epoch of Faith $\quad$. 6

- of Hope $\quad$. 70

- of Charity • . 223

Equal opportunities . $\quad$. 232

Evolution of Emotions $\quad .55,60$

— of Science . 123, 148, 204

- of Governments 190, 203

- of Comprehension . 77

- of Imagination $77,101,11$ s

— of Religion . 154

of Civilisation and Understanding . 121

- of Idolatry . . $\quad 134$

— of ChristiantTy . 159

- of Mind . . 49

Evolution and Genesis $\quad 42$

- A summary of . . 1

- Course of

\section{F.}

Fear, Growth of religion from 82, 134

Failure of past forms of government

238

Faith, The epoch of : 6

Federation, International • 254

Final Chapter . . 223

Finity and Infinity : $\quad 267$

Fear that I may have destroyed

more than I can rebuild . 234

Future duties of mankind 122, 242

G.

God in terms of electricity . 274

Government, Evolution of 190, 213

- Failures of in the past . 238 versus religion . 175, 177

- of R.C. Church 260

Growth of religion . $\quad 82,134$ 
H.

$\begin{array}{lr}\text { Human and animal emotions } & \text { PAGE } \\ \text { Heredity } & \mathbf{4 9} \\ \text { Holy Ghost, The descent of } 188, & 264 \\ \text { Hope, The epoch of . } & 70 \\ \text { Hypothesis, A resume of } & 7\end{array}$

I.

Idolatry, Evolution of $82,93,127,134,141,154$

Intolerance, Evil of .

Imagination, The evolution of $77,101,113$

Invention, The evolution of $216,219,242,258$

L.

Laziness destroys the power to perpetuate brain

131,164 League of nations

M.

Male and female heredity

Man and monkey

Memory, Withdrawal of 82,134

Mind, The evolution of and opinions there-

on - expressed by Profs.

Huxley, Clifford, Louis

Raymond, Lloyd Morgan,

Romanes and Drummond.

Minds, Our, recapitulate the minds of our ancestors

Metal, Stone, and Stick Ages 87, 101

Miracles in Nature. . 185

Murder of Cain . $\quad 90$

N.

Necessity for creation for Redemption

Northern and Southern civilisations

. 8

. 185

90,101 o.

Objectives of creation

Opportunities are equal, talents unequal . 232

Our minds are the reduplication of the minds of our ancestors

61

Periods during which emotions are evolved . $\quad 55$

Preference to birth : 263

Prevention of crime . 112, 263

Prehistoric religious migrations 175

R.

Religion, The evolution of

$82,93,127,134$

- versus governments . 135

__ prehistoric migrations of 175

- persecutions of 206

Reason of failure in past governments . . 238

Redemption, The necessity for $73,102,136$

1

(1)

St

Stick, Stone, and Metal Age 86

Summary of evolution 1

\section{W.}

Work is the highest of virtues $\begin{array}{ll}\text { Withdrawal of memory } & 66,232 \\ & .77,62\end{array}$ 


This label must not be removed from this book, nor the figures thereon altered.

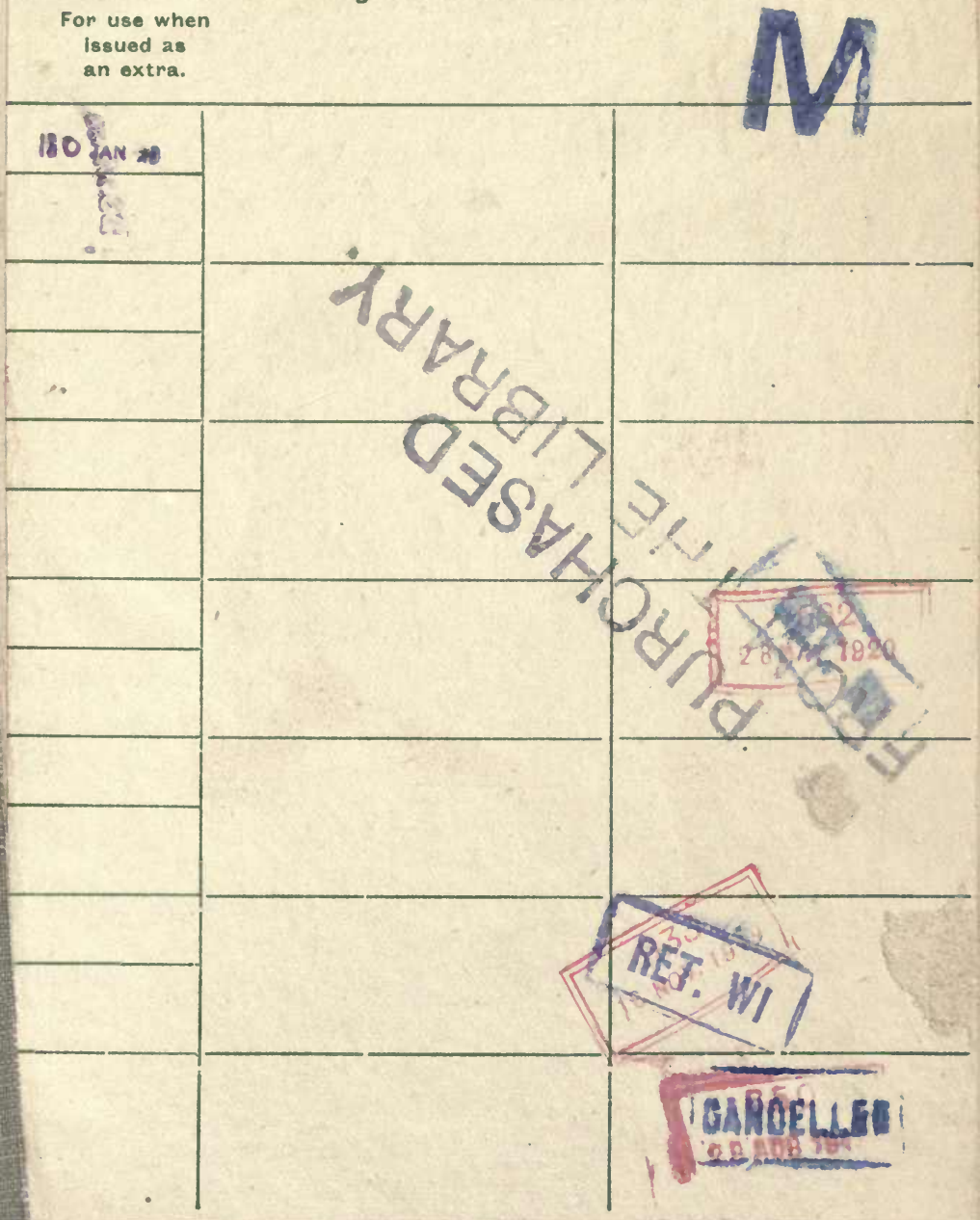


